\title{
Plantas útiles y prácticas cotidianas entre los aldeanos al sur de los Valles Calchaquíes (600 a.C. - 900 d.C.)
}

\author{
Lic. C. Marilin Calo
}

\author{
Director: Alcides A. Sáenz \\ Co-directora: María Esther Albeck \\ Tesis para optar por el grado académico de \\ Doctora en Ciencias Naturales \\ (FCNyM - UNLP)


A mis padres, Susana y Mario 


\section{Índice General}

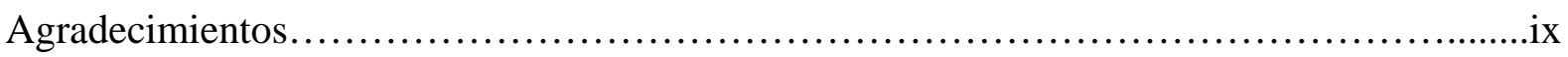

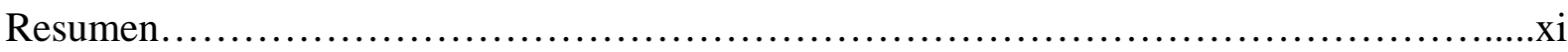

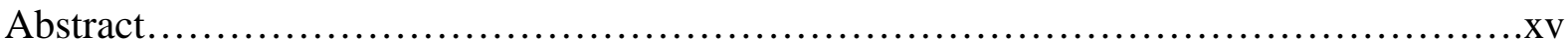

Índice de Figuras.................................................................

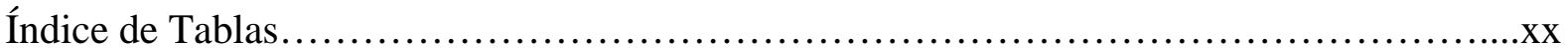

Índice de Gráficos.............................................................. xxii

\section{CAPÍTULO 1. Introducción, problemática y objetivos}

Introducción.....................................................................

El espacio doméstico en Cardonal: problemática y objetivos de la investigación...............3

Organización de la tesis.............................................................

La vida doméstica aldeana al sur de los Valles Calchaquíes.............................8

\section{CAPÍTULO 2. La molienda, los vegetales y la vida doméstica}

Consideraciones teóricas para el estudio de los materiales del Núcleo 1. Actividades y espacio doméstico..................................................................... 15

Las actividades y las unidades domésticas................................... 15

La arquitectura y el uso del espacio...........................................16

La propuesta de Rapoport: actividades y escenarios.............................. 17

La cultura material y las unidades habitacionales: objetos, rasgos y estructuras........19

De semillas y molinos. Los artefactos como referentes materiales de actividades domésticas.

El estudio de la vida cotidiana andina a través de los artefactos domésticos arqueológicos.

Abordajes y estado del conocimiento en el Noroeste argentino.

\section{CAPÍTULO 3. Caso de estudio y arqueología del área. Marco geográfico-ambiental}

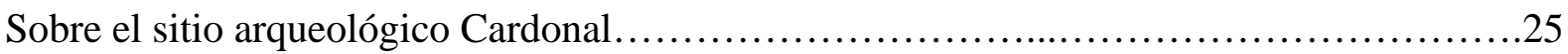

La arqueología del valle del Cajón.........................................25

Ubicación y cronología del sitio arqueológico Cardonal...........................28

Descripción del sitio....................................................28

El núcleo habitacional excavado............................................ 31 
Muros, accesos y circulación...............................................31

Otros rasgos arquitectónicos............................................32

Objetos y acciones..................................................33

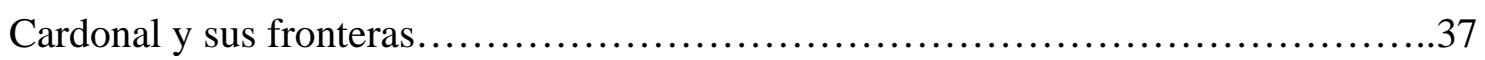

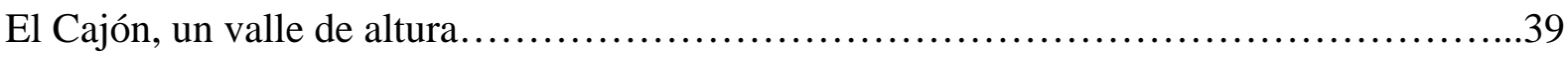

Geografía, vegetación y clima actual....................................... 39

Estimaciones paleoambientales para los valles del Noroeste argentino...............43

\section{CAPÍTULO 4. Aspectos metodológicos y materiales de estudio}

La excavación del Núcleo 1 de Cardonal................................................51

Metodología para el análisis de macrorrestos vegetales arqueológicos.....................52

Desde la Arqueobotánica................................................... 52

Diseño de muestreo: muestras de flotación y muestras puntuales................54

Muestras directas o in situ.........................................55

Muestras de sedimento para flotación................................56

Procesar las muestras de sedimento: la flotación..............................58

Sistema no mecanizado: Balde de flotación.............................59

Sistema mecanizado: Cubeta de de flotación............................60

Procesamiento de las muestras flotadas..................................62

Determinación taxonómica de restos vegetales...........................63

Análisis de los caracteres externos macroscópicos......................63

Variables utilizadas en la descripción de restos botánicos.................64

Material bibliográfico de referencia y consulta..........................65

Elaboración y uso de colecciones de referencia.............................66

La flora silvestre local. Colección de herbario...........................66

La colección de frutos y semillas comestibles del Noroeste argentino.......66

El material de referencia arqueológico...............................67

Presentación y cuantificación de los datos................................67

Cantidad absoluta y Peso............................................68

Porcentaje relativo...................................................68

Ubicuidad......................................................68

Densidad............................................................69

Tareas de control de datos............................................69

Prueba experimental de confiabilidad.................................69 
Muestras de flotación off-site. .70

Metodología para el análisis de los artefactos de molienda...............................70

Clasificación, análisis e interpretación de los artefactos de molienda.............70

Análisis tipológico de los artefactos de molienda............................71

Segmentación del conjunto.......................................72

Orientación, ilustración y segmentación de los artefactos................72

Descripción de los artefactos.....................................72

Clasificación de los artefactos........................................73

Primer nivel de clasificación: artefactos y preformas...............73

Segundo nivel de clasificación: grupos y subgrupos tipológicos......74

Composición y distribución del conjunto de artefactos de molienda en el sitio...75

\section{CAPÍTULO 5. Resultados del análisis de restos vegetales}

Conformación de las colecciones de referencia y control del procedimiento de flotación......77

La flora silvestre local: colección de herbario...................................77

El uso actual de las plantas silvestres...........................................77

Colección de frutos y semillas de especies comestibles del Noroeste Argentino.........78

Test experimental de confiabilidad de los sistemas de flotación empleados.............80

Análisis de los restos arqueobotánicos recuperados en Cardonal.........................81

Consideraciones generales............................................... 81

Procedencia taxonómica y anatómica de los restos vegetales.......................83

Dicotiledoneae.......................................................... 83

CHENOPODIACEAE ................................................83

FABACEAE....................................................88

MALVACEAE .......................................................100

SOLANACEAE.................................................. 100

Monocotiledoneae.....................................................101

POACEAE......................................................101

Otros restos.......................................................... 104

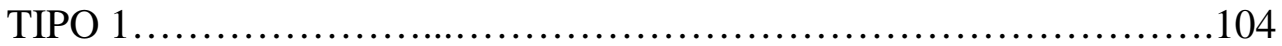

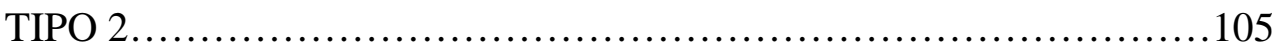

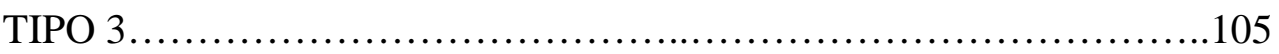

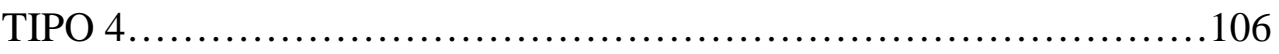

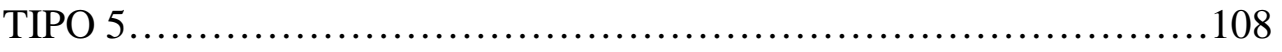


TIPO 6. .109

Distribución de los restos carpológicos carbonizados en el Núcleo $1 . \ldots \ldots \ldots \ldots \ldots \ldots \ldots 110$

Cantidades absolutas de restos recuperados.............................110

Porcentajes y porcentajes relativos de restos comparados entre estructuras......115

Ubicuidad de los restos en muestras de flotación.............................118

Densidad de carbón de leño y restos carpológicos.............................124

La distribución inter-estructura de los restos botánicos...........................125

\section{CAPÍTULO 6. Resultados del análisis de los artefactos de molienda}

Caracterización general del conjunto de instrumentos de molienda.

Piedras de moler en la ocupación del Núcleo 1: instrumentos activos y pasivos y material fragmentario.

Fragmentos de artefactos de molienda..........................................133

Artefactos de molienda completos...........................................133

Molinos de mano y morteros.............................................136

Manos de molino......................................................137

Caracterización de los conjuntos de molienda de cada Estructura...........................139

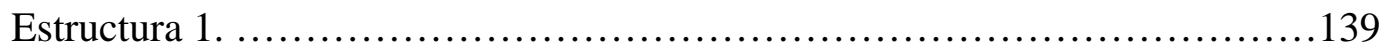

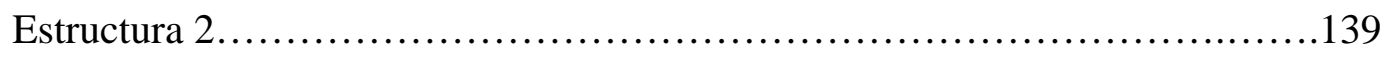

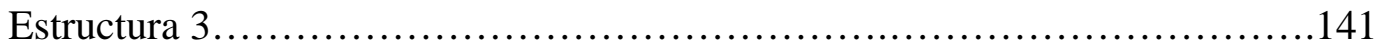

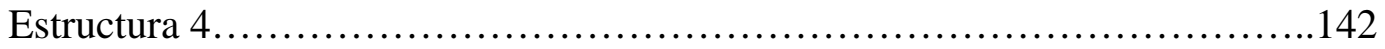

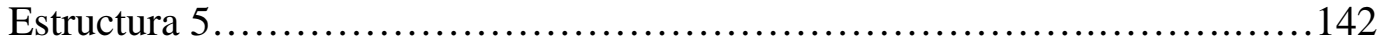

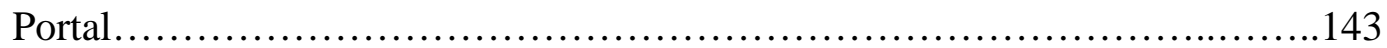

Las áreas de molienda en el Núcleo 1 y otros fines útiles de las piedras de moler...........146

\section{CAPÍTULO 7. Apuntes para una discusión del espacio doméstico del Núcleo 1}

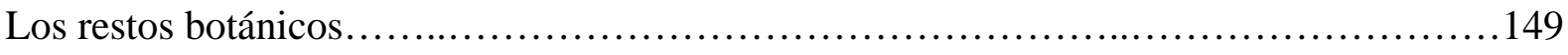

La presencia de restos botánicos carbonizados en el Núcleo $1 \ldots \ldots \ldots \ldots \ldots \ldots \ldots \ldots \ldots . . .149$

Las plantas depositadas por procesos culturales en Núcleo $1 . \ldots \ldots \ldots \ldots \ldots \ldots \ldots \ldots . . \ldots 153$

Vegetales comestibles del Núcleo 1: ¿silvestres?, ¿domesticados?, ¿locales?...............154

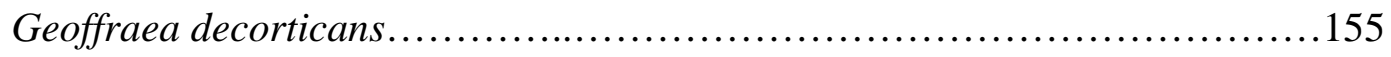

Phaseolus vulgaris var. vulgaris y $P$. v. var. aborigineus........................156

Zea mays var. minima y Z. m. AMARILLO.................................158

Chenopodium aff. quinoa o pallidicaule...................................160 
La distribución de los restos botánicos

Los artefactos de molienda....................................................... 168

Instrumentos de molienda: modo de empleo..................................168

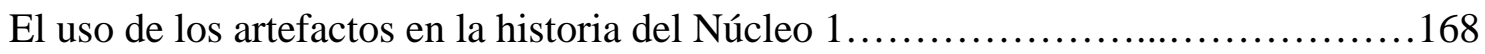

Reutilización de los artefactos y relevancia de la práctica de molienda................171

\section{CAPÍTULO 8. Conclusiones}

Algunas consideraciones acerca del abordaje y la metodología de trabajo. ...

Las actividades en el Núcleo 1. Una mirada a través de restos de plantas y artefactos de molienda.

Aspectos de la economía doméstica y la organización de la subsistencia en las aldeas del sur de los valles Calchaquíes: aportes desde el Núcleo 1.

ANEXO 1. Frutos y semillas hallados en sitios arqueológicos del Noroeste Argentino (primer milenio d.C.)

ANEXO 2 Variables empleadas para la descripción de los artefactos de molienda de

Cardonal

ANEXO 3 Valores de referencia empleados en la identificación de tipos de artefactos de molienda en Cardonal.

ANEXO 4. Las plantas silvestres utilizadas actualmente en La Quebrada que integran la colección de herbario.

ANEXO 5. Especies que integran la colección de referencia de frutos y semillas comestibles

del Noroeste Argentino. 248

ANEXO 6. Muestras de Flotación. Contenidos de material carbonizado....................250

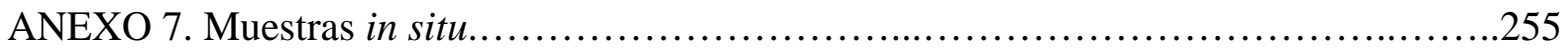

ANEXO 8. Restos carpológicos recuperados .........................................256

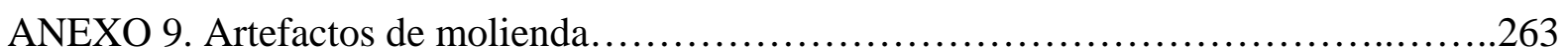

ANEXO 10. Artefactos de molienda en niveles ocupacionales.............................269

ANEXO 11. Artefactos de molienda pasivos........................................275

ANEXO 12. Artefactos de molienda activos..........................................276 


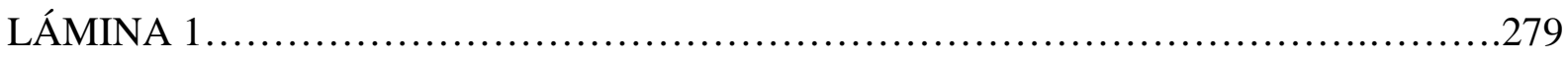

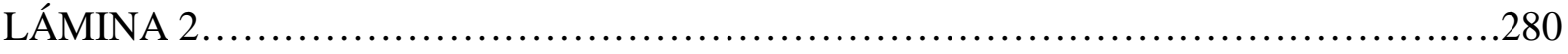




\section{Agradecimientos}

Quisiera mencionar aquí a todas aquellas personas e instituciones a quienes debo mi más sincero reconocimiento, por el apoyo y la confianza que han depositado en mí y en mi trabajo.

Esta tesis ha sido posible gracias al aval y sostén económico de la Agencia Nacional de Promoción Científica y Técnica (ANPCyT) y del Consejo Nacional de Investigaciones Científicas y Técnicas (Conicet). La primera me otorgó una Beca Inicial de investigación para comenzar con el proyecto de doctorado. Luego, la Beca Interna Doctoral Tipo II de Conicet me permitió avanzar hacia la finalización del mismo.

De igual manera, en el transcurso de estos años el Museo Etnográfico “J. B. Ambrosetti” - UBA y la Facultad de Ciencias Naturales y Museo - UNLP, me han brindado los espacios de trabajo y estudio indispensables para el desarrollo de mi investigación. Entre ellos agradezco a la Cátedra de Morfología Vegetal, por permitirme utilizar material instrumental del Laboratorio.

Al Dr. Alcides A. Sáenz y la Dra. María Esther Albeck tengo retribuirles el haber confiado y aceptado dirigir el plan de tesis, cuyos resultados presento en esta oportunidad. Menciono también aquí y muy especialmente a Ma. Cristina Scattolin, por brindarme la posibilidad de trabajar en el marco de los proyectos que dirige, por su estímulo constante, su guía profesional, y además por su generosa amistad. A todos ellos gracias por su ayuda a tiempo, sugerencias bibliográficas, revisiones del material y correcciones del manuscrito.

Hago parte de este reconocimiento a mis queridos compañeros de equipo: Ma. Fabiana Bugliani, Lucas Pereyra Domingorena, Leticia Cortés, Joaquin Izaguirre, Andrés Izeta y Marisa Lazzari, por su colaboración, sostén y amistad. Por los interminables días de campaña que acaban siempre siendo pocos en tan buena compañía. A los Dres. Andrés Izeta y Ma. Fabiana Bugliani también por la lectura y correcciones de algunos capítulos de esta tesis. A Fabiana quisiera agradecerle además su buena disposición en todo momento para responder a mis dudas. A la Dras. Nurit Oliszewski y Alejandra Korstanje por la atención que han prestado a mis consultas. Gracias también a Lautaro Villarino, por su hábil y fructuosa intervención en la fabricación del sistema de flotación.

A Blanca Gutiérrez, Fátima Liendro y Dora Chaile quiero agradecerles su gran ayuda con las muestras de sedimento y los días compartidos al borde de las acequias de La 
Quebrada. A todos los quebradeños, gracias por la hospitalidad y gentileza que nos han mostrado año a año durante este trabajo.

A mis padres y hermanos, Susana, Mario, Laura y Joaquin y a mi abuela Margarita, mi reconocimiento por su cariño y apoyo inquebrantable. Lo mismo para las personas que han estado a mi lado en este tiempo, brindándome su compañía y amistad, y con los que hemos compartido innumerables buenos momentos: Javier, Ana Laura, Mariela, Diego, María Luz, Laura, Luciano y Edgardo. A Karina Contana también, por sus oídos y palabras a tiempo.

Por último y con gran alegría, quiero expresar mi más profundo agradecimiento a Santiago, por estar a mi lado con amor, paciencia y constancia. Y gracias a nuestro hijo, por haber invocado en mí el resto de fuerzas necesarias para llegar hasta aquí. 


\section{Resumen}

Esta tesis es una contribución al conocimiento de las sociedades aldeanas del primer milenio de la era asentadas al sur de los Valles Calchaquíes. Dicho espacio comprende el valle del Cajón, el sur del valle de Santa María y la falda occidental de la sierra del Aconquija. El estudio se enfoca en el análisis de ámbitos de vivienda, particularmente en el conjunto de recintos que forman uno de los núcleos habitacionales del sitio arqueológico Cardonal (ca. 200 d.C.) ubicado sobre la porción meridional del valle del Cajón (Santa María, Catamarca).

La selección de una escala micro para el abordaje de la naturaleza y dinámica de las comunidades agropastoriles tempranas, es coherente con la perspectiva teórica que considera que el estudio minucioso y en profundidad de la configuración de los espacios domésticos y las actividades allí desarrolladas, es capaz de revelar aspectos más generales de la cultura y la organización social en el pasado de los grupos involucrados. De acuerdo a ello, se parte aquí de una conceptualización empírica y operativa del espacio doméstico, definido en términos de la realización de actividades cotidianas, evidenciadas arqueológicamente a través de la presencia y particularidades de sus restos materiales.

Esta investigación se basa puntualmente en el análisis de la composición y distribución espacial de dos conjuntos de artefactos presentes en el Núcleo 1 de Cardonal, las plantas comestibles y los artefactos de molienda. Su objetivo es dar cuenta de la ocurrencia y características de una serie de acciones y actividades implicadas en su uso diario. De tal modo se intenta profundizar en la comprensión del complejo de prácticas y modos de hacer cotidianos de los aldeanos que habitaron el valle hace unos dieciocho siglos. En esta dirección, los fines específicos incluyen la identificación del rango de recursos vegetales comestibles utilizados, el reconocimiento de las áreas dónde se desarrollaron actividades cotidianas de procesamiento y consumo de los recursos vegetales, la caracterización del conjunto de artefactos de moler y la distinción de los espacios donde ocurrió cotidianamente la molienda y otras prácticas relativas al uso de estos instrumentos.

Para cumplir con estos propósitos se aplican herramientas y procedimientos metodológicos propios de la arqueobotánica y del análisis tipológico de los moledores líticos. La primera incluye el diseño de toma de muestras de sedimento que son luego procesadas por la técnica de flotación para la recuperación de material vegetal carbonizado leñoso y carpológico. Sobre este último se realizan determinaciones taxonómicas a nivel de Familia, 
Género, Especie y Variedad, a partir de la comparación de una serie de atributos morfológicos cualitativos y cuantitativos con ejemplares de referencia, actuales y arqueológicos, así como material bibliográfico. En base a la información obtenida se procede a la sistematización cuantitativa de los datos, a través del empleo de conteos absolutos de ejemplares y cálculos de porcentajes relativos, frecuencias y densidades. Los resultados alcanzados permiten analizar comparativamente las diferencias y similitudes en la presencia y composición de los conjuntos de restos botánicos, tanto entre las estructuras del núcleo así como al interior de cada una de ellas, lográndose una imagen clara de la distribución de los restos carpológicos y leñosos en los pisos ocupacionales de los recintos.

De manera sumaria, la recuperación e identificación taxonómica de macrorrestos botánicos carbonizados permitió dar cuenta del uso de diferentes recursos vegetales comestibles. El rango de plantas alimenticias halladas comprende las especies cultivadas Zea mays y Phaseolus vulgaris var. vulgaris y las especies silvestres Geoffraea decorticans, Prosopis alba o chilensis y Phaseolus vulgaris var. aborigineus. También se encontraron semillas asignables al género Chenopodium afines a especies alimenticias como Chenopodium quinoa ó Chenopodium pallidicaule. Sin ser extenso, este abanico de recursos permite apreciar no sólo la existencia combinada de prácticas de cultivo de plantas domésticas y de actividades recolección de otras silvestres, sino que remite al conocimiento y uso de espacios ecológicos diversos y a la vez complementarios como la Prepuna, el Monte y las Yungas de la vertiente oriental andina. De igual modo pone de relieve la participación de los pobladores del valle en redes de interacción social a larga distancia y el contacto con poblaciones vecinas y contemporáneas. Todos estos rasgos hacen a un modo de subsistencia mixto que conjuga la explotación de un área ecológica extensa y variada a través de mecanismos diversos, entre ellos el intercambio de productos, tal como ha sido señalada a partir de diversos materiales, tanto para Cardonal como para varios sitios de la falda oeste del Aconquija.

Asimismo, la caracterización cualitativa del conjunto de restos botánicos, efectuada a partir de observaciones y datos complementarios procedentes de fuentes antropológicas, históricas y agronómicas, permite plantear hipótesis y líneas de interpretación sobre la presencia y particularidades del uso de los frutos y semillas recuperados. Por otra parte esta información enriquece las consideraciones efectuadas en torno a los resultados obtenidos del análisis cuantitativo de los datos, cotejados a la luz de una serie de problemáticas particulares de los procesos de formación del registro arqueobotánico. Tal procedimiento dio lugar al reconocimiento de dos áreas distintivas y diferenciadas entre sí, vinculadas con el 
procesamiento de plantas comestibles que combinan la cocción de semillas y frutos así como el descarte y/o el uso de partes no comestibles con otros fines, entre otras acciones que intervinieron en la distribución no simétrica de los restos al interior de los recintos.

Por su parte, el registro exhaustivo de los artefactos de molienda presentes en la estratigrafía del sitio permite dar cuenta de una enorme cantidad de piezas en diferentes estados de preservación, muchas de las cuales pertenecían a los niveles de la ocupación. El análisis tipológico aplicado a estos últimos dió lugar a la caracterización del conjunto de instrumentos líticos usados para moler, tanto desde sus aspectos morfológicos como funcionales, en base a un conjunto de variables cualitativas y cuantitativas previamente seleccionadas. Asimismo, al recabar información acerca de la posición y disposición de los artefactos y su estado de conservación, fué posible realizar inferencias acerca de las condiciones de su abandono, ya se encontraran estos en uso, almacenados/guardados, descartados o reutilizados en funciones iguales o diferentes a la molienda. De este modo se obtuvo una visión comparativa de la ocurrencia de actividades de molienda entre y al interior de las habitaciones, algunas características relevantes de la práctica y los espacios a ella destinados, en tanto pudieron inferirse otras acciones mediadas por los mismos instrumentos.

La caracterización del conjunto lítico de molienda, según los tipos y cantidades de artefactos que lo componen, dio cuenta de una práctica de notable importancia, que fuera realizada fundamentalmente con sistemas formados por grandes molinos y sus respectivas manos. Se integraban además, en muy escaso número, morteros muy pequeños acompañados de pilones cuidadosamente confeccionados. El análisis de la distribución espacial de las piezas y la observación de las condiciones de uso y disposición de cada instrumento al momento del abandono de sitio, permitieron distinguir tres espacios efectivamente vinculados con las acciones de moler, diferenciables entre sí de acuerdo a los instrumentos que allí se asocian. A su vez se reconocieron áreas de guardado de piezas, así como acciones de descarte y reutilización de las mismas en funciones diferentes de la molienda.

Otros aportes de la tesis comprenden la confección de una colección herborizada de plantas que crecen actualmente en una amplia zona en torno al sitio arqueológico, la cual cuenta con información sobre nombres vernáculos y usos tradicionales. Conjuntamente se recolectó un repertorio de semillas y frutos comestibles de importancia en el Noroeste argentino que se emplearon como referencias para el reconocimiento de los ejemplares arqueológicos. Asimismo se provee de un modelo de fabricación de cubeta de flotación asistida por flujo de agua, testeado con buenos resultados, de particular utilidad en sitios de difícil acceso y escasa disponibilidad de agua o bien de otras fuentes de energía. 
En términos generales este estudio ha permitido ahondar en el conocimiento de la organización de los espacios domésticos, así como diversos aspectos de las actividades desarrolladas en contextos aldeanos de los primeros siglos de la era cristiana. Así también hace su aporte a la comprensión de la economía doméstica, el aprovechamiento de recursos y modalidades de uso de artefactos y bienes de subsistencia del sur de los Valles Calchaquíes. Propone a su vez una serie de interrogantes e hipótesis ligadas a la interpretación de los materiales y contextos domésticos arqueológicos del área, así como plantea algunas consideraciones metodológicas, como punto de partida para futuras investigaciones. 


\section{Abstract}

This thesis is a contribution to the knowledge of the village societies of the first millennium of the Christian Era settled in the south of the Calchaquíes valleys, a place that comprises the Cajón valley, the southern part of the Santa María valley and the western flanks of the Aconquija mountain range. This study focuses on the analysis of the dwelling areas, particularly the group of structures that form one of the residential compound of the archaeological site of Cardonal (ca. 200 d.C.) located in the southern part of the Cajón valley (Santa María, Catamarca).

Choosing a micro-scale to deal with the nature and dynamics of the early agriculture and herding communities of the area is coherent with the theoretical perspective that considers that the detailed study of the configuration of the domestic spaces as well as the activities that where there developed is capable of revealing general aspects of the culture and social organization of the groups involved. In concordance, I depart from an empirical and operative conceptualization of the domestic space, defined in terms of daily activities, which are archaeologically evidenced in the presence and particularities of their material remains.

This investigation is based on the analysis of the composition and spatial distribution of two sets of artefacts of the Núcleo 1 at Cardonal site -the edible plants and the milling tools- in order to characterize the actions and activities that were implied in their daily use. In this way, this thesis delves into the comprehension of the habitual practices and ways of doing of the village societies that inhabited the valley some eighteen centuries ago. Accordingly, specific objectives include the identification of the range of the edible vegetable resources used, distinguishing the areas where the daily processing and consumption of those resources took place and characterizing the set of milling artefacts as well as the spaces reserved for their daily use.

To accomplish such objectives, archaeobotanical methodological principles and typological analysis of the grinding artefacts were employed. The first includes the design of recovery procedures used to obtain the sediment samples which were later floated to recover charred firewood, seeds and fruits. By comparing a series of qualitative and quantitative morphological attributes, seeds and fruits are taxonomically determined in terms of Family, Genre, Species and Variety using comparative archaeological and modern reference samples as well as bibliographical material. The information is then systematically quantified by the absolute counting, calculation of relative percentages, frequencies and densities. The results 
thus obtained, allow the comparative analysis of the differences and similarities in the presence and composition of botanical remains, both between and within each structure. This in turn offers a clear image of the distribution of the remains found in the habitation floors.

In summary, the recuperation and taxonomical identification of charred botanical macro-remains revealed the use of different edible vegetable resources. The range of alimentary plants found include the cultivated species of Zea mays and Phaseolus vulgaris var. vulgaris and the wild species of Geoffraea decorticans, Prosopis alba or chilensis and Phaseolus vulgaris var. aborigineus. Seeds assigned to the genre Chenopodium which have affinity to alimentary species such as Chenopodium quinoa or Chenopodium pallidicaule were also found. The identification of such range of resources points to the existence of combined practices of cultivation of domestic plants and gathering of wild species. Moreover, it makes reference to the acquaintance with and use of diverse but complementary ecological spaces such as the Prepuna, the Monte, and the eastern Yungas. Similarly, it highlights the participation of the valley communities in long-distance webs of social interaction as well as their contact with neighbouring and contemporary groups. Altogether, these evidences point towards a mode of mixed subsistence which articulates the exploitation of an extended and varied ecological area through diverse mechanisms, such as the exchange of diverse products, an activity that has been previously observed as far as different types of materials are concerned, both in Cardonal and the various sites of the western flanks of the Aconquija mountain range.

The qualitative characterization of the botanical remains using anthropological, historical and agronomic sources, allowed the proposal of hypothesis and interpretations over the presence and particularities in the use of the recovered fruits and seeds. On the other hand, this information enriched those interpretations obtained through the analysis of quantitative data, a task that also included the consideration of a series of specific situations inherent to the formational process of the archaeobotanical record. As a result, two distinctive and differentiable areas involved in the processing of edible plants were recognized. This processing combined the cooking of seeds and fruits as well as the discard and/or use of nonedible parts for different purposes as well as other actions that shaped the asymmetrical distribution of the remains inside the structures.

The exhaustive register of the milling artefacts present in the site's stratigraphy allows identifying an enormous quantity of instruments with different states of preservation, many of which belonged to the occupational levels. The typological analysis applied to these resulted in the morphological and functional characterization of the group of lithic grinding tools, 
based on a series of pertinent qualitative and quantitative variables. Inferences about the conditions of abandonment of these artefacts -whether these were actually in use or kept away, discarded or reused with other purposes- were possible thanks to the recovering of information of their position, disposition and state of preservation. In this way, a comparative vision of the occurrence of milling activities both within and in-between each room, together with some characteristics relevant to the practice of milling and the spaces that were destined to this task is obtained. Other types of actions mediated by the same instruments could also be inferred.

The characterization of the set of milling instruments with regards to types and quantities brings to forth practices of major importance that were done using systems of grinding stones molinos and manos. Also, a very scant number of small morteros and carefully crafted pilones were integrated within this system. The analysis of the spatial distribution of the tools and the observation of the conditions of use and disposition of each instrument at the moment of their abandonment are used to distinguish three spaces that were effectively related to milling actions. These where in turn differentiable according to the instruments associated to each area. Furthermore, areas where the tools were kept away as well as actions of discard and reuse of these instruments with different purposes were recognised.

An additional contribution of this thesis is the assemblage of a herbal collection of plants that presently grow within a wide zone surrounding the archaeological site. This collection also gathers information regarding vernacular names and traditional uses of each plant. A repertoire of reference samples of edible seeds and fruits of great importance in current Northwestern Argentina were also collected to use them for the recognition of archaeological samples. Besides these further contributions, a model of a floating device which has been tested with positive results is provided. This model is of particular utility in archaeological sites of difficult access and scant water availability or other sources of energy.

In general terms, this study has allowed deepening the knowledge of the organization of domestic spaces, as well as diverse aspects of the activities that were developed within preHispanic village contexts dated to the first millennium of the Era. Moreover it contributes to the comprehension of the domestic economies, the use of resources as well as the modes of use of artefacts and staples within the Cajón valley. This study also proposes a series of questions and hypothesis related to the interpretation of the archaeological materials and domestic contexts of the area as well as some methodological considerations as a departing point to further investigations. 


\section{Índice de Figuras}

Figura 1. Plano general del sitio Cardonal........................................27

Figura 2. Ubicación la aldea arqueológica Cardonal y otros sitios formativos................29

Figura 3. Plano del sitio Cardonal sobre foto aérea.....................................30

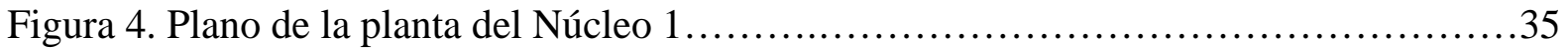

Figura 5. Recipientes hallados en el Núcleo 1 de Cardonal..............................36

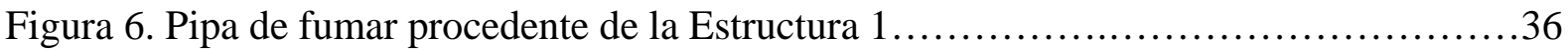

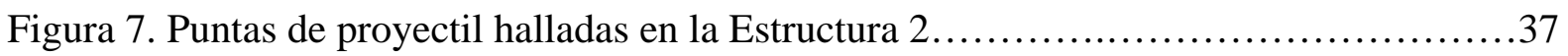

Figura 8. Improntas de cestería recuperadas en E2.....................................37

Figura 9. Fitogeografía de los alrededores de La Quebrada............................41

Figura 10. Ciénagos utilizados para la cría de animales en La Quebrada..................42

Figura 11. Paisaje de Prepuna y Monte en La Quebrada...............................44

Figura 12. Paleoambiente. Cambios en las condiciones de humedad ambiental..............50

Figura 13. Partes que componen la cubeta de flotación...................................61

Figura 14. Cubeta de flotación en funcionamiento...................................62

Figura 15. Área de recolección de ejemplares de herbario...............................78

Figura 16. Carbonización experimental de ejemplares de referencia.......................79

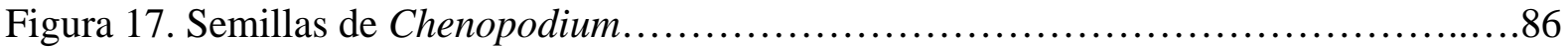

Figura 18. Semillas de Chenopodium arqueológicas.................................... 87

Figura 19. Semillas de $C$. quinoa hervidas.............................................

Figura 20. a- Semillas de C. quinoa hervidas y posteriormente carbonizadas..................88

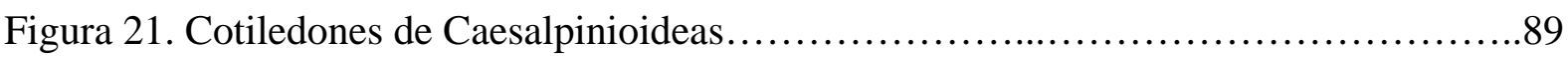

Figura 22. Mimosoideas.........................................................90

Figura 23.Semillas de Geoffraea decorticans......................................91

Figura 24- Fragmentos de endocarpos de Geoffraea decorticans........................93

Figura 25. Cotiledones de $P$. $v$. var. vulgaris...................................... 98

Figura 26. Cotiledones de $P$. v. var. aborigineus.......................................99

Figura 27. Semilla de MALVACEAE.................................................100

Figura 28. Semilla Solanoideae...................................................101

Figura 29. Granos de Zea mays................................................ 104

Figura 30. Cúpulas de Zea mays AMARILLO.......................................104

Figura 31. Semillas no identificadas............................................. 107 
Figura 32. Cubiertas de frutos.................................................. 109

Figura 33. Tallos y pedúnculos.................................................. 110

Figura 34. Molinos de mano recuperados en niveles ocupacionales.......................136

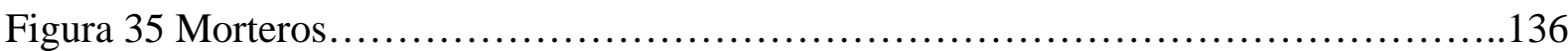

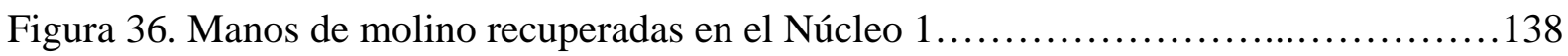

Figura 37. Área de molienda en E1..............................................140

Figura 38. Mano de molino E2-M1 en hueco de pared de E2 ...........................140

Figura 39. Molino de mano utilizado como jamba.....................................142

Figura 40. Molinos de mano en E3................................................144

Figura 41. Mano de mortero o pilón E5-M23........................................145

Figura 42. Molinos de mano E1-C11 y E1-C4 excavados en E5...........................145

Figura 43. Pozo cavado en la roca de base del Portal de E5..........................146

Figura 44 Diferentes usos de las manos de molino..................................148 
Índice de Tablas

Tabla 1. Fechados radiocarbónicos del Núcleo 1 de Cardonal..............................29

Tabla 2. Número de unidades de excavación por Estructura...............................51

Tabla 3. Número de muestras obtenidas según su procedencia ............................56

Tabla 4. Tipo y cantidad de ejemplares en muestras experimentales......................80

Tabla 5. Cantidades y porcentajes de recuperación en test experimental............................81

Tabla 6. Restos vegetales carbonizados recuperados..................................81

Tabla 7. Cantidad de restos recuperados por diferentes técnicas.........................82

Tabla 8. Cantidades ( $n$ ) y porcentajes (\%) de carporrestos completos y fragmentarios.........82

Tabla 9. Descripción de los ejemplares de Chenopodium...............................83

Tabla 10. Dimensiones en ejemplares de referencia de semillas de quinoa no carbonizadas..85

Tabla 11. Dimensiones en ejemplares de referencia de semillas de quinoa carbonizadas......85

Tabla 12. Dimensiones en ejemplares de referencia de semillas de cañiwa no carbonizadas..85

Tabla 13. Descripción de los ejemplares de Caesalpinioideas.............................88

Tabla 14. Descripción de los ejemplares de Mimosoideae....................................89

Tabla 15. Descripción de los ejemplares de semillas de Geoffraea decorticans................91

Tabla 16. Descripción de los endocarpos de Geoffraea decorticans.......................92

Tabla 17. Descripción de los cotiledones de P. vulgaris...............................98

Tabla 18. Descripción de los granos de Zea mays.....................................101

Tabla 19. Medidas de longitud y latitud de las cúpulas de Zea mays AMARILLO...........103

Tabla 20. Descripción de restos TIPO 1 (semillas).....................................105

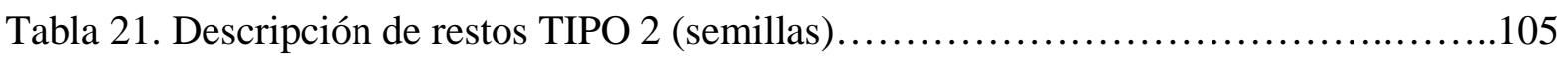

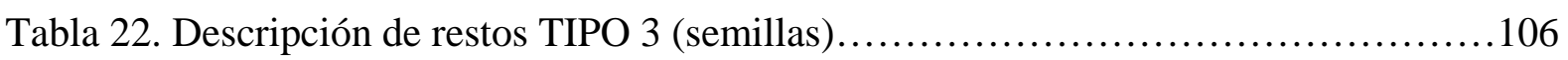

Tabla 23. Descripción de restos TIPO 4 (semillas)...................................106

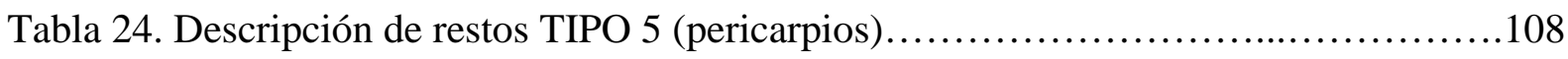

Tabla 25. Descripción de restos TIPO 6 (tallos y pedúnculos)............................109

Tabla 26. Cantidades absolutas de restos recuperados en flotación e in situ..................110

Tabla 27. Cantidades absolutas de restos recuperados in situ ...........................113

Tabla 28. Cantidad de muestras conteniendo cada tipo de carporresto. Ubicuidad.............122

Tabla 29. Cálculo global y por estructura de las densidades de carporrestos .................124

Tabla 30. Promedio de las densidades de carbón de leño y carporrestos......................125

Tabla 31. Densidades de carporrestos en diferentes espacios...........................129 
Tabla 32. Cantidad de artefactos completos y fragmentarios.............................131

Tabla 33. Cantidades de fragmentos de artefactos con diferentes ubicaciones................134

Tabla 34. Cantidades de artefactos de molienda completos con diferentes ubicaciones.....134

Tabla 35. Cantidades de artefactos de molienda activos, pasivos y de posición

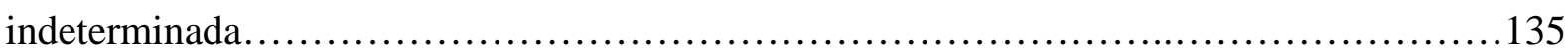




\section{Índice de Gráficos}

Gráfico 1. Porcentajes de plantas silvestres en la colección clasificadas por Familia..........79

Gráfico 2. Porcentajes de restos recuperados por diferentes técnicas.......................82

Gráfico 3. Distribución por tamaños de los cotiledones de $P$. vulgaris....................99

Gráfico 4. Cantidades absolutas de restos carpológicos presentes en cada recinto...........111

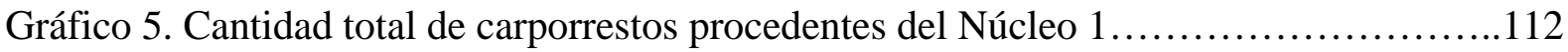

Gráfico 6. Cantidad de carporrestos en muestras obtenidas in situ.......................113

Gráfico 7. Tamaño y composición de los conjuntos de restos recuperados.................116

Gráfico 8. Porcentaje relativo de restos por habitación.................................117

Gráfico 9. Porcentaje relativo de restos correspondientes a cada grupo identificado..........117

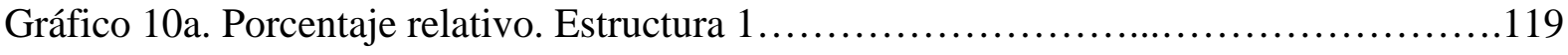

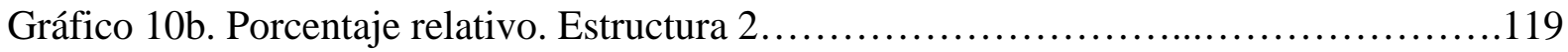

Gráfico 10c. Porcentaje relativo. Estructura 3.......................................120

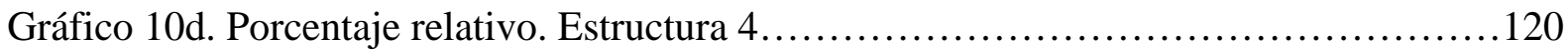

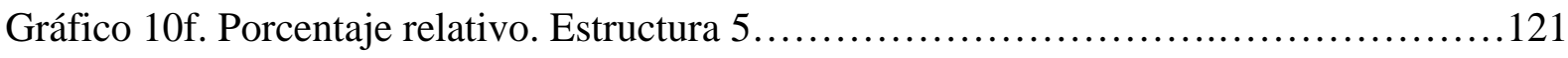

Gráfico 10g. Porcentaje relativo. Portal...........................................121

Gráfico 11. Valores generales de la ubicuidad de los restos recuperados por flotación........123

Gráfico 12. Ubicuidad de los restos de flotación recuperados por Estructura.................124

Gráfico 13. Promedio de las densidades de carbón de leño por nivel.....................126

Gráfico 14. Promedio de las densidades de carporrestos por nivel excavado.................127

Gráfico 15. Correlación de las variables ‘densidad de carbón de leño’ y ‘densidad de carporrestos'....

Gráfico 16. Cantidades y densidades de carporrestos comparadas entre espacios y rasgos

Gráfico 17. Cantidades relativas y porcentajes de artefactos de molienda completos y

fragmentarios

Gráfico 18. Cantidades relativas de artefactos de molienda completos y fragmentarios.....132

Gráfico 19. Cantidades y porcentajes de artefactos por nivel y en derrumbes................132

Gráfico 20. Cantidades de fragmentos de artefactos con diferentes ubicaciones..............134

Gráfico 21. Cantidades de artefactos de molienda completos en diferentes.....................135

Gráfico 22. Cantidad de artefactos activos, pasivos y de posición indeterminada............135 


\section{CAPÍTULO 1}

\section{Introducción, problemática y objetivos}

\section{Introducción}

Este trabajo de tesis ha tenido lugar en el marco de un proyecto mayor de estudios arqueológicos sobre las sociedades agropastoriles prehispánicas asentadas al sur de los Valles Calchaquíes. Los objetivos de dichas investigaciones se orientan a comprender la naturaleza de los sistemas aldeanos del primer milenio d.C. y los procesos de cambio de las condiciones materiales y sociales experimentadas por los pobladores de estas comunidades. En tal dirección se han producido numerosos artículos y trabajos de tesis que avanzan en la comprensión de las trayectorias de diferenciación social, mecanismos de subsistencia y sistemas de representación en sitios de la falda oeste del Aconquija, sur del valle de Santa María y valle del Cajón (e. g. Bugliani 2008, Cortés 2007, Izeta 2007, Lazzari 2006, Pereyra Domingorena 2007, Scattolin 2000, 2004, 2006a, 2006b, 2007a).

El abordaje de tales problemáticas es múltiple e incluye el examen y la interpretación de diferentes indicadores arqueológicos. Varios estudios se han dedicado a la caracterización de los conjuntos cerámicos y repertorios decorativos vinculados a interrogantes sobre el consumo doméstico de objetos y estilos alfareros (Bugliani 2008), así como el uso de representaciones plásticas en contextos funerarios (Bugliani 2007), aspectos relativos a la dinámica del cambio cultural y cronología del área (Scattolin 2000, 2003a, 2004, 2004b 2006a, 2006b, 2007b, 2007c, Scattolin et al. 2001), jerarquización social (Scattolin 2003b, 2006c) y redes de circulación de bienes e información (Lazzari et al. 2009, Pereyra Domingorena 2007). Esta última temática ha sido objeto además de una serie de estudios sobre artefactos líticos y procedencia de las materias primas utilizadas (Lazzari 1997, 1999a, 1999b, 2003, 2005, 2006, Scattolin y Lazzari 1997, Lazzari et al. 2009). Se han estudiado también prácticas inhumatorias y ajuares funerarios a partir del hallazgo y análisis de varios enterrarorios, contextos poco conocidos en el área hasta el momento (Cortés 2007, Scattolin et al. 2005, 2007-2008). Los restos de fauna son, al día de hoy, los artefactos mayormente analizados en torno a la subsistencia y economía doméstica del primer milenio al sur del Calchaquí (Izeta 2006, 2007a, 2007b, 2008a, 2008b, Izeta y Cortés 2006, Izeta y Scattolin 
2002, 2006, Izeta et al. 2000, Izeta et al. 2009), en tanto que las prácticas agrícolas y el uso de plantas ha sido tratado esporádicamente (Pochettino y Scattolin 1991, Calo et al. 2006-2007). En este sentido, algunas consideraciones han tenido lugar a partir de las primeras caracterizaciones de los asentamientos aldeanos de la falda oeste del Aconquija, al centrar el análisis en los modos en que se disponen las áreas productivas de los sitios respecto de las domésticas (Scattolin 1990, 1994a, 1994b, 2001, 2004, 2007a, Scattolin y Albeck 1994). Sin embargo el estudio de los poblados derivó luego en un interés creciente por las áreas habitacionales, en especial sobre la configuración interna y aspectos cronológicos de las casas (Gero y Scattolin 1994, 1999, Scattolin y Gero 1994, 1999, Scattolin et al. 2007a, 2007b, 2009a, 2009b).

Sin abandonar la problemática planteada en el proyecto mayor, las investigaciones más recientes se han dedicado a la exploración de la historia de las sociedades tempranas en relación a la arquitectura de los espacios domésticos y de las actividades cotidianas. Se ha puesto el foco en las maneras en que se construyen y transmiten las tradiciones, prácticas y modos de hacer propios, que expresan las permanencias y los cambios culturales ocurridos en el pasado de los grupos sociales (Scattolin et al. 2007a, 2007b, Scattolin et al. 2009a, 2009b). De esta forma, la producción de información así como su análisis e interpretación han acentuado su carácter "acumulativo, minucioso, ricos en datos y a escalas múltiples" (Scattolin 2008: 1) en la búsqueda de respuestas posibles a los interrogantes planteados.

Dentro de tal perspectiva de estudios surge el plan de tesis que se presenta en esta oportunidad. Su cometido ha sido entrever una parte del complejo de actividades y prácticas que tuvieron lugar en el transcurso de la vida cotidiana de los primeros aldeanos del valle del Cajón (Catamarca) hace unos dieciocho siglos. La mirada se centró entonces en las acciones, los modos de hacer y los gestos vinculados en particular al uso de artefactos de molienda y plantas comestibles en uno de los núcleos habitacionales del sitio Cardonal. Se exploraron aspectos composicionales y distribucionales de ambos conjuntos de objetos al interior del núcleo, desde una perspectiva que ha permitido reconocer y caracterizar una serie de acciones e interacciones sociales intrínsecas a la utilización, elaboración, consumo, guardado, descarte de los artefactos mencionados.

De esta manera se intentó profundizar en el conocimiento de la vida cotidiana de las comunidades tempranas del Cajón, con el objeto último de contribuir a la comprensión de la naturaleza de las sociedades aldeanas del sur de los Valles Calchaquíes, así como generar datos que colaboren en el avance de los estudios sobre la dinámica cultural del primer milenio en la región. A su vez se intentó aportar al conocimiento del uso de vegetales comestibles y el 
empleo de instrumentos molienda, dos tópicos para los cuales prácticamente no existen estudios sistemáticos en el área de estudio, en tanto su desarrollo más o menos reciente dentro de la arqueología del Noroeste argentino requiere aún de grandes esfuerzos de producción y análisis de datos.

\section{El espacio doméstico en el valle del Cajón: problemática y objetivos de la investigación}

Los estudios más recientes desarrollados en los sitios Cardonal y en menor medida Bordo Marcial, los refieren como dos aldeas de los primeros siglos de la era cristiana de notable similitud constructiva, separadas entre sí por un cerro de mediana altura. “Ambos sitios se organizan en el espacio guardando cierto sentido de simetría, replicando modos de organización, lo cual denota maneras compartidas de construir, organizar y habitar” (Scattolin et al. 2009a: 266). El análisis de estos sitios ha dado cuenta de varias particularidades de las áreas habitacionales y los espacios domésticos de valle del Cajón que avanzan sobre los primeros datos obtenidos a partir de los trabajos desarrollados en Yutopián (Gero y Scattolin 1994, 1999, Scattolin y Gero 1994, 1999).

Partiendo de algunas nociones complementarias sobre el espacio, la arquitectura y los paisajes, elaboradas por autores como Bourdieu [1972] 2000, De Certeau 2000, Goodman 1990, Ingold 1993, 2000, entre otros, se ha sugerido que el espacio doméstico de Cardonal y su análogo Bordo Marcial, fue construido y modelado a través de un continuum de prácticas que involucran acciones diarias recurrentes y renovadas, como encender fuego, hacer cerámica, tallar líticos, moler, circular, remodelar muros, fumar, comer (Scattolin et al. 2009a, 2009b). La historia de las áreas habitacionales tiene así sus referentes materiales en la presencia de artefactos y las relaciones que guardan entre ellos dentro de un espacio construido cotidianamente, siendo él mismo también el creador de las prácticas y relaciones sociales que se establecen entre las personas, las cosas y los lugares.

En este sentido se ha apuntado que en la historia de la casa de Cardonal existen múltiples referencias espacio-temporales manifiestas tanto en las formas de hacer propias como en objetos de alfarería, materias primas líticas y los esquemas generales empleados en la construcción de las casas. Tales materialidades e ideas evocan a su vez elementos presentes en las regiones de Yungas, Puna y algunos valles distantes, recombinándolos en nuevos objetos y modos de hacer propios de las comunidades del valle del Cajón. 
Así por ejemplo se observó que el patrón de construcción de espacios residenciales en “Unidades Circulares Compuestas”, compartido con una amplia franja de asentamientos que se extiende desde la Puna catamarqueña hasta la vertiente oriental andina en Tucumán (ver Scattolin et al. 2007a), se distingue por una organización propia de los espacios internos en Cardonal y Bordo. Se ha observado que el núcleo habitacional 1 de Cardonal comprende un área segmentada en cinco recintos, uno de los cuales funciona como patio, delineando así pautas de acceso y circulación entre las habitaciones que le son propias. Sin embargo, tal segmentación parece haber cumplido un rol secundario respecto de la organización de las tareas desarrolladas en cada uno de los espacios así definidos.

Es decir, si bien fue posible diferenciar recintos donde se realizaron preferentemente determinadas labores, otras distintas parecen haberse desarrollado en simultáneo y de forma no excluyente en la misma habitación. Los materiales recuperados indican a la vez que ciertas tareas se llevaron a cabo en varias de las estructuras que componen el núcleo habitacional analizado, en particular el encendido de fuego, la cocción de alimentos y la molienda, como así también la construcción y remodelación de estructuras, el almacenaje de materiales y objetos, la talla lítica o el modelado de cerámica, sin que necesariamente éstas guarden características simétricas entre las habitaciones (Scattolin et al. 2009a).

Es sobre estos aspectos que se realizaron algunas de las consideraciones más interesantes y reveladoras sobre la organización de las actividades y la organización de la vida doméstica en Cardonal y su articulación con la dinámica regional de las comunidades. En este sentido, progresar en su conocimiento puede brindar resultados sumamente enriquecedores para la comprensión del pasado del área de estudio. Un avance tal se relaciona en gran medida con el planteamiento de nuevos interrogantes, así como con la aplicación de abordajes metodológicos específicos de los materiales y los contextos. En base a estos procedimientos el presente trabajo de tesis centra su atención en la caracterización de las acciones $\mathbf{y}$ actividades que involucran específicamente el uso de plantas comestibles y artefactos de molienda, en un intento de profundizar la exploración de las prácticas vinculadas al uso y consumo de bienes alimenticios de las poblaciones tempranas del valle.

Al respecto, el análisis e interpretación de los contextos excavados en el Núcleo 1 de Cardonal refieren la ocurrencia de actividades de combustión en tres de las habitaciones, las cuales fueron asociadas a actividades de preparación de alimentos en función del hallazgo de algunos restos de origen animal y vegetal entre el carbón de leña, así como de otros ítems relativos a estas acciones, como las ollas con tizne y sedimentos grasos y ennegrecidos. Sin embargo, tal distinción no ha sido referida aún a datos que permitan evaluar diferencias 
significativas en la presencia/ausencia de restos de plantas y/o animales comestibles con otras áreas y rasgos del núcleo habitacional, de manera que los espacios de combustión aparezcan distintivamente enriquecidos en vestigios producto de la manipulación de alimentos (Scattolin et al. 2009a).

Asimismo se ha señalado que existen variaciones de grado en la estructuración de las prácticas generadoras de los rasgos de combustión. Se refiere particularmente que el fogón de "E1, por ejemplo, probablemente fuera utilizado en la cocción de alimentos de manera cotidiana, mientras que otros espacios con evidencias de combustión habrían implicado la utilización del fuego de forma menos sistemática (E2, E5).” (Scattolin et al. 2009a: 264). Esta diferenciación de grado se basa en la observación de cambios notables en la estructuración misma de los fogones y en la presencia más o menos recurrente y dispersa de restos orgánicos asociados a enseres de cocina con evidencias de uso. Nuevamente aquí la distinción en base a datos sistemáticos de la presencia en número y tipo de restos botánicos permitiría evaluar no sólo el grado en que las actividades varían de una a otra área de combustión, sino también reconocer posibles diferencias en la naturaleza de las acciones que se desarrollaron en cada una.

Además, se ha mencionado que las actividades de molienda habrían tenido lugar en varias de las habitaciones, tal como lo evidencia la presencia de los numerosos artefactos empleados para tal fin distribuidos en casi todos los espacios de la casa. Aún así se hace referencia a algunas configuraciones particulares de conjuntos de artefactos en diferentes habitaciones que suscitan interrogantes sobre posibles diferencias en el uso de estos instrumentos según el lugar donde se encuentren emplazados, su relación con actividades que impliquen la manipulación de alimentos y la relevancia de la práctica (Scattolin et al. 2009a).

Una característica notable observada de los pisos del Núcleo 1 es la ocurrencia de numerosos pozos cavados en la roca de base. Sin embargo en Cardonal, los escasos contenidos relevados hasta ese momento en dichas cavidades (residuos primarios, lascas, astillas óseas o puntas de proyectil) y la ausencia de diferencias texturales o tonales de la matriz sedimentaria del relleno de los pozos con los pisos no permitieron realizar ninguna asignación funcional. En cambio esta si ha sido más evidente en los casos en que se encontraban rellenos de un sedimento limo-arenoso blanco bien distintivo, el cual probablemente proceda de la limpieza de los fogones, a los cuales se asocian espacialmente estos rasgos. Otra incógnita fueron aquellos que contenían piedras pulidas apoyadas en el fondo (Scattolin et al 2009a). En otros sitios del área como Yutopián los pozos cavados en la roca de base fueron asociados a la posible conservación de productos vegetales (Gero y 
Scattolin 1994). De acuerdo con estos indicios cabe reconsiderar la posibilidad que los pozos hallados en el piso de Cardonal tuvieran en el pasado funciones distinguibles a través de otros procedimientos de recuperación y análisis de los contenidos vegetales y/o instrumentos pulidos empleados en la molienda.

Asimismo, varias estructuras de cultivo y manejo del agua han sido mencionados como posibles evidencias del desarrollo de actividades de cultivo.

"(...) Descendiendo por la pendiente sur de la mesada de Cardonal, se construyó otro conjunto de estructuras de contención del terreno y manejo del agua que se disponen perpendiculares a la pendiente. Mientras tanto, sobre la parte baja de la ladera de enfrente se extiende en sentido oeste-este una acequia paralela al área de viviendas que tiene su toma aguas arriba en el arroyo El Cardonal. Luego de un extenso recorrido, esta acequia se aleja en dirección sur hasta alcanzar el curso del río La Quebrada. La parte baja del cerro que flanquea el sitio por el norte presenta, además, un conjunto de canchones de cultivo subcirculares delimitados por muros de piedra. El material cerámico recolectado en estos sitios agrícolas vecinos de Cardonal y Bordo Marcial es asignable al I milenio d.C." (Scattolin et al. 2009a: 254255).

A pesar de las numerosas marcas en el paisaje, aún no ha sido fehacientemente registrada la presencia de plantas domesticadas al interior de los recintos habitacionales que sugiera el uso y consumo de vegetales cultivados que pudieran cultivarse en el área y asociables con mayor grado de certeza a la práctica agrícola, así como al posible empleo de las estructuras de cultivo circundantes. Por otra parte y de manera particular, los restos de “chañar” mencionados remiten al empleo de vegetales silvestres, para los cuales se desconoce aún su grado de incidencia dentro del conjunto de recursos comestibles empleados, incluyendo los productos animales, que definen el sistema de subsistencia "mixto" referido para otras aldeas formativas del área (e.g. Izeta 2007a, Lazzari 1997, Scattolin 1994a). En el mismo orden resta evaluar las implicancias del consumo de determinados alimentos no disponibles localmente, lo cual ha comenzado a vislumbrarse desde otro tipo de materiales en términos de la integración de espacios ecológicos disímiles y el establecimiento de relaciones sociales. 
De acuerdo a los interrogantes planteados anteriormente, el objetivo general que orienta este trabajo es dar cuenta de una serie de acciones y actividades involucradas en el uso de plantas de uso comestible e instrumentos de molienda, a partir del análisis de la composición y distribución espacial de ambos conjuntos de evidencias al interior del Núcleo 1, a fin de profundizar la comprensión del complejo de acciones y modos de hacer cotidianos de las aldeas agropastoriles del valle del Cajón.

En tal dirección, los objetivos específicos planteados incluyen:

1) identificar el rango de recursos vegetales comestibles utilizados, con vistas a la distinción entre aquellos de origen cultivado o silvestre y la localización de su área de obtención/producción.

2) reconocer al interior de las habitaciones del núcleo las áreas donde se desarrollaron actividades cotidianas de procesamiento y consumo de los recursos vegetales.

3) caracterizar el conjunto de artefactos de molienda según el tipo de piezas que lo componen y sus condiciones de uso al momento del abandono de sitio.

4) distinguir al interior de los recintos las áreas donde se desarrollaron cotidianamente actividades de molienda y otras prácticas relativas al uso de estos artefactos.

\section{Organización de la tesis}

El Capítulo 1 presenta una introducción general al tema. Estas palabras preliminares se siguen de la exposición de las más recientes investigaciones desarrolladas en el valle del Cajón, a las cuales se vincula directamente la problemática abordada en esta tesis. Se explicitan luego los interrogantes planteados y los objetivos generales y específicos que orientan el estudio, detallándose también brevemente el orden de los contenidos. Los antecedentes de investigación y el estado de conocimiento sobre el tema en el área tratada constituyen el último apartado de este Capítulo.

El Capítulo 2 expone los conceptos teóricos relevantes que guían el presente trabajo. Asimismo se plantea el estado avance de los estudios arqueológicos dedicados al análisis de los artefactos de molienda y de vegetales comestibles en contextos domésticos del Noroeste Argentino. Se hace hincapié en los problemas abordados con mayor interés y los diferentes enfoques considerados en el tratamiento de la temática. 
El Capítulo 3 presenta de manera detallada el sitio arqueológico Cardonal, del cual proceden los materiales y contextos que se analizan en esta tesis. A continuación se realiza una descripción del paisaje en que se halla emplazado, desde el punto de vista geográfico y ecológico. Se incluye hacia el final un recuento y breve discusión de los resultados conocidos hasta el momento sobre las condiciones ambientales imperantes hacia los inicios de la era Cristiana en los Andes Meridionales, considerándose sus implicancias durante la ocupación de Cardonal.

El Capítulo 4 se dedica a exponer y explicar los procedimientos metodológicos empleados en la recuperación, registro y análisis de los conjuntos botánicos y de los instrumentos de molienda de Cardonal. Se refieren algunas problemáticas puntuales acerca de los métodos y técnicas aplicados y se detallan los mecanismos de control de datos. En este Capítulo se expone además el proceso de construcción y las características del funcionamiento del sistema de flotación utilizado en la recuperación de restos vegetales.

Los Capítulos 5 y 6 muestran los resultados de los estudios efectuados sobre los materiales. El primero corresponde a los vestigios botánicos e incluye las determinaciones taxonómicas y el análisis, presentación y discusión preliminar de los datos. Por su parte el Capítulo 6 refiere la información obtenida a partir del examen de los artefactos de molienda, la clasificación por tipos de artefactos presentes, disposición y características de los contextos.

El Capítulo 7 se dedica a la discusión e interpretación de los datos derivados de los análisis en relación a problemáticas específicas de los restos estudiados y finalmente a la temática central y objetivos que motivan este trabajo de tesis. De tal forma se integran los nuevos resultados a la información previa existente para Cardonal y el valle del Cajón.

Por último, el Capítulo 8 refiere las conclusiones de la tesis remitiéndose a los objetivos planteados en el primer Capítulo. Asimismo, se evalúan los avances logrados con este trabajo, así como los nuevos y viejos interrogantes abiertos que requerirán de otras investigaciones a futuro. De esta manera se visualizan los pasos a seguir en el estudio de las actividades y configuración de los espacios domésticos prehispánicos al sur de los Valles Calchaquíes.

\section{La vida doméstica aldeana al sur de los Valles Calchaquíes}

Diferentes aspectos de la vida cotidiana de las comunidades formativas asentadas al sur de los Valles Calchaquíes han sido abordados con gran interés, especialmente aquellos en 
relación a la economía doméstica y los bienes de subsistencia. Desde el inicio de las investigaciones, la amplia presencia de canchones de cultivo y canales de irrigación asociados a los sitios de habitación puso de relieve el rol de los productos agrícolas en el sustento de las antiguas poblaciones locales (Scattolin 1990, Scattolin y Albeck 1994). Al respecto, uno de los primeros trabajos concernientes a los recursos vegetales cultivados y silvestres hallados en contextos formativos del área Valliserrana refiere a hallazgos de restos de maíz, chañar, porotos domesticados y silvestres en tres sitios de la falda oeste del Aconquija (Pochettino y Scattolin 1991). Este estudio da cuenta además de la incidencia de las actividades de recolección de recursos silvestres en los sistemas de subsistencia agrícola tempranos, así como del contacto con paisajes y poblaciones de la vertiente oriental de la sierra.

No obstante, la mayor parte de lo que se conoce acerca de las prácticas ligadas a la producción y consumo de bienes alimenticios en el sur del los Valles Calchaquíes han sido abordadas a partir del análisis de restos faunísticos. La tesis doctoral de Andrés Izeta se enfoca en los vestigios óseos procedentes de sitios de la falda oeste del Aconquija y el valle del Cajón, identificando la presencia de huesos de camélidos, cérvidos y roedores con marcas de diversos tratamientos de sus partes esqueletales. Este tipo de indicios sumados a la distribución de los residuos óseos permiten reconocer actividades y prácticas de consumo, trozamiento, reparto y distribución de recursos de origen animal a través del espacio y el tiempo. Señala asimismo que el manejo y uso de animales domesticados en los valles privilegia la cría de hatos de camélidos y su conservación hasta la edad adulta, diferenciándose así del modelo generado para las comunidades agropastoriles puneñas (Izeta 2007, 2008a).

En otro trabajo sobre restos óseos de animales recuperados en el Núcleo Habitacional E de Loma Alta, se observó además que el manejo pastoril, evidenciado por la presencia de huesos de camélidos domesticados, se complementaba en el pasado con actividades de caza de varias especies silvestres y con el uso oportunista de animales muertos por presiones ambientales (Izeta y Scattolin 2006). La incidencia de los recursos animales silvestres en la subsistencia en las aldeas de la falda oeste del Aconquija se ve sustentada además por la presencia de un conjunto lítico que abunda en variedades de piezas orientadas a mediar necesidades prácticas de la caza. Según Lazzari (2006) tales conjuntos líticos generalmente clasificados dentro de las llamadas tecnologías expeditivas, se combinan en este caso particular, con una circulación fluida de materia prima y un uso intenso y selectivo de diferentes obsidianas de zonas lejanas. Este carácter los vincula a una decisión cultural en intima relación con un modo de vida, que en el caso de los sitios del Aconquija, corresponde a 
comunidades agropastoriles que mantienen una marcada presencia del componente de caza en la dieta (Lazzari 2006).

A partir de estos estudios se ha sugerido que la subsistencia en la falda oeste del Aconquija podría haberse resuelto dentro de una serie de áreas complementarias: el sector occidental de la Falda propiamente dicho, el sector oriental de la misma y muy posiblemente los valles más bajos ubicados a ambos lados de la sierra, por medio del entrelazamiento de ciclos productivos también complementarios. Los ciclos de producción agrícola y pastoril se desenvolverían dentro de los límites del sector occidental del Aconquija. En tanto, los ciclos de extracción de productos silvestres incluirían los valles más bajos en una y otra ladera: caza en el Campo del Arenal, recolección de chañar en los valles occidentales y de poroto silvestre en los orientales. Serían estas últimas acciones tendientes a equilibrar los recursos entre las estaciones. A ello deben sumarse también las posibles evidencias de almacenaje, las cuales podrían estar indicando el manejo de un pequeño excedente de producción que contribuiría a mitigar las deficiencias estacionales de recursos (Lazzari 1997, Scattolin 1994c, Scattolin y Korstanje 1994).

Esta región, así definida por la complementariedad de recursos de diferente índole puede ser considerada la escala mínima de circulación de bienes y de la interacción social fuera de la Falda y puede incluir la circulación no sólo de bienes de subsistencia, sino además de prestigio o ambos, así como también alianzas matrimoniales o mano de obra. De igual manera excluye la circulación de otro bienes como la obsidiana, cuya procedencia excede los límites de esta “área de actividades de subsistencia” (Lazzari 1997: 44).

Al mismo tiempo de la publicación de estos estudios, una cantidad considerable de restos vegetales fue recuperada en diferentes recintos de habitación excavados en Yutopián. En este sitio se aplicaron técnicas de flotación que resultaron en la recuperación de restos carbonizados de chañar, maíz, Chenopodiáceas, Opuntia y Prosopis, entre otros mencionados en informes de gabinete (Meldem 1996, Rossen 1998a, 1998b). Asimismo, el análisis de microrrestos botánicos realizado por sobre material cerámico reveló la presencia de granos de almidón muy semejantes a los de una variedad de maíz de tipo reventón (Thompson 1998).

A pesar de tratarse de análisis preliminares de identificación taxonómica y conteos de restos de plantas, estos materiales vinieron a ampliar el abanico de recursos vegetales útiles conocidos hasta el momento para el sur de los Valles Calchaquíes. A su vez, la presencia de especies silvestres y domesticadas brindó renovado sustento al postulado de la existencia de prácticas de cultivo integradas con la recolección de plantas no cultivadas. No obstante, los datos proveyeron información insuficiente y poco clara acerca de la complementariedad de 
áreas ecológicas, especialmente la vertiente oriental andina, para la obtención de recursos de subsistencia, tal como ésta había sido planteada para la falda occidental del Aconquija.

Una buena parte de los restos botánicos de Yutopián se recuperaron en un contexto habitacional en donde la cocción de alimentos, la molienda efectuada con instrumentos de gran tamaño y el almacenaje de comestibles en pozos cavados en la roca de base, se hallaron en clara asociación la actividad metalúrgica. Las autoras sugieren que un grupo distintivo habría habitado este núcleo residencial emplazado en un espacio particular de la aldea, dedicado a la fundición de metales. Asimismo, la presencia simultánea de varias evidencias de actividades cotidianas, entre ellas la preparación de alimentos, halladas en el mismo espacio, pueden indicar que la producción especializada de bienes metálicos, generalmente considerada una práctica de carácter individual, involucraba en el caso de Yutopián a un grupo más o menos extenso de personas (Gero y Scattolin 1994, Scattolin y Gero 1994).

De esta manera, el interés por los recursos y la organización de la subsistencia en las aldeas del primer milenio se colocó ante sugerentes escalas de indagación, donde los modos de uso y consumo de tales recursos al interior de unidades domésticas particulares, podían poner a la luz diferentes aspectos de la naturaleza y la dinámica de las sociedades pasadas. Es así que nuevos análisis arqueofaunísticos del material óseo recuperado en el patio del Núcleo E de Loma Alta avanzaron hacia algunos aspectos finos de la economía doméstica del sitio, a través de una metodología geoestadística (Izeta 2008a). Se observó entonces que los restos óseos de animales no adultos, se asociaban en gran medida a la presencia de estructuras de combustión, lo cual los vinculaba a la ocurrencia de actividades de preparación de alimentos, particularmente la cocción. En cambio, la dispersión de los huesos de individuos adultos parece corresponder a diferentes actividades de preparación de alimentos, entre ellas la molienda. El autor señala asimismo que este patrón diferencial de descarte de huesos podría relacionarse con actividades culinarias disociadas en el tiempo y también posiblemente la redistribución de las partes hacia fuera de la unidad doméstica (Izeta 2008a).

Las actividades relativas a la preparación y consumo de productos alimenticios también han recibido atención desde estudios centrados en otros ítems recuperados en sitios arqueológicos del área. Algunos datos relevantes sobre las prácticas relativas al consumo y procesamiento de recursos comestibles proceden del análisis de microrrestos vegetales depositados en artefactos de molienda. Tres manos de molino halladas en un gran patio de actividades múltiples excavado en Loma Alta (Scattolin 1990) formaron parte del conjunto de instrumentos de moler analizados por Babot (2004). Dos de ellas mostraron que los recursos de molienda incluían plantas cultivadas y silvestres, tanto de procedencia local como del área 
al Este de la sierra del Aconquija: maíz, porotos silvestres, Cucurbita, tubérculos y/o raíces. El tercer artefacto sin embargo sólo presentó restos pulverizados de sustancias minerales (yeso y calcita) (Babot 2004). Más allá de este estudio, las piedras de moler recuperadas en sitios del sur de los Valles Calchaquíes no han recibido mayor atención. Si bien la mayoría de ellas han sido incorporadas a la caracterización, definición e interpretación de los contextos domésticos (e.g. Scattolin 1990, Scattolin y Gero 1999, Scattolin et al. 2009a, Scattolin et al. 2009b), aún no se han llevado adelante estudios sistemáticos de los conjuntos de molienda.

La tesis doctoral de Bugliani (2008) por otra parte, se enfoca en el consumo y las representaciones plasmadas en piezas de alfarería, formulando una serie de consideraciones significativas sobre el uso diferencial de la cerámica en distintas actividades y situaciones domésticas. Señala por un lado que las decoraciones y pulidos se concentran en artefactos cerámicos de factura fina, utilizados como contenedores asociados al servicio de alimentos. Los mismos habrían sido utilizados para el consumo de sólidos, líquidos u otros productos, tratándose además de artefactos manuables y livianos entre los que se cuentan escudillas, cuencos, jarras, jarros y botellas, aptos para actividades de contención y circulación de los productos en el ámbito doméstico. Sostiene por otra parte que este conjunto presenta una alta variabilidad de formas en las que se invirtieron la mayor cantidad de recursos estilísticos, lo cual indica su importancia en las actividades humanas y en la generación y mantenimiento de las relaciones sociales. Estas piezas tendrían también otras aplicaciones más allá de la función primaria de contención o servicio de comida u otros productos, puesto que generalmente se trata de categorías de vasijas de alta visibilidad y exposición colectiva.

En cambio, el conjunto cerámico ordinario es útil para la preparación y cocción de alimentos, pensado para una circulación restringida al interior de la cocina y al ámbito más privado de la casa. Su alta exposición a agentes de desgaste como el fuego puede explicar la menor inversión de trabajo y habilidades en la expresión de representaciones y terminaciones cuidadas, las cuales están prácticamente ausentes. El rango de estos recipientes normalmente incluye vasijas globulares, con aberturas medianamente restringidas del tipo olla en las cuales es común la presencia de hollín o de otros rastros producto de la exposición al fuego, pero no necesariamente todos los recipientes tienen indicios de uso en la cocción. También este grupo reúne los recipientes utilizados para el almacenamiento de alimentos sólidos o líquidos, las cuales, además de ollas, pueden ser jarras, tinajas o cántaros.

Otros materiales como los cestos espiralados, de los cuales fueron halladas sus improntas, han sido relacionados con actividades de recolección, cosecha y almacenamiento de comestibles y/u otros objetos en el ámbito doméstico del sitio Cardonal del valle del Cajón 
(Calo 2008). Asimismo se ha planteado la importancia del consumo de maíz para las poblaciones del área, en base a los resultados obtenidos del análisis de isótopos estables sobre restos óseos humanos procedentes de enterratorios datados en los inicios de la era en el valle de Santa María (Calo y Cortés 2008).

En suma, las investigaciones arqueológicas al sur de los Valles Calchaquíes comentadas anteriormente han logrado exponer varios aspectos de la naturaleza de economía doméstica y los bienes de subsistencia durante el primer milenio d.C. En primera instancia han establecido la existencia de un tipo de subsistencia mixto, que combina el cultivo de vegetales y el pastoreo de camélidos. Se pudo saber también que ambas prácticas coexistían a la vez con actividades de caza de animales silvestres y la recolección de frutos y semillas de especies no domesticadas que procedían de espacios ecológicos diversos y complementarios. Desde una perspectiva regional amplia este carácter de la subsistencia ha sido interpretado como un indicio fuerte de la movilidad de las poblaciones asentadas en el área de estudio, del conocimiento y manejo de paisajes disímiles, del contacto e interacción con poblaciones vecinas, de la integración de redes de intercambio de productos y de circulación de ideas.

Al mismo tiempo, se ha señalado que estas acciones se plasman en el interior de las áreas habitacionales, tanto en la presencia y distribución de conjuntos específicos de recursos vegetales, animales y minerales, como en la asociación con objetos diversos como las vasijas cerámicas, los artefactos líticos y los instrumentos de molienda. De esta manera se obtuvo una fructífera visión de la organización del espacio doméstico y las personas a través de los objetos y las prácticas que los involucran. Se observó por ejemplo que existe una diferencia notable en los enseres de preparación y servicio de alimentos en relación a la situación más o menos pública o privada a las que son destinados y los espacios más o menos visibles o íntimos en los que se los emplea. A su vez, se estimó la posible existencia de prácticas de redistribución de recursos comestibles de origen animal por fuera de los núcleos domésticos y se refirió la aplicación de procesos de preparación diferenciales según los distintos grupos etarios de animales consumidos, entre los cuales se encuentra la cocción en fogones y la molienda.

En síntesis, un buen número de estudios que preceden a este trabajo se han interesado por comprender el modo en que los bienes de subsistencia, instrumentos, estructuras y demás objetos son sensibles a los cambios y persistencias ocurridos en los grupos sociales pasados. Así, el análisis y la interpretación de los materiales y contextos arqueológicos domésticos del sur de los Valles Calchaquíes han permitido develar diversos aspectos de la dinámica de la producción y reproducción de las comunidades allí asentadas, tales como la producción 
agrícola, el aprovechamiento de recursos silvestres, el intercambio de bienes y objetos, el manejo de las áreas productivas, la redistribución y el consumo de alimentos. De este modo ha comenzado a elaborarse un cuadro acerca de los procesos de desarrollo y la naturaleza de las sociedades aldeanas del primer milenio de la era, al que se intenta contribuir desde la presente investigación. 


\section{CAPÍTULO 2}

\section{La molienda, los vegetales y la vida doméstica}

\section{Consideraciones teóricas para el estudio de los materiales del Núcleo 1: actividades y espacio doméstico}

Este estudio se interesa en la presencia y distribución espacial de materiales específicos al interior de un área habitacional circunscripta al espacio interno de un núcleo habitacional. De esta forma intenta caracterizar dicho espacio dando cuenta de las acciones y actividades cotidianas transcurridas en el pasado del núcleo. Para lograr este objetivo toma como base una serie de conceptos teóricos que han sido problematizados y discutidos en el marco de la llamada Household Archaeology (Wilk y Rathje 1982): espacio doméstico, unidad habitacional, actividades domésticas, cultura material.

La Arqueología de la Unidades Domésticas, tal como suele denominarse en nuestra lengua, refiere a un conjunto de aproximaciones teóricas y metodológicas que buscan comprender diferentes aspectos sociales, políticos y económicos de los grupos humanos a partir del análisis a microescala de su dinámica organizacional (Wilk y Rathje 1982).

\section{Las actividades y las unidades domésticas}

Dado que la arqueología no trabaja directamente con las unidades domésticas sino con sus vestigios materiales, sus caracteres más accesibles se encuentran en relación con las diferentes actividades que el grupo social desarrolla dentro de un área física interior y exterior. Dicha área es identificable a través de un conjunto de evidencias arqueológicas: la unidad habitacional (Aldenderfer y Stanish 1993, Wilk y Ashmore 1988, Wilk y Rathje 1982). En general se considera que dichas actividades incluyen la producción, el consumo, el reparto de bienes y recursos, la reproducción, la corresidencia y la propiedad compartida (Wilk y Ashmore 1988). Varios estudios se han dedicado a la identificación de actividades y su localización dentro de las unidades habitacionales con el fin de dar cuenta de algunas tareas 
culturalmente reconocidas que los grupos domésticos llevan a cabo en determinadas sociedades (i. e. Flannery 1976, Hendon 1996, Manzanilla 1986, 1990, Stanish 1989)

Se ha señalado sin embargo que si bien este tipo de abordaje permite acceder a la caracterización de los grupos domésticos pasados por lo que hacen, haciendo a un lado rasgos más problemáticos y menos accesibles arqueológicamente como el parentesco o la composición social de las unidades, presenta dificultades de índole similar a aquellos. Las mismas tienen que ver con que el empleo que generalmente se hace de supuestos a priori acerca de los procesos culturales que articulan la unidad doméstica -en este caso la realización de determinadas actividades- y en base a los cuales se buscan los correlatos materiales de dichas relaciones (Nielsen 2001).

Estas ideas previas acerca de la naturaleza de las unidades domésticas surgen generalmente de analogías con modelos etnográficos o históricos a través de los cuales se asume el riesgo de sesgar u ocultar gran parte de la variabilidad del pasado, refiriéndolo a situaciones culturales, temporales o espaciales que le son ajenas (Allison 1999, Nielsen 2001). Una visión de este tipo genera gran ambigüedad en el reconocimiento de la estructura y dinámica de los grupos domésticos, debido principalmente a que existe una inmensa variación intercultural en los modos en que se organizan las actividades y en la composición de las unidades sociales que las llevan a cabo. En este sentido, la unidad social implicada y su correlato material serán muy diferentes según cuál de estas actividades se considere (Nielsen 2001, Wilk y Ashmore 1988).

\section{La arquitectura y el uso del espacio}

Una problemática similar a la señalada anteriormente está presente en estudios arqueológicos como los de Blanton (1994) o Kent (1990), en los cuales se considera los restos de la arquitectura doméstica para describir el comportamiento de los grupos sociales pasados (Allison 1999). Nuevamente aquí cabe recordar que los lugares de habitación son unidades físicas a través de las cuales es posible ver el patrón cultural del ordenamiento del espacio, y no el comportamiento y la percepción del espacio de las unidades domésticas que construyeron y/o habitaron las unidades habitacionales. Esto es así puesto que de igual modo que no puede plantearse la uniformidad entre las actividades y/o la composición social de diferentes grupos, tampoco es posible obviar la alteridad en la percepción del espacio de quienes diseñan, construyen, habitan o remodelan una misma unidad de habitación (Rapoport 1990). 
Otros problemas señalados por Allison respecto de esta perspectiva arquitectónica del estudio de las unidades domésticas son, por un lado, sobrevaloración de los pisos ocupacionales en detrimento al carácter intrínsecamente tridimensional de las proporciones arquitecturales, las ventanas, perspectivas y decoraciones. Asimismo observa la tendencia a considerar en el análisis a unidades habitacionales individuales tal y como si éstas hubieran sido habitadas por grupos domésticos individuales. Otros trabajos han mostrado que una misma unidad de habitación puede estar ocupada por más de una unidad doméstica, a la vez que un mismo grupo doméstico puede residir en diferentes estructuras habitacionales o bien prescindir totalmente de ellas (Allison 1999).

\section{La propuesta de Rapoport: actividades y escenarios}

Una forma de evitar las problemáticas señaladas antes ha sido considerar que tanto las actividades, como el comportamiento y las unidades domésticas mismas no son el punto de partida sino el objetivo de las inferencias realizadas en base a estructuras y objetos excavados en áreas habitacionales (Wilk y Ashmore 1988, Nielsen 2001). Uno de los enfoques más utilizados en este tipo de estudios ha sido propuesto por Rapoport (1990). Esta perspectiva arquitectónica no parte de un modelo previo de la unidad doméstica y el espacio físico que esta ocupa sino que se centra en la definición del espacio doméstico como un sistema de escenarios donde se llevan a cabo sistemas de actividades unidos entre sí a través de los significados. Según el autor, la noción de actividades no es autoevidente y requiere de una definición en torno al tratamiento de dos cuestiones fundamentales, a saber:

A) La relación de las actividades con la cultura de un grupo social

Según Rapoport (1990) las expresiones sociales de la cultura, como son los grupos, la estructura familiar, las instituciones, las redes sociales, el estatus y muchas otras, a menudo tienen espacios asociados a ellas, o bien se ven reflejadas en el ambiente construido. Dicho ambiente puede tomarse como punto de partida más específico para el estudio de un grupo, ya que se trata de una de las expresiones sociales más concretas de la cultura.

Las actividades, por su parte, son consideradas una de las expresiones sociales más específicas de una cultura en particular, entre las que se encuentran también los estilos de vida, valores, cosmovisiones, entre otros, que también se relacionan o son congruentes con determinadas partes del ambiente construido. De esta forma, el autor sostiene que la relación entre las actividades y el ambiente construido o la arquitectura, está mediada por la cultura. Señala a su vez que las actividades tienden a modelar la arquitectura y por tal motivo esta 
última es capaz de dar cuenta tanto del comportamiento y las acciones de los diferentes grupos sociales. Tal premisa se ha basado generalmente en dos supuestos:

a- que la arquitectura y el ambiente construido en general afectan el comportamiento, lo guían y lo constriñen y

b- que el ambiente construido es creado para sustentar un comportamiento deseado y que lo hace de una manera muy ajustada.

Para Rapoport tal premisa corresponde a una suposición lógica y en cierta medida correcta. No obstante, las proposiciones en que las está basada no logran explicarla íntegramente con mayor certeza. En esta dirección se propone alcanzar una definición clara de la noción de actividades, la cual es expresada en términos de

B) Los cuatro aspectos fundamentales que las definen. Los mismos se manifiestan en los materiales en diferente grado $(\downarrow)$ y de manera inversa a la medida en que varían a través de diferentes grupos sociales $(\uparrow)$.

1- la naturaleza de las actividades o sus aspectos instrumentales

2- el modo en que son llevadas a cabo

3- la manera en que se asocian a otras actividades

4- el significado de las mismas

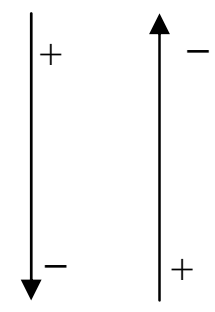

Remarca a su vez que el análisis de todos estos aspectos debe tener en cuenta lo que queda sugerido en el tercer punto, es decir que las actividades siempre se encuentran asociadas en sistemas de actividades donde el análisis de partes (actividades) aisladas no es posible. Los sistemas de actividades son secuencias específicas en cuanto a su naturaleza, la forma en que se conectan o se separan, las personas involucradas, el lugar y el momento en donde ocurren. Asimismo debe tenerse en cuenta que los sistemas de actividades se organizan no sólo en el espacio sino también en el tiempo.

Ello indica que, por un lado, los sistemas de actividades no pueden comprenderse a través del análisis de determinados espacios construidos, como partes aisladas del contexto amplio del paisaje cultural. Los mismos deben considerarse como espacios formados por lo que el autor llama una serie de escenarios interconectados entre sí a través de las actividades mismas, es decir un sistema de escenarios. Los escenarios y sus límites se definen culturalmente a la vez que ellos mismos constituyen espacios que definen las situaciones, las reglas y las conductas apropiadas para la acción y la relación. Asimismo el autor considera que el significado constituye una de las principales funciones de las actividades, hallándose 
entre los aspectos fundamentales a considerar en términos de los mecanismos que relacionan las personas y sus actividades a los escenarios en que estas se llevan a cabo.

Por otro lado, la noción de que las actividades se organizan también en el tiempo ha sido considerada uno de los aportes más interesantes de la propuesta de Rapoport (1990) (Vaquer 2007). Dicha idea ha sido desarrollada posteriormente por varios autores interesados en una redefinición del concepto de espacio y en particular del espacio doméstico. Para Tilley (1994) por ejemplo el espacio está siempre relacionado con diferentes temporalidades debido a que los mismos son creados, reproducidos y transformados en relación con otros espacios cuya construcción y establecimiento los precede. Para este autor el tiempo representa en sí mismo un componente fundamental del espacio y del espacio doméstico en particular, al que le corresponde el tiempo humano, el tiempo de la vida cotidiana y el de las actividades diarias.

A su vez se ha propuesto que la cultura material y el uso del espacio se encuentran imbuidos con varias temporalidades diferentes que son producto de su articulación con los patrones del tiempo diario, biográfico e institucional dentro de una sociedad (Lane 1994 en Vaquer 2007). El espacio doméstico puede entonces apreciarse en dos dimensiones temporales: la de la vida de los individuos y la de la vida de las generaciones. La primera se identifica con el espacio de la vida diaria y las actividades cotidianas ocurridas en el tiempo biográfico de los agentes. La segunda en cambio se expresa en el espacio del ciclo de vida de la vivienda y las actividades de la vida cotidiana que corresponden al tiempo biográfico de varias generaciones. Es esta última la dimensión mejor abordada por la arqueología, ya que generalmente los conjuntos artefactuales de los pisos de ocupación domésticos representan un palimpsesto que cubre actividades de la vida cotidiana de diferentes generaciones. De acuerdo con ello, los restos de cultura material pueden y deben ser empleados para investigar patrones de actividad doméstica que persisten por generaciones (Vaquer 2007).

\section{La cultura material y las unidades habitacionales. Objetos, rasgos y estructuras}

Junto con la propuesta de Rapoport (1990) comentada en el apartado anterior, el presente estudio toma en consideración una perspectiva complementaria, que dirige su atención hacia los conjuntos de artefactos en sí mismos (Allison 1999, 2001, 2004). En este caso, la respuesta a la pregunta planteada en el primer acápite diría que los arqueólogos no excavan unidades domésticas así como tampoco excavan unidades habitacionales. De un modo más amplio, la arqueología interesada en los grupos domésticos trabaja con la cultura 
material de dichos grupos, siendo los restos arquitectónicos parte constitutiva de dicha cultura material junto con los restos artefactuales. Uno y otro tipo de vestigios, a los que Rapoport en el citado trabajo, denomina fijos y semifijos, son capaces de dar cuenta de las actividades desarrolladas en un espacio habitacional determinado.

"In this connection it is useful to conceptualize the environment as consisted of fixed-feature elements (buildings, floors, walls, etc.), semi-fixedfeature elements (“furnishings," interior and exterior, of all sorts), and non-fixedfeature elements (people and their activities and behaviour).” (Rapoport 1990: 13)

Las actividades se hacen visibles a través del análisis e identificación de patrones recurrentes de distribución espacial de estos elementos, por lo cual no requiere del empleo de modelos procedentes de sociedades actuales o históricas que adelanten inferencias acerca del comportamiento y las acciones, así como del uso y la percepción del espacio de las unidades domésticas del pasado.

Por último, cabe remarcar que los artefactos suelen ser uno de los contenidos más abundantes de las unidades habitacionales, cuyo estudio es capaz de brindar gran cantidad de información acerca de las relaciones que existen entre las actividades y los materiales involucrados. A diferencia de los rasgos arquitectónicos, el arreglo espacial de los objetos y otros vestigios es generalmente efímero y no se encuentra necesariamente delimitado por aquellos. Este carácter le da la ventaja de introducir nuevos parámetros para la comprensión del rango y distribución de las actividades, denotar permanencias y cambios, así como posiblemente también echar luz sobre los comportamientos y las ideologías involucradas (Allison 1999, 2004, Rapoport 1990).

\section{De semillas y molinos. Los artefactos como referentes materiales de actividades domésticas.}

A pesar de las reservas que han sido planteadas respecto del uso de datos etnográficos e históricos en el estudio arqueológico de las unidades domésticas, este tipo de información, así como aquella generada desde perspectivas teórico-metodológicas diversas, no puede ni debe ser considerado periférico al análisis del registro material de las actividades pasadas. Si bien el foco de la crítica está puesto en el uso directo de modelos actuales, o bien aquellos 
referidos en los textos de historia o arqueología, para la descripción del comportamiento de los grupos en el pasado, existen otros procedimientos deseables y enriquecedores en la interpretación del registro arqueológico. Los mismos pueden advertir acerca del potencial de cambio y la diversidad del mundo doméstico, así como también servir de indicadores de la complejidad de las actividades y los comportamientos. Los abordajes cross-culturales y la comparación entre contextos antiguos y presentes significan aportes sustanciales para la comprensión de las unidades domésticas, del mismo modo que la integración de la información arqueológica de amplias regiones puede poner a la luz aspectos que están ausentes en las poblaciones contemporáneas (Allison 1999).

El recorte analítico efectuado en esta tesis hace referencia a dichos procedimientos en el estudio de dos conjuntos particulares de artefactos arqueológicos, los restos de plantas comestibles y los instrumentos de molienda, sobre los cuales se cuenta al día de hoy con una serie de abordajes desde las diferentes perspectivas mencionadas. Brevemente, vale decir que buena parte de los trabajos previos que consideran este tipo de vestigios han logrado de inferir y/o caracterizar el conjunto de actividades vinculadas a la alimentación de grupos sociales particulares. Entre ellas pueden mencionarse, por ejemplo la selección, obtención, preparación, almacenamiento, descarte, consumo, etc. Asimismo ha habido interés en indagar diversos aspectos de estas actividades, tales como los criterios empleados en la selección de productos comestibles, la secuencia temporal de las acciones, su localización espacial, entre otros considerados vías de aproximación válidas a la comprensión de la vida doméstica de los grupos sociales pasados (Atalay y Hastorf 2006).

El estudio de los moledores de piedra y los restos de comida, como así también de los fogones, las ollas de cocina y sus contextos, han sido con frecuencia vinculados a datos procedentes de observaciones actuales y pasadas de diferentes poblaciones andinas. En base a ello se sugirió que dichos materiales forman una parte importante del conjunto de artefactos y rasgos inmersos en el accionar cotidiano de los grupos sociales de la región y que constituyen elementos esenciales para la producción diaria de comida (Coleman Goldstein 2008). Estas premisas se fundan además en una idea más amplia acerca de la naturaleza de la alimentación como práctica social. En este sentido se sostiene que la comida y todo lo que a ella concierne constituyen acciones manifiestas en el día a día de los grupos domésticos, puesto que son imprescindibles para su reproducción. Se las estima entonces en términos de un conjunto de actividades preeminentemente cotidianas presentes entre las más evocativas y fundamentales de todas las estudiadas por los arqueólogos (Atalay y Hastorf 2006). 


\section{El estudio de la vida cotidiana andina a través de los artefactos domésticos arqueológicos. Abordajes y estado del conocimiento en el Noroeste argentino}

Tanto los estudios sistemáticos sobre restos botánicos como aquellos dedicados a los artefactos de molienda, cuentan con una historia relativamente reciente en la arqueología del Noroeste argentino. Unos y otros muestran momentos iniciales en los que la descripción y clasificación, o identificación taxonómica en el caso de los vegetales, bastaban a los fines de incorporar este tipo de vestigios al inventario de los sitios (Babot 2004, Capparelli et al. 2001).

Por su parte, los análisis de restos vegetales en contextos arqueológicos realizados desde perspectivas más abarcadoras, como el consumo y la producción de recursos de subsistencia, tienen su inicio recién en los años '90, momento en el cual las temáticas y especializaciones de la Arqueobotánica se diversifican y enriquecen (Capparelli et al. 2001). Los objetivos principales de los numerosos trabajos producidos a partir de este período se concentran en realizar interpretaciones acerca del abanico de recursos alimenticios empleados por un grupo, los mecanismos de obtención, las áreas de aprovisionamiento, los criterios de selección de los mismos, los cambios ocurridos en el tiempo, entre otras temáticas abordadas a partir de restos macroscópicos de plantas recuperadas en contextos habitacionales. Entre estos trabajos podemos citar las publicaciones de Capparelli y Raffino (1997), Capparelli et al. (2004), Capparelli et al. (2007), Carrizo et al. (2003), Korstanje y Würdschmidt (1999), Oliszewski (2004, 2005), Oliszewski y Olivera (2009), Rodríguez (1999a, 1999b, 2004), Rodríguez y Aschero (2007), Rodríguez et al. (2006), Scattolin y Pochettino (1991), entre otros.

A los análisis de restos macroscópicos se sumaron poco después los estudios de microrrestos en contextos productivos (Korstanje 2003, 2005) y de actividades de procesamiento, especialmente la molienda (Babot 2004, 2006). En este último trabajo la autora encara con renovado interés el estudio de las prácticas de molienda a través del examen minucioso de la tecnología, la morfología y los restos microscópicos de almidón en piedras de moler de contextos cronológicamente diferenciados de la Puna, los Valles y las Yungas del Noroeste argentino. De esta forma logra establecer conclusiones sobre la intensificación de la molienda a través del tiempo, la multifuncionalidad de los artefactos y los correlatos orgánicos de la actividad (Babot 2004). 
En un trabajo más reciente esta misma autora advierte que tanto la morfología como la función de un artefacto de molienda se encuentran influidas por consideraciones tecnológicas y por los diferentes usos dados durante su vida útil y no tanto por el tipo de material que se procesa con ellos. Es por esta razón que la asociación de determinados vegetales alimenticios a los instrumentos de moler, como se ha pretendido desde algunos enfoques tradicionales en el caso del maíz y otras especies agrícolas, asume una serie de riesgos. Tales correlaciones sólo son posibles a través de evidencias directas, como los microvestigios botánicos y rastros químicos depositados en las superficies activas, o bien en base a las huellas de uso presentes en el artefacto. No obstante ello, los restos macroscópicos de plantas comestibles brindan información sobre los recursos potencialmente molidos, cuando se los interpreta en relación a un contexto de preparación y consumo de alimentos en los que se incluyen artefactos de molienda. A su vez, el análisis contextual y espacial permite avanzar en la comprensión de la organización del trabajo de molienda y en las relaciones sociales que modelan esta práctica (Babot 2007).

El material cerámico, especialmente las ollas de cocina, han sido empleadas para complementar la información obtenida a través del análisis de restos macroscópicos de plantas y restos óseos recuperados en estructuras identificadas como habitaciones y patios de carácter doméstico del sitio incaico Shincal de Quimivil. El objetivo es discernir el espectro de recursos utilizados y dilucidar estrategias de aprovisionamiento y empleo de los recursos. En base a la comparación de materiales se da cuenta de tendencias disímiles entre los conjuntos artefactuales de diferentes recintos, señaladas por un aumento en la cantidad y diversidad de recursos vegetales y animales, ligada a la presencia de abundantes fragmentos de ollas manchadas de hollín entre las que se encuentran fragmentos de cerámica inca provincial. Proponen además que el carácter del sitio ha sido fundamentalmente doméstico (Lema et al. 2009).

El artículo de Capparelli (2009) se enfoca en el patrón de distribución de recursos vegetales comestibles al interior de once estructuras del mismo sitio arqueológico. Este estudio comprende un abordaje diferente de los restos botánicos respecto de los análisis publicados anteriormente en el marco del mismo proyecto (Capparelli y Raffino 1997, Capparelli et al. 2004). Aquí prevalece el interés en las actividades que la autora denomina “post-harvest” y que incluyen los tratamientos y usos subsecuentes de las plantas luego de haber sido obtenidas (Capparelli 2009:115). Para ello utiliza cálculos de densidad y ubiquidad de restos vegetales de manera comparativa entre las estructuras. Señala la presencia y el uso de especies domésticas y silvestres, destacándose la importancia de estas últimas, 
particularmente del algarrobo, el cual la autora relaciona con uno de los recursos importantes para el control estatal incaico. Examina cuidadosamente los procesos de formación de sitio que podrían haber afectado la conservación de restos como los tubérculos y el maíz, representados en proporciones singularmente menores a las esperables. Apunta algunos aspectos del procesamiento de diferentes plantas de acuerdo a las partes representadas en el registro. Concluye que los conjuntos vegetales recuperados en cada una de las estructuras permiten observar diferencias entre ellas, relacionadas con funciones específicas y actividades asociadas a la estructura, incluso en aquellas que son arquitecturalmente similares, advirtiendo sobre las consideraciones a tener en cuenta en la interpretación de la economía incaica (Capparelli 2009).

La presente tesis se vincula a estos abordajes recientes que, fundados en la consideración de conjuntos de restos vegetales distribuidos en los pisos ocupacionales de las viviendas ó de los sistemas de molienda dispuestos en las habitaciones de las casas, buscan dilucidar aspectos culturales y sociales de la vida doméstica en el pasado, tales como modalidades de uso y obtención de materiales y objetos, actividades desarrolladas y funcionalidad de los espacios a los que se circunscriben. Partiendo del estudio combinado de ambos tipos de restos, este trabajo se interesa específicamente por el carácter de las acciones y actividades relativas a su uso a través del análisis composicional y distribucional de los mismos al interior de un espacio habitacional excavado en su totalidad. 


\section{CAPÍTULO 3}

\section{Caso de estudio y arqueología del área. Marco geográfico-ambiental}

\section{Sobre el sitio arqueológico Cardonal}

\section{La arqueología del valle del Cajón}

Los primeros trabajos exploratorios y descriptivos de los sitios y materiales de este valle, ubicado entre el valle de Santa María y el borde sur oriental de la Puna catamarqueña, datan de fines del siglo XIX y principios del siglo XX (Ten Kate 1983, Bruch 1911, Schreiter 1919, Weiser 1920-1928). Más adelante, Cigliano publica su tesis doctoral en la que analiza las colecciones antiguas (las urnas excavadas por Weiser en Campo del Fraile), revisita Famabalasto y elabora la primera cronología de la zona basada en el estudio de sitios tardíos y residenciales complejos de la ladera oriental del valle (Cigliano 1956-1957, 1958, Cigliano et al. 1972). Luego, el trabajo de Arena (1975) ajusta dicha cronología, mencionando además varias ocupaciones del Formativo.

Otros estudios posteriores focalizados en el período incaico del valle (de Hoyos 1994a, 1994b, 1996, 1999; de Hoyos y Williams 1994) y con arte rupestre (de Hoyos y Lanza 2000, de Hoyos et al. 2000) se desarrollan paralelamente a las excavaciones que llevaban adelante M. Cristina Scattolin y Joan Gero en Loma Yutopián, en la localidad de La Quebrada.

Es en Yutopián, en los años '90, donde comienzan las investigaciones arqueológicas sobre los asentamientos tempranos del valle del Cajón. Este sitio ha sido descripto como una aldea temprana de unas tres hectáreas dispuesta en la parte superior y la ladera de una loma. Está compuesto por numerosos recintos construidos en piedra que conforman concentraciones de diferente densidad en las que pueden distinguirse áreas de habitación, estructuras amplias y recintos agrícolas. En este asentamiento se ha identificado más de una ocupación, correspondientes a distintos períodos cronológicos y de desarrollo. Hacia el sur del sitio se encuentran las construcciones asignables al Período de Desarrollos Regionales, en tanto que las más tempranas se ubican hacia el norte, donde también se detectaron algunas áreas circunscriptas que posiblemente dataran de momentos algo más tardíos. En la parte central del 
sitio, en cambio, se observaron casos claros de ocupaciones superpuestas, donde los estratos con materiales tardíos se disponían sobre capas con restos asignables al período temprano. En esta misma zona, las áreas menos profundas presentaron una notable mezcla de vestigios pertenecientes a uno y otro momento de desarrollo (Scattolin y Gero 1999). Los trabajos arqueológicos subsiguientes en Yutopián incluyeron la excavación dos núcleos habitacionales ubicados en el sector norte del sitio y una estructura (Estructura 11) en el área central Este del mismo, correspondientes al momento de ocupación más temprano del sitio (Scattolin y Gero 1999; Gero y Scattolin 2002; Izeta 2007a; Bugliani 2008).

Poco después se inicia la exploración del sitio Cardonal, ubicado unos 7 km al sureste de Yutopián. El relevamiento preliminar de las estructuras de superficie, llevado a cabo por Scattolin, da como resultado un primer plano donde se identifican sectores y núcleos habitacionales. Dicho plano fue revisado, corregido y aumentado en varias campañas posteriores desarrolladas por los equipos de la Dra. Gero en 2004 y Scattolin en 2004 y 2005, con lo cual se logra delinear la organización arquitectónica general del sitio que se conoce actualmente.

En cuanto a las excavaciones, en mayo de 2004 la Dra. Gero y su equipo realizan los primeros pozos de prueba con el objetivo de comprender la estratigrafía general del sitio. Uno de estos sondeos (PP3) deja a la vista la estructura de un fogón circular en uno de los recintos del Núcleo 1 (Gero 2004). A partir de este hallazgo se da comienzo a la ampliación del pozo y la excavación en área de una parte de la estructura. Los trabajos de excavación subsiguientes fueron desarrollados por el equipo que dirige la Lic. Scattolin. En campañas consecutivas a partir de 2004 y hasta 2008 se ampliaron las excavaciones en área a los cinco recintos adyacentes y comunicados entre sí que componen el Núcleo 1 y se efectuó un pozo de sondeo en el Recinto 14 del Sector I (PP13) (Figura 1).

Casi simultáneamente con los trabajos en Cardonal, se releva y excava parcialmente un recinto en Bordo Marcial, una aldea contigua que presenta notables similitudes arquitectónicas y de organización del espacio construido con Cardonal (Scattolin et al. 2009a). Ambos sitios, junto con Yutopián y otros cuatro asentamientos de vivienda asignables a momentos temporales diferentes dentro del período Formativo e incluso, posiblemente al período Tardío (1000-1500 d.C.), denotan la complejidad y diversidad arqueológica de este sector del valle del Cajón. Tal carácter alude indudablemente a una larga historia y dinámica de ocupación del paisaje, del cual se ha señalado que conforma una localidad arqueológica que suma nueva información a la historia ocupacional del valle (Ten Kate 1896; Schreiter 1919; Arena 1975; de Hoyos 1996, 1999; Scattolin et al. 2009a, Scattolin y Gero 1999). 


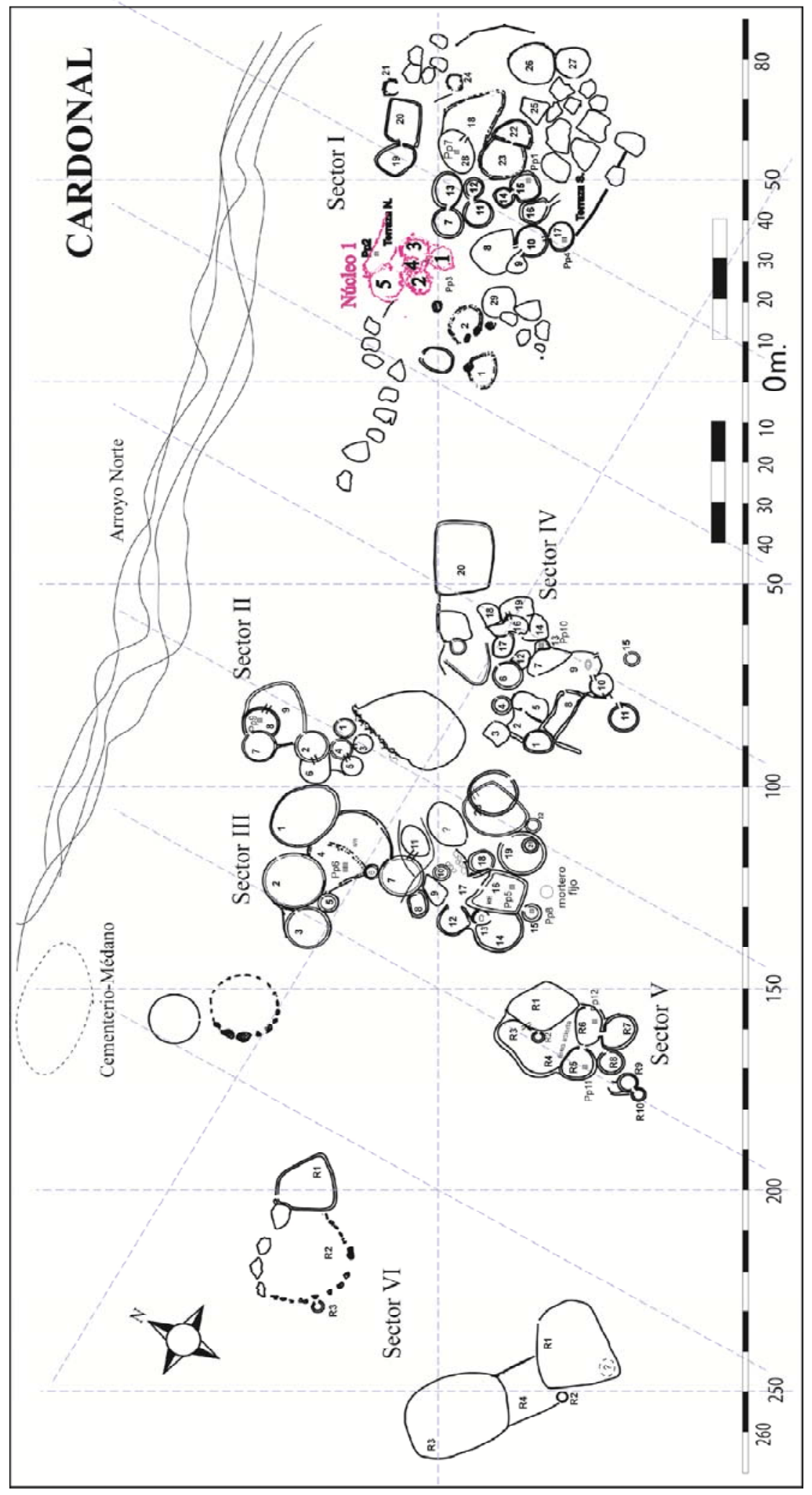

Figura 1. Plano general del sitio Cardonal con indicación de los Sectores I a VI, pozos de prueba efectuados y ubicación del Núcleo 1. 


\section{Ubicación y cronología del sitio arqueológico Cardonal}

Los materiales estudiados en esta tesis proceden de las excavaciones desarrolladas en el sitio arqueológico Cardonal. El mismo está ubicado sobre una mesada de escasa pendiente a 3000 msnm, en la porción meridional del valle del Cajón (2641’13,29”S y 66²7’29,97’O), al suroeste del Departamento de Santa María, Catamarca (Scattolin et al. 2007a, Scattolin et al. 2009a) (Figura 2). Según las dataciones radiocarbónicas, esta aldea estuvo habitada hacia los primeros siglos de la era cristiana. Los fechados de cada una de las cinco estructuras del núcleo habitacional indican que el mismo estuvo ocupado hacia los primeros dos siglos de la era, tratándose estadísticamente de fechas idénticas (Scattolin com. pers.) (Tabla 1).

\section{Descripción general del sitio}

Cardonal se compone de unas 100 estructuras circulares a subcirculares, de diámetro variable (2 a $6 \mathrm{~m}$ ), que cubren una superficie de aproximadamente tres hectáreas sobre una terraza de poca pendiente. Dichas unidades se encuentran dispuestas en grupos discretos de recintos adyacentes, conformando de esta manera los núcleos habitacionales del sitio. Cada núcleo está separado de los otros por algunos metros de distancia, formando seis concentraciones mayores que han sido denominadas Sectores (Scattolin et al. 2007a, 2007b). El núcleo habitacional cuyos materiales se estudian en esta tesis es el Núcleo 1, ubicado en el Sector I del sitio (ver Figura 1).

Entre las áreas de habitación y los espacios más altos empleados para entierros se ubicaron estructuras de diámetros mayores, que posiblemente fueran utilizadas como corrales. Otros espacios productivos como áreas destinadas al cultivo se destacan en laderas y cerros adyacentes por la presencia de arreglos de piedra diversos, como canchones y estructuras de control del agua. Cardonal también presenta áreas de cementerio distinguibles en la parte norte y este de la aldea. El material lítico y cerámico en estado fragmentario abunda sobre toda la superficie del sitio, así como también se encontraron grandes cantidades de artefactos de molienda (Figura 3). 


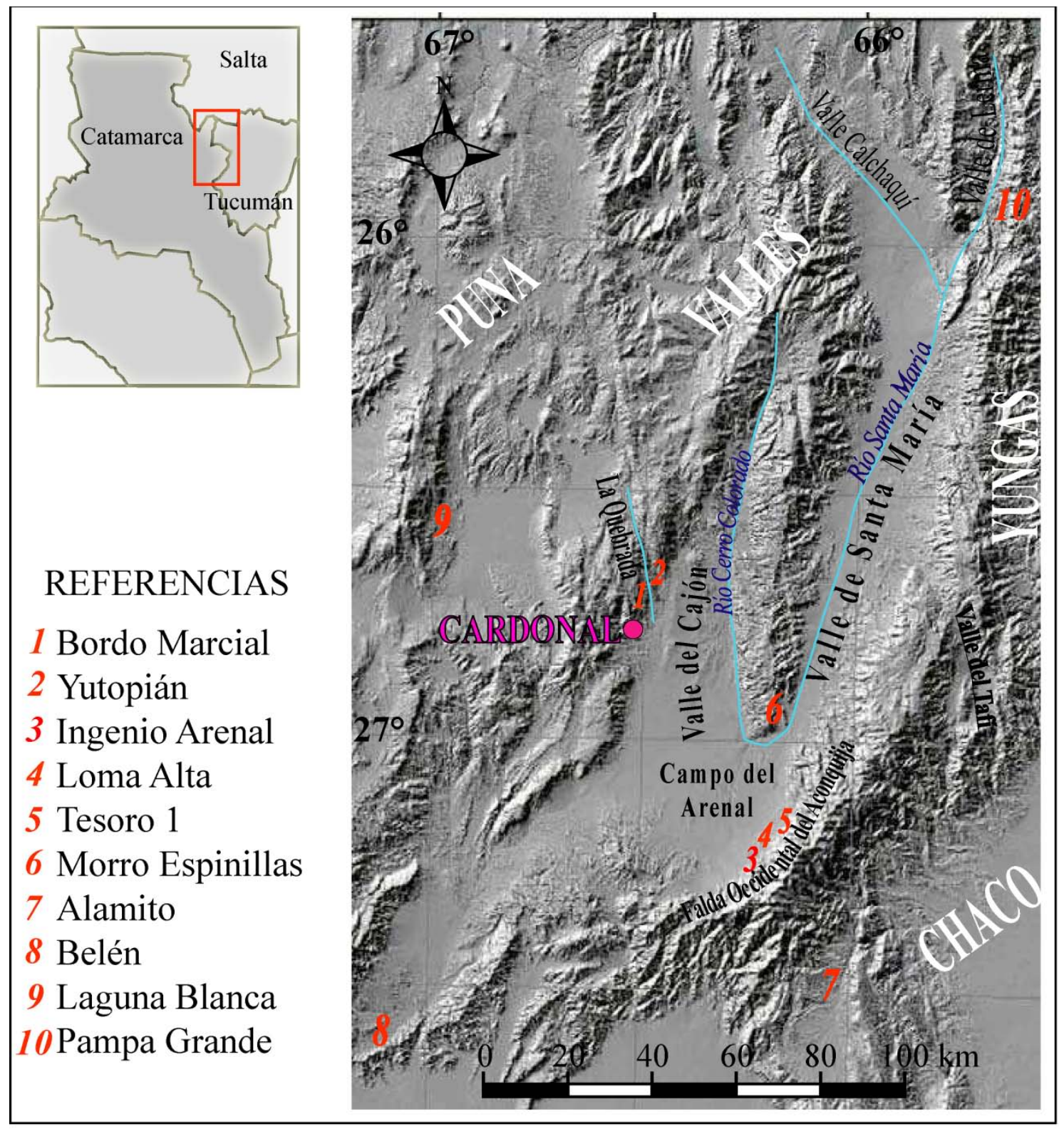

Figura 2. Ubicación la aldea arqueológica Cardonal y otros sitios formativos mencionados anteriormente en el texto.

Tabla 1. Fechados radiocarbónicos del Núcleo 1 de Cardonal. Las calibraciones se realizaron con el programa CALIB5 (modificado de Scattolin et al. 2009a).

\begin{tabular}{|c|c|c|c|c|c|}
\hline $\begin{array}{c}\text { Fechado } \\
{ }^{14} \text { C AP }\end{array}$ & $\mathrm{N}^{\mathbf{0}} \mathrm{Lab}$ & Procedencia & Material & $\begin{array}{c}\text { Años Cal } \\
1 \text { sigma }\end{array}$ & $\begin{array}{c}\text { Años Cal } \\
2 \text { sigma }\end{array}$ \\
\hline $1932 \pm 35$ & AA82260 & E5 Nivel 6 & Carbón vegetal & $\begin{array}{l}27 \text { a } 41 \text { d.C. } \\
48 \text { a } 89 \text { d.C. } \\
101 \text { a } 123 \text { d.C. }\end{array}$ & $\begin{array}{c}\text { 8-39 a.C. } \\
3 \text { a.C. a } 34 \text { d.C. }\end{array}$ \\
\hline $1878 \pm 57$ & AA67778 & E2 Nivel 6 & Carbón vegetal & $\begin{array}{l}70 \text { a } 220 \text { d.C. } \\
73 \text { a } 180 \text { d.C. } \\
186 \text { a } 214 \text { d.C. }\end{array}$ & $\begin{array}{c}1 \text { a } 320 \text { d.C. } \\
3 \text { a } 255 \text { d.C. } \\
304 \text { a } 315 \text { d.C. }\end{array}$ \\
\hline $1841 \pm 35$ & AA82262 & E1 Fogón & Carbón vegetal & 130 a 220 d.C. & 80 a 245 d.C. \\
\hline $1831 \pm 35$ & AA82258 & E3 Nivel 3 & Carbón vegetal & 134 a 222 d.C. & $\begin{array}{l}83 \text { a } 254 \text { d.C. } \\
307 \text { a } 312 \text { d.C. }\end{array}$ \\
\hline $1781 \pm 35$ & AA82259 & E4 Nivel 5 & Carbón vegetal & $\begin{array}{l}175 \text { a } 191 \text { d.C. } \\
211 \text { a } 262 \text { d.C. } \\
279 \text { a } 327 \text { d.C. }\end{array}$ & 133 a 340 d.C. \\
\hline
\end{tabular}




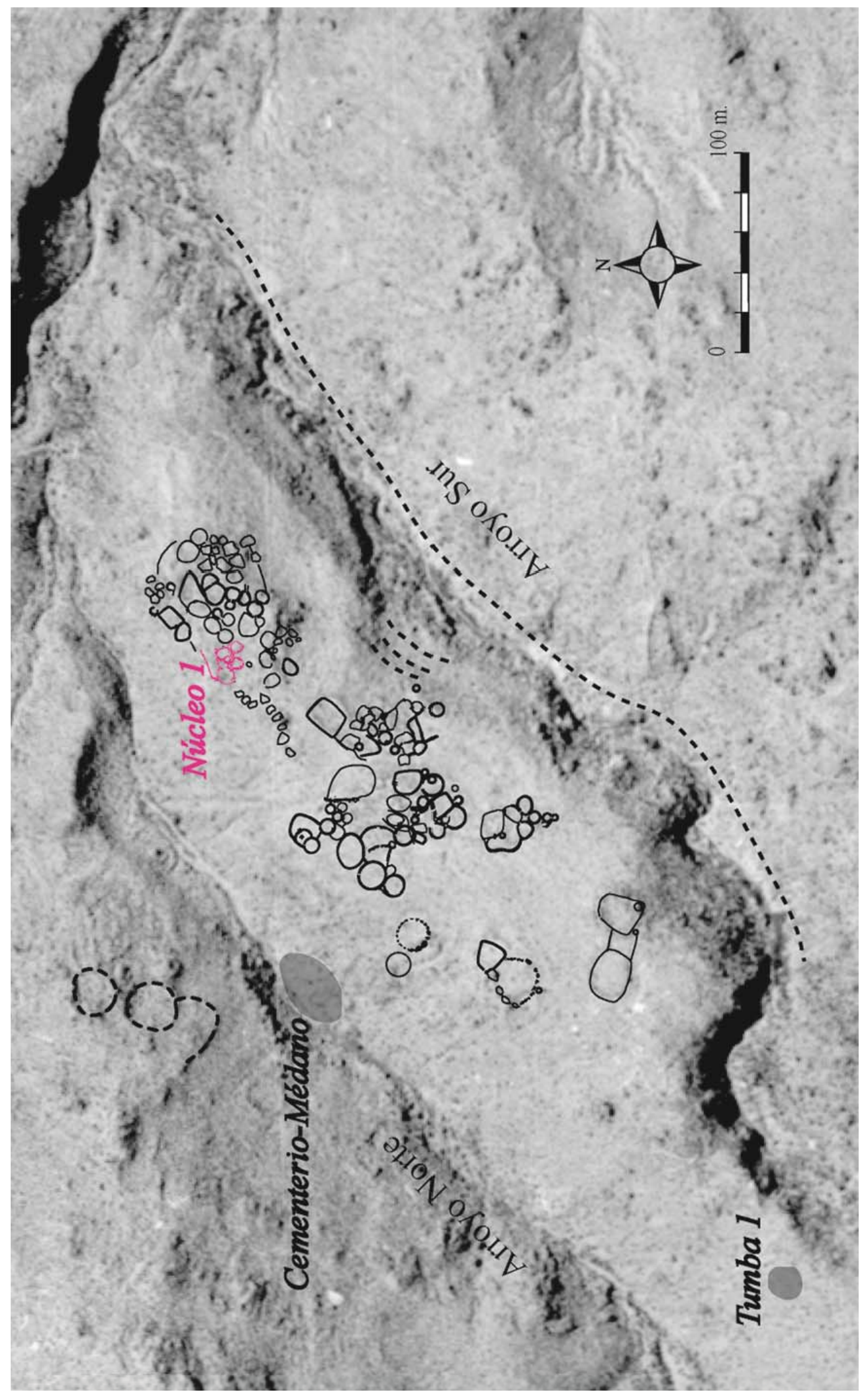

Figura 3. Plano del sitio Cardonal sobre foto aérea de la terraza en la que está emplazado (las líneas punteadas corresponden a estructuras de cultivo y de manejo del agua). 


\section{El núcleo habitacional excavado}

La descripción y análisis de los contextos excavados en el Núcleo 1 realizados hasta la fecha fueron publicados en cuatro trabajos correspondientes a los últimos cinco años (Scattolin et al. 2007a, Scattolin et al. 2007b, Scattolin et al. 2009a, Scattolin et al. 2009b). Los artículos de 2007 refieren especialmente a los hallazgos efectuados en el recinto E2 y algunos restos de E3, mientras que los dos últimos incorporan los materiales y contextos procedentes de la excavación íntegra del núcleo.

Dichos estudios permitieron caracterizar el Núcleo 1 como un espacio de habitación conformado por cinco estructuras subcirculares adosadas (E1, E2, E3, E4, E5) y un espacio común por el cual el núcleo se comunica con el exterior (Portal) (Figura 4). La apariencia general del conjunto sugiere que durante su construcción, la roca de base fue cavada y ahuecada para alojar cada una de las habitaciones, lo cual le otorga cierto grado de subterraneidad respecto del terreno circundante. Los muros en el perímetro de este 'piso hundido' fueron construidos con hiladas simples de piedras de migmatita granítica, que abunda en la zona. Estas piedras se disponen unas junto a otras sin argamasa, dando lugar a muros consistentes, asegurados con cuñas y levemente inclinados hacia el interior de los recintos.

En la parte inferior de las paredes se ubicaron y aseguraron las piedras más grandes, que continúan hacia arriba con rocas más pequeñas y probablemente luego, con adobes hasta alcanzar la altura del techo. La techumbre fue soportada por uno o más postes de madera de los que sólo se conservan varias marcas de los hoyos donde estaban sostenidos. Algunos de estos pozos son simples agujeros redondos cavados en la roca base, mientras que otros han sido reforzados con algunas rocas e instrumentos de piedra pulida utilizados como cuñas. La localización y cantidad de estos pozos de poste en relación al tamaño de las habitaciones ha permitido inferir la presencia de techumbres completas en los tres recintos más pequeños (E1, E2 y E4), mientras que E3 y E5 podrían haber sido espacios semitechados. Otro rasgo característico del piso de las habitaciones es la presencia de pozos circulares cavados en la roca de base, sin que ninguna función haya podido adjudicárseles en función de los contenidos o características de los sedimentos que los rellenan. Sólo algunos de ellos contenían todavía un sedimento limo-arenoso blanco bien distintivo o piedras pulidas.

Muros, accesos y circulación. En el Núcleo 1 la disposición y caracteres particulares de los muros y las aberturas que conectan las habitaciones proponen variables de 
desplazamiento y posibles vías de circulación particulares en el interior de la casa. En el lado norte del núcleo las excavaciones mostraron la única vía de acceso al interior de la vivienda. Para acceder al conjunto de las habitaciones, era necesario bordear el lado exterior de la pared de la E3 y luego ingresar al 'portal', un espacio previo de distribución anterior al resto de las habitaciones. Hacia la derecha se abre el acceso a la E5 -la mayor del conjunto- y hacia la izquierda se encuentra la abertura de acceso a la E3, que le sigue en tamaño a la anterior. Es únicamente a través de la E3 que se puede ingresar al resto de las estructuras -E4, E2 y E1-, las cuales habrían quedado así reservadas al sector más íntimo de la casa.

Finalmente, otro aspecto interesante de esta casa es que ciertas características naturales del terreno fueron modeladas para conseguir un orden de circulación específicos entre sus espacios internos. Por ejemplo, la entrada a la E2 desde la E3 está marcada por una elevación natural de la roca base, la cual desciende hacia el centro de la habitación, incrementando la sensación de piso hundido del interior de la habitación. En otros lugares, como las entradas a E5 desde el portal o a E3 desde E1, la presencia de superficies a diferentes niveles se denota en la ubicación de uno o dos escalones de piedra (ver Figura 4).

Otros rasgos arquitectónicos. Entre los rasgos sobresalientes del interior de E5 se encuentra una línea de piedras encajadas en la roca de base y aseguradas por varias manos de moler a modo de cuñas, que corre paralela al muro copiando su forma curva. El espacio entre esta línea de piedras y la pared fue rellenada con sedimentos y deshechos de fragmentos cerámicos, líticos y hueso. Esta construcción ha sido descripta como ‘terraplén’ o ‘zócalo’, en tanto que algunos ejemplos actuales sugieren que el mismo podría haber funcionado a modo de banco o tarima. La presencia del terraplén parece estar asociada a una reconfiguración del recinto, ya que su remoción completa expuso un pozo de poste.

En uno de los extremos de este ‘terraplén' semianular se encuentra una zona de sedimento carbonoso y graso que ha sido interpretado como un área de combustión circunscripta y de uso más o menos frecuente. A su lado se halló un pozo cavado en la roca de base y relleno de un sedimento blanquecino, probablemente cenizas. Otro fogón acompañado de un pozo con características similares se excavó en la E1. En este caso se trata de un fogón conformado por tres arcos protuberantes de arcilla cocida y piedras redondeadas que lo asemejan a los fogones multilobulados y en trípode descriptos para el sitio de Yutopián (Scattolin y Gero 1999; Gero y Scattolin 2002).

Asimismo, cerca del umbral de la E2 se observó un semianillo de arcilla endurecida que pudo ser parte de un fogón anulado, o que había dejado de ser usado un tiempo antes del 
momento de abandono de la vivienda. Si bien el rasgo mantiene en relieve parte del círculo como estructura inmóvil, no se encuentran a su alrededor trozos de carbón y cenizas que caracterizan a los fogones de E1 y E5, sino más bien un sector de sedimento oscurecido similar al hallado en E4 (ver Figura 4).

Objetos y acciones. Entre los objetos y residuos recuperados en el Núcleo 1 se cuentan fragmentos de diferentes piezas cerámicas, puntas de proyectil y deshechos de talla lítica, restos óseos de camélidos y otros animales, instrumentos de hueso e improntas de material cestero (Bugliani et al. 2009, Calo 2008, Cattáneo y Oliva Bustamante 2008, Izeta 2007b, Pereyra Domingorena 2007a). Una parte considerable de estos conjuntos de materiales se encuentran aún en proceso de análisis en tanto otros son sustancia del presente estudio. Hasta el momento, uno de los avances más importantes en el conocimiento de la dinámica del Núcleo 1 proceden de abordajes centrados en la configuración integrada del contexto doméstico, su arquitectura, la conformación de espacios de actividad específicos en torno a diferentes asociaciones de rasgos y objetos y su ordenamiento particular al interior de los recintos.

De esta manera, la E5 ha sido definida como un 'patio' semicubierto en el cual la presencia de un fogón, abundantes espículas de carbón y sedimentos grasosos se han vinculado con la ocurrencia de actividades de combustión. Las mismas parecen tener además implicancias culinarias, ya que allí entre los sedimentos carbonosos se hallaron huesos quemados de camélidos y algunos restos de vegetales comestibles. De allí también procede una olla cerámica antropomorfa y varios artefactos de molienda.

Otro contexto claro de cocción de alimentos fue señalado para el fogón de E1. En este caso la totalidad del sedimento del piso del recinto estaba impregnado de hollín, y contenía pequeños fragmentos de huesos y algunos porotos. Cerca del fogón había una gran olla globular con restos de tizne, muy deteriorada por la exposición al fuego, y otra beige de terminación pulida (Figura 5e), con dos asas, así como también un cántaro con baño rojo y una pequeña olla globular beige (Figura 5g). Hacia el fondo una gran 'conana' y manos de moler sugerían que E1 fue una 'cocina' donde se procesaban y cocinaban alimentos. Se observó además la presencia de algunos elementos que sugieren que este ámbito relacionado fundamentalmente a las actividades de preparación y consumo de alimentos también albergó otras prácticas, como es el caso de la pipa de fumar cuyo hornillo contenía indicios del uso de cebil (Figura 6). 
En la estructura E2 en cambio, los restos de combustión hallados parecen corresponder a un fogón fuera de uso, en tanto su aspecto general remite a una habitación que contenía numerosos objetos al momento del abandono de la vivienda. En su interior quedaron varios recipientes cerámicos que corresponden a dos grandes ollas ordinarias de cocina o almacenamiento sin señales de haber sido expuestas al fuego (Figuras $5 a$ y 5j), un cántaro beige pulido (Figura 5k) y tres recipientes finos más pequeños: una vasija efigie con motivo zoomorfo ('quirquincho') (Figura 5b), un cuenco pulido (Figura 5c) y una vasija de cuerpo globular (Figura 5d). Además de las piezas de alfarería se hallaron seis puntas de proyectil (Figura 7), algunos cuchillos, raederas, artefactos de formatización sumaria y raspadores, entre casi 600 desechos de talla en cuarzo, pedernal y obsidiana.

También se hallaron allí varias manos de moler, las impresiones de tres cestos tejidos en espiral (Figura 8) y más de 1900 huesos fragmentados de camélidos, quirquincho y taruca, algunos de ellos afectados por termoalteración o transformados en instrumentos. De acuerdo a la composición y el arreglo de los elementos hallados en el interior de esta habitación se ha sugerido que la misma funcionaría como depósito de suministros y resguardo de instrumentos.

El recinto E3 por su parte se propuso como un sector de alto tránsito en el Núcleo 1, ya que es necesario atravesarlo de principio a fin para acceder a las demás habitaciones. En su interior se hallaron una olla calceiforme ordinaria fragmentada y una punta de proyectil. De este recinto también procede parte de una vasija zoo-antropomorfa así como una gran cantidad de artefactos de molienda. Finalmente, la E4 se presenta como la estructura más pequeña y tal vez más enigmática del Núcleo 1. Sus dimensiones reducidas sólo habrían permitido el ingreso de una persona a la vez en tanto el piso de ocupación cuenta con unos pocos artefactos de piedra pulida y un instrumento de hueso.

Los resultados precedentes han sugerido que los contextos excavados en las habitaciones del Núcleo 1 contienen áreas de tareas específicas o prioritarias combinadas con otras múltiples actividades que parecen haber ocurrido simultáneamente. Tal es la característica que confiere la particular configuración interna de la casa de Cardonal. 


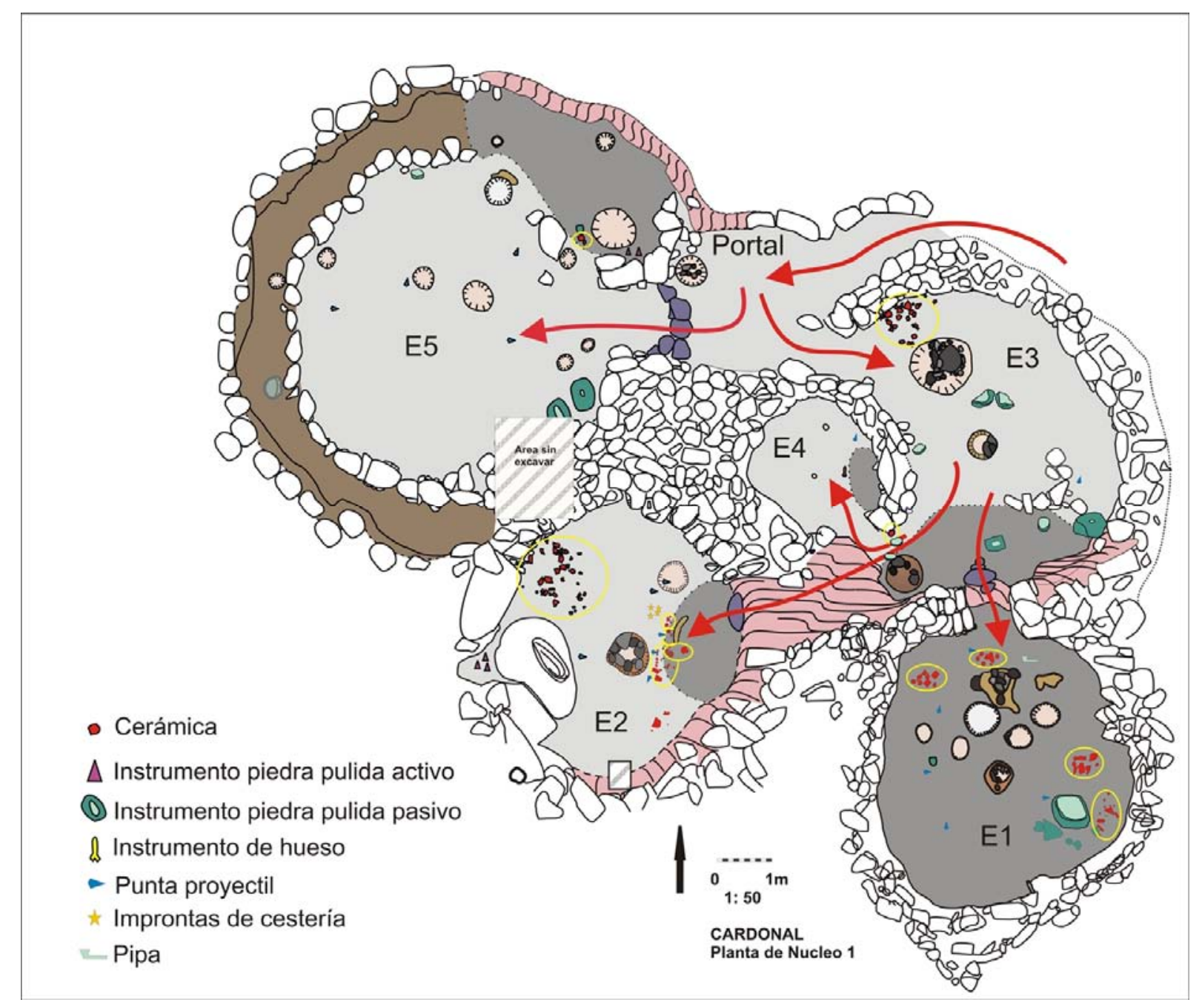

Figura 4. Plano de la planta del Núcleo 1. Las flechas rojas indican de modo general la circulación entre los recintos. Los círculos rosados y blancos corresponden a los pozos de la roca de base (extraído de Scattolin et al. 2009a) 


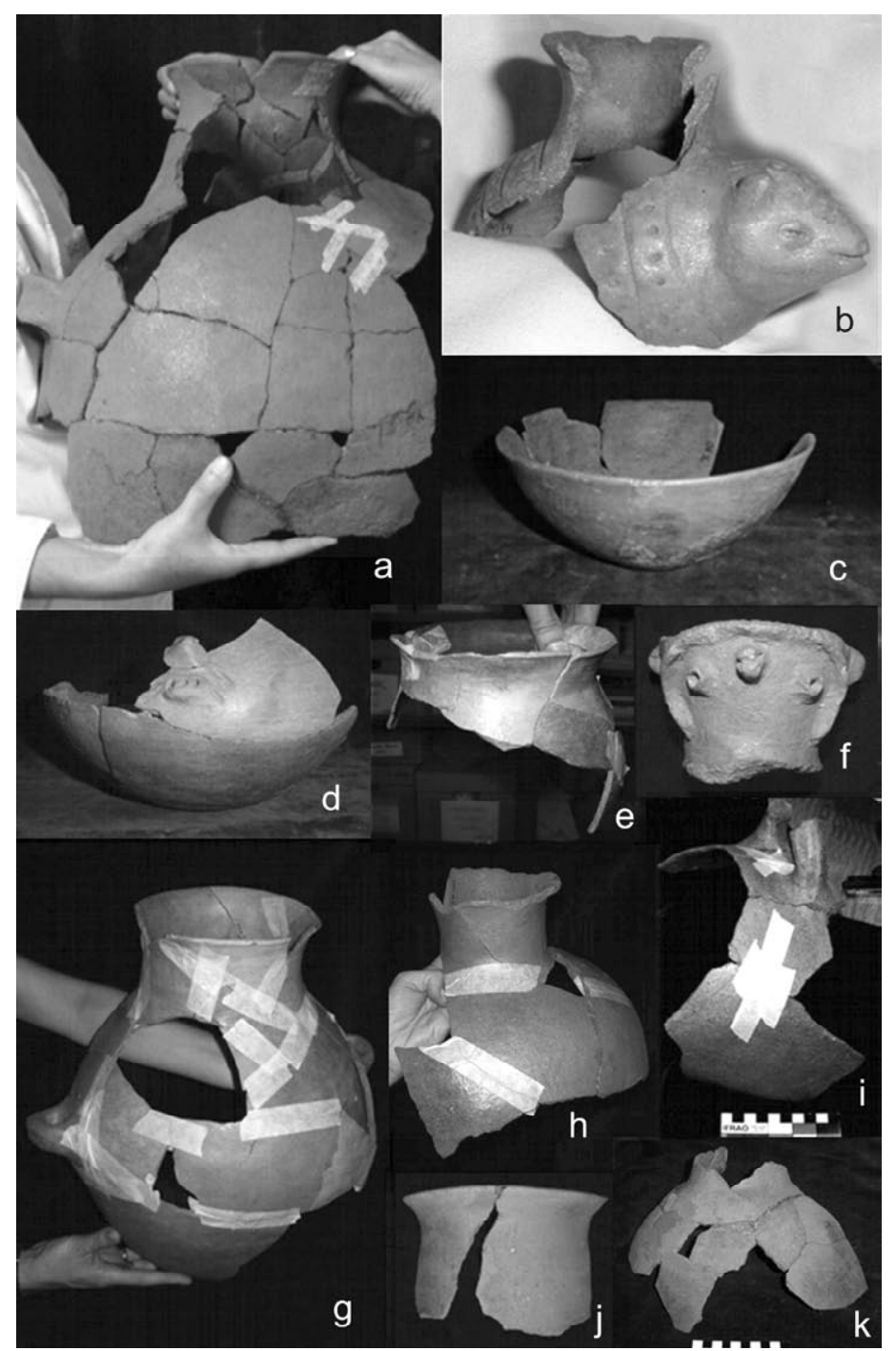

Figura 5. Recipientes hallados en el Núcleo 1 de Cardonal. a. Olla ordinaria (E2). b. Vasija efigie ‘quirquincho' (E2). c. Cuenco pulido (E2). d. Vasija beige pulida (E2). e. Ollita beige pulida (E1).

f. Vasija zoo-antropomorfa (E4). g. Olla beige pulida (E1). h. Cántaro rojo pulido (E1). i. Olla calceiforme (E3). j. Olla ordinaria (E2). k. Cántaro beige pulido (E2) (Tomado de Scattolin 2009a).

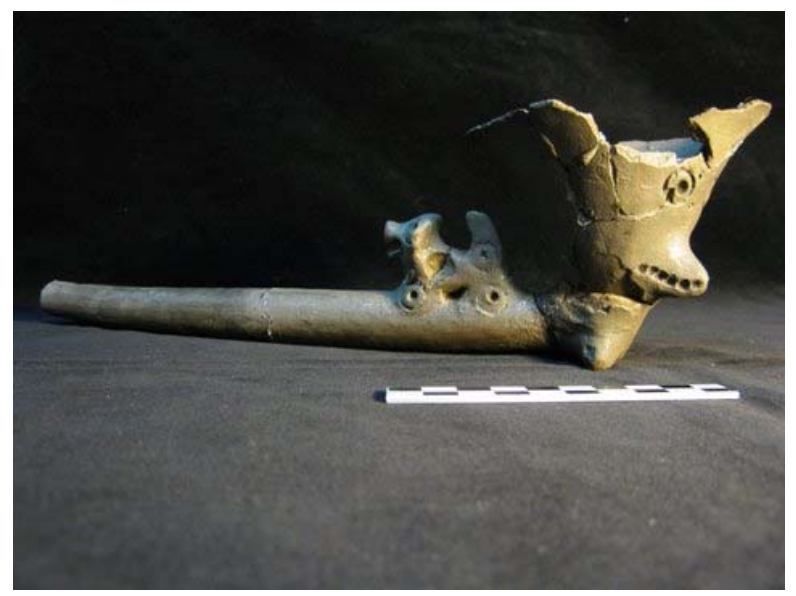

Figura 6. Pipa de fumar procedente de la Estructura 1. 


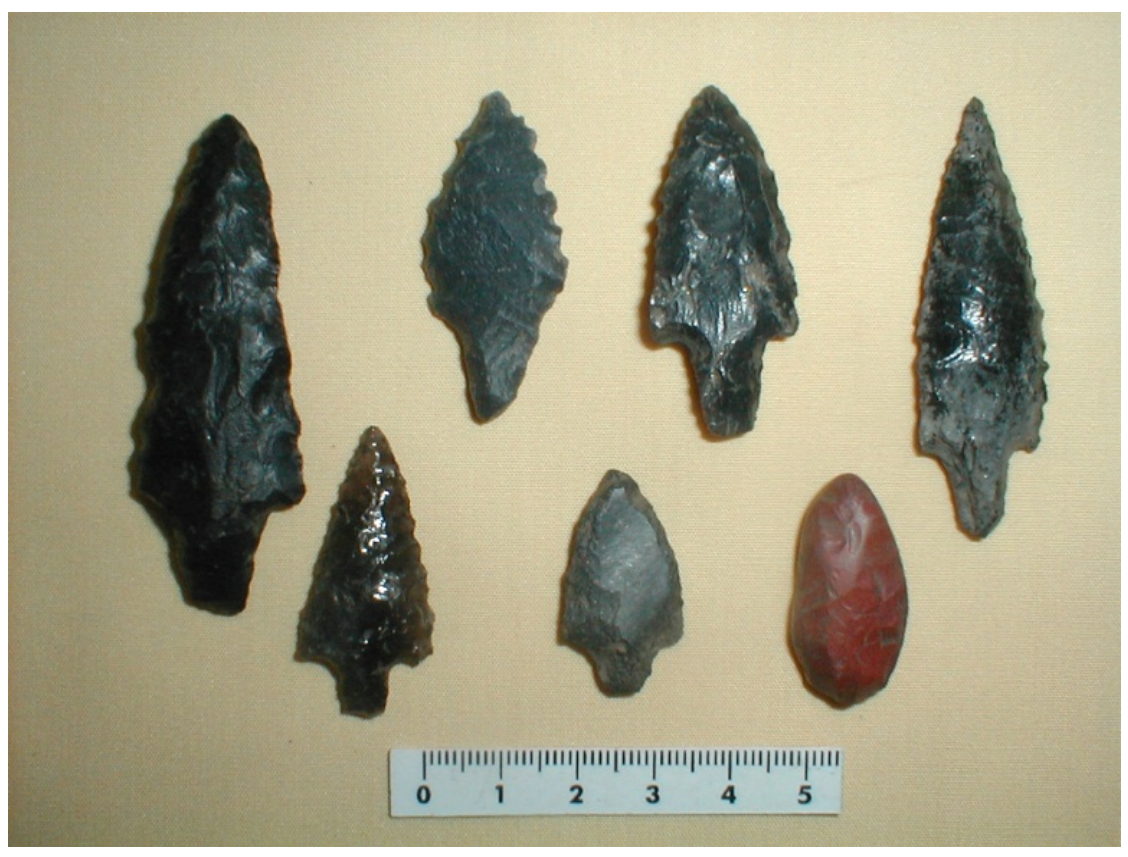

Figura 7. Puntas de proyectil halladas en la Estructura 2.

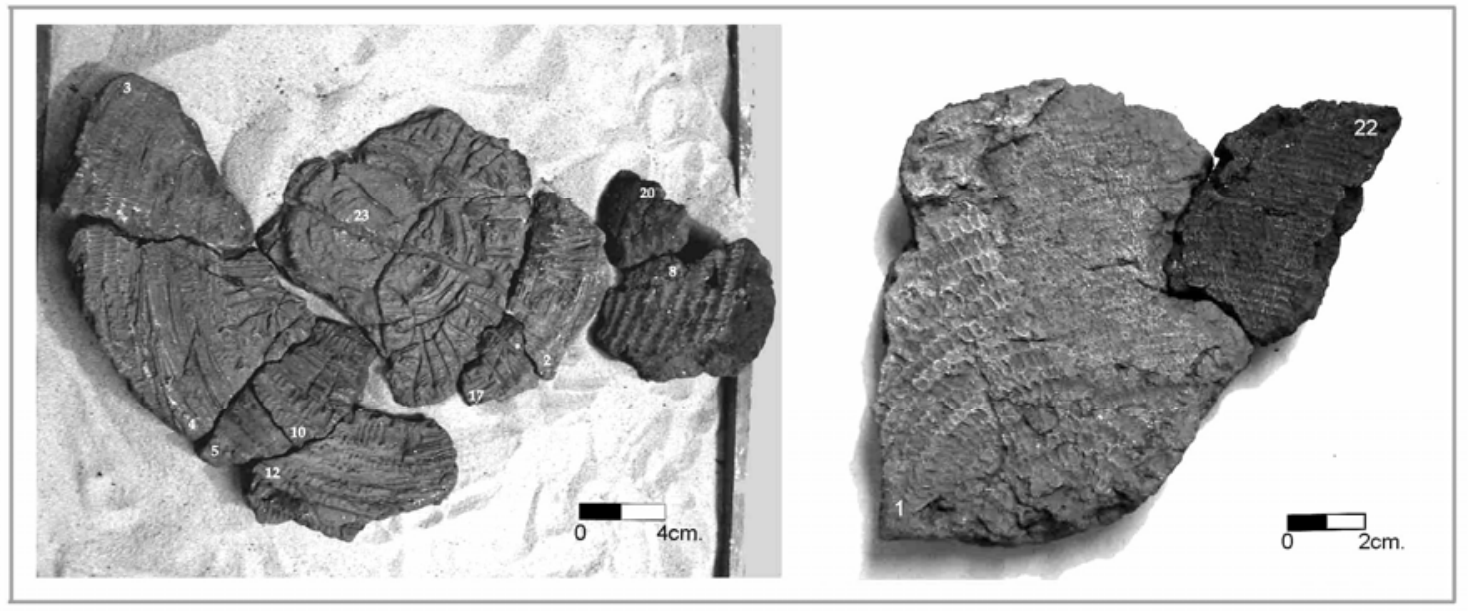

Figura 8. Improntas de cestería recuperadas en E2.

\section{Cardonal y sus fronteras}

Emplazado en un valle de altura que promedia el trayecto entre las regiones de la Puna, los Valles y las Yungas, Cardonal remite a aquel mundo de tránsito y comunicación sostenida entre poblaciones y lugares diversos, tal como ha sudo planteado y modelizado en varios estudios del pasado surandino (e.g. Albeck 1994, Browman 1980, Lazzari 1999a, 1999b, Núñez y Dillehay 1979, Scattolin et al. 2007a). De igual modo, los objetos, el paisaje construido y los modos de hacer estudiados en Cardonal, en especial en el Núcleo 1, han dado 
cuenta del universo de relaciones sociales creado a partir de tal dinámica (Scattolin et al 2009a).

Varias referencias a lugares distantes, como los valles húmedos del oriente y las tierras altas de la Puna al oeste, han sido puestas a la luz en combinación con maneras de hacer particulares del valle del Cajón. Por un lado, los rasgos generales de la construcción de los núcleos de habitación muestran similitudes con el patrón constructivo descripto como “Unidades Circulares Compuestas” para sitios de los valles de Tafí, de la Ciénega y de Anfama, o de Caspinchango-El Ciénago y de Bajo Los Cardones en el valle de Santa María (Cigliano 1960, González y Núñez Regueiro 1962, Berberián y Nielsen 1988, Cremonte 1996, Sampietro y Vattuone 2005, Somonte 2007: Croquis 1). Sin embargo, según Scattolin et al. (2009a), la falta de entierros en los patios y el patrón de circulación impuesto por el arreglo espacial de los recintos en ausencia de un patio central, se asemeja más al tipo observado en sitios como Loma Alta, Antigal de Tesoro e Ingenio del Arenal-Faldas del Cerro o en El Remate-Amaicha del Valle (Scattolin 1990, Lazzari 2006, Aschero y Ribotta 2007: Figura 2). Otras variantes similares se encuentran en Tebenquiche (Krapovickas 1955, Haber 1999) y en Laguna Blanca (Delfino 1999).

También en el caso de la cerámica, los estilos decorativos han sido seleccionados y combinados de maneras originales e históricamente particulares. En este sentido se han señalado ciertas combinaciones estilísticas no usuales para la región. Entre ellas se menciona el hallazgo de cerámica monocroma roja que normalmente se encuentra en Tafí del Valle, modelados zoomorfos incisos comunes en el área de La Candelaria y varias modalidades de cerámicas pulidas muy similares a otras usadas en la Puna de Catamarca. No obstante, el análisis de las matrices de arcilla de estas piezas indican que éstas habrían sido manufacturadas localmente (Pereyra Domingorena 2007). En el conjunto además, se encuentran fragmentos de cerámica de estilo Vaquerías de origen probablemente alóctono (Bugliani y Pereyra Domingorena 2009).

Finalmente, la materia prima de varias de las puntas de proyectil expresa posibles conexiones e interacción con los paisajes de la Puna (Scattolin et al. 2007a, Scattolin et al. 2007b). Las obsidianas translúcidas provendrían de la cantera de Ona, mientras que una de las puntas de obsidiana negra opaca podría corresponder a la cantera de Cueros de Purulla. Una tercera fuente identificada como materia prima usada en Cardonal es la de Laguna Cavi, más cercana, pero igualmente ubicada en la puna sur (Yacobaccio et al. 2003, 2004, ver también Lazzari et al. 2009). 


\section{El Cajón, un valle de altura}

\section{Geografía, vegetación y clima actual}

El valle del Cajón comprende una amplia cuenca que se extiende en dirección noroeste-sureste por unos $90 \mathrm{~km}$. sobre la porción nororiental de la provincia de Catamarca (66 $00^{\prime}$ y $66^{\circ} 30^{\prime}$ de Long. W y los $26^{\circ} 10^{\prime}$ y $27^{\circ} 00^{\prime}$ de Lat. S.). Hacia el norte, culmina a 4200 msnm. en unas pocas elevaciones, hasta alcanzar la Cuchilla de la Ciénaga. El límite sur y más bajo del valle (2200 msnm.) lo constituye el Campo del Arenal. En sentido este-oeste, presenta un desarrollo asimétrico del relieve. Las áreas más elevadas se encuentran al poniente, delimitadas por el cordón que integran la sierra de Las Cuevas y los cerros Ciro, Laguna Piedrosa, Olla Quebrada, Ciénaga Redonda y Mollar, cuyo extremo septentrional se desprende del borde suroriental de la Puna, en tanto la sierra del Cajón o de Quilmes recorre todo el límite oriental del valle (Turner 1973).

Cubre la superficie del valle del Cajón un manto de material de acarreo de color gris oscuro de escasa estratificación. Dicho material está conformado por sedimentos pobremente consolidados, areniscas, conglomerados y gravas procedentes de las rocas que se hallan en las inmediaciones. Allí se destacan algunos afloramientos de bancos tufíticos que corresponden a redepositaciones de material de la formación El Cajón (Turner 1973).

Los dos cauces de importancia que irrigan este valle corresponden a la cuenca imbrífera del río Santa María. El curso principal es el Cerro Colorado, que nace en la región septentrional del valle y corre en dirección norte-sur por su flanco oriental. Al rodear el extremo sur de la sierra del Cajón e invertir su dirección, comienza a denominarse río Santa María, curso principal del valle homónimo. Los afluentes transversales más relevantes, Yutoyaco, Ovejería, Totoral y Los Sasos vierten sus aguas por la margen occidental del río Cerro Colorado.

Por el lado oeste del valle del Cajón corre el río La Quebrada. Sus cabeceras se encuentran entre los cerros Chorros Blancos y Overo, dirigiéndose hacia el norte hasta Médano Trancado, donde gira su dirección hacia el sudeste, al tiempo que recibe como afluente, un curso que proviene de la Laguna Negra. Poco al sur de la localidad de La Quebrada, presenta un nuevo giro en su rumbo para dirigirse hacia el sur. En este tramo recibe varios tributarios de importancia: Volcán, Agua Amarilla, Chinocán, Blanco y Chafiñán. Aunque corresponden al mismo sistema tributario, las aguas del río La Quebrada rara vez 
alcanzan el curso del Cerro Colorado, infiltrándose en los sedimentos del Campo del Arenal (Turner 1973).

El valle del Cajón comprende uno de los valles altos del Noroeste argentino, que se distinguen de los valles bajos (e. g. el valle de Hualfín a 1500 msnm.) por tener características ambientales marcadamente diferentes. Los valles de altura comprenden zonas de transición y de límite entre el comienzo de la Puna y el resto de la subárea Valliserrana (Aschero y Korstanje 1996, Korstanje 2005). Dentro del área comprendida por este valle pueden distinguirse cuatro franjas sucesivas de vegetación diferenciada que corresponden a otras tantas provincias fitogeográficas. En las altitudes mayores se extiende la provincia Altoandina, que va descendiendo de los picos más altos y nevados hasta alcanzar los 3700 msnm. A partir de esa cota comienza la Puna, cuyo borde se encuentra en términos generales a unos 3000 msnm. Hacia abajo se extiende el paisaje de Prepuna que a partir de los 2000 msnm comienza a interdigitarse con la provincia de monte. En el sector sur el Monte bordea una amplia zona del cauce del río Cerro Colorado y las desembocaduras de sus principales afluentes, y trepa finalmente por los faldeos más abrigados de la sierra del Cajón (Figura 9).

Las provincias Altoandina y Puneña forman parte del Dominio Andino-Patagónico. Dentro del área delimitada para esta descripción (aproximadamente unos $40 \mathrm{~km}$ en torno al sitio Cardonal), el deslinde entre una y otra área fitogeográfica resulta dificultoso, sobre todo en los bordes elevados del límite oriental de la puna donde generalmente se encuentra un paisaje bastante extendido de carácter ecotonal (Morlans 1995). La primera de ellas se extiende sobre las altas cumbres de la cordillera de San Buenaventura, la sierra del Chango Real y la sierra del Cajón. El ambiente altoandino se caracteriza por una estepa de gramíneas duras de color amarillo pálido que forman comunidades generalmente abiertas, excepto en las vegas, donde el verde intenso está dado por la presencia de varias especies de ciperáceas, cariofiláceas y gramíneas.

En cambio, los arbustales más bien abiertos y abundantes en especies espinosas son comunes y notorios en las áreas llanas de la provincia puneña. Algo más achaparrados se los puede encontrar en las partes altas y pedregosas, acompañados generalmente de gramíneas. También aquí se dan varias especies de plantas aromáticas y medicinales como la 'rica-rica', la 'salvia' y la 'muña-muña', aunque actualmente son poco frecuentes debido a su marcado uso en la farmacopea popular (Morlans 1985). A

la vera de ríos y arroyos de la Puna se destacan las comunidades de cortadera y enormes cardones. Las vegas puneñas o ciénagos también constituyen un rasgo notable del paisaje y son de fundamental importancia para la producción ganadera en la zona (Figura 10). El rico 
tapiz herbáceo de los ciénagos se encuentra bordeado por comunidades de tola (Parastrephia) y de Lycium que constituyen recursos leñosos muy apreciados en la zona (Turner 1973).

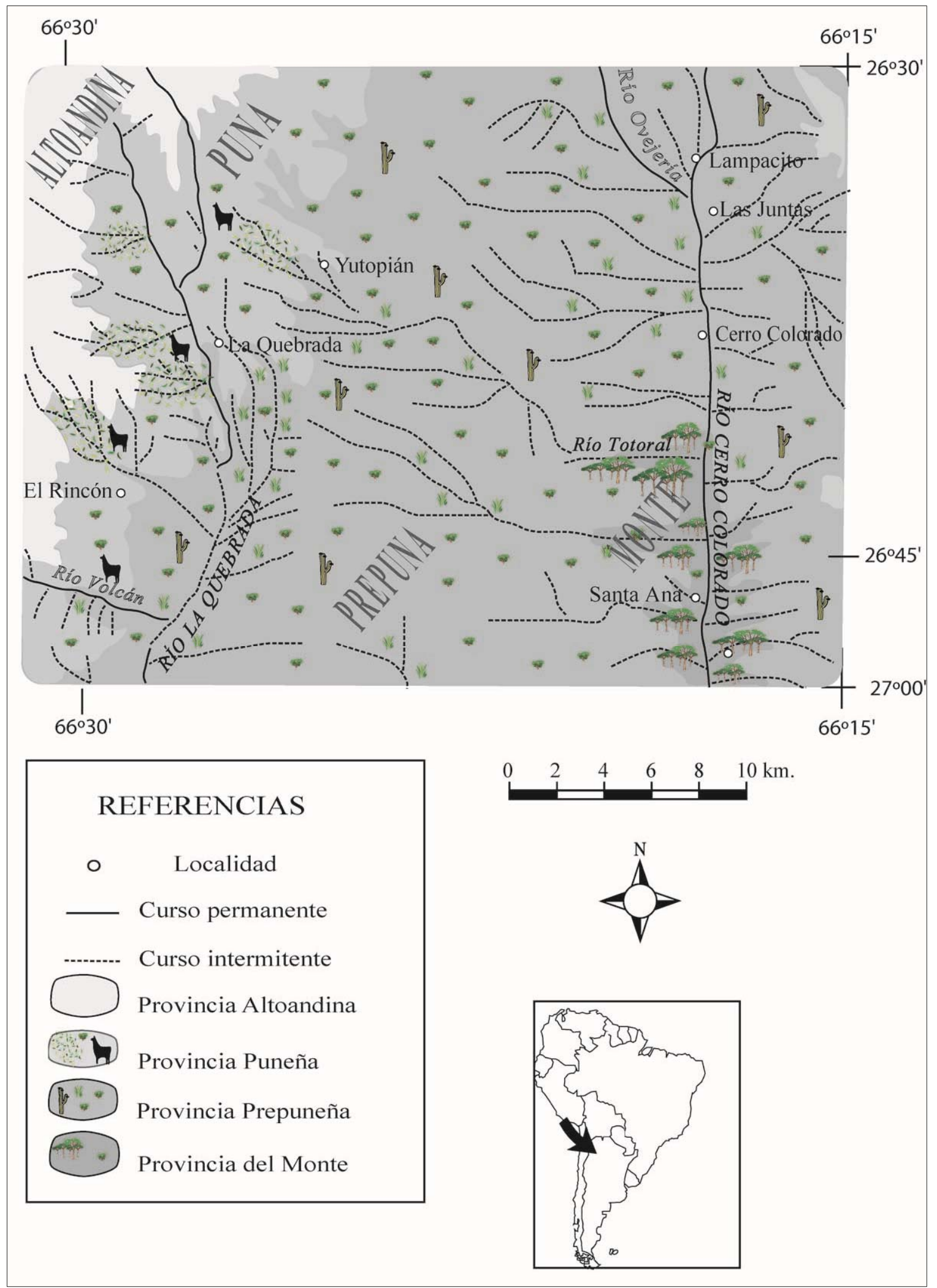

Figura 9. Fitogeografía de los alrededores de La Quebrada (basado en Morlans 1985). 

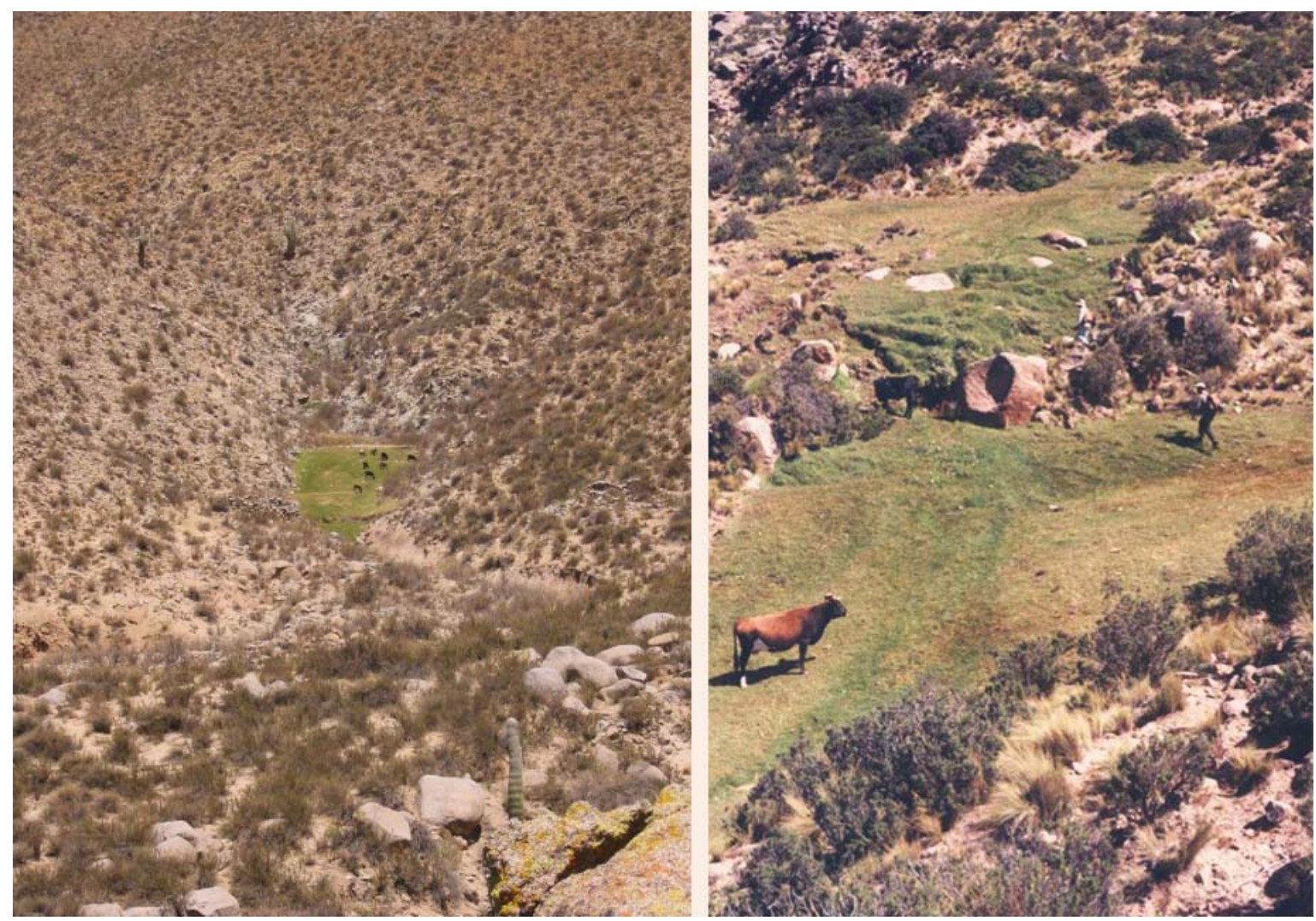

Figura 10. Ciénagos utilizados para la cría de animales en La Quebrada.

Al Dominio Chaqueño corresponden las provincias Prepuneña y Monte. La característica más sobresaliente de la Prepuna catamarqueña es la abundancia de cactáceas columnares de gran tamaño (Cabrera 1953), la ausencia del género Larrea que la distingue de la provincia del Monte (Cabrera 1976) y la presencia de comunidades de 'chaguar' en los faldeos y lomas de los cerros más bajos (Paredes 1980). También pueden presentarse en las quebradas angostas y márgenes de ríos, bosquecitos bajos de Acacia visco (viscote), acompañados de Schinus areira ('molle’) y Prosopis arbóreos ('algarrobos’) (Cabrera 1976). Aquí también la delimitación con el Monte suele ser dificultosa, aunque en el área que nos ocupa la Prepuna se extiende fundamentalmente sobre las laderas de la Sierra del Chango Real y la Cordillera de San Buenaventura (Figuras 11a y 11b).

Por su parte, en el sector descrito la provincia del Monte se ubica sobre los conos y bajadas del piedemonte occidental de la sierra del Cajón, en ambas márgenes de la porción sur de los ríos La Quebrada y Cerro Colorado, así como el campo de derrame de sus afluentes. Junto con otras interdigitaciones más al sur, estos parches se integran en la amplia zona que dicha provincia fitogeográfica ocupa en el Campo del Arenal. En el Monte de Catamarca es posible distinguir dos comunidades climáxicas principales: un arbustal abierto con predominio de especies caducifolias espinosas en las zonas más altas y de mayor pendiente, 
seguido de un arbustal igualmente abierto, con predominio de especies micrófilas perennifolias. En las zonas más bajas, próximas a los cursos de agua y desembocaduras pueden encontrarse diversas comunidades edáficas, como retamal, algarrobal, comunidades de vegetación pasammófila, etc. (Morlans 1995). Asimismo, según Turner (1973) el sector de mayor desarrollo de la vegetación arbórea es el valle del río Cerro Colorado. A lo largo de los cursos de agua, como en las quebradas de la margen izquierda del río, la vegetación arbórea penetra en la sierra del Cajón hasta la cota de 2700 msnm (Figuras 11c y 11d).

El clima del valle del Cajón está comprendido dentro de la región de clima continental, templado cálido y semiárido característico del noroeste argentino. En verano las temperaturas sobrepasan los $30{ }^{\circ} \mathrm{C}$, mientras que en invierno alcanzan varios grados bajo cero. Las heladas son frecuentes durante siete meses del año y casi diarias entre abril y agosto. Las lluvias presentan una marcada concentración estival y no sobrepasan los 100-250 mm promedio al año. Las precipitaciones son generalmente localizadas y de carácter torrencial, con alta variabilidad y erraticidad dentro del año y de un año para otro (Morlans 1995).

El factor decisivo para las lluvias es el viento húmedo del este. En cambio el viento norte resulta altamente desecante y arrastra mucho polvo. Este viento se origina en el sector de alta presión del borde de la puna y se precipita hacia abajo, hacia el mínimo del relieve. En invierno los vientos del sur soplan a diario y casi sin interrupción. Los vientos del oeste suelen soplar después de mediodía.

\section{Estimaciones paleoambientales para los valles del Noroeste argentino}

Hasta el momento, y pese a que la información sobre condiciones ambientales pasadas se ha ido incrementando en las últimas décadas en función del aporte de nuevas metodologías (secuencias polínicas, indicadores paleolacustres, paleosuelos, diatomeas, entre otros), resulta dificultoso elaborar un cuadro de los últimos diez mil años con algún grado de detalle para el Noroeste argentino.

La escasez o la ausencia de datos paleoclimáticos para algunas zonas en lapsos temporales cortos representan una de las mayores limitaciones, en vistas de la gran variabilidad microambiental que caracteriza la región. Este rasgo presente a lo largo del Área Andina en general, reduce en sumo grado las posibilidades de establecer analogías entre zonas, aunque estas se encuentren próximas entre sí. A su vez, la interpretación regional de los datos paleoclimáticos se ve obstaculizada por la gran variación presente en la resolución 
de las escalas temporales y los indicadores paleoambientales tenidos en cuenta en los diferentes estudios para la caracterización de los ambientes pasados (Korstanje 2005).
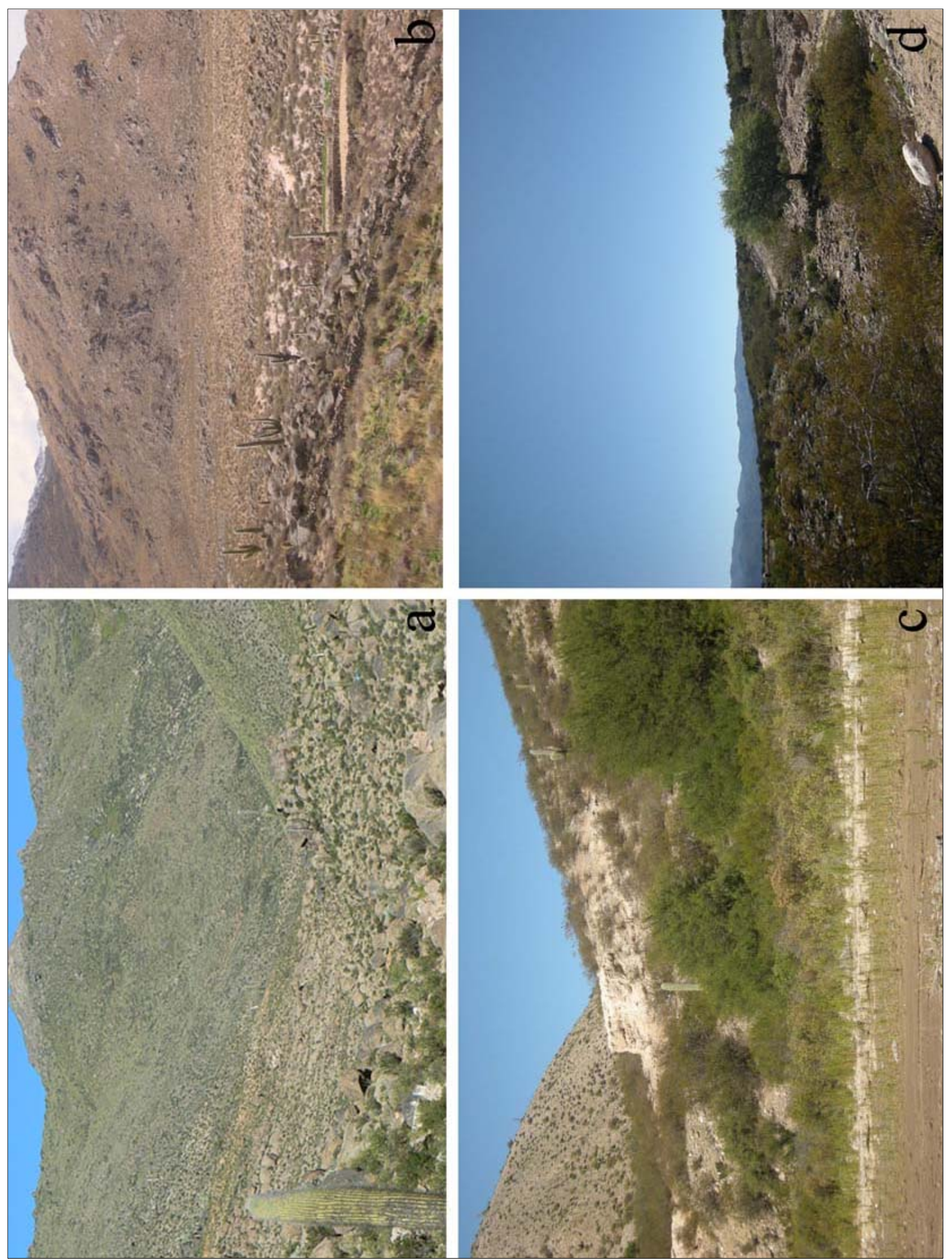

Figura 11. La Quebrada, Valle del Cajón. a- y b- paisaje de Prepuna; c- y d- vegetación de Monte. 
Al día de hoy las investigaciones desarrolladas a nivel mundial señalan que los inicios del Holoceno, hace unos 10000 años, están marcados por un cambio climático drástico hacia condiciones más cálidas y húmedas que las anteriores. En sí mismo el Holoceno se caracteriza por una serie de fluctuaciones climáticas que han sido expresadas por modificaciones en los regímenes pluviométricos y en la temperatura media, con algunas variantes según el lugar geográfico que se trate.

Varios estudios llevados a cabo en diferentes sectores de los Andes meridionales coinciden en señalar la presencia de condiciones climáticas más húmedas y frías que las actuales en momentos anteriores a los 8000 - 7000 años AP, que luego se tornarían en un clima árido y caluroso establecido hasta los 3000 - 4000 años AP. Posteriormente se produciría un retorno de las condiciones más húmedas y frescas pero que no alcanzarían la magnitud de las anteriores y que paulatinamente marcarían una tendencia general hacia las condiciones climáticas actuales, excepto por un recrudecimiento de estas condiciones durante la llamada Pequeña Edad del Hielo (Baied 1999, Baied y Wheeler 1993, Barker et al 2001, Bush et al. 2004, Garleff et al. 1993, Graff 1992 citado en Korstanje 2005, Kolata 1993, Lupo 1998, Núñez y Grosjean 1994, Markgraff 1985, Núñez et al. 1997, Olivera 2000, Olivera et al. 2004, Sayago et al. 1998, Schäbitz et al. 2001, Thompson et al. 1994, 1998, Valero Garcés et al. 2000, 2005, Yacobaccio 1994, Zinck y Sayago 1998)

Entre dichos estudios se encuentran los análisis del polen y el carbón recuperados en el perfil de un depósito de turba del sitio El Aguilar en la puna jujeña. Este estudio establece tres intervalos paleoambientales para el Holoceno del Área Andina meridional. La primera fase se ubica entre 10000 y 7500 AP y presenta las condiciones climáticas más frías y húmedas del Holoceno. También en ese momento se establece el régimen de lluvias estivales. Una segunda fase entre 7500 y 4000 AP muestra un régimen climático más cálido y seco que el actual. En relación con esto, el abundante carbón obtenido en los sedimentos correspondientes a este lapso temporal sugiere la ocurrencia frecuente de incendios naturales. Finalmente, durante la tercera fase, fechada entre el 4000 AP y 500 AP, se establecen condiciones ambientales similares a las de hoy (Markgraff 1985).

Esta tendencia general de los cambios climáticos de los últimos diez milenios no ha sido homogénea. Así lo demuestran varios estudios de los citados más arriba enfocando esta secuencia a escalas menores de resolución, especialmente en lo que respecta al tercer intervalo de 4000 años. Las secuencias de alta resolución más completas para el Holoceno medio y tardío de los Andes meridionales proceden de la región del lago Titicaca (Kolata 1993, Thompson et al. 1994, Barker et al. 2001). Estudios realizados en el altiplano en base a 
testigos polínicos del Titicaca señalan que el nivel del lago fue significativamente más alto entre 350 y 500 d.C., lo que implicaría un incremento notable de las precipitaciones o bien un descenso de la evaporación o ambas a la vez. El testigo, tomado a 65 metros al noroeste de la costa del sitio Lukurmata, representa aproximadamente 2000 años de historia sedimentaria (la base está datada en $1950 \pm 80$ AP). La sección media posee $1445 \pm 210$ años AP y manifiesta notable abundancia de polen de macrofitos acuáticos y algas planctónicas. Los sedimentos en los 30 centímetros superiores exhiben dominancia relativa de juncos en concomitancia con la disminución de macrofitos acuáticos, reflejando el descenso de las aguas del lago. Más tarde se produjo el regreso a condiciones litorales en el sector, en un período posterior al 1000 d.C. (Ortloff y Kolata 1993).

El estudio de Baker et al. (2001) sobre diatomeas le permite evaluar los cambios en el nivel del lago Titicaca que se correlacionarían con cambios en la cantidad de precipitación. La secuencia muestra la ocurrencia de un período extremadamente seco entre el 6000 y 5000 AP y otro de niveles de humedad creciente entre el 4500 y el 3500 AP. Esta secuencia se completa, para el Holoceno tardío con los estudios realizados en el lago Wiñaymarca, que deja de estar conectado con el Titicaca hacia el final de este período húmedo. Allí ha sido posible establecer la siguiente secuencia de períodos húmedos y secos: húmedo 3500-3200 AP, seco 3200-2800 AP, húmedo 2800-2500 AP, seco 2500-2200 AP, húmedo 2200-2000 AP, seco 2000-500 AP, húmedo 500 AP-presente.

Por otra parte, los estudios realizados en base a datos de $\mathrm{O}^{16 / 18}$ y depositación de partículas de polvo en la capa de hielo del volcán Sajama (Bolivia) señalan que los períodos fríos del altiplano se asocian generalmente a incrementos en las condiciones de humedad, en oposición a lo que ocurre en los registros polares, donde los mismos se asocian a períodos de sequedad ambiental. Esto podría ser el resultado de las frecuentes incursiones de masas de aire polares húmedas y frías desde el sureste. En cambio, las actuales lluvias estivales características de la zona están en relación con el incremento de la radiación solar (Thompson et al. 1998).

El análisis de secuencias polínicas en la cuenca del río Yavi (borde oriental de la Puna jujeña) señala el advenimiento de un clima árido entre el 8000-6000 AP. La transición hacia menor humedad se dio con buen desarrollo de la flora local, existiendo ciclos de aumento de humedad restringidos a sectores específicos. Entre el 5000 y 4000 AP se dio un período seco seguido de un aumento paulatino de la humedad que se acentúa hacia el 2380 AP (Lupo 1998). Posteriormente se establecen las condiciones climáticas más áridas que caracterizan el clima actual. 
En la Puna catamarqueña, los análisis sedimentológicos, geoquímicos e isotópicos de una columna sedimentaria de 2 metros en la laguna El Peinado (Antofagasta de la Sierra) muestran una fase paleoclimática de humedad creciente hacia 3000 AP. La evidencia sedimentológica y geomorfológica también sugiere un reciente aumento en la tabla de agua en la cuenca de San Francisco (Tinogasta). Esta fase culminaría alrededor de 1800 AP según lo indican los datos obtenidos en el salar Las Coladas ubicada en dicha cuenca. Este incremento de la humedad durante el Holoceno Tardío resulta concordante con otros registros de latitudes similares en los Andes Chilenos y argentinos. La secuencia del lago El Peinado también evidencia una disminución en los niveles de humedad correspondientes a la Pequeña Edad del Hielo (Siglos XVI Y XVII de nuestra era) (Valero Garcés et al. 2000).

Un trabajo posterior de Valero Garcés et al. (2005) resume los resultados de análisis sedimentológicos y geoquímicos aplicados a varios registros lacustres del Altiplano de Atacama (Chile) y en la zona de puna del departamento Tinogasta (Catamarca) Estas fuentes de evidencias indican que el Holoceno medio (8000 a 3600 AP) fue en general muy árido, con niveles hidrológicos en los lagos muy bajos, aunque existieron fases húmedas cortas favorables para el mantenimiento de la vegetación. En la región de Atacama la precipitación anual descendió a menos de $200 \mathrm{~mm}$ anuales y alcanzó los niveles actuales de $200 \mathrm{~mm}$ a partir de los 3000 AP. Durante el Holoceno tardío se observa un aumento general de las precipitaciones y las condiciones de humedad. Para el caso argentino se registran cambios en la dinámica fluvial de los ríos del bolsón de Fiambalá, Chaschuil, Ranchillos, Abaucán y Grande, entre los 6000 y los 2000 a AP (Valero Garcés et al. 2005).

En la cuenca de Antofagasta de la Sierra se utilizaron imágenes satelitales Aster (1:40.000), fotografías aéreas (1:15.000) y reconocimiento de campo para ubicar archivos ambientales (salares, planicies aluviales con vegas y valles glaciares) relacionados con sitios arqueológicos. Los datos obtenidos a partir del muestreo de suelos, aguas y sedimentos para realizar análisis biológicos (diatomeas, ostrácodos, macrorestos), edáficos (porcentaje de matera orgánica, isótopos ${ }^{13} \mathrm{C}$ y ${ }^{18} \mathrm{O} /{ }^{16} \mathrm{O}$ ), sedimentológicos (facies sedimentarias) y geomorfológicos (morenas, paleocostas, terrazas, dunas) permitieron establecer una secuencia paleoclimática de cuatro fases climáticas principales. La primera fase correspondería a los primeros momentos del Holoceno temprano, con un clima marcadamente más frío y húmedo y de mayor disponibilidad de agua que en la actualidad. Entre los 8700 y 3000 años AP se observa un proceso hacia un clima más cálido, alcanzando condiciones generalizadas de aridez hacia los 6000 años AP. A partir de ca. 1600 años AP los valores crecientes de $\mathrm{O}^{18}$ indican un aumento de evaporación posiblemente por aumento de la temperatura. Finalmente, 
cerca del 1000 AP se registra un máximo de sequedad con elevación de la temperatura que coincide con la Anomalía Climática Medieval (Olivera et al. 2004).

En el área de yungas, las llanuras y piedemontes de la provincia de Tucumán muestran secuencias alternantes áridas y húmedas durante el Holoceno temprano y medio (Sayago et al 1998a, Sayago 1999a). Allí el paleosuelo más antiguo data de $6290 \pm 120$ AP (Zinck y Sayago 1998), habiéndose desarrollado bajo condiciones climáticas algo más húmedas que las actuales (Sayago et al. 1998b).

Asimismo, la información palinológica obtenida para la Cuenca Tapia-Trancas evidencia un período anterior a los $1020 \pm 35$ AP caracterizado por condiciones ambientales húmedas. En este momento el espectro polínico pertenece mayoritariamente a especies arbóreas tales como Schinus, Prosopis y Acacia, vegetación arbustiva, hierbas (Poaceae y Cyperaceae) y a esporas monoletes y triletes (Caria 2004). A partir de ese momento, se produce una reducción de los taxa característicos de ambientes húmedos, que son reemplazados por otros propios de regiones con condiciones más áridas y frías, principalmente vegetación arbustiva xerófila, acompañados de una alta concentración de sedimentos loéssicos (Caria 2004, Caria y Garralla 2003, Caria y Sayago 2008).

Al norte del valle del Tafí, un perfil de 16 m realizado en la zona de El Infiernillo muestra el predominio de la vegetación herbácea con asociación polínica característica de la estepa graminosa antes del $2000 \pm 50$ AP. Desde este momento hasta el $875 \pm 20$ AP se registró el incremento en el porcentaje de polen arbóreo y arbustivo con especies típicas del bosque montano conjuntamente con vegetación herbácea con mayor variedad de tipos polínicos que en el estrato anterior. Esta asociación sugiere un incremento del aporte polínico por vientos provenientes del este y cambio de condiciones frías y secas de la porción anterior a frías más húmedas. A partir de $875 \pm 20$ AP hasta la actualidad el porcentaje de polen arbóreo y arbustivo volvió a disminuir con dominancia de las especies herbáceas sugiriendo una disminución de la humedad respecto al período anterior (Garralla 1999).

Sampietro (2002) establece una secuencia similar a partir de la descripción de los perfiles de suelo y paleosuelo efectuados en el sitio El Tolar y en otros sectores del valle de Tafí. La integración de estos datos con la información paleoclimática existente para la zona (Berberián y Nielsen 1988, Cremonte 1996, Garralla 1999, González 1960, Spalletti y Salazar 1988) sugiere la presencia de condiciones de humedad superiores a las actuales durante el tercer y segundo milenio AP. Hacia el $875 \pm 20$ AP comienza a establecerse un clima más árido que el de hoy cuyo posterior retorno a niveles superiores de humedad no alcanzaría el grado de las anteriores. 
Los datos paleoclimáticos más próximos al valle del Cajón proceden de sedimentos antiguos depositados en las márgenes del río Santa María. Allí se dataron arenas ricas en materia orgánica en $2190 \pm 530$ AP, en base a lo cual ha sido posible considerar la ocurrencia de un período de bonanza climática para los valles al oeste de Tucumán (Strecker 1987), seguidos luego por el establecimiento de condiciones ambientales más áridas determinadas en base al análisis de sedimentos correspondientes al 800 d.C. del mismo valle de Santa María. Para lapsos temporales previos se cuenta con los datos paleoclimáticos obtenidos por Garleff et al. (1993 citado en Lupo 1998) en el valle de Fiambalá (Catamarca), donde se observa el comienzo de un momento de aridez hacia el 3000 AP, precedido de un período húmedo iniciado hacia el 6000 AP.

En lo que se refiere específicamente a los datos paleoambientales de los últimos dos milenios en el Noroeste argentino, se ha señalado que la instalación del clima y el ambiente actual es difícil de determinar debido a las modificaciones que podría haber introducido el impacto antrópico en el área (Lupo 1998, Markgraff 1985, Caria y Sayago 2008). Dentro de este tipo de estimaciones se han considerado los cambios que ocurren con la vegetación a través del tiempo. Por ejemplo, para áreas como el valle de Ambato actual se ha observado que tras el abandono de tierras empleadas para cultivos, de terrenos desmontados deteriorados por efecto del sobrepastoreo, se dan procesos de cicatrización y colonización por especies invasoras (Saravia Toledo et al. 1995 en Marconetto 2005). Por otra parte, el estudio que lleva a cabo Baied (1999) sobre la distribución actual del género Polylepis en varios sectores de los Andes meridionales se opone a las conclusiones que otorgan mayor importancia a la acción humana (quema, tala, agricultura, pastoreo, recolección) en el proceso de retracción de los matorrales. Sugiere que la estructura y dinámica natural de estas poblaciones, modeladas por los cambios ocurridos en el ambiente habrían generado el patrón de distribución presente de ésta y otras comunidades vegetales andinas.

De todos modos, las investigaciones paleoambientales realizadas en diferentes áreas de los Andes Centro-Sur han incorporado escasamente la evaluación de los efectos que la actividad humana puede tener en los ambientes estudiados. Como hemos visto en los trabajos anteriormente citados, éstos se enfocan principalmente en la interpretación de datos paleoclimáticos procedentes de secuencias polínicas, diatomeas, isótopos, geoformas, sedimentos y suelos, los cuales comienzan a integrarse en un cuadro general de las modificaciones ambientales ocurridas en el pasado del área.

En relación con la información existente hasta el momento, es posible considerar que la ocupación del Núcleo 1 de Cardonal se da conjuntamente con la presencia de un clima más 
húmedo que el actual, detectado en el cercano valle de Santa María y en regiones más alejadas de las Yungas, la Puna, el Norte chileno y la región del lago Titicaca. A su vez, el lapso de tiempo en que el núcleo estuvo habitado corresponde a una etapa transicional hacia condiciones de mayor aridez.

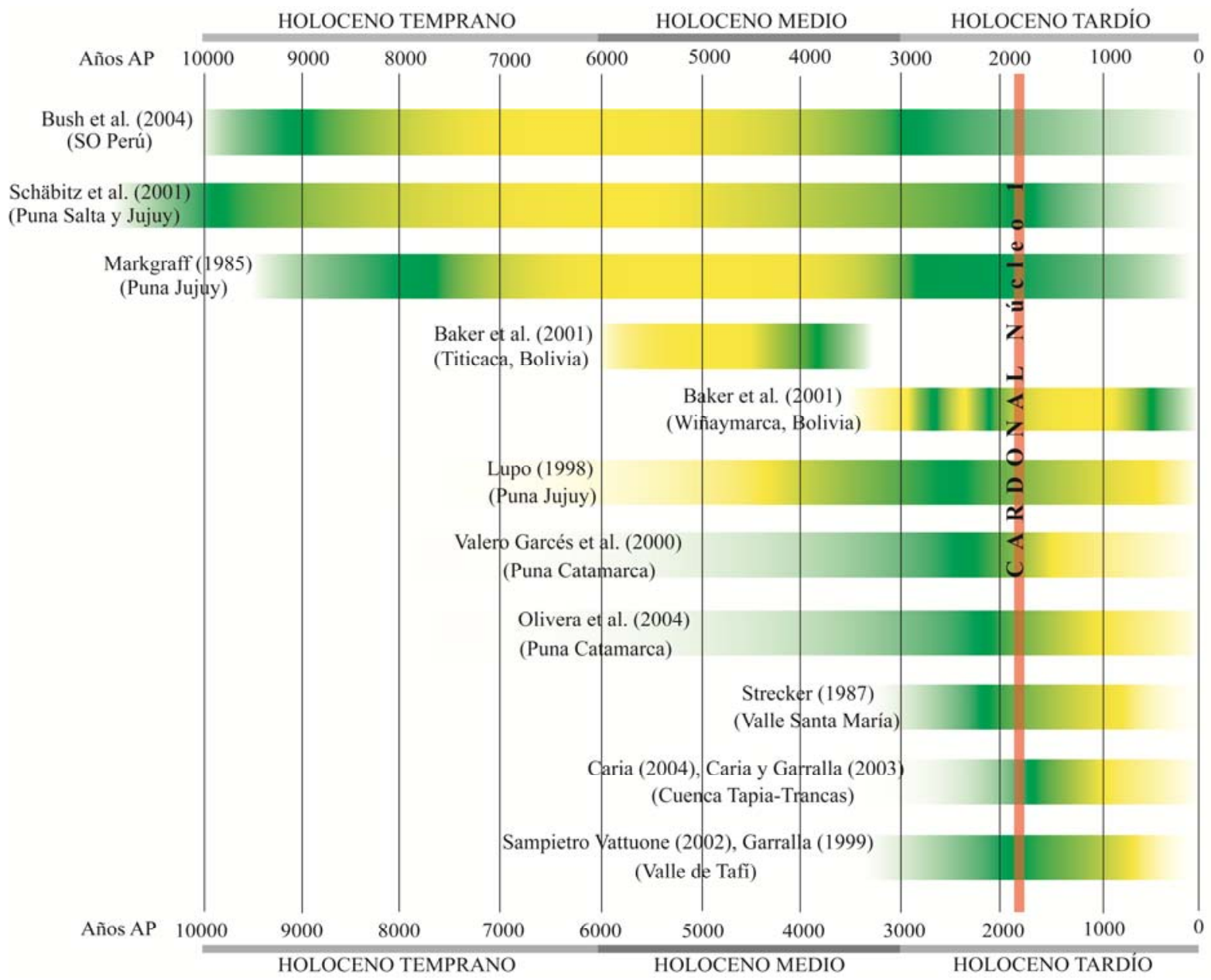

Figura 12. El gráfico muestra los cambios en las condiciones de humedad ambiental en términos absolutos, es decir, más seco (en amarillo) o húmedo (en verde) que el intervalo anterior. 


\section{CAPÍTULO 4}

\section{Aspectos metodológicos y materiales de estudio}

\section{La excavación del Núcleo 1 de Cardonal}

Las excavaciones en Cardonal se realizaron a lo largo de cinco campañas arqueológicas consecutivas en los años 2004 (E1 y E2), 2005 (E3), 2006 (E4), 2007 (E5) y 2008 (E1). De las primeras excavaciones de una parte de la E1 se cuenta con los registros de campo completos elaborados por el equipo arqueológico dirigido por Joan Gero (2004). Aunque desafortunadamente aún no se disponen de informes sobre los contenidos de las muestras de flotación que se mencionan en los manuscritos, si se hace referencia a los especímenes vegetales recuperados in situ. Los trabajos subsiguientes se desarrollaron bajo la dirección de M. Cristina Scattolin.

Cardonal se excavó siguiendo un esquema general basado en la subdivisión del espacio interior de las estructuras en Cuadrantes que luego fueron sectorizados en Cuadrículas de $1 \mathrm{~m}^{2}$ cada una, excepto en algunas regiones donde el límite de la pared curva de los recintos alteró tal demarcación. De cada cuadrícula, se extrajo el sedimento en capas o niveles artificiales de $10 \mathrm{~cm}$. de espesor. Las unidades de excavación así definidas recibieron un número de identificación o CAT. La excavación íntegra del Núcleo 1 sumó un total de 357 unidades de extracción (abreviadamente CATs) cuyo volumen estándar puede asumirse en 100 litros para cada uno (Tabla 2). La totalidad de la matriz sedimentaria removida fue tamizada en seco con malla 1/8, a excepción de la fracción destinada a muestras de flotación (ver infra). Al final de cada nivel se realizó el mapeo de la planta, con registro tridimensional de los hallazgos.

Tabla 2. Número de unidades de excavación por Estructura

\begin{tabular}{|c|c|c|c|c|c|c|c|c|}
\hline \multicolumn{9}{|c|}{ Cantidad de CAT excavados por Estructura } \\
\hline & & E1 & E2 & E3 & E4 & E5 & Portal & TOTALES \\
\hline UNIDADES & NIVELES DE RELLENO & 19 & 39 & 27 & 9 & 45 & 3 & 142 \\
\hline EXCAVADAS & NIVELES OCUPACIONALES & 13 & 28 & 41 & 12 & 114 & 7 & 215 \\
\hline (n) & TOTALES & 32 & 67 & 68 & 21 & 159 & 10 & 357 \\
\hline
\end{tabular}




\section{Metodología para el análisis de macrorrestos vegetales arqueológicos}

\section{Desde la Arqueobotánica}

En este trabajo de tesis, la identificación e interpretación de restos macroscópicos de plantas se realiza desde un abordaje arqueobotánico. Varios autores desde distintas perspectivas han proporcionado definiciones de este quehacer en torno a su objeto, procedimientos y vínculos con otras disciplinas, proponiendo incluso diferentes denominaciones -Arqueobotánica, Arqueoetnobotánica, Arqueología de las plantas- (e. g. Buxó 1997, Cotton 1998, Ford 1979, Helbaek 1960, Pearsall 2001, Popper y Hastorf 1988, Renfrew 1973). Esta variedad de enfoques ha dado lugar a cierta incertidumbre acerca la designación adecuada para esta práctica, preocupación que radica no en preferencias por uno u otro nombre, sino en los vínculos con campos disciplinarios y áreas de interés disímiles que cada uno comporta. En Argentina el tema ha derivado en múltiples y ricas discusiones desarrolladas en el ámbito de los Congresos Nacionales de 2001, 2004 y 2007, que finalmente confluyeron en la organización de una Mesa de Discusión en Arqueobotánica en el marco de la Cuarta Reunión Internacional de Teoría Arqueológica en América del Sur (TAAS) Intercongreso del World Archaeological Congress (WAC)- (Archilla et al. 2008 vs. artículos).

En relación a los lineamientos adoptados en dicha oportunidad, se considera en esta tesis la denominación Arqueobotánica, en tanto ésta se define como una práctica científica en el seno de (Korstanje 2008) o vinculada a (Giovannetti et al. 2008) la Arqueología. Dicha práctica aborda el análisis de materiales arqueológicos que son en su naturaleza plantas, partes de plantas o representaciones de ellas. A tal efecto requiere que el arqueólogo conozca y aplique técnicas y procedimientos a través de los cuales dichos materiales pueden aportar información relevante para la resolución de determinados interrogantes arqueológicos -del mismo modo que otros saberes particulares son indispensables para el arqueólogo que estudia la cerámica, los líticos, los huesos, la arquitectura, etc. -. Dada la naturaleza de las evidencias que aborda la Arqueobotánica, tales estrategias metodológicas pueden proceder en buena medida del campo de la Botánica, la Ecología, la Morfología Vegetal, la Sistemática Vegetal, la Etnobotánica, la Bioquímica; pero también del Arte, la Etnohistoria, la Culinaria, la Paleografía, entre otros.

En el caso de los restos macroscópicos de plantas, como los que se analizan en esta tesis, existen al día de hoy varios manuales y estudios de caso que exponen de manera 
ordenada y exhaustiva los procedimientos básicos, así como diversas problemáticas concernientes al trabajo arqueobotánico con este tipo de material (e. g. Buxó 1997, Capparelli 1997, Hastorf y Popper 1988, Hather 1994, Pearsall 2001, Oliszewski 2004, Renfrew 1973). Asimismo, numerosos artículos han avanzado sobre temas específicos como por ejemplo los tipos, características y confiabilidad de las técnicas de recuperación de restos, entre los que pueden citarse Dye y Moore (1978), Hunter y Gassner (1998), Jarman et al. (1972), López (1999), Marinval (1988), Minnis y Le Blanc (1976), Oliszewski (2003), Pendleton (1983), Struever (1978), Wagner (1982, 1988), Watson (1976), Williams (1973). Asimismo varios trabajos se han dedicado a evaluar la adecuación de los sistemas de muestreo de sedimentos para la obtención de macrovestigios vegetales (v. g. Gasser 1985, Lennstrom y Hastorf 1992, Toll 1988, Van der Veen 1985, 1991, Wright 2005).

Otros estudios se enfocan en dilucidar y discutir acerca de los diferentes procesos naturales y culturales que afectan la conservación de los vestigios botánicos y/o dificultan su identificación e interpretación (Boardman y Jones 1990, Braadbaart y Wright 2007, Gasser y Adams 1981, Gustafsson 2000, Hillman 1991, Hubbard y al Azm 1990, Keepax 1977, Kislev y Rosenwaig 1991, Märkle y Rösch 2008, Miksicek 1987, Rossen et al. 1996, Stewart y Robertson 1971), así como exponen las virtudes y desventajas de las diferentes modalidades y técnicas de presentación, análisis cuantitativo e interpretación de los resultados (Green 2009, Hastorf y Popper 1988 vs. artículos).

En esta tesis, la organización del trabajo arqueobotánico toma como principal referencia la propuesta de Pearsall (2001), la cual descompone el conjunto procedimientos metodológicos a seguir en tres partes consecutivas: recuperación, identificación e interpretación de los macrorrestos botánicos. Siguiendo este esquema, la instancia de recuperación incluyó la implementación de un diseño de muestreo adecuado a las características del sitio, las necesidades de la investigación y el procedimiento de flotación en sí mismo. Su ejecución requirió de la adecuación de algunos medios básicos a las condiciones en las que se realizó el trabajo de campo. La identificación de los ejemplares recuperados se inició con el examen del material recuperado en las dos fracciones de muestra de flotación y en las muestras directas. Luego se prosiguió con la descripción y clasificación de los restos y su determinación taxonómica a partir de la comparación con material de referencia y consultas bibliográficas. Por último, la interpretación del registro arqueobotánico se basó en la información brindada por las determinaciones, por la aplicación de técnicas de cuantificación de los restos y consideraciones concernientes a la tafonomía de los restos vegetales y los procesos de formación que podrían haber afectado al sitio. 


\section{Diseño de muestreo: muestras de flotación y muestras puntuales}

El muestreo implementado en Cardonal obedece a dos requerimientos específicos de esta investigación. El primero de ellos está en relación a las preguntas planteadas en torno a la composición del conjunto arqueobotánico. En este sentido se consideró de vital importancia el poder acceder a la mayor cantidad de información posible acerca del número y variabilidad de especímenes y taxones presentes en el sitio. ¿De qué manera pueden optimizarse los resultados de esta búsqueda?

Tal como muestran varios estudios alrededor del mundo, existe un amplio rango de variaciones en la abundancia absoluta y diversidad taxonómica entre los restos de plantas preservados en los sitios arqueológicos. Estos caracteres de los conjuntos dependen de la antigüedad de los asentamientos, las condiciones ambientales de preservación y la historia de la formación del depósito en sí mismo (Carbone y Keel 1985, Gustafsson 2000, Hillman 1991, Märkle y Rösch 2008, Miller 1989, Miksicek 1987, Munson et al. 1971, Wilson 1984). $\mathrm{Al}$ respecto, las investigaciones desarrolladas hasta el momento en sitios arqueológicos valliserranos, cronológicamente próximos a Cardonal, advierten sobre la inusitada pobreza del registro arqueobotánico (Rossen 1998a, 1998b, Oliszewski 2004, 2005). Dichas investigaciones refieren algunos agentes naturales que podrían haber actuado sobre el material, como las características friables y alcalinas del suelo y/o la humedad ambiental general, que diferencia a los valles y quebradas de las zonas de conservación óptimas, como podría ser la Puna, un caso próximo.

En vistas de este panorama para la arqueobotánica de macrorrestos del área Valliserrana, en Cardonal se consideró la posibilidad de tomar la mayor cantidad posibles de muestras de un volumen no menor que el que venía siendo utilizado hasta entonces en el área. Sin embargo, tal consideración está sujeta también a las posibilidades y constricciones logísticas atribuibles a las características geográficas y topográficas donde se localiza el sitio y la disposición real de tiempo y recursos para llevar a cabo los trabajos de campo (ver Miksicek 1987).

Esto último ha sido de particular importancia en Cardonal, cuyo acceso dificulta notablemente el transporte de objetos de gran porte, incluidos instrumental voluminoso y pesado, así como reduce las chances de acarrear grandes muestras de sedimento hasta el laboratorio. Asimismo, la escasez o la alternancia en la disposición de agua corriente o energía eléctrica contribuyen a limitar las posibilidades de realizar trabajos de flotación extensos, sin contemplar el tiempo y los recursos invertidos en el mismo. 
Otro de los intereses específicos de este estudio, referidos a la recuperación de restos botánicos en Cardonal, es reconocer el patrón de distribución de los vegetales arqueológicos al interior de las habitaciones del Núcleo 1. Por lo tanto era necesario preguntarse qué tipo de muestreo conduciría a resultados que permitan establecer comparaciones entre sí y revelaran diferencias y similitudes en la disposición de los restos y las acciones pasadas que pudieron estar en su origen. En este sentido, es de vital importancia que la toma de muestras incluya unidades muestrales que den cuenta de la presencia de vestigios de plantas a través de toda el área de ocupación, así como de los niveles de sedimento que corresponden al relleno posterior.

Partiendo de estas consideraciones, el diseño de muestreo en Cardonal involucró la toma de 1) muestras directas que proceden de la recuperación in situ durante la excavación y del tamizado en seco aplicado regularmente a la totalidad de la matriz sedimentaria excavada y 2) muestras de sedimento con las características que se detallan más adelante, que serán procesadas mediante sistemas de flotación no mecanizados.

Muestras directas o in situ. Se agrupan bajo esta denominación 35 muestras de restos recuperados in situ, es decir detectados y separados durante la remoción de los depósitos de una unidad de extracción, así como aquellos que se obtuvieron en el proceso de tamizado que se aplicó a todos los sedimentos excavados en Cardonal. Aunque no obedece a un esquema pautado como en el caso de las muestras de flotación, esta forma de hallazgo ha sido frecuente en sitios contemporáneos del área (ver Oliszewski 2004, 2005, Pochettino y Scattolin 1991, Rossen 1998 a, 1998b, Gero 2004) a la vez que constituye el tipo de muestras botánicas que ha brindado la mayor parte de la información sobre restos vegetales previa al desarrollo de los estudios arqueobotánicos propiamente dichos (Capparelli et al. 2001).

De todos modos, su inclusión en el análisis de los conjuntos botánicos de sitios arqueológicos ha merecido varias observaciones por parte de los especialistas. Por una parte se considera que la recuperación se verá afectada en gran medida por la habilidad del excavador en visualizar los restos carbonizados en la matriz sedimentaria (Marinval 1988) o bien de la mayor o menor visibilidad de determinados restos en contextos particulares, como los contenidos de un silo o de un recipiente cerámico. Se ha advertido además que si bien este tipo de hallazgo aumenta las posibilidades de conocer la frecuencia de un taxón desconocido o poco conocido, por la misma razón puede falsear la representatividad de los conjuntos de vestigios botánicos recuperados (Buxó 1997). 
En Cardonal, la obtención de muestras directas se incluyó de manera complementaria al muestreo de flotación, ya que las mismas introducen información relevante sobre la composición de los conjuntos, así como aumentan el número de ejemplares recuperados en un área donde generalmente su presencia ha sido referido como escasa (Oliszewski 2004, 2005, Rossen 1998a, 1998b). Por otra parte, puesto que el sitio ha sido excavado de forma íntegra empleando los mismos procedimientos, todos los sedimentos removidos han recibido atención semejante respecto de los posibles hallazgos in situ o entre los materiales del tamiz.

Muestras de sedimento para flotación. La estrategia de toma de muestras de sedimentos para flotación se elaboró con el fin de obtener un conjunto representativo de la presencia, variabilidad y distribución de macrorrestos vegetales en el Núcleo 1 de Cardonal, reduciendo el volumen de sedimentos a manipular y/o almacenar. Su diseño se basó además en la evaluación de las condiciones y características específicas del paisaje y del sitio. Por otra parte se previó una dinámica de la toma de muestras acorde al desarrollo general de los trabajos de campo y las necesidades de cada especialista integrante del equipo (ver Buxó 1997).

Se tomaron 171 muestras no proporcionales ${ }^{1}$ (sensu van der Veen 1985, Jones 1978) cuyo volumen se fijó en un balde de 6 litros de sedimento, recogido en diferentes puntos de cada una de las unidades de excavación muestreadas, también llamadas "scatter sample" (Gasser 1985, Lennstrom y Hastorf 1992, Popper y Hastorf 1988, Pearsall 2001). El procedimiento de muestreo empleado incluyó la obtención de muestras en unidades de excavación o CAT correspondientes a pisos de ocupación, niveles de relleno y diferentes rasgos (Tabla 3).

Tabla 3. Número de muestras obtenidas según su procedencia (niveles de relleno, pisos ocupacionales y rasgos)

\begin{tabular}{|c|c|c|c|c|c|c|c|c|c|}
\hline \multicolumn{9}{|c|}{ Cantidad y procedencia de las muestras tomadas } & \multirow[b]{3}{*}{ TOTALES } \\
\hline & & & \multicolumn{6}{|c|}{ ESTRUCTURAS } & \\
\hline & & & E1 & E2 & E3 & E4 & E5 & Portal & \\
\hline $\begin{array}{l}\text { NIVELES } \\
\text { RELLENO }\end{array}$ & & & - & 5 & 4 & 9 & 17 & 3 & 38 \\
\hline 乙 & PISO & & 2 & 15 & 22 & 12 & 42 & 6 & 99 \\
\hline U্ড & $\mathrm{DACCOC}$ & $\begin{array}{l}\text { Área de } \\
\text { combustión }\end{array}$ & 1 & - & - & - & 14 & - & 15 \\
\hline $\overrightarrow{0}$ & RASGUS & $\begin{array}{l}\text { Pozo de } \\
\text { poste }\end{array}$ & - & 1 & & - & - & - & 1 \\
\hline
\end{tabular}

\footnotetext{
${ }^{1}$ Las muestras de tipo no proporcional se caracterizan por mantener un volumen constante en relación a las posibles variaciones de volumen de las unidades de excavación muestreadas (van der Veen 1985).
} 


\begin{tabular}{llllllllll}
\hline & $\begin{array}{l}\text { Pozo roca } \\
\text { base }\end{array}$ & - & - & 6 & - & 3 & 1 & 10 \\
& \begin{tabular}{l} 
Terraplén \\
\cline { 2 - 9 }
\end{tabular} & & - & - & - & - & 8 & - & \\
\hline TOTALES & & 3 & 21 & 32 & 21 & 84 & 10 & 171 \\
\hline
\end{tabular}

Aunque tanto Pearsall (2001) como Toll (1988) sostienen que el procedimiento ideal implica obtener muestras de todas las unidades de excavación -de forma que el investigador pueda escoger luego en el laboratorio cuáles muestras procesar y/o analizar en relación a las preguntas que pretenda responder- en el caso de Cardonal se optó por una estrategia de toma de muestras diseñada para sitios de gran escala (van der Veen 1992). En tales casos, ante la imposibilidad de procesar muestras de todos los contextos, el investigador debe seleccionar al azar aquellos que serán muestreados. Aunque no se trata específicamente de la escala del sitio, la problemática del muestreo en Cardonal dificulta la aplicación en un muestreo global en dos sentidos. Por un lado, el elevado número de muestras que supondría obtener una por cada unidad de excavación no podría haber sido transportado hasta el gabinete para su posterior selección y flotación. En relación a ello y en segunda instancia, puesto que las muestras debían procesarse necesariamente en el campo, un número elevado de ellas requeriría más tiempo y recursos que los disponibles en las campañas arqueológicas efectuadas en el sitio.

Por otra parte se ha señalado que la delimitación de rasgos durante la excavación y la toma de muestras para flotación en los mismos depende en gran parte del conocimiento previo que se tiene de la población muestreada (Buxó 1997, Jones 1991, Toll 1988). Por ejemplo se ha estimado en general que los espacios y estructuras como fogones y hornos domésticos, pozos de poste u otras oquedades en el piso, rincones y rellenos de estructuras arquitectónicas, son lugares propicios para la acumulación de material vegetal, puesto que están relacionados con actividades como la cocción de alimentos, el barrido, el relleno intencional, el descarte de materiales, etc. (Buxó 1997, Pearsall 2001). En este sentido, el muestreo dirigido o localizado en dichos sectores específicos suele ser poco recomendado como método general. Por ejemplo Toll (1988), sostiene que cualquier estudio que se base en este tipo de muestreo puede derivar en una imagen sesgada de la presencia y distribución de vestigios botánicos, puesto que descarta a priori los sectores donde no prevé obtenerlos.

Para el caso de Cardonal, sin embargo, la aplicación de este tipo de procedimiento tomó en consideración el modo en que este potencia las posibilidades de recuperación de restos, lo cual tiene una incidencia positiva en el reconocimiento de la composición y 
variabilidad de los conjuntos botánicos arqueológicos. De igual manera resultan altamente informativos respecto de una serie de actividades localizadas en dichos espacios (Buxó 1997, Pearsall 2001). De modo que no se descartó la toma de muestras localizadas en diferentes rasgos excavados en el Núcleo 1, ya que los mismos representan áreas con muy buena conservación y abundancia de restos vegetales.

Por otra parte, se ha sugerido que la combinación de este tipo de muestras con otras de tipo estratificado o al azar, procedentes tanto de los pisos como de los niveles de relleno postocupacional, permite establecer comparaciones entre los diferentes conjuntos, enriqueciendo de esta manera las interpretaciones. Tal contraste habilita además la evaluación del contenido de los rasgos, a fin de analizar los procesos que los formaron e interpretar sus posibles funciones y significados (Lennstrom y Hastorf 1992). Como señala Deborah Pearsall “...how can one argue that the contents of a pit reflect activities involving food specific to that context, if one has not examined samples from floor deposits into which the pit was dug, or the deposits overlying it?” (Pearsall 2001:67).

Finalmente, cada muestra recuperada en el Núcleo 1 se guardó en doble bolsa de polietileno, con rótulo señalando la procedencia y el número de muestra dentro de la segunda bolsa transportándose así hasta el lugar del terreno donde serían flotadas. Los datos de cada muestra extraída se volcaron en planillas de registro de muestras de flotación por estructura excavada.

\section{Procesar las muestras de sedimento: la flotación}

Las muestras de sedimento tomadas en el Núcleo 1 de Cardonal fueron procesadas por flotación, una de las técnicas de recuperación de macrorrestos vegetales cuya eficiencia ha sido probada en varios estudios desarrollados alrededor del mundo desde hace ya medio siglo (v. g. Buxó 1997, Hastorf 1991, Jarman et al. 1972, Marinval 1988, Pearsall 2001, Renfrew 1973, Wagner 1988, Watson 1976). La misma se aplica con éxito a muestras de sedimento que contienen restos carbonizados, ya que su acción se basa en la diferencia de densidades del carbón y el agua. La aparición de espacios aireados en la estructura de los restos vegetales afectados por la carbonización reduce su densidad y posibilita así el ascenso de gran parte de ellos a la superficie en un cuerpo de agua junto con otros materiales poco densos, mientras los 
demás tienden a sumergirse (Renfrew 1973). A uno y otro conjunto se los llama fracción liviana y fracción pesada, respectivamente ${ }^{2}$.

En la mayoría de los casos la sola agitación del líquido hace que los restos floten con facilidad y ayudan a desprender aquellos que puedan estar atrapados entre los sedimentos. El medio por el cual se produce la agitación del agua hace que existan dos modos diferentes de implementar la flotación. En los sistemas de flotación mecanizados el efecto de agitación del agua (Watson 1976, Williams 1973) o de burbujeo (Jarman et al. 1972) lo produce algún agente distinto de la mano del operador. Este último mecanismo es el que corresponde a los llamados sistemas no mecanizados.

En Cardonal se probaron ambos tipos de sistemas con resultados similares en la recuperación de restos vegetales carbonizados (ver más adelante el apartado Prueba experimental de confiabilidad). Sin embargo, el equipo no mecanizado -empleado en E2 y E3- demostró ser más lento en relación al tiempo invertido en la flotación de cada muestra, lo cual impedía seguir correctamente el ritmo de las excavaciones y dificultaba el trabajo del operador del sistema. Se dispuso entonces diseñar y aplicar un sistema mecanizado de flotación para los sedimentos de E1, E4, E5 y Portal.

Sistema no mecanizado: Balde de flotación. Según Pearsall (2001) los sistemas no mecanizados se caracterizan por requerir de muy poca agua y ser fáciles de instalar y transportar en el campo, aunque operarlos puede resultar una tarea extenuante, con gran insumo de tiempo. A su vez, gran parte de la fiabilidad del mismo se basa en la pericia del técnico para producir la agitación y recoger los restos que van emergiendo simultáneamente (Watson 1976).

En el caso de Cardonal el sistema no mecanizado empleado incluyó un balde cuyo fondo se reemplazó por una malla metálica fina $(1 \mathrm{~mm}$. de abertura) junto a un colador revestido con tela 'voile'. Cada una de las muestras debió procesarse por pequeñas partes para facilitar la agitación de sedimento. Ésta se logró moviendo el balde hacia arriba y abajo en la corriente de agua, así como con movimientos laterales y de rotación. La fracción liviana se recogió con el colador y se volcó en sacos de ‘voile’ y la fracción pesada se destinó a un paño del mismo material. Ambas se dispusieron en un lugar sombreado y reparado para que sequen acompañadas del rótulo que indicaba su procedencia.

\footnotetext{
${ }^{2}$ Para más detalles sobre la técnica de flotación, tipos, ventajas y desventajas de su aplicación pueden consultarse Dye y Moore (1978), Hunter y Gassner (1998), Jarman et al. (1972), López (1999), Marinval (1988), Miksicek (1987), Minnis y Le Blanc (1976), Oliszewski (2003), Pearsall (2001), Pendleton (1983), Renfrew (1973), Struever (1965), Wagner (1988), Watson (1976), Williams (1973).
} 
Sistema mecanizado: Cubeta de de flotación. Los sistemas mecanizados son en general, más rápidos y por ello altamente compatibles con excavaciones de tipo extensivo. Tales equipos requieren de una manipulación mínima por parte del operario, aunque su transporte y montaje en áreas aisladas pueden resultar complicados y/o caros. Las dificultades de transporte e instalación de un motor y la no disponibilidad de combustible o energía eléctrica en el campo hacen impensable el uso de un sistema con estas características. En este sentido, los equipos que emplean la fuerza de aguas corrientes para producir la agitación necesaria del material resultan óptimos en términos de eficacia, practicidad y costo. (Dye y Moore 1978, Minnis y Le Blanc 1976, Oliszewski 2004, Pearsall 2001, Struever 1965, Wagner 1988, Watson 1976). El sistema flotación mecanizado que utilizamos en Cardonal fue diseñado acorde a las necesidades propias de esta investigación y teniendo en cuenta las características del entorno en el que se desarrollaba el trabajo y que describimos en párrafos anteriores. Este equipo funciona con la fuerza del flujo de agua que ingresa al mismo directamente de un curso natural o acequia. Su construcción se basó en los modelos utilizados en Yutopián por Jack Rossen y Robert G. Thompson.

Estructura de la cubeta: Se utilizó un recipiente plástico cuadrangular de unos 45 cm. de largo por $30 \mathrm{~cm}$. de ancho y $20 \mathrm{~cm}$. de profundidad, introduciendo modificaciones en su cara anterior. En este sector se soldó un segmento de caño de PVC de unos $12 \mathrm{~cm}$. cortado longitudinalmente para que funcionara como vertedor del agua de rebase que lleva consigo la fracción liviana de la muestra.

Para el control del ingreso de agua a la cubeta se utilizó un conducto (caño de PVC o manguera) dispuesto sobre el borde posterior de la misma. Un conjunto de varillas de hierro se dispusieron de manera entrecruzada entre sí, formando un armazón que se sostiene por los bordes en el interior de la cubeta. Sobre la misma se apoyó el rectángulo de malla metálica de 1,5 mm de abertura que soportó la fracción pesada de cada muestra (Figura 13).

Funcionamiento: La cubeta pudo montarse tanto en las acequias o en tramos poco torrentosos de los cursos de agua naturales. En cada ocasión el recipiente se ubicó con la desembocadura “aguas abajo”. Cuando el nivel del cauce sobrepasaba la cubeta se colocaron piedras en la base para elevarlo. Una vez lograda la posición correcta se adosaba el conducto de entrada de agua, apoyando uno de sus extremos en el borde posterior de la cubeta mientras que la toma se dirigía “aguas arriba”.

Luego se introducía el armazón de metal, suspendido más o menos hacia la mitad de la cubeta y sobre éste se extendía una de las mallas metálicas. Finalmente se ajustaba al extremo de la desembocadura el paño de ‘voile’ que recibiría la fracción liviana. Una vez listo el 
montaje del equipo se iniciaba la flotación, volcando de a poco la muestra sobre la malla metálica, por porciones tales que pudieran ser removidas por el flujo de agua que atravesaba la cubeta desde la entrada de agua hasta la boca de salida, llevando suspendidos los materiales menos densos de la muestra (Figura 14).

Posteriormente se retiraba la malla metálica con la fracción pesada y se dejaba secar en un lugar reparado y sombreado sobre la misma malla, junto con el rótulo que la identifica. Luego se desprendía el saco de 'voile’ con la fracción liviana y se colgaba, una vez rotulado, en la sombra o al interior de una habitación aireada. Antes de comenzar a flotar la muestra siguiente, se retiraba el armazón metálico y se quitaban los restos de sedimento que hubieran quedado depositados en el fondo de la cubeta.

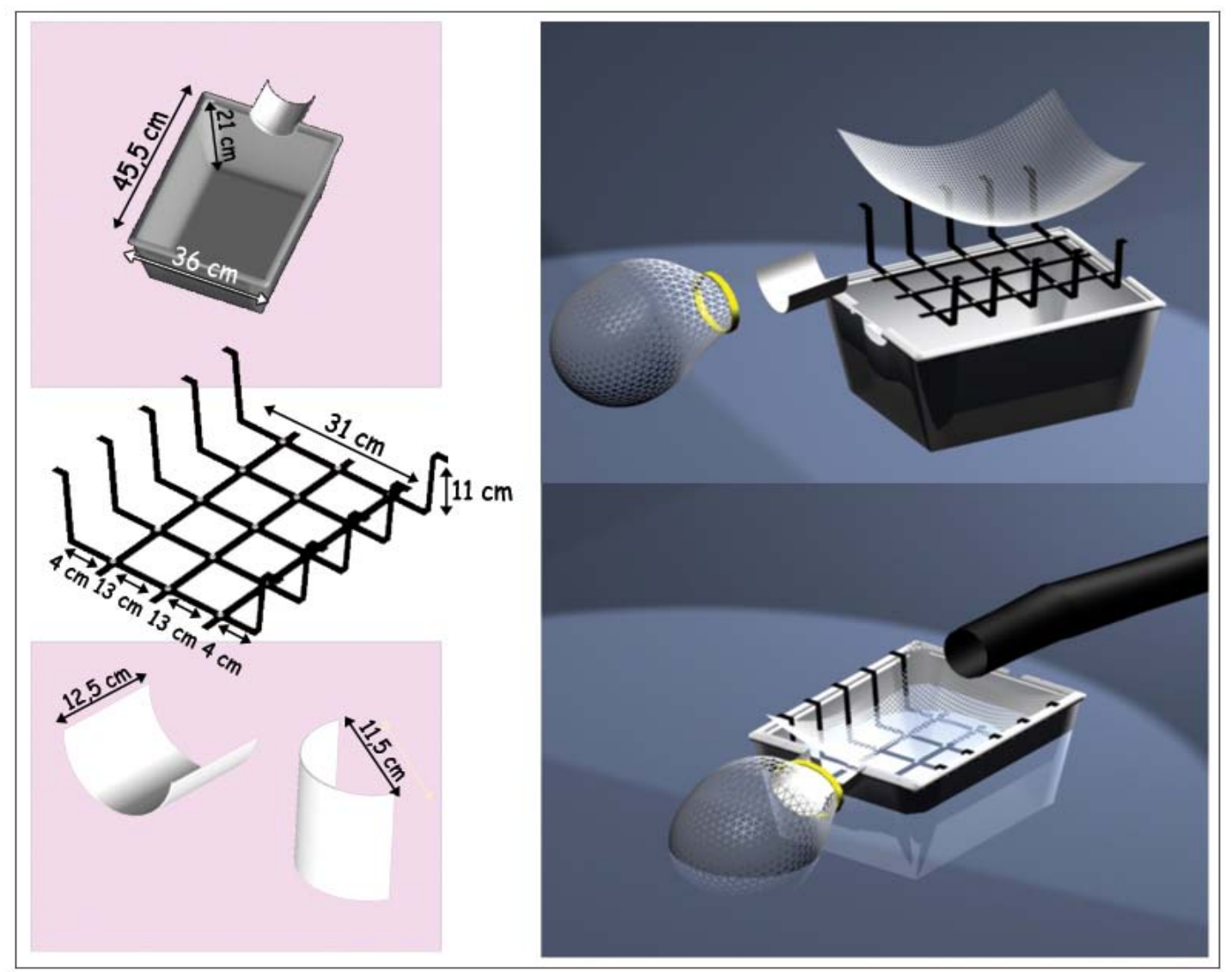

Figura 13. Esquemas aproximados de las partes que componen la cubeta de flotación empleada en Cardonal. 

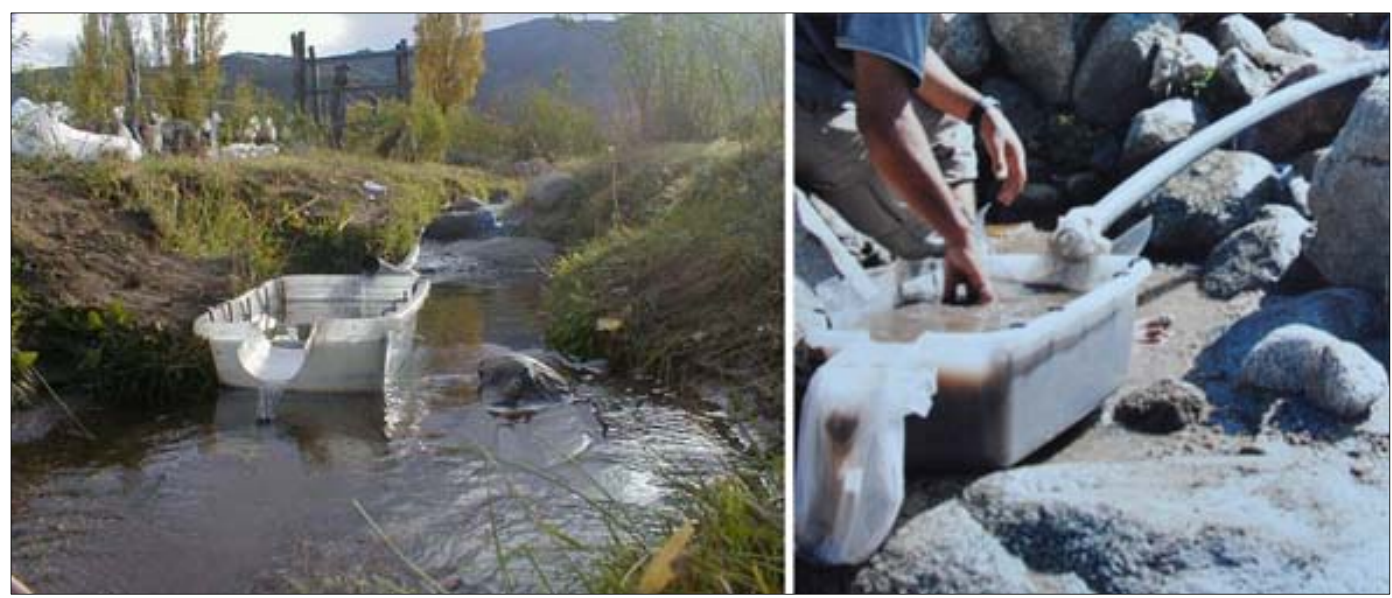

Figura 14. Cubeta ya armada y en funcionamiento, respectivamente.

\section{Procesamiento de las muestras flotadas}

El examen de cada fracción de muestra de flotación comenzó con la separación del material, a través del cernido en tamices Macotest ASTM E-11, con mallas de 2 mm y 0,8 mm de abertura. En el caso de las fracciones pesadas sólo se utilizó el primer tipo de tamiz, debido a los daños que la fricción produce en el material carbonizado. La separación por tamaños de los contenidos de las fracciones fue de utilidad en los casos de las muestras más grandes y con gran variedad en las dimensiones de los componentes, ya que redujo los movimientos de reenfoque del instrumental de aumento. Las fracciones livianas fueron previamente pesadas en una una balanza ACCULAB Sartorius Group ALC-150.3, con precisión de milésima de gramo, la cual también se empleó en el pesaje del carbón de leña separado de las muestras.

Luego, cada subfracción fue examinada individualmente apartando a ojo desnudo el material mayor a $2 \mathrm{~mm}$, mientras que las subfracciones menores a $2 \mathrm{~mm}$ se examinaron íntegramente bajo lupa binocular Wild M5, con ocular 10X y objetivos 6X, 12X, 25X y 50X. A modo de portaobjetos se utilizó la base de cajas de Petri ubicadas sobre papel blanco para obtener contraste. El escaneo del material disperso en el fondo del portaobjeto se organizó en un barrido de izquierda a derecha en línea recta bajo el campo visual de la lupa. El material revisado fue empujado hacia el borde del portaobjeto, para que no se mezclase con el material no examinado. 
Bajo la lupa se separaron fragmentos de carbón de leño, restos carpológicos ${ }^{3}$ carbonizados, fragmentos pequeños de cerámica, líticos, huesos, cuentas y otros objetos arqueológicos diminutos, con la ayuda de pinzas de diversos tipos y tamaños. Los carporrestos se depositaron individualmente en recipientes Eppendorf rotulados. Los resultados se volcaron en planillas de registro por cada muestra.

\section{Determinación taxonómica de restos vegetales}

Todos los restos carpológicos carbonizados recuperados en Cardonal fueron examinados con el objeto de determinar su ubicación taxonómica (Familia, Subfamilia, Género, Especie, Subespecie). De manera general, este procedimiento se basa en reconocer el grado de semejanzas entre 1) las características del ejemplar botánico arqueológico con 2) elementos de comparación bibliográficos y 3) especímenes de colecciones de referencias (ver Buxó 2007, Renfrew 1973; Johannessen 1988; Pearsall 2001).

Análisis de los caracteres externos macroscópicos. Dicho análisis incluyó el examen de caracteres morfológicos y morfométricos de cada ejemplar arqueobotánico mediante el uso de una lupa binocular Wild M5 con aumentos 10X en el ocular y 6X a 50X en las lentes. Cada ejemplar fue esquematizado empleando la cámara clara anexada a la misma lupa, lo cual complementa el registro fotográfico. Algunos ejemplares y caracteres específicos fueron observados con microscopio de barrido electrónico JEOL JSM 6360 LV (Museo de Ciencias Naturales - FCNyM).

Las variables utilizadas para la descripción del material carpológico de Cardonal se basan en las caracterizaciones e identificaciones de material vegetal actual y arqueológico presentes en la bibliografía consultada (ver más abajo). En total se emplearon 18 caracteres de tipo morfológico y morfométrico que se describen a continuación, a los cuales se sumaron algunos descriptores relevantes para casos particulares de determinación que se especifican en el capítulo siguiente.

\footnotetext{
${ }^{3}$ En sentido estricto se denomina “carporrestos” a los vestigios arqueológicos de órganos vegetales que la botánica considera como derivados de hojas carpelares y por tanto constituyen diferentes estructuras reproductivas de las plantas como frutos, semillas, endocarpos, cúpulas, etc. (ver Buxó 1997). A los fines de este trabajo se incluyen en esta categoría pequeños tallos y pedúnculos no leñosos carbonizados.
} 


\section{Variables utilizadas en la descripción de los restos botánicos}

1- Órgano representado: clasifica la parte de la planta analizada para su determinación taxonómica. Puede tomar los valores fruto, carozo, pericarpo (endocarpo, mesocarpo, epicarpo), grano, semilla, cotiledón, tallito, pedúnculo.

3- Estado de conservación: refiere al porcentaje conservado de cada ejemplar, pudiéndose ser este completo (100\%), semicompleto (>50\%), fragmentario $(\leq 50 \%)$.

4- Caracteres morfológicos:

a- Forma: indica la forma tridimensional general del especímen según sea ésta reniforme, ovada/obovada, ovalada, cuadrangular, fusiforme, ahuecada, acuminada, lenticular, esférica.

b- Textura de la cubierta seminal / superficie externa: refiere a las características de la superficie exterior del ejemplar. Esta puede ser lisa, rugosa, surcada, punteada, reticulada, pusticulada.

c- Textura de la superficie interna: Caracteriza la superficie interior del ejemplar en los casos en que esta es visible. Adquiere los mismos valores que la variable anterior.

d- Configuración de los márgenes: Indica la forma adquirida en la zona de convergencia de las caras del ejemplar. La configuración puede derivar en formas convexas, redondeadas, trucadas o cóncavas.

e- Forma del contorno: refiere al diseño del borde del espécimen visto en dos dimensiones, pudiendo variar entre formas angulosas, lisas/redondeadas, onduladas, irregulares.

f- Forma de las caras. Indica la forma de las caras vistas en corte transversal pudiendo ser éstas redondeadas, planas o cóncavas.

g- Forma de los ápices: refiere a la morfología general de los extremos de la semilla que puede describirse como redondeados, truncados, agudos o combinaciones de una y otra forma. 
h- Visibilidad de la radícula: Se aprecia en el grado en que ésta sobresale de los bordes de la semilla y puede describirse como muy visible, visible, poco visible, no visible.

i- Forma del embrión: indica el modo en que se dispone el embrión en la semilla, dando cuenta si este es recto, curvo, en espiral.

j- Posición del hilo: Señala el lugar de la semilla donde se encuentra la marca de la separación con el funículo pudiendo encontrarse ésta en posición apical, subapical o ventral.

k- Presencia / ausencia de la línea fisural: da cuenta de la existencia o no de una estría bien marcada en las caras de la semilla.

5- Caracteres morfométricos:

a- Largo: es la medida en milímetros del eje mayor del espécimen.

b- Ancho: es la medida en milímetros del eje perpendicular al eje mayor.

c- Índice largo/ancho

d- Espesor: es la medida en milímetros de la distancia entre las dos caras del ejemplar.

e- Altura: es la medida en milímetros de la distancia entre la base y el borde superior del espécimen (se utiliza en el caso de las cúpulas).

Material bibliográfico de referencia y consulta. Las principales obras consultadas para la determinación taxonómica de los ejemplares incluye trabajos de índole botánica y agronómica sobre la morfología de frutos y semillas en diferentes especies (Boelcke 1946, Burkart 1952, Cialdella 1984, Gallardo et al. 1997, Gentry 1969, Gepts 2006-2007, Gepts y Debouck 1961, Giberti 1981, 1983, Hunziker 1969, Martin y Barkley 2000, Niembro Rocas 1989, Parodi 1978, Petetin y Molinari 1982, Planchuelo 1975, Sing et al. 1991), floras regionales (Bianco et al. 2001, Cabrera 1983, Kiesling 1994, Ruiz Leal 1972), estudios etnobotánicos y arqueobotánicos en los Andes Centro-Sur (Abiusso y Cámara Hernández 1974, Babot et al. 2007, Berglund-Brücher y Brücher 1976, Bruno 2005, 2006, Bruno y 
Whitehead 2003, Lema 2009, Miante Alsogaray y Cámara Hernández 1996, Oliszewski 2004, 2005, 2008, Oliszewski y Olivera 2009, Pochettino 1985, Pochettino y Scattolin 1991, Tagle y Planella 2002)..

\section{Elaboración y uso de colecciones de referencia}

La flora silvestre local: la colección de herbario: El reconocimiento y documentación de gran parte de las especies vegetales que crecen en los alrededores del sitio Cardonal se realizó en base a la conformación de un herbario de la zona. La recolección de ejemplares se realizó a lo largo de una transecta de unos $40 \mathrm{~km}$. Dicho recorrido atraviesa en sentido noroeste-sureste el cerro donde se ubica Cardonal e incluye 6 zonas entre las cuales se observaron notables cambios en la composición florística: 1) área de ciénagos, 2) tramos de los ríos Cardonal y La Quebrada, 3) alrededores próximos del sitio arqueológico, 4) alrededores del poblado actual, 5) tramo del camino actual que une la localidad de La Quebrada con El Totoral y 6) área de vegetación de monte a la vera del río Totoral.

Teniendo en cuenta la marcada estacionalidad del clima de la región, se colectaron especímenes en dos momentos del año en que la flora presenta diferencias muy notorias. Poco después de finalizada la estación lluviosa (fines de marzo y abril), cuando la humedad de las precipitaciones aún perdura y poco antes del inicio de la misma (fines de octubre y noviembre), cuando la sequedad del ambiente llega a su máxima expresión. Los ejemplares fueron secados entre hojas de papel de diario y luego montados sobre cartulinas blancas etiquetadas. Las determinaciones del material de herbario se llevaron a cabo en el Laboratorio de Morfología Vegetal del Museo de Ciencias Naturales (FCNyM - UNLP).

\section{La colección de frutos y semillas de especies comestibles del Noroeste Argentino:}

Esta colección incluye por un lado ejemplares de las partes comestibles de varias especies cultivadas actualmente en La Quebrada. Asimismo se incorporaron varios frutos y semillas de plantas de importancia alimenticia mencionadas en la bibliografía de índole botánica, etnobotánica y agronómica del Noroeste argentino (e. g. Cámara Hernández y Arancibia de Cabezas 2007, Cárdenas 1989, Carrizo 1995, Hunziker 1952, Martínez Ungría 1989, Parodi 1932, 1966, Parodi y Pastore 1939, Ragonese y Martínez Crovetto 1947, Storni 1937,

Villafuerte 1984. Asimismo se consultaron numerosos estudios de carácter arqueológico y arqueobotánico del área que dan cuenta del espectro de plantas consumidas en el pasado 
(ANEXO 1). Dicha tabla resume los hallazgos de diferentes especies en sitios del Noroeste argentino del primer milenio y la referencia bibliográfica correspondiente.

Una parte de los ejemplares que componen esta colección fueron adquiridos en mercados de Argentina, Bolivia y Perú. Otros se colectaron en diferentes áreas de la región. Algunos de ellos se seleccionaron para su carbonización, ya sea a fuego directo, envueltas en papel de aluminio o en horno, a fin de obtener muestras comparativas próximas para la identificación de los restos arqueológicos.

El material de referencia arqueológico: Por último, los especímenes arqueológicos utilizados a modo de referencia en esta tesis pertenecen a la colección de restos vegetales recuperados en sitios del área sur de los Valles Calchaquíes, depositada en el Museo Etnográfico “J. B. Ambrosetti” - UBA.

\section{Presentación y cuantificación de los datos}

La presentación de los resultados arqueobotánicos incluye información cualitativa acerca de la presencia de los diferentes taxones determinados (Pearsall 2001). Para los restos botánicos recuperados en el Núcleo 1 se refieren datos bibliográficos relevantes acerca de la biología, ecología y utilidad de los taxones representados. A su vez se indaga su ocurrencia en sitios arqueológicos coetáneos a Cardonal en una amplia área que comprende la Puna, los valles y sierras vecinos y aquellos ubicados al este de la sierra del Aconquija.

Por su parte, la cuantificación de los restos recuperados en el Núcleo 1 comprende un abordaje no multivariado de los datos. Según Pearsall (2001) este tipo de análisis es útil para revelar patrones, ayudar en la interpretación y dar algunas pistas acerca de la importancia relativa de los taxones. Para ello se vale de una serie de procedimientos que permiten la estandarización de la información obtenida de la identificación de los macrorrestos botánicos (e.g. Capparelli 2009, Hastorf 1988, 1990, Lennstrom y Hastorf 1992, Llano 2008, Oliszewski 2004, 2005, Pearsall 1988). Estos incluyen conteos, pesaje, determinación de presencia/ausencia, grado de fragmentación, porcentajes, abundancia, número mínimo, y diferentes índices como densidad, ubicuidad, porcentajes relativos y diversidad (Hubbard y Al Azm 1989, Hubbard y Claphman 1992, Jones 1991, Miller 1988, Pearsall 2001, Popper 1988, Popper y Hastorf 1988).

Por tanto, para la cuantificación de los datos en Cardonal se tuvieron en cuenta cinco de estas estrategias de cuantificación (sensu Lennstrom y Hastorf 1992): 1- cantidades 
absolutas, 2- porcentajes relativos y la 3- ubicuidad de cada taxón identificado se aplicaron al conjunto de restos carpológicos. Por otra parte, el carbón de madera fue contabilizado y 4pesado (peso) por muestra para el cálculo de 5- densidad. La interpretación de los datos cuantitativos incluye finalmente el análisis comparativo de los resultados obtenidos entre los recintos, al interior de los mismos y por niveles de procedencia de los restos analizados. Finalmente se grafican las procedencias de cada uno de los restos recuperados sobre el diseño de planta del Núcleo 1.

Cantidad absoluta y Peso. Si bien los conteos y el pesaje de los restos aportan escasa información al análisis, resultan indispensables para la aplicación de otros procedimientos como el cálculo de índices, la aplicación de estadística multivariada (Pearsall 2001) o el análisis gráfico (Green 2009). En esta instancia entonces se presentaron las cantidades de carporrestos recuperados y determinados para la totalidad del conjunto y para cada una de las habitaciones en forma de tablas.

Porcentaje relativo. Este índice permite comparar la importancia de un taxón en relación con otro, puesto que permite estandarizar el contenido de cada muestra y de cada ítem a comparar. Se trata simplemente de una proporción multiplicada por 100 (Miller 1988). Este cálculo tiene en cuenta las cantidades absolutas en que se presenta cada taxón a la vez que permite comparar muestras o grupos de muestras diferentes tamaños, lo cual es imposible entre los resultados de un simple conteo (Lennstrom y Hastorf 1992).

Los porcentajes relativos han sido empleados en general para localizar actividades de procesamiento y almacenamiento de vegetales comestibles (Jones et al. 1986 en Lennstrom y Hastorf 1992). En Cardonal los porcentajes relativos de los diferentes taxones se calculan para la totalidad del conjunto de carporrestos así como en los subconjuntos presentes en cada estructura, estableciéndose comparaciones entre los porcentajes en que ocurre cada taxón según su procedencia.

Ubicuidad. Puede expresarse como el porcentaje de muestras que contienen un taxón dado, sin tener en cuenta las cantidades absolutas en que se presenta cada taxón (Lennstrom y Hastorf 1992). De esta manera hace posible dejar de lado el problema de la preservación diferencial de los restos, ya que cada taxón es considerado como presente ya sea que la muestra contenga uno o 100 restos del mismo (Popper 1988). Al igual que los porcentajes 
relativos, en Cardonal la ubicuidad se calcula para la totalidad del conjunto de restos botánicos y para cada estructura, a fin de establecer comparaciones entre ellas.

Densidad. El denominador de este índice representa la cantidad de sedimento muestreado, mientras que el numerador contiene la cantidad de restos recuperados en dicha muestra. Esta cantidad puede expresarse como una cantidad o bien como un peso y no es necesario que la unidad de medida seleccionada coincida con la utilizada en el denominador. El cálculo de la densidad permite estandarizar los datos de manera que sean comparables entre muestras u otros ítems equivalentes ya que asume que a mayor cantidad de sedimentos, mayor será el contenido de restos si las demás variables se mantienen constantes. De esta forma, si se utiliza la cantidad de sedimento como parámetro contra el cual comparar otras variables, es posible testear dicho presupuesto de uniformidad en los rangos de depositación, preservación y recuperación de restos (Miller 1988).

En este trabajo se calculan las densidades de carbón de leño y carporrestos a través de las muestras recuperadas en diferentes estructuras y niveles de excavación. Las comparaciones se establecen en base al cálculo de densidades promedio por estructura y nivel que se grafican con diagramas de columnas. Se adiciona a los mismos una línea de tendencia que permite reconocer similitudes y diferencias en la distribución de las densidades de carbón respecto de las de carporrestos. Se examina la relación entre ambas en base a un test de correlación de variables. Finalmente se comparan las densidades entre las diferentes procedencias de los restos carpológicos (piso de ocupación, relleno y rasgos) al interior de las habitaciones y entre ellas.

\section{Tareas de control de datos}

Prueba experimental de confiabilidad. La flotación es una técnica de recuperación de restos altamente eficiente aunque no infalible. Parte de esta eficiencia está dada por la capacidad de recuperación de restos del sistema de flotación utilizado. Puesto que ningún sistema de flotación garantiza la recuperación total de los restos y que pueden existir diferencias entre sus tasas de recuperación, la confiabilidad de los sistemas empleados deben testearse y compararse.

Por esto motivo se han realizado pruebas experimentales (Oliszewski 2003, Pearsall 2001) en los dos sistemas de flotación utilizados en Cardonal con el fin de evaluar el rango de pérdida de material vegetal arqueológico. Asimismo se buscó detectar posibles variaciones 
entre ellos para proyectarlas en el análisis e interpretación de los datos (Oliszewski 2003, Pearsall 2001). Con este objeto se procesaron muestras de sedimento del lugar adicionadas cada una con un número conocido de semillas carbonizadas de diferentes tipos y tamaños. La carbonización se realizó en recipientes metálicos colocados a fuego directo con las semillas envueltas en aluminio dispuestas en su interior.

Las muestras se procesaron cada una con las variantes técnicas mencionadas y luego se examinaron las fracciones, a fin de determinar los porcentajes de material recuperado en cada caso, confeccionándose tablas comparativas de las cantidades y porcentajes de material carpológico presente en cada uno.

Muestras de flotación off-site. A fin de establecer la distinción entre las características de material vegetal arqueológico presente en los recintos excavados en el Núcleo 1 con el tipo de material depositado que podría haberse incluido naturalmente en áreas ajenas a éstos, se procedió a muestrear áreas alejadas del espacio construido. Allí se tomaron dos muestras de sedimento de 8 litros cada una hacia los 70-80 cm de profundidad. Las mismas fueron procesadas por flotación y examinadas siguiendo el procedimiento empleado para las muestras arqueológicas.

\section{Metodología para el análisis de los artefactos de molienda}

\section{Clasificación, análisis e interpretación de los artefactos de molienda}

El trabajo de Tesis doctoral de M. P. Babot (2004) representa uno de los estudios más importantes sobre los artefactos de molienda arqueológicos del Noroeste argentino. La autora aborda problemáticas relativas a la clasificación de este tipo de instrumentos a través de la descripción y análisis de diversos aspectos tecnológicos y funcionales de las piedras de moler, para dar cuenta finalmente de los rangos artefactuales y los cambios ocurridos en las prácticas de molienda desde las sociedades cazadoras y recolectoras hasta el avance del Imperio Inca en la región.

Los aspectos metodológicos comprendidos en dicho trabajo cobran gran relevancia en el presente estudio de los artefactos de molienda en Cardonal, ya que ofrecen una serie de procedimientos sólidos a través de los cuales es posible dar cuenta de las especificidades de los conjuntos de molienda e interpretarlas en relación a problemáticas de orden social y 
cultural. De acuerdo a ello se toma aquí como referencia el análisis tipológico de los artefactos de molienda propuesto por Babot (2004).

Una parte importante de tal metodología de análisis ha sido desarrollada en base a estudios previos inéditos realizados por Aschero (1975 en Babot 2004) acerca de la clasificación morfológica de las piedras de moler, así como otros trabajos complementarios de tecnología lítica (Laming-Emperaire 1967, Leroi-Gourhan 1971, Mansur-Franchomme 1987, Semenov 1964). La aplicación del análisis tipológico permite por una parte, organizar y caracterizar los conjuntos de molienda de sitios del Noroeste argentino en referencia a materiales de la misma área. Por otro lado, a diferencia de otras clasificaciones (González 1960, Nardi y Chertudi 1969-70, Fernández Distel 1994, ver sin embargo Quinteros 1997, Roldán 1999), el análisis tipológico otorga gran relevancia a los aspectos morfológicos vinculados con la funcionalidad de los artefactos.

Por este motivo se considera que el mismo constituye una herramienta idónea para este abordaje de las piedras de moler en Cardonal, ya que es principalmente a través de los caracteres funcionales que pueden explorarse diferentes modos de acción y pautas de uso de los artefactos (Babot 2004) en ámbitos domésticos. Tales propiedades permiten, en una etapa de análisis posterior, indagar sobre problemáticas relacionadas no ya con la funcionalidad misma de los artefactos, sino con la organización de la práctica que los involucra: la molienda (Babot 2007).

\section{Análisis tipológico de los artefactos de molienda}

El análisis efectuado sobre los artefactos de molienda de Cardonal se basa en los procedimientos y descriptores definidos y empleados por Babot (2004), adaptados para el presente caso de estudio. De tal modo se emplea una selección de las variables involucradas en el examen morfológico-funcional expuesto por la autora, que sirven para dar cuenta de los grupos tipológicos de artefactos presentes en los pisos ocupacionales del Núcleo 1.

Tal como ha sido estipulado en el trabajo de Babot, el análisis consta de cuatro etapas consecutivas denominadas 1- segmentación del conjunto, 2- orientación, ilustración y segmentación de los artefactos, 3- descripción técnico-morfológica y morfológico-funcional y 4- clasificación.

Segmentación del conjunto lítico. Tiene por objeto distinguir entre núcleos, deshechos y artefactos de molienda formatizados o empleados sin manufactura previa, de 
diferente procedencia. En Cardonal dicha tarea se desarrolló en el campo, clasificando entre aquellas piezas líticas que presentaron signos de haber sido empleadas en actividades de molienda (rastros de uso claramente asignables a la molienda: redondeo, pulido, alisado, estrías, esquirlamientos, residuos macroscópicos), se encontrasen o no manufacturadas, separándolas de aquellas correspondientes a núcleos, desechos o materiales dudosos. Los primeros se integraron al registro de artefactos de molienda del Núcleo 1. En segunda instancia se separaron aquellos instrumentos correspondientes a la ocupación del núcleo habitacional en estado completo y semicompleto, que se analizaron según el procedimiento que se detalla a continuación.

Orientación, ilustración y segmentación de los artefactos. Puesto que no se realizaron dibujos de las piezas recuperadas en el Núcleo 1, la orientación de los artefactos refiere principalmente a la ubicación otorgada a los mismos para su posterior descripción. De este modo, la orientación siguió el procedimiento empleado por Babot (2004) en el cual el eje de alargamiento de una forma, o el eje mayor de una pieza (denominado eje A), se dispone de manera vertical y la cara activa hacia el observador, a la vez que se distingue entre un extremo proximal y otro distal respecto del mismo. En la segmentación de los artefactos se diferenciaron caras activas, bordes, oquedades y rasgos morfológicos complementarios.

Descripción de los artefactos. Para la descripción de los instrumentos se empleó un conjunto de variables morfológicas, definidas y sistematizadas por Babot (2004) en base a la propuesta de clasificación morfológica de artefactos de molienda realizada por Aschero (1975 en Babot 2004). En el presente trabajo se utilizaron 15 de tales descriptores, seleccionados en relación a las propiedades generales del conjunto de artefactos depositados en el piso de ocupación del Núcleo 1. Dichas variables proveyeron información relevante para la clasificación de las piedras de moler de Cardonal en categorías morfológico-funcionales (ANEXO 2):

1-Variables de procedencia: Unidad de excavación, Posición del hallazgo, Características del descarte.

2-Variables de identificación: Código de identificación del artefacto

3-Variables de estado: Estado de conservación de la pieza

4-Variables dimensionales: Medidas de los ejes principales de la pieza, Profundidad máxima de la oquedad. 
5- Variables morfológico-funcionales: Portabilidad, Forma de la pieza, Posición de la cara activa respecto del eje longitudinal de la pieza, Forma de la cara activa, Disposición de la oquedad respecto del eje longitudinal del artefacto, Presencia de rastros macroscópicos de uso y mantenimiento, Modo de acción, Posición durante el uso.

Este procedimiento de clasificación permitió el reconocimiento de tipos y modos de acción de los instrumentos, así como las modalidades de uso de los diferentes artefactos en las actividades de molienda.

Clasificación de los artefactos. La clasificación de los instrumentos de molienda de Cardonal se realizó en base a su asignación a diferentes grupos jerárquicos, ordenados en tres niveles que se definen en referencia a las variables descriptivas correspondientes. En el primer nivel se consideran aquellos atributos que dan cuenta de la posición de la pieza en el sistema artefactual y el grado de definición de las mismas como moledores. El segundo nivel comprende variables directamente relacionados con la funcionalidad de los artefactos, ordenándolos en grupos y subgrupos tipológicos. Por último, el tercer nivel incluye descriptores funcionales y tecnológicos que permiten observar la variabilidad al interior del nivel anterior, estableciendo distinciones entre tipos morfológicos de instrumentos.

Primer nivel de clasificación: artefactos y preformas. Siguiendo la definición de Babot (2004) se considera que los artefactos de molienda propiamente dichos son aquellos utensilios empleados de a pares para quebrantar o reducir sustancias intermedias, no artefactuales, a un tamaño más pequeño que el original. De este modo, sus características esenciales son: a) requieren para funcionar, por lo menos, de dos partes, las cuales se complementan mutuamente; b) el fin de su utilización no es reducir su propio tamaño, sino el de otras sustancias y c) estas sustancias deben ubicarse entre las dos partes para ser procesadas.

Los artefactos o litos de difícil definición como instrumentos de molienda, ya sea por su elevado nivel de fragmentación, porque carecen de los elementos básicos para ser clasificados como tales, o porque presentan atributos que puedan corresponder a más de un grupo de molienda o a un grupo destinado a otros fines, se denominan aquí artefactos indefinidos, sin hacer mayores alusiones funcionales. En el caso de Cardonal, se aplica un procedimiento de clasificación similar en el caso de aquellos artefactos en proceso de 
formación o preformas de artefactos ya sea que ellos anticipen o no a un artefacto de molienda.

Según su grado de definición como moledores, se clasifican como artefactos de molienda formatizados o bien como litos no manufacturados. Estos últimos reúnen las características de los artefactos de molienda formatizados -función primaria y modo de uso, más los caracteres diagnósticos dados naturalmente- pero sin presentar indicios de haber sido manufacturados previamente a su utilización, denominándose a los fines de la descripción como artefactos de molienda no formatizados.

Dado que los artefactos de molienda funcionan de a pares, pueden ser considerados como sistemas cuyo funcionamiento requiere de dos elementos: un útil activo y un útil pasivo, los que en algunos casos pueden estar constituidos por piezas no formatizadas con antelación al uso. Esta consideración permite introducir el primer nivel de clasificación al distinguir por su posición o función general en el sistema de molienda entre artefactos de molienda pasivos o inferiores o artefactos de molienda activos o superiores. Aquellos artefactos que, aun pudiendo ser calificados como instrumentos de molienda, no pueden describirse como pasivos o inferiores o bien activos o superiores se denominan artefactos de molienda de posición indeterminada. Los valores de referencia de cada variable para la clasificación de cada grupo de artefactos según su posición en el sistema se sintetizan en el ANEXO 3.

Segundo nivel de clasificación. Grupos y subgrupos tipológicos: Los grupos tipológicos diferencian a los artefactos según su diseño como un utensilio determinado. Babot (2004) conserva entonces aquí la distinción tradicional entre mortero y molino de mano o moledera con sus respectivas, mano de mortero o pilón y mano de molino o moledera. Se agregan además los artefactos de molienda pasivos o inferiores no diferenciados y los artefactos de molienda activos o superiores no diferenciados. La autora considera también la ocurrencia de dos grupos de instrumentos de origen sudamericano, el maray y sus bases o soleras, no observados en los conjuntos de molienda de Cardonal.

Asimismo estos grupos tipológicos pueden diferenciarse en subgrupos según el número y funcionalidad de las caras activas en simples (1 sola cara activa), dobles (dos caras activas de función similar), múltiples (más de dos caras activas de función similar) y compuestos (más de una cara activa de función diferente, de uso alternativo o producto del reciclado de la pieza. Estos grupos se caracterizan por 1) sus usos o funciones primarias más adecuados que pueden desarrollar, definidos sobre la base de datos etnográficos y experimentales. Los morteros y manos de mortero tienen como función primaria majar, 
machacar, triturar, descascarar, moler o pulverizar. Los molinos y manos de molino por su parte, tienen como función primaria moler, pulverizar, triturar. 2) También se distinguen por los posibles modos de acción y movimiento con que pueden actuar, definidos sobre la evaluación de los caracteres morfológicos seleccionados para optimizar el trabajo invertido en procesamiento de sustancias intermedias. Los modos de acción en los morteros y manos de mortero son por tanto de percusión y de prensión vertical o puntual. En cambio, los modos de acción de los molinos de manos y las manos de molino suman a los modos de acción anteriores los movimientos deslizantes o con desplazamientos.

La asignación de los artefactos de molienda analizados a diferentes grupos y subgrupos tipológicos se realizó a partir de la evaluación conjunta de las variables Portabilidad, Forma general de la pieza, Posición relativa de las caras activas (en artefactos activos), Posición de la cara activa respecto del eje longitudinal del artefacto, Forma del contorno de las caras activas, Longitud de la cara activa /longitud el eje A de la pieza, Disposición de la oquedad respecto del eje longitudinal del artefacto, Curvatura de la oquedad, Razón ancho máximo de la oquedad/máxima profundidad de la oquedad, Razón máxima profundidad de la oquedad/ancho máximo de la oquedad, Rastros de uso, Modos de acción, Posición de la pieza durante el uso.

Tales atributos morfológico-funcionales y dimensionales fueron empleados en la descripción de los grupos tipológicos de artefactos del Noroeste argentino analizados por Babot (2004). De esta forma, cada variable posee valores pautados que definen cada uno de los grupos tipológicos, si bien cabe considerar que algunas de ellas resultan más significativas en la distinción de un grupo que en otros. La comparación de los valores obtenidos para los artefactos de Cardonal con dichos valores de referencia permite su asignación a los diferentes grupos y subgrupos tipológicos (ver Anexo 3).

\section{Composición y distribución del conjunto de artefactos de molienda en el sitio}

Una vez realizada la asignación de los artefactos de molienda a los diferentes grupos tipológicos se procedió a determinar la composición de los conjuntos depositados en cada una de las habitaciones del núcleo, según el grupo tipológico de pertenencia y la unidad de procedencia correspondiente en cada caso. El análisis comparativo entre recintos de los conjuntos de molienda, así como entre diferentes sectores en su interior, se expresaron a través de tablas y gráficos de barras, teniendo en cuenta cantidades y porcentajes de tipos de instrumentos representados por estructura, nivel y unidad de excavación del núcleo 
habitacional. Se analiza finalmente la disposición y asociación espacial de los artefactos en relación con los contextos y áreas de actividad para el Núcleo 1 (Scattolin 2009a, 2009b). La misma se representa gráficamente en el piso de ocupación de los recintos. 


\section{CAPÍTULO 5}

\section{Resultados del análisis de restos vegetales}

\section{Conformación de las colecciones de referencia y control del procedimiento de flotación}

\section{La flora silvestre local: colección de herbario}

De las seis áreas delimitadas a lo largo de un recorrido de $40 \mathrm{Km}$. que atraviesa en sentido NO - SE el cerro donde se ubica Cardonal, se recolectaron 131 ejemplares de flora silvestre local que conforman la colección de herbario (Figura 15). Dominan esta colección numerosas especies de ASTERACEAE, seguidas por las Familias POACEAE, FABACEAE, CACTACEAE y CYPERACEAE (Gráfico 1).

El uso actual de las plantas silvestres. Notablemente, la gran mayoría de las plantas que componen la colección de herbario tienen en la actualidad uno o más usos definidos, muchos de ellos citados por los mismos pobladores de La Quebrada y registrados en la libreta de campo de la autora ${ }^{1}$. De esta manera se pudo observar que POACEAE y CYPERACEAE son plantas empleadas por los lugareños fundamentalmente como forraje; las ASTERACEAE en cambio comportan también otros usos como medicinales, combustibles, aromáticas, ornamentales y cosméticas. Lo mismo puede decirse de algunas especies de FABACEAE, aunque éstas junto con las CACTACEAE son utilizadas además en la construcción.

De todos modos, la escasa cantidad de especies silvestres mencionadas como alimento humano en la actualidad es notoria ('frutilla silvestre’, 'pusquillo', 'pasacana', 'molli', 'algarrobo', 'chañar’) en comparación con las plantas destinadas a otros usos. Por último se pudo observar una marcada abundancia y variedad de especies biodinámicas, ingeridas junto con otras preparaciones de comida o infusiones, con el objeto de dar sabor y aroma. Estas

\footnotetext{
${ }^{1}$ Con el objeto de enriquecer la información brindada por las colecciones de referencia se incorporaron datos de nombres vernáculos y usos de varias plantas, obtenidos a través de entrevistas no estructuradas realizadas a dos informantes y las charlas habituales con otros pobladores de La Quebrada. De ninguna manera dicha información responde a la aplicación sistemática de una metodología etnobotánica, la cual escapa a los fines del presente trabajo.
} 
plantas a menudo coinciden con aquellas que poseen propiedades curativas: 'charroa', 'matico', 'borraja', 'copa-tola', 'santamaría’, 'azafrán medicinal', 'albahaca de vaca', 'chachacoma’, ‘paico’, ‘nencia’, ‘arca', 'yerbabuena’, ‘muña-muña’, 'rica-rica’ y plantas comprendidas en el género Mentha (ANEXO 4).

\section{Colección de frutos y semillas de plantas comestibles del Noroeste Argentino}

Este conjunto de muestras comprende uno o más ejemplares de 35 frutos y semillas de diferentes plantas de uso reconocido en el área, con especialmente en aquellas empleadas como recursos alimenticios (ANEXO 5). Varios de estos especímenes se separaron para obtener muestras de referencia carbonizadas experimentalmente a fuego directo, en horno y envueltas en papel de aluminio (Figura 16).
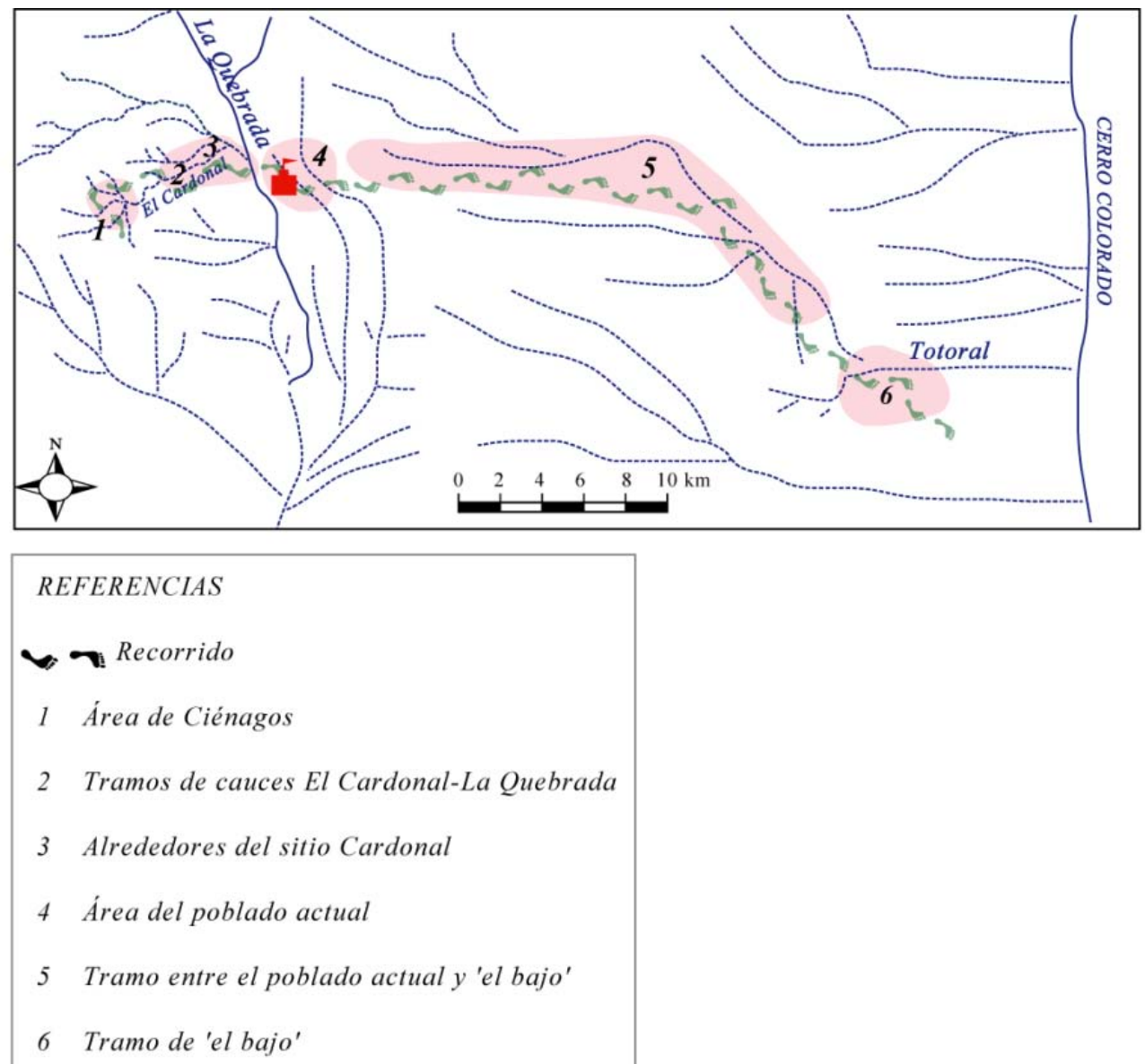

Figura 15. Croquis del área cubierta por la colección de referencia de plantas silvestres. 


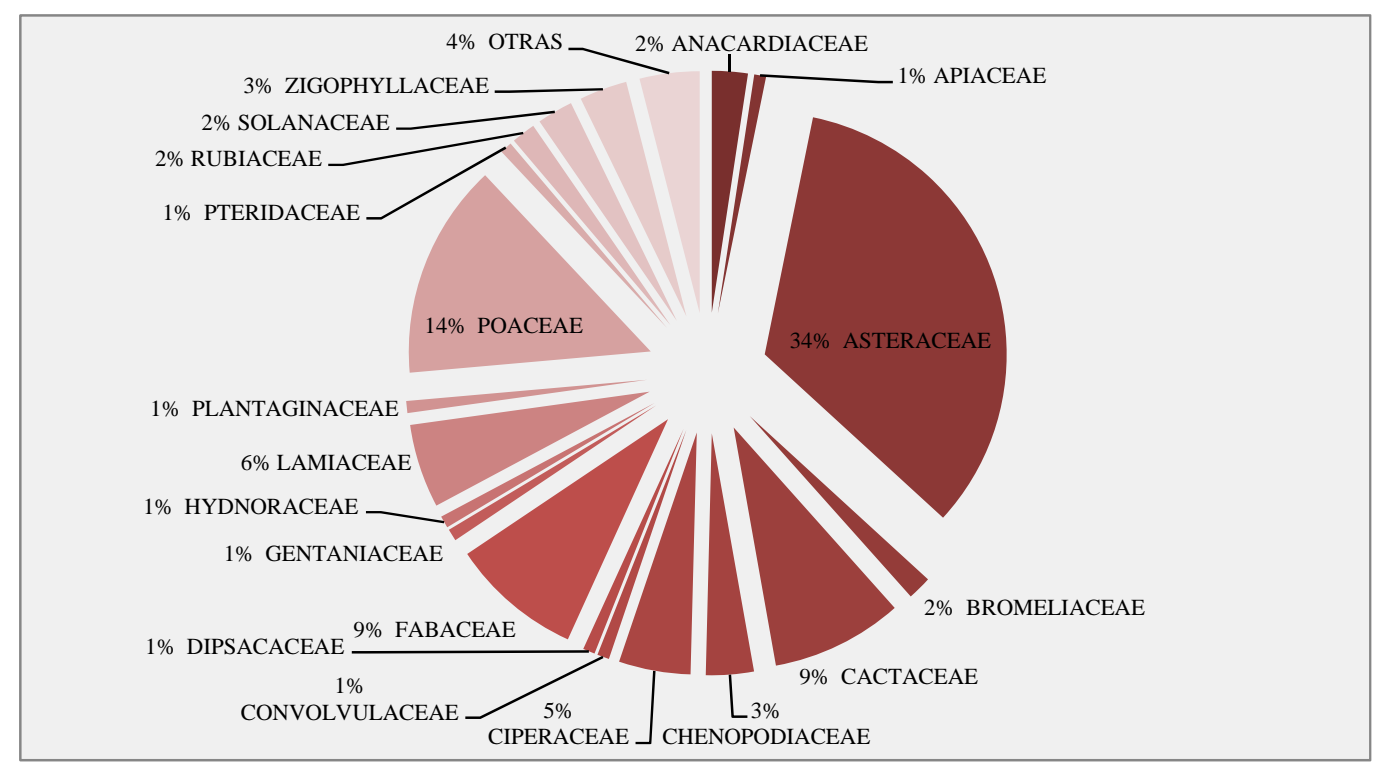

Gráfico 1. Porcentajes de plantas silvestres en la colección clasificadas por Familia.

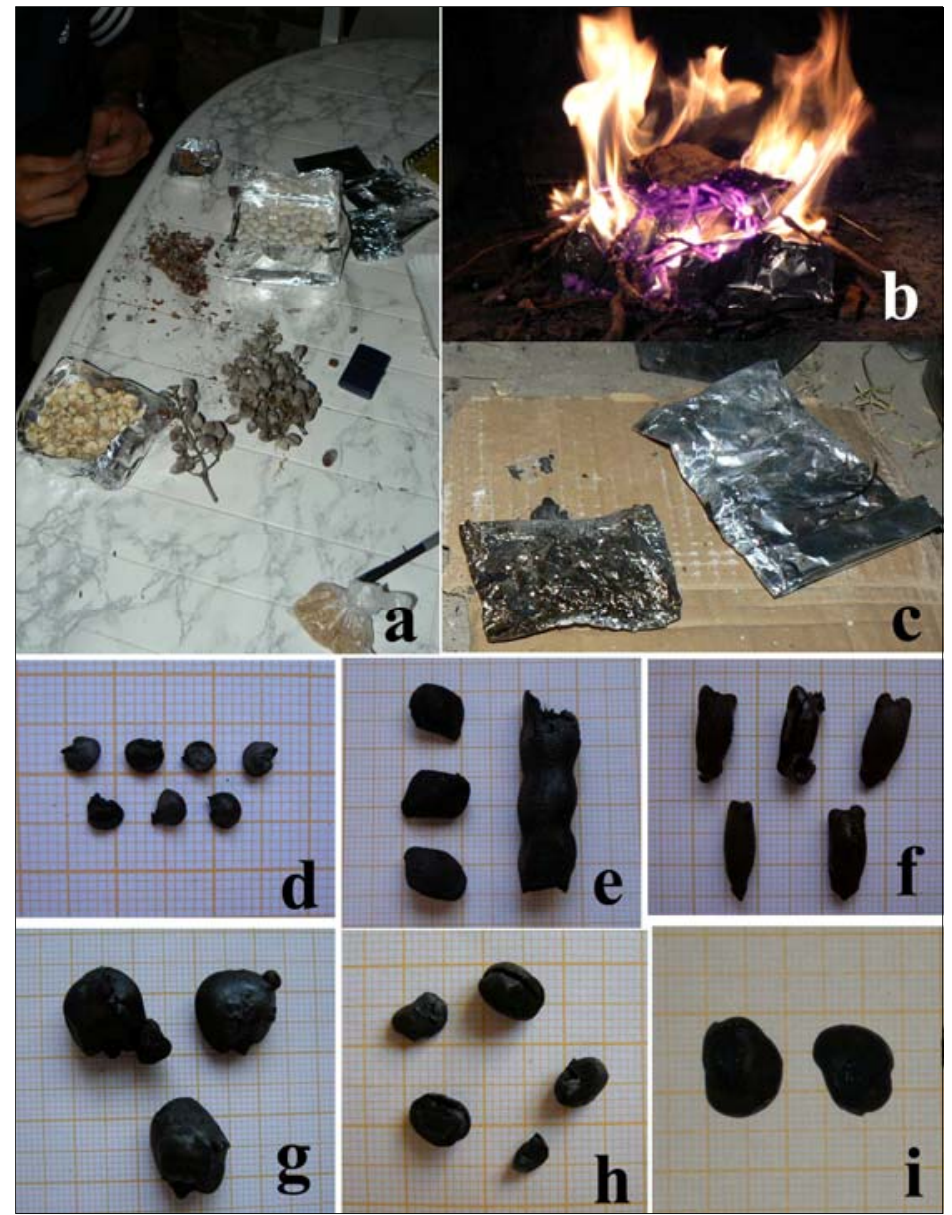

Figura 16. Carbonización experimental de especímenes de referencia; a-, b- y c- ilustran el procedimiento desde la preparación de los ejemplares hasta que fueron retirados del fuego envueltos en láminas de aluminio. Algunos de las referencias obtenidas comprenden: d- semillas de Capsicum sp; e-endocarpos y fragmento de vaina de Prosopis nigra; f- semillas de Lagenaria; g- granos de Zea mays CAPIA; h- semillas y cotiledones de Phaseolus vulgaris var. vulgaris; i- semillas de Anadenanthera colubrina var. cebil. 


\section{Test experimental de confiabilidad de los sistemas de flotación empleados}

Se procesaron ocho muestras de flotación (M) de 6 litros de sedimento cada una, adicionadas con semillas carbonizadas de diferentes tamaños (Tabla 4). Las muestras se procesaron utilizando las dos variantes de flotación empleadas en Cardonal, cuatro de ellas con el sistema de flotación no mecanizado (SFn) empleado en E2 y E3. A las restantes se aplicó el sistema de flotación mecanizado (SFm) usado en los demás recintos. En todos los casos los vegetales recuperados corresponden a unidades completas o cuyas partes son reconstruibles, de manera que puedan contabilizarse como una unidad. No se tuvieron en cuenta aquellos que se presentaron como fragmentos sueltos.

Según el test, el sistema mecanizado es capaz de recuperar el 95,3\% de los restos presentes en una muestra, superando en un 1,7\% la capacidad del sistema no mecanizado, que obtuvo un resultado de $93,6 \%$. Por otra parte, se pudieron observar algunas diferencias en cuanto a las tasas de recuperación por tamaño de los especímenes. Las mayores dificultades parecen hallarse en la recuperación de semillas muy pequeñas, como es el caso de la quinoa, que mostró los porcentajes más bajos (SFn: 87,8\% y SFm: 92\%). En cambio, los vegetales carbonizados resistentes como los mesocarpos de algarrobo, los cotiledones de poroto pallar y los granos de maíz capia, tuvieron altas tasas de recuperación en ambos sistemas. El maíz pisingallo presenta algunas variaciones muestra a muestra, posiblemente debido a que los ejemplares quemados experimentalmente resultaron en estructuras porosas y lábiles a la impregnación con agua (Tabla 5).

Tabla 4. Tipo y cantidad de ejemplares agregados a cada una de las muestras experimentales

\begin{tabular}{l|l}
\hline $\begin{array}{l}\text { Material vegetal } \\
\text { Adicionado }\end{array}$ & $\begin{array}{l}\text { Cantidad adicionada } \\
\text { por muestra (n) }\end{array}$ \\
\hline Cotiledones de porotos pallares & 20 \\
granos de maíz capia & 20 \\
Mesocarpos de algarrobo & 15 \\
Granos de maíz pisingallo & 30 \\
Semillas de quinoa & 60 \\
\hline Total & 145 \\
\hline
\end{tabular}


Tabla 5. Cantidades y porcentajes de recuperación comparados en ambos sistemas de flotación (SFn: sistema de flotación no mecanizado y SFm: sistema de flotación mecanizado).

\begin{tabular}{|c|c|c|c|c|c|c|c|c|c|c|c|c|c|}
\hline & & \multicolumn{2}{|c|}{ Pallar } & \multicolumn{2}{|c|}{ Capia } & \multicolumn{2}{|c|}{ Algarrobo } & \multicolumn{2}{|c|}{ Pisingallo } & \multicolumn{2}{|c|}{ Quinoa } & \multicolumn{2}{|c|}{ Total } \\
\hline & & $n$ & $\%$ & $n$ & $\%$ & $n$ & $\%$ & $n$ & $\%$ & $N$ & $\%$ & $n$ & $\%$ \\
\hline \multirow{5}{*}{$\frac{5}{5}$} & M1 & 19 & 95 & 20 & 100 & 15 & 100 & 28 & 93,3 & 51 & 85,0 & 133 & 91,7 \\
\hline & M2 & 20 & 100 & 20 & 100 & 15 & 100 & 29 & 96,7 & 53 & 88,3 & 137 & 94,5 \\
\hline & M3 & 20 & 100 & 20 & 100 & 15 & 100 & 28 & 93,3 & 54 & 90 & 137 & 94,5 \\
\hline & M4 & 19 & 95 & 19 & 95 & 15 & 100 & 28 & 93,3 & 51 & 85 & 132 & 91 \\
\hline & $\bar{X}$ & 19,7 & 98,3 & 20 & 100 & 15 & 100 & 28,3 & 94,4 & 52,7 & 87,8 & 135,7 & 93,6 \\
\hline \multirow{5}{*}{$\frac{\Sigma}{[1}$} & M5 & 20 & 100 & 20 & 100 & 15 & 100 & 29 & 96,7 & 55 & 91,7 & 139 & 95,9 \\
\hline & M6 & 20 & 100 & 20 & 100 & 15 & 100 & 30 & 100 & 57 & 95 & 142 & 97,9 \\
\hline & M7 & 19 & 95 & 19 & 95 & 15 & 100 & 27 & 90 & 54 & 90 & 134 & 92,4 \\
\hline & M8 & 20 & 100 & 19 & 95 & 15 & 100 & 28 & 93 & 55 & 92 & 137 & 94,5 \\
\hline & $\bar{X}$ & 19,7 & 98,3 & 19,7 & 98,3 & 15 & 100 & 28,7 & 96 & 55,3 & 92 & 138,3 & 95,4 \\
\hline
\end{tabular}

\section{Análisis de los restos arqueobotánicos recuperados en Cardonal}

\section{Consideraciones generales}

La suma total de restos botánicos recuperados en el Núcleo 1 de Cardonal es de 10632 unidades. Más del 98\% de las 171 muestras de flotación analizadas contenían restos vegetales carbonizados (ANEXO 6). Entre ellos, unos 9443 corresponden a fragmentos de leño y 215 a carporrestos (Tabla 6). Estos 215 (86\%) vestigios junto a otros 35 (14\%) recuperados in situ (ANEXO 7), conforman un conjunto de 250 especímenes (Tabla 7, Gráfico 2).

La mayor parte de los frutos y semillas carbonizados se recuperó en la fracción liviana de las flotaciones (ver Tabla 10). Sin embargo la fracción pesada presentó una cantidad superior de ejemplares completos y semicompletos respecto de la otra parte de la muestra y del material in situ. Aún así, visto en conjunto, más de la mitad del material carpológico tratado se encuentra en estado fragmentario (Tabla 8).

Tabla 6. Restos vegetales carbonizados recuperados en el Núcleo 1

\begin{tabular}{cccccc}
\hline & \multicolumn{4}{c}{ Muestras de flotación } & \multirow{2}{*}{$\begin{array}{c}\text { Muestras } \\
\text { directas }\end{array}$} \\
\cline { 2 - 5 } & \multicolumn{2}{c}{ Fracción Liviana } & \multicolumn{2}{c}{ Fracción Pesada } & \\
\cline { 2 - 5 } & Leños & Carporrestos & Leños & Carporrestos & \\
\hline Subtotales & 9385 & 157 & 997 & 58 & 35 \\
\hline Subtotales & 9542 & & 1055 & 35 \\
\hline Total & \multicolumn{5}{c}{$\mathbf{1 0 6 3 2}$} \\
\hline
\end{tabular}


Tabla 7. Cantidad de restos recuperados por diferentes técnicas por Estructura

\begin{tabular}{ccc}
\hline Restos de flotación & Restos in situ & Total \\
\hline 215 & 35 & 250 \\
\hline
\end{tabular}

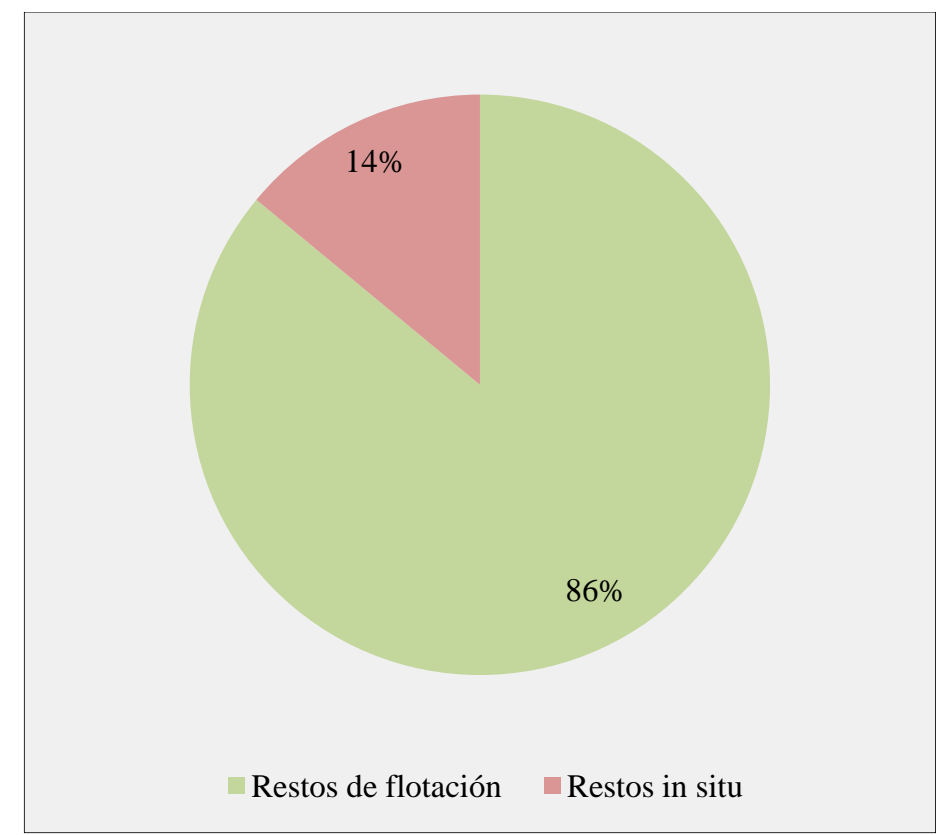

Gráfico 2. Porcentajes de restos recuperados por diferentes técnicas.

Tabla 8. Cantidades $(n)$ y porcentajes (\%) de carporrestos completos y fragmentarios por tipo y fracción de muestra. FL: fracción liviana; FP: fracción pesada

\begin{tabular}{cccccc}
\hline & \multicolumn{2}{c}{ Restos completos } & Restos fragmentarios & Total \\
\cline { 2 - 5 } & $\boldsymbol{n}$ & $\%$ & $\boldsymbol{n}$ & $\%$ & \\
\hline $\boldsymbol{F L}$ & 63 & 40,6 & 94 & 65,7 & 157 \\
\hline $\boldsymbol{F P}$ & 30 & 51,7 & 28 & 19,6 & 58 \\
\hline In $\boldsymbol{s i t u}$ & 14 & 40 & 21 & 14,7 & 35 \\
\hline Total & 107 & 43,1 & 143 & 57,2 & 250 \\
\hline
\end{tabular}

\section{Procedencia taxonómica y anatómica de los restos vegetales}

El conjunto de 250 restos carpológicos recuperados en Cardonal comprende restos de semillas, cotiledones, granos, pericarpos, endocarpos, tallos y pedúnculos en diferentes estados de conservación. Entre ellos se encuentran representantes de las Familias CHENOPODIACEAE, FABACEAE, MALVACEAE, SOLANACEAE y POACEAE. 


\section{Dicotiledoneae}

\section{CHENOPODIACEAE}

\section{Chenopodium}

Órgano representado: semillas.

Ejemplares: 63, 65, 70, 71, 74, 82, 83, 89, 90, 91, 105, 108, 115, 116, 127, 140.

Caracteres considerados: 1- Estado de conservación, 2- Forma general, 3- Largo, 4Ancho, 5- Configuración de los márgenes, 6- Visibilidad de la radícula, 7- Textura de la cubierta seminal.

Descripción: Se identificaron 17 semillas completas, semicompletas e incompletas pertenecientes a Chenopodium (Tabla 9). Cinco de ellas (82, 83, 90, 91 y 135) presentan forma lenticular, superficie de la testa seminal lisa, excepto en el ejemplar 83 donde ésta no se observa por estar recubierta por el pericarpio reticulado. Los márgenes son truncos a redondeados o redondeados, no ondulados. El tamaño de estos ejemplares oscila entre $1 \mathrm{~mm}$ y 1,2 mm de largo por 0,8 mm y 1,1 mm de ancho. Se observa la radícula sobresaliendo del contorno.

Un segundo grupo, formado por los ejemplares 63, 65, 70, 71, 74, 89, 105, 108, 115, 116, 127 y 140, pudo distinguirse del anterior en base a la forma esférica y borde notablemente cóncavo, formando un surco en el contorno de las semillas. Ninguno de los especímenes supera los 1,4 mm de largo máximo y los más chicos pueden llegar hasta los 0,7 mm. A pesar de los caracteres atípicos observados en relación a Chenopodium, su determinación se logró en base a la búsqueda experimental de morfologías similares en semillas del mismo género. Para ello se tomaron como punto de partida hipótesis sobre las posibles modificaciones que se producen en las mismas durante su exposición al calor en medio acuoso (hervido) o seco (tostado). Se exploraron alteraciones en la forma, cambios en el tamaño, pérdida de estructuras, desintegración de los ejemplares.

Tabla 9. Descripción de los ejemplares de Chenopodium

\begin{tabular}{cccccccc}
\hline Ejemplar & Estado & Forma & $\begin{array}{c}\text { Largo } \\
(\mathbf{m m})\end{array}$ & $\begin{array}{c}\text { Ancho } \\
(\mathbf{m m})\end{array}$ & Borde & Radícula & Testa \\
\hline $\mathbf{6 3}$ & completo & esférica & 0,9 & 0,8 & cóncavo & - & - \\
\hline $\mathbf{6 5}$ & incompleto & esférica & 1,2 & 1,1 & cóncavo & visible & - \\
\hline $\mathbf{7 0}$ & completo & esférica & 2 & 1,9 & cóncavo & visible & - \\
\hline $\mathbf{7 1}$ & completo & esférica & 1,2 & 1,1 & cóncavo & - & - \\
\hline $\mathbf{7 4}$ & incompleto & esférica & 0,8 & 0,5 & cóncavo & - & - \\
\hline $\mathbf{8 2}$ & completo & lenticular & 1 & 0,8 & redondeado & notoria & - \\
\hline
\end{tabular}




\begin{tabular}{cccccccc}
\hline $\mathbf{8 3}$ & completo & lenticular & 1,1 & 1,1 & $\begin{array}{c}\text { truncado a } \\
\text { redondeado }\end{array}$ & $\begin{array}{c}\text { notoria } \\
\text { recubierta } \\
\text { por } \\
\text { pericarpio } \\
\text { reticulado }\end{array}$ \\
\hline $\mathbf{9 0}$ & completo & lenticular & 1,2 & 1,1 & $\begin{array}{c}\text { redondeado } \\
\text { a truncado }\end{array}$ & notoria & lisa \\
\hline $\mathbf{9 1}$ & completo & lenticular & 1 & 0,9 & redondeado & notoria & lisa \\
\hline $\mathbf{8 9}$ & completo & esférica & 0,9 & 0,8 & cóncavo & visible & - \\
\hline $\mathbf{1 0 5}$ & completo & esférica & 1,4 & 1 & cóncavo & visible & - \\
\hline $\mathbf{1 0 8}$ & completo & esférica & 1,4 & 1,1 & cóncavo & - & - \\
\hline $\mathbf{1 1 5}$ & completo & esférica & 0,8 & 0,8 & cóncavo & - & - \\
\hline $\mathbf{1 1 6}$ & semicompleta & esférica & 1 & 0,8 & cóncavo & - & - \\
\hline $\mathbf{1 2 7}$ & semicompleta & esférica & 0,7 & 0,5 & cóncavo & - & - \\
\hline $\mathbf{1 3 5}$ & semicompleta & lenticular & 1,2 & 1 & redondeado & notoria & lisa \\
\hline $\mathbf{1 4 0}$ & completa & esférica & 1,1 & 1 & cóncavo & visible & - \\
\hline
\end{tabular}

\section{Identificación:}

Grupo 1: Las dimensiones observadas en las semillas 82, 83, 90, 91 y 135 recuperadas en Cardonal son algo más pequeñas que las registradas por Bruno (2005, 2006), Bruno y Whitehead (2003), Gallardo et al. (1997) y Planchuelo (1975), para las dos variedades actuales de Chenopodium quinoa var. quinoa Willd. ('quinoa') y C. q. var. melanospermum Hunziker ('quinoa negra'), aunque el ejemplar 83 comparte con éstas el pericarpio reticulado (Bruno 2005). También comparadas con el material de referencia, los diámetros de los ejemplares arqueológicos son algo menores que el promedio de las semillas comercializadas de la misma especie (Tablas 10 y 11). Por el contrario, los ejemplares arqueológicos son más grandes que las semillas de especies aromáticas como C. ambrosioides L. ('paico’) y C. graveolens Willd. ('arca', 'arcayuyo'), referenciadas a partir de material fresco (Bruno 2005, 2006, Planchuelo 1975), y que crecen de manera abundante en el área de estudio (Figura 17).

Dentro del mismo rango de tamaño que los ejemplares analizados Planchuelo (1975) menciona las siguientes especies de Chenopodium que crecen actualmente en el Noroeste argentino: C. hircinum Schrader, C. murale L., C. papulosum Moq., C. pallidicaule Aellen. Del primero son distintivos los bordes irregulares o jibosos que no han sido observados entre las semillas del Núcleo 1, como tampoco los bordes agudos o subagudos de las dos especies que siguen en la lista.

Ciertamente, en relación al tamaño y la configuración de los márgenes redondeados a truncos o redondeados, los ejemplares arqueológicos de Cardonal resultan próximos a las semillas de C. pallidicaule Aellen descriptas por Planchuelo (1975) en ejemplares de Jujuy y La Rioja (0,9-1 mm. de latitud × $1 \mathrm{~mm}$. de longitud), así como las estudiadas por Bruno (2005) 
en Bolivia ( 1 - 1,4 mm de diámetro), y las observadas en material de referencia propio (entre 0,9 a 1,2 mm de diámetro) (Tabla 12). Asimismo no se observaron acanalamientos ni rugosidades notorias en la cubierta seminal de los especímenes arqueológicos, cuya superficie es más bien suave y lisa. De todos modos, la superficie notablemente reticulada del pericarpio conservado en el ejemplar 83 y ausente en las semillas restantes remite a alguna de las especies silvestres de semillas pequeñas como C. murale (Planchuelo 1975) o bien a las variedades de C. quinoa tal como han sido descriptas para Bolivia por Bruno (2005), algo menores que las estudiadas en territorio argentino, especialmente la variedad melanospermum.

En resumen, considerando que el conjunto de semillas recuperadas en Cardonal presentan una combinación de caracteres relevantes adjudicables a $C$. pallidicaule y a $C$. quinoa y teniendo en cuenta la abundancia actual de especies silvestres de Chenopodium en el área, especialmente C. murale, se asignan los cuatro ejemplares arqueológicos de manera general al género Chenopodium, en tanto se reconocen las afinidades para su discusión.

Tabla 10. Dimensiones obtenidas sobre ejemplares de referencia de semillas de quinoa no

\begin{tabular}{cccccccccccc}
\multicolumn{10}{c}{ carbonizadas } \\
\hline Quinoa & $\mathbf{1}$ & $\mathbf{2}$ & $\mathbf{3}$ & $\mathbf{4}$ & $\mathbf{5}$ & $\mathbf{6}$ & $\mathbf{7}$ & $\mathbf{8}$ & $\mathbf{9}$ & $\mathbf{1 0}$ & Prom. \\
\hline $\begin{array}{c}\text { Diámetro } \\
\text { (mm) }\end{array}$ & 2,4 & 2,6 & 2,3 & 2,6 & 2,0 & 2,1 & 2,5 & 2,3 & 2,1 & 2,0 & 2,3 \\
\hline $\begin{array}{c}\text { Espesor } \\
\text { (mm) }\end{array}$ & 0,9 & 1,1 & 1,1 & 1,2 & 1,0 & 0,9 & 1,1 & 0,9 & 0,9 & 0,8 & 0,9 \\
\hline
\end{tabular}

Tabla 11. Dimensiones obtenidas en ejemplares de referencia de semillas de quinoa carbonizadas

\begin{tabular}{cccccccccccc}
\hline $\begin{array}{c}\text { Quinoa } \\
\text { carbonizada }\end{array}$ & $\mathbf{1}$ & $\mathbf{2}$ & $\mathbf{3}$ & $\mathbf{4}$ & $\mathbf{5}$ & $\mathbf{6}$ & $\mathbf{7}$ & $\mathbf{8}$ & $\mathbf{9}$ & $\mathbf{1 0}$ & Prom. \\
\hline $\begin{array}{c}\text { Diámetro } \\
(\mathrm{mm})\end{array}$ & 2,1 & 2,2 & 2,2 & 2,3 & 2,2 & 1,9 & 2,0 & 2,0 & 2,2 & 2,1 & 2,1 \\
\hline $\begin{array}{c}\text { Espesor } \\
(\mathrm{mm})\end{array}$ & 0,8 & 1 & 0,8 & 1,0 & 0,8 & 0,7 & 0,6 & 0,8 & 0,8 & 0,7 & 0,8 \\
\hline
\end{tabular}

Tabla 12. Dimensiones obtenidas en ejemplares de referencia de semillas de cañiwa no carbonizadas

\begin{tabular}{cccccccccccc}
\hline Cañiwa & $\mathbf{1}$ & $\mathbf{2}$ & $\mathbf{3}$ & $\mathbf{4}$ & $\mathbf{5}$ & $\mathbf{6}$ & $\mathbf{7}$ & $\mathbf{8}$ & $\mathbf{9}$ & $\mathbf{1 0}$ & Prom. \\
\hline $\begin{array}{c}\text { Diámetro } \\
(\mathrm{mm})\end{array}$ & 1,1 & 1,0 & 1,2 & 0,9 & 1,0 & 0,9 & 0,9 & 0,8 & 1,0 & 0,9 & 1 \\
\hline $\begin{array}{c}\text { Espesor } \\
(\mathrm{mm})\end{array}$ & 0,7 & 0,6 & 0,6 & 0,5 & 0,6 & 0,5 & 0,6 & 0,5 & 0,6 & 0,6 & 0,5 \\
\hline
\end{tabular}




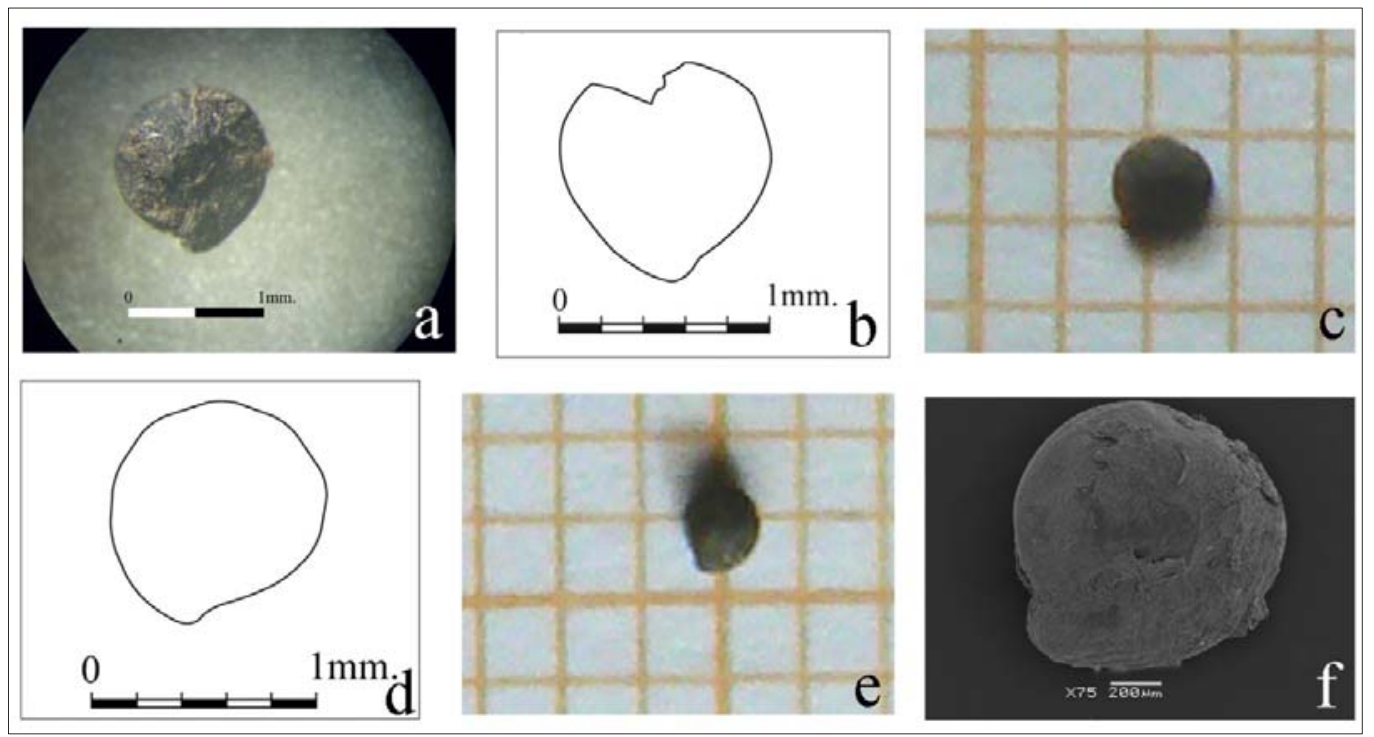

Figura 17. Semillas de Chenopodium (grupo 1): a- 83, b- 135, c 91, d- e- 82, f- 90.

Grupo 2: Las dimensiones de estos 12 ejemplares (63, 65, 70, 71, 74, 89, 105, 108, 115, 116, 127 y 140) son próximas a las observadas en las semillas pequeñas de Chenopodiáceas mencionadas anteriormente descriptas por Planchuelo (1975). Asimismo, aunque la forma general y de los bordes de varias de las semillas poco se ajustan a las descripciones botánicas del género Chenopodium, los ejemplares mostraban indicios de haber sufrido modificaciones, tales como la porosidad y brillo de la superficie, especialmente en la zona del surco y las diferentes roturas y pérdidas de material (Figura 18). En base a estas observaciones se consideró la posibilidad de indagar sobre los procesos que habrían dado lugar a esas formas en semillas que por su tamaño y contorno circular, podrían corresponder a Chenopodium.

Puesto que las semillas en cuestión están carbonizadas, uno de los factores a considerar es la acción del calor y el fuego. La gran mayoría de las semillas tostadas y finalmente carbonizadas en horno o a fuego directo envueltas en aluminio, reventaron e incluso se desintegraron. Las pocas que no sufrieron estos procesos, adquirieron formas esféricas y de bordes redondeados.

Otro de los procesos considerados fue la impregnación con agua, lo cual podría ocurrir con el remojo y/o hervido de las semillas. Entre los ejemplares hervidos con o sin remojo previo, pudo observarse la ocurrencia del desprendimiento total o parcial del embrión (Figura 19). Finalmente la carbonización de estas semillas resultó en la obtención de morfologías similares a las estudiadas como material arqueológico (Figura 20). 
En base a estos resultados, se considera que los ejemplares estudiados corresponden al género Chenopodium. Entre las especies más afines se mencionan aquellas comprendidas en el Grupo 1, en razón de su tamaño y de la relación contextual que guardan con aquellas.

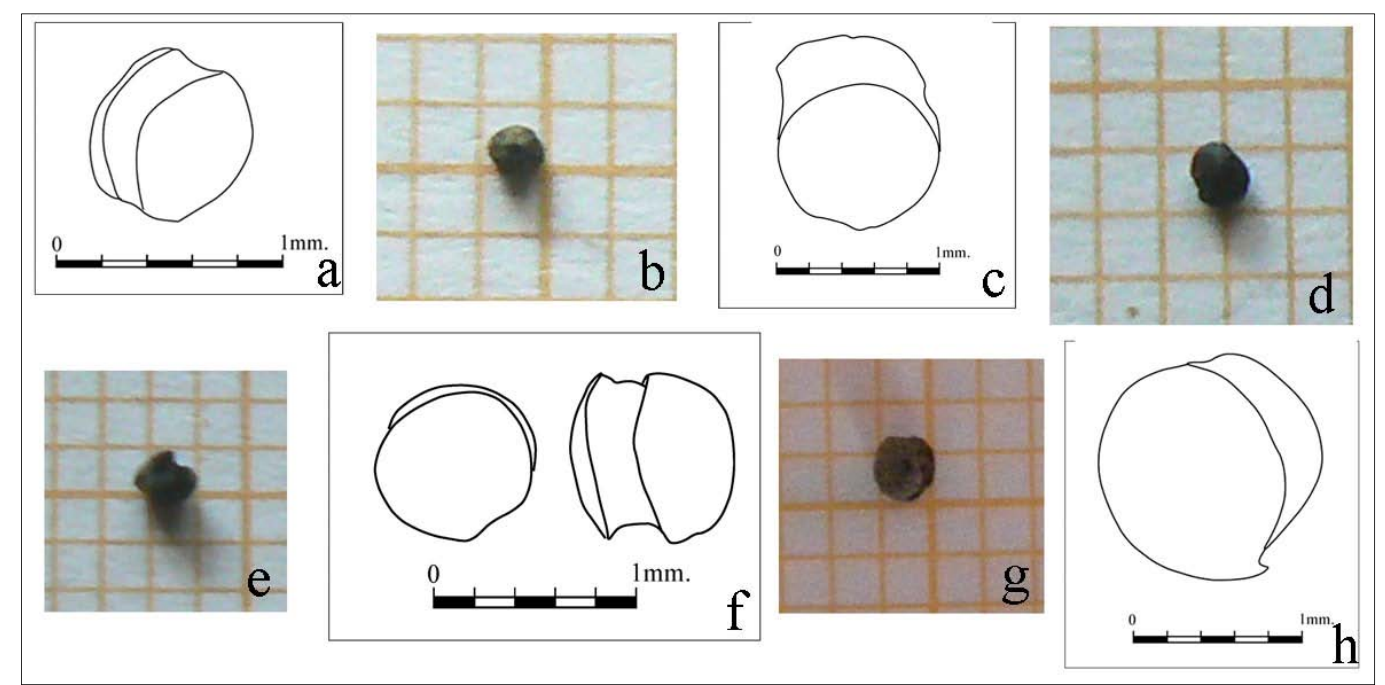

Figura 18. Semillas de Chenopodium: a- b- 63, c- 105, d- 116, e- f- 70, g- h- 140.

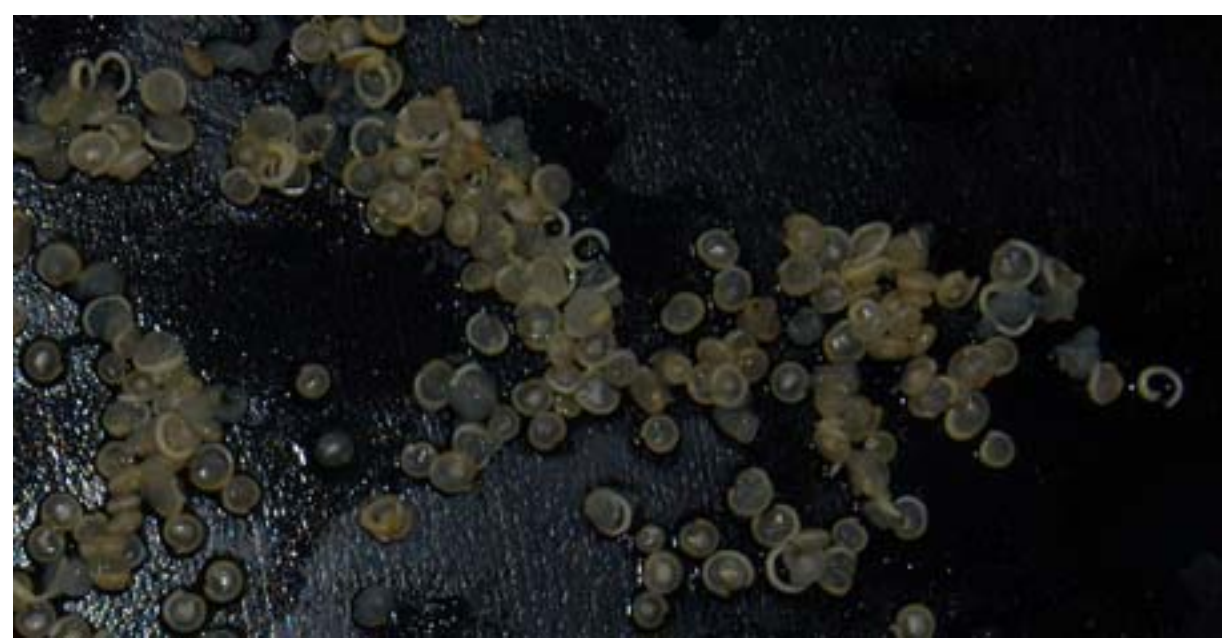

Figura 19. Semillas de C. quinoa hervidas (material de referencia). Notar que en varias de las semillas el embrión se halla totalmente desprendido. 


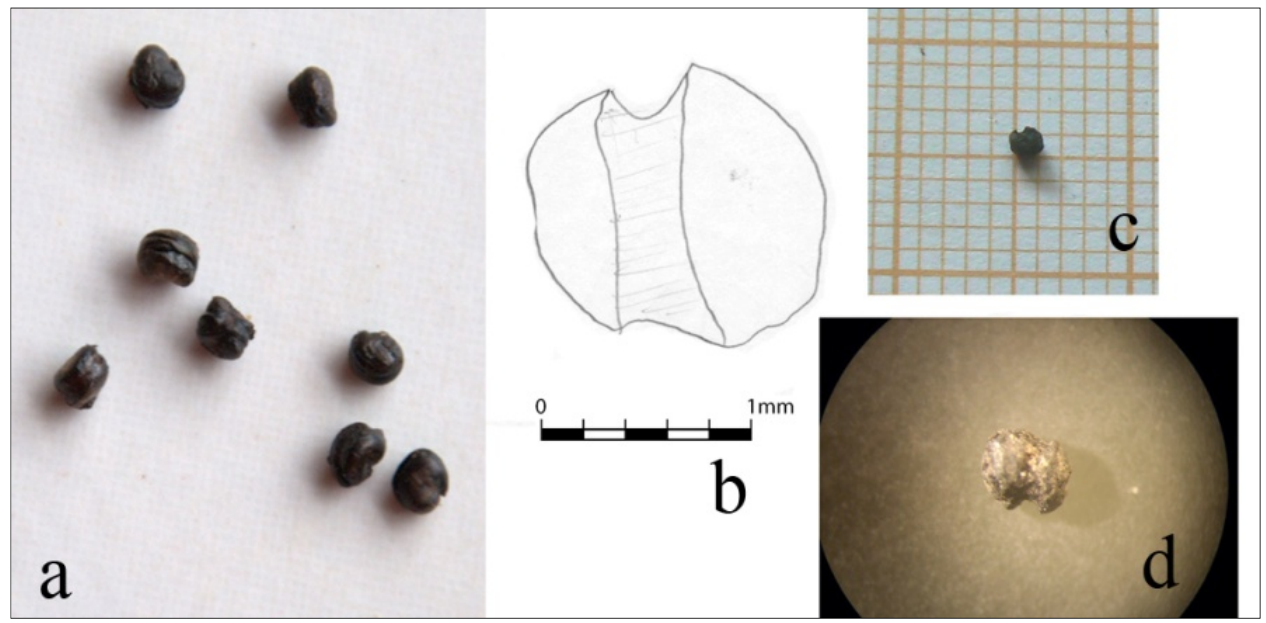

Figura 20. a- Semillas de C. quinoa hervidas y posteriormente carbonizadas (material de referencia), b-c-d- ejemplar arqueológico 71.

\section{FABACEAE}

Caesalpinioideae

Órganos representados: semilla, cotiledones.

Ejemplares: 2, 3, 8.

Caracteres observados: 1- Estado de conservación; 2- Forma; 3- Largo; 4- Ancho; 5Posición del hilo; 6- Presencia/ausencia de línea fisural; 7- Textura de la superficie.

Descripción: Se describen como pertenecientes a este taxón dos cotiledones (2 y 3) y una semilla entera compuesta por dos cotiledones (8) que se separaron durante el análisis (Tabla 13). El tamaño del ejemplar completo es de 1,5 mm de largo por $1 \mathrm{~mm}$ de ancho, en tanto que los restantes poseen dimensiones menores. Presentan formas ovaladas y achatadas de superficie muy lisa y lustrosa (Figura 21). No se observa línea fisural. El hilo se encuentra en posición apical.

Identificación: Según la clave de identificación de subfamilias de Leguminosas elaborada por Boelcke (1846) se estima que estas semillas corresponden a la Subfamilia Caesalpinioideae, posiblemente a alguno de los géneros con frutos y semillas pequeños como Cassia u Hoffmanseggia (Burkart 1952) presentes en la flora catamarqueña.

Tabla 13. Descripción de los ejemplares de Caesalpinioideas

\begin{tabular}{cccccccc}
\hline Ejemplar & Estado & Forma & $\begin{array}{c}\text { Largo } \\
(\mathbf{m m})\end{array}$ & $\begin{array}{c}\text { Ancho } \\
(\mathbf{m m})\end{array}$ & Hilo & $\begin{array}{c}\text { Línea } \\
\text { fisural }\end{array}$ & Textura \\
\hline $\mathbf{2}$ & incompleto & $\begin{array}{c}\text { elíptica?, } \\
\text { comprimida } \\
\text { lateralmente }\end{array}$ & 1,1 & 1,1 & apical & no presenta & $\begin{array}{c}\text { lisa, } \\
\text { lustrosa }\end{array}$ \\
\hline $\mathbf{3}$ & semicompleto & $\begin{array}{c}\text { elíptica, } \\
\text { comprimida } \\
\text { lateralmente }\end{array}$ & 1,2 & 1 & apical & no presenta & $\begin{array}{c}\text { lisa, } \\
\text { lustrosa }\end{array}$ \\
\hline
\end{tabular}




\begin{tabular}{ccccccc}
\hline $\mathbf{8}$ & completo & $\begin{array}{c}\text { elíptica, } \\
\text { comprimida } \\
\text { lateralmente }\end{array}$ & 1,5 & 1 & apical no presenta & $\begin{array}{c}\text { lisa, } \\
\text { lustrosa }\end{array}$ \\
\hline
\end{tabular}
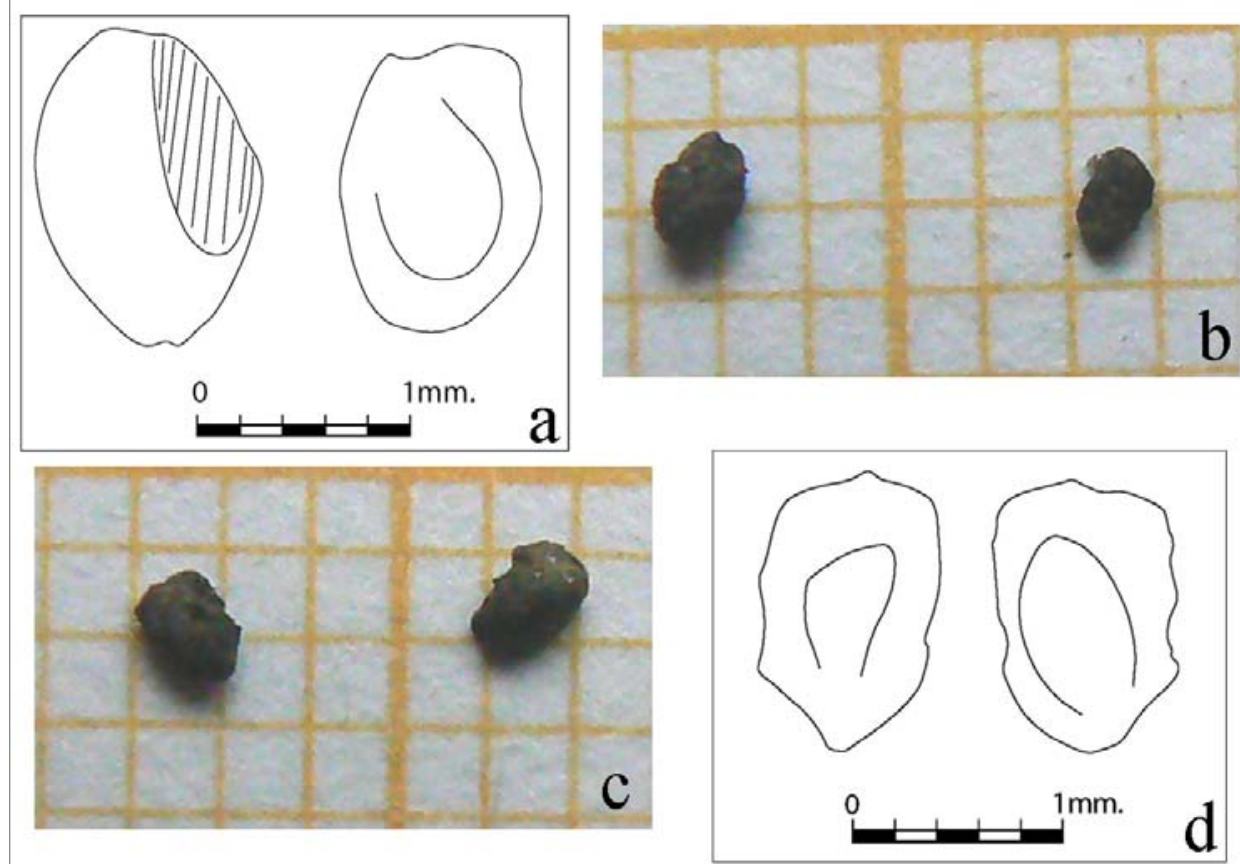

Figura 21. Cotiledones de Caesalpinioideas: a- b- 3, c- d- 8.

\section{Mimosoideae}

Órgano representado: semilla

Ejemplares: 18, 69, 72, 102, 114, 239.

Caracteres considerados: 1- Estado de conservación, 2- Largo, 3- Presencia/ausencia de línea fisural.

Descripción: se hallaron 4 ejemplares fragmentarios cuyo largo máximo supera los 3,5 mm En todos ellos se observó la presencia notoria de la línea fisural próxima a los márgenes (Tabla 14). El estado de conservación impidió reconocer otros caracteres diagnósticos.

Identificación: La presencia de línea fisural permite adscribir estos ejemplares a la Subfamilia Mimosoideae (Figuras 22a, 22b, 22c).

Tabla 14. Descripción de los ejemplares de Mimosoideae

\begin{tabular}{|c|c|c|c|}
\hline Ejemplar & Estado & Largo (mm) & Línea fisural \\
\hline 18 & & & \\
\hline 69 & fragmento & 3,5 & presente \\
\hline 72 & fragmento & 3,9 & presente \\
\hline 102 & fragmento & 6 & presente \\
\hline
\end{tabular}




\begin{tabular}{llll}
$\mathbf{1 1 4}$ & fragmento & 4,5 & presente \\
\hline $\mathbf{2 3 9}$ & & & \\
\hline
\end{tabular}

Prosopis sp.

Órgano representado: semilla

Ejemplar: 68

Caracteres considerados: 1- Estado de conservación, 2- Largo, Ancho, 3- Forma de las caras, 4- Forma de la línea fisural, 5- Forma de los ápices (extremos chalazar y radicular), 6- Textura de la testa seminal.

Descripción: El ejemplar examinado representa sólo la cuarta parte de una semilla, en la que puede observarse una de sus caras casi completa en vista frontal. La forma general del espécimen es ovalada a algo oblonga. Los extremos chalazar y radicular redondeados, este último no afinado, aunque su deterioro impide observar otros caracteres. Los bordes y la mayor parte de la estructura interna están ausentes. Las dimensiones de largo y ancho son de 3,9 mm y 2,5 mm, respectivamente. La línea fisural en amplia herradura, ubicada hacia el centro de la cara, ocupa más de las tres cuartas partes de la misma. La superficie de la testa se encuentra muy agrietada (Figuras 22d, 22e).

Identificación: La morfología general de este ejemplar incompleto en presencia de la línea fisural de la forma descripta se ajustan a las características observadas tanto en Prosopis chilensis (Mol.) Stuntz como en Prosopis alba Griseb. (Boelcke 1946, Burkart 1952) aunque el tamaño es sensiblemente menor a los $5 \mathrm{~mm}$. de largo, muy posiblemente debido a la pérdida de material en los bordes.

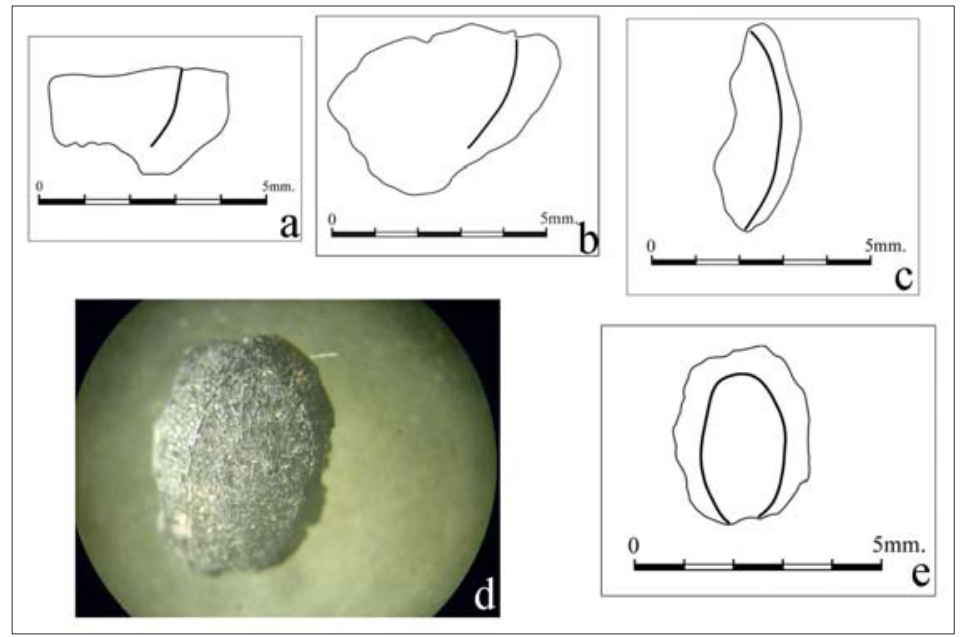

Figura 22. Mimosoideas: a-72, b-69, c- 114, d- e- 68. 


\section{Papilionoideae}

Geoffraea decorticans (Gillies ex Hook. \& Arn.) Burkart

Órganos representados: a- semilla, b- endocarpo

Ejemplares: a- semillas: 19, 20.

Caracteres observados: 1- Estado de conservación, 2- Forma, 3- Largo, 4- Ancho, 5- Textura de la superficie externa, 6- Posición del hilo.

Descripción: Los dos ejemplares recuperados completos presentan morfología fusiforme-navicular, con la superficie externa notablemente surcada. Las dimensiones son de 9,5 mm de largo por $4 \mathrm{~mm}$ de ancho y de 10,5 mm de largo por $5 \mathrm{~mm}$ de ancho, respectivamente (Tabla 15, Figura 23). El hilo se encuentra en posición lateral.

Identificación: Los caracteres cualitativos y cuantitativos considerados permiten adjudicar estos restos a semillas de la especie Geoffraea decorticans de acuerdo a las descripciones efectuadas por Burkart (1952).

Tabla 15. Descripción de los ejemplares de semillas de Geoffraea decorticans.

\begin{tabular}{ccccccc} 
Ejemplar & Estado & Forma & Superficie & Largo (mm) & Ancho (mm) & Hilo \\
\hline $\mathbf{1 9}$ & completo & fusiforme-navicular & surcada & 9,5 & 4 & lateral \\
\hline $\mathbf{2 0}$ & completo & fusiforme-navicular & surcada & 10,5 & 5 & lateral \\
\hline
\end{tabular}

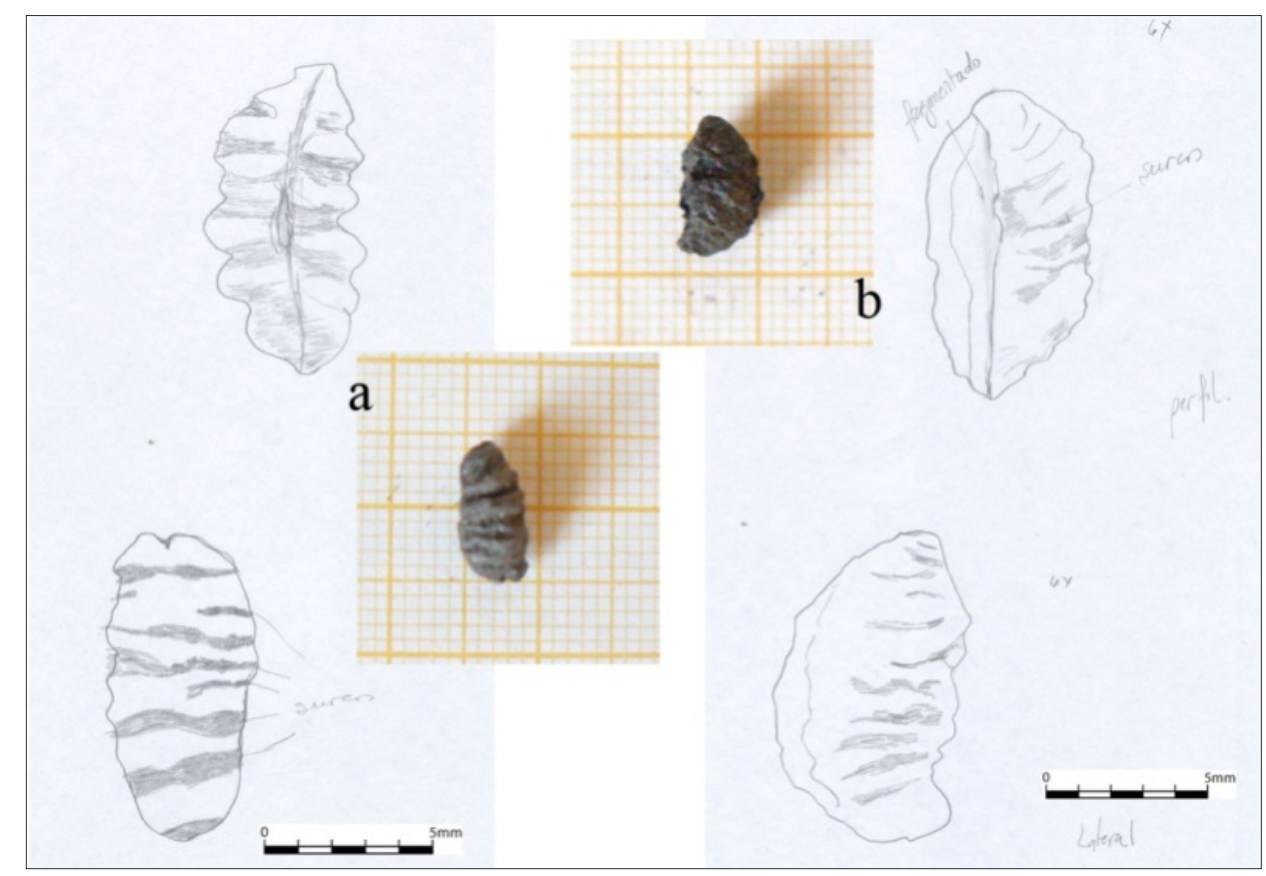

Figura 23. Esquemas y fotografías del las semillas de Geoffraea decorticans 19 y 20. 
Ejemplares: b- endocarpos: 28, 39, 40, 43, 49, 78, 94 a 100, 137, 138, 144.

Caracteres observados: a- 1- Estado de conservación, 2- Forma general, 3- Forma de la superficie interna, 4- Largo, 5- Ancho.

Descripción: Los 15 ejemplares fragmentarios presentan dimensiones variadas que no superan los $7 \mathrm{~mm}$ de largo por $7 \mathrm{~mm}$ de ancho. Presentan una forma aplanada y curva con la superficie interna surcada (Tabla 16, Figura 24).

Identificación: La morfología general y los surcos marcados en la superficie interna de los fragmentos corresponden a endocarpos de Geoffraea decorticans tal como los describe por Burkart (1952).

Tabla 16. Descripción de los fragmentos de endocarpos de Geoffraea decorticans

\begin{tabular}{cccccc}
\hline Ejemplar & Estado & Forma & Superficie & Largo (mm) & Ancho (mm) \\
\hline $\mathbf{2 8}$ & fragmento & aplanada, curvada & surcada & 4,1 & 2,3 \\
\hline $\mathbf{3 9}$ & fragmento & aplanada, curvada & surcada & 2,1 & 0,6 \\
\hline $\mathbf{4 0}$ & fragmento & aplanada, curvada & surcada & 2,3 & 1,6 \\
\hline $\mathbf{4 3}$ & fragmento & aplanada, curvada & surcada & 1 & 1,2 \\
\hline $\mathbf{4 9}$ & fragmento & aplanada, curvada & surcada & 7 & 4 \\
\hline $\mathbf{7 8}$ & fragmento & aplanada, curvada & surcada & 2,2 & 1,5 \\
\hline $\mathbf{9 4}$ & fragmento & aplanada, curvada & surcada & 6 & 7,5 \\
\hline $\mathbf{9 5}$ & fragmento & aplanada, curvada & surcada & 7 & 7 \\
\hline $\mathbf{9 6}$ & fragmento & aplanada, curvada & surcada & 3,5 & 8,5 \\
\hline $\mathbf{9 7}$ & fragmento & aplanada, curvada & surcada & 3 & 8,5 \\
\hline $\mathbf{9 8}$ & fragmento & aplanada, curvada & surcada & 5 & 8 \\
\hline $\mathbf{9 9}$ & fragmento & aplanada, curvada & surcada & 5 & 6 \\
\hline $\mathbf{1 0 0}$ & fragmento & aplanada, curvada & surcada & 3 & 3 \\
\hline $\mathbf{1 3 7}$ & fragmento & aplanada, curvada & surcada & 2,1 & 1 \\
\hline $\mathbf{1 3 8}$ & fragmento & aplanada, curvada & surcada & 3 & 2,1 \\
\hline $\mathbf{1 4 4}$ & fragmento & aplanada, curvada & surcada & 3,5 & 2,2 \\
\hline
\end{tabular}




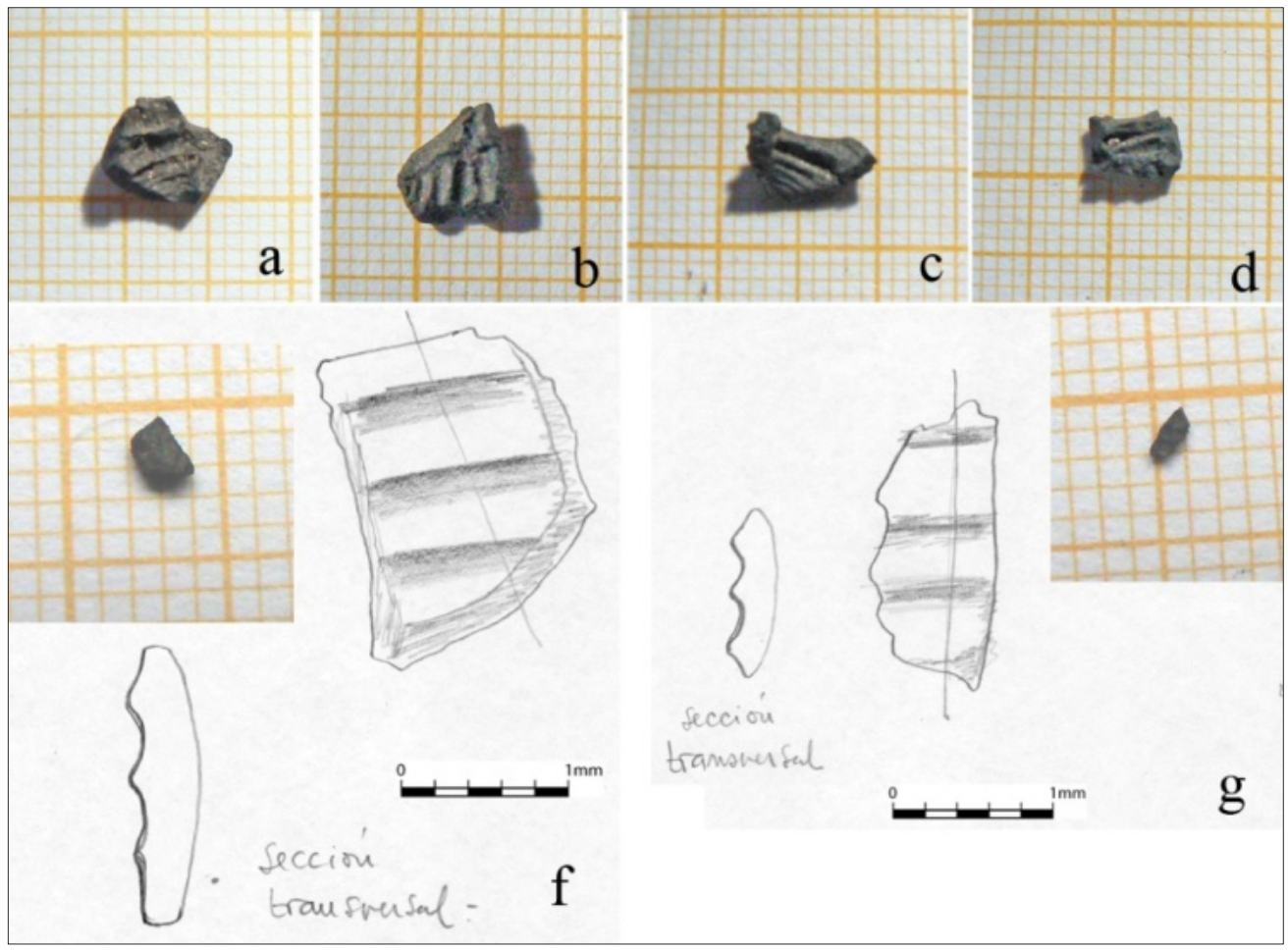

Figura 24- Fragmentos de endocarpos de Geoffraea decorticans, a-94, b-95, c-98, d-99, f-39, g-40.

Phaseolus sp.

Ejemplares: 23, 111, 149, 160, 161, 163, 164, 165, 166, 167, 168, 170, 171, 173, 174, 175, 177, 179, 180, 181, 199, 200, 203, 204, 205, 206, 207, 240, 243, 244.

Órganos representados: cotiledones

Caracteres observados: 1- Estado de conservación, 2- Forma general, 3- Forma en corte transversal, 4- Largo, 5- Ancho, 6- Espesor, 7- Textura de la superficie.

Descripción: Los 25 ejemplares considerados se encuentran en estado fragmentario. El largo de los restos se encuentra entre los 6 mm y los 3mm; el ancho entre los 7,2 mm y los 2,5 mm; el espesor, entre los $2 \mathrm{~mm} \mathrm{y} \mathrm{3,5} \mathrm{mm,} \mathrm{es} \mathrm{la} \mathrm{dimensión} \mathrm{menos} \mathrm{afectada} \mathrm{por} \mathrm{la}$ fragmentación. La forma general definida en función de su similitud a una figura geométrica pudo conocerse de manera estimativa en algunos ejemplares elípticos o reniformes. En vista transversal, la mayor parte de los especímenes mostraron formas semiovaladas u oblongas, aplanadas. En todos los casos la superficie es lisa. Los fragmentos correspondientes a los ápices no mostraron en ningún caso la presencia del hilo o señales de la radícula. 
Identificación: La morfología y tamaño de los ejemplares presenta el aspecto general de cotiledones fragmentarios de especies del género Phaseolus tal como se describen en Burkart (1952) y en Babot et al. (2007).

Phaseolus vulgaris (Burk.)

Ejemplares: 59, 147, 148, 189, 190, 194 a 198, 201, 203, 208, 235 a 237.

Órganos representados: cotiledones.

Caracteres observados: 1- Estado de conservación, 8- Posición del hilo 7- Textura de la superficie 2- Largo, 3- Ancho, 4- Índice Largo/Ancho, 5- Forma, 6- Forma del contorno.

Descripción: Se examinaron 23 ejemplares de cotiledones con hilo en posición lateral y superficie lisa. La mayor parte de ellos se encuentran completos, en tanto que 2 están semicompletos y otros 6 incompletos. De estos últimos sólo se tomaron las medidas de largo o ancho según el grado de deterioro de cada uno. En conjunto las dimensiones oscilan entre los 6,5 mm y los 10,8 mm de largo por 3,8 y 6,8 mm de ancho. El cálculo del índice L/A resultó en valores que van desde 1,47 a 1,86 lo cual indica la presencia de diversas formas empleadas por Lema (2009) para la caracterización de diferentes variedades de porotos arqueológicos del Noroeste argentino ${ }^{2}$ : elíptica $(1,43-1,65)$, esférica $(1,16-1,42)$ y oblonga o reniforme (corta: 1,66-1,85; media: 1.86-2; larga: más de 2), predominando la tercera en su variedad corta. El trazado anguloso del contorno de los cotiledones pudo observarse en unos pocos ejemplares, mientras que la mayor parte tiene contornos redondeados (Tabla 17, Figuras 25 y 26)

Identificación: La forma general, posición del hilo, textura y tamaño permite adjudicar los ejemplares a Phaseolus vulgaris, de acuerdo a las descripciones efectuadas por Burkart (1952). Asimismo, la variedad de tamaños presentes en los ejemplares completos analizados permite distinguir dos grupos de cotiledones (Gráfico 3). Uno de ellos está formado por especímenes cuyas medidas están por debajo de los $8 \mathrm{~mm}$ de longitud por los 5 $\mathrm{mm}$ de ancho. El segundo grupo, más variable, comprende aquellos cotiledones que superan los $9 \mathrm{~mm}$ de longitud y los 5,5 mm de ancho. Tanto en uno como en otro grupo predomina la forma oblonga o reniforme corta, seguida por la elíptica. Una sola forma esférica aparece entre los ejemplares más pequeños.

\footnotetext{
${ }^{2}$ Los valores empleados por Lema para la identificación de porotos arqueológicos no carbonizados del Noroeste Argentino fueron obtenidos por Menéndez Sevillano a partir del estudio de especímenes actuales correspondientes a las variedades silvestre y cultivada de porotos de la misma región por (Menéndez Sevillano 1992 en Lema 2009).
} 
Si se proyectan estos ejemplares sobre los rangos de tamaños empleados por Lema (2009) (áreas amarillas del Gráfico 3), los especímenes de Cardonal caen por fuera de los valores estipulados (Porotos domésticos: Largo 9,9 - 16,3 mm; Ancho 7 - 9,6 mm Porotos silvestres: Largo 7,05 - 8,65 mm; Ancho 4,6 - 5,91 mm).

Una muestra más restringida de porotos domésticos actualmente cultivados en el vecino Campo del Pucará (Oliszewski 2004, 2005 Babot et al. 2007) resultó en la determinación de rangos comprendidos entre valores próximos a los anteriores, aunque algo menores. En el caso de los porotos domésticos, los valores mínimos del ancho de los ejemplares estudiados son menores que en el estudio antes citado (Porotos domésticos: Largo 9,95 - 13,93 mm; Ancho 6,90 mm; Porotos silvestres: Largo 6,68 - 8,54 mm; Ancho: 4,72 $5,90 \mathrm{~mm}$ ). Por el contrario, en la muestra de porotos silvestres, recolectados en localidades de Tucumán y Catamarca, es el largo de las semillas el que adquiere valores mínimos inferiores (áreas rosadas del Gráfico 3). También para estos rangos de especímenes actuales, deshidratados naturalmente del Campo del Pucará, la gran mayoría de los cotiledones procedentes de Cardonal restan por fuera de los parámetros establecidos.

De todas maneras, estos valores fueron tenidos en cuenta para la determinación de variedades de porotos carbonizados procedentes del mismo Campo del Pucará (Oliszewski 2004, 2005). En esta localidad arqueológica se recuperaron catorce cotiledones de los cuales seis corresponden porotos silvestres y ocho a porotos cultivados. Los valores obtenidos para esta muestra arqueológica también se ubican por debajo de los parámetros establecidos por el material actual (Porotos domésticos: Largo 9 - 11,32 mm, Ancho 4 - 6,48 mm Porotos silvestres: Largo 4,98 - 8 mm; Ancho 3,7 - 5 mm), aunque la distinción entre uno y otro grupo sigue siendo clara (área azulada del Gráfico 3).

Resulta interesante notar que la variación del tamaño de los cotiledones estudiados en el Campo del Pucará, así como los que se analizan en esta tesis, se manifiesta en ambos casos en una tendencia a la disminución del tamaño respecto de los parámetros existentes en la actualidad. Tales rangos han sido obtenidos a partir de conjuntos muestrales deshidratados naturalmente, a diferencia de los restos arqueológicos carbonizados recuperados en los sitios mencionados. Aunque no se han realizado aún estudios experimentales específicos sobre los efectos de la carbonización en cotiledones de porotos, los experimentos realizados sobre otros grupos de plantas muestran el modo y el grado en que la carbonización afecta la forma y el tamaño de frutos y semillas (e. g. Braadbaart y Wright 2007, Johannessen et al. 1990, Kislev y Ronsenzweig 1991, Stewart y Robertson 1971). 
Se han considerado también para los casos arqueológicos otros agentes de modificación mecánicos, químicos y culturales (ver más adelante). A ellos cabría agregar la variación producida en las poblaciones de plantas a través del tiempo. Entre los factores implicados se ha señalado la ocurrencia de híbridos entre la forma cultivada y no cultivada, ya que en general ambas formas son genéticamente compatibles y su cruza produce individuos viables y fértiles (Freyre et al. 1996), las modificaciones en el tamaño y otros caracteres morfológicos relativos al proceso de domesticación (Brücher y Berglund-Brücher 1976, Gepts y Debouck 1991, Lema 2009) y la distribución geográfica de las poblaciones (Galván 2006, Menéndez Sevillano 2002 en Lema 2009).

Notablemente los valores de las muestras de Cardonal presentan una distribución congruente con los datos arqueológicos del Campo del Pucará, geográfica y cronológicamente próximos, en tanto que no dejan de ser concordantes en su agrupamiento y distribución, con las variaciones señaladas por los estudios sobre las medidas lineales de ejemplares actuales. Asimismo, las formas de los especímenes analizados por Oliszewski (2004, 2005), expresadas en función de la relación numérica entre el largo y el ancho, son elíptica y oblonga o reniforme para los especímenes cultivados, en tanto se incorporan semillas esféricas en el conjunto silvestre. Estos valores y las formas observadas se encuentran dentro de lo esperado según la clasificación empleada por Lema (2009). Según dicha clasificación, la predominancia de las formas elípticas seguidas de las oblongas en los conjuntos de porotos cultivados guarda algunas diferencias con la mayoría de semillas elípticas halladas en las muestras de porotos silvestres, con algunos ejemplares atribuibles a la morfología esférica. En el caso de los especímenes de Cardonal, la distribución de las formas es similar a la de las semillas de Campo del Pucará y congruente con los resultados de la clasificación mencionada anteriormente, si bien la forma esférica aparece entre los cotiledones de mayor tamaño.

Lamentablemente se cuenta con escasas descripciones cualitativas y cuantitativas de otros conjuntos de restos de porotos carbonizados hallados en sitios del Noroeste argentino. En Casas Viejas - El Mollar (Valle de Tafí), se han identificado casi 200 fragmentos y cotiledones completos de ambas variedades de porotos (Carrizo et al. 1999, 2003), cuya descripción no ha sido publicada aún, como así tampoco se ha dado a conocer la caracterización morfológica de algunos restos de $P$. vulgaris carbonizados recuperados en Loma Yutopián (Valle del Cajón) (Meldem 1996, Rossen 1998a, 1998b). Dicha información sería de gran utilidad para obtener rangos de variación del tamaño y la forma en el pasado, tanto en una como en otra subespecie. 
Sí, en cambio, se cuenta con los datos dimensionales obtenidos en dos ejemplares procedentes de Loma Alta (Falda Occidental del Aconquija) (Pochettino y Scattolin 1991). El cotiledón identificado como poroto doméstico coincide plenamente con los rangos de tamaño (15 mm de largo por $8 \mathrm{~mm}$ de ancho) y forma (relación L/A: 1,875) oblongo o reniforme medio, utilizados por Lema 2009) para la caracterización y determinación de esta variedad sobre material arqueológico. En cambio, el poroto completo asignado a la variedad silvestre (10 mm de largo por 4,5 mm de ancho) parece no corresponder a ninguno de los rangos mencionados anteriormente en este apartado, aunque se encuentra más próximo de las variedades cultivadas. La relación L/A indica un valor de 2,22 el cual lo ubica entre las formas oblongas o arriñonadas más largas.

Asimismo, tres cotiledones de P. vulgaris carbonizados y completos se hallaron en los depósitos de Tesoro 1 (Falda Occidental del Aconquija), cuyas dimensiones y forma general se ajustan a una y otra variedad de porotos comunes. Uno de los ejemplares domésticos mide 9,5 mm de largo por $5 \mathrm{~mm}$ de ancho (relación L/A: 1,9). El segundo cotiledón, también asignado a la variedad cultivada, alcanza los $11 \mathrm{~mm}$ de largo por $6 \mathrm{~mm}$ de ancho (relación L/A: 1,83). En ambos casos la forma es oblongo o reniforme medio. Por último, el espécimen silvestre tiene $7 \mathrm{~mm}$ de largo por $5 \mathrm{~mm}$ de ancho (relación L/A: 1,4) y es de forma esférica (Calo 2007). Proyectados sobre los rangos delineados en el Gráfico 1 los valores se ajustan a las descripciones efectuadas sobre las muestras arqueológicas del Campo del Pucará (Oliszewski 2004) y en muestras actuales de Catamarca, Tucumán y Salta estudiadas por Babot et al. (2007).

Considerando los caracteres mencionados anteriormente, la separación clara en dos grupos de tamaños. Los ejemplares 59, 189, 190, 195, 196, 197 y 235 concuerdan con los parámetros dados en función del material arqueológico carbonizado y muestras actuales no carbonizadas asignadas a Phaseolus vulgaris var. aborigineus (Figura 22). De la misma forma los restos 147, 148, 236, 237, 238, 242, 245, 246 y 247 se ajustan a los rangos de tamaño evaluados para Phaseolus vulgaris var. vulgaris (Figura 23). En ambos casos los restos analizados se muestran más acordes a los parámetros definidos para los conjuntos arqueológicos que a los ejemplares actuales no carbonizados de referencia. Respecto de estos últimos se observa generalmente una reducción de tamaño para lo cual, en el caso de los porotos ubicados dentro de la variedad doméstica debería también considerarse la posibilidad de ocurrencia de tipos intermedios (ver Lema 2009). En tanto, los especímenes no completos 194, 198, 201, 203, 208, 241 y 248 se identifican sólo a nivel de especie como Phaseolus vulgaris. 
Tabla 17. Descripción de los cotiledones de P. vulgaris

\begin{tabular}{|c|c|c|c|c|c|c|c|c|}
\hline Ejemplar & Estado & Hilo & Textura & $\begin{array}{c}\text { Largo } \\
(\mathrm{mm})\end{array}$ & $\begin{array}{c}\text { Ancho } \\
(\mathrm{mm})\end{array}$ & $\begin{array}{c}\text { Indice } \\
\text { L/A }\end{array}$ & Forma & Contorno \\
\hline 59 & completo & lateral & lisa & 7,5 & 5 & 1,5 & elíptico & anguloso \\
\hline 147 & completo & lateral & lisa & 10 & 6,2 & 1,61 & elíptico & redondeado \\
\hline 148 & completo & lateral & lisa & 9 & 6 & 1,42 & esférico & redondeado \\
\hline 189 & completo & & & 8 & 5 & 1,8 & oblongo & \\
\hline 190 & completo & & & 8 & 4,3 & 1,86 & $\begin{array}{c}\text { oblongo o } \\
\text { reniforme } \\
\text { medio }\end{array}$ & \\
\hline 194 & incompleto & & & 6,5 & - & - & - & redondeado \\
\hline 195 & completo & & & 8 & 4,5 & 1,77 & $\begin{array}{c}\text { oblongo o } \\
\text { reniforme corto }\end{array}$ & \\
\hline 196 & completo & & & 7,5 & 4,5 & 1,66 & $\begin{array}{c}\text { oblongo o } \\
\text { reniforme corto }\end{array}$ & \\
\hline 197 & completo & & & 7 & 4,5 & 1,55 & elíptico & \\
\hline 198 & incompleto & lateral & lisa & & 4 & & & redondeado \\
\hline 201 & incompleto & lateral & lisa & & 3,8 & & & redondeado \\
\hline 203 & incompleto & lateral & lisa & & 4,1 & & & redondeado \\
\hline 208 & incompleto & lateral & lisa & & 3,8 & & & redondeado \\
\hline 235 & completo & & & 7,2 & 4,1 & 1,76 & $\begin{array}{l}\text { oblongo o } \\
\text { reniforme corto }\end{array}$ & \\
\hline 236 & completo & lateral & lisa & 9,2 & 6,1 & 1,5 & elíptico & redondeado \\
\hline 237 & completo & lateral & lisa & 9,2 & 5,5 & 1,7 & $\begin{array}{l}\text { oblongo o } \\
\text { reniforme corto }\end{array}$ & redondeado \\
\hline 238 & completo & lateral & lisa & 9,2 & 5,5 & 1,67 & $\begin{array}{c}\text { oblongo o } \\
\text { reniforme corto }\end{array}$ & redondeado \\
\hline 241 & incompleto & lateral & lisa & & 5 & & & redondeado \\
\hline 242 & completo & lateral & lisa & 10,8 & 6,5 & 1,7 & elíptico & redondeado \\
\hline 245 & completo & lateral & lisa & 10 & 6,6 & 1,51 & $\begin{array}{l}\text { oblongo o } \\
\text { reniforme corto }\end{array}$ & redondeado \\
\hline 246 & semicompleto & lateral & lisa & 10 & 6,8 & 1,47 & elíptico & redondeado \\
\hline 247 & semicompleto & lateral & lisa & 10 & 6,2 & 1,61 & elíptico & redondeado \\
\hline 248 & semicompleto & lateral & lisa & & 5 & & & redondeado \\
\hline
\end{tabular}

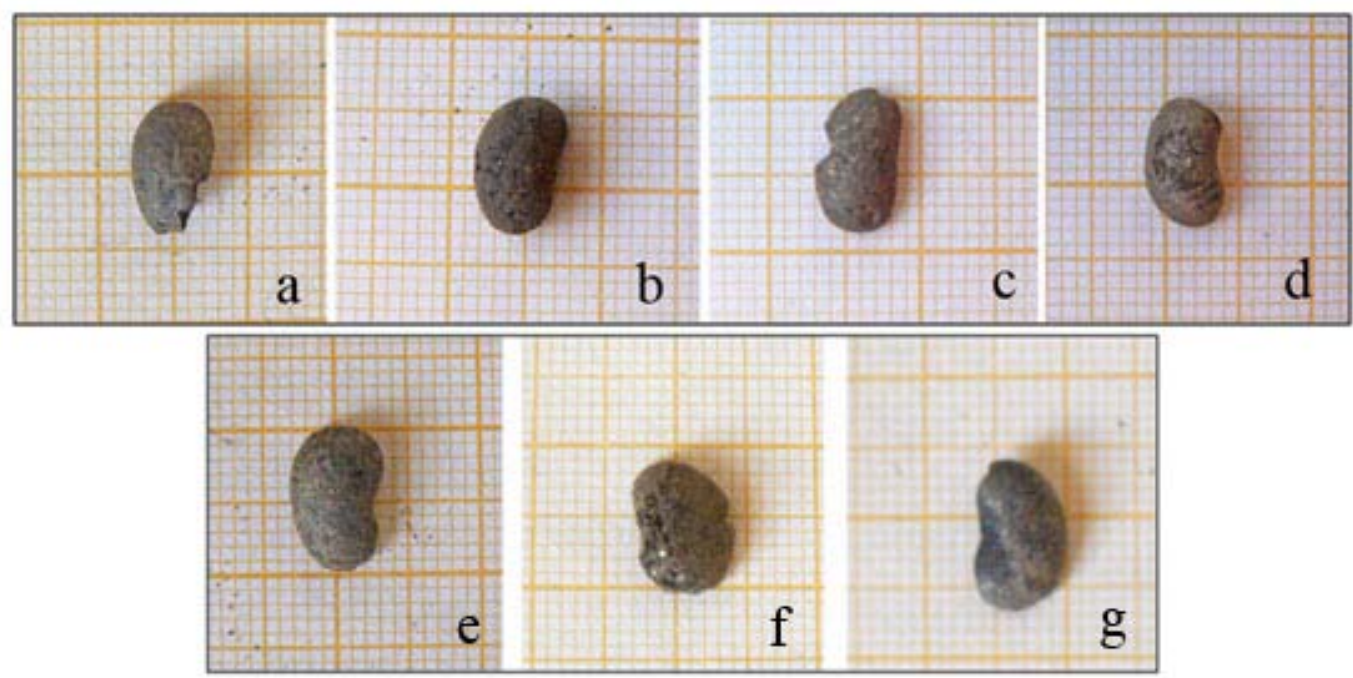

Figura 25. Cotiledones de P. v. var. vulgaris: a-148; b-236; c-237; d-238; e- 147; f-246; g-242. 


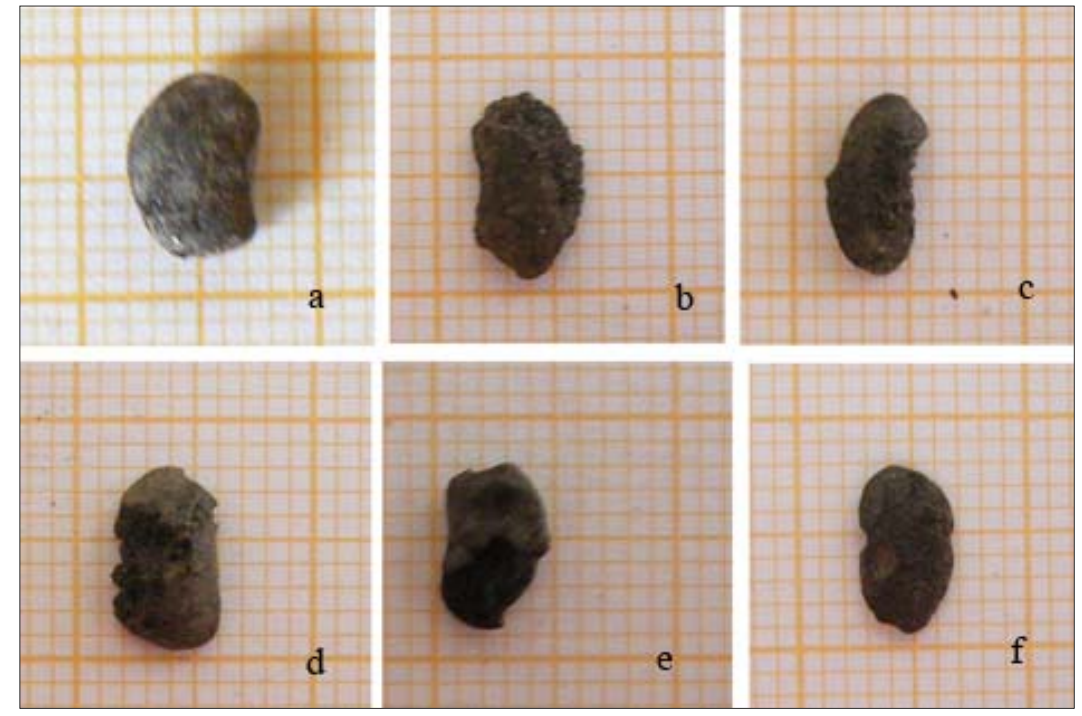

Figura 26. Cotiledones de P. v. var. aborigineus: a- 59, b-190, c-195, d-196, e-197, f-235.

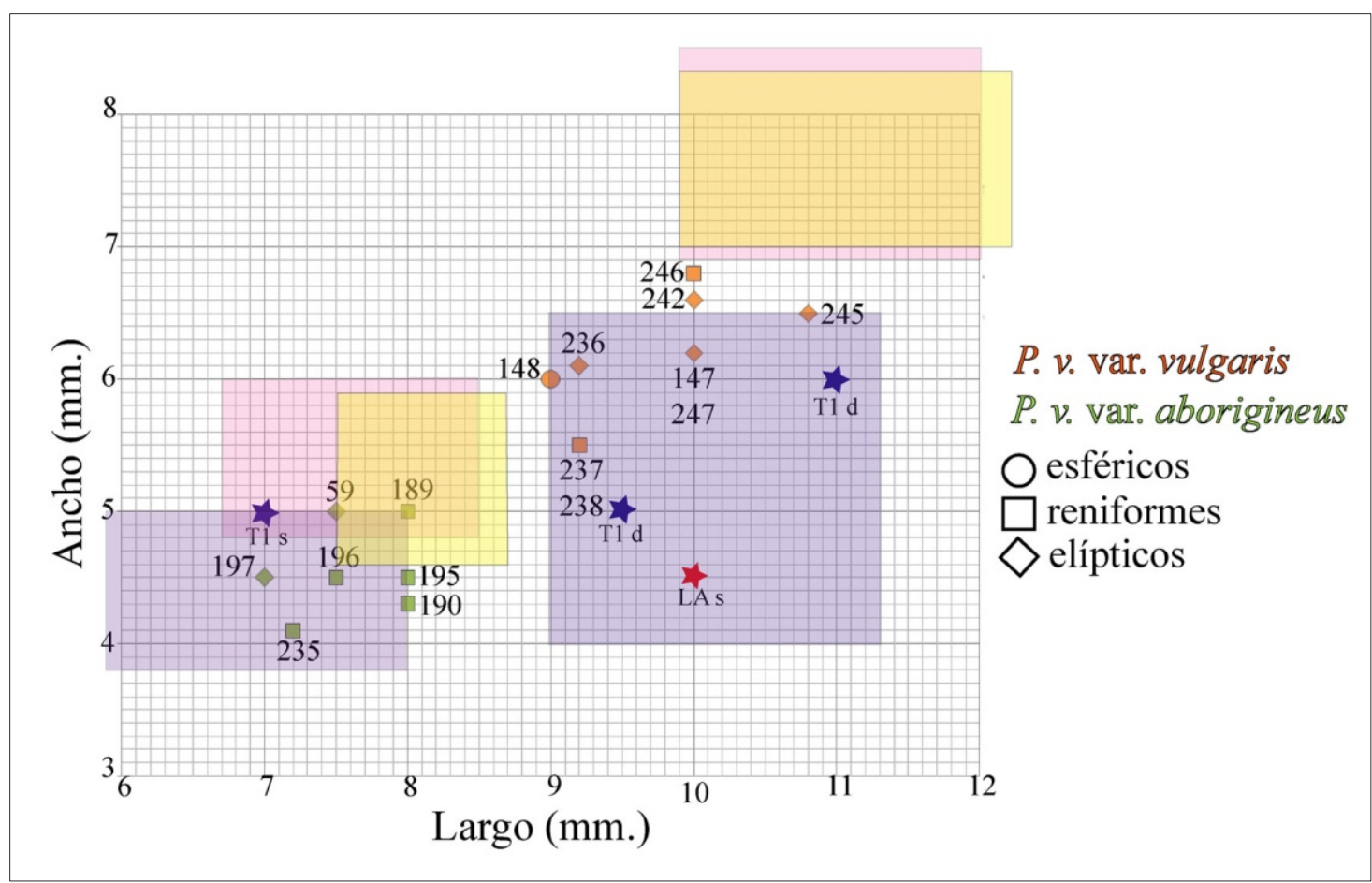

Gráfico 3. Distribución por tamaños de los cotiledones de $P$. vulgaris. Las áreas cuadrangulares corresponden a los rangos de tamaños señalados para cada subespecie: el área amarilla (Menéndez sevillano 2002 en Lema 2009), el área rosada (Babot et al. 2007), el área azulada (Oliszewski 2004). Las estrellas azules señalan la posición de los restos procedentes de Tesoro 1 (Calo 2008) y las estrellas rojas a los analizados en Loma Alta (Pochettino y Scattolin 1991), asignados a la variedad silvestre (LAs y T1s) o doméstica (T1s). 


\section{MALVACEAE}

Órgano representado: semilla

\section{Ejemplar: 13.}

Caracteres observados: 1- Estado de conservación, 2- Forma, 3- Largo, 4- Ancho.

Descripción: El ejemplar completo presenta una forma arriñonada, globosa, con uno de los extremos afinado y el otro algo redondeado. El contorno exterior es ensanchado, en tanto que el margen interno es estrecho. Largo: 1,2 mm; Ancho: 1,1 mm (Figura 27).

Identificación: La forma general de la semilla indica que el embrión en su interior se dispone de manera arqueada (Martin y Barkley 2000). Tal morfología y las dimensiones observadas en el espécimen analizado permiten asignarlo a la Familia de las Malváceas.

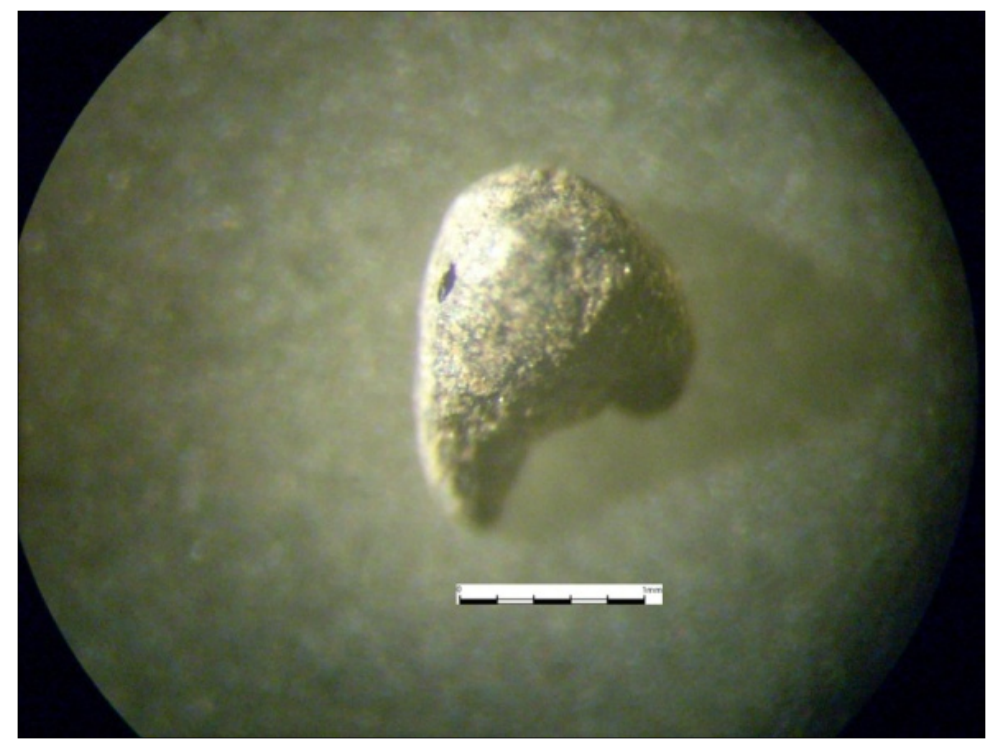

Figura 27. Semilla de MALVACEAE

SOLANACEAE

Solanoideae

Ejemplar: 54.

Órgano representado: semilla

Caracteres observados: 1- Estado de conservación, 2- Forma general, 3- Largo máximo, 3- Textura de la cubierta seminal, 4- Forma de contorno, 5- Visibilidad de la radícula, Forma del embrión.

Descripción: El ejemplar analizado corresponde a una semilla semicompleta, de forma lenticular, algo comprimida hacia el centro. Del contorno irregular sobresale la radícula bien visible. El diámetro máximo del ejemplar alcanza los 1,3 mm La superficie externa es de superficie rugosa, granulosa y se encuentra incrustada de sedimentos (Figura 28a). En el 
interior de la semilla, visible a raíz del tipo de fragmentación ocurrido, es posible observar el embrión y la radícula, dispuestos en espiral (Figura 28b).

Identificación: Las características de la testa, así como la forma y el tamaño del ejemplar, junto con la visible disposición del embrión son concordantes con la descripción de las semillas de la Subfamilia Solanoideae, en especial a los géneros Solanum o Capsicum (Hunziker 1979, 2001, Barboza com. pers.).
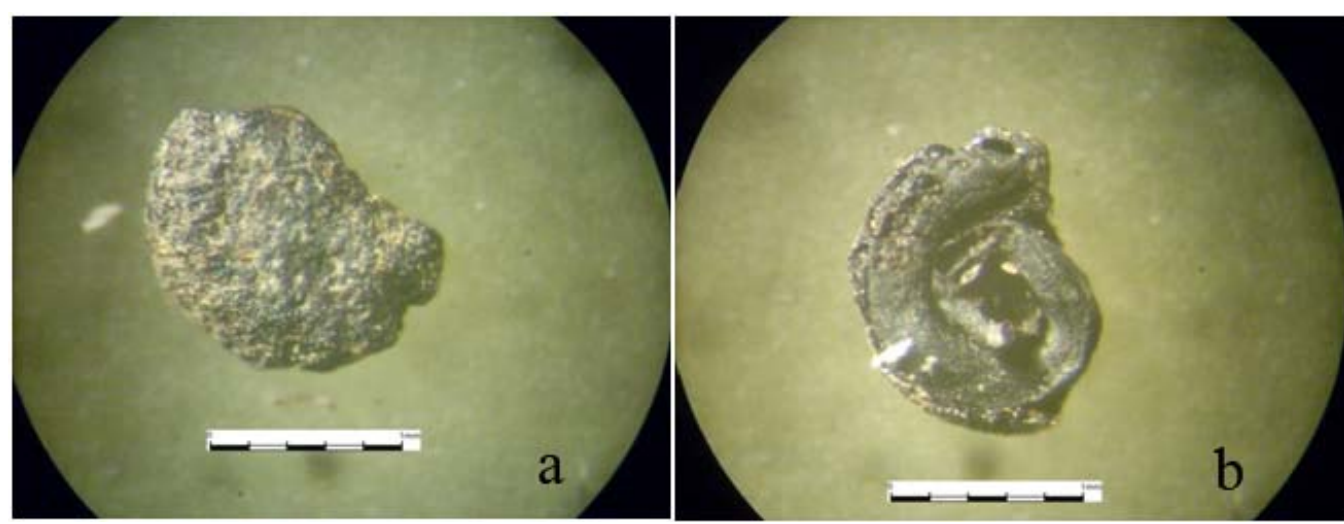

Figura 28. Detalle de a- textura de la testa seminal y b- embrión anular en el ejemplar 54.

\section{Monocotiledoneae}

POACEAE

Zea mays L.

Ejemplares: 80, 141, 150 al 158, 183 al 188, 193, 210 al 213, 214 al 234, 250.

Órganos representados: a- granos, b- cúpulas.

a- Granos:

Caracteres observados: 1- Estado de conservación, 2- Forma, 3- Dentado, 4- Largo, 5- Ancho, 6- Dureza.

Descripción: Se hallaron tres ejemplares completos de forma obovada y acuminada, no dentados, menores a $5 \mathrm{~mm}$ de largo por 3,5 mm de ancho. Son granos duros en los que predomina el largo sobre el ancho (Tabla 18, Figura 29).

Tabla 18. Descripción de los granos de Zea mays

\begin{tabular}{ccccccc}
\hline & Estado & Forma & Dentado & Largo (mm) & Ancho (mm) & Dureza \\
\hline & & & & & & \\
80 & completo & obovado, globoso, turgente & no & 3,8 & 2,5 & duro \\
\hline
\end{tabular}




\begin{tabular}{lllcccc}
\hline 141 & completo & acuminado - obovado & no & 4,8 & 3,5 & duro \\
\hline & & & & & & \\
250 & completo & obovado, globoso, turgente & no & 5 & 3,3 & duro \\
\hline
\end{tabular}

Identificación: Los caracteres observados son próximos a la descripción de variedades de maíces de granos pequeños. Por un lado se corresponden con Zea mays var. minima Bonafus caracterizada por Parodi (1959) y conocido con los nombres vernáculos de 'perla’, ‘pororó', 'rosero’, 'reventón’ (Parodi 1959, 1966). Asimismo quedan comprendidos dentro de la categoría "Perla”, según la clasificación subespecífica de maíces del Noroeste Argentino propuesta por Oliszewski (2008), en base a los datos que brinda el mismo Parodi (1959) y el trabajo de Abiusso y Cámara Hernández (1974).

b- Cúpulas:

Ejemplares: 150 al 158; 183 al 188; 193; 210 al 213; 214 al 234.

Caracteres observados: 1- Forma, 2- Profundidad, 3- Ancho, 4- Altura.

Descripción: En total se hallaron 43 ejemplares de los cuales 29 están completos o semicompletos, algunos unidos de a pares, sobre los cuales fue posible conocer las dimensiones con mayor precisión. Otros 14 ejemplares se hallaron incompletos. Presentan formas ahuecadas, profundas. La altura de las cúpulas varía entre 4,65 mm y 3,12 mm (Promedio: 3,85 mm) y el ancho lo hace entre 5,92 mm y 4,5 mm (Promedio: 5,16 mm) (Tabla 19, Figura 30).

Identificación: Las dimensiones promedio de las cúpulas recuperadas en el Núcleo 1 de Cardonal resultan grandes comparadas con el tamaño de los granos asociables al maíz AMARILLO, que describimos anteriormente. Incluso son mayores que las cúpulas estudiadas en Campo del Pucará (Oliszewski 2004, 2005), las cuales fueron asignadas a la misma raza. A pesar de ello, el promedio del ancho y la altura de las cúpulas de Cardonal son próximos a los obtenidos sobre algunos granos de maíz no carbonizados hallados en Pampa Grande, y que Miante Alsogaray y Cámara Hernández (1996) asocian a la raza AMARILLO actual del Noroeste argentino.

Cabe señalar además que si bien las cúpulas estudiadas en Cardonal presentan una disminución en el ancho respecto de aquellos ejemplares, tal carácter podría estar relacionado con los efectos de reducción en el ancho y aumento en la altura que la carbonización produce sobre las cúpulas de maíz, observados experimentalmente sobre tipos de maíz actuales de Perú (Johannessen et al. 1990). 
Si bien el ancho y altura características de las cúpulas del maíz AMARILLO de Pampa Grande sólo se pueden utilizar comparativamente en forma de promedios, la presencia en Cardonal de granos asignables a esta raza, la profundidad observada en las cúpulas, la congruencia de las dimensiones y la consideración de los efectos de la carbonización sobre este tipo de restos, permiten referir las cúpulas halladas en el Núcleo 1 como maíz AMARILLO.

Tabla 19. Medidas de longitud y latitud de las cúpulas de Zea mays AMARILLO y cálculo del promedio.

\begin{tabular}{|c|c|c|}
\hline Ejemplar & Ancho (mm) & Altura (mm) \\
\hline 150 & 4,5 & 3,84 \\
\hline 151 & 5 & 3,75 \\
\hline 153 & 5,41 & 4,65 \\
\hline 154 & 4,52 & 3,36 \\
\hline 157 & 5,54 & 4,44 \\
\hline 158 & 5,9 & 3,18 \\
\hline 183 & 5,24 & 3,69 \\
\hline 184 & 4,95 & 4,03 \\
\hline 185 & 5,32 & 3,43 \\
\hline 187 & 5,57 & 3,98 \\
\hline 188 & 5,92 & 3,95 \\
\hline 193 & 4,82 & 4,09 \\
\hline 210 & 5,54 & 4,4 \\
\hline 211 & 5,61 & 3,93 \\
\hline 212 & 5,71 & 3,38 \\
\hline 215 & 5,45 & 3,62 \\
\hline 216 & 4,92 & 5,09 \\
\hline 217 & 4,53 & 3,38 \\
\hline 219 & 4,69 & 3,66 \\
\hline 220 & 5,25 & 4,26 \\
\hline 221 & 5,11 & 3,36 \\
\hline 222 & 5,02 & 3,31 \\
\hline 224 & 5,49 & 4,32 \\
\hline 225 & 4,11 & 3,56 \\
\hline 226 & 4,95 & 4,17 \\
\hline 227 & 5,82 & 3,98 \\
\hline
\end{tabular}




\begin{tabular}{ccc}
\hline 228 & 5,11 & 4,27 \\
\hline 230 & 4,53 & 3,65 \\
\hline 231 & 5,02 & 3,12 \\
\hline Promedio & 5,15 & 3,85 \\
\hline
\end{tabular}

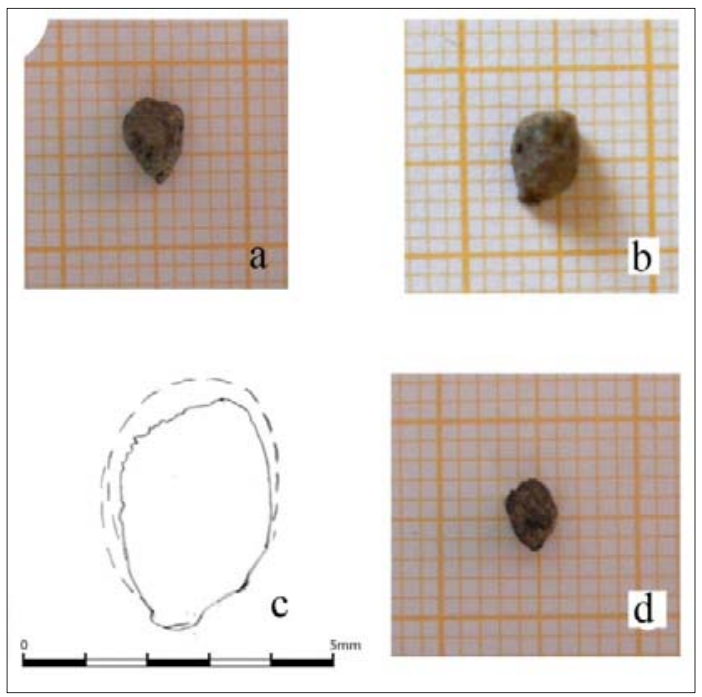

Figura 29. Granos de Zea mays a- 141; b- 250; c- d- 80.

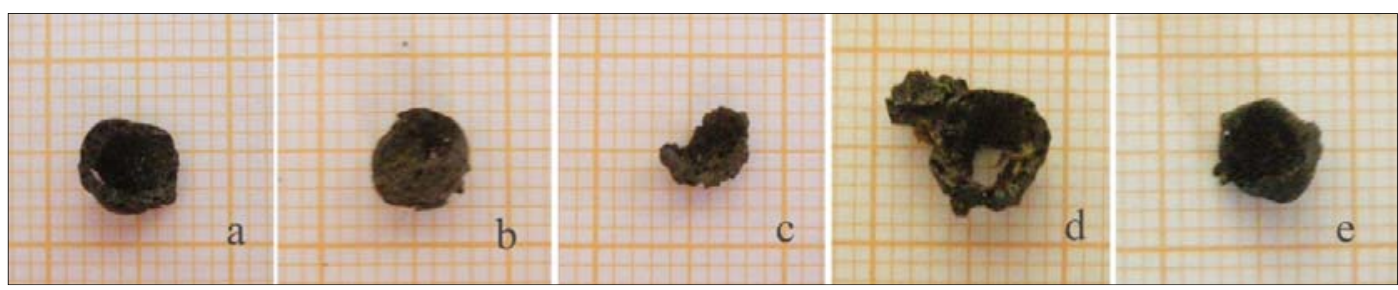

Figura 30. Cúpulas de Zea mays AMARILLO.

\section{Otros restos}

TIPO 1

Órganos representados: Semillas

Ejemplares: 52, 81, 92, 110, 117, 118, 134, 136

Caracteres observados: 1- Estado de conservación, 2- Forma, 3- Largo, 4- Ancho, 5- Textura de la superficie externa.

Descripción: Este grupo reúne ejemplares de semillas completas y semicompletas cuyo largo no supera los $2 \mathrm{~mm}$. La forma general es obcónica a piriforme y la superficie, lisa (Tabla 20, Figuras 31a, 31b, 31c). 
Tabla 20. Descripción de restos TIPO 1 (semillas)

\begin{tabular}{cccccc}
\hline Ejemplar & Estado & Forma & Largo (mm) & Ancho (mm) & Textura \\
\hline 52 & Fragmento & - & 0,9 & 0,8 & lisa \\
\hline 81 & Completo & obcónica & 1,5 & 1,1 & lisa \\
\hline 92 & semicompleto & obcónica & 1,9 & 1,1 & lisa \\
\hline 110 & incompleto & - & 1,5 & 1,2 & lisa \\
\hline 117 & semicompleto & obcónica & 1,5 & 0,9 & lisa \\
\hline 118 & semicompleto & obcónica & 1,5 & 1,5 & lisa \\
\hline 134 & Completo & obcónica & 1,4 & 1 & lisa \\
\hline 136 & Completo & obcónica & 1,2 & 1,1 & lisa \\
\hline
\end{tabular}

TIPO 2

Órganos representados: semillas.

Ejemplares: 29, 37, 44, 66, 77, 79, 107, 129, 142.

Caracteres observados: 1- Estado de conservación, 2- Forma, 3- Largo, 4- Ancho, 5- Textura de la superficie externa.

Descripción: Tres de los ejemplares se encuentran en estado completo, dos semicompletos y los restantes fragmentarios. Las dimensiones varían entre 3 y 1,9 mm de largo por 2,6 y 1,1 mm de ancho. La forma tridimensional de los ejemplares completos es obcónica. La superficie es de textura algo rugosa (Tabla 21, Figuras 31a - 31m).

Tabla 21. Descripción de restos TIPO 2 (semillas)

\begin{tabular}{cccccc}
\hline Ejemplar & Estado & Forma & Largo (mm) & Ancho (mm) & Textura \\
\hline 29 & Incompleto & - & 2,1 & 1 & rugosa \\
\hline 37 & semicompleto & obcónica & 1,9 & 1,1 & rugosa \\
\hline 44 & Completo & obcónica & 2,3 & 1,6 & rugosa \\
\hline 76 & Incompleto & - & 2 & 1,2 & rugosa \\
\hline 79 & Fragmento & - & 2,5 & 2 & rugosa \\
\hline 79 & semicompleto & obcónica & 2,5 & 1,9 & rugosa \\
\hline & Completo & obcónica & 3 & 2,8 & rugosa \\
\hline
\end{tabular}




\begin{tabular}{rrrrrr}
\hline 129 & Completo & acuminada & 2 & 1,2 & rugosa \\
\hline 142 & Completo & acuminada & 2 & 1,2 & rugosa \\
\hline
\end{tabular}

TIPO 3

Órganos representados: semillas

Ejemplares: 7, 9, 27, 133.

Caracteres observados: Estado de conservación, Forma, Largo, Ancho, Textura de la superficie externa.

Descripción: Este grupo incluye semillas completas y fragmentos. Los ejemplares completos tienen entre 1 y 2 mm de largo y forma lenticular que comparten entre si la cubierta seminal reticulada, en dos casos además presentan estructuras mamelonares (Tabla 22, Figuras 31n,31o, 31p).

Tabla 22. Descripción de restos TIPO 3 (semillas)

\begin{tabular}{cccccc}
\hline Ejemplar & Estado & Forma & Largo ( $\mathbf{m m})$ & Ancho (mm) & Textura \\
\hline 7 & completo & lenticular & 1,9 & 1,5 & reticulada con mamelones \\
\hline 9 & fragmento & lenticular & 1 & 1 & pusticulada \\
\hline 27 & completo & lenticular & 1,3 & 1,2 & pusticulada \\
\hline 133 & incompleto & lenticular & 1,6 & 1,2 & reticulada \\
\hline
\end{tabular}

TIPO 4

Órganos representados: semillas

Ejemplares: 32, 61, 84, 86, 93.

Caracteres observados: 1- Estado de conservación, 2- Forma, 3- Largo, 4- Ancho, 5Textura de la superficie externa.

Descripción: El conjunto reúne semillas alargadas, fusiformes, de 1,8 a 2,5 mm de longitud por 1 a 1,1 mm de ancho. La superficie es lisa y en corte transversal son redondeadas a ovales (Tabla 23, Figuras 31q a 31x).

Tabla 23. Descripción de restos TIPO 4 (semillas)

\begin{tabular}{cccccc}
\hline Ejemplar & Estado & Forma & Largo (mm) & Ancho (mm) & Textura \\
\hline & & & & & lisa \\
\hline
\end{tabular}




\begin{tabular}{rrrrrr}
\hline 61 & Incompleto & fusiforme & 1,3 & 0,5 & lisa \\
\hline 84 & semicompleto & fusiforme & 1,8 & 1 & lisa \\
\hline 86 & Completo & fusiforme & 2,5 & 1,5 & lisa \\
\hline 93 & Completo & fusiforme & 2,2 & 1,1 & lisa \\
\hline
\end{tabular}

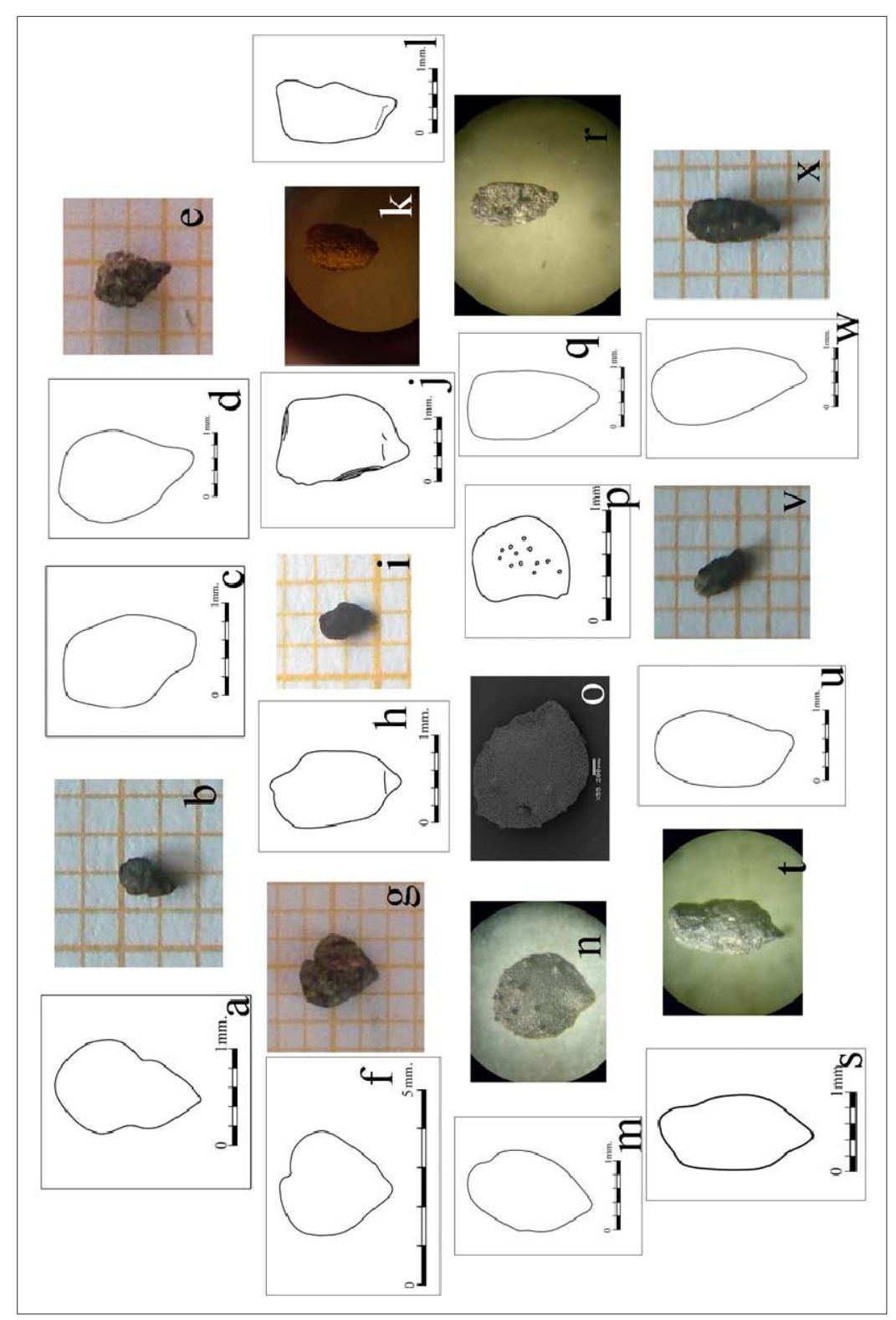

Figura 31. Semillas no identificadas. TIPO 1 a- b- 134, c- 81; TIPO 2 d- e- 129, f- g- 107, h- i- 37, jk- 79, l- 44, m- 142; TIPO 3 n- o- 7, p- 9; TIPO 4 q- r- 86, s- t- 32, u- v- 84, w- x- 93. 


\section{TIPO 5}

Órganos representados: pericarpios

Ejemplares: 6, 12, 14, 16, 21, 25, 26, 35, 41, 55, 58, 64, 85, 120.

Caracteres observados: 1- Estado de conservación, 2- Forma, 3- Largo, 4- Textura de la superficie externa, 5- Textura de la superficie interna.

Descripción: Se trata de un grupo de 12 fragmentos agrupados en función de su forma ahuecada o cóncava y consistencia rígida. Presentan tamaños diversos y particularidades morfológicas que los distinguen entre sí (Tabla 24, Figura 32).

Tabla 24. Descripción de restos TIPO5 (pericarpios)

\begin{tabular}{|c|c|c|c|c|c|}
\hline Ejemplar & Estado & Forma & $\operatorname{Largo}(\mathrm{mm})$ & Textura externa & Textura interna \\
\hline 6 & fragmento & ahuecado & 2 & lisa & lisa \\
\hline 12 & fragmento & ahuecado & 2,3 & lisa & lisa \\
\hline 14 & fragmento & ahuecado & 1,5 & lisa & lisa \\
\hline 16 & fragmento & ahuecado & 2,1 & lisa & lisa \\
\hline 21 & fragmento & ahuecado & 2,5 & lisa & lisa \\
\hline 25 & fragmento & ahuecado & 2 & lisa & lisa \\
\hline 26 & semicompleto & ahuecado & 4,1 & corrugada & lisa \\
\hline 35 & fragmento & ahuecada & 3,4 & rugosa, porosa & lisa \\
\hline 41 & fragmento & ahuecada & 2,1 & corrugada & lisa \\
\hline 55 & fragmento & ahuecada & 1,5 & lisa & lisa \\
\hline 58 & fragmento & ahuecado & 2,3 & corrugado & lisa \\
\hline 64 & fragmento & ahuecada & 3,4 & lisa & lisa \\
\hline 85 & fragmento & ahuecada & 2,5 & lisa & lisa \\
\hline 120 & fragmento & ahuecada & 3 & lisa & lisa \\
\hline
\end{tabular}




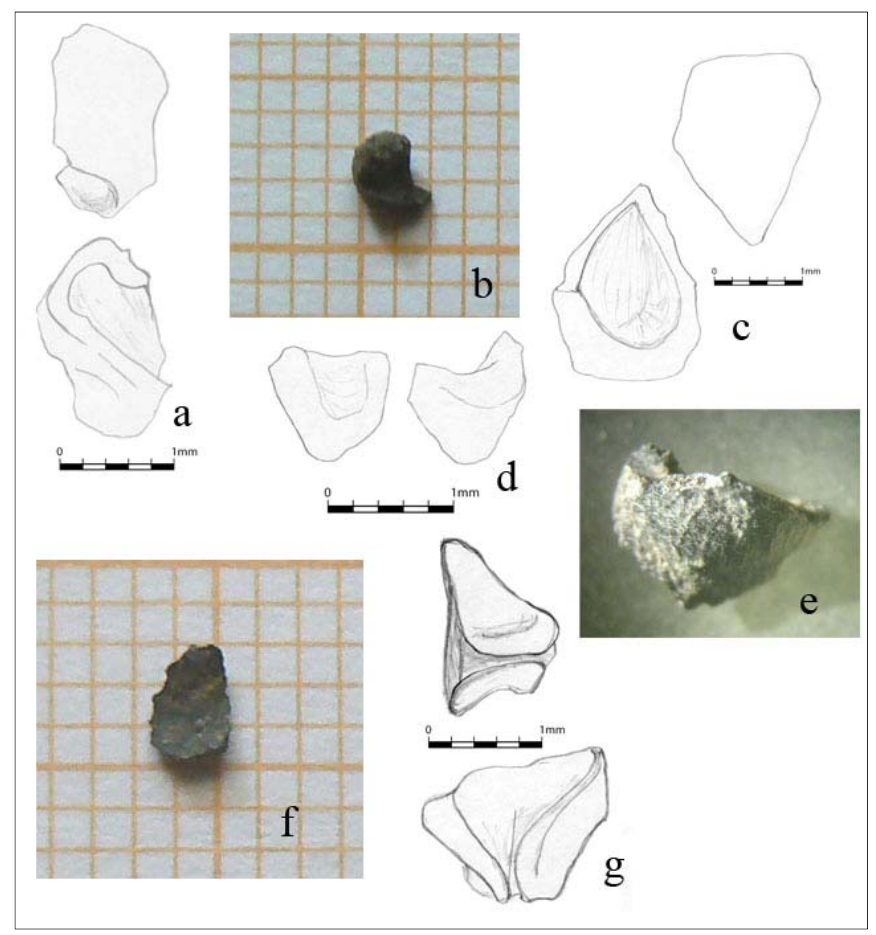

Figura 32. Cubiertas de frutos a-14, b- 85, c- 21, d- 16, e- 85, f- 120, g- 41.

\section{TIPO 6}

Órgano representado: Tallos, pedúnculos.

Ejemplares: 50, 73, 119, 126, 128, 143, 145, 146.

Caracteres observados: 1- Estado de conservación, 2- Forma, 3- Largo, 4- Presencia de nudos, 5- Presencia de cáliz.

Descripción: Se trata de estructuras cilíndricas, alargadas, de sección circular. En dos de ellos pueden observarse entrenudos y en otros la presencia del cáliz en uno de sus extremos (Tabla 25, Figura 33).

\begin{tabular}{cccccc}
\multicolumn{6}{c}{ Tabla 25. Descripción de restos TIPO 6 (tallos y pedúnculos) } \\
\hline Ejemplar & Estado & Forma & Largo ( $m$ m) & Nudos & Cáliz \\
\hline 50 & incompleto & cilíndrico & 4,5 & si & no \\
\hline 73 & incompleto & cilíndrico & 2,5 & no & si \\
\hline 119 & incompleto & cilíndrico & 6,5 & no & no \\
\hline 126 & incompleto & cilíndrico & 4,2 & no & no \\
\hline 128 & incompleto & cilíndrico & 2,5 & no & si \\
\hline 143 & incompleto & cilíndrico & 2,7 & no & no \\
\hline
\end{tabular}




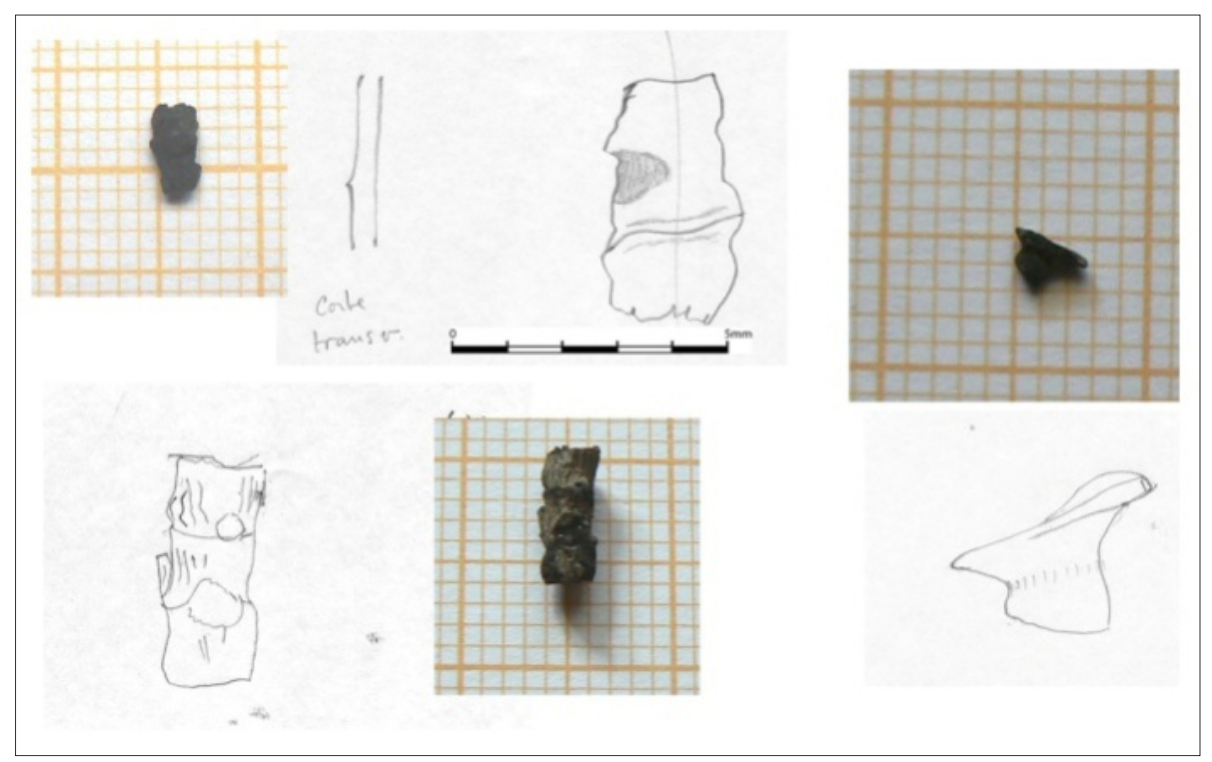

Figura 33. a- tallo 50; b- pedúnculo128; c- tallo 119.

\section{Distribución de los restos carpológicos carbonizados en el Núcleo 1}

Cantidades absolutas de restos recuperados. La mayor parte de los restos carpológicos estudiados en el Núcleo 1 proceden de muestras de flotación y material in situ hallado en E1 y E5. El espacio del Portal en cambio, presentó la cantidad más baja en carporrestos, los cuales sólo se recuperaron en flotación. Las demás Estructuras (E2, E3 y E4) presentan cantidades intermedias, aunque bastante menores que en las dos primeras (Tabla 26, Gráfico 4).

Tabla 26. Cantidades absolutas de restos recuperados en flotación e in situ clasificados por taxón, incluyendo los ejemplares no identificados

\begin{tabular}{cccccccc}
\hline & E1 & E2 & E3 & E4 & E5 & E5p & Totales \\
\hline Semillas de Chenopodium & 0 & 0 & 0 & 0 & 17 & 0 & 17 \\
\hline Semilla Caesalpinioideae & 0 & 3 & 0 & 0 & 0 & 0 & 3 \\
\hline Semillas Mimosoideae & 1 & 1 & 0 & 0 & 5 & 0 & 7 \\
\hline Semillas Geoffraea decorticans & 0 & 2 & 0 & 0 & 0 & 0 & 2 \\
\hline Endocarpos Geoffraea decorticans & 1 & 0 & 5 & 0 & 10 & 0 & 16 \\
\hline Cotiledones Phaseolus sp. & 28 & 0 & 1 & 0 & 1 & 0 & 30 \\
\hline Cotiledones $P$. vulgaris & 6 & 0 & 0 & 0 & 0 & 0 & 6 \\
\hline Cotiledones $P . v$. var. aborigineus & 6 & 0 & 0 & 1 & 0 & 0 & 7 \\
\hline Cotiledones $P$. v. var. vulgaris & 9 & 0 & 0 & 0 & 0 & 0 & 9 \\
\hline Semilla MALVACEAE & 0 & 1 & 0 & 0 & 0 & 0 & 1 \\
\hline
\end{tabular}




\begin{tabular}{cccccccc}
\hline Semilla Solanoideae & 0 & 0 & 0 & 1 & 0 & 0 & 1 \\
\hline Granos Zea mays var. mínima & 0 & 0 & 0 & 1 & 1 & 1 & 3 \\
\hline Cúpulas Zea mays AMARILLO & 42 & 0 & 0 & 1 & 0 & 0 & 43 \\
\hline Semillas TIPO 1 & 0 & 0 & 0 & 1 & 7 & 0 & 8 \\
\hline Semillas TIPO 2 & 0 & 0 & 3 & 0 & 5 & 1 & 9 \\
\hline Semillas TIPO 3 & 0 & 2 & 1 & 0 & 1 & 0 & 4 \\
\hline Semillas TIPO 4 & 0 & 0 & 1 & 1 & 3 & 0 & 5 \\
\hline Pericarpios TIPO 5 & 0 & 4 & 5 & 2 & 3 & 0 & 14 \\
\hline Tallos y Pedúnculos TIPO 6 & 2 & 0 & 1 & 0 & 5 & 0 & 8 \\
\hline No Clasificados & 10 & 7 & 15 & 4 & 21 & 0 & 57 \\
\hline Totales & $\mathbf{1 0 5}$ & $\mathbf{2 0}$ & $\mathbf{3 2}$ & $\mathbf{1 2}$ & $\mathbf{7 9}$ & $\mathbf{2}$ & $\mathbf{2 5 0}$ \\
\hline
\end{tabular}

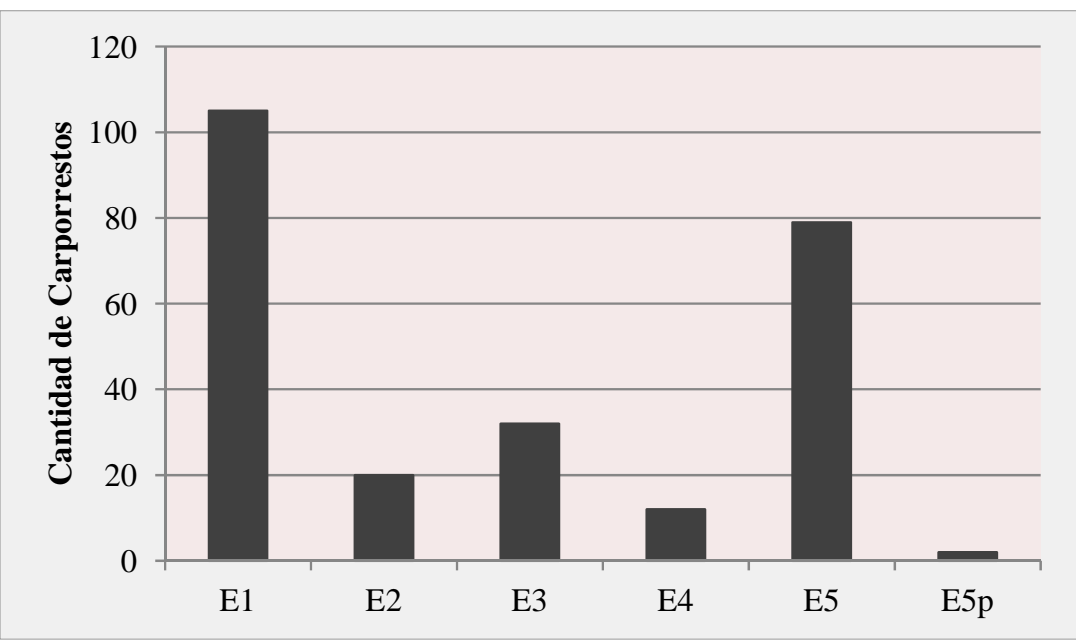

Gráfico 4. Cantidades absolutas de restos carpológicos presentes en cada recinto, incluyendo los ejemplares no identificados.

La última columna de la Tabla 26 presentada anteriormente considera las cantidades netas de restos carpológicos que cada taxón o grupo clasificado de carporrestos aporta al total del conjunto arqueobotánico recuperado en el Núcleo 1. Como puede observarse, los restos más profusos son los cotiledones de porotos que en total suman 52 ejemplares. Los siguen las cúpulas de maíz, halladas principalmente en estado completo y que junto a los ejemplares fragmentarios comprenden 43 unidades.

También se halló una cantidad considerable (16) de fragmentos de endocarpos de chañar y otras cubiertas de frutos (16), semillas de Chenopodium (17) y un número importante de pequeñas semillas de plantas herbáceas silvestres. Por último, un 23\% de los restos recuperados no pudieron asignarse a ninguno de los subconjuntos antes mencionados (NC) debido mayormente a las condiciones de preservación en que se encontraba dicho material 
(Gráfico 5). Por último, se ha observado que el conjunto de restos procedente de muestras de flotaciones es mayor y más variado en tipos de restos y taxones representados que en el caso de los vestigios recuperados de manera directa. Las muestras in situ suman sólo 35 carporrestos de los 250 contabilizados en total, mientras que los restantes 215 han sido flotados.

Asimismo se recuperaron en forma directa sólo algunos taxones que corresponden a semillas de Mimosoideae, semillas y endocarpos de G. decorticans, cotiledones de Phaseolus sp. y P. vulgaris y cúpulas de Z. mays (Tabla 27, Gráfico 6). Tales ejemplares se encuentran entre los más grandes y consistentes de conjunto total, mientras que los otros más pequeños y frágiles sólo aparecieron en las flotaciones. Una observación similar ha sido efectuada por Rossen (1998b) acerca del material arqueobotánico de Loma Yutopián y es una característica del muestreo directo que ha sido señalada por varios autores como Buxó (1997), Marinval (1988), entre otros.

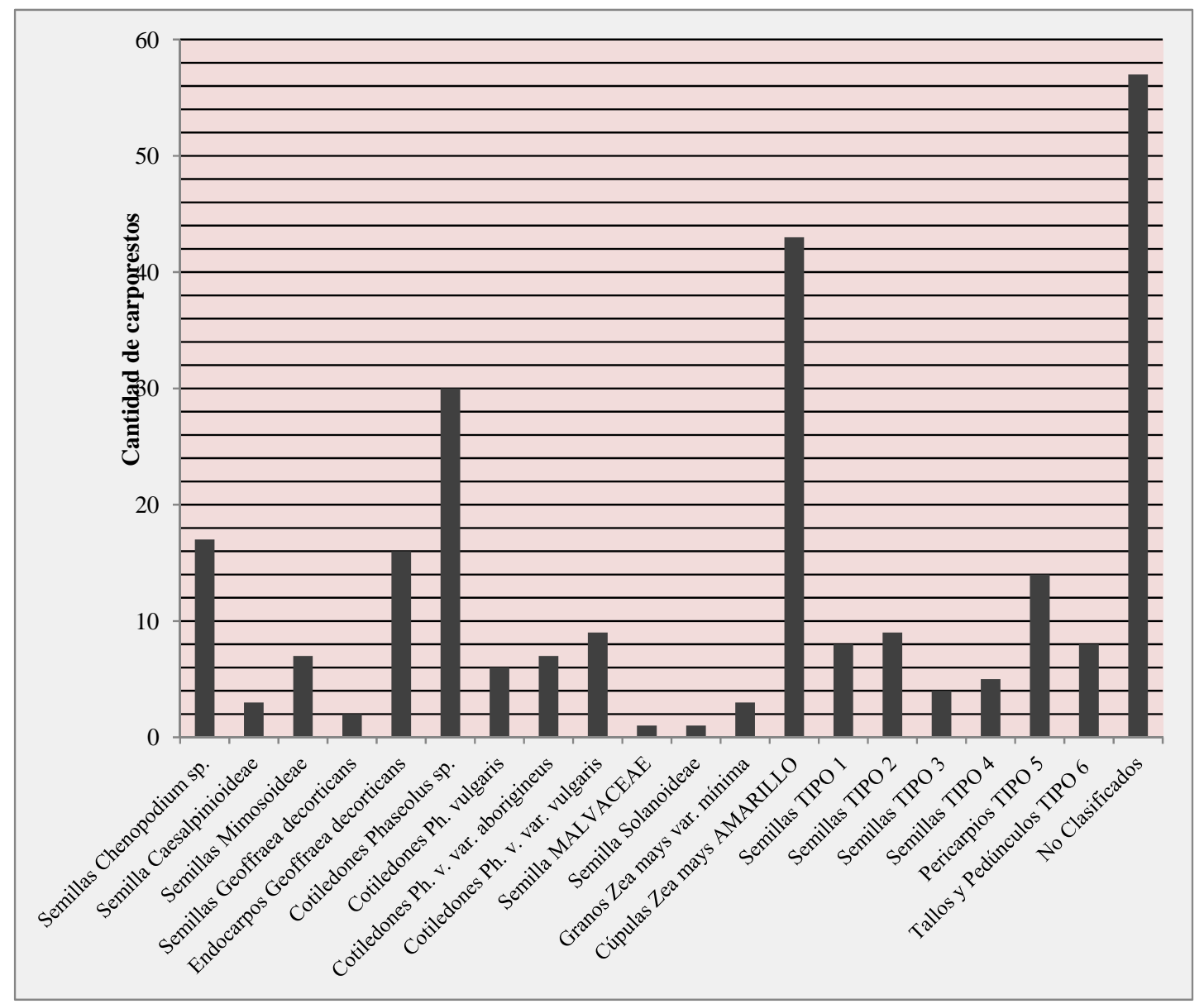

Gráfico 5. Cantidad total de carporrestos procedentes del Núcleo 1 
Tabla 27. Cantidades absolutas de restos recuperados in situ en cada recinto, clasificados por taxón

\begin{tabular}{lccccccc}
\hline & E 1 & E2 & E3 & E4 & E5 & E5p & Totales \\
\hline Semillas Mimosoideae & 1 & 0 & 0 & 0 & 1 & 0 & 2 \\
\hline Semillas Geoffraea decorticans & 0 & 2 & 0 & 0 & 0 & 0 & 2 \\
\hline Endocarpos Geoffraea decorticans & 0 & 0 & 0 & 0 & 7 & 0 & 7 \\
\hline Cotiledones Phaseolus sp. & 4 & 0 & 0 & 0 & 0 & 0 & 4 \\
\hline Cotiledones Phaseolus vulgaris & 2 & 0 & 0 & 0 & 0 & 0 & 2 \\
\hline Cotiledones P. v. var. vulgaris & 9 & 0 & 0 & 0 & 0 & 0 & 9 \\
\hline Cotiledones P. v. var. aborigineus & 0 & 0 & 0 & 1 & 0 & 0 & 1 \\
\hline Cúpulas Zea mays AMARILLO & 0 & 0 & 0 & 1 & 0 & 0 & 1 \\
\hline No Clasificados & 0 & 1 & 1 & 0 & 5 & 0 & 7 \\
\hline Totales & 16 & 3 & 1 & 2 & 13 & 0 & 35 \\
\hline
\end{tabular}

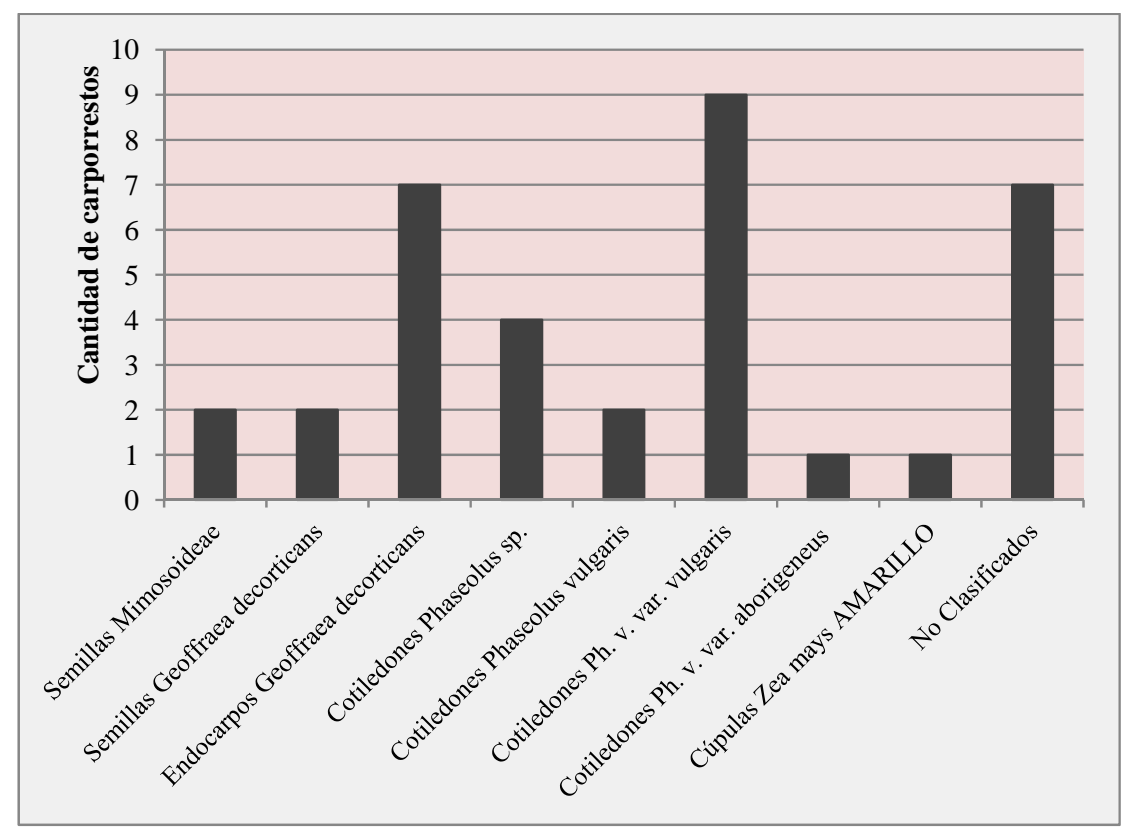

Gráfico 6. Cantidad de carporrestos en muestras obtenidas in situ.

Tal como se desprende de la comparación de los datos mostrados en las Tablas 26 y 27, las 32 cúpulas de Zea mays completas forman el taxón de carporrestos más numerosos recuperados por flotación. De las mismas muestras también proceden diez fragmentos de cúpulas de maíz, mientras que un único ejemplar fue recuperado in situ en el Nivel 5 de la E4. Es decir que casi la totalidad de los ejemplares de cúpulas proceden de la muestra tomada en el nivel 4 de la E1. No ocurre lo mismo en el caso de los granos de maíz, hallados todos por flotación y en estado completo, aunque en escaso número (3). 
Junto con las cúpulas de maíz, también en el Nivel 4 de la E1 se obtuvieron siete cotiledones completos y parciales de porotos silvestres y cinco domésticos, así como una buena cantidad de fragmentos de porotos (22), que posiblemente correspondan a alguna de las variedades anteriores. También allí se realizaron varios hallazgos de porotos in situ entre los cuales se cuentan ocho cotiledones de porotos domésticos completos y tres fragmentos de la misma variedad, así como otros cinco fragmentos de cotiledones de P. vulgaris. Otros dos hallazgos de fragmentos de cotiledones de porotos se llevaron a cabo en el Nivel 4 de la E3 y el Nivel 5 de la E5. Un cotiledón de poroto silvestre fue recuperado de forma directa junto con la cúpula de maíz de la E4, que ya se mencionara anteriormente.

Los fragmentos de semillas de Mimosoideas se encontraron repartidos en los niveles inferiores de la E1, E2 y E5, cinco en flotación y dos en muestras directas. De la muestra de flotación tomada en el Nivel 5 de la E5 procede el ejemplar mejor conservado, determinado como Prosopis aff. alba o Acacia aff. aroma, depositado junto con otros tres fragmentos de semillas de la misma Familia. Otras FABACEAE presentes en el conjunto arqueobotánico de Cardonal son los tres pequeños cotiledones de Caesalpinioideae. Estos se encontraron por flotación en las capas más superficiales de la E2, junto con dos fragmentos de cubierta de fruto, una semilla del Tipo C y dos indeterminados.

Un cuarto subconjunto de restos pertenecientes a esta Familia de plantas son las dos semillas completas de Geoffroea decorticans recuperadas de manera directa en el Nivel 6 de la E2. Los endocarpos de chañar en cambio, aparecen concentrados en la E5, obteniéndose allí diez fragmentos por flotación y muestreo directo en los Niveles 5 y 6 . Otros cinco fragmentos proceden de las muestras de flotación tomadas en Rasgos 1 y 2 de la E3 y otro resto pequeñísimo del Nivel 4 de la E1.

También de las capas inferiores de la E5 proceden cinco de los seis fragmentos de tallos y pedúnculos integrados al conjunto de restos recuperados por flotación. De muestras extraídas en los mismos niveles de la E5 provienen doce semillas determinadas como Chenopodium. Otras cinco semillas del mismo Género se hallaron en las muestras de flotación tomadas en las capas profundas de E5, el cual ha sido profuso en ejemplares pequeños de semillas.

Dichas semillas han sido obtenidas sólo por flotación, dispersas en todos los recintos, salvo en la E1 (Tabla 4, Gráfico 9). En la E5 recuperaron siete semillas clasificadas como Tipo A, cinco del Tipo B, una del Tipo C y tres del Tipo D. También se manifiestan en las capas próximas a la roca de base en la E3, la E4 y el Portal, aunque en menor proporción y también se hallaron unas pocas en niveles superficiales. 
De los niveles más próximos a la superficie proceden tres cotiledones completos de Caesalpiniodeas recuperados en las muestras de flotación de la E2. Uno de ellos, procedente del Nivel 2 se cuenta entre los hallazgos más superficiales, junto con dos fragmentos de cubiertas de fruto, una semilla del Tipo C y dos indeterminados. Las cubiertas de fruto comprendidas en los Tipos F y G se distribuyen tanto en capas superficiales como en las más profundas de diferentes recintos.

Finalmente, de los 215 restos carpológicos recuperados por flotación en Cardonal, 49 no pudieron ser clasificados dentro de ninguno de los grupos mencionados. El estado de conservación de estos ejemplares impidió observar caracteres morfológicos cualitativos y/o cuantitativos que permitieran reconocer a qué parte de la planta correspondían y menos aún realizar una asignación taxonómica. Los mismos se distribuyen en todos los recintos, junto con unos siete ejemplares recuperados de manera directa. El Gráfico 7 muestra las cantidades totales de restos obtenidos en los recintos comparando a la vez la composición de dichos conjuntos.

\section{Porcentajes y porcentajes relativos de restos comparados entre Estructuras.} Considerando la totalidad de los restos arqueobotánicos recuperados en el Núcleo 1, los porcentajes expresan las cantidades netas referidas en el apartado anterior en forma porcentual. Es decir, por un lado muestra el aporte que cada Estructura hace al conjunto total de carporrestos (Gráfico 8) y por otro da a conocer la parte del conjunto total que cada grupo de restos o taxón representa (Gráfico 9).

El cálculo de los porcentajes relativos de los diferentes grupos de restos al interior de cada Estructura, permitió observar en qué grado varían los conjuntos de restos recuperados en cada una (Gráficos 10a a 10f). En E1 prácticamente el 90\% de los restos se compone de cúpulas de Zea mays AMARILLO (40\%) y cotiledones de Phaseolus sp. (27\%), P. vulgaris (6\%), P. v. var. vulgaris (9\%) y P. v. var. aborigineus (6\%).

En E2 los porcentajes de restos están dominados por las semillas pequeñas de plantas herbáceas como las Caesalpinioideas (15\%), MALVACEAE (5\%), TIPO 3 (10\%) y fragmentos de pericarpios (20\%), así como las semillas de especies silvestres arbóreas o arbustivas de la Familia Mimosoideae (5\%) y Geoffraea decorticans (10\%). 


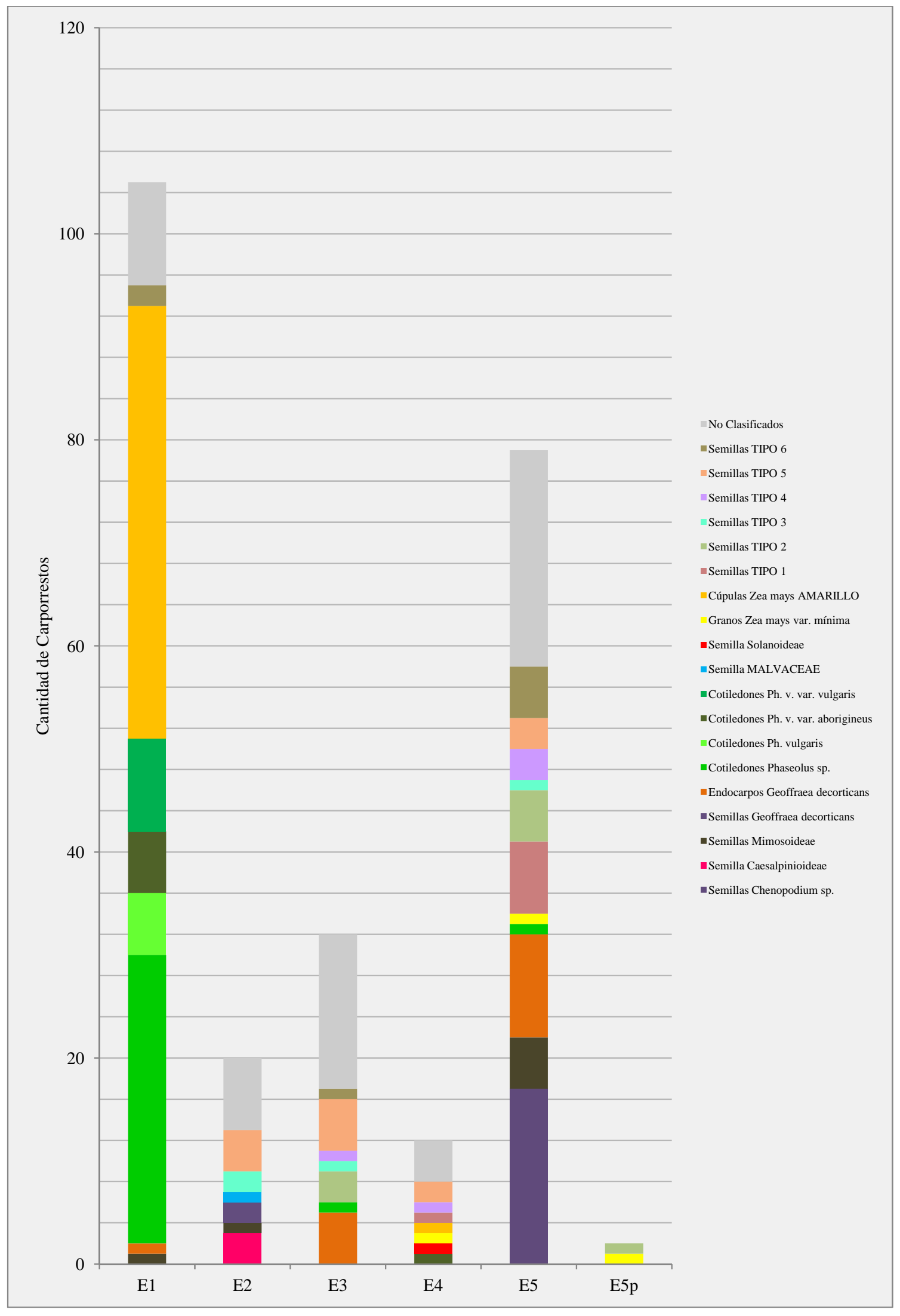

Gráfico 7. Tamaño y composición de los conjuntos de restos recuperados en cada uno de los recintos del núcleo habitacional. 


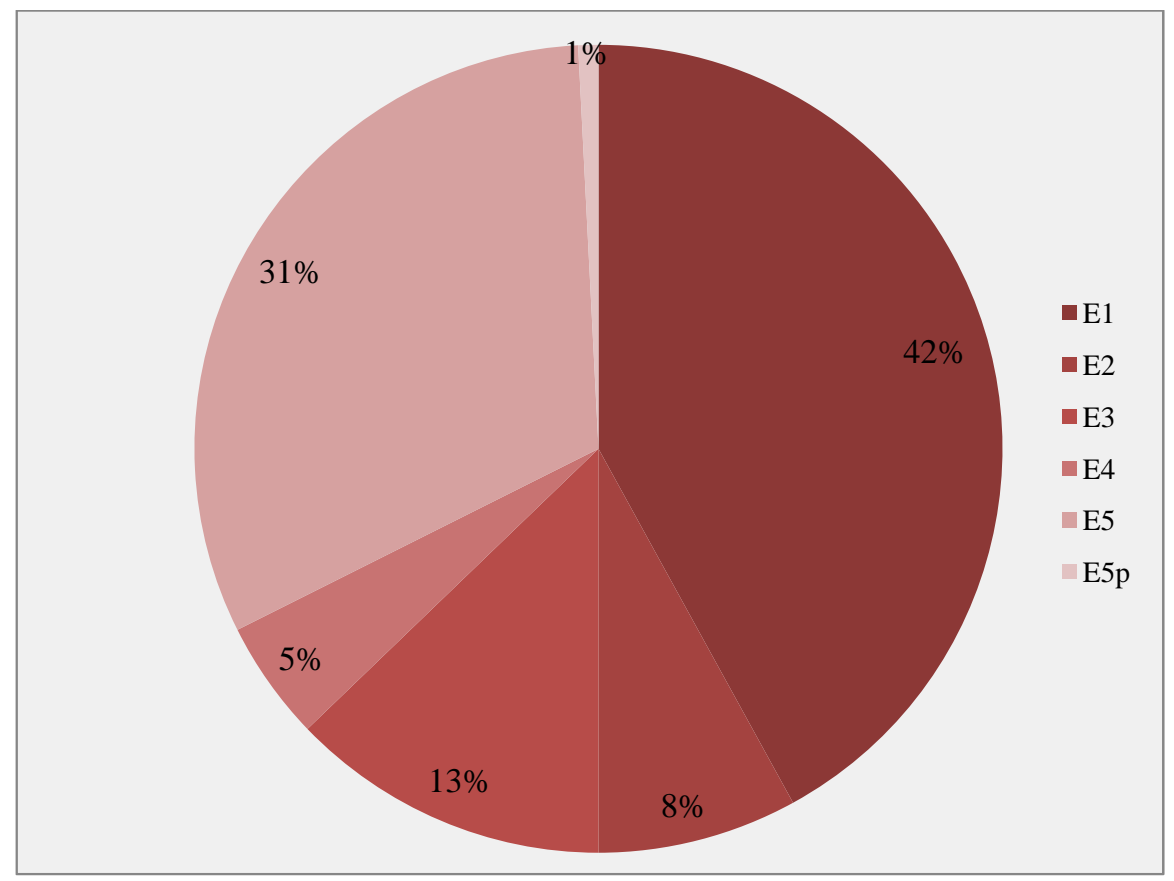

Gráfico 8. Porcentaje relativo de restos por habitación.

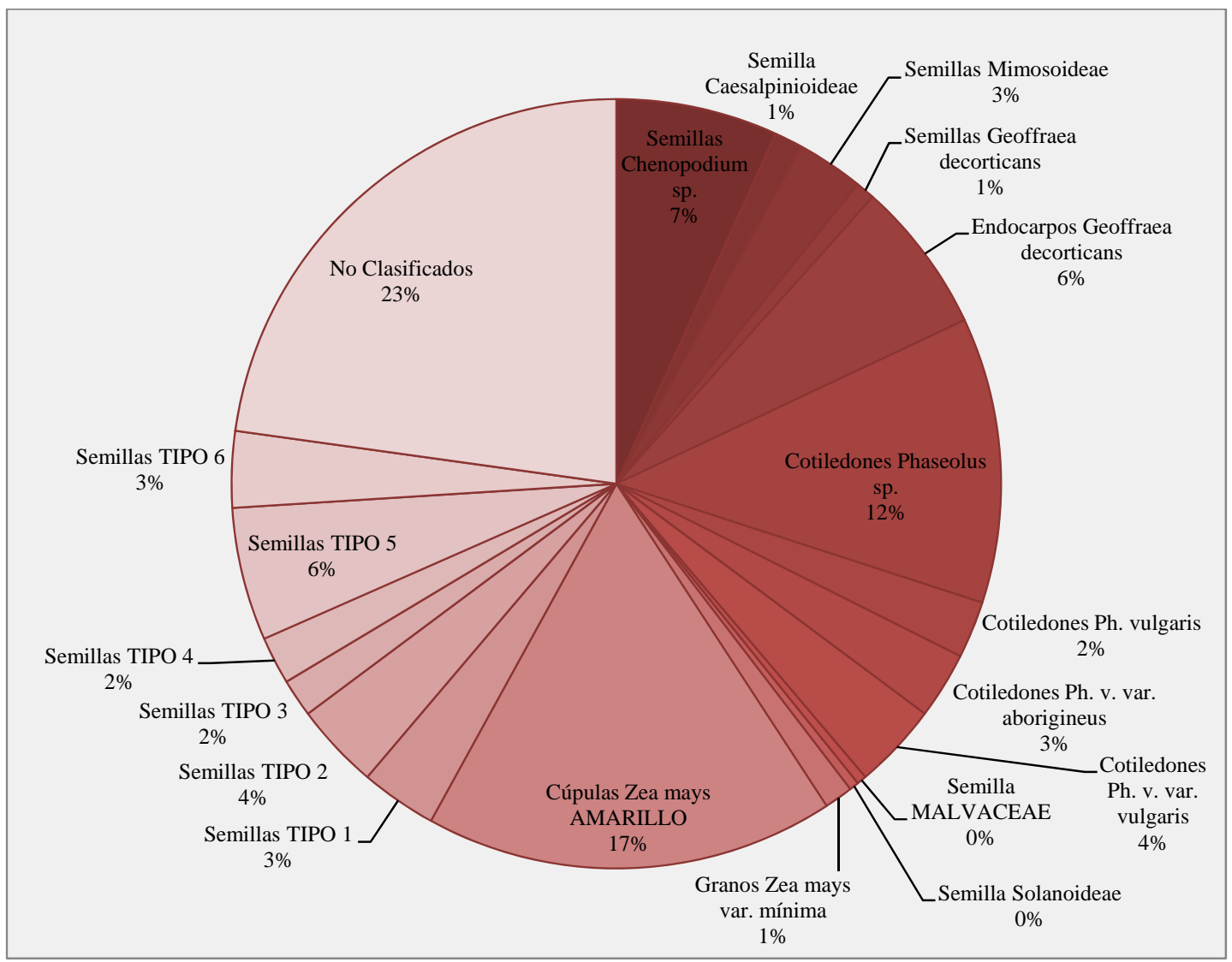

Gráfico 9. Porcentaje relativo de restos correspondientes a cada grupo identificado. 
Un panorama similar se presenta en E3, donde las pequeñas semillas de hierbas TIPO 2 (9\%), TIPO 3 (3\%), TIPO 4 (3\%), fragmentos de pericarpios (16\%), tallos y pedúnculos (3\%) se acompañan por cotiledones rotos de Phaseolus sp. (3\%) y un porcentaje relativamente alto de fragmentos de endocarpos de G. decorticans (16\%). Esta habitación contiene además el mayor porcentaje de material fragmentario no identificable por las técnicas empleadas (47\%).

Las cúpulas de Zea mays AMARILLO y los cotiledones de P. v. var. aborigineus vuelven a aparecer en E4 pero en proporciones menores (8\% cada uno), junto con el grano de Zea mays var. minima (8\%). Nuevamente una gran cantidad de semillas pequeñas de TIPO 1 (8\%), TIPO 4 (8\%), Solanoideae (8\%) y fragmentos de pericarpios (17\%).

Entre los variados restos de la E5 abundan las semillas de Chenopodium (22\%) seguidas por los fragmentos de endocarpos de G. decorticans (13\%) y de semillas de Mimosoideae (6\%). Aun así una gran parte del conjunto está conformado por semillas de herbáceas de TIPO 1 (9\%), TIPO2 (6\%), TIPO 3 (1\%) Y TIPO 4 (4\%), fragmentos de pericarpios (4\%) y tallos y pedúnculos (6\%). Una proporción muy pequeña incluye granos de Z. m. var. minima (1\%) y cotiledones de Phaseolus sp. (1\%). Finalmente, el área del portal de la E5 presenta en proporciones similares granos de Z. m. var. minima (50\%) y semillas TIPO 2 (50\%).

Ubicuidad de los restos en muestras de flotación. En términos generales, los restos carpológicos son más ubicuos en la E1 y E3, seguidos por E2, que en los recintos restantes, superando inclusive la ubicuidad general de los vestigios en todo el Núcleo 1 (Tabla 28). A partir de los resultados expuestos en la última columna de la misma tabla se observó que los restos más ubicuos del conjunto recuperado en Cardonal son los que se manifiestan en más del $4 \%$ de las muestras flotadas ${ }^{3}$, entre los que se encuentran las

\footnotetext{
${ }^{3}$ La ubicuidad sólo ha sido calculada en base a los restos recuperados por muestras de flotación, ya que la misma considera el número de muestras en que un tipo de resto se halla representado (Miller 1988). A diferencia de las muestras de sedimento para flotación, cada resto recuperado in situ representa una muestra en sí mismo. En este sentido, los resultados de la ubicuidad de los restos obtenidos por este procedimiento no difieren de aquellos que podrían esperarse del cálculo de porcentajes o porcentajes relativos para este tipo de muestras. Puesto que la ubicuidad es un índice que implica directamente el número de muestras tomadas y supone la comparabilidad entre ellas y en tanto no se conoce el sesgo conferido por el uso indistinto de una y otra en el mismo cálculo, se consideró la utilización del índice en los términos expresados por Miller (1988).
} 


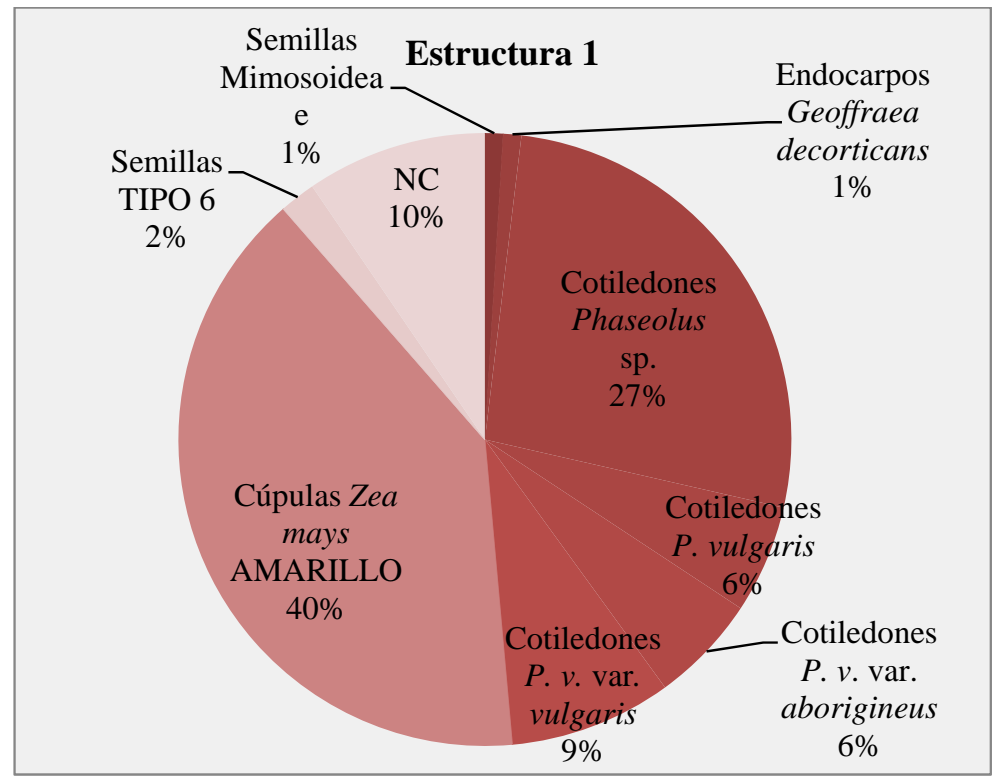

Gráfico 10a. Porcentaje relativo. Estructura 1

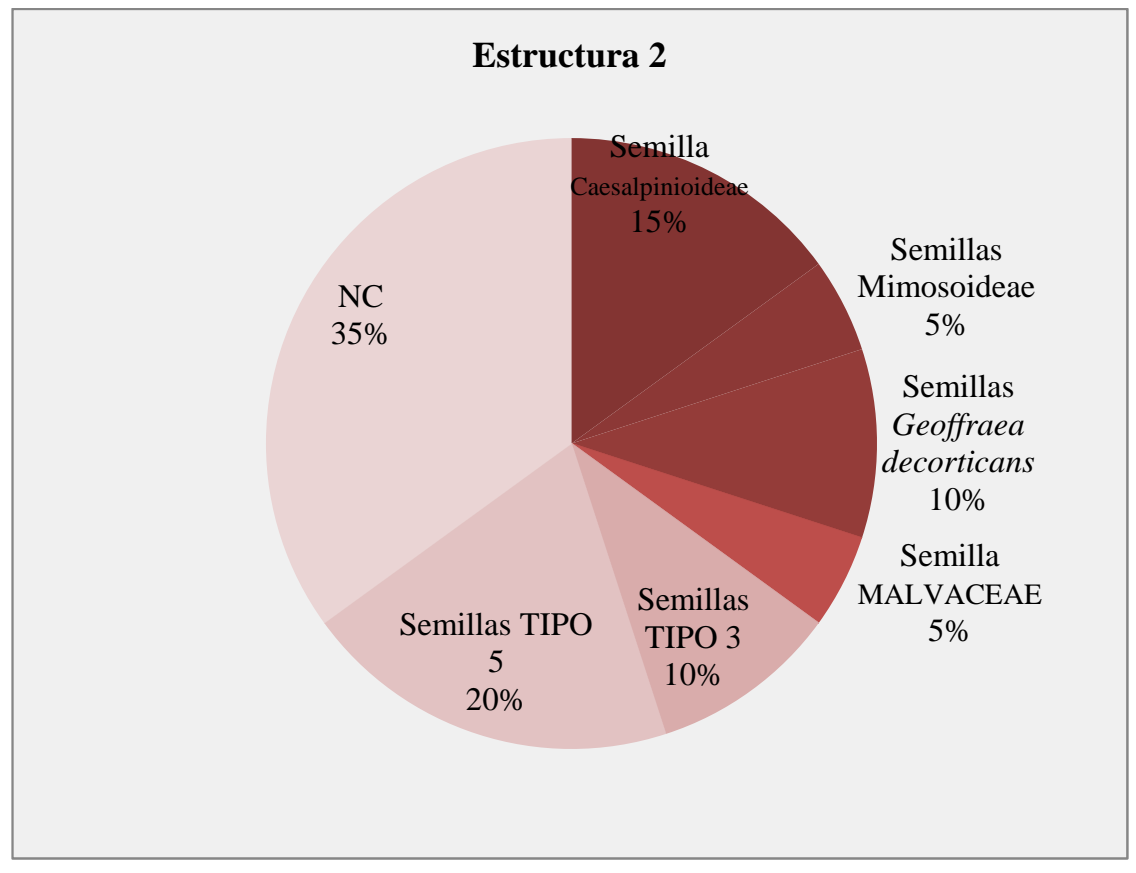

Gráfico 10b. Porcentaje relativo. Estructura 2. 


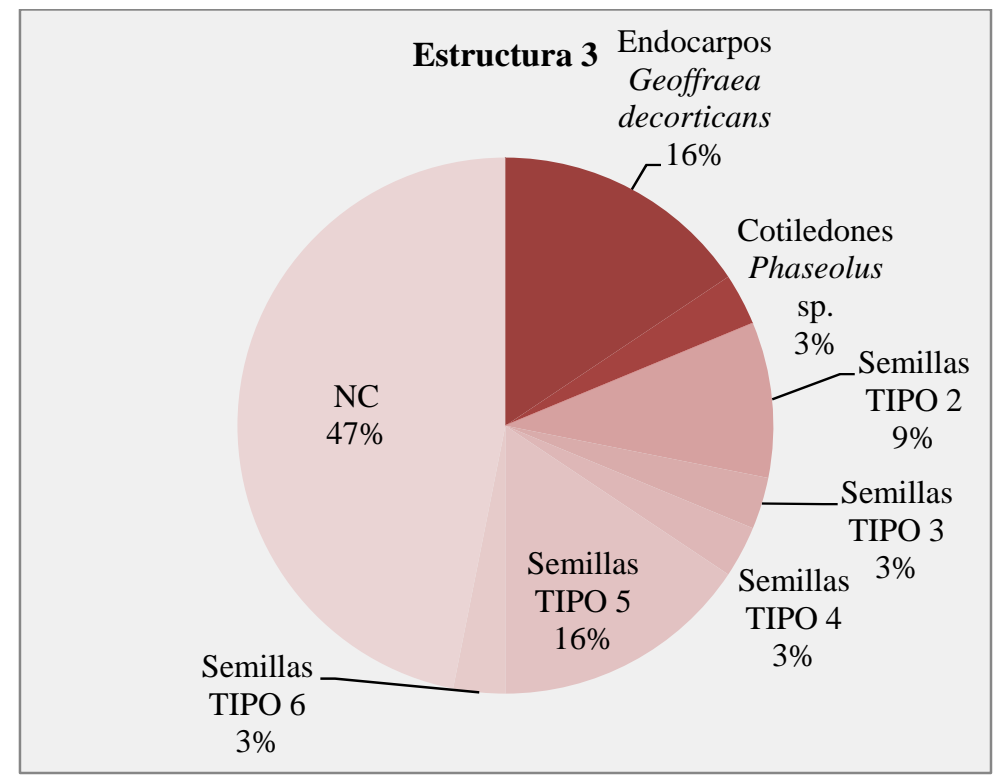

Gráfico 10c. Porcentaje relativo. Estructura 3.

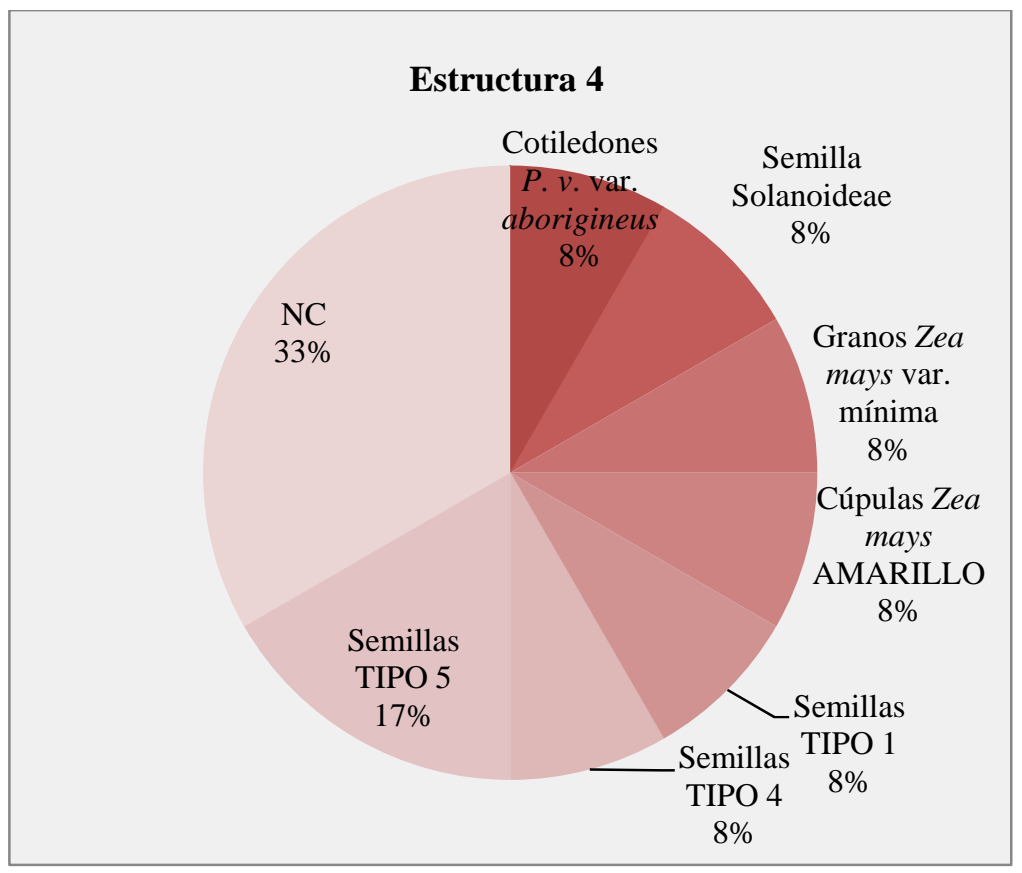

Gráfico 10d. Porcentaje relativo. Estructura 4. 


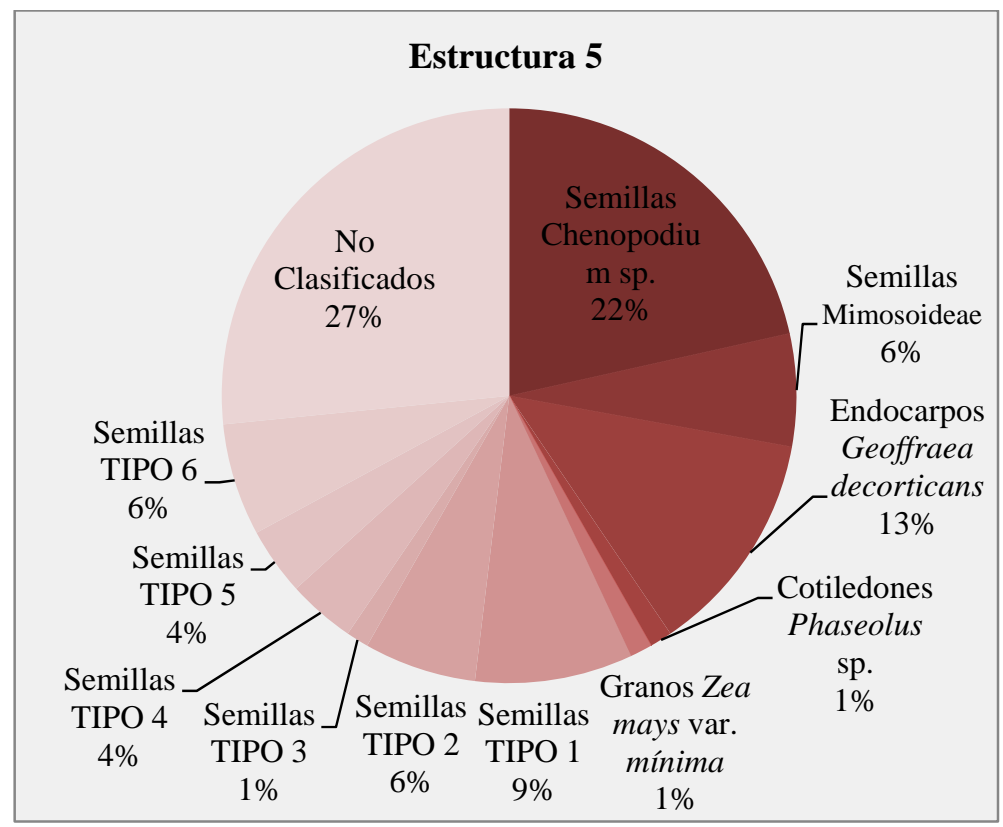

Gráfico 10e. Porcentaje relativo. Estructura 5.

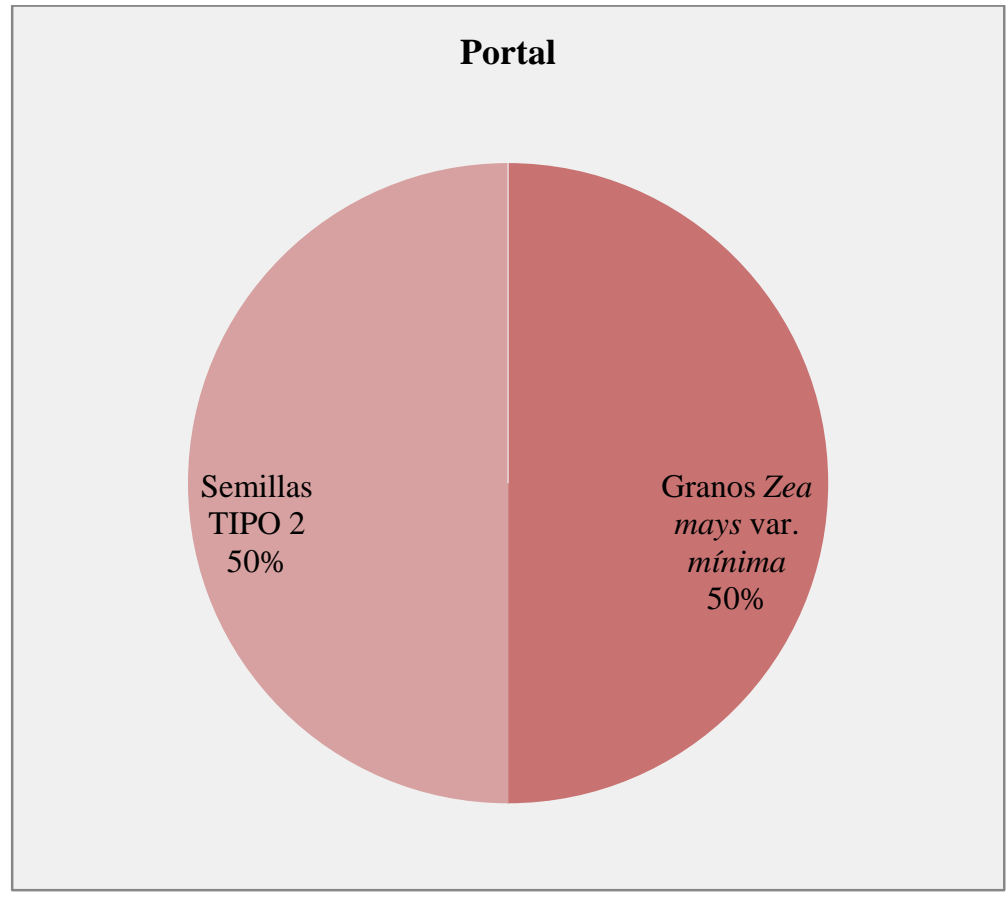

Gráfico 10f. Porcentaje relativo. Portal.

semillas de Chenopodium (7,60\%), los fragmentos de endocarpos de Geoffraea decorticans (4,68\%) y demás pericarpios TIPO 5 (7,02\%), las pequeñas semillas de herbáceas TIPO 1 (4,09\%) y TIPO 2(5,26\%) y los Tallos y pedúnculos (4,09\%). Los demás restos aparecen en cantidades menores al 3\% de las muestras flotadas del Núcleo 1, siendo los menos ubicuos las 
semillas de MALVACEAE y Solanoideas, que están representadas por un único ejemplar y los cotiledones de $P$. v. var. aborigineus, que a pesar de ser más numerosos aparecieron concentrados en una única muestra de flotación. Lo mismo puede decirse de los restos asignados a $P$. vulgaris y las cúpulas de $Z$. mays AMARILLO que presentan porcentajes de ubicuidad bajos, mientras que la presencia de $P$. v. var. vulgaris en las muestras de flotación fue nula. Los escasos granos de Z. m. var. mínima en cambio se muestran más ubicuos comparados con los taxones anteriores, puesto que aparecieron dispersos en diferentes muestras (Gráfico 11).

Si se comparan las ubicuidades entre las Estructuras que componen el Núcleo 1 (Tabla XX) es posible ver con mayor claridad la situación de los restos recuperados en E1. El alto porcentaje de muestras en que se presenta cada uno de los restos (33,33\%) se debe básicamente al bajo número y concentración espacial de las muestras procedentes de dicha habitación (ver infra). Entre las estructuras restantes se destacan las semillas de Chenopodium, (15,48\%) que sólo aparecen en las muestras de E5, seguidas de los restos TIPO 1 (7,14\%) y TIPO 2 (5,95\%) y finalmente los endocarpos de G. decorticans (3,57\%) en el mismo recinto. Este último taxón está representado en el 10\% de las muestras del portal de la E5, al igual que los granos de Z. m. var. mínima y las semillas TIPO 2.

Los endocarpos de G. decorticans y otros restos de pericarpios TIPO 5 son además los restos más ubicuos de E3 (10,50\% cada uno), seguidos por las semillas TIPO 2 (9,38\%). Otros grupos como los cotiledones de Phaseolus sp., las semillas TIPO 3, TIPO 4 y los tallos y pedúnculos TIPO 6 se hallaron en 3,13\% de las muestras. Por último, en E2 y E4 los fragmentos de pericarpios TIPO 5 se presentaron en la mayor proporción de muestras (14,29\% y 9,52\% respectivamente). Son ubicuos en E2, además las semillas TIPO 3 (9,52\%) y los cotiledones de Caesalpinoideae (9,52\%) que sólo están presentes en este recinto. En cambio, en E4 aparecen representadas por única vez en muestras de flotación las semillas de Solanoideae (4,76\%), junto con granos de Z. m. var. minima, las cúpulas de Z. mays AMARILLO y las semillas TIPO 1 y TIPO 4, en igual porcentaje (4,76\% cada uno) (Gráfico 12).

Tabla 28. Cantidad de muestras conteniendo cada tipo de carporresto (n) y ubicuidad (U\%) calculada en cada Estructura (E1, E2, E3, E4, E5, E5p) y para el Núcleo 1 (General)

\begin{tabular}{|c|c|c|c|c|c|c|c|c|c|c|c|c|c|c|}
\hline \multirow[t]{2}{*}{ Carporrestos } & \multicolumn{2}{|c|}{$E 1$} & \multicolumn{2}{|c|}{ E2 } & \multicolumn{2}{|c|}{ E3 } & \multicolumn{2}{|c|}{ E4 } & \multicolumn{2}{|c|}{$E 5$} & \multicolumn{2}{|c|}{$E 5 p$} & \multicolumn{2}{|c|}{ General } \\
\hline & $n$ & $U \%$ & $n$ & $U \%$ & $n$ & $U \%$ & $n$ & $U \%$ & $n$ & $U \%$ & $n$ & $U \%$ & $n$ & $U \%$ \\
\hline Semillas Chenopodium & 0 & 0,00 & 0 & 0,00 & 0 & 0,00 & 0 & 0,00 & 13 & 15,48 & 0 & 0,00 & 13 & 7,60 \\
\hline Semilla Caesalpinioideae & 0 & 0,00 & 2 & 9,52 & 0 & 0,00 & 0 & 0,00 & 0 & 0,00 & 0 & 0,00 & 2 & 1,17 \\
\hline
\end{tabular}




\begin{tabular}{|c|c|c|c|c|c|c|c|c|c|c|c|c|c|c|}
\hline Semillas Mimosoideae & 0 & 0,00 & 1 & 4,76 & 0 & 0,00 & 0 & 0,00 & 2 & 2,38 & 0 & 0,00 & 3 & 1,75 \\
\hline Endocarpos Geoffraea decorticans & 0 & 0,00 & 0 & 0,00 & 4 & 12,50 & 0 & 0,00 & 3 & 3,57 & 1 & 10,00 & 8 & 4,68 \\
\hline Cotiledones Phaseolus sp. & 1 & 33,33 & 0 & 0,00 & 1 & 3,13 & 0 & 0,00 & 1 & 1,19 & 0 & 0,00 & 3 & 1,75 \\
\hline Cotiledones $P$. vulgaris & 1 & 33,33 & 0 & 0,00 & 0 & 0,00 & 0 & 0,00 & 0 & 0,00 & 0 & 0,00 & 1 & 0,58 \\
\hline Cotiledones $P . v$. var. aborigineus & 1 & 33,33 & 0 & 0,00 & 0 & 0,00 & 0 & 0,00 & 0 & 0,00 & 0 & 0,00 & 1 & 0,58 \\
\hline Cotiledones $P . v$. var. vulgaris & 0 & 0,00 & 0 & 0,00 & 0 & 0,00 & 0 & 0,00 & 0 & 0,00 & 0 & 0,00 & 0 & 0,00 \\
\hline Semilla MALVACEAE & 0 & 0,00 & 1 & 4,76 & 0 & 0,00 & 0 & 0,00 & 0 & 0,00 & 0 & 0,00 & 1 & 0,58 \\
\hline Semilla Solanoideae & 0 & 0,00 & 0 & 0,00 & 0 & 0,00 & 1 & 4,76 & 0 & 0,00 & 0 & 0,00 & 1 & 0,58 \\
\hline Granos Zea mays var. mínima & 0 & 0,00 & 0 & 0,00 & 0 & 0,00 & 1 & 4,76 & 1 & 1,19 & 1 & 10,00 & 3 & 1,75 \\
\hline Cúpulas Zea mays AMARILLO & 1 & 33,33 & 0 & 0,00 & 0 & 0,00 & 1 & 4,76 & 0 & 0,00 & 0 & 0,00 & 2 & 1,17 \\
\hline Semillas TIPO 1 & 0 & 0,00 & 0 & 0,00 & 0 & 0,00 & 1 & 4,76 & 6 & 7,14 & 0 & 0,00 & 7 & 4,09 \\
\hline Semillas TIPO 2 & 0 & 0,00 & 0 & 0,00 & 3 & 9,38 & 0 & 0,00 & 5 & 5,95 & 1 & 10,00 & 9 & 5,26 \\
\hline Semillas TIPO 3 & 0 & 0,00 & 2 & 9,52 & 1 & 3,13 & 0 & 0,00 & 1 & 1,19 & 0 & 0,00 & 4 & 2,34 \\
\hline Semillas TIPO 4 & 0 & 0,00 & 0 & 0,00 & 1 & 3,13 & 1 & 4,76 & 2 & 2,38 & 0 & 0,00 & 4 & 2,34 \\
\hline Pericarpios TIPO 5 & 0 & 0,00 & 3 & 14,29 & 4 & 12,50 & 2 & 9,52 & 3 & 3,57 & 0 & 0,00 & 12 & 7,02 \\
\hline Tallos y Pedúnculos TIPO 6 & 1 & 33,33 & 0 & 0,00 & 1 & 3,13 & 0 & 0,00 & 5 & 5,95 & 0 & 0,00 & 7 & 4,09 \\
\hline No Clasificados & 1 & 33,33 & 6 & 28,57 & 11 & 34,38 & 3 & 14,29 & 11 & 13,10 & 0 & 0,00 & 31 & 18,13 \\
\hline General & 2 & 66,67 & 9 & 42,86 & 17 & 53,13 & 7 & 33,33 & 30 & 35,71 & 1 & 10,00 & 66 & 38,60 \\
\hline $\begin{array}{l}\text { Cantidad total de muestras } \\
\text { flotadas }\end{array}$ & & 3 & & 21 & & 32 & & 21 & & 84 & & 10 & & 171 \\
\hline
\end{tabular}

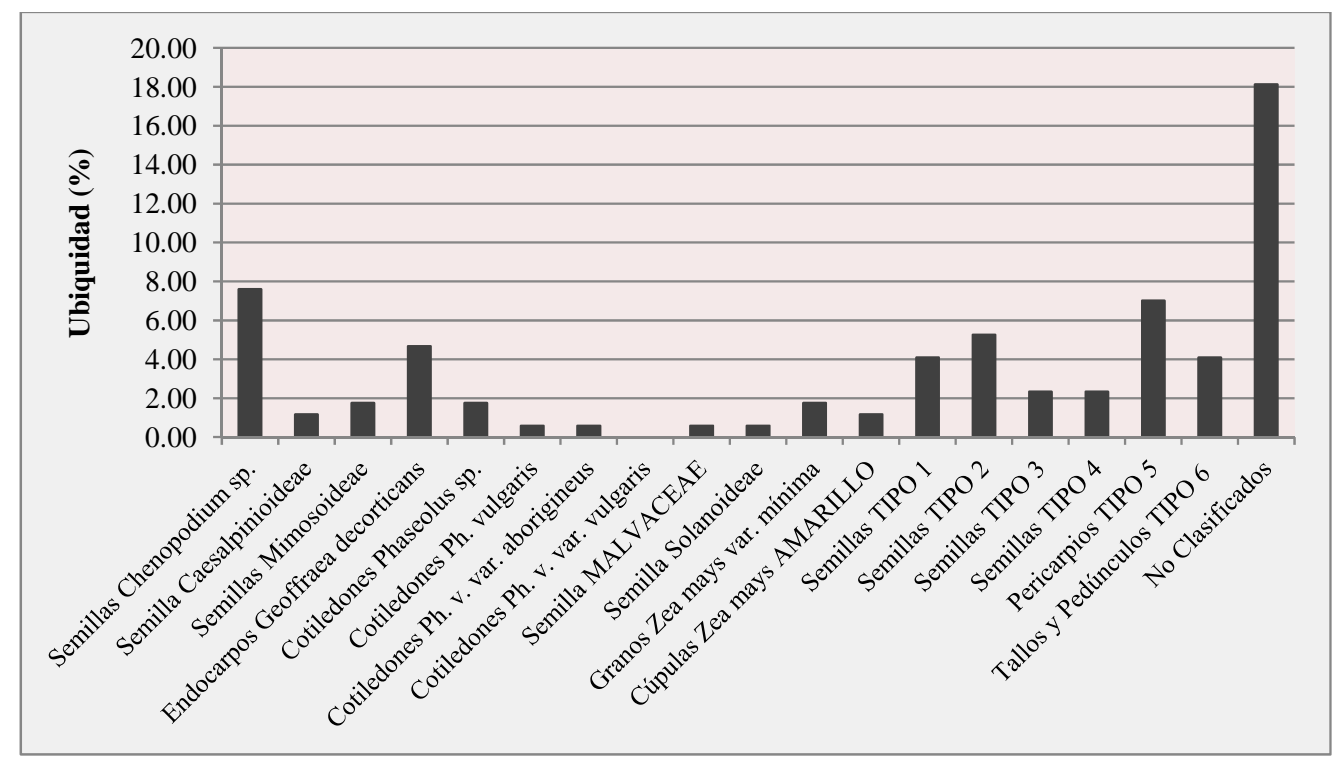

Gráfico 11. Valores generales de la ubicuidad de los restos recuperados por flotación en el Núcleo 1. 


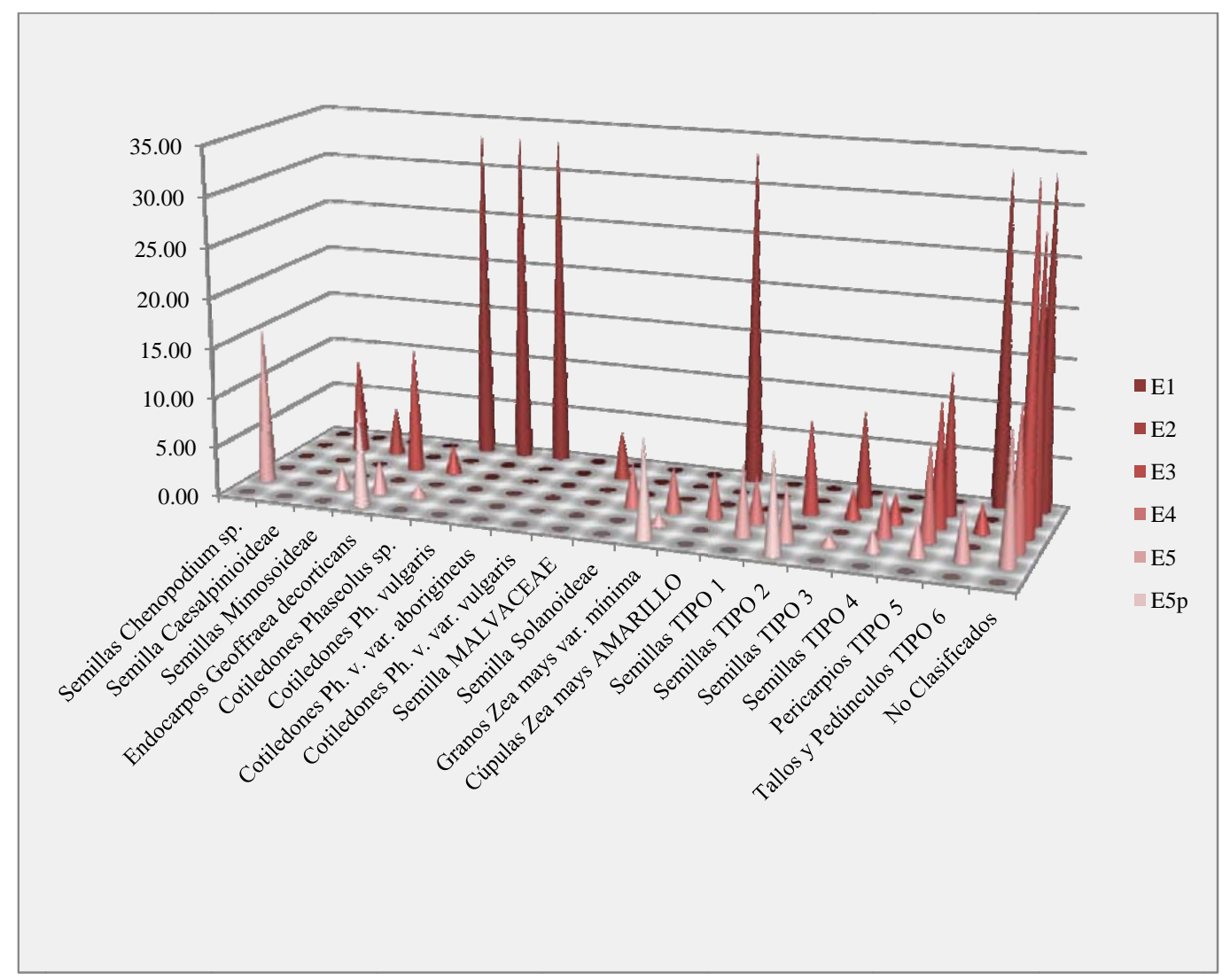

Gráfico 12. Ubicuidad de los restos de flotación recuperados por Estructura.

Densidad de carbón de leño y restos carpológicos. La densidad de restos recuperados por flotación en Cardonal es de 0,21 carporrestos por litro de sedimento. Las E2, E4 y E5 presentan densidades similares $(0,13 \mathrm{c} / \mathrm{l})$, mientras que en E3 es poco más elevada (0,16 c/l). En E1 la cantidad de carporrestos por litro de sedimento es notablemente alta lo cual se relaciona con un bajo número de muestras localizadas en un área de alta presencia de restos (Tabla 29). Comportamientos similares han sido observados en el cálculo de porcentajes y ubicuidad de los restos de la E1.

Tabla 29. Cálculo global y por estructura de las densidades de carporrestos presentes en el Núcleo 1.

*Cada muestra contiene 6 litros de sedimento

\begin{tabular}{ccccc}
\hline & Muestras (n) & Litros (l) & Carporrestos (c) & Densidad (c/l) \\
\hline E1 & 3 & 18 & 89 & 4,94 \\
\hline E2 & 21 & 126 & 17 & 0,13 \\
\hline E3 & 32 & 192 & 31 & 0,16 \\
\hline E4 & 21 & 126 & 10 & 0,08 \\
\hline E5 & 84 & 504 & 66 & 0,13 \\
\hline E5p & 10 & 60 & 2 & 0,03 \\
\hline Totales & 171 & 1024 & 215 & 0,21 \\
\hline
\end{tabular}




\section{La distribución inter-estructura de los restos botánicos}

A través del cálculo del promedio de las densidades de carbón de leño y restos carpológicos por niveles artificiales de excavación (ANEXO 8) es posible evaluar el modo en que éstos se distribuyen a diferentes profundidades (Tabla 30) representa la distribución de tales densidades, individualizando las estructuras del Núcleo 1.

Tabla 30. Promedio de las densidades de carbón de leño y carporrestos por Nivel excavado en cada una de las Estructuras

\begin{tabular}{|c|c|c|}
\hline & \multicolumn{2}{|c|}{ Densidades } \\
\hline & Carbón de leño (g/l) & Carporrestos (u/l) \\
\hline E1 Niv.4 & 0,032 & 4,944 \\
\hline E2 Niv.1 & 0,007 & 0,007 \\
\hline E2 Niv.2 & 0,005 & 0,250 \\
\hline E2 Niv.3 & 0,005 & 0,119 \\
\hline E2 Niv.4 & 0,006 & 0,095 \\
\hline E2 Niv.5 & 0,007 & 0,167 \\
\hline E2 Niv.6 & 0,004 & 0,004 \\
\hline E3 Niv.1 & 0,003 & 0,003 \\
\hline E3 Niv.2 & 0,005 & 0,111 \\
\hline E3 Niv.3 & 0,010 & 0,200 \\
\hline E3 Niv.4 & 0,006 & 0,136 \\
\hline E3 Rgo.1 & 0,006 & 0,250 \\
\hline E3 Rgo.2 & 0,007 & 0,007 \\
\hline E3 Rgo.3 & 0,005 & 0,005 \\
\hline E3 Rgo.4 & 0,001 & 0,001 \\
\hline E3 Rgo.5 & 0,004 & 0,004 \\
\hline E3 Rgo.6 & 0,001 & 0,001 \\
\hline E4 Niv.1 & 0,000 & 0,000 \\
\hline E4 Niv.2 & 0,000 & 0,000 \\
\hline E4 Niv.3 & 0,002 & 0,083 \\
\hline E4 Niv.4 & 0,003 & 0,208 \\
\hline E4 Niv.5 & 0,002 & 0,056 \\
\hline E4 Niv.6 & 0,002 & 0,083 \\
\hline E5 Niv.1 & 0,021 & 0,000 \\
\hline E5 Niv.2 & 0,012 & 0,000 \\
\hline E5 Niv.3 & 0,009 & 0,000 \\
\hline E5 Niv.4 & 0,034 & 0,250 \\
\hline E5 Niv.5 & 0,043 & 0,157 \\
\hline E5 Niv.6 & 0,028 & 0,118 \\
\hline E5 Rgo.1 & 0,055 & 0,167 \\
\hline Ptal.Niv.3 & 0,012 & 0,000 \\
\hline Ptal Niv.4 & 0,009 & 0,000 \\
\hline Ptal Niv.5 & 0,016 & 0,167 \\
\hline Ptal Niv.6 & 0,035 & 0,000 \\
\hline
\end{tabular}


El Gráfico 13 corresponde a los valores de densidad del carbón de leño y muestra la línea de tendencia (promedio: 3) de ésta a través de los niveles de las Estructuras. Las tres muestras analizadas en la E1, que corresponden al nivel más profundo del piso ocupacional, promedian una densidad que supera los 0,03 gramos de carbón de madera por litro de sedimento procesado. Lo mismo ocurre con las muestras obtenidas en la E5 a partir del nivel 3 y la capa más profunda del Portal.

Los promedios de las densidades en los diferentes niveles de la E2, E3 y E4 se mantienen por debajo de los 0,01 g/l, siendo esta última la más pobre en carbón de madera. Cabe señalar además que la distribución de las densidades entre los diferentes niveles de la Estructura 2 contiene carbón de leño en densidades similares entre las capas superficiales y las inferiores, lo cual no ocurre por cierto en las demás Estructuras. Una situación semejante se observa en la E3, aunque en este recinto puede visualizarse una tendencia a aumentar la densidad de carbón de leño hacia los niveles 3 y 4, lo cual es más evidente en las Estructuras restantes y el Portal.

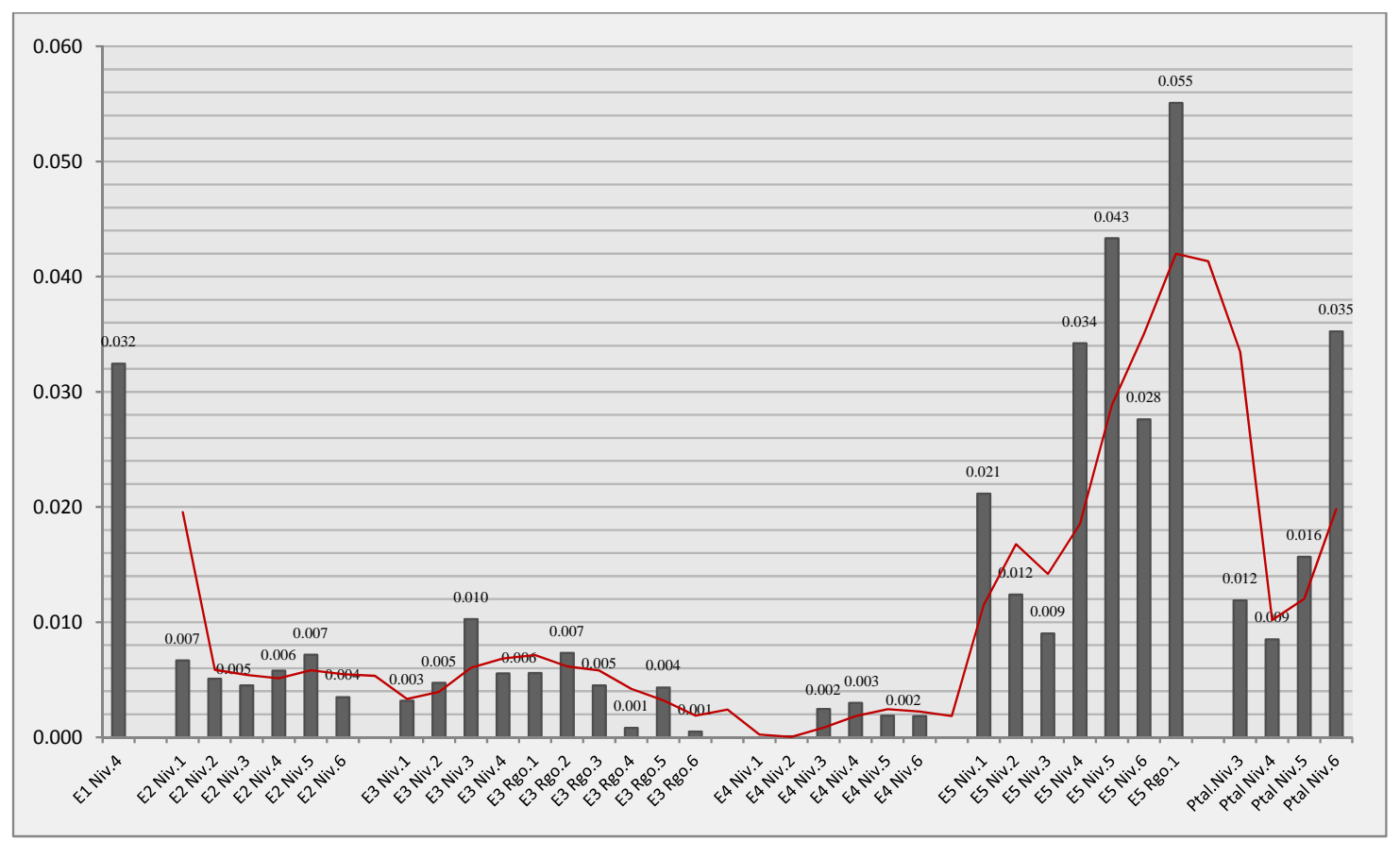

Gráfico 13. Promedio de las densidades de carbón de leño por nivel excavado en cada una de las Estructuras y curva de tendencia de la densidad.

Si se observa el comportamiento de los valores de densidad de carporrestos en los diferentes niveles de las estructuras (Gráfico 14) también las muestras de la E1 son 
notablemente densas, con casi 5 carporrestos por litro de sedimento. De manera general puede decirse que las Estructuras 4, 5 y el Portal son más densas en restos carpológicos hacia los niveles 4 y 5 (entre 0,15 y 0,25 carporrestos por litro de sedimento). La E3, además presenta un Nivel 3 enriquecido, así como la E2 muestra una densidad que crece abruptamente en la capa 2 y decrece poco hacia los estratos subsiguientes.

Cabe notar además que los pozos excavados como Rasgo 1 en las Estructuras 3 y 5 respectivamente muestran densidades de carbón altas en relación a las demás procedencias consideradas. Las capas y rasgos restantes presentan densidades bajas, las cuales superan las 0,01 unidades por litro de sedimento.

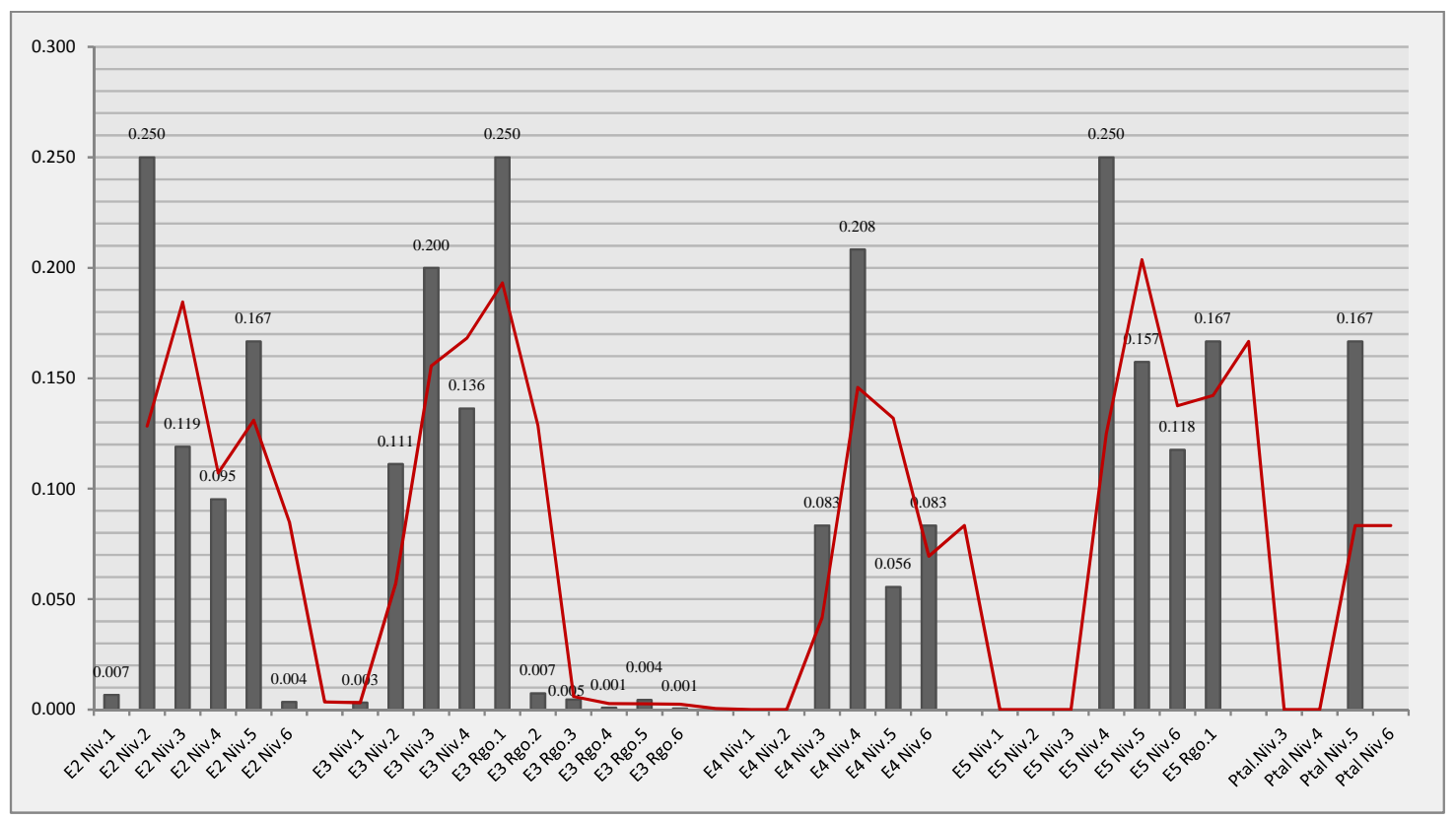

Gráfico 14. Promedio de las densidades de carporrestos por nivel excavado en cada una de las Estructuras y curva de tendencia de la densidad.

Visualmente, los gráficos muestran cierta semblanza, que podría estar dada por la relación que existe entre la distribución de la variable densidad para uno y otro tipo de resto (carbón de leño y restos carpológicos). En efecto, el índice de correlación entre dichas variables para cada una de las muestras de flotación analizadas (IC 0,29) señala la existencia de una relación entre ambas de signo positivo, aunque de magnitud débil a mediana (Gráfico 15). 


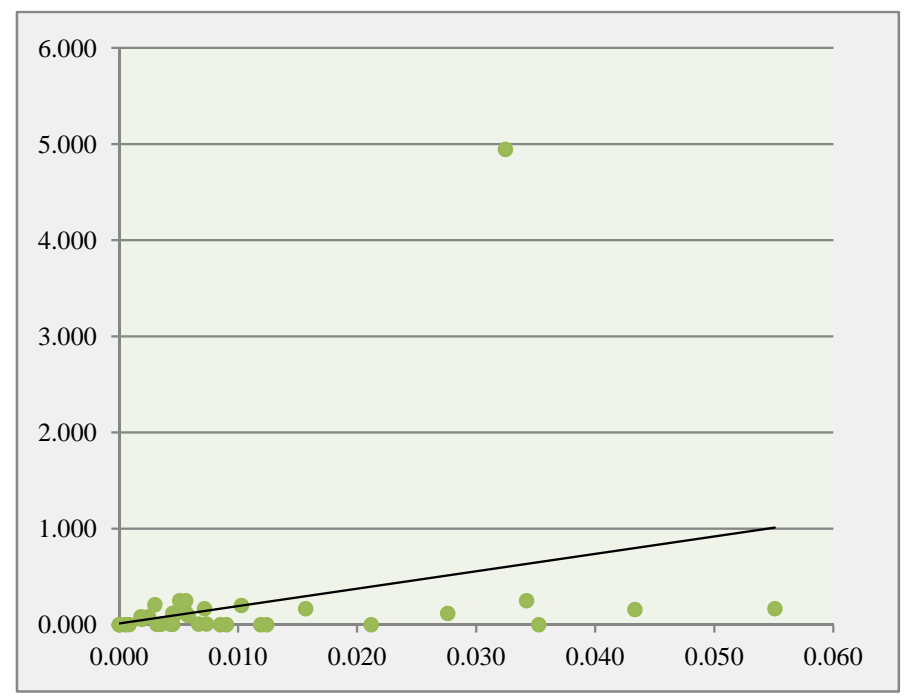

Gráfico 15. Correlación de las variables ‘densidad de carbón de leño’ y ‘densidad de carporrestos’ en cada una de las muestras de flotación analizadas del Núcleo 1.

A fin de reconocer y comparar la variabilidad de la distribución de los restos al interior de las Estructuras, se calcularon las densidades promedio para los grupos de muestras de flotación procedentes de unidades de excavación correspondientes a los diferentes espacios y rasgos arquitectónicos reconocidos al interior del Núcleo 1: pisos de ocupación, áreas carbonosas del piso de ocupación, áreas de fogón, pozos de poste, pozos rellenos con ceniza, otras cavidades practicadas en la roca de base, terraplén y capas de relleno. A esta información se sumaron los datos procedentes del número neto de restos recuperados directamente del sedimento en cada una de las áreas mencionadas (Tabla 31).

Se destaca en primer lugar las muestras densas tomadas en el área del fogón de E1 $(14,33)$ muy superior a la densidad de restos presente en el área de fogón algo más dispersa de E5. A pesar que en esta última aparecieron diez restos in situ, tal cantidad tampoco supera el número hallado en el piso de E1.

Ninguno de los otros rasgos o pisos muestran valores semejantes para uno y otro tipo de muestras. Comparado con las demás áreas de piso ocupacional, el sector de piso ennegrecido por el carbón tiene una densidad considerable de vestigios botánicos $(0,33)$ y presenta unos cuatro recuperados de forma directa, al igual que el piso carbonoso de E4. De los demás pisos de ocupación, E5 es el más denso $(0,19)$, seguido por E4 $(0,14)$, E2 $(0,11)$, E3 $(0,11)$ y el Portal de E5 $(0,08)$. E2 y E5 tienen además restos in situ (2).

Los pozos en general (excepto en el Portal de E5), ya sean de sostén de postes, contenedores de cenizas del fogón o cavidades practicadas en la roca de base con otro fin, contenían restos botánicos en densidades equivalentes a las reconocidas en los sedimentos de 
los pisos aunque en ninguno de ellos se obtuvieron restos directos. Asimismo las muestras procedentes del terraplén que rodea el espacio interno de E5 mostraron la presencia de vestigios carbonizados de plantas, aunque en densidad menor $(0,06)$. Finalmente, cabe destacar la ocurrencia de restos en las capas consideradas de relleno de E2, para los cuales se ha estimado una densidad $(0,23)$ sólo superada por las muestras tomadas dentro del pozo de poste de dicha Estructura (0,33) (Gráfico 16). Finalmente, la LÁMINA 1 muestra gráficamente la distribución de la totalidad de los restos vegetales recuperados.

Tabla 31. Densidades de carporrestos correspondientes a los diferentes espacios y rasgos arquitectónicos reconocidos al interior del Núcleo 1

\begin{tabular}{|c|c|c|c|c|c|c|}
\hline & & $\begin{array}{l}\text { Cantidad } \\
\text { muestras flot. }\end{array}$ & $\begin{array}{l}\text { Litros } \\
\text { sedimento }\end{array}$ & $\begin{array}{l}\text { Cantidad } \\
\text { restos in situ }\end{array}$ & $\begin{array}{l}\text { Cantidad } \\
\text { restos flot. }\end{array}$ & $\begin{array}{l}\text { Densidad } \\
\text { restos flot. }\end{array}$ \\
\hline \multirow[t]{2}{*}{ E1 } & piso & 2 & 12 & 13 & 3 & 0,25 \\
\hline & área fogón & 1 & 6 & 3 & 86 & 14,33 \\
\hline \multirow[t]{4}{*}{ E2 } & relleno & 5 & 30 & 1 & 7 & 0,23 \\
\hline & piso & 12 & 72 & 2 & 8 & 0,11 \\
\hline & piso carbonoso & 3 & 18 & 0 & 0 & 0,00 \\
\hline & pozo de poste & 1 & 6 & 0 & 2 & 0,33 \\
\hline \multirow[t]{4}{*}{ E3 } & relleno & 4 & 24 & 0 & 2 & 0,08 \\
\hline & piso & 17 & 102 & 0 & 11 & 0,11 \\
\hline & piso carbonoso & 5 & 30 & 1 & 10 & 0,33 \\
\hline & pozos & 6 & 36 & 0 & 8 & 0,22 \\
\hline \multirow[t]{3}{*}{ U4 } & relleno & 9 & 54 & 0 & 2 & 0,04 \\
\hline & piso & 6 & 36 & 0 & 5 & 0,14 \\
\hline & piso carbonoso & 6 & 36 & 2 & 3 & 0,08 \\
\hline \multirow[t]{6}{*}{ U5 } & relleno & 17 & 102 & 0 & 0 & 0,00 \\
\hline & piso & 42 & 252 & 2 & 49 & 0,19 \\
\hline & area fogón & 14 & 84 & 11 & 10 & 0,12 \\
\hline & pozo con cenizas & 2 & 12 & 0 & 2 & 0,17 \\
\hline & pozo & 1 & 6 & 0 & 2 & 0,33 \\
\hline & terraplén & 8 & 48 & 0 & 3 & 0,06 \\
\hline \multirow[t]{3}{*}{ Portal } & relleno & 3 & 18 & 0 & 0 & 0,00 \\
\hline & piso & 6 & 36 & 0 & 2 & 0,06 \\
\hline & pozo & 1 & 6 & 0 & 0 & 0,00 \\
\hline & Totales & 171 & 1026 & 35 & 215 & 0,21 \\
\hline
\end{tabular}




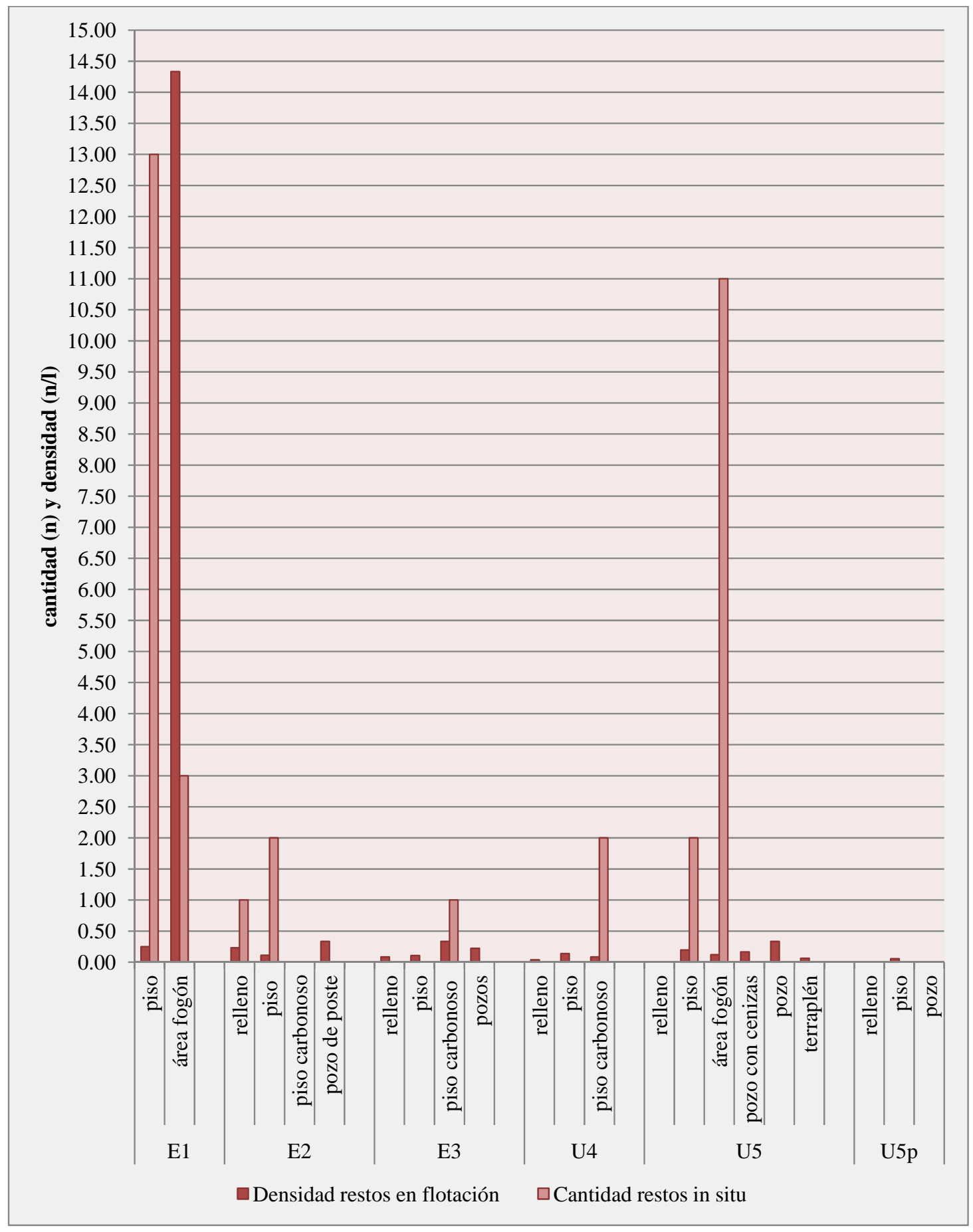

Gráfico 16. Cantidades y densidades de carporrestos comparadas entre espacios y rasgos arquitectónicos al interior del núcleo habitacional. 


\section{CAPÍTULO 6}

\section{Resultados del análisis de los artefactos de molienda}

\section{Caracterización general del conjunto de instrumentos de molienda}

En el Núcleo 1 se recuperaron 337 instrumentos líticos pulidos, de superficies alisadas y redondeadas, algunas de ellas ahuecadas, lustrosas y con rastros de pátinas, que caracterizan de manera general a los artefactos empleados en actividades de molienda (ANEXO 9). La mayor parte de ellos está confeccionada sobre migmatita granítica, el tipo de rocas más frecuente en los alrededores del sitio y principal componente de la Formación Chango Real que domina el área (Turner 1973). Más de la mitad de las piezas (206) se hallaron en estado íntegro o muy poco deterioradas, mientras que las 131 restantes corresponden a fragmentos de artefactos que conservan menos de las tres cuartas partes del mismo (Tabla 32, Gráfico 17). Los recintos E5 y E3 presentan mayores cantidades de instrumentos de uno y otro tipo (Gráfico 18).

El conjunto de instrumentos de molienda analizado se distribuye entre los niveles de relleno (107) y ocupacionales (160) de las cinco estructuras que componen el Núcleo 1. Además, unos 70 artefactos y partes de ellos se encontraron dispuestos entre las piedras caídas en zonas donde habían ocurrido derrumbes de la pared. Esta situación de hallazgo dificultó el reconocimiento de la posición previa del instrumento o fragmento, no pudiéndose determinar si se trataba de artefactos integrados a las paredes o depositados en el piso, o bien si forma parte del material post-ocupacional (Gráfico 19).

Tabla 32. Cantidad de artefactos completos y fragmentarios por estructura

\begin{tabular}{cccc}
\hline & $\begin{array}{c}\text { Artefactos de molienda } \\
\text { completos }\end{array}$ & $\begin{array}{c}\text { Artefactos de molienda } \\
\text { fragmentarios }\end{array}$ & Totales \\
\hline E1 & 23 & 7 & 30 \\
\hline E2 & 43 & 20 & 63 \\
\hline E3 & 57 & 22 & 79 \\
\hline E4 & 4 & 11 & 15 \\
\hline E5 & 69 & 65 & 134 \\
\hline E5p & 10 & 6 & 16 \\
\hline Totales & 206 & 131 & 337 \\
\hline
\end{tabular}




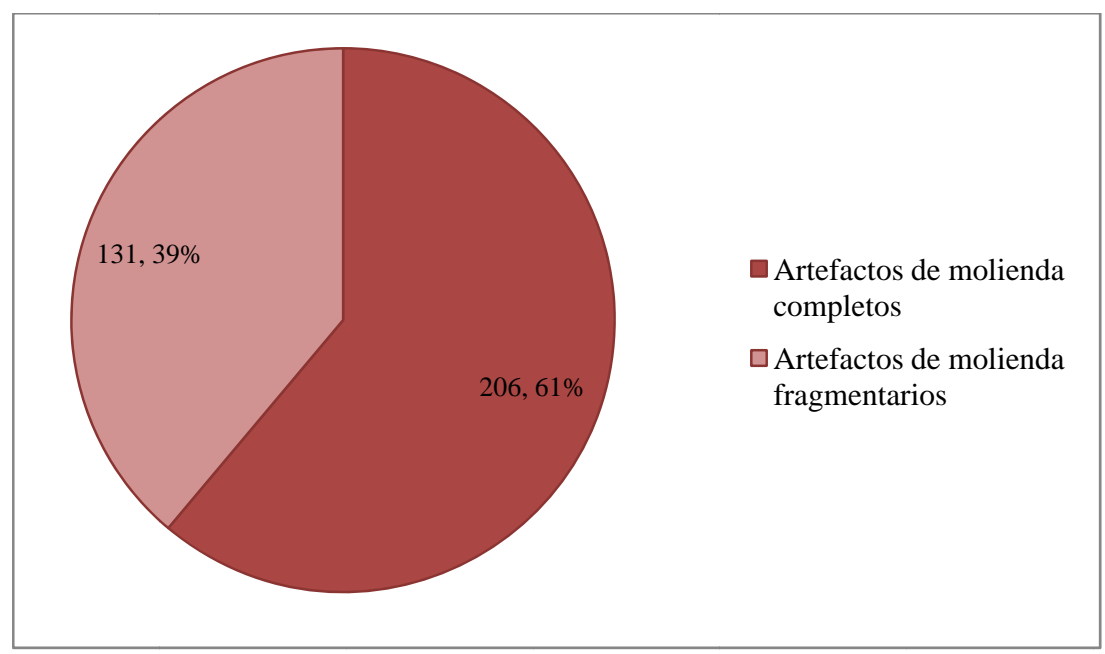

Gráfico 17. Cantidades relativas y porcentajes de artefactos de molienda completos y fragmentarios.

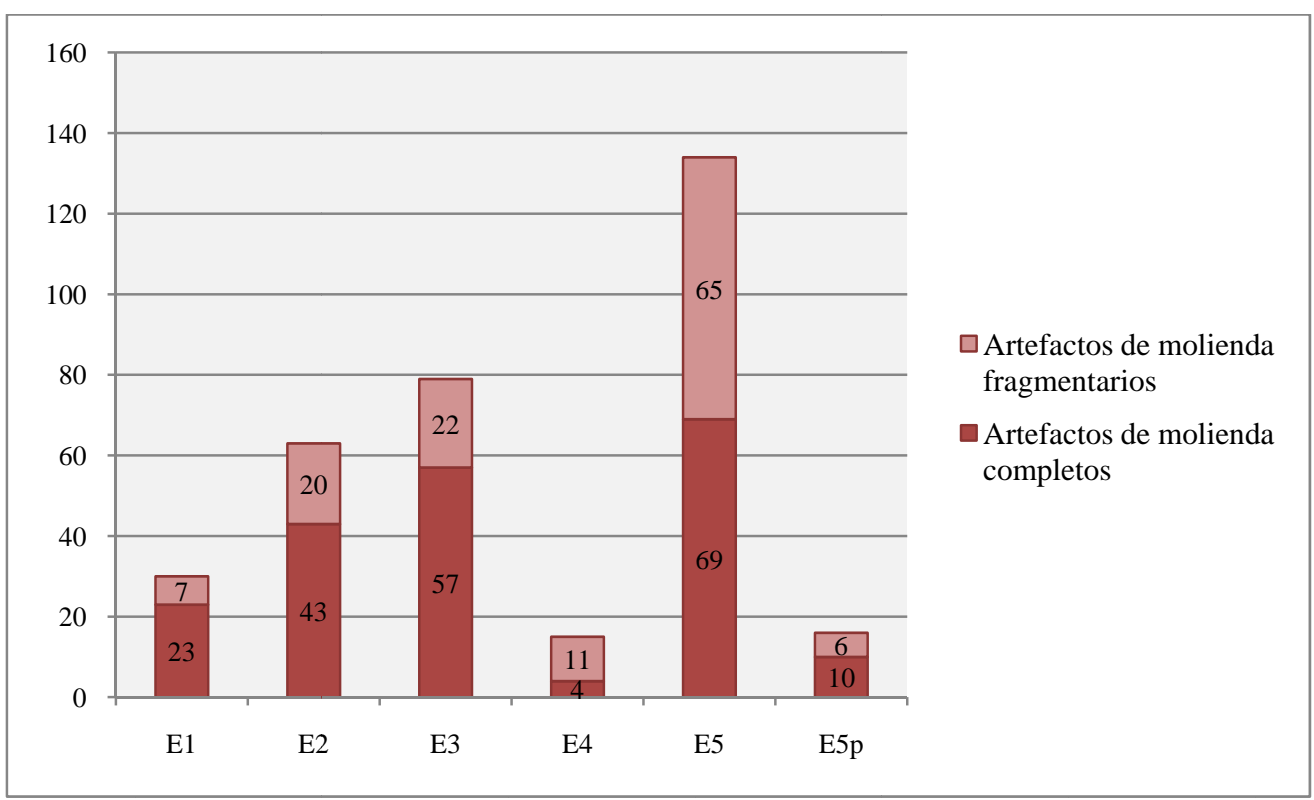

Gráfico 18. Cantidades relativas de artefactos de molienda completos y fragmentarios en cada estructura del Núcleo 1.

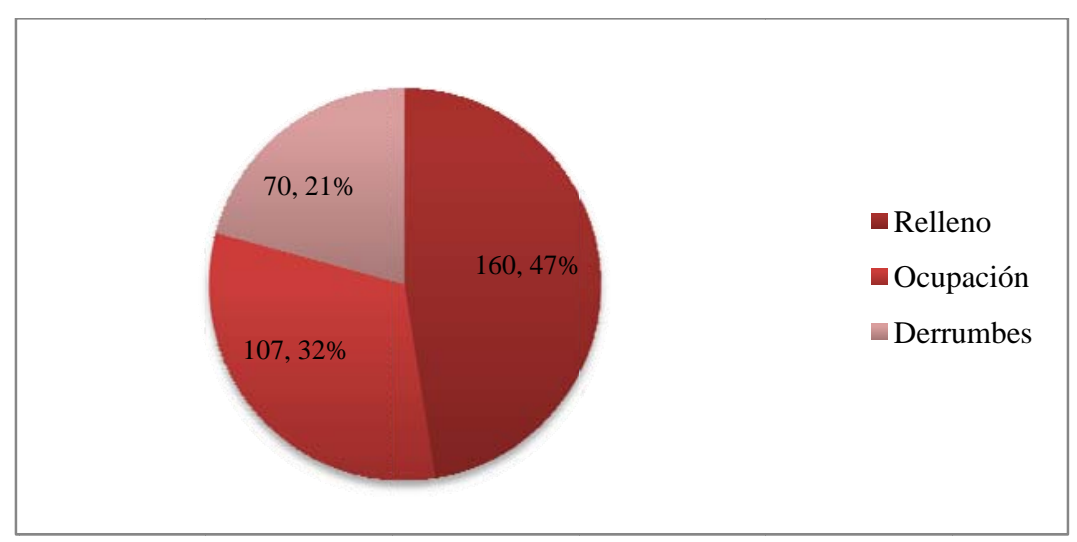

Gráfico 19. Cantidades y porcentajes de artefactos recuperados en niveles de relleno, niveles de ocupación y áreas de derrumbe de muros. 


\section{Piedras de moler en la ocupación del Núcleo 1: instrumentos activos y pasivos y material fragmentario}

\section{Fragmentos de artefactos de molienda}

La gran mayoría de los artefactos procedentes de los niveles ocupacionales corresponde a piezas completas (114), en tanto sólo unos 46 son piezas fragmentarias. Como tales, muchas de estas últimas forman parte del material descartado, distribuido en los pisos de los recintos. Sin embargo, otras fueron halladas en situación de reutilización, abandonadas en usos diferentes a la molienda (Tabla 33, Gráfico 20). De este modo, se detectaron fragmentos de moledores empleados a modo de cuña dentro de los pozos que aseguran los postes de la techumbre (E1-C1, E1-C2), como piedras de construcción integradas a los muros de diferentes habitaciones (E2-C1, E2-C2, E3-C9, E3-M64, E5-C3) y a la pared del terraplén de E5 (E5-M11, E5-M159). Otros se han utilizado para sostener y asegurar la parte inferior o pasiva de sistemas de molienda en uso (E1-C7) (ver ANEXO 9). Un único fragmento, que representaba menos de la mitad de un artefacto de grandes dimensiones, presentó indicios de haber sido reutilizado para moler (E1-C12), tales como el redondeamiento y alisado de las aristas producidas por la rotura previa, el aspecto lustroso de la superficie activa de molienda y su posición de hallazgo.

\section{Artefactos de molienda completos}

El conjunto de instrumentos completos en niveles ocupacionales está formado en su totalidad por instrumentos móviles o muebles, dentro de los cuales se encuentran 19 artefactos pasivos o inferiores, 71 artefactos activos o superiores y 34 artefactos de posición indeterminada que se describen en el mismo ANEXO 10. Las piedras de moler incluidas en este grupo ocupan espacios y rasgos diferentes dentro de los recintos que componen el Núcleo 1. Se los halló tanto en la superficie del piso como en las paredes y al interior de los pozos de poste, del terraplén de E5 y en otras cavidades practicadas en la roca de base (Tabla 34, Gráfico 21). Las partes activas de los sistemas de molienda del Núcleo 1 (manos de molino) son los artefactos más abundantes del conjunto, seguidos por los molinos de mano y finalmente los de posición indeterminada (Tabla 35, Gráfico 22). 


\begin{tabular}{ccccccc}
\hline & Piso & Pozos de poste & Cavidades en RB & Paredes/puertas & \multicolumn{2}{c}{ Terraplén } \\
\hline E1 & 3 & 0 & 0 & 0 & 0 & 3 \\
\hline E2 & 2 & 2 & 0 & 2 & 0 & 6 \\
\hline E3 & 6 & 0 & 4 & 2 & 0 & 12 \\
\hline E4 & 2 & 0 & 0 & 0 & 0 & 2 \\
\hline E5 & 14 & 0 & 0 & 3 & 2 & 19 \\
\hline E5p & 1 & 0 & 3 & 0 & 0 & 4 \\
\hline Totales & 28 & 2 & 7 & 7 & 2 & 46 \\
\hline
\end{tabular}

Tabla 33. Cantidades de fragmentos de artefactos con diferentes ubicaciones en el Núcleo 1.

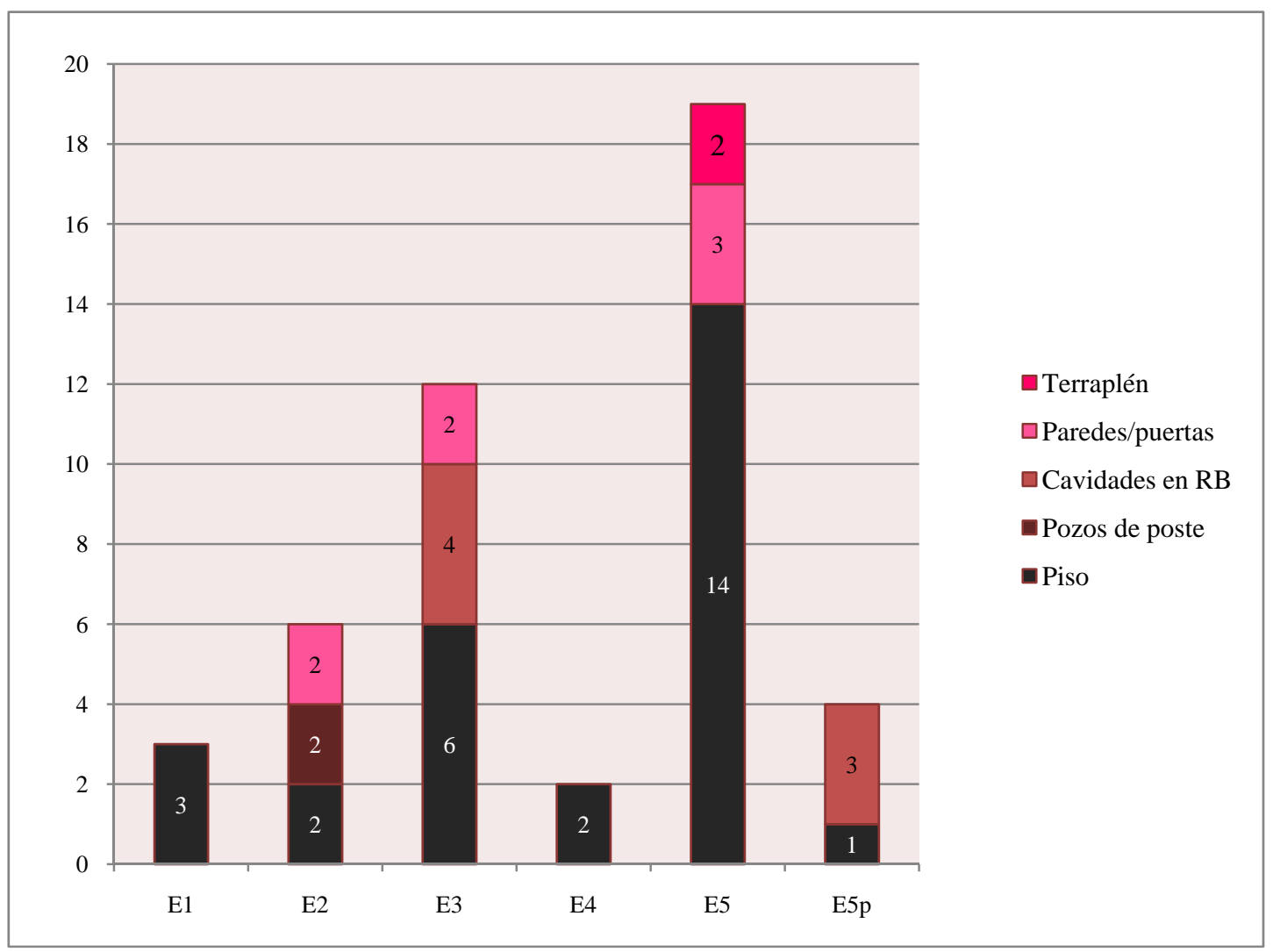

Gráfico 20. Cantidades de fragmentos de artefactos con diferentes ubicaciones en el Núcleo 1.

Tabla 34. Cantidades de artefactos de molienda completos procedentes de diferentes espacios y rasgos en el Núcleo 1

\begin{tabular}{cccccccc}
\hline & Piso & Pozos de poste & Cavidades en RB & Paredes/puertas & Escondrijos & Terraplén & Totales \\
\hline E1 & 14 & 0 & 0 & 2 & 0 & 0 & 16 \\
\hline E2 & 14 & 2 & 0 & 1 & 2 & 0 & 19 \\
\hline E3 & 33 & 0 & 5 & 5 & 0 & 0 & 43 \\
\hline E4 & 1 & 0 & 0 & 0 & 0 & 0 & 1 \\
\hline E5 & 23 & 0 & 0 & 5 & 0 & 1 & 29 \\
\hline E5p & 5 & 0 & 0 & 0 & 0 & 0 & 5 \\
\hline Totales & 90 & 2 & 5 & 13 & 2 & 1 & 113 \\
\hline
\end{tabular}




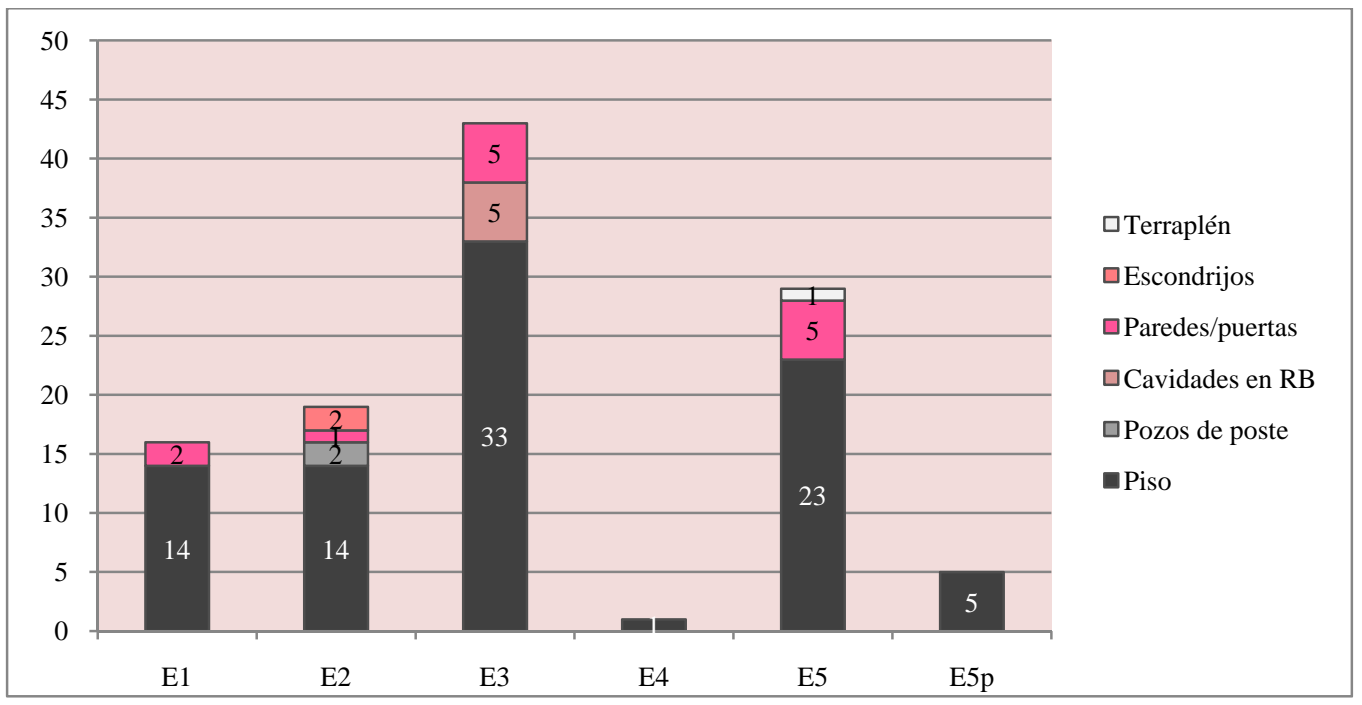

Gráfico 21. Cantidades de artefactos de molienda completos en diferentes ubicaciones del Núcleo 1.

Tabla 35. Cantidades de artefactos de molienda activos (manos de molino), pasivos (molinos de mano, morteros) y de posición indeterminada por estructura.

\begin{tabular}{lccccc}
\hline & Manos de molino & Molinos de mano & Morteros & Art. Mol. Pos. Indet. & Totales \\
\hline E1 & 10 & 3 & 1 & 0 & 14 \\
\hline E2 & 18 & 1 & 0 & 0 & 19 \\
\hline E3 & 16 & 10 & 0 & 17 & 43 \\
\hline E4 & 1 & 0 & 0 & 6 & 7 \\
\hline E5 & 20 & 3 & 1 & 0 & 24 \\
\hline E5p & 6 & 0 & 0 & 23 & 6 \\
\hline Totales & 71 & 17 & 2 & & 113 \\
\hline
\end{tabular}

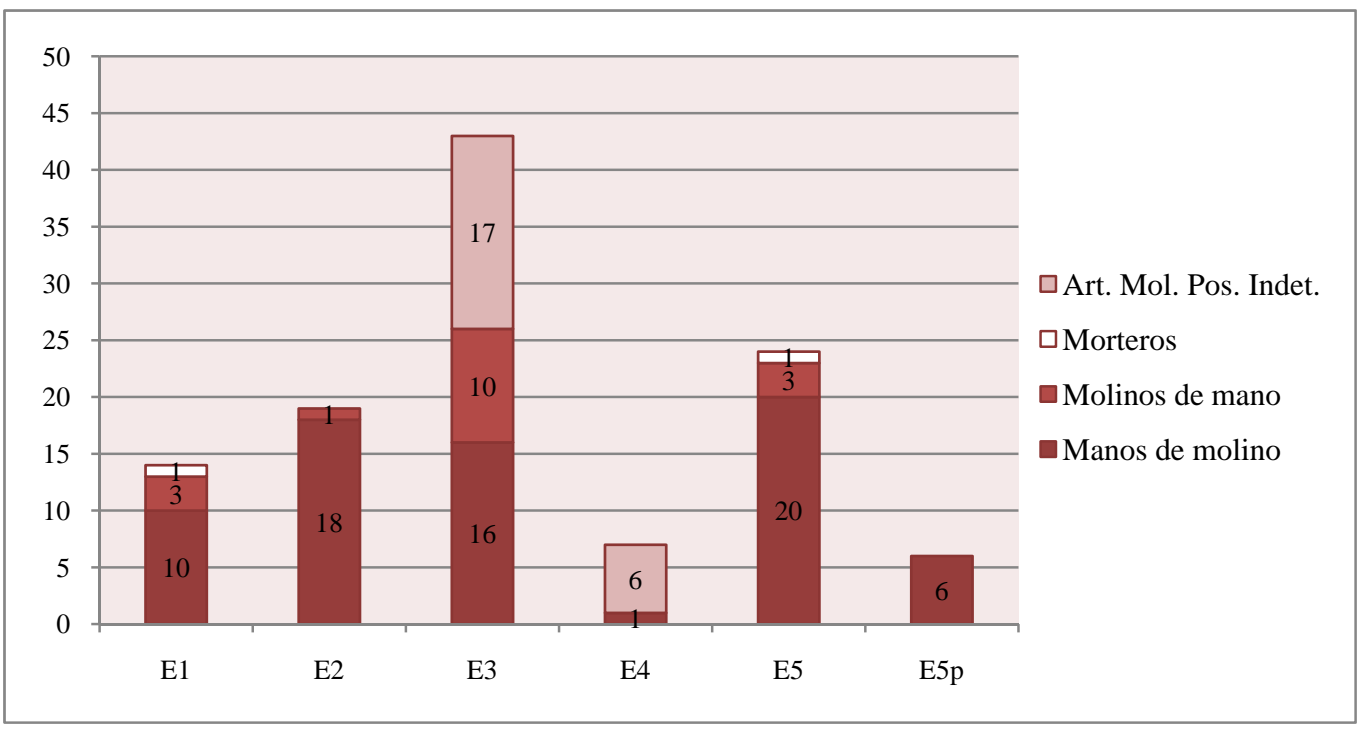

Gráfico 22. Cantidad de artefactos de molienda activos (manos de molino), pasivos (molinos de mano, morteros) y de posición indeterminada por Estructura. 
Molinos de mano y morteros. Los 19 instrumentos pasivos completos comprenden 17 molinos de mano y 2 morteros. Los molinos son más abundantes en E3 que en el resto de las habitaciones. Presentan en general grandes dimensiones, con superficies activas solitarias de tamaño considerable y contornos planos, planos a algo cóncavos y cóncavos, entre estos, varios con alto grado de desgaste y base perforada. Las dimensiones varían entre 19 - $90 \mathrm{~cm}$ de largo por 45 - $14 \mathrm{~cm}$ de ancho y 0 - $23 \mathrm{~cm}$ de profundidad (Figura 34). Los morteros, por el contrario son dos piezas muy pequeñas y de gran similitud entre ambas. El tamaño del ejemplar E1-C8 es de $12 \mathrm{~cm}$ de largo por $11 \mathrm{~cm}$ de ancho y $7 \mathrm{~cm}$ de alto, mientras que el mortero E5-C23 es algo mayor, con 13,5 cm de largo por $12 \mathrm{~cm}$ de ancho y $7 \mathrm{~cm}$ de alto. Las oquedades tienen contorno casi circular y en corte transversal dan lugar a una U algo abierta. La misma alcanza los $4 \mathrm{~cm}$ de profundidad en la pieza mencionada en primer lugar, mientras que en la segunda es de $5 \mathrm{~cm}$ (Figura 35) (ANEXO 11).

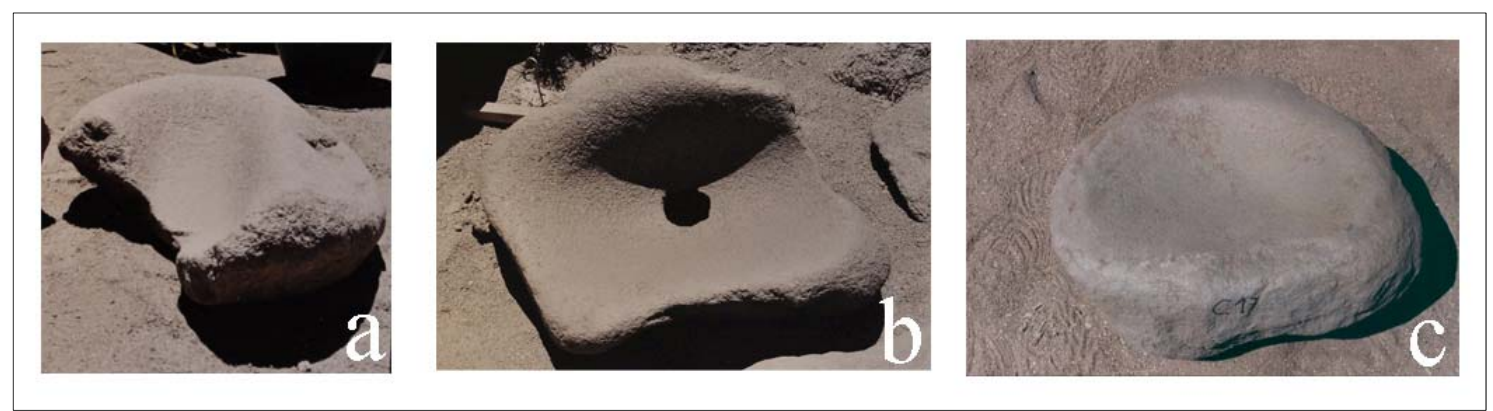

Figura 34. Molinos de mano recuperados en niveles ocupacionales del Núcleo 1: a- E3-C10, b- E3-C8, c-E5-C17.

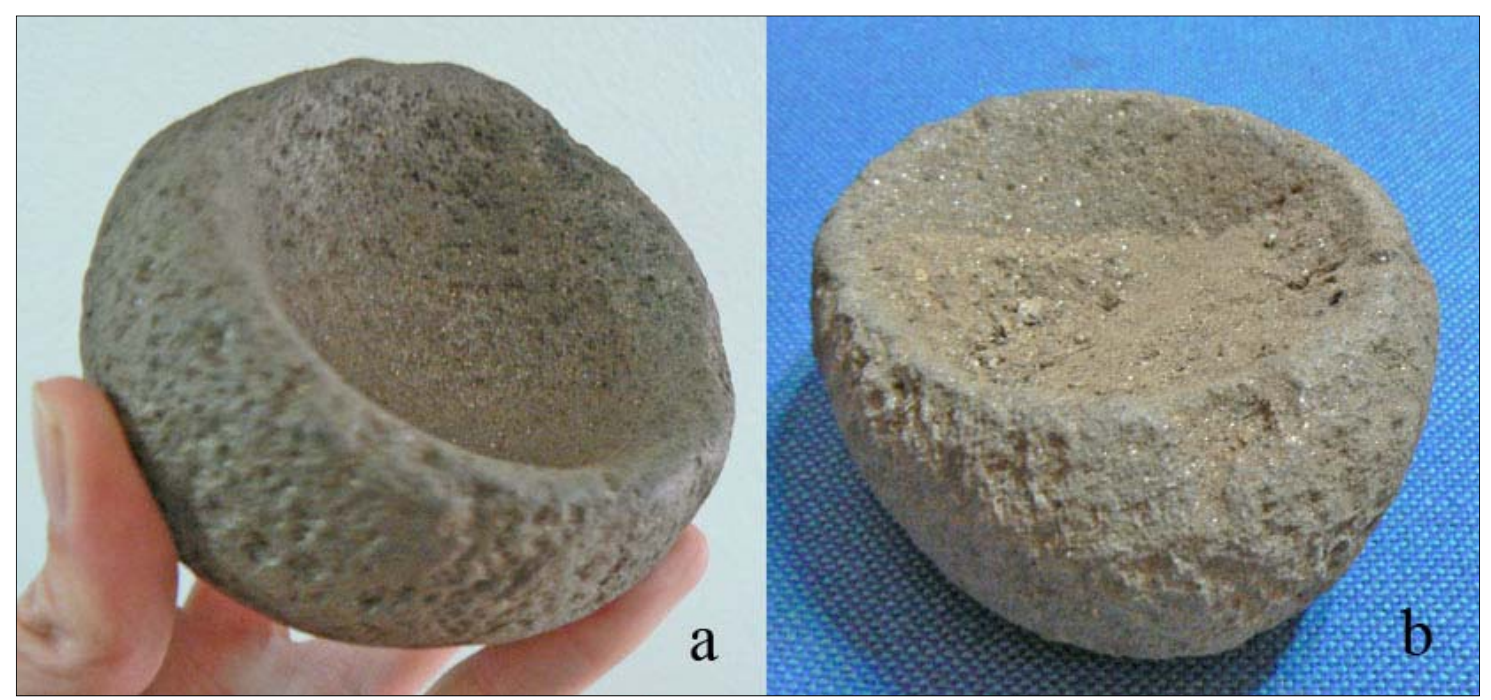

Figura 35. Morteros: a- ejemplar hallado en la E1; b- ejemplar C23 hallado en la E5 con restos de sedimento en el interior de la oquedad. 
Tres de los artefactos inferiores completos fueron empleados en actividades diferentes a la molienda. El molino de mano E3-C20 fue transformado en la jamba de una de las puertas, E5-C17 forma parte del material con el que se rellenó el terraplén, mientras que E2-C3 se halló colocado en la parte superior del muro de E2, tal vez como parte del mismo. En cambio, los instrumentos que estaban siendo utilizados como moledores al momento del abandono del Núcleo 1 (E1-C8, E1-C9, E1-C98, E5-C22, E5-C23) se encontraron acomodados en posición de uso, asegurados con piedras por la base y acompañados de instrumentos activos compatibles. Los más pequeños y por tanto más transportables, estaban asociados a zonas de alta actividad cotidiana y de reunión frecuente tal como pudo observarse en los contextos de fogón excavados en las habitaciones E3 y E5 (Scattolin et al. 2009a, 2009b). A su vez, ninguna de estas piezas en uso presentó grados de desgaste avanzados, como oquedades muy cavadas o perforaciones.

Por el contrario, varios molinos de mano se hallaron en las áreas de tránsito y circulación de E3 (Scattolin 2009a, 2009b). Una de ellas ya inutilizable para la molienda se dispuso invertida contra la pared (E3-C8), mientras que las restantes presentan cavidades poco profundas o superficies activas planas que permanecieron ubicadas hacia arriba, tal como se las emplea en los sistemas de molienda en funcionamiento. Sin embargo estos instrumentos no mostraron asociaciones claras con sus partes activas ni se encuentran emplazados en espacios adecuados para el desarrollo de la actividad. Próximos entre sí y ordenados en el perímetro interno de la pared no sugieren ser producto del descarte primario, sino más bien del resguardo temporal al interior del área habitacional de al menos algunos de ellos (E3-C12, E3-C17, E3-C19).

Los instrumentos de molienda de posición no determinada forman un conjunto de piezas cuyos atributos no permiten asignarlos a ninguna de las categorías anteriores. Se encuentran generalmente sobre los pisos ocupacionales en E3 y E4, ya sea abandonados en uso o descartados, o bien cumplen funciones diversas como piedras de construcción en muros y puertas. También los artefactos de molienda pasivos y activos completos guardan este tipo de emplazamientos. A su vez se los puede encontrar dentro de los pozos de poste (manos de molinos) a modo de cuña, al interior de cavidades cavadas en la roca de base y en escondrijos o “estantes” en huecos dentro de las rocas de las paredes.

Manos de molino. Las manos se encuentran en proporciones altas y semejantes entre sí en los recintos E2, E3 y E5, seguidas por E1. Son piezas de tamaño variable entre 8 - 26 cm de largo por 7-18 cm de ancho y 1,5 - $10 \mathrm{~cm}$ de espesor. Las formas se agruparon en 
discoidales y laminares, mientras que los instrumentos esféricos, aunque estuvieron presentes, fueron raros. Todos ellos corresponden al grupo tipológico manos de molino (sensu Babot 2004), con una o más caras activas ubicadas de manera paralela, subparalela o curva respecto del eje longitudinal de la pieza. Los contornos de las caras activas son de tipo convexo y/o plano, plano a convexo y viceversa. Los tipos de movimiento principalmente aplicados a estos artefactos durante la molienda comprenden presión deslizante, con desplazamientos de vaivén, presión puntual y en algunos casos también percusión (ANEXO 12).

Las manos de molino recuperadas en el Núcleo 1 han tenido usos múltiples. Como moledores se encuentran en cantidades considerables dispersas en los pisos ocupacionales de todas las habitaciones. Algunas de ellas descartadas o bien reservadas hacia los bordes de las paredes (ver ANEXO 5), dentro de cavidades en la roca de base (E3-M45, E3-M46, E3-M49, E3-M52, E3-M59) o en huecos de los muros (E2-M1, E2-M3), otras asociadas espacialmente a instrumentos pasivos de los que fueron complemento (E1-M1006, E1-M1007, E1-M1008, E1-M1009, E5-M80, E5-M81, E5-M83, E5-M139). Otras en cambio han sido empleadas en la construcción de los muros (E3-M42, E3-M62, E3-M63, E3-M65, E5-M8, E5-M9, E5-M10, E5-M131, E5-M160, E5p-M68, E5p-M69), sostén de postes de techo (E2-M61, E2-M62), como soportes por debajo de la base de artefactos pasivos (E1-M1004) (Figura 35).

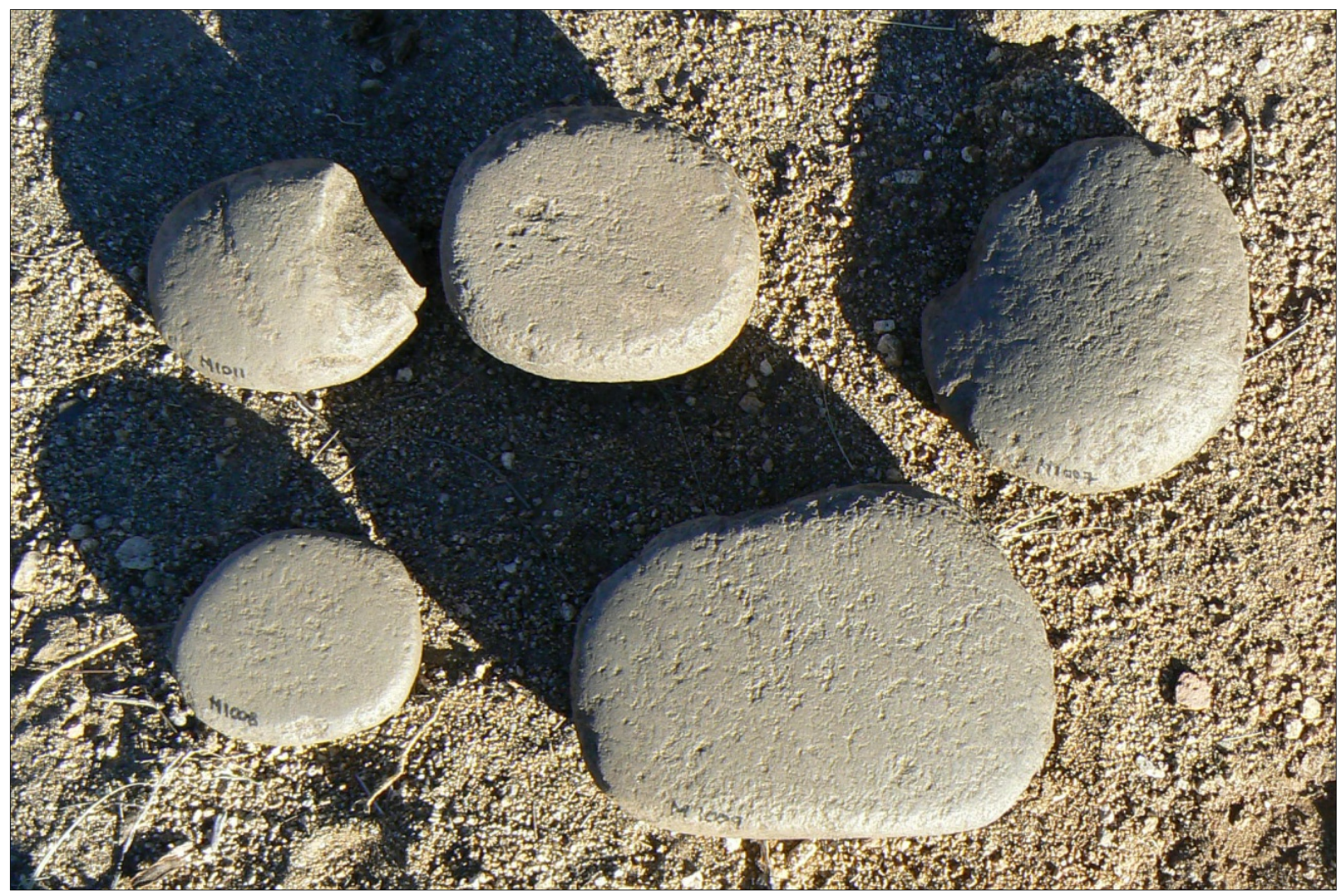

Figura 36. Algunas de las manos de molino recuperadas en el Núcleo 1. 


\section{Caracterización de los conjuntos de molienda de cada Estructura}

De acuerdo a los análisis presentados precedentemente, es posible describir y comparar los conjuntos de artefactos y su distribución en cada una de las Estructuras (LÁMINA 2).

\section{Estructura 1}

El piso de ocupación de la E1 cuenta en total con 19 artefactos de molienda, 5 de ellos en estado fragmentario. Los molinos de mano E1-C9, E1-C98 y el mortero E1-C8 son los tres artefactos pasivos completos en uso al momento del abandono del sitio, junto con el fragmento de molino reutilizado E1-C12. Este último y E1-C98 dan lugar a un espacio de molienda ubicado hacia el fondo de la habitación. A su alrededor se reúnen varias manos de molino (E1-M1006, E1-M1007, E1-M1008, E1-M1009) complementarias. Otras dos manos (E1-M1011 y E1-M1012), fragmentos (E1-M1004) y piedras sostienen por la base y dan estabilidad al molino E1-C98, elevándolo algunos centímetros del piso (Figura 36).

Próximos a la puerta de entrada y al fogón de E1 se hallaron el mortero E1-C8 y el molino E1-C9, remanentes de las actividades de molienda que se desarrollaron en torno al fuego. Este molino se apoyaba sobre E1-C4, otro molino completo aunque totalmente agotado por el uso y perforado en la base. A su lado se halló también la mano de moler E1-M11. Dentro del pozo de poste, empleados a modo de cuñas se encontraron dos fragmentos de piedras de moler (E1-C1, E1-C2). Por último, el material descartado en E1 comprende un fragmento de artefacto (E1-M10) y posiblemente también la mano E1-M13, ubicada en el extremo opuesto a la entrada del recinto y alejada de los sistemas de molienda mencionados antes.

\section{Estructura 2}

En E2 se hallaron 23 artefactos de molienda concentrados principalmente hacia la mitad norte del espacio interno del recinto, de los cuales unos cinco corresponden a fragmentos de diferentes piezas. En general se trata de instrumentos activos dispersos en el piso ocupacional, descartados o resguardados, sin que se hayan observado asociaciones contextuales con artefactos pasivos dentro de E2. De hecho esta habitación presenta un único molino de mano desgastado y perforado en la base que formaba parte del muro (E2-C3) junto 
con otras dos piezas fragmentarias utilizadas para el mismo fin (E2-C1, E2-C2). Dos manos de molino completas (E2-M61, E2-M62) se ubicaron dentro del pozo de poste, a modo de piedras de sostén. Por último, dos pequeñas manos se encontraron cuidadosamente dispuestas juntas en un hueco del muro, como guardadas (E2-M1, E2-M3) (Figura 37).
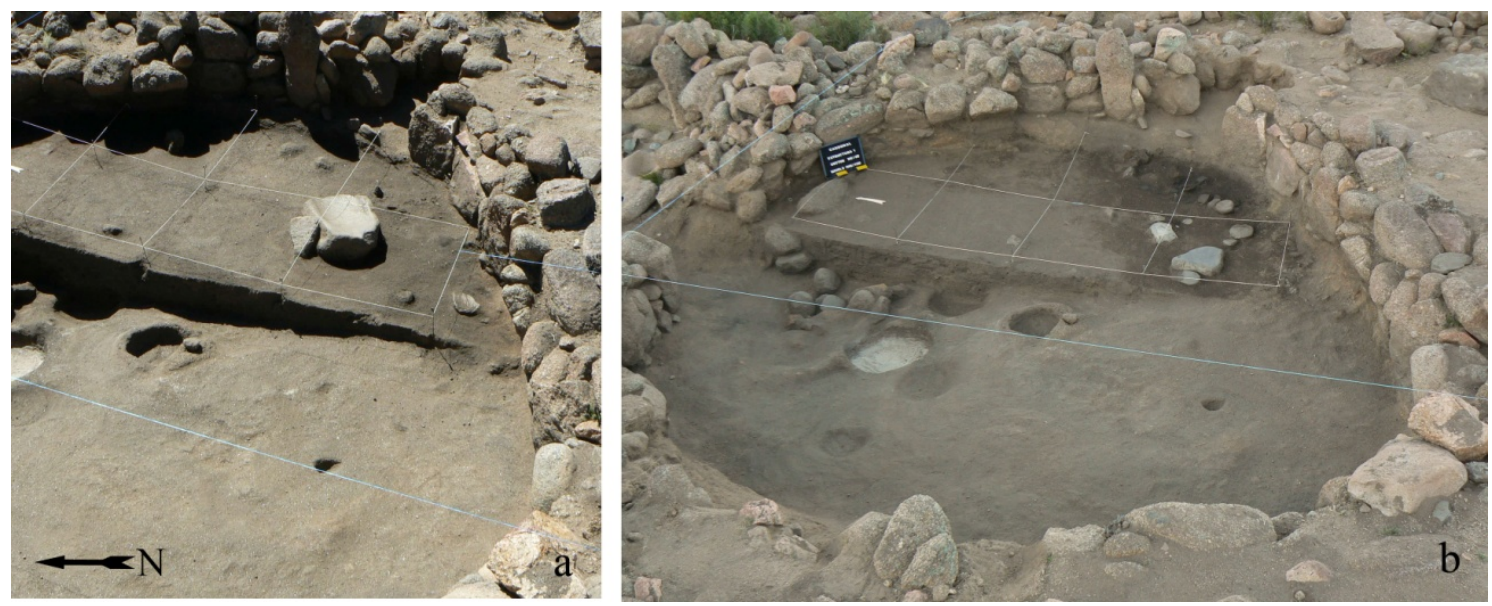

Figura 37. Área de molienda en E1 ubicada hacia la pared Este del recinto; a- ubicación del molino de mano E1C98; b- el nivel por debajo, una vez retirado E1-C98, donde pueden verse las piedras de apoyo del mismo, el molino E1-C12 y las manos de moler asociadas.

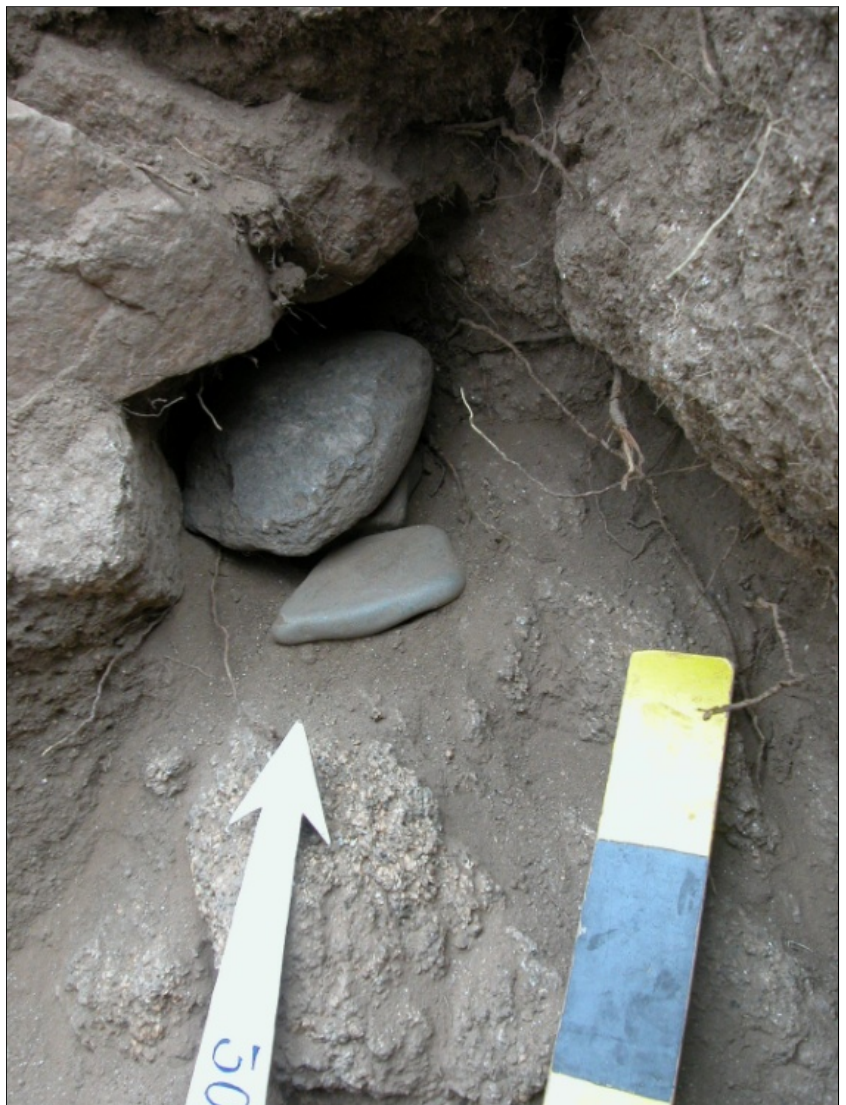

Figura 38. Mano de molino E2-M1 en hueco de pared de E2. Junto a ella un pequeño pulidor. 


\section{Estructura 3}

De este recinto proceden 43 artefactos de molienda completos y 11 fragmentarios. Algunos de estos fragmentos han sido empleados como piedras de muro (E3-C9, E3-M64), aunque la gran mayoría permanecieron como material de descarte en el piso (E3-C6, E3-M20, E3-M29, E1-M33, E1-M55, E1-M57) y dentro de las cavidades practicadas en la roca de base (E3-C18, E3-M48, E3-M54, E3-M58). Entre las piezas completas se cuentan 10 molinos de mano, uno de ellos con la base perforada y empleado finalmente como jamba de la puerta que comunica con E1 (E3-C20) (Figura 38). Los restantes incluyen cuatro artefactos pasivos que se disponen siguiendo la línea de pared unos metros antes de llegar a la puerta que conecta con E1 (C8, C9, C12 y C19), en un rincón al costado de la puerta de entrada a E2 (E3-C15), contra la pared externa de E4 (E3-C17) y finalmente, hacia el centro de la habitación se encuentra E3-C2.

El molino E3-C9 es un instrumento grande y cuadrangular dispuesto a un lado de los escalones que descienden de la puerta E3-E1, apoyado directamente sobre el piso. A su lado se encontró E3-C12, entre una acumulación de rocas de dimensiones reducidas. Menos de un metro de distancia lo separan E3-C19, un molino amplio y poco profundo que se dispuso detrás de un grupo de rocas alineadas sobre el piso. A pesar que junto a este grupo de artefactos inferiores se hallaron varias manos de moler completas (M27, M29, M33, M36, M55), el espacio reducido donde los cuatro sistemas de molienda deberían haber funcionado crea dudas acerca del uso efectivo de los mismos, al menos en esa ubicación. El estado de estas piezas sugiere, en cambio que podrían estar al resguardo o almacenados para su utilización cuando fueran necesarios.

Además de las piedras alineadas y otras rocas sueltas presentes en ese mismo lugar, también allí se encontró el artefacto pasivo de mayor tamaño hallado en la habitación (E3C8), un molino de mano con la base perforada por el uso, recostado en la parte baja del muro en posición invertida. Estas características sugieren que el artefacto se encontraba fuera de uso y fue ubicado allí, junto con los instrumentos referidos para despejar el espacio de circulación de la habitación (ver Scattolin et al. 2009a, 2009b). Algo similar manifiestan las ubicaciones en las que se hallaron los molinos E3-C15 y E3-C17 (Figura 39)

Finalmente, sobre el sector central del piso ocupacional de la E3, se halló un molino de mano de grandes dimensiones completo aunque partido a la mitad (E3-C2). La disposición próxima y simétrica de ambos fragmentos parece indicar que este artefacto recibió un impacto fuerte durante o luego del abandono del sitio, en tanto ninguna porción fue retirada ni 
movilizada. Las dos manos de moler más próximas son M42 y M17 aunque la mayoría de ellas, junto con los artefactos de molienda de posición indeterminada abundan en diferentes sectores de la habitación, especialmente contra las paredes, formando parte de ellas o dentro de las cavidades practicadas en la roca de base de E3.

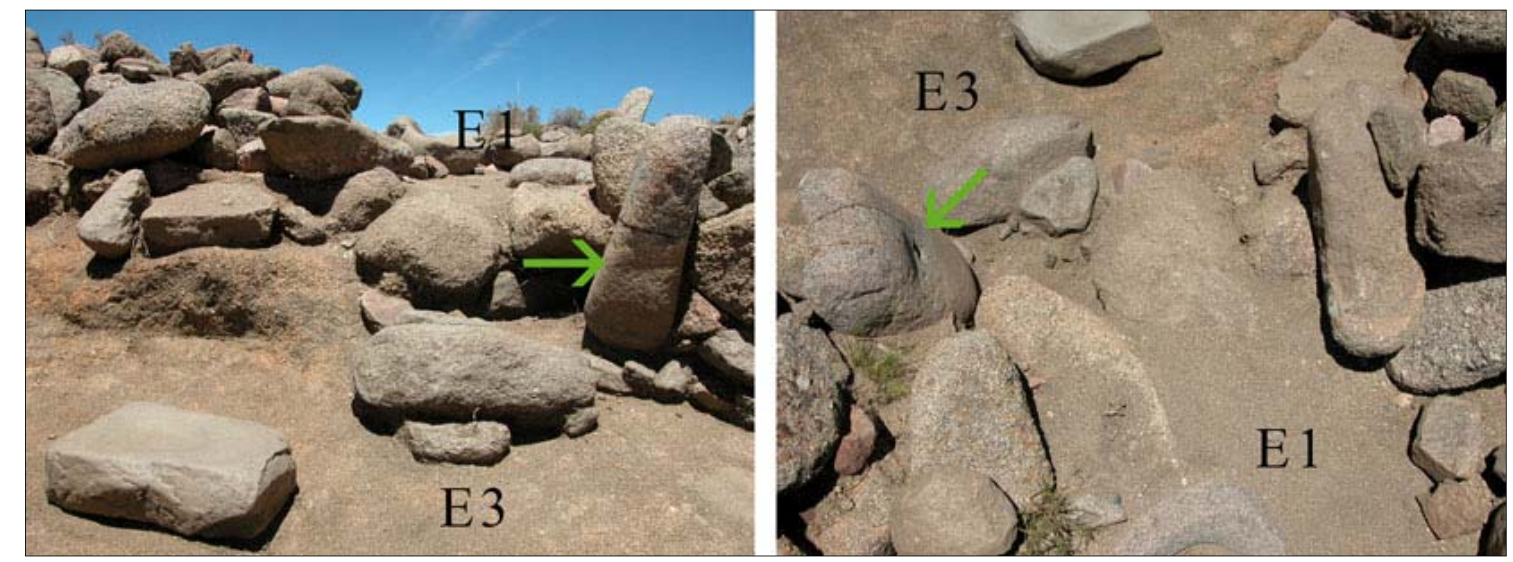

Figura 39. Vista lateral y superior de la posición del molino de mano (indicado con la flecha verde) utilizado a modo de jamba en la abertura que comunica E3 con E1.

\section{Estructura 4}

Al igual que E2, este recinto sólo presenta artefactos activos en el piso ocupacional (M7, M8, M9). Los tres corresponden a manos de molino de las cuales sólo uno se halló completa (M9).

\section{Estructura 5}

Los artefactos completos y fragmentos suman 48 piezas depositadas durante la ocupación en E5. El material fragmentario descartado contra el perímetro de la pared del terraplén en los pisos, también ha sido en parte reutilizado como piedras del muro del terraplén (E5-C3, E5-M11, E5-M134, E5-M136, E5-M159); otras han sido introducidas entre los materiales del relleno del mismo rasgo (E5-M13, E5-M14). El grupo de instrumentos completos incluye 4 artefactos de posición indeterminada (E5-M114, E5-M115, E5-M160, E5-M161), 3 molinos de mano, un pequeño mortero y 21 manos de molino. Uno de los molinos apareció solitario contra la pared del terraplén (E5-C19), posiblemente descartado y otro fue hallado entre los materiales con que se rellenó dicho rasgo (E5-C17). El pequeño molino de mano restante (E5-C22) y el mortero (E5-C23) similar al hallado en E1 proceden del área de fogón de E5 y se encuentran muy próximos entre sí, asociados a otros materiales 
en uso como ollas de cocina, restos óseos de camélidos, restos vegetales producto de la intensa actividad ocurrida en torno al fuego de la habitación. Las piezas que por su tamaño y forma podrían corresponder a manos de molino complementarias situadas en el mismo espacio son E5-M139, E5-M142 y E5-M144. Las demás manos de molino completas se concentran en el área que bordea el terraplén, varias de ellas utilizadas a modo de cuña de las piedras de la base de la pared, al igual que el material fragmentario.

El único pilón (E5-M162) del conjunto fue hallado hacia el oeste del fogón, por debajo de un área donde se retiraron varias piedras derrumbadas de la pared. Por este motivo no fue incluido en el grupo de piezas de molienda del piso ocupacional, aunque su afinidad con el pequeño mortero de E5 (e inclusive del morterito de E1) se evidencia en el tamaño y complementariedad de formas de ambos artefactos (Figura 40). Otros instrumentos notables hallados en áreas de derrumbe y que podrían corresponder a material de descarte de la ocupación de E5 se ubicaron hacia el sureste de la habitación. Allí apareció un gran molino de mano (E5-C11) con la base perforada y en posición invertida. Uno de sus extremos se apoya contra el muro, de forma muy similar al artefacto descripto en E3. A su lado se encontró otro molino de grandes dimensiones con la superficie de molienda u oquedad sumamente desgastada y profundizada (E5-C4) que se dispone por debajo de varias rocas y sedimento suelto del relleno (Figura 41).

\section{Portal}

$\mathrm{Al}$ igual que en E2 y E4, ningún artefacto de molienda pasivo fue hallado en el piso que corresponde al Portal, en el acceso al Núcleo 1. Sí, en cambio, se encontraron 6 manos de molino completas y 1 artefacto de molienda de posición indeterminada (E5p-M66) descartados contra el muro que separa el Portal del resto del recinto E5 (E5p-M67, E5p-M82, E5p-M120, E5p-M153) y formando parte de la misma pared (E5p-M56, E5p-M69). El material fragmentario corresponde a cuatro piezas, tres de las cuales se ubicaron dentro de la cavidad practicada a un lado de la abertura que da a E5 (E5-M156, E5-M157, E5-M158) (Figura 42). 

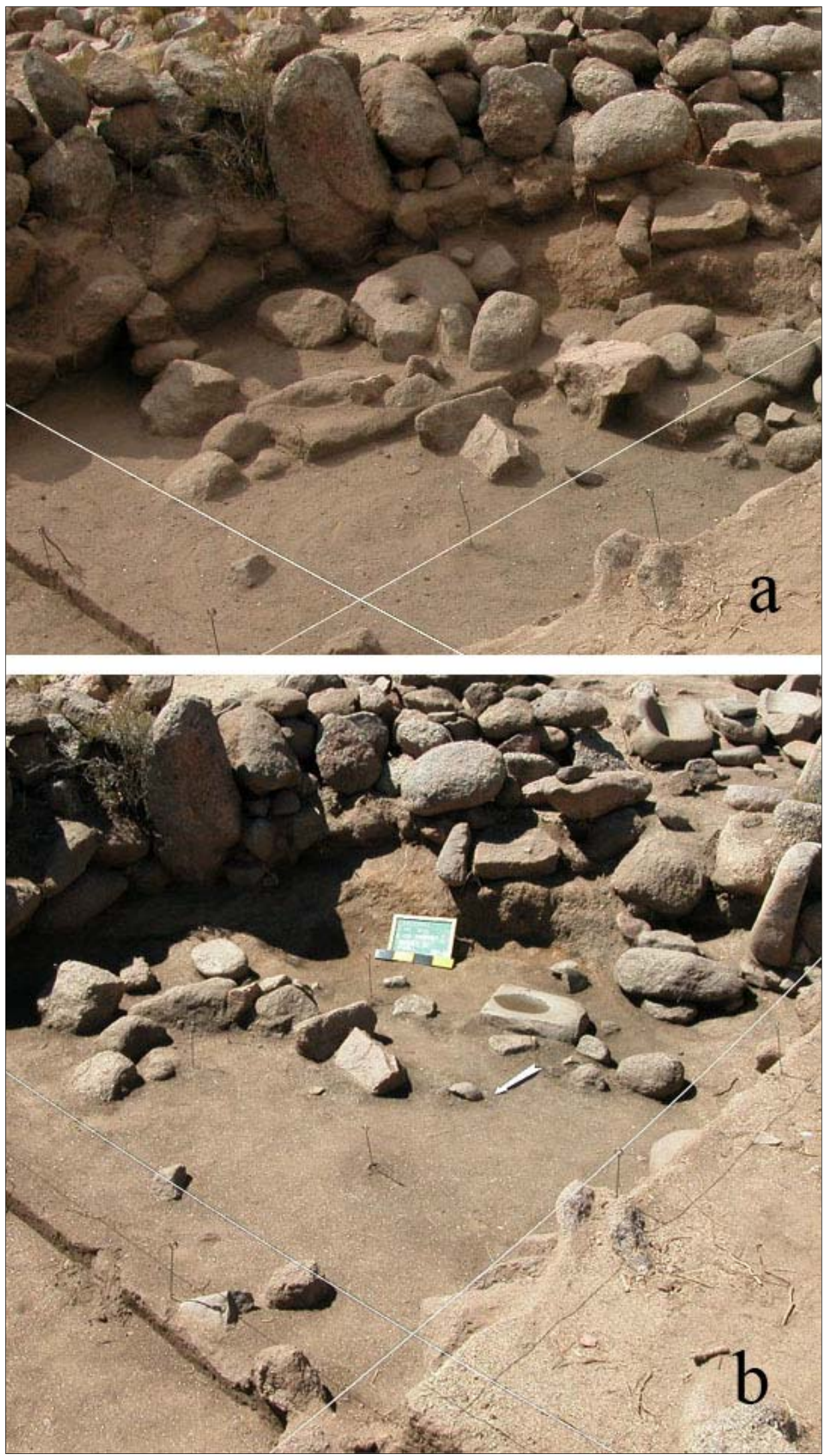

Figura 40. Molinos de mano en E3; a- molino E3-C8 contra el muro Este del recinto; b- directamente apoyados sobre la roca de base los molinos E3-C19 y E3-C9 (de izquierda a derecha). 


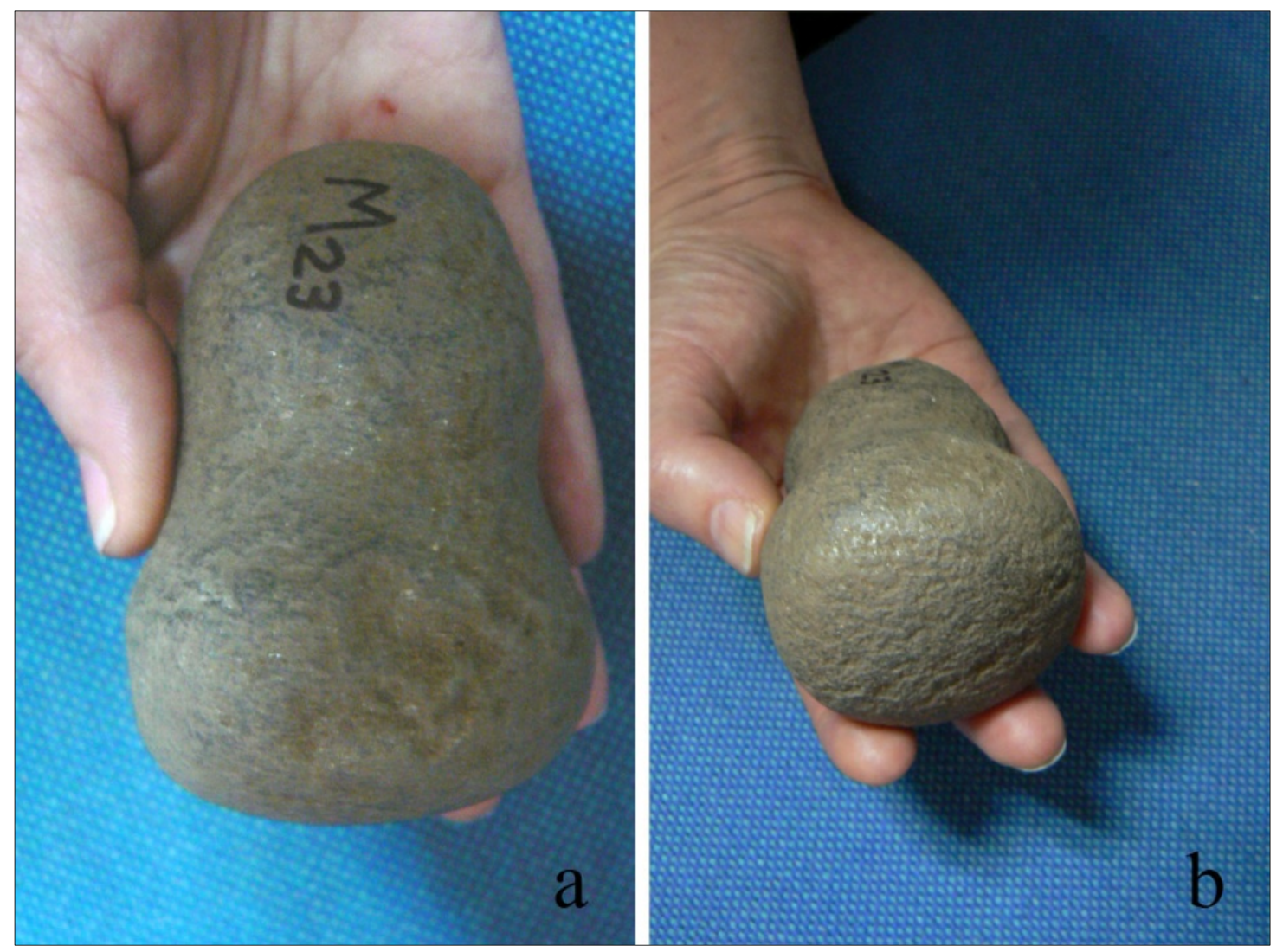

Figura 41. Mano de mortero o pilón E5-M23 recuperado en E5.

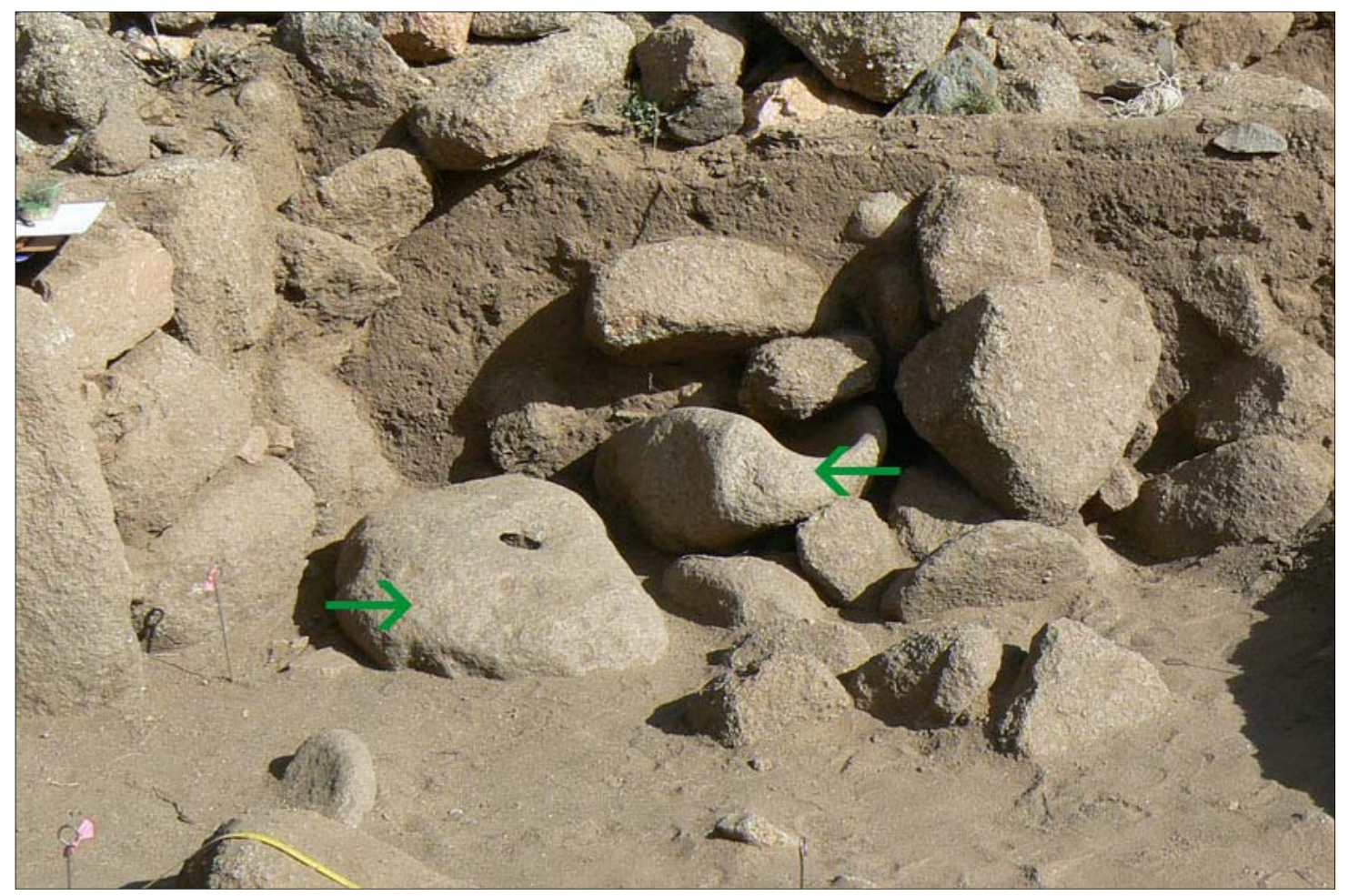

Figura 42. Molinos de mano E1-C11, en posición invertida y con perforación en la base, y E1-C4 excavados en E5. 


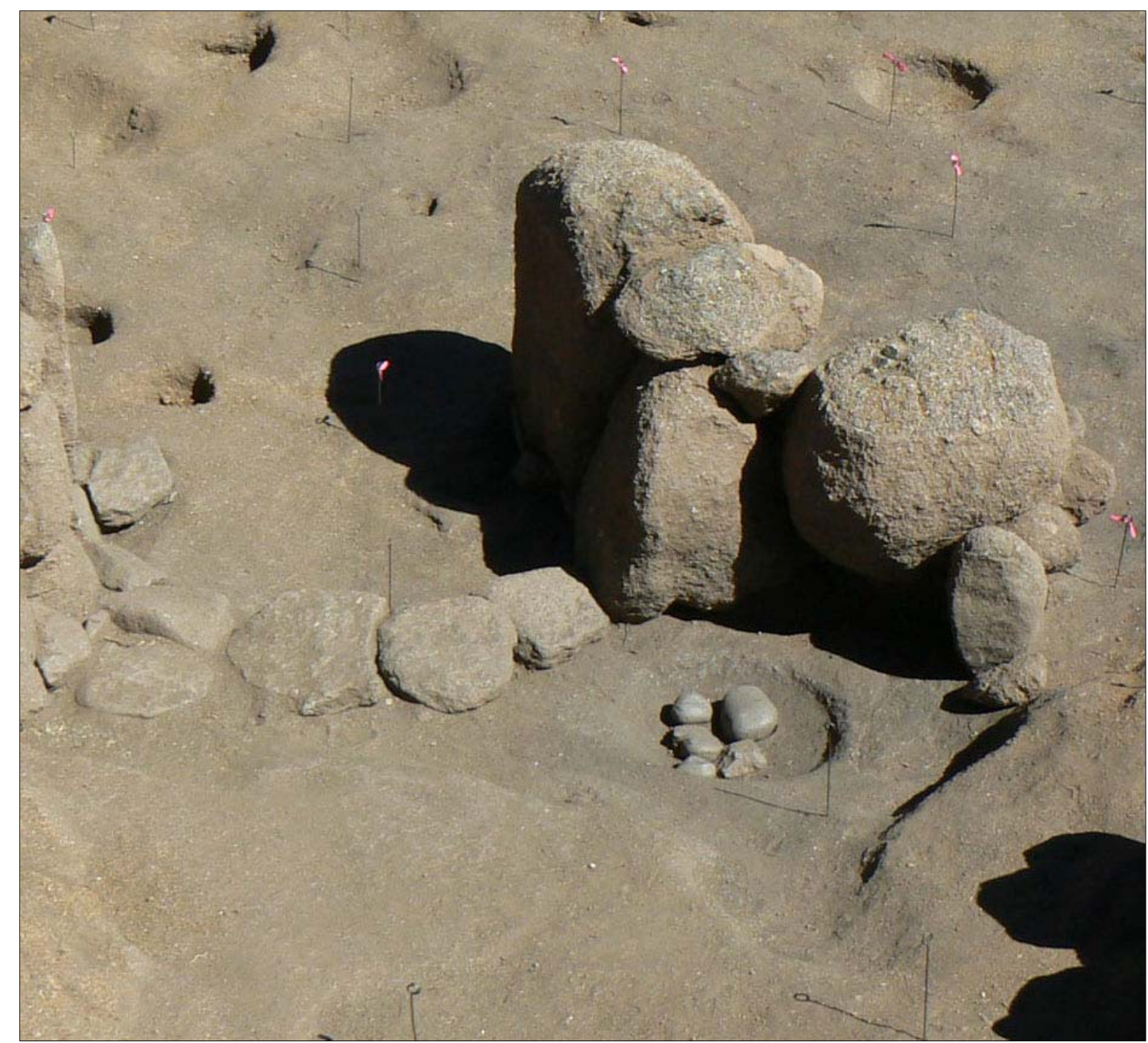

Figura 43. Pozo cavado en la roca de base del Portal de E5, a un lado de la entrada.

\section{Las áreas de molienda en el Núcleo 1 y otros fines útiles de las piedras de moler}

La presencia de artefactos pasivos conservados completos y asociados espacialmente a una o más manos de moler sugiere la ocurrencia de actividades de molienda en dos de las habitaciones del Núcleo 1. A diferencia de los demás instrumentos registrados, estos sistemas de molienda se disponen en tres áreas circunscriptas de los recintos E1 y E5. Conjuntos similares de piezas, formados por un pequeño mortero, un molino de mano de tamaño mediano y manos de moler, ocupan sectores muy próximos a los fogones domésticos presentes en una y otra estructura. A su vez, una tercera área de molienda se ubica hacia el fondo de E1, formada por un gran molino de mano sostenido y asegurado por la base con piedras, artefactos de moler fragmentarios y activos completos, junto al molino varias manos de molino que completan el sistema (ver Figura 36). Tanto una como otra habitación cuentan con evidencias que apoyan la ocurrencia de diferentes actividades relacionadas con el procesamiento de alimentos a las cuales puede sumarse la molienda de diversos productos. En 
primer lugar los dos únicos recintos que cuentan con fogones de tamaños considerables y abundante carbón de madera mezclado con restos de plantas comestibles y huesos de camélidos (Scattolin 2009 a, 2009 b). Asimismo se hallaron aquí ollas ordinarias destinadas a la cocción y cubiertas de tizne, el cual impregna el piso y cubre las paredes de todo el recinto E1 identificado como una “cocina”, y parte del "patio” E5.

Configuraciones tales de artefactos de molienda y otros materiales están ausentes en E2, E3, E4 y el Portal de E5 (Scattolin et al. op. cit.). A pesar de que varios de los instrumentos pasivos recuperados en E3 no presentan signos de agotamiento, los mismos se disponen en posiciones en las cuales difícilmente podrían haber sido utilizados, próximos o contra el perímetro interno de los muros, agrupados con poco espacio entre sí y rodeados de fragmentos de artefactos de molienda, molinos descartados, manos y piedras. Emplazados de tal modo, es muy probable que estos instrumentos no estuvieran en uso al momento del abandono del Núcleo 1, aunque tal situación no represente necesariamente el descarte de los mismos. Aunque de tamaños considerables, se trata de artefactos muebles que podrían reubicarse y ponerse en uso eventualmente y en circunstancias determinadas. En este sentido los molinos de mano de E3 habrían formado parte de un conjunto de instrumentos disponibles oportunamente para la molienda y resguardados en lugares donde no obstaculizaran la intensa circulación a la que estaría expuesto el "pasillo” del Núcleo 1 (Scattolin 2009 a, Scattolin 2009 b).

Tal puede ser el caso también de varias de las manos de moler agrupadas en el piso de E2 o las pocas presentes en E4, en donde se hallaron también otros indicios de almacenamiento y guardado de diferentes materiales, como grandes ollas y jarrones cerámicos, cestería, instrumentos de hueso, las dimensiones mismas de estos recintos y la presencia techados completos, así como también la ausencia de fogones permanentes (Scattolin 2009 a, Scattolin 2009 b). Por el contrario, otros artefactos como los molinos de mano agotados, con la base perforada y/o ubicados en posición invertida, así como todo el material de molienda fragmentario y algunas de las manos dispersas en los pisos corresponden a piezas efectivamente fuera de uso y descartadas al menos para las actividades de molienda. Una buena cantidad de instrumentos completos o fragmentos de ellos fueron empleados ya no para moler diferentes sustancias sino con fines más diversos, como sostén de palos de poste, piedras de muro, cuñas y rellenos en cada una de las habitaciones del Núcleo 1 (Figura 43). Sólo un artefacto pasivo hallado en E1 presentó signos de haber sido reutilizado para acciones de molido luego de la fractura del molino de mano de tamaño mayor que le dio origen. Junto con él podrían también contarse las manos y molinos desbastados que fueron integrados a 
otros sistemas como sostén de las bases de grandes artefactos inferiores.
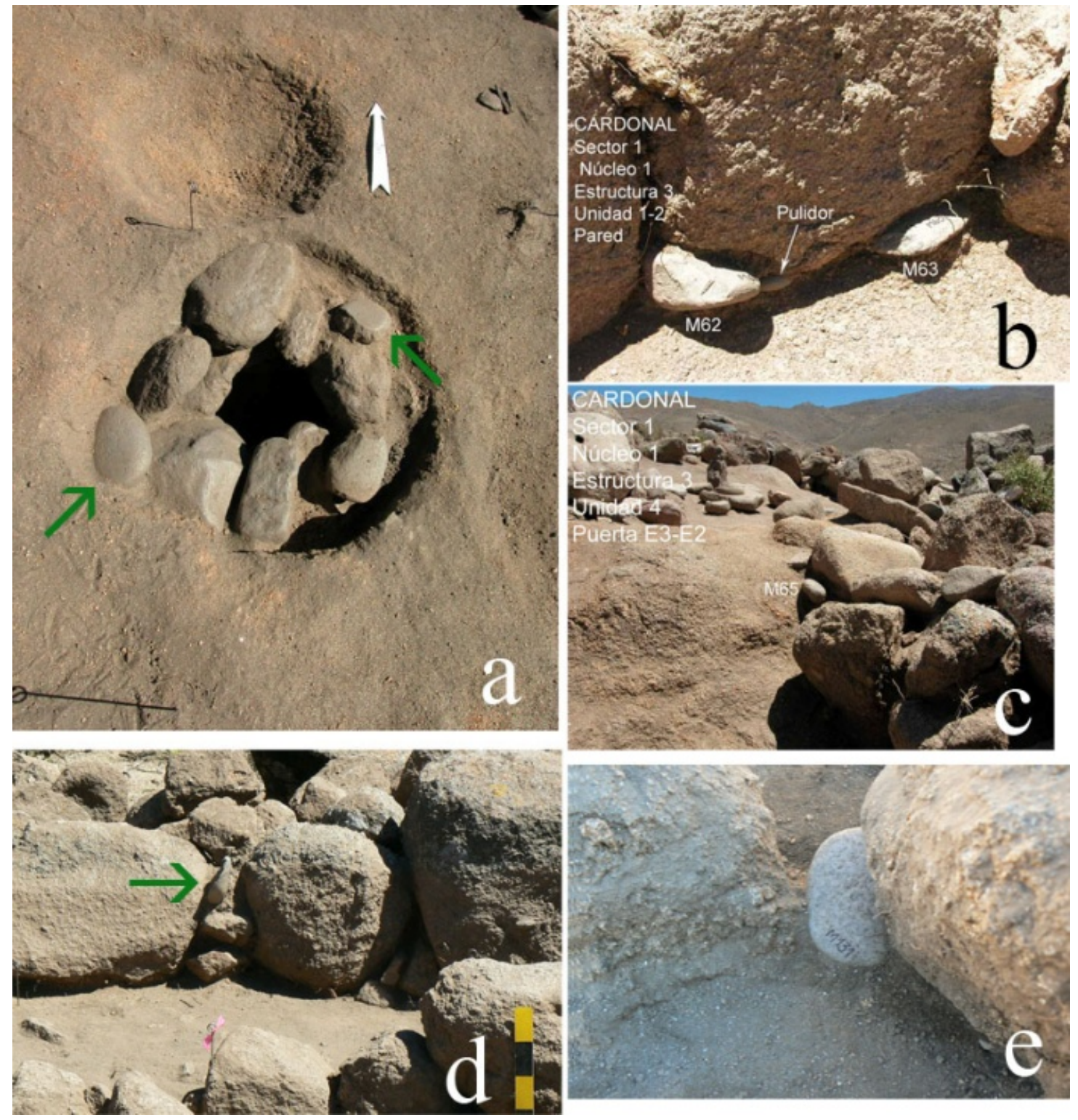

Figura 44 a- manos de molino en pozo de poste de la E2; b- y c- a modo de cuña en los muros de la E3; d- y e- a modo de cuña en el muro externo y terraplén de la E5, respectivamente. 


\section{CAPÍTULO 7}

\section{Apuntes para una discusión del espacio doméstico del Núcleo 1}

\section{Los restos botánicos}

\section{La presencia de restos botánicos carbonizados en el Núcleo 1}

¿Cómo asignar los restos de plantas analizados al contexto de las acciones que tuvieron lugar en el pasado del Núcleo 1? Tal como ocurre con la mayoría de los artefactos arqueológicos, en dicha asociación es pertinente considerar una serie de procesos de orden cultural y natural que afectan la depositación de los vestigios (Schiffer 1972, 1983). En primera instancia, es posible preguntarse acerca del modo en que los restos arqueobotánicos estudiados en este trabajo ingresaron y se preservaron en el sitio. Es decir, si puede interpretárselos en relación a un conjunto de actividades humanas o bien si son el resultado de diferentes procesos de orden natural.

En Cardonal se ha dado con varios indicadores de la alta correspondencia de los restos carbonizados de frutos y semillas con la ocupación del sitio. En primer lugar se hace mención en este apartado que el examen de las muestras off-site tomadas para el control de datos resultó en cantidades prácticamente nulas de carbones. Por otra parte, de acuerdo a los materiales analizados hasta el momento, es muy poco probable que los restos vegetales recuperados en el sitio correspondan a inclusiones fortuitas de material, ocurridas en momentos posteriores a su abandono. Por un lado se trata de material orgánico carbonizado depositado a $1 \mathrm{~m}$ de profundidad, dentro de recintos en los que no se ha detectado ninguna señal de incendios naturales o intencionales que pudiera eventualmente producirlos en el pasado (ver Keepax 1977, Miksicek 1987, Miller 1989, Minnis 1981). Por el contrario, se han hallado allí mismo variadas manifestaciones de actividades de combustión individuales y culturalmente pautadas, como marcas de fogones, restos óseos con alteraciones térmicas, masas de barro semicocido y hollín adherido a muros y bases de ollas (Scattolin et al. 2007a, 2007b, 2009a, 2009b). Más aún, la asociación espacial de porcentajes proporcionalmente altos de restos vegetales quemados a las estructuras de fogón sugiere la existencia de prácticas sociales vinculantes, así como la concomitante coetaneidad de los frutos y semillas con la 
ocupación del núcleo.

De manera general se conoce también que existen muy raros casos arqueológicos en que material vegetal acarreado por procesos naturales se ha carbonizado accidentalmente en fogones u hornos. Del mismo modo, el material moderno ya carbonizado tiene escasas chances de ingresar al sitio por la acción de acarreo de los pájaros, roedores o insectos, ya que carece de valor alimenticio (Minnis 1981, Miller 1989). En este sentido, los procesos concernientes a la carbonización proporcionan en Cardonal un camino claro para establecer asociaciones entre los restos botánicos y los contextos arqueológicos estudiados.

A su vez, la carbonización es el mecanismo de transformación fisicoquímica ${ }^{1}$ que ha colaborado en mayor medida en la conservación del material vegetal dentro del núcleo excavado. Una vez quemados, los restos orgánicos presentan una barrera ineludible a la acción destructiva de los hongos y bacterias presentes normalmente en los suelos de ambientes semiáridos (Miller 1989) como en los que se emplaza Cardonal. Además, es este mismo proceso el responsable de las modificaciones sufridas en grado variable por la morfología de los restos, la composición de los conjuntos arqueobotánicos y la conservación diferencial de los componentes de una misma planta (Boardman y Jones 1990, Braadbaart y Wright 2007, Hubbard y al Azm 1990, Johannessen et al. 1990, Kislev y Rosenzweig 1991, Märkle y Rösch 2008, Renfrew 1973, Stewart y Robertson 1971).

Es así que la distorsión de los caracteres morfológicos cuantitativos y cualitativos producidos por la carbonización se ha observado en la mayor parte de los restos examinados. En algunos casos esta acción dificultó en gran medida la determinación de los ejemplares, tal como se expone en las observaciones realizadas al respecto, por ejemplo, para las cúpulas de maíz. En otros casos ha reducido las posibilidades de efectuar determinaciones que accedan a niveles taxonómicos como la especie o la variedad a través de los procedimientos empleados, como es el caso de las semillas de Chenopodium y Solanoideae. Es posible que técnicas histológicas más afinadas u otras aplicables al estudio de la morfología de estos restos, así como el análisis experimental sobre los efectos de la carbonización, permitan ir más allá en la identificación que la alcanzada en este trabajo para algunos ejemplares. A los fines de este estudio, la distinción entre diferentes partes de plantas de reconocido uso comestible permite

\footnotetext{
${ }^{1}$ Sometidos a la acción del fuego, los restos vegetales se transforman física y químicamente en carbón, mientras su estructura originaria se conserva casi sin cambios. La carbonización ocurre de manera gradual y resulta completa a temperaturas entre los $200^{\circ} \mathrm{C}$ y $500^{\circ} \mathrm{C}$ en condiciones anaeróbicas. Las temperaturas superiores y la presencia de oxígeno reduce los restos orgánicos a cenizas (Meyer 1980). La transformación del material vegetal en carbón ocurre en tres estadios: ablandamiento, tostado y finalmente carbonizado, en el cual la mayor parte, aunque no toda la estructura, se convierte en carbón. Por esta razón, el material final que compone los restos carbonizados de frutos y semillas no es carbón elemental sino que se asemeja al carbón de madera, cuya composición química no se conoce aún con precisión (Kislev y Ronsenzweig 1991; ver también Märkle y Rösch 2008).
} 
avanzar algún grado en la composición del conjunto, de manera que admita indagar en las particularidades de su distribución e interpretación en el contexto de las acciones pasadas.

Respecto del modo en que la carbonización afecta los conjuntos de restos botánicos, se han realizado ya algunas observaciones. En particular se ha señalado que los restos recuperados de manera sistemática y por flotación en sitios formativos de tipo abierto del área Valliserrana son generalmente escasos (Oliszewski 2004, 2005, Rossen 1998b). De acuerdo con los parámetros referidos por ambos autores en los sitios de Campo del Pucará y Yutopián respectivamente, el Núcleo 1 de Cardonal manifiesta valores aún menores en la cantidad total de restos carpológicos. En alguna medida, tal diferencia parece no estar ligada al tratamiento de las muestras de sedimento, puesto que el test de confiabilidad aplicado a los sistemas de flotación empleados indica una tasa de recuperación promedio bastante alta (93\%), equivalente a la obtenida por Oliszewski $(2003,2004)$ para la máquina de flotación utilizada en Campo del Pucará (90,2\%). Por último, aunque no se tienen datos experimentales de la cubeta empleada en Yutopián, la estructura de este sistema de flotación es análoga al que se puso en funcionamiento en Cardonal.

De acuerdo a lo anterior, resulta de importancia considerar otras variables capaces de introducir tal diferencia en las cantidades absolutas de restos recuperados en estos sitios. Más allá de procesos ecológicos y tafonómicos particulares de la formación de los diferentes contextos implicados cabe considerar, como parte de las diferencias observadas, que muestras de sedimento de tamaño similar (6 litros) proceden de contextos alternos en cada uno de los sitios. En Campo del Pucará se tomaron muestras en varios montículos que habrían funcionado como depósitos de basura (Oliszewski 2004, 2005), en tanto que en Yutopián el material procede de áreas de habitación similares a las de Cardonal. Este último muestreo, sin embargo, no tiene por objeto cubrir el área de los recintos excavados, sino que se basa en la toma de diferentes cantidades de muestras en sectores específicos de cada una de las estructuras, correspondientes incluso a núcleos habitacionales distintos (Meldem 1996, Rossen 1998a, 1998b). Finalmente, a las disparidades referidas a los tipos de contextos estudiados y el modus operandi de la toma de muestras para flotación, se suma la variación que muy probablemente introduce el número total de muestras consideradas. Sin duda, una parte importante de los restos vegetales presentes en los depósitos del Núcleo 1 se hallaron entre los pisos repletos de carbón que distinguen a E1 de los recintos restantes, y que fueran excavados previamente a este estudio. Los informes señalan que de allí proceden varios restos hallados in situ de porotos y chañar (Gero 2004), en tanto no se han reportado aún resultados obtenidos de las muestras de flotación tomadas en aquella oportunidad. 
Tanto así como la cantidad de restos, el proceso de carbonización también afecta la composición de los conjuntos de vestigios arqueobotánicos. En este sentido, los trabajos basados en el análisis de microrrestos vegetales de sitios del área han logrado dar cuenta del rango de plantas y partes de plantas desintegrados por el contacto con el fuego u otros mecanismos que intervinieron en la composición final de los conjuntos de macrorrestos (Babot 2004, 2008, Korstanje 2005). Entre ellos se cuentan, por ejemplo los tubérculos y raíces de diversas plantas andinas de reconocido uso actual y pasado en el Noroeste argentino, aunque ausentes en el registro de restos macroscópicos carbonizados. La causa de su “invisibilización” reside muy probablemente en la presencia de estructuras biológicas con un alto contenido de agua, las que derivan en restos menos resistentes a varios factores naturales y culturales, si se los compara con las semillas y algunos frutos (Gustaffson 2000, Munson et al. 1971, Wilson 1984).

Además de los citados estudios experimentales, que evalúan las variaciones del efecto de la carbonización en función de las características naturales de los restos vegetales, otros trabajos exploran el modo en que algunas prácticas culinarias u otras actividades afectan el estado final de preservación de los restos. Es decir de qué manera se comportan, frente a la exposición al fuego, aquellos restos que han sido previamente procesados, así como el grado en que estos procedimientos modifican sus probabilidades de ingresar a los fogones (Hubbard y al Azm 1990, Gasser y Adams 1981, Munson et al. 1971, Capparelli en prensa).

El mismo estudio de Munson et al. (1971) sugiere que aquellos frutos y semillas que poseen una parte no comestible y de alta densidad, como por ejemplo los marlos de maíz, tienen más posibilidades de entrar en contacto con el fuego que otro tipo de vegetales, ya que también pueden ser utilizados como combustible. En el caso de Cardonal, las cúpulas de maíz recuperados en los fogones pueden interpretarse como consecuencia del uso sistemático o eventual de los deshechos de la mazorca como leña. Como contraparte, los frutos y semillas comestibles como los granos de maíz, las semillas de Chenopodium y los cotiledones de porotos suceden a un accionar diferente, como caídas accidentales durante el proceso de cocción o como material descartado directamente en el fogón.

Por otra parte, el uso de las partes carnosas de frutos como las vainas de algarrobo y el chañar puede inferirse a partir de las partes desechadas, como las semillas y endocarpos hallados en el Núcleo 1. En relación a los procesamientos, Munson et al. (1971) previenen también acerca de las interpretaciones realizadas en relación a la ausencia o subrepresentación de ciertos taxones potencialmente utilizados en un sitio arqueológico. Aquí nuevamente los tubérculos o algunas verduras podrían consumirse frescos o hervidos, por tanto sus 
posibilidades de entrar en contacto con el fuego se ven reducidas respecto de aquellos recursos que se prefieren tostados o asados, y que caen al fuego con mayor frecuencia.

En términos de la representación o subrepresentación de algunos taxones en Cardonal, llama la atención en primer lugar, la escasez de granos de maíz respecto de la cantidad de cúpulas recuperadas, aunque es posible que todas ellas formaran parte de un único marlo desgranado que se arrojó al fuego. Asimismo resulta sugerente la presencia equivalente de porotos silvestres y domésticos, o las varias semillas de Chenopodium respecto de los pocos hallazgos efectuados hasta ahora en sitios a cielo abierto de los valles y sierras. De todas maneras, en los casos mencionados, así como para el resto de los taxones presentes, el limitado número de especímenes por cada grupo admite básicamente comparaciones con fines descriptivos del conjunto, que se presentan en el Capítulo 5 de este trabajo de tesis.

\section{Las plantas depositadas por procesos culturales en Núcleo 1}

Tal como se expresa en los párrafos anteriores, las plantas representadas en el conjunto de restos carbonizados de Cardonal han ingresado al núcleo habitacional fundamentalmente a través de diferentes acciones de orden cultural. A su vez, su preservación entre los sedimentos del piso de las habitaciones ha estado fuertemente influida por el proceso de carbonización ocurrido en los fogones, cuya acción varía en relación a las características naturales de los restos orgánicos implicados, así como a las prácticas culturales que posibilitan o impiden el contacto de los restos con el fuego.

Los restos ingresados a los sitios arqueológicos a través de diferentes prácticas culturales pueden distinguirse en: a- plantas y partes de plantas que son el resultado intencional de dichas acciones y b- aquellas que siendo también una consecuencia de las mismas, fueron depositadas de manera no intencional (Miksicek 1987, Popper 1988). Dentro de estas últimas se encuentran las porciones no comestibles y desechadas de las plantas alimenticias, que en Cardonal podrían asociarse a las cúpulas de maíz, los endocarpos y semillas de chañar, la semilla de algarrobo y posiblemente también algunos de los demás fragmentos pericarpios y de semillas de Mimosoideas y Caesalpinioideas.

Este mismo grupo incluye semillas y frutos u otras partes de plantas que ingresan al sitio como producto no intencional de otras actividades, como por ejemplo las semillas de los vegetales empleados en la fabricación de los techos o de los que sirvieron como leña. En este rango de acciones, Miksicek (1987) señala que el uso de heces de animales herbívoros como combustible suele incorporar granos y semillas a los depósitos. De igual modo, la presencia 
de estas plantas puede ser también el producto accidental de la cosecha y la recolección, que acarrean conjuntamente plantas ruderales y malezas de cultivo al interior de los espacios de procesamiento y almacenamiento (Hillman 1991, Buxó 1997). Lamentablemente, el nivel de determinación alcanzado con las semillas pequeñas, clasificadas en TIPO 1, TIPO 2, TIPO 3 y TIPO 4 no permiten ir más allá en la discusión sobre su posible pertenencia a este grupo, al igual que las identificadas como correspondientes a Malváceas y Solanoideas.

El segundo grupo de plantas definido por Hastorf (1988), incluye plantas y partes de plantas cuya presencia en los pisos ocupacionales está en relación a su carácter de recurso efectivamente consumido o utilizado como alimento, medicina, para la extracción de tintes, combustible, etc. De acuerdo a esta descripción, los restos asignables a tal categoría entre los hallados en Cardonal, corresponden a frutos y semillas comestibles, representados por granos de maíz y cotiledones de porotos, a los que podrían sumarse las semillas de Chenopodium de acuerdo a las consideraciones realizadas en el apartado siguiente.

\section{Vegetales comestibles del Núcleo 1: ¿silvestres?, ¿domésticados?, ¿locales?}

Del Núcleo 1 se han identificado varios taxones vegetales cuyo uso como alimento ha sido reportado e investigado en varios estudios de índole agronómica etnohistórica y etnobotánica del área andina en general y del Noroeste argentino en particular. Asimismo, estas plantas han sido halladas con mayor o menor frecuencia en diferentes contextos domésticos en los cuales los restos de frutos, semillas u otras partes comestibles de plantas se encuentran asociados a fogones, ollas de cocina, artefactos de molienda, restos óseos faunísticos, sedimentos impregnados de sustancias orgánicas e incluso basureros relacionados a las áreas de habitación (Pochettino y Scattolin 1991, Scattolin y Gero 1999, Carrizo et al. 1999, 2003, Oliszewski 2004, 2005, Würshmidt y Korstanje 1998-1999, entre otros). En otros casos, las mismas han sido detectadas en contextos propios de la producción de alimentos y de procesamiento de vegetales en el pasado (Babot 2004, 2006, Korstanje 2003, 2005).

En Cardonal, el conjunto completo de plantas estudiado fue recuperado en un área habitacional en la cual están presentes varios de los elementos mencionados anteriormente. Allí, varios de los taxones determinados son referidos en la bibliografía como plantas de importancia alimenticia de recurrente hallazgo en sitios contemporáneos del Noroeste argentino. Este subconjunto de restos comprende endocarpos y semillas de Geoffraea decorticans, granos de Zea mays var. minima, cúpulas de Zea mays AMARILLO, cotiledones de Phaseolus vulgaris, Ph. v. var. vulgaris, Ph. v. var. aborigineus y posiblemente también las 
semillas de Chenopodium aff. quinoa o pallidicaule y de Prosopis aff. alba o chilensis.

Geoffraea decorticans ('Chañar’). Los ‘chañares’ son árboles de marcada abundancia en el paisaje del Noroeste argentino, que crecen habitualmente asociados a otras especies como Prosopis sp., o bien formando pequeños bosques puros. Aún así, actualmente en el área de Monte próxima a Cardonal, cerca de la desembocadura del río Totoral, su presencia es más bien escasa.

El uso que tradicionalmente se ha dado al chañar es como alimento, siendo muy apreciada la pulpa blanco amarillenta (mesocarpo) de los frutos. Estos son y han sido muy utilizados para la elaboración del arrope, aunque también lo es en otro tipo de comidas como los bolillos con grasa de pescado, o bebidas refrescantes y alcohólicas tales como la añapa y la aloja en diferentes regiones del norte y centro de Argentina (Burkart 1952, Figueroa y Dantas 2006). Otros órganos de la planta como flores, hojas y corteza se aprovechan por poseer propiedades terapéuticas (Ragonese y Martínez Crovetto 1947).

En un estudio etnoarqueológico llevado a cabo en Andalgalá (Catamarca), Figueroa y Dantas (2006) refieren el proceso de fabricación actual del arrope de chañar. La elaboración de este jarabe comienza con la recolección del fruto, que madura a inicios del verano. Recién colectados los frutos se muelen en morteros de piedra o de madera para lograr romper la cáscara y permitir así que salga la pulpa. Luego de la molienda se colocan los frutos molidos sobre una batea y se amasan para separar la "champa” que son los restos de carozos, semillas y otros elementos no deseados de la pulpa. Finalmente los restos de "champa” se remojan y lavan en un balde con agua que luego se cuela, mientras los restos de carozos y semillas se desechan ya definitivamente. La pulpa limpia así obtenida se lleva a fuego continuo, generalmente en los fogones de los patios, durante 8 o 10 horas. En el mismo trabajo se señala que si bien el arrope se almacena, no ocurre lo mismo con los frutos del chañar. Las cosechas no se guardan para utilizarse en momentos posteriores. Lo que sobra de la fabricación de arrope se desecha o se deja que lo coman los animales (Figueroa y Dantas 2006).

Los restos de la utilización de los frutos de 'chañar', especialmente los endocarpos fragmentados o enteros, se encuentran entre los hallazgos más recurrentes en sitios formativos de la Puna y los Valles del Noroeste argentino. Las semillas en cambio son más raras, posiblemente en razón de la estructura blanda y oleaginosa que las caracteriza (Burkart 1952) y dificulta su preservación. Hasta el momento se han registrado carozos completos y endocarpos en Costa de Reyes (Gonzáles y Pérez 1968), Alamito (Núñez Regueiro 1971), Punta Colorada (Sempé de Goméz Llánez 1975, Gonzáles y Sempé 1975), Pampa Grande 
(Tarragó 1980), Los Viscos (Korstanje y Würschmidt 1999), Tesoro 1 (Pochettino y Scattolin 1991), Yutopián (Rossen 1998 a y b), Palo Blanco (Sempé de Gómez Llanez 1977), Bañado Viejo (Scattolin 2001), Casas Viejas (Carrizo et al. 1999, 2003), Punta de la Peña 9 (López Campeny 2000, 2001b), Piedras Blancas (Marconetto 2005) y Cueva Cacao 1A (Oliszewski y Olivera 2009).

En Cardonal, los vestigios de chañar comprenden las partes no comestibles de los frutos entre los que se cuentan endocarpos en estado muy fragmentario, y dos semillas muy bien preservadas. La recolección de este recurso en el pasado habría implicado al menos, el desplazamiento de algunos individuos hasta el fondo de valle, donde se desarrolla la vegetación de Monte y junto con el chañar se obtendrían otros recursos de importancia para las poblaciones prehispánicas, como los algarrobos.

Phaseolus vulgaris var. vulgaris y $P$. v. var. aborigineus. El poroto común ( $P$. vulgaris) constituye uno de los cultivos más comunes en el Noroeste argentino actual, preparándose diversos platos tales como guisos o sopas, ya sea con las semillas o las vainas inmaduras (Burkart 1952). Las semillas de la variedad silvestre se consumen del mismo modo que las de su pariente cultivado (Horkheimer 1990).

Ambas variedades crecen comúnmente en el Noroeste argentino. El antecesor silvestre del poroto domesticado, $P$. v. var. aborigineus se da de manera espontánea en los valles húmedos de la Cordillera Oriental de los Andes, por debajo de los 2800 msnm., distribuido en las provincias fitogeográficas de Yungas, Prepuna y Monte. En Argentina se da actualmente en Jujuy, Salta y Tucumán, siendo particularmente abundante en los valles intermontanos de las laderas orientales del sistema del Aconquija. Con menor frecuencia ocurre también en Catamarca, Córdoba y San Luis (Berglund-Brücher y Brücher 1976). Por su parte, P. v. var. vulgaris es una variedad de poroto domesticada muy común en los valles y faldas templadas de Sudamérica (Parodi 1991). Las mejores condiciones para su cultivo se dan entre los 0 y los 2000 msnm, aunque en algunas áreas pueden obtenerse cosechas hasta los 3500 msnm. (Tapia 1990).

Se ha señalado además que si bien las poblaciones de poroto silvestre crecen en zonas no antropizadas de las laderas orientales andinas (Berglund-Brücher \& Brücher 1976, Menéndez Sevillano 2002 en Lema 2009) también se lo ha hallado en áreas cultivadas y entremezclados en los cultivos actuales de porotos domésticos, formando lo que algunos autores denominan complejos maleza-cultivo-domesticado (Freyre et al. 1996, Menéndez Sevillano en Lema 2009). Se conoce además que una y otra variedad de porotos pueden 
cruzarse naturalmente entre sí dando lugar a híbridos viables (Gepts y Debouck 1991) con características intermedias, es decir semillas de porotos domesticados mas chicas que el rango existente en el conjunto cultivado, y porotos silvestres con semillas mas grandes respecto del rango de tamaño registrado en la población natural (Drewes 2006).

En el Noroeste argentino, el poroto común ha sido hallado en varios sitios del primer milenio d.C. En Casas Viejas - El Mollar (Carrizo et al. 1999, 2003), Pampa Grande (Tarragó 1980), Campo del Pucará (Oliszewski 2004, 2005) y Los Viscos (Korstanje y Würschmidt 1999) se determinaron restos pertenecientes a la especie $P$. vulgaris aunque sólo en Loma Alta fueron halladas ambas variedades (silvestre y doméstica) en contextos específicos de preparación (fogones) de alimentos (Pochettino y Scattolin 1991).

Al igual que en Loma Alta, los porotos silvestres y domésticos recuperados en el Núcleo 1 se encuentran en su mayoría en estrecha relación con el fogón, en un contexto donde abundan otras evidencias de preparación de alimentos como las ollas con tizne y el molino de mano con sus respectivas manos ubicado en posición de uso.

Proponer la posibilidad del cultivo del poroto común doméstico en este valle alto de Prepuna implica considerar la presencia en el valle de un clima más húmedo y cálido que el actual hace unos 1800 años atrás, así como el implemento de alguna forma de riego. No obstante ello se ha mencionado ya que la siembra de porotos es posible en algunos ambientes particulares por encima de los 2000 msnm. Por otra parte, aunque no han sido estudiadas en detalle aún, los alrededores de Cardonal presentan varias estructuras destinadas al cultivo, como canchones y aterrazamientos espacialmente asociados al sitio y que podrían haber estado funcionando durante la ocupación. Al respecto también se ha sugerido que la agricultura temprana podría estar más en relación con el tipo de horticultura que actualmente se practica en el Noroeste argentino, de escala doméstica y favoreciendo la heterogeneidad de especies cultivadas (Lema 2009). Tal comportamiento es también mucho más acorde con el tipo de asociación de restos de porotos hallados en contextos de consumo y preparación, particularmente en el caso de los porotos domésticos que comúnmente aparecen junto a su antecesor silvestre en varios sitios de Noroeste argentino. Hasta el momento tal combinación había sido detectada en sitios de áreas próximas a las laderas orientales andinas (Lema 2009), pero no en los valles altos.

Sin embargo, las plantas de porotos silvestres actuales tienen escasa representación dentro de la provincia de Catamarca, en tanto el límite altitudinal de su distribución indica que estos difícilmente podrían darse de forma espontánea en las proximidades de Cardonal. En este caso, el área de procedencia de las semillas que aparecieron en uno de los fogones del 
Núcleo 1 parece ubicarse en lugares más alejados, como los valles vecinos más bajos o las laderas orientales del Aconquija y más al Este, donde podrían recolectarse o bien intercambiase por otros productos con las poblaciones locales. No sería osado preguntarse además si $P$. v. var. aborigineus crecería como una variedad asociada a los sembrados, propiciada por los mismos agricultores de esas zonas con el objeto de diversificar el cultivo de porotos, como ha sido señalado actualmente en Salta (Menéndez Sevillano en Lema 2009) y tal como sugiere también Lema (2009) para los casos arqueológicos, donde incuso ha sido posible observar la presencia de variedades con caracteres intermedios. Cabría también preguntarse entonces si los habitantes de Cardonal no podrían haber requerido de porotos silvestres de las laderas orientales para diversificar las cosechas de sus propios huertos.

Zea mays var. minima y Z. m. AMARILLO. Varios autores sostienen que el maíz ha sido el cultivo principal de los grupos agricultores prehispánicos, así como un componente fundamental de su alimentación, del mismo modo en que actualmente se da entre muchas poblaciones andinas (Gonzáles y Pérez 1968, Martínez Crovetto 1968, Oliszewski 2004, 2005, Parodi 1959, Tarragó 1980). El consumo y los modos de preparar el maíz son además sumamente variados, ya que los granos suelen comerse molidos, tostados, asados, hervidos o fermentados, y servidos en diversos platos y bebidas: mazamorra, humita, pochoclo, chicha, entre otros.

En efecto, el maíz es otro de los restos macroscópicos que aparece más recurrentemente en contextos arqueológicos prehispánicos del Noroeste argentino. El mismo ha sido registrado a través de toda la secuencia del Formativo, tanto en forma de microrrestos depositados durante su procesamiento en artefactos de molienda (ver Babot 2004, 2006), como vestigios macroscópicos de su consumo. Estos últimos se han encontrado tanto entre los sedimentos de pisos de ocupación en áreas habitacionales, en fogones y dentro de silos.

Para los primeros diez siglos de la era, los pisos ocupacionales de Palo Blanco y Costa de Reyes (Sempé de Gómez Llanez 1975), Potrero Antigal (Pochettino y Scattolin 1991), Cueva de los Corrales I (Carrizo et al. 1999, 2003) y El Altillo (Ávila y Herrero 1991), presentaron restos de maíz “perla”. Este también fue hallado en los fogones excavados en Campo Colorado (Tarragó 1996), La Mesada (Würschmidt y Korstanje 1998-1999), Barrealito (Balesta y Zagorodny 1999) y estructuras de almacenaje en Campo del Pucará (Núñez Regueiro 1998). Sólo las cúpulas de maíz recuperadas en Campo del Pucará fueron determinadas por Oliszewski $(2004,2005)$ como correspondientes a la raza AMARILLO (Miante Alsogaray y Cámara Hernández 1996), aunque la autora señala finalmente que las 
características morfológicas son coincidentes con la variedad minima, descripta por Parodi (1959).

Más allá de la distinción entre variedades y razas de maíz, la ausencia en la región de antecesores silvestres de esta planta o especies emparentadas con las cuales pudieran confundirse los vestigios arqueológicos, facilitan su determinación a nivel específico. De todos modos, el maíz es un cultivo de considerable profundidad temporal para el área. El mismo se desarrolla mejor en tierras de baja y de mediana altitud -hasta los $2000 \mathrm{msnm}$-, aunque sus restos han sido identificados también en sitios arqueológicos ubicados a 3000 e incluso a más de 3500 msnm. (Olivera et al. 2001, Rodríguez 2003, Babot 2006, Quesada 2007). Asociados a estos sitios se hallaron además estructuras agrícolas de diferente complejidad.

En torno a tales hallazgos, se ha comenzado a pensar acerca de la posibilidad del desarrollo de este cultivo en zonas altas de la Puna y Prepuna (Oliszewski 2008, Quesada 2007), posiblemente a partir de variedades más resistentes y adaptadas a las condiciones imperantes. Avalando esta hipótesis, los estudios realizados hasta la fecha sobre la variabilidad del maíz en Argentina, han dado con una amplia diversidad de tipos, tanto en épocas actuales como pasadas (Parodi 1959, Abiusso y Cámara Hernández 1974).

Las clasificaciones realizadas por ambos autores se basan en caracteres del grano y/o la mazorca de Zea mays, que los distinguen en variedades (Parodi 1959) o razas (Abiusso y Cámara Hernández 1974), no opuestas entre sí. Según Oliszewski (2008: 185) muchas de las razas propuestas por cámara Hernández coinciden con las variedades propuestas por Parodi. Como ejemplo se puede citar el caso de las razas de maíz de endosperma harinoso determinadas por Cámara Hernández como “capia”, "harinoso”, "harinoso amarillo”, “culli” y “garrapata”, que quedan comprendidas en Z. m. var. amylacea según la clasificación de Parodi. Otro ejemplo es el maíz pisingallo determinado por Cámara Hernández, que es homologable a Z. m. var. oryzaea de acuerdo a la clasificación de Parodi.

A partir de estos trabajos es posible considerar de modo general la existencia de tres grandes grupos de maíces en la región, que se distinguen entre sí principalmente según las características del endosperma (Oliszewski 2008). Así, un primer grupo incluye los maíces de endosperma duro o córneo, que incluye variedades y razas de maduración temprana como PERLA, AMARILLO, MOROCHO e inclusive el MOROCHO AMARILLO, de dureza media. Se trata de maíces de granos pequeños y en general reventadores, del tipo de los que se usan para freír, los cuales serían a su vez más aptos para su cultivo en las zonas altas y áridas de la Puna que otras razas de maíz. 
En segundo lugar se encuentran los maíces de endosperma harinoso, blando, entre los cuales se cuentan razas/variedades como CAPIA, HARINOSO, HARINOSO AMARILLO, CULLI, GARRAPATA de maduración tanto temprana como tardía. Estos y el tercer grupo de maíces dulces y de maduración tardía como el CHULLPI presentan granos más grandes que los anteriores y son en general más o menos dentados.

Los granos y cúpulas de maíz identificados entre los materiales arqueobotánicos del Núcleo 1 se encuentran entre las razas/variedades del primer grupo, es decir que son variedades de grano pequeño y duro que podrían haberse sembrado localmente en los campos de cultivo próximos. A favor de esta hipótesis cabe mencionar que, a pesar del ambiente de Prepuna que caracteriza el área donde se emplaza el sitio y bajo las condiciones imperantes actuales, el maíz es un cultivo común en las chacras de los pobladores de La Quebrada y otras localidades del valle.

Es posible que los ambientes más benévolos establecidos en el Noroeste argentino a partir del 3000 AP mejorarían las condiciones para el crecimiento y fructificación de las plantas de maíz. A su vez la presencia de parte de los marlos (cúpulas) y no solo de las partes comestibles de la mazorca, indicaría que el maíz no ha llegado hasta allí desgranado, que es la forma habitual en que suelen transportarse los granos de maíz desde lugares alejados para reducir el peso y el volumen (Nielsen 2001). De igual modo, en base a los resultados obtenidos en investigaciones actuales sobre agricultura prehispánica (Quesada 2006, Korstanje 2005) así como las crecientes evidencias de maíz en sitios tempranos de la puna y los valles altos (Babot 2004, 2005, Korstanje y Würschmidt 1999, Olivera 1991, Oliszewski y Olivera 2009, López Campeny 2001, Rodríguez 2004, Haber 1999) es muy probable que este recurso formara parte de los sembrados a $3000 \mathrm{msnm}$ del sitio estudiado. Los estudios sobre las variedades de maíz presentes en Noroeste argentino indican además que los maíces de grano duro y pequeño, de tipo reventón, reúnen las condiciones para crecer en los ambientes áridos y altos de la Puna y Prepuna (Gonzáles y Pérez 1968, Parodi 1966, Oliszewski 2008).

\section{Chenopodium aff. quinoa o pallidicaule (Quinoa, Quinoa Negra o Cañiwa).}

Existen hasta el momento unos pocos hallazgos de semillas u otras partes de plantas de la Familia de las Chenopodiáceas asignables al período Formativo. Una cantidad importante de semillas muy pequeñas recuperadas en pisos de ocupación excavados Yutopián podrían corresponder a alguna de las especies y variedades mencionadas aquí para Cardonal, según las descripciones efectuadas por Rossen (1998a, 1998b). Otras semillas fueron reportadas en Los Viscos (Korstanje 2001), Cueva Cacao 1A (Oliszewski y Olivera 2009) y Pampa Grande 
(Tarragó 1980) donde se hallaron tanto la variedad cultivada como la variedad silvestre (Ch. q. var. melanospermum) de quinoa (Ch. q. var. quinoa).

En Argentina se dan 28 especies americanas y cosmopolitas de Chenopodium de las cuales unas nueve son comunes en la región Noroeste. Entre las representantes silvestres se encuentran C. ambrosioides L. ('paico'), C. graveolens ('arca', 'arcayuyo', 'yerba del arca’), C. carnulosum Moq., C. murale L., C. papulosum Moq., C. pallidicaule Aellen ('Cañiwa') y la variedad C. quinoa Willd. var. melanospermum Hunz. ('quinoa negra', 'quinoa gris', 'ajara'); la variedad C. quinoa Willd. var. quinoa ('quinoa', ‘quinua') crece bajo cultivo (Planchuelo 1975). Las dos primeras especies mencionadas son hierbas silvestres, abundantes en el área de estudio y que han sido colectadas entre las plantas del herbario elaborado para esta tesis. Ambas son actualmente muy utilizadas entre los pobladores de La Quebrada como terapéuticas, aromáticas y también en la fabricación de llicta.

La variedad domesticada C. quinoa var. quinoa ha sido cultivada y consumida desde épocas prehispánicas en Bolivia, Ecuador, Perú y en el Norte argentino, aunque actualmente su siembra y consumo se encuentran muy restringidos (Hunziker 1952). Según L. Parodi hace unos 40 años se hallaban cultivos entre los 1200 y 3600 msnm. en Salta y Jujuy en tanto que antiguamente los sembrados abarcarían la Puna de Atacama, Valles Calchaquíes, las quebradas preandinas del Noroeste argentino y en las Sierras de Córdoba, siendo un recurso alimentario de máxima importancia en las grandes alturas donde no se cría el maíz (Parodi 1966: 22).

Junto con los sembrados de quinoa habría evolucionado también una hierba que crece espontánea, generalmente asociada a los sembrados de quinoa, C. quinoa var. melanospermum, dando lugar a un complejo maleza-cultivo-domesticado ("crop/weed complex”), tal como ha sido propuesto por autores como Ruas (1999 en Bruno 2006). Asimismo, la cruza entre ejemplares de 'quinoa negra' y 'quinoa' da lugar a híbridos que han sido hallados en campos abandonados de quinoa en Ecuador (Nelso 1968 en Haiser y Nelson 1974). Otra especie que se comporta como invasora de cultivos y que habita las regiones templadas y cálidas de todo el mundo es $C$. murale, presente actualmente en la provincia de Catamarca (Planchuelo 1975, Zuloaga y Morrone 1996-1999).

En territorio argentino, C. pallidicaule ha sido registrada a partir de ejemplares espontáneos y ruderales colectados en diferentes localidades de Jujuy y La Rioja. Dichos especímenes fueron determinados dentro de la misma especie que en Bolivia, Perú y Ecuador crece bajo cultivo. En estas regiones se la denomina vulgarmente como 'cañagua o cañahua' en Bolivia, 'cuchiquinoa’ en Ecuador, 'cañihua o cañahua’ en Perú C. pallidicaule y su 
siembra se realiza en altiplanicies a 3500-4000 msnm. (Planchuelo 1975). Asimismo se la considera como una planta doméstica "rústica", porque mantiene varias características silvestres (Gade 1970 en Bruno 2006) y resulta a la vez muy apta para el cultivo en las regiones altas y secas del altiplano andino.

Teniendo en cuenta las características ecológicas de las plantas cultivadas y las ruderales, así como las condiciones ambientales del valle del Cajón, es posible considerar el cultivo de Chenopodium en el área de estudio, o bien la presencia de especies y variedades ruderales entre los sembrados, aunque no con demasiada certeza. De hecho los restos hallados en el Núcleo 1 podrían corresponder a plantas silvestres y cultivadas a la vez. De todos modos es interesante notar que además de hallarse integrados al fogón, en un contexto general de preparación de alimentos, una parte de las semillas presenta indicios de la aplicación de procedimientos como la cocción con agua u otro. Esta presencia permite vincularlas, aunque no exclusivamente con su uso como alimento.

Prosopis aff. alba o chilensis (algarrobo blanco o algarrobo de Chile). Son éstas dos de las cuatro especies de algarrobo más conocidas en el Noroeste argentino, junto con $P$. flexuosa y P. nigra (Demaio et al. 2002). Los Prosopis en general, poseen una amplia distribución en las provincias del Noroeste argentino, en áreas bajas. En La Quebrada, los algarrobos crecen hacia el fondo de valle, en las proximidades del río Cerro Colorado y El Totoral, donde se extiende una estrecha faja de Monte espinoso (Morlans 1995). La distancia a recorrer actualmente desde Cardonal hasta este sector de Monte (unos 20 o $30 \mathrm{~km}$.), hacen que prácticamente no se colecte, aunque sí dicen utilizarse frutos traídos de Santa María o de localidades del valle ubicadas más hacia el sur.

En el Noroeste argentino, los algarrobos poseen hasta el día de hoy usos muy diversos, como la obtención de tintes, medicinas, combustible y material de construcción. Asimismo, las vainas o "algarroba” de estas plantas tienen gran variedad de aplicaciones culinarias, tanto en la elaboración de bebidas fermentadas (“aloja”) o refrescante (“añapa”), dulces o jarabes (“arrope”) o de harina para panes y otras masas (“patay”). El trabajo de Capparelli (2007) comprende un estudio detallado de la utilización actual de dos especies de algarrobo ( $P$. chilensis y $P$. flexuosa) en el valle de Hualfín (Catamarca), en el que se exploran los procedimientos empleados en la producción y el almacenamiento de harinas, patay, bebidas (aloja, añapa) y jarabes (arrope) de los algarrobos que se consumen en la región. Respecto de la elaboración del “patay” también se han realizado investigaciones en la localidad de Añatuya (Santiago del Estero) (Figueroa y Dantas 2006). 
En ambos estudios se observa que el uso del algarrobo con fines alimenticios involucra el desarrollo de actividades de recolección de tipo familiar o colectivo en la época de maduración de los frutos, la transmisión generacional de los modos particulares de elaborar los productos y el almacenamiento en lugares especiales de la casa (Caparelli 2007, Figueroa y Dantas 2006). La parte útil de las vainas de algarrobo es el mesocarpo dulce, que se separa del resto de los componentes del fruto por medio de diferentes procesos como el secado, el molido y el cernido final del producto, para separar los restos de semillas, cáscaras y fibras en la elaboración de la harina de algarroba. Las Semillas y el afrechillo pueden usarse luego para la fabricación de añapa; también todo el producto molido, sin tamizar se remoja y deja fermentar para hacer aloja (Capparelli 2007, Figueroa y Dantas 2006). En el proceso inicial de la preparación de arrope, el colado del líquido en el que se hirvieron las vainas "pisoteadas” de algarrobo da lugar a esta misma disgregación de los subproductos obtenidos.

Dos trabajos experimentales posteriores avanzan sobre los productos intermedios y residuos que derivan de cada tipo de procedimiento empleado en la fabricación de diferentes derivados del algarrobo blanco y el algarrobo negro (Capparelli 2008), así como las modificaciones sufridas en el proceso de carbonización que afecta gran parte de los conjuntos arqueobotánicos del área (Capparelli en prensa). A partir de esta información se realizan inferencias acerca de los procedimientos empleados y productos obtenidos en torno al uso del algarrobo en épocas incaicas en el valle de Hualfín.

Para sitios formativos en cambio, el procesamiento por molido de los frutos de algarrobo ha sido observado sólo a partir del hallazgo de granos de almidón y otros microrrestos en artefactos de molienda (Babot 2004). Otros varios hallazgos como los de Cardonal, dan cuenta de su presencia y uso en diferentes contextos domésticos del área. Generalmente se trata de vainas y semillas determinados como $P$. alba que han sido recuperados en pisos ocupacionales de Costa de Reyes y Palo Blanco (Sempé de Gómez Llanez 1977) y Casas Viejas (Carrizo et al. 1999). Algunos artejos y semillas de Prosopis determinados como afines a P. alba o P. nigra proceden de Pampa Grande (Tarragó 1980) y de contextos de descarte en Campo del Pucará (Olisewski 2004, 2005). Se menciona a los algarrobos además como recursos maderables y combustibles de notable importancia en el pasado (Marconetto 2005, Calo et al. 2006, Capparelli et al. 2003).

Como se dijo al principio, es probable que el algarrobo hallado en el piso ocupacional de Cardonal proceda de su recolección en el área de Monte más próxima al sitio. Lamentablemente los restos son muy escasos como para aplicar el modelo experimental de Capparelli (2008) y Capparelli (en prensa) comentado anteriormente. 


\section{La distribución de los restos botánicos}

Desde el punto de vista de su distribución espacial, el conjunto de restos arqueobotánicos procedentes de los pisos ocupacionales excavados en el Núcleo 1 se consideran también como resultado final de una sucesión de eventos. Tales eventos incluyen procesos naturales y acciones culturales que colaboraron en diferente grado y de forma acumulativa en el tiempo de la ocupación y post-ocupación de los recintos (ver Miksicek 1987).

Entre los procesos ocurridos sin intervención humana, aún no ofreciendo ningún sustento a los microorganismos activos en el suelo, los restos carbonizados corren con la posibilidad de dañarse, mezclarse y desplazarse de su ubicación original por acción mecánica. En este caso deben considerarse como agentes principales, el crecimiento de las raíces de diversas plantas, así como la acción que el viento y el agua que pueden remover y destruir los vestigios botánicos una vez depositados (Gasser 1985, Kreuz 1990, Popper 1988).

Respecto de estos sucesos y sus consecuencias sobre el material vegetal carbonizado, los estudios y observaciones tafonómicas realizadas hasta el momento en Cardonal dan cuenta de la exigua perturbación sufrida por los pisos ocupacionales excavados. El material óseo depositado en las habitaciones muestra grados de meteorización bajos y las evidencias de actividad de roedores sobre los mismos son igualmente escasas. Asimismo, las señales de la acción de animales o insectos cavadores, como cuevas, túneles o sedimentos removidos son más bien raras y poco notorias (Scattolin et al. 2007). El crecimiento de raíces más conspicuo se dio en los niveles superiores, aunque en algunos casos se lo encontró asociado a los sectores del piso de sedimento graso y carbonoso próximo a los muros. A su vez en algunos sectores se observó el derrumbe de algunas piedras de los muros, que afectaron áreas circunscriptas hacia los bordes de las paredes.

De acuerdo con esos resultados, se considera que el examen de la organización y estructuración del registro arqueobotánico en el Núcleo 1 puede brindar información importante acerca de las actividades y acciones culturales desarrolladas en torno al uso y consumo de vegetales. Asimismo, el análisis de las densidades de carporrestos y carbón de madera procedente de los fogones permitió diferenciar los niveles estratigráficos formados por sedimentos correspondientes a la ocupación en cada estructura y aquellos depositados luego del abandono del núcleo. Dicho límite es altamente coincidente con el patrón de depositación de fragmentos cerámicos, algunos de ellos correspondientes a contenedores 
completos o semicompletos, instrumentos líticos y desechos de talla, artefactos de molienda completos y en posición de uso, restos óseos de camélidos y otras especies menores, improntas de cestos, etc. (Scattolin et al. 2007, 2008, 2009a).

Entre los diferentes rasgos y espacios arquitectónicos que componen el piso ocupacional de cada uno de los recintos se observan diferencias en términos de cantidad, ubicuidad y densidad de los restos carpológicos y del carbón de madera. En el caso de E1, de donde proceden unas pocas muestras del interior y áreas aledañas al fogón, los resultados son más comparables a aquellos obtenidos de las muestras del área de fogón excavada en E5, lo cual se discute más adelante. Hecha esta salvedad, se observa que aunque el material de flotación e in situ ha sido recuperado en mayor cantidad en E5, los restos de flotación son allí menos ubicuos y en general menos densos que en E2 y E3. En decir en E5 los vestigios botánicos tienden a aparecer en unas pocas muestras, que en términos de densidad se concentran en los pisos en general y en el relleno de uno de los pozos más que en el área del fogón misma. Lo mismo ocurre con los restos recuperados por flotación en el caso de E2 y E3, aunque aquí son en general más ubicuos, procedentes de muestras distribuidas incluso en las capas inmediatamente superiores a los pisos.

Ante la ausencia de un fogón en uso al momento del abandono del sitio, es posible que una parte importante de los materiales presentes en E3 y E3 se hayan desplazado desde las habitaciones donde las estructuras de combustión estaban en uso cotidianamente. Aunque podría considerarse también el aporte menor de material del fogón en desuso y limpio hallado en las proximidades de la puerta en E2 (Scattolin et al. 2007, Scattolin et al 2009 a) o algún evento de combustión aislado, como los que suelen emplearse para calefaccionar o secar ambientes u otras actividades puntuales. De todos modos, tanto E2 como E3 y parte también de E4 presentan un área de piso negruzco y grasoso en común, que se observó como una gran mancha que desciende desde el piso algo elevado de E1 y se esparce hacia el interior de dichos recintos (Scattolin et al. 2008, Scattolin et al 2009 a, Scattolin et al. 2009 b). Esto da una pauta del modo en que sedimentos y carbones se desplazaron desde el fogón, tiñendo la totalidad del piso en E1 y esparciéndose hacia otros espacios del núcleo habitacional. A este evento pueden haber colaborado la misma circulación de las personas y objetos de un lado a otro de la casa o actividades de barrido y descarte de carbón de la E1.

Notablemente, los restos desplazados y/o depositados en E3 y E2 corresponden a las partes no comestibles del chañar (endocarpos y semillas) y otros restos probablemente no alimenticios como los tallitos y pedúnculos, fragmentos de pericarpios y de semillas de Mimosoideas, así como cantidades considerables de pequeñas semillas adjudicadas a plantas 
silvestres herbáceas. En términos generales puede inferirse que la mayor parte de los restos recuperados en E2 y E3 son restos primarios de diferentes acciones llevadas a cabo en el Núcleo 1, como la extracción de la pulpa de chañar y desecho de los carozos o el acarreo de plantas recolectadas o cosechadas junto con otras no comestibles diversas, el techado total o parcial de los recintos con materiales vegetales, el procesamiento de fibras y la posterior elaboración de cestería (Calo 2008, Scattolin et al 2007, Scattolin et al. 2009 a).

Los conjuntos de restos vegetales recuperados en E4 y el Portal son más bien exiguos, comparados con las demás estructuras aunque su composición resulta algo curiosa. En el piso de E4 están representados los cotiledones de porotos silvestres y los granos de maíz, junto con una cantidad considerable de semillas de herbáceas, entre ellas una Solanoidea y cúpulas de maíz. De todos modos el origen de este material parece corresponder a las mismas causas que las mencionadas para E2 y E3 ya que la presencia de fuego aquí no parece haber dejado huellas considerables. De igual modo, el escaso material del portal parece haberse desplazado desde E5 fundamentalmente, en tanto que los hallazgos correspondientes a partes comestibles de plantas sólo están representados por el grano de maíz.

Existe una clara distinción en la distribución espacial de los restos carbonizados recuperados en E1, al menos en términos comparables con los demás recintos del Núcleo 1. El número de vestigios recuperados en unas pocas muestras de flotación, sumados a las muestras in situ procedentes de las mismas unidades de excavación hacen del fogón y áreas de piso inmediatas un locus importante de depositación de restos. Por otro lado, se hallaron cantidades relevantes (en términos del conjunto estudiado) de vestigios que corresponden a partes comestibles de plantas: cotiledones de porotos comunes, algunos de ellos asignables a la variedad silvestre y otros a la variedad cultivada. Asimismo se halla allí presente un conjunto abundante de cúpulas de maíz, fragmentos de endocarpos de chañar y otros pericarpios y semillas de herbáceas silvestres. Es decir, el conjunto se compone de una serie de restos como los porotos que pueden haber caído accidentalmente al fuego mientras se los cocía o haber sido arrojados allí como restos de comida o como ejemplares descartados. También fueron desechados allí marlos o fragmentos de marlos, de los cuales sólo permanecieron las cúpulas y otros restos de frutos en cantidades menores.

Acciones similares parecen haber tenido lugar en el contexto del fogón de E5, de la cual proceden buenas cantidades de restos recuperados in situ, en tanto las flotaciones no resultaron tan exitosas. En este caso dominan la composición del conjunto los fragmentos de endocarpos de chañar y las semillas de Chenopodium acompañadas de unas pocas semillas de herbáceas silvestres y fragmentos de semillas de Mimosoideae. La presencia de desechos de 
chañar es más importante aquí que en otros sectores y estructuras, mientras que las semillas de Chenopodium sólo se hallan en E5, gran parte de ellas concentradas en el área de combustión y con algunos indicios de procesamiento. En este caso es posible también considerar que estos restos procedan de acciones relacionadas con la preparación que con su descarte en el fuego, aunque es necesario para ello confirmar su pertenencia a plantas efectivamente consumidas.

En términos de densidad de restos carpológicos, el fogón de E5 no constituye un rasgo sobresaliente en dicha estructura, e inclusive es bastante menos denso en promedio que la estructura de combustión excavada en E1 a la cual se aproxima en relación a los hallazgos in situ. Tal carácter permite inferir en principio que el fogón de E5 habría sido utilizado con menos frecuencia, o tal vez por menos tiempo, en actividades relacionadas con la preparación de alimentos vegetales. Asimismo, las muestras tomadas en toda la extensión del piso de E5, y dentro de los pozos cavados en la roca de base, presentan cantidades considerables de restos comparables como se dijo al principio, con aquellas del piso y los pozos en E2 y E3. En E5 el piso presenta también una buena cantidad de semillas de herbáceas silvestres, fragmentos de pericarpios, tallitos, algunas semillas de Chenopodium y otras pocas fragmentarias de Fabáceas, desplazadas desde el fogón luego de carbonizarse.

Por su parte, los pozos cavados en la roca de base en las diferentes estructuras dan la impresión de haber “atrapado” algunos restos carpológicos entre los sedimentos de relleno, sin que ello permita la asignación de usos posibles de estas cavidades, al menos desde lo que muestra el material carpológico carbonizado. La elevada densidad de carbón de leña observada en uno de los pozos de E3, tiene que ver con la ubicación del pozo en la salida de E1 y el desplazamiento de material de combustión comentado en párrafos anteriores. Inclusive la cavidad rellena con cenizas procedentes de la limpieza del fogón en E5, que tiene su homólogo en E1 (Scattolin et al. 2009 a), no muestra diferencias considerables en relación al piso y los demás pozos, en términos de la presencia de restos carpológicos, si bien se da una alta densidad de carbón de leño. Es posible que este rasgo fuera a su vez limpiado o vaciado periódicamente, impidiendo de esta forma la acumulación de restos de comida en su interior.

Finalmente, el contenido de restos del terraplén construido en E5 muestra una baja cantidad y densidad de restos. Los pocos vestigios carbonizados presentes en el interior de este rasgo se asemejan a los contenidos en el piso de E5 (Chenopodium, herbáceas silvestres, pedúnculos). De acuerdo a estos resultados es posible que el sedimento con el que se rellenó el terraplén proceda en su mayor parte del exterior del Núcleo 1 aunque cabe señalar en este 
caso que las muestras de flotación analizadas corresponden a un sector del mismo, con lo cual bien podrían estar reflejando de manera muy sesgada la presencia de restos.

\section{Los artefactos de molienda}

Instrumentos de molienda: modo de empleo

Las actividad de molienda desarrollada en el Núcleo 1 involucró el uso de instrumentos variados en tamaños y formas, lo cual podría vincularse con una práctica diversificada tanto en el uso de los artefactos por parte de diversos usuarios, así como a la molienda de diferentes cantidades y tipo de sustancias a lo largo de la ocupación del núcleo. De esta forma el conjunto de artefactos de molienda incluye piezas completas y fragmentarias, de las cuales las primeras se clasifican según su posición como artefactos inferiores o pasivos, artefactos superiores o activos y artefactos de posición indeterminada. Las dos primeras categorías permitieron su clasificación en diferentes grupos tipológicos de artefactos: molinos de mano, morteros, manos de molino y finalmente una mano de mortero o pilón. Cada uno de estos tipos de instrumentos poseen características morfológicas y de uso que los distinguen de los demás, así como los hacen complementarios en los sistemas de molienda del tipo mortero-pilón y molino-mano. Los primeros han sido empleados preferentemente para triturar, machacar y descascarar con movimientos de percusión y presión vertical. Eventualmente estos artefactos pueden emplearse para moler o pulverizar, aunque estas acciones son características de los sistemas de molienda compuestos por molinos y manos de moler, que combinan movimientos de presión deslizante y semirrotativa (Babot 2004, 2006).

El uso de los artefactos en la historia del Núcleo 1

Las diferencias observadas en la composición y distribución de los conjuntos de artefactos de molienda presentes en cada una de las habitaciones sugieren que esta actividad se ha desarrollado en lugares preferenciales del Núcleo 1. En primer lugar, la tarea de moler tuvo lugar dentro de los dos recintos, donde también existen indicios del procesamiento y consumo de alimentos. Tanto en E1 como en E5 están presentes estructuras de fogón abundantes en carbón de leña, restos de frutos, semillas (ver apartado anterior) y huesos de 
animales comestibles. Estos contextos se caracterizan además por el hallazgo de ollas ordinarias manchadas con tizne, jarras, pucos y otros utensilios de servicio de comida, así como el aspecto graso e impregnado de sustancias orgánicas de los sedimentos del piso y las superficies de las paredes.

Aún así, los contextos que albergan la molienda en E1 y E5 muestran entre sí diferencias notables. El conjunto de ítems materiales presentes en E1 y otros rasgos constitutivos han dado lugar a su identificación como una antigua “cocina”, un recinto techado donde tuvieron lugar acciones de preparación y posiblemente consumo de alimentos. Es a su vez, de acuerdo a su ubicación en la configuración general del núcleo, uno de los espacios más internos y privados de la casa, al que sólo se accede luego de recorrer el Portal de E5 y el espacio de circulación E3 (Scattolin et al. 2009 a y 2009 b). En su interior, hacia el extremo opuesto de la única puerta de entrada de E1, se dispone un conjunto de artefactos que dan lugar a un área de molienda con características distintivas respecto del resto de las habitaciones. Se observó allí la presencia de dos sistemas de molienda en uso, compuestos por un molino de mano de gran tamaño y otro molino reciclado. El primero sostenido y asegurado por la base, y ambos asociados a una serie de manos complementarias. El segundo espacio de molienda en E1 tuvo lugar cerca de la puerta y en torno al fogón. En este caso las piezas en uso comprenden un molino de mano pequeño y plano, también afirmado sobre una pieza descartada, algunas manos de moler y un pequeño mortero de cual no se halló el pilón en este recinto.

Un cuadro semejante que incluye un molino de mano de tamaño reducido, manos de moler y un morterito, presenta el fogón de E5, próximo y lateral a la puerta de entrada. Uno o dos metros más al Oeste se encontró el pilón cuyas dimensiones y forma permiten asociarlo a dicho mortero y también inclusive al mencionado en E1, ya que los mismos guardan características muy similares. Sin embargo, el contexto de E5 no se corresponde en varios aspectos con la E1. Por un lado ha sido definido como un patio semicubierto al que se accede directamente desde el Portal, sin habitaciones intermediarias. Asimismo, se ha señalado de acuerdo a los materiales presentes que en esta habitación se desarrollaron actividades de procesamiento y cocción de alimentos, aunque de forma menos sistemática que aquellas que tuvieron lugar en E1 (Scattolin et al. 2009 a y 2009 b).

El hecho de que el patio E5 no incluyera una segunda área de molienda alejada del fogón y de características particulares como la que se halló en E1, sugiere que la tarea de moler en molinos de mano de grandes dimensiones sólo ocurrió en esta habitación, posiblemente en relación con la mayor intensidad o recurrencia con que se habría desarrollado 
la molienda en E1. Sustancialmente diferentes a ella, los dos conjuntos de artefactos de molienda en los fogones de E1 y E5 sugiere que una serie de acciones de moler diferentes a las anteriores ocurrían indistintamente en una y otra habitación. Más allá de la composición y disposición de los grupos de artefactos, aquello que distingue o asemeja a las tres áreas de molienda puede estar en relación con los elementos procesados, aunque los datos generados en este trabajo no permiten plantear hipótesis de gran alcance en este sentido.

Antes bien es posible sólo sugerir algunas direcciones en torno a una problemática que ha sido abordada a partir de residuos microscópicos y otros indicadores de uso en artefactos de molienda en el Noroeste argentino. En este sentido se ha señalado que los diferentes útiles empleados para moler pudieron ser empleados de manera indistinta en el procesamiento de varios recursos de diferente origen. Es decir que podrían haberse utilizado para moler recursos comestibles, no comestibles o bien una combinación de ambos. De todas maneras ha sido posible establecer algunos parámetros generales respecto del modo en que son empleados con mayor frecuencia.

1) Se ha indicado que el uso de moledores en el pasado se vincula principalmente con el procesamiento de recursos comestibles de origen vegetal (Babot 2004, 2006, Cigliano et al. 1972, Olivera 1991, Raffino 1977, Tarragó 1980) o subproductos de los mismos como ‘chuño', 'tunta' (tubérculos deshidratados), granos tostados, plantas calcinadas para la elaboración de 'llipta', etc. En segundo término, entre los recursos comestibles de procedencia animal se menciona la molienda de ‘chuño’ (Babot 2004, 2006). La ocurrencia de estas acciones es altamente factible tanto en E1 y E5, teniendo en cuenta la relativa abundancia de frutos y semillas comestibles y con evidencias de procesamiento allí recuperadas. Asimismo es significativa las diferencias halladas en la representación de taxones en una y otra habitación y que podrían hipotéticamente traducirse en los recursos molidos en cada una (ver I- Los restos botánicos en este mismo Capítulo).

2) Sin embargo, también se ha observado que eventualmente los artefactos de molienda fueron empleados a menudo también para el procesamiento de sustancias no comestibles de origen animal e inorgánico. Los instrumentos de molienda empleados para el procesamiento de estos materiales han sido mayormente reservados para tales usos específicos, aunque en general se trata de artefactos que no presentan manufactura ni mantenimiento y que generalmente evidencian un desgaste bajo a moderado. Entre los usos a los que se destinaron estos productos molidos en el pasado se encuentran producción de manufacturas cerámicas y en fibras vegetales, tinción de lanas, preparación y aplicación de recubrimientos para pisos y paredes de piedra, elaboración de pigmentos para 
representaciones rupestres o decoración de tecnofacturas, posible realización de rituales, fabricación de llipta asociada al uso de coca, y curtido de pieles (Babot 2004, 2006). También podría mencionarse aquí el molido de sal para lo cual aún en la actualidad siguen utilizándose morteros.

La relación entre algunos de los instrumentos hallados en uso en el Núcleo 1 podría estar presente aunque las evidencias no son decisivas. Por un lado, si bien los morteritos de E1 y E5 presentan una morfología de notable particularidad, en ambos casos se trata de instrumentos manufacturados y con un grado considerable de desgaste por uso. Por su parte, los molinos de tamaño reducido que los acompañan presentan en general la superficie de molienda plana, poco desgastada. Guardan además similitud con otras piezas recurrentes en el material descartado o “resguardado” del núcleo habitacional.

Cabe mencionar además que el vínculo entre instrumentos de molienda pequeños con el procesamiento de minerales, pinturas corporales e incluso vegetales no comestibles, ha sido sugerido ya por varios autores a partir de la asociación contextual de hallazgos realizados en sitios del Noroeste argentino (Fernández Distel 1980, Boman 1908, Krapovickas 1958-59, Raffino 1977, Tarragó 1996). En este sentido, el uso de diferentes sustancias no comestibles se manifiesta también en los materiales excavados en las habitaciones del Núcleo 1. Entre los más significativos se encuentran los pigmentos de origen mineral recuperados entre los sedimentos o adheridos a artefactos, cuya caracterización fisicoquímica se encuentra aún en análisis. Asimismo se tienen evidencias del uso de sustancias psicoactivas de origen vegetal, procedentes específicamente de plantas del género Anadenanthera, en el interior de pipas de fumar depositadas en E1 (Bugliani et al. 2009). Respecto de los compuestos alucinógenos mencionados, su presencia en artefactos de molienda no ha sido detectada aún y el consumo de semillas de cebil previamente molidas ha sido abordado fundamentalmente a través de la presencia de material pulverizado y diferentes ítems de la parafernalia del consumo de alucinógenos (Bugliani et al. 2009, Kvist y Moraes 2006, Pérez Gollán 2000, Pérez Gollán y Gordillo 1993, Pochettino et al. 1999).

\section{Reutilización de los artefactos y relevancia de la práctica de molienda}

Tal como ha sido mencionado para los instrumentos de molienda en contextos del Noroeste argentino, la ruptura, el desgaste intenso y el abandono último del sitio han sido los motivos principales de la finalización de la vida útil de las piedras de moler recuperadas en Cardonal. En los dos primeros casos (piezas rotas y agotadas por el uso), resulta sorprendente 
la cantidad de artefactos que fueron descartados en el mismo lugar donde fueron empleados, es decir en los pisos ocupacionales de las habitaciones. Este comportamiento dificultó en gran medida establecer distinciones cabales entre el material efectivamente desechado y aquellas también numerosas piezas resguardadas o almacenadas en el interior de las habitaciones. Excepto en los pocos casos en que la posición de guardado es claramente distintiva, como ocurre con las piezas introducidas en huecos de la pared, los numerosos artefactos pasivos y activos dispuestos principalmente contra los muros de E3, aunque también en E5, así como las manos de moler aparentemente almacenadas en un sector de E2 y E4, están mezclados con el material de descarte.

Por otra parte, a diferencia de lo observado por Babot (2004, 2006), el reciclaje de instrumentos de molienda en el Núcleo 1 se ha dado con notable frecuencia. Tal como se desprende del registro exhaustivo y análisis de las piedras de moler en el sitio una cantidad considerable de artefactos han sido reutilizados para sostener palos de poste, levantar paredes y rellenar rasgos. Algunos pocos se reintegraron a los sistemas de molienda en uso, ya sea como moledores o como piedras de sostén de los artefactos inferiores. El conjunto de piezas recicladas en otros usos comprende no solamente aquellas fracturadas o desgastadas, sino que además incluye ejemplares que según los criterios de clasificación podrían seguir siendo empleados para moler.

De esta manera es posible observar la semejanza que existe entre la composición del conjunto de instrumentos reutilizados y el grupo de materiales descartados y "guardados” que se reúnen indistintamente en los pisos ocupacionales. En este sentido es posible que gran parte de los instrumentos que permanece en los pisos ocupacionales formara parte del material disponible para ser eventualmente reutilizado con fines diversos, estuviera o no en condiciones aptas para su uso en la molienda.

Estos comportamientos remiten no sólo a la multiplicidad de usos concernientes a estos artefactos más allá de la molienda de diferentes sustancias sino que también atestiguan el paso del tiempo de una ocupación prolongada y posiblemente también recurrente del Núcleo 1 de Cardonal. La presencia de varios instrumentos de molienda pasivos de grandes dimensiones, en los cuales la pared del fondo de la oquedad se ha desgastado y debilitado hasta perforarse, refiere no sólo al uso intenso sino también prolongado de estos artefactos. Lo mismo cabe decir para las numerosas piezas activas y pasivas que se acumulan en los pisos. De igual modo, aquellas empleadas como cuñas desde la base de los muros o en los hoyos de poste testimonian su presencia en momentos tempranos de la construcción de la casa, así como las posibles reconstrucciones y remodelaciones ocurridas subsecuentemente, de lo cual 
también es testimonio el terraplén construido en algún lapso de la historia de E5 (Scattolin et al. 2009 a, 2009 b).

La profusión de instrumentos de molienda, las diferentes modalidades de uso observadas, así como la larga trayectoria temporal de la que son parte, les otorga finalmente un carácter relevante en la historia de la vida cotidiana del Núcleo 1. De este modo, resulta ineludible considerar por fin la relevancia de la práctica para la que estos artefactos han sido concebidos en primera instancia, la molienda de productos comestibles y el aprecio que en términos prácticos y/o afectivos se observa en la preservación de las piezas. Puede observarse, por ejemplo, como algunas de ellas fueron cuidadosamente resguardadas y organizadas en diversos espacios (ver también Babot 2007) o bien como otras se emplearon en los espacios funerarios asociados a la aldea, a modo de tapa de enterratorio (Cortés com. pers.). 


\section{CAPÍTULO 8}

\section{Conclusiones}

\section{Algunas consideraciones acerca del abordaje y la metodología de trabajo}

Los aportes al conocimiento de las comunidades aldeanas del primer milenio realizados en este trabajo proceden en alguna medida de la aplicación de los procedimientos empleados en la obtención de los datos analizados y en la escala de abordaje seleccionada. A pesar de que en los últimos años los estudios dedicados al análisis de los espacios domésticos del Noroeste argentino han avanzado sobre diferentes áreas y lapsos temporales, sólo unos pocos han hecho énfasis en el análisis de múltiples aspectos de materiales específicos y su comportamiento en dichos contextos (Babot 2007, Capparelli 2009). La presente tesis se vincula con estos enfoques más recientes, fundándose en la consideración de conjuntos de restos vegetales y de los sistemas de molienda dispuestos en los pisos de ocupación de una unidad habitacional particular.

A su vez constituye un abordaje a microescala, a través del cual ha sido posible dar cuenta de aspectos culturales y sociales de la vida doméstica pasada que suelen quedar ocultos en estudios más amplios, que contemplan la totalidad de los ítems presentes en las áreas habitacionales o que avanzan a través del análisis de varias unidades o sitios. Dichos enfoques son sin embargo necesarios para alcanzar una comprensión amplia de los contextos domésticos, la caracterización de los grupos sociales pasados y la elucidación de los procesos y las trayectorias de las sociedades prehispánicas. En tal dirección se dirigen las investigaciones que dan inicio en este trabajo de tesis, enmarcada en un proyecto amplio que busca comprender la dinámica de las sociedades tempranas al sur de los valles Calchaquíes.

Por el momento, los análisis efectuados sobre los restos de plantas y el conjunto de artefactos de molienda del Núcleo 1 de Cardonal ha dado cuenta del vínculo de las actividades relacionadas con la alimentación con otras ocurridas al interior de la misma habitación, de las implicancias sociales y culturales de dichas actividades, el modo en que éstas se organizan en relación con los espacios a los que se circunscriben y los procedimientos por los cuales algunos objetos y materiales fueron obtenidos, empleados y descartados. Asimismo se 
destacaron algunos procedimientos involucrados en la preparación y consumo de diferentes especies vegetales. También se han señalado algunas cuestiones relativas a la tafonomía de los restos vegetales y los procesos de formación de sitio, que afectan los contextos domésticos dificultando, y a la vez enriqueciendo, el análisis y las interpretaciones del registro arqueológico.

En relación con los procedimientos y las técnicas empleadas en esta tesis resulta remarcable el hecho de que los materiales estudiados proceden de un conjunto de recintos adosados que fue excavado en área y de manera íntegra, lo cual no ha sido habitual en la arqueología del sur de los Valles Calchaquíes, excepto Yutopián, en el mismo valle del Cajón. Los sitios ubicados sobre la falda oeste del Aconquija y sur del valle de Santa María sólo cuentan con sondeos o recintos excavados parcial o totalmente, no con la excavación de núcleos habitacionales completos como es el caso del Núcleo 1.

Este carácter particular de las excavaciones desarrolladas en Cardonal se suma al diseño y la aplicación de métodos sistemáticos de recuperación y registro de los materiales sobre los que se basa esta tesis, a través de los cuales pudieron establecerse comparaciones al interior del núcleo y de las habitaciones mismas. Estos procedimientos permiten dar cuenta simultáneamente de los mecanismos empleados en la obtención de los datos, problemática que ha sido señalada frecuentemente en relación con los restos botánicos, y que los convierte en información utilizable en estudios comparativos entre diferentes sitios cuyos restos de plantas hayan sido documentados del mismo modo. En este sentido, los trabajos desarrollados en Cardonal contribuyen de manera sustantiva al registro arqueobotánico del Noroeste argentino.

Otros aportes que cabe señalar aquí son, por un lado la realización, testeo y utilización de un modelo de cubeta de flotación asistida por el flujo de agua, de fácil transporte y bajo costo. Dicho artefacto mostró ser eficiente (en términos de cantidad de restos recuperados y tiempo invertido) en la recuperación de vestigios botánicos en sitios con las características de los sedimentos presentes en Cardonal y con escasa disponibilidad de agua corriente y/o energía eléctrica, así como la dificultad de acceso a combustibles que permitan poner en funcionamiento un motor. Finalmente se ha proveído de un modelo de registro y descripción de campo para los artefactos de molienda del área basado en los descriptores definidos en estudios especializados. El mismo permite dar cuenta de caracteres relevantes a tener en cuenta en piezas que, una vez exhumadas, difícilmente pueden ser transportadas al gabinete para análisis más exhaustivos. Por último, goza de considerable importancia para estudios futuros en el valle del Cajón las colecciones de referencia de la flora actual y de 
frutos y semillas comestibles andinas secas y carbonizadas que se elaboraron y sistematizaron en este trabajo de tesis. La misma cuenta además con valiosa información acerca de los nombres vernáculos y usos tradicionales recopilados entre los pobladores actuales del valle.

\section{Las actividades en el Núcleo 1. Una mirada a través de restos de plantas y artefactos de molienda}

De acuerdo con la problemática y objetivo general de esta tesis, los capítulos precedentes procuran develar una parte del complejo de acciones cotidianas que transcurrieron a lo largo del tiempo en que el espacio del Núcleo 1 estuvo habitado, plasmándose en objetos y rasgos creados y utilizados en el pasado. Cada lugar, cada cosa y las relaciones que guardan entre ellos se interpretan no tanto como la manifestación de eventos puntuales en la historia del sitio, sino como la materialización de numerosos gestos diarios o periódicos, más o menos repetitivos, pero siempre acumulativos y creadores. Es así que, entre las acciones más evidentes e ineludibles ocurridas dentro del núcleo habitacional estudiado, se trae a consideración el encendido del fuego y su mantenimiento, no porque constituya en sí mismo el objeto de la tesis, sino porque en torno a él ha sido posible explorar varios otros sucesos de la vida diaria.

En primer lugar, al alumbrar el fogón periódicamente hace unos 1800 años en el Núcleo 1, ya sea con el fin de calefaccionar, cocinar, secar o cualquier otro propósito, se dio lugar a la carbonización y preservación de numerosos restos de frutos y semillas comestibles de los cuales una -probablemente exigua- parte ha perdurado hasta el momento de su recuperación y análisis. A su vez, los fogones tienen como carácter distintivo su legado de notables concentraciones de carbón de madera, presentes de manera casi obvia como rasgos de los pisos arqueológicos del Núcleo. Los lugares elegidos para el emplazamiento de los fogones son las proximidades de las aberturas de salida de los recintos E1 y E2, y un sector lateral de la habitación E5.

La estructura de combustión en E2 ha sido señalada, en estudios anteriores (Scattolin et al. 2009a, 2009b), como un fogón en desuso prácticamente limpio de carbón, lo cual se corrobora con la alta presencia de este material en las muestras de flotación, remanente de las combustiones allí ocurridas, pero de ninguna manera concentrado en el rasgo. Tampoco se hallaron cantidades relevantes de especies vegetales comestibles, carácter distintivo de los fogones de E1 y E5. El primero de ellos cuenta con tres piedras dispuestas a su alrededor, posiblemente para el sostén de ollas y otros enseres expuestos al fuego, que faltan en el 
segundo, simplemente definido como un área carbonosa. Ambos casos se denotan sin embargo en la ocurrencia repetida y localizada de combustiones que resultaron en acumulaciones de carbón de madera proporcionalmente mayores al resto del área de las habitaciones (ver Scattolin et al. 2009a, Scattolin et al. 2009 b). Es así que el acarreo sistemático y diario de leña hacia el interior de los recintos puede considerarse una de las actividades más importantes relacionadas con los fogones. Este tipo de acciones tiene además como consecuencia el aporte no intencional de semillas y otras partes de plantas silvestres que por su intermedio (entre otros mecanismos que se mencionan en el Capítulo 7) podrían acceder una vez carbonizadas, a los pisos de ocupación del Núcleo 1. Esta serie de actividades culturalmente pautadas se dio de manera conjunta durante un período determinado de tiempo que corresponde al lapso de la ocupación de los recintos. Además la presencia de materiales carbonizados permite distinguir aquellos sedimentos coetáneos con las combustiones y los artefactos arqueológicos asociados a ellos, de los materiales más recientes que rellenaron los depósitos.

Al mismo tiempo el uso cotidiano de los fogones se vinculó con otras prácticas, como la elaboración de comida y el descarte de residuos, dando lugar a la conservación y acumulación paulatina de una buena cantidad de semillas y frutos comestibles carbonizados en los pisos y rasgos del sitio, especialmente dentro de los mismos fogones. A diferencia de las plantas utilizadas como leña, las alimenticias ingresaron al núcleo con la intención de ser consumidas, procesadas y almacenadas. Los restos recuperados e identificados permitieron reconocer el consumo simultáneo de plantas de origen cultivado y silvestre, correspondientes a diferentes especies vegetales cuyas implicancias se discuten en el apartado siguiente. El espectro de frutos y semillas identificados incluye el maíz (Zea mays "Perla” y Z. m. AMARILLO), los porotos comunes cultivados (Phaseolus vulgaris var. vulgaris) y silvestres (P. v. var. aborigineus), el chañar (Geoffraea decorticans), el algarrobo blanco (Prosopis aff. alba o chilensis) y ejemplares afines a la quinoa negra o a la cañiwa (Chenopodium aff. quinoa o pallidicaule).

La presencia y distribución de estos recursos en el interior del núcleo habitacional estudiado permiten considerar la ocurrencia de actividades de procesamiento y probablemente también consumo de los mismos en relación con algunos espacios preferenciales. Estos lugares corresponden fundamentalmente a los fogones ubicados al interior de las habitaciones E1 y E5, denotados por la densidad y variabilidad de restos de vegetales comestibles dispuestos entre acumulaciones de carbón de leña y la estructura general del rasgo. Como también pudo advertirse a través de estos materiales, el conjunto de acciones y prácticas 
relacionadas con la preparación de alimentos y la ingesta de comida guardan sensibles diferencias entre una y otra habitación. Estos resultados dan sustento a interpretaciones previas realizadas acerca del uso del espacio en el Núcleo 1, en base al aporte de la recuperación sistemática de las muestras de flotación y el énfasis puesto en el reconocimiento de la distribución espacial y características generales de los restos botánicos. Hasta el momento las acciones de procesamiento de alimentos se sugerían en base a la estructuración desigual de los fogones, la mayor o menor abundancia y extensión de los sedimentos carbonosos en el piso, la presencia más o menos marcada de tizne y aspecto "graso" en las superficies de paredes y ollas, así como la configuración general de los conjuntos cerámicos, pero no en relación directa a la presencia de restos de comida.

Los indicadores empleados parecían mostrar además que en E1 la combustión y la manipulación de sustancias orgánicas alimenticias de origen animal y vegetal había sido más frecuente y sistemáticamente emprendida que en E5, donde se refiere un uso más espaciado o eventual del fogón en actividades similares (Scattolin et al. 2009a, Scattolin et al. 2009b). El análisis de los restos carpológicos recuperados en las habitaciones E1 y E5 corrobora la existencia de diferencias importantes en el mismo sentido, marcadas fundamentalmente en la disposición, tamaño y composición de los respectivos conjuntos de vestigios botánicos, a la vez que permite extender las interpretaciones acerca de dicho fenómeno.

El fogón de E1, delimitado por tres piedras colocadas de forma equidistante, hoy recuerda la morfología del fogón excavado en Yutopián (Gero y Scattolin 1999), con la particularidad de contener casi exclusivamente restos de especies comestibles domesticadas. Las semillas de porotos que por algún motivo no fueron consumidas, bien porque se trata de sobras de comida o de ejemplares caídos o descartados en el procedimiento de preparación, corresponden tanto a porotos cultivados como silvestres. Junto con ellos se concentran las cúpulas de maíz que, al contrario de los restos anteriores, representan la parte desechable del procesamiento de las mazorcas. Entre las acciones que podrían vincularse con este hecho pueden considerarse desde el uso, eventual o sistemático, de los marlos de maíz como combustible del fogón de E1 o bien su descarte. Resulta interesante además señalar que ningún grano de maíz apareciera asociado a los fogones y que en cambio unos escasos tres ejemplares aparecieran dispersos en los pisos de aquellos recintos sin estructuras de combustión en uso, del tipo de las halladas en E5 o en E1. Esta situación podría responder a varias causas que no necesariamente invocan la baja utilización o exigua importancia del maíz como recurso comestible. Por un lado es posible que los granos de maíz enteros tuvieran menos oportunidades de entrar al fogón, debido a que se los consumía preferentemente 
molidos, sin previo proceso de tostado o reventado, en forma de harina o en preparaciones fermentadas; o bien frescos, con lo cual su estructura permanece menos resistente a la acción del fuego.

El área de fogón de E5 por su parte, está delimitada únicamente por la extensión de sedimentos grasos y carbonosos en un sector circunscripto al costado de la abertura de ingreso al recinto. Entre estos sedimentos se recuperaron buenas cantidades de carbón de leña y restos de carozos de chañar, un fragmento de semilla identificable de algarrobo blanco y semillas de Chenopodium. La menor sistematicidad y frecuencia de uso que se adjudica a este rasgo, por comparación con las características estructurales y contextuales del fogón de E1, también queda sugerida en relación a las plantas comestibles asociadas al mismo. Los restos de chañar y algarrobo blanco coinciden en ser recursos silvestres y de recolección, cuyo consumo fresco o procesamiento para la elaboración de diversas preparaciones, según datos actualísticos (Capparelli 2007, Figueroa y Dantas 2006), se da principalmente en la época en que los frutos maduran y se colectan. Las harinas, jarabes y bebidas obtenidas pueden, en gran parte, conservarse durante un tiempo, o bien se consumirse en el momento. La fabricación de los mismos en otras épocas del año requiere del almacenamiento de los frutos, tal como ocurre en con las vainas de algarrobo. El guardado del chañar, en cambio es poco habitual ya que los frutos carnosos se echan a perder fácilmente. En este caso el sobrante generalmente se desecha o se deja para los animales, de modo los procesos de preparación tienen una frecuencia marcadamente anual.

De todos modos, aunque la reserva de frutos ocurriera en el pasado, es probable que el ritmo de la elaboración de harinas y jarabes estuviera ligado al agotamiento de las reservas de estos productos o bien a la preparación de bebidas refrescantes o alcohólicas en eventos particulares de tipo ceremonial o de rituales propiciatorios, como se ha podido observar durante las reuniones de señalada y marcada de animales que se celebran en la actualidad en el valle del Cajón. Por otra parte, los espacios de almacenamiento en el Núcleo 1 han sido señalados a partir de la presencia de vasijas, jarras y ollas ordinarias de gran porte sin evidencias de exposición al fuego (hollín, deterioro), grandes cestos tejidos en espiral y artefactos singulares, como un instrumento de hueso y puntas de proyectil de obsidiana, dispuestos en E2 y también E4. Estas áreas de almacenaje sin embargo no se han evidenciado por la presencia y distribución de restos botánicos de valor alimenticio. Aunque algunos fragmentos de carozos y semillas de chañar, uno de los granos de maíz y otros vestigios están presentes en el piso de ambos recintos, no alcanzan a dar una idea clara de reservas de comestibles o en todo caso de semillas para la siembra. Además, la variedad y dispersión de 
estos restos en los pisos ocupacionales podrían más bien obedecer a causas ligadas a otras acciones, como el barrido o la misma circulación de los habitantes del núcleo, que desplazaron de esta forma los restos carbonizados desde los fogones.

El examen íntegro de los depósitos del Núcleo 1 permitió además reconocer la ocurrencia diferencial de restos de plantas en torno a otros rasgos, así como en toda la superficie asignable a los pisos de ocupación de la casa, tal como es esperable en relación con la ocurrencia de acciones de orden cultural. Por fuera de las áreas comprendidas por los dos fogones, puntos álgidos de concentración de restos de plantas comestibles, los espacios de los recintos resultaron en hallazgos mucho más raros y aislados de vestigios procedentes de otras especies en su mayoría no asignables a alimentos comestibles por el momento. Algunas de ellas también se recuperaron entre la leña y los frutos y semillas comestibles de los fogones. Es en este sentido que se ha planteado a las áreas de combustión del núcleo habitacional, por una parte, como agentes importantes de la formación del registro arqueobotánico del sitio y por otra, como espacios donde mayormente ocurrieron acciones vinculadas con la manipulación de plantas alimenticias, ya sea procesamientos diversos, descarte de partes no comestibles, eventuales “pérdidas”, o su reciclaje como combustible, etc.

Asimismo, son las habitaciones provistas de fogón las que contienen sendas áreas dedicadas a la actividad de molienda. Estos sectores se demarcan por la presencia de molinos, morteros y sus respectivas manos, muy probablemente relacionadas con el procesamiento de alimentos, entre otros usos menores como el molido de fumitorios (Anadenanthera) y pigmentos. Entre los posibles recursos de moler más sobresalientes presentes en el conjunto de vegetales arqueológicos se encuentra el maíz, aunque otros de los recursos comestibles y no comestibles recuperados en los mismos recintos podrían haber sido pulverizados, machacados o quebrados en los sistemas de molienda contextualmente asociados, como las semillas de algarrobo y de chañar o el mismo Chenopodium. Aunque no se han hallado evidencias directas de productos de moler de origen animal como el charqui (Babot 2004, 2006) sí están presentes gran cantidad de huesos pertenecientes principalmente a llamas, entre otros camélidos, tarucas y quirquinchos.

El abordaje del instrumental de molienda efectuado en este trabajo no había sido efectuado con anterioridad en sitios del área al sur del los Valles Calchaquíes, a pesar de que los mismos han sido hallados en la mayoría de los sitios estudiados previamente. Los grandes molinos de piedra y las manos de moler se referencian como ítems recurrentes en las áreas habitacionales y en general relacionados con la ocurrencia de prácticas de procesamiento de alimentos, aunque se ha invertido poco esfuerzo en el análisis de sus características 
morfológicas y contextuales. No obstante en esta contribución dichos aspectos han brindado buenas referencias para la caracterización e interpretación de las actividades de molienda y su importancia para la economía de las aldeas tempranas del área, entre otros aportes.

En primer lugar se ha podido constatar que, al igual que los restos de plantas alimenticias, la distribución de los sistemas de molienda en el Núcleo 1 manifiesta contrastes y similitudes entre las dos habitaciones involucradas en la actividad de molienda. Por un lado, el uso de sistemas provistos de instrumentos pequeños, los cuales podrían relacionarse con el procesamiento de sustancias no comestibles (Babot 2004), como las semillas de cebil o los pigmentos, tuvo lugar en ambas habitaciones, especialmente ligado a los espacios donde se encendía el fuego. Estas áreas de molido integran un sistema molino de mano - mano de molino y otro mortero - mano de mortero, ambos de características morfológicas muy similares en uno y otro fogón. En cambio, la molienda de productos comestibles, se caracteriza por el empleo de sistemas de molienda de grandes dimensiones, integrados por molinos de mano a los que en general se asocian varios instrumentos activos, tal como lo señalara Babot (2007) para varios sitios tempranos del Noroeste argentino. Este tipo de molienda, sin embargo se manifiesta únicamente en un sector circunscripto al interior de E1. Dicha área incluye dos molinos con poco desgaste y algunas manos de molino que quedaron abandonadas a su alrededor, mientras que algunas manos y otras piedras fueron empleadas como sostén del artefacto pasivo de mayor tamaño.

Las demás habitaciones, especialmente E3 y muy probablemente E2, presentan áreas de guardado de los instrumentos pero no de molienda propiamente dicha. La primera de ellas, siendo un espacio de tránsito obligado en el acceso a tres de las habitaciones restantes, alberga varios molinos de mano medianos y grandes con poco desgaste dispuestos perimetralmente en un sector del muro, muy próximas con varias manos de moler. En E2 sólo manos de moler fueron almacenadas en la parte norte de la habitación, junto a los otros varios materiales que se disponían en este recinto. Algunos de entre estos instrumentos de molienda, así como muchos otros depositados en E5, el Portal y E4 probablemente hayan sido empleados también en determinadas circunstancias para cumplir funciones diferentes. Estas acciones han sido observadas en varios instrumentos que, sin poseer roturas ni signos visibles de agotamiento, fueron utilizados a modo cuñas en la base de los muros y pozos de poste, como piedras en la construcción de paredes, para asegurar los palos de sostén de la techumbre y también como material de relleno, indistintamente de los muchos artefactos de molienda fragmentarios destinados a fines semejantes. 
Entre los hechos más remarcables sugeridos por la cantidad, variedad y distribución espacial de los artefactos de molienda y las actividades asociadas se encuentra la extensión temporal que puede adjudicarse a la ocupación del Núcleo 1. El empleo de artefactos usados o ya descartados en la construcción y remodelaciones efectuadas indican que varios artefactos preexistieron al levantamiento de muros o la fabricación de un techo o reemplazo de un palo de poste. De igual modo, la presencia de artefactos pasivos de grandes dimensiones, completamente desbastados y perforados en los pisos y cavidades de los recintos, muestran el tiempo transcurrido desde que uno de esos instrumentos comenzó a usarse hasta que tuvo que ser reemplazado por otro.

Por otra parte, la marcada presencia y diversidad de artefactos en uso o en posición de guardados dan cuenta de la relevancia de la actividad de molienda para los habitantes del Núcleo 1. Esta práctica involucraba una serie de recursos que se preparaban, y de manera regular, principalmente en el ámbito del recinto E1, donde se ha conservado la mayor parte de los restos de porotos y maíz, el fogón diario y los sistemas de molienda de artefactos grandes, normalmente asociados al procesamiento de recursos alimenticios (Babot 2004, 2006). Otros productos, comestibles o no, en cambio podrían vincularse con acciones de preparación y consumo efectuadas con los molinos de mano más pequeños, presentes en las inmediaciones de los fogones de E1 y E5. Asimismo, es posible que se dieran instancias particulares en las que fuera necesario emplear parte de los instrumentos guardados, por ejemplo para procesar cantidades mayores que la habitual de determinados productos. Circunstancias como estas pueden incluir actividades relativas a la preparación de alimentos y bebidas en eventos de reunión social, la recolección estacional o cosechas de cantidades significativas de ciertos recursos empleados en la elaboración colectiva de diferentes productos para consumir o almacenar, entre otras innumerables actividades que futuros estudios podrán seguir indagando en los espacios domésticos aldeanos del sur de los Valles Calchaquíes y que hasta ahora sólo han sido esbozadas en base a los materiales estudiados en esta tesis.

En conjunto, las actividades y acciones inferidas a partir del estudio de los restos vegetales y los instrumentos de molienda al que se dedica esta tesis, muestran la ocurrencia de prácticas situadas en espacios delimitables arqueológicamente a través de la distribución contextual de los materiales. Sin embargo, ninguna de las actividades manifiestas en cada uno de los recintos del Núcleo 1 se muestra aislada de otras actividades. Sobre este punto han llamado la atención algunos trabajos previos realizados en relación con otros ítems y conjuntos excavados dentro del área de estudio (Bugliani 2008, Bugliani et al. 2009, Izeta 2008, Scattolin 2009 a, 2009b). Incluso se han hallado en estrecha asociación actividades de 
producción de bienes especializados, como la metalurgia, con el procesamiento y consumo de alimentos en los recintos excavados en Yutopián (Gero y Scattolin 1999) en tanto están ausentes los enterratorios que suelen reportarse en otros contextos domésticos del Noroeste argentino (Albeck 1995-1996, Salazar 2007, Tarragó 2007). En el Núcleo 1 de Cardonal, la molienda de recursos alimenticios, entre otros procedimientos de preparación y cocción de semillas y frutos, se dieron en espacios compartidos con la talla de artefactos líticos, la preparación de pigmentos minerales, el consumo de alucinógenos, la remodelación de muros y rasgos arquitectónicos, el almacenamiento de materiales y guardado de objetos, tal como se manifiesta en la presencia y distribución de molinos de mano de grandes dimensiones en posición de uso y los restos de diversas plantas comestibles en relación con otros ítems del contexto de las habitaciones.

Quedan como incógnita aquellas acciones relativas al uso de plantas y la molienda que tuvieron lugar por fuera de las paredes del núcleo. Los ámbitos exteriores tienen gran importancia como espacios donde se desarrolla la vida doméstica entre los pobladores actuales del área y ha sido planteado a modo hipotético también para el pasado (Albeck 19951996, Babot 2007, Calo et al. 2010, Nielsen 2001). No obstante, muchas de las prácticas de subsistencia de los habitantes del Núcleo 1 se evocan desde los mismos materiales hallados en su interior y a través de ellas se han podido abordar aspectos relevantes de la economía doméstica de las aldeas al sur de los Valles Calchaquíes que se tratan en el apartado siguiente.

\section{Aspectos de la economía doméstica y la organización de la subsistencia en las aldeas del sur de los valles Calchaquíes: aportes desde el Núcleo 1}

Para el área en cuestión, son principalmente los estudios arqueofaunísticos, aunque también los análisis de materiales líticos y alfareros, los que han colaborado en la definición de aspectos sobresalientes de la economía doméstica y la explotación de recursos alimenticios y otros bienes por parte de las comunidades tempranas. Tal como se detalla en los apartados introductorios de esta tesis, dichas investigaciones plantean la existencia de un sistema de subsistencia de tipo mixto, en el que la práctica del cultivo de vegetales se combinaba con el pastoreo de camélidos. A su vez, la obtención de recursos se complementaría con ítems procedentes de las actividades de caza y recolección de animales y plantas silvestres y el almacenaje, acciones tendientes a equilibrar los recursos entre las estaciones (Izeta 2007, Izeta y Scattolin 2006, Lazzari 2006). 
Respecto de los recursos vegetales, no obstante la evidencia estaba representada fundamentalmente por los restos recuperados in situ en depósitos de la Falda Occidental del Aconquija, así también gran parte de los demás materiales estudiados proceden de sitios de este mismo sector. De este modo se ha considerado que la subsistencia de los grupos asentados en la zona podría haberse resuelto dentro de una serie de áreas complementarias. Tales áreas comprenden el sector occidental de la Falda propiamente dicho, el sector oriental de la misma y muy posiblemente los valles más bajos ubicados a ambos lados de la sierra, relacionadas a través del entrelazamiento de ciclos productivos también complementarios. Así, los ciclos de producción agrícola y pastoril se desenvolverían dentro de los límites del sector occidental del Aconquija. En tanto, los ciclos de extracción de productos silvestres incluirían los valles más bajos en una y otra ladera: caza en el Campo del Arenal, recolección de chañar en los valles occidentales y de poroto silvestre en los orientales (Lazzari 2006).

Los resultados obtenidos a partir de este trabajo de tesis constituyen un aporte de considerable relevancia para la discusión de dicho modelo de explotación y uso de los recursos, por parte de los grupos asentados sur de los Valles Calchaquíes durante los primeros siglos de la era cristiana, ya que contribuye con información hasta el momento inexistente para el Valle del Cajón. Este estudio se cuenta además entre los escasas publicaciones que aplican de manera exhaustiva procedimientos de flotación para el reconocimiento del rango de recursos vegetales domesticados y silvestres presentes en sitios arqueológicos tempranos del Noroeste argentino.

En primer lugar, la existencia de prácticas de cultivo se insinúa en los hallazgos de diferentes cultígenos realizados en el núcleo habitacional muestreado. Entre las especies domesticadas identificadas se encuentra el maíz (Zea mays), representado por la variedad Z. m. var. minima ('maíz perla') y la raza Z. m. AMARILLO descripta por Miante Alsogaray y Cámara Hernández (1974); asimismo se consumía la variedad cultivada de los porotos comunes (Phaseolus vulgaris var. vulgaris).

Por su parte, los recursos vegetales no domesticados empleados como alimento también están presentes en número considerable y se asocian a la ocurrencia de actividades de recolección. Los mismos comprenden el chañar (Geoffraea decorticans), el algarrobo blanco (Prosopis aff. alba o chilensis) y la variedad silvestre del poroto común ( $P$. v. var. aborigineus). Otra planta comestible del Género Chenopodium, presente en el conjunto de restos de Cardonal, es afín a dos especies con semillas más pequeñas que la quinoa común ( $C$. quinoa var. quinoa). Una de ellas es un cultivo andino rústico, la cañiwa (C. pallidicaule) que ha sido registrado arqueológicamente en la altiplanicie boliviana (Bruno 2006) y que se da 
silvestre en el norte argentino. La otra es una variedad de tipo ruderal que se conoce en el Noroeste con el nombre de quinoa negra (C. q. var. melanospermum). Aunque el nivel de identificación alcanzado no es suficiente para asignar este recurso a la categoría de domesticado o silvestre (o ruderal), sí es posible asociarlo al grupo de vegetales comestibles, dada su presencia dentro de los carbones del fogón de E5 junto con otros indicios de preparación de alimentos, así como señales de algún tipo de procesamiento como la cocción en agua observada en los vestigios mismos.

Un caso interesante representan las semillas de Chenopodium remanentes del encendido eventual o periódico del fuego en E5, puesto que representan una incógnita respecto de su uso 1) como recurso utilizado o disponible periódica o eventualmente y no almacenable o bien 2) como producto de consumo regular y preservado luego de su cosecha o recolección. Por una parte, su asociación al fogón de E5 podría interpretarse como indicio de un uso menos frecuente. En tanto, la segunda opción tiene sustento en el hecho de que los pseudocereales son y han sido cultivos de importancia para las regiones altas de los Andes, y sus semillas secas pueden almacenarse por largos períodos. El problema sobre la posibilidad de su cultivo en Cardonal, sin embargo, sólo podrá resolverse a la luz de nuevos hallazgos y el alcance de niveles más afinados en la determinación taxonómica (especie y variedad) de los restos. De todas maneras, cabe resaltar como un aporte de considerable importancia que la recuperación sistemática de las pequeñas semillas de Chenopodium en el Núcleo 1, contextualmente asociadas a un fogón doméstico de inicios de la era, representa una de las primeras evidencias concretas de uso de estas plantas en el área de valles, la cual hasta el momento sólo había sido mencionada en los informes de Yutopián (Rossen 1998b).

Las demás evidencias de vegetales útiles halladas en Cardonal forman parte del conjunto de recursos presentes con mayor o menor asiduidad en diferentes contextos de procesamiento y consumo en sitios agropastoriles de los Valles, Puna y Yungas del Noroeste argentino. En cambio, si se compara con la totalidad de frutos y semillas comestibles registradas hasta el momento en esta región, existe una amplia gama de especies que no forman parte del rango de recursos del Núcleo 1. Entre las ausencias más destacables se encuentran, por ejemplo, los zapallos (Cucurbita maxima) y el algarrobo negro (Prosopis nigra), todos ellos disponibles y muy usados en la actualidad, así como profusamente representados en contextos arqueológicos contemporáneos del sitio aquí estudiado. De acuerdo a lo discutido en el Capítulo 7, más allá de la posibilidad de que estas especies no fueran utilizadas antiguamente, la ausencia de sus restos da una pauta del camino a seguir en el estudio de los conjuntos de plantas útiles representadas en el registro arqueobotánico del 
Noroeste, el cual adolece hasta el momento de estudios tafonómicos y de los procesos de formación de sitio que afectan a las especies involucradas. La interpretación y evaluación de los restos recuperados a la luz de estos procesos, enriquecería en gran medida la comprensión de la subsistencia y la economía doméstica de las sociedades pasadas. De igual modo se ha señalado la falta de estudios sobre la biología y ecología de varias especies útiles, a través de las cuales podrían lograrse no sólo mejores determinaciones sino también se accedería a niveles más profundos y meticulosos de conocimiento de diferentes aspectos de las relaciones establecidas con el mundo vegetal en el pasado (ver Lema 2009).

En vistas del último punto señalado arriba, ha sido posible establecer algunas consideraciones acerca de las prácticas de cultivo sugeridas en Cardonal por la presencia de especies domesticadas en contextos de uso y la ocurrencia de estructuras agrícolas en su perímetro. Por un lado se ha señalado que las dos posibles especies representadas por las pequeñas semillas de Chenopodium, procedan ellas o no de los campos de cultivo que circundan la aldea, corresponden a plantas de gran valor alimenticio, aptas para crecer en la región de borde de puna donde se emplaza Cardonal. De igual modo, los maíces de grano duro, pequeño y de tipo reventón presentes entre los recursos domesticados comestibles del sitio, reúnen las condiciones para considerarlos producto de la siembra local.

Estos hallazgos apoyan la hipótesis de la existencia de un sistema de subsistencia mixto, en el cual la cría de animales domesticados (ver Scattolin et al. 2007) se combina con el cultivo de vegetales. Este último se caracterizaría en parte por el manejo de especies adaptadas a las condiciones ambientales propias del borde de Puna, y que de tal modo podrían sembrarse y cosecharse en las estructuras de cultivo espacialmente asociadas a los sitios. Por el contrario, en el caso de los porotos cultivados, la posibilidad de crecer en altitudes por encima de los 2000 msnm se ven reducidas, en la actualidad, a unas pocas áreas circunscriptas. Aún en condiciones climáticas más húmedas que las de hoy (ver Capítulo 3), a casi $3000 \mathrm{msnm}$, es probable que el logro de cosechas de porotos en el pasado tendría como condición el uso de riego artificial, lo cual no es posible afirmar en base al escaso conocimiento que se tiene actualmente de las técnicas agrícolas empleadas en Cardonal. En todo caso, la presencia de porotos de cultivo puede sugerir también el control y explotación agrícola de áreas de menor altitud, o bien el intercambio de estos productos con poblaciones vecinas de los valles mesotermales y de las Yungas del oriente andino.

Prácticas similares, que implican la existencia de redes sociales extensas y/o el conocimiento y manejo de un territorio amplio y ecológicamente diverso, pueden inferirse también en base a la presencia de restos de consumo de porotos silvestres en el Núcleo 1. Este 
recurso crece en la actualidad de forma espontánea o asociado a los cultivos en valles bajos y húmedos del Noroeste argentino. Si bien es raro encontrarlo dentro del territorio de la provincia de Catamarca, el área más próxima al sitio donde esta especie se da profusamente es en el límite con Tucumán, sobre la ladera oriental de la sierra del Aconquija, continuando también más al Este. Otros ítems materiales hallados en el Núcleo 1 también aluden a la existencia de este vínculo con la región de Yungas, desde donde se obtendrían diversos productos directamente o a través del contacto y la interacción con comunidades del este andino y el Chaco. Se ha mencionado por ejemplo la presencia de elementos estilísticos cerámicos evocativos del estilo Candelaria y de otras piezas alfareras características de las selvas orientales, así como también varios fragmentos de vasijas afines al tipo Tafí Monocromo Rojo de la ladera Este del Aconquija (Scattolin et al. 2007). Asimismo, el análisis de los contenidos de la pipas de fumar de Cardonal indican el uso de Anadenanthera (Bugliani et al. 2009), un género arbóreo cuyos representantes crecen a lo largo de la ceja de selva del oriente andino.

Bastante más próximos que las poblaciones de porotos silvestres o de Anadenanthera, aunque igualmente restringidos en un espacio ecológico diferenciado, se dan algarrobos y chañares. Durante la ocupación de Cardonal, los frutos comestibles obtenidos de estas plantas debieron recolectarse en una franja de Monte que se extiende sobre la parte más baja del mismo valle del Cajón, en las márgenes de los ríos Cerro Colorado y la desembocadura del Totoral. Llegar hasta allí implica hoy en día recorrer casi 30 km, aunque es posible considerar un área de árboles y arbustos antiguamente más extensa, que fue retrayéndose con el avance de las condiciones áridas del ambiente actual y/o la explotación intensa de estos recursos. Otros mecanismos que podrían explorarse al respecto se vinculan con los modos en que se obtiene en la actualidad el algarrobo para su uso en La Quebrada y otras localidades de la vertiente oeste del valle. En general, es un producto apreciado para el consumo y utilizado a veces como ofrenda a la Pacha Mama, que se obtiene sin embargo esporádicamente, a través de amigos y familiares que vienen de Santa María o poblados ubicados hacia el Sur o al Este del valle.

En síntesis, lo expuesto precedentemente muestra que el estudio de los restos botánicos de Cardonal aquí presentado, contribuye a reforzar con nuevos datos la idea de la existencia de un sistema de subsistencia mixto agrícola y pastoril, en el cual las actividades extractivas mantienen un grado de importancia considerable. Asimismo, los recursos comestibles documentados en el Núcleo 1 dan cuenta de la integración y explotación de áreas ecológicamente disímiles y complementarias, tal como había sido planteado principalmente 
para sitios de la Falda Occidental del Aconquija. En este caso la organización de la subsistencia de las aldeas del Valle del Cajón incluye cultivos locales y posiblemente también otros de fondo de valle, la recolección de recursos vegetales silvestres en las áreas de Monte y el intercambio de productos y bienes con poblaciones distantes y diferentes de la vertiente oriental andina. Es decir que el abanico de recursos comestibles empleados en el Núcleo 1 de Cardonal requirió del desarrollo de estrategias sociales y económicas diversas.

Para finalizar, queda por decir que más allá de la abundancia y variedad de restos de plantas alimenticias o de tipos de instrumentos de molienda representados en el contexto doméstico analizado en esta tesis, son las implicancias sociales, culturales y económicas de las acciones y actividades que los involucran, las que permiten vislumbrar la significación de cada uno. Los materiales aquí estudiados, entendidos como manifestaciones de gestos reiterados y cotidianos, han permitido avanzar en el conocimiento de una serie de rasgos y matices que definen el carácter de la economía doméstica y la subsistencia de las comunidades aldeanas asentadas al sur de los Valles Calchaquíes en los inicios del primer milenio de la era. 


\section{Bibliografía}

Abiusso, N.G. y J. Cámara Hernández

1974 Los maíces autóctonos de la Quebrada de Humahuaca (Jujuy, Argentina). Sus niveles nitrogenados y su composición en aminoácidos. Revista de la Facultad de Agronomía (Tercera Época) 1(1-2): 1-25, La Plata.

Adams, J.L.

1996 Manual for a technological approach to ground stone analysis Center for Desert Archeology. Tucson.

Albeck, M.E. (ed.).

1994 Taller “De Costa a Selva”. Producción e Intercambio entre los Pueblos Agroalfareros de los Andes Centro Sur. Instituto Interdisciplinario de Tilcara, Facultad de Filosofía y Letras, Universidad de Buenos Aires, Tilcara, Jujuy.

Albeck, M.E.

1995-1996 Áreas de actividad doméstica en Pueblo Viejo de Tucute (Puna de Jujuy). Estudios Atacameños 12: 61-73. San Pedro de Atacama, Chile.

Albeck, M.E.

2000 La vida agraria en los Andes del sur. En (M. N. Tarragó Dir.) Nueva Historia Argentina. Tomo I, Los Pueblos Originarios y la Conquista, pp.187-288. Editorial Sudamericana, Buenos Aires.

Aldenderfer, M. y C. Stanish

1993 Domestic Architecture, Household Archaeology and the past in the South Central Andes. En: M. Aldenderfer (ed.) Domestic Architecture, Ethnicity and Complementarity in the South-Central Andes. University of Iowa Press, Pp. 1-12.

Allison, P.M.

1999 Introduction. En Allison P.M. (Ed.) The Archaeology of the Household Activities. Routledge, Londres-Nueva York. Pp. 1-18. 
Allison, P.M.

2001 Using the Material and Writing Sources: Turn of the Millenium Approaches to Roman Domestic Space. American Journal of Archeology 105: 181-208.

Allison, P.M. (ed.)

2004 Pompeian Households: An Analysis of the Material Culture. Cotsen Institute of Archaeology, UCLA, Los Angeles.

Archilla, S. M. Giovannetti y V. Lema (comp.)

2008 Arqueobotánica y Teoría Arqueológica. Discusiones desde Suramérica. Uniandes. Bogotá.

Arena, M.D.

1975 Arqueología del Campo del Fraile y aledaños (Valle del Cajón, Depto. Santa María, Catamarca). En: Actas y trabajos del Primer Congreso de Arqueología Argentina: 43-96. Buenos Aires.

Aschero, C. y M. A. Korstanje

1996 Sobre figuraciones humanas, producción y símbolos. Aspectos del arte rupestre del noroeste argentino. En XXV Aniversario Museo Arqueológico Dr. Eduardo Casanova, editado por María Clara Rivolta, pp. 13-32. Instituto Interdisciplinario Tilcara, Facultad de Filosofía y Letras, Universidad de Buenos Aires, Tilcara, Jujuy.

Atalay, S. y C.A. Hastorf

2006 Food, Meals, and Daily Activities: Food Habitus at Neolithic Çatalhöyük American Antiquity 71(2): 283-319 Society for American Archaeology.

Avila, A. y R. Herrero

1991 Secuencia estratigráfica 1 del sitio arqueológico Martínez 3 (SCatAmb 003), Depto. Ambato, Catamarca. Publicaciones 46, Arqueología, Centro de Investigaciones de la Facultad de Filosofía y Humanidades. Universidad Nacional de Córdoba.

Babot, M.P. 
2004 Tecnología y utilización de artefactos de molienda en el noroeste prehispánico. Tesis Doctoral inédita. FCNeIML, Universidad Nacional de Tucumán.

Babot, M.P.

2006 El papel de la molienda en la transición hacia la producción agropastoril: Un análisis desde la Puna Meridional argentina. Estudios Atacameños 32: 75-92. San Pedro de Atacama, Chile.

Babot, M.P.

2007 Organización social de la práctica de molienda: casos actuales y prehispánicos del Noroeste Argentino. En: Nielsen A.E., M.C. Rivolta, V. Seldes, M.M. Vázquez y P.H. Mercolli (Comp.) Procesos Sociales Prehispánicos en el Sur Andino. La Vivienda, la Comunidad y el Territorio. Editorial Brujas. Córdoba. Pp. 259-290.

Babot, M.P.

2008 Reflexiones sobre el abordaje de la molienda vegetal desde una experiencia de integración disciplinaria. En S. Archila, M. Giovannetti y V. Lema (eds.) Arqueobotánica y Teoría Arqueológica. Discusiones desde Suramérica. Ediciones Uniandes, Bogotá. Pp. 203230.

Babot, M.P., N. Oliszewski y A. Grau

2007 Análisis de caracteres macroscópicos y microscópicos de Phaseolus vulgaris (Fabaceae, Faboideae) silvestres y cultivados del Noroeste argentino: una aplicación en arqueobotánica. Darwiniana 45(2): 149-162.

Baied, C.

1999 Distribución actual de matorrales altoandinos de Polylepis en los Andes centro-sur: oscilaciones climáticas y el impacto de la actividad humana en el pasado. En En los tres reinos: prácticas de recolección en el cono sur de América, editado por C. A. Aschero, M. A. Korstanje y P. M. Vuoto, pp. 129-140. Instituto de Arqueología y Museo Facultad de Ciencias Naturales e Instituto Miguel Lillo, UNT.

Baied, C. y J. Wheeler 
1993 Evolution of High Andean Puna Ecosystem: Environment, climate and culture change over the last 12000 years in the Central Andes. Mountain Research and Development 13: 145156

Baker, P., G. Seltzer, S. Fritz, R. Dunbar, M. Grove, P. Tapia, S. Cross, H. Rowe y J. Broda 2001 The History of South American Tropical Precipitation for the Past 25000 Years. Science Vol. 291: 640-643.

Balesta, B. y N. Zagorodny 1999 La transición Ciénaga/Aguada en el valle de Hualfín. Actas del XII Congreso Nacional de Arqueología Argentina, 3:271-276. Universidad Nacional de La Plata, La Plata,

Berberián, E.E. y A.E. Nielsen

1988 Sistemas de asentamiento prehispánico en la etapa Formativa del valle de Tafí (Pcia. de Tucumán, Rep. Argentina.) En E. Berberián, (dir.), Sistemas de asentamiento prehispánicos en el valle de Tafí, p. 21-51. Córdoba, Comechingonia.

Berglund-Brücher, H. y Brücher O.

1976 The South american wild bean (Phaseolus aborigineus Burk.) as ancestor of the common bean. Economic Botany 30:257-272.

Bianco, César Augusto; Cantero, Juan José; Nuñez, César Omar y Letizia Petrina. 2001. Flora del centro de la Argentina. Iconografía. Universidad Nacional de Río Cuarto.

Blanton, R.E.

1994 Houses and Households: A Comparative Study, Interdisciplinary Contributions to Archaeology. Plenum Press. London and New York.

Boardman, S. y G. Jones

1990 Experiment on the Effects of Charring on Cereal Plant Components. Journal of Archaeological Sciences 17: 1-11.

Boelcke, O. 
1946 Estudio morfológico de las semillas de Leguminosas Mimosoideas y Caesalpinoideas de interés agronómico en la Argentina Darwiniana 7(2): 240-321.

Boman, E.

1908 Antiquités de la région andine de la République Argentine et du désert d'Atacama. Imprimerie Nationale, París.

Bourdieu, P.

1977 Outline of a Theory of Practice. Cambridge University Press, Cambridge

Braadbaart, F. y P.J. Wright

2007 Changes in Mass and Dimensions of Sunflower (Helianthus annus L.) Achenes and Seeds Due to Carbonization. Economic Botany 6(2): 137-153.

Browman D.L.

1980 Tiawanaku expansion and altiplano economic patterns. Estudios Arqueológicos 5: 107120. San Pedro de Atacama.

Bruch, C.

1911 Exploraciones arqueológicas en las provincias de Tucumán y Catamarca. Revista del Museo de La Plata 19. UNLP. La Plata.

Bruno M.C.

2005 Domesticado o silvestre? Resultados de la investigación de semillas de Chenopodium. Chiripa, Bolivia (1500-100 A.C.) Textos Antropológicos 15(2): 39-50. Universidad Mayor de San Andrés. La Paz.

Bruno M.C.

2006 A Morphological Approach to Documenting Domestication of Chenopodium in the Andes En: Seder M.A., Bradley D.G., Emshwiller E., y B.D. Smith (Eds.) Documenting Domestication. New genetics and archaeological paradigms. University of California Press. Berkeley. Pp. 32- 45.

Bruno, M.C. y W.T. Whitehead 
2003 Chenopodium cultivation and Formative Period agriculture at Chiripa, Bolivia. Latin American Antiquity 14(3): 339-355.

Bugliani, M.F.

2007 Representaciones visuales y prácticas en contextos funerarios. Las vasijas del Formativo en las tumbas del sur de los valles Calchaquíes. XVI Congreso Nacional de Arqueología Argentina. Número Especial de Revista Pacarina (resumen ampliado), Tomo II: 421-426. FHyCS, Universidad Nacional de Jujuy.

Bugliani, M.F.

2008 Consumo y Representación en el Sur de los Valles Calchaquíes (Noroeste Argentino): Los Conjuntos Cerámicos de las Aldeas del Primer Milenio A.D. B. A. R. International Series, S1774. Oxford, John and Erica Hedges.

Bugliani, M.F., Calo C.M, Scattolin M.C

2009 Fumando en la cocina: determinación de contenidos por técnicas físico químicas en dos pipas cerámicas del sitio Cardonal. Actas del $3^{\circ}$ Congreso Argentino de Arqueometría y $2^{\circ}$ Jornadas Nacionales para el Estudio de Bienes Culturales.

Burkart, A.

1952 Las leguminosas argentinas silvestres y cultivadas. ACME, Buenos Aires.

Bush, M.B., Silman M.R. y D.H. Urrego

2004 48,000 Years of Climate and Forest Change in a Biodiversity Hot Spot. Science 303: 827-829.

Buxó, R.

1997 Arqueología de las Plantas. Crítica, Barcelona.

Cabrera, A.

1976 Regiones Fitogeográficas Argentinas. Enciclopedia Argentina de Agricultura y Jardinería, tomo II, Buenos Aires.

Cabrera, A. 
1983 Flora de Jujuy. INTA, Jujuy.

Calo, C.M.

2006 Arqueobotánica de la falda occidental del Aconquija (Catamarca) Informe ms.

Calo, C.M.

2007 Informe sobre restos botánicos carbonizados procedentes del Aconquija. MS.

Calo, C. M.

2008 Improntas del pasado: las canastas de Cardonal. Revista Española de Antropología Americana. 38-2: 39-55. Universidad Complutense, Madrid.

Calo, C.M., M.F. Bugliani, M.C. Scattolin

2010 Allí algo se cocina... espacios de preparación de alimentos en el Valle del Cajón. I Jornadas de Arqueología de la Alimentación. Presentación oral, Córdoba.

Calo, C.M. y L.I. Cortés

2008 A contribution to the study of diet of Formative societies in North-western Argentina: isotopic and archaeological evidences. International Journal of Osteoarchaeology 19: 192203.

Calo, C.M., S.M. Rivera, M. C. Scattolin

2006-2007 Los recursos combustibles arqueológicos en Loma Alta (Catamarca, Argentina). Anales de Arqueología y Etnología 61-62: 165-175. Instituto de Arqueología y Etnología. Facultad de Filosofía y Letras. Universidad Nacional de Cuyo. Mendoza, Argentina.

Cámara Hernández J. y D. Arancibia de Cabezas

2007 Maíces andinos y sus usos en la Quebrada de Humahuaca y regiones vecinas. Ed. FAUBA. Buenos Aires.

Cámara Hernández, J. y J.C. Rossi

1968 Maíz arqueológico de Cafayate, Salta. Boletín de la Sociedad Argentina de Botánica 12: 234-242. 


\section{Capparelli A.}

1997. Reconstrucción ambiental del sitio arqueológico Inka El Shincal. Tesis Doctoral Inédita. Facultad de Ciencias Naturales y Museo. UNLP.

Capparelli, A.

2007 Los productos alimenticios derivados de Prosopis chilensis (Mol.) Stuntz y P. flexousa DC., Fabaceae, en la vida cotidiana de los habitantes del NOA y su paralelismo con el algarrobo europeo. Kurtziana 33(1) 1-19. Córdoba, Argentina.

Capparelli, A.

2009 Intra-site comparison of the archaeological evidence of El Shincal: implications about the inka economy En: A. Capparelli, A. Chevalier y R. Piqué (Coords.) La alimentación en la América precolombina y colonial: una aproximación interdisciplinaria. Treballs d’Etnoarqueología 7: 113-131. Madrid.

\section{Capparelli, A.}

En prensa. Archaeobotanical recognition of food products derived from the algarrobo (Prosopis flexuosa DC and P. chilensis (Mol.) Stuntz, (FABACEAE) charred remains and its application to the case of El Shincal, Hualfín Valley, Argentina. En: Traditions and Transformations in Ethnobotany, Pochettino, M.L. y A. Ladio (eds.). S.S. de Jujuy.

\section{Capparelli, A., M.A. Giovannetti y V. Lema}

2007 Primera evidencia arqueológica de cultivos europeos (trigo, cebada, durazno) y de semillas de algodón en el NOA: su significación a través del Shincal de Quimivil. En: B.

Capparelli, A., V. Lema y M.A. Giovannetti

2004 El poder de las plantas En: R.A. Raffino (ed.) El Shincal de Quimivil. Sarquís. Pp. 141164.

Capparelli, A., N. Oliszewski y M.L. Pochettino

2001 Historia y Estado Actual de las Investigaciones Arqueobotánicas en Argentina. Actas del XIV Congreso Nacional del Arqueología Argentina. Facultad de Humanidades y Artes, Universidad de Rosario. En prensa. 
Capparelli A. y R.A. Raffino

1997 Arqueobotánica de El Shincal I : tallos finos, frutos y semillas. Tawantinsuyu 3:40-57. Canberra.

Capparelli, A., Zagorodny, N. y B. Balesta.

2003 Wood remains from andean argentina: the use of Prosopis sp. L. in hut construction. Journal of Ethnobiology 23(1): 143-154.

Carbone, V.A. y B.C. Keel

1985 Preservation of plant and animal remains. En The análisis of prehistoric diets editado por R.I. Gilbert Jr. y J.H. Mielke, pp. 1-19. Academic Press, Orlando.

Cárdenas, $\mathrm{M}$.

1989 Manual de Plantas Económicas de Bolivia (2ª Edición) Ed. Los Amigos del Libro. La Paz - Cochabamba, Bolivia.

Caria M.

2004 “Arqueología del paisaje en la Cuenca Tapia- Trancas y áreas vecinas. Tucumán. Argentina.” Tesis Doctoral en Arqueología (Inédita). Facultad de Ciencias Naturales e IML. Universidad Nacional de Tucumán. San Miguel de Tucumán.

Caria, M. y S. Garalla

2003. “Caracterización arqueopalinológica del Sitio Ticucho I (Cuenca Tapia- Trancas. Tucumán. Argentina)” En: Actas II Congreso Argentino de Cuaternario y Geomorfología. San Miguel de Tucumán.

Caria, M.A. y J.M. Sayago

2008 Arqueología y ambiente en un valle intermontano del piedemonte oriental de las Cumbres Calchaquíes (Tucumán, Argentina). Runa 28: 11-28.

Carrizo, J.M.

1995 (1972). La alimentación popular en el noroeste argentino. Con algunas estampas tradicionales. Colección Arte-Ciencia, Serie Jujuy en el Pasado. San Salvador de Jujuy. 
Carrizo, J., S. Cano y M. Soler Nixdorf

1999 Recursos vegetales comestibles en el Valle de Tafí durante el período formativo: análisis arqueobotánico I del sitio Casas Viejas-El Mollar (S TUC TAV 2) En: C. Diez Marín (ed.) Actas del XII Congreso Nacional de Arqueología Argentina Tomo I: 65-73. La Plata.

Carrizo, J., N. Oliszewski, J. Martínez

2003 Macrorrestos vegetales del sitio arqueológico Cueva de los Corrales (El Infiernillo, Tafí del Valle, Tucumán) Revista del Museo Argentino de Ciencias Naturales, n.s., 5 253-260.

Certeau, M. de

2000. La invención de lo cotidiano. I. Artes de Hacer. México: Universidad Iberoamericana.

Cialdella, A.M.

1984 El género Acacia (Leguminosae) en la Argentina. Darwiniana 25 (1-4): 59-111.

Cigliano, E.

1956-1957 Investigaciones arqueológicas en la zona de Famabalasto (Prov. de Catamarca). Runa VIII $2^{\text {a }}$ parte: 241-269. Buenos Aires.

Cigliano, E.

1958. Arqueología de la Zona de Famabalasto, Departamento de Santa María, Catamarca. Extracto de la Revista del Museo de la Plata (Nueva Serie), Sección Antropología, Tomo V: 29-122. FCNyM. UNLP, La Plata.

Cigliano, E.M., R.A. Raffino, H.A. Calandra.

1972 Nuevos aportes para el conocimiento de las entidades alfareras más tempranas del Noroeste Argentino. Relaciones de la Sociedad Argentina de Antropología VI: 225-236.

Cigliano, E.M., R.A. Raffino y H.A. Calandra

1976 La aldea formativa de Las Cuevas (Provincia de Salta). Relaciones de la Sociedad Argentina de Antropología 10: 73-140.

Coleman Goldstein, R. 
2008 Hearths, Grinding Stones, and Households: Rethinking Domestic Economy in the Andes. Archaeological Papers of the American Anthropological Association 18(1): 37-48.

Cortés, L.I.

2007 Material Confines. Conceptualizations of death through the materiality of burial structures, Tesis de Maestría Inédita. Departamento de Arqueología. Universidad de Sheffield.

Cotton, C.M.

1998 Ethnobotany. Principles and Applications. John Willey \& Sons. New York.

Cremonte, M.B.

1996 Investigaciones arqueológicas en la quebrada de La Ciénaga (departamento de Tafí, Tucumán). Tesis doctoral inédita. Facultad de Ciencias Naturales y Museo, Universidad Nacional de La Plata, La Plata.

Davidson, T. 2009. The role of Domestic Architecture in the Structuring of Memory. Space and Culture 12: 332-342.

Delfino, D.D.

1999 Prospecciones en los '90: Nuevas evidencias para repensar la arqueología de Laguna Blanca (Dpto. Belén. Catamarca). Revista de Ciencia y Técnica 7:55-80. Secretaría de Ciencia y Tecnología.Universidad Nacional de Catamarca, San Fernando del Valle de Catamarca.

Demaio, P., U. O. Karlin y M. Medina

2002. Árboles nativos del centro de Argentina. L.O.L.A. (Literature of Latin America), Buenos Aires.

Douglas, Mary

1997 Deciphering a Meal. En Food and Culture, edited by Carole Counihan and Penny Van Esterik, pp. 36-54. Routledge, New York.

Drenes, S. 
2006 Sobre Phaseolus vulgaris var. aborigeneus (Fabaceae) en Córdoba. Boletín de la Sociedad Argentina de Botánica (3-4): 323-324.

Dye, D. y K. Moore

1978 Recovery systems for subsistence data: water screening and water flotation Tennessee Anthropologist 3(1): 59-69.

Fernández Distel, A.

1974 Excavaciones arqueológicas en las cuevas de Huachichocana, Dep. de Tumbaya, Prov. de Jujuy, Argentina. Relaciones de la Sociedad Argentina de Antropología 8: 101-127 (N.S.).

Fernández Distel, A.

1980 Hallazgo de pipas en complejos precerámicos del borde de la Puna jujeña (República Argentina) y el empleo de alucinógenos por parte de las mismas culturas. Estudios Arqueológicos 5:55-79. San Pedro de Atacama.

Fernández Distel, A.

1994 Noticia sobre el sitio arqueológico de Abra de los Morteritos y otros lugares de valor prehistórico de la región de Santa María (Jujuy, República Argentina). En M.E. Albeck (ed.) De costa a selva. Producción e intercambio entre los pueblos agroalfareros de los Andes Centro Sur, Pp. 255-259. Instituto Interdisciplinario Tilcara. Universidad de Buenos Aires. Tilcara. Jujuy.

Fernández Distel, A.

1998 Arqueología del Formativo en la Puna jujeña (1800 a.C. al 650 d.C.) Centro Argentino de Etnología Americana, Colección Mankacén, Buenos Aires.

Figueroa, G.G. y M. Dantas

2006 Recolección, procesamiento y consumo de frutos silvestres en el noroeste semiárido argentino. Casos actuales con implicancias arqueológicas. La Zaranda de Ideas 2: 35-50.

Flannery, K.V. (ed.)

1976 The Early Mesoamerican Village. Academic Press, Nueva York. 
Ford, R.

1979 Paleoethnobotany in American Archaeology. En Schiffer M. (ed.) Advances in archaeological method and theory. Vol. 2. Academic Press, Nueva York.

Freyre, R., R. Ríos, L. Guzmán, G. Debouck y P. Gepts

1996 Ecogeographic distribution of Phaseolus spp. (Fabaceae) in Bolivia. Economic Botany 50(2): 195-215.

Galván, M.Z.

2006 Análisis de la variabilidad genética en poblaciones primitivas y silvestres de Phaseolus vulgaris, mediante marcadores bioquímicos y moleculares. Tesis Doctoral Inédita. FCNyM. Universidad Nacional de La Plata.

Gallardo, M., González J. y G. Ponessa

1997 Morfología del fruto y la semilla de Chenopodium quinoa Wild. Chenopodiaceae. Lilloa 39(1): 71-80.

Garleff , K., H. Stingl y H. Veit

1993 New dates on the Late Quaternary History of landscape and climate in the Bolsón of Fiambalá/Argentina (Province of Catamarca). Zentralbatt für Geologie und Paläontologie. Teil I. H. 11/12: 1479-1496. Sttutgart

Garrilla, S.

1999 Análisis polínico de una secuencia sedimentaria en el Abra del infiernillo, Tucumán, Argentina. $1^{\circ}$ Congreso Argentino de Cuaternario y Geomorfología. Actas y Resúmenes: 11. La Pampa.

Gasser, R.E.

1985 Archaeological trash mound and floor features: don't believe everything. Paper presented at the 50th Annual Meeting of the Society for American Archaeology, SAA Papers. Denver, Colorado.

Gasser, R.E. y C. Adams 
1981 Aspects of deterioration of plant remains in archaeological sites: the Walpi Archaeological Project. Journal of Ethnobiology 1 (1):182-192.

Gentry, H.S.

1969 Origin of the common bean, Phaseolus vulgaris. Economic Botany 23(1):55-69.

Gepts, P.

2006-2007 Crop evolution, domestication and biodiversity [on line]. Fezocaonline (California, USA): Department of Plant Sciences, University of California. Davis. <http://www.agronomy.ucdavis.edu/gepts>. [Consulta: diciembre 2008].

Gepts P. y Debouck D.

1991 Origen, domestication and evolution of the commom bean (Phaseolus vulgaris L) En Schoonhoven y Voysest (Ed.) Common beans: research for crop improvement, pp 7-53, Washington.

Gero, J. M.

2004. Informe preliminar de la temporada 2004 (mayo y junio), Sitio Cardonal (La Quebrada, Departamento de Santa María). Ms.

Gero, J.M. y M.C. Scattolin

1994 Hacia la comprensión del desarrollo de la jerarquización: un estudio en el Valle del Cajón (Catamarca, Argentina). Actas y Memorias del XI Congreso Nacional de Arqueología Argentina. San Rafael. Mendoza (en prensa).

Gero, J.M. y M.C. Scattolin

1999 Household Chronology at Yutopian, Valle del Cajón, Northwest Argentina. Northeast Andean Archaeology and Ethohistory Conference, Amherst, Massachusetts. MS

\section{Girad, L.}

1998 Doing-Cooking. En: Certeau, M. de; L. Giard y P. Mayol (eds.) The Practice of Everyday Life. Volumen 2: Living \& Cooking, pp. 152-246. Minneapolis, University of Minessota Press. 
Giberti, G.C.

1981 Las malvas y las salvias de la medicina popular del noroeste argentino. Parodiana 1(1): 31-96.

Giberti, G.C.

1983 Sinopsis de caracteres anatómicos de especies de la tribu senecioneae (compositae) utilizadas en la medicina popular en el noroeste argentino. Parodiana 2(1): 99-115.

Giovannetti, M., A. Capparelli, y M.L. Pochettino

La Arqueobotánica en Sudamérica. ¿Hacia un equilibrio de enfoques? Discusión en torno a las categorías clasificatorias y la práctica arqueobotánica y paleoetnobotánica En S. Archila, M. Giovannetti y V. Lema (eds.) Arqueobotánica y Teoría Arqueológica. Discusiones desde Suramérica. Ediciones Uniandes, Bogotá. Pp. 17-34

\section{González A.R.}

1960 La estratigrafía de la Gruta de Intihuasi. Revista del Instituto de Antropología de Córdoba.

González, A.R. y V.A. Núñez Regueiro

1962 Preliminary report on archaeological research in Tafí del Valle, N.W. Argentina. Akten des 34 Internationalen Amerikanisten Kongress, p. 485-496. Viena.

González, A.R. y J.A. Pérez

1968 Una nota sobre etnobotánica del N. O. argentino En: Actas y Memorias del 37 Congreso Internacional de Americanistas Tomo 2: 209-228.

González, A.R. y M.C. Sempé de Gómez Llánez

1975 Prospección arqueológica en el Valle de Abaucán. Revista del Instituto de Antropología 2: 49-130. Córdoba.

Green, W.A.

2009 Hatching seeds before they're counted. Graphical methods for interpreting archaeobotanical data. Archaeological \& Antropological Science 1:1-13 
Gustafsson, S.

2000 Carbonized Cereal Grains and Weed Seed in Prehistoric Houses-an Experimental Perspective. Journal of Archaeological Sciences 27: 65-70.

Haber, A. F.

1999 Una arqueología de los oasis puneños. Domesticidad, interacción e identidad en Antofalla, primer y segundo milenios d.C. Tesis doctoral inédita. Facultad de Filosofía y Letras, Universidad de Buenos Aires.

Hastorf, C. A.

1988. The use of paleoethnobotanical data in prehistoric studies of crop production, processing and consumption. En Current Paleoethnobotany editado por Hastorf C. A. y V. S. Popper. The University of Chicago Press, Chicago and London.

Hastorf, C.A.

1990 The effect of the Inka state on Sausa agricultural production and crop consumption American Antiquity 55(2): 262-290.

Hastorf, C.A.

1991. Gender, Space, and Food in Prehistory. En Engendering Archaeology. Women and Prehistory, Gero J M, Conkey M W (eds.). Blackwell: Oxford; 132-159.

Hastorf, C.A y V.S Popper (eds.)

1988 Current Palaeobotany. Analytical Methods and Cultural Interpretations of Archaeological Plant Remains. The University Chicago Press. Chicago.

Hather, Jon G. (Ed.)

1994 Tropical Archaeobotany: Applications and new developments. Routledge. USA-Canadá.

Helbaek, H.

1960 The Palaeoethnobotany of the Near East and Europe. En R.J. Braiwood y B. Howe (eds.) Prehistoric Investigations in Iraqi Kurdistan, Studies in Oriental Civilization. 31 Chicago, Oriental Institute, pp. 99-118. 
Hendon, J.A.

1996 Archaeological Approaches to the Organization of Domestic Labor: Household Practice and Domestic Relations. Annual Review of Anthropology 25: 45-61.

Hillman, G.

1991 Phytosociology and Ancient Weed Floras: Taking Account of Taphonomy and Changes in Cultivation Methods. En Modelling Ecological Change Editado por D.R. Harris y K.D. Thomas, pp. 27-40 The Institute of Archaeology, UCL, London,

Horkheimer, $\mathrm{H}$.

1990 Alimentación y obtención de alimentos en los Andes prehispánicos. Editorial Hisbol, La Paz, Bolivia.

Hoyos, M. de

1996. Centros de producción agrícola en el Valle del Cajón. Revista del Museo de Historia Natural de San Rafael XXIV (3/4): 295-317. San Rafael.

Hoyos, M. de

1999. Asentamiento inka en San Antonio del Cajón (Dpto. de Santa María-Catamarca). Actas del XII Congreso Nacional de Arqueología Argentina. TomoI: 194-198. La Plata.

Hoyos, M. de y M. Lanza.

2000. Arte rupestre en San Antonio del Cajón. Provincia de Catamarca. Relaciones de la Sociedad Argentina de Antropología XXV: 119-144.

Hoyos, M. de, M. Lanza y L. Horlent. 2000. Bloques con grabados en San Antonio del Cajón, Catamarca. En: Podestá, M.M. y M. de Hoyos (Eds.). Arte en las rocas. Sociedad Argentina de Antropología y Asociación Amigos del INAPL: 83-93. Buenos Aires.

Hubbard, R.N.L.B. y A. al Azm

1990 Quantifying Preservation and Distortion in Carbonized Seeds; and Investigating the History of Friké Production. Journal of Archaeological Sciences 17: 103-106.

Hubbard, R. N. L. B. y A.Clapham 
1992. Quantifying macroscopic plant remains, Review of Palaeobotany and Palynology 73: 117-132.

Hunter, A.y B. Gassner

1998. Recovery systems for subsistence data: water screening and water flotation. Tennessee Anthropologist 3 (1): 59-69.

Hunziker, A.T.

1943 Granos hallados en el yacimiento arqueológico de Pampa Grande (Salta, Argentina) Revista Argentina de Agronomía 10(2): 146-154.

Hunziker, A.T.

1952 Los pseudocereales de la agricultura indígena de América. ACME Agency. Buenos Aires.

Hunziker, A.T.

1969 Estudios sobre Solanaceae V. Contribución al conocimiento de Capsicum y géneros afines (Witheringia, Acnistus, Athenaea, etc.): primera parte. Kurtziana 5: 101-179. Córdoba.

Hunziker, A.T.

1979 South American Solanaceae: a synoptic survey. En The Biology Taxonomy of the Solanaceae (Eds. J.G. Hawkes, R.N. Lester and A.D. Skelding). Linnean Society symposium series 7: 49-86.

Hunziker, A.T.

2001. Genera Solanacearum. The Genera of Solanaceae Illustrated, Arranged According to a New System.Gantner Verlag.Liechtenstein.

Ingold, Tim

2000. The Perception of the Environment. Essays in Livelihood, Dwelling and Skill. Londres, Routledge.

Izeta, A.D. 
2006 Utilización de camélidos silvestres y domésticos en el sur de los Valles Calchaquíes durante el Período Formativo. En: G. Mengoni Goñalons, D. Olivera y H. Yacobaccio (eds.) El Manejo de los Camélidos Sudamericanos: Perspectivas Multidisplinarias. GZC/ICAZ. En prensa.

Izeta, A.D.

2007a Zooarqueología del Sur de los Valles Calchaquíes (Provincias de Catamarca y Tucumán, República Argentina): Análisis de Conjuntos Faunísticos del Primer Milenio A.D. B.A.R. International Series S1612. Oxford, John and Erica Hedges.

Izeta, A.D.

2007b. Zooarqueologia del formativo del valle del Cajón. Simposio 9: de la puna a las sierras: Avances y perspectivas en Zooarqueología. Pacarina. Número Especial Actas del XVI Congreso Nacional de Arqueología Argentina. T. I: 471-476. San Salvador de Jujuy, EdiUNJU.

Izeta A.D.

2008a Análisis especial del descarte de camélidos en una unidad doméstica formativa. Loma Alta Núcleo “E” (Catamarca, Argentina) Arqueobios 2: 1-10, Trujillo, Perú.

Izeta, A.D.

2008b Late Holocene camelid use tendencies in two different ecological zones of Northwestern Argentina. Quaternary International 180: 135-144.

Izeta, A.D. y L.I. Cortés

2006 Southamerican camelid palaeopathologies. Examples from Loma Alta (Catamarca, Argentina) International Journal of Osteoarchaeology 16(3): 269-275. UK

Izeta A.D., A.G. Laguens, M.B. Marconetto y M.C. Scattolin

2009. Camelid Handling in the Meridional Andes during the First Millennium AD: A Preliminary Approach Using Stable Isotopes International Journal of Osteoarchaeology 19: 204-214.

Izeta, A.D y M.C. Scattolin 
2002 Bañado Viejo: análisis faunístico de un sitio formativo en el fondo del Valle de Santa María. Actas del XIII Congreso Nacional de Arqueología Argentina Tomo II: 385-397.

Izeta, A.D. y M.C. Scattolin

2006 Zooarqueología de una unidad doméstica formativa. El caso de Loma Alta (Catamarca Argentina). Intersecciones en Antropología 7: 193-205. Olavarría.

Izeta, A.D., M.C. Scattolin y J.M. Gero

2000 Espacios domésticos y recursos faunísticos durante el primer milenio A.D. en las áreas valliserrana y circumpuneña de los Andes. Resúmenes precirculados del XV Congreso Nacional de Arqueología Chilena. P.138. Arica.

Jarman, H.N., A.J. Legge and J.A. Charles

1972 Retrieval of plant remains from archaeological sites by froth flotation. En E. Higgs (ed.) Papers in economic prehistory, pp. 39-48. Cambridge: Cambridge University Press

Johannessen, S.

1988 Plant Remains and Culture Change: Are Paleoethnobotanical Data Better Than We Think? En (Hastorf C. A y V. S. Popper) Current Paleoethnobotany. The University of Chicago Press. Chicago y Londres.

Johannessen, S., S. Goette y C. Hastorf

1990 Modern and ancient maize fragments: an experiment in variability. Journal of Quantitative Anthropology 2: 179-200.

Jones, $\mathrm{M}$.

1991 Sampling in Paleoethnobotany. En Progress in Old World Palaeoethnobotany, editado por W. van Ziest, K. Wasilikowa y K-E. Behre, K-E, pp. 53-62. Balkema, Rotterdam.

Keepax, C.

1977 Contamination of archaeological deposits by seeds of modern origin with particular referente to the use of flotation. Journal of Archaeological Science 4: 221-229.

Kent, S. (ed.) 
1990 Domestic Architecture and the Use of Space: An Interdisciplinary Cross-cultural Study. Cambridge University Press. Cambridge.

Kiesling, R.

1994 Flora de San Juan. República Argentina. Volumen I: Pteridofitas, Gimnospermas, Dicotiledóneas Dialipétalas (Salicaceas a Leguminosas). Vazquez Manzini Editores. Buenos Aires.

Kislev, M.E. y S. Rosenzweig

1991 Influence of experimental charring on seed dimensions of pulses. En Palaeoethnobotany and Archaeology editado por E. Hajnalova, pp. 143-157. Archaeological Institute of the Slovak Academy of Sciences, Nitra

Kolata, A.

1993. The decline and fall of Tiwanaku. En: The Tiwanaku. Portrait of an Andean Civilization. Cap. 8, pp 282-302. Ed Blakwell, Cambridge MA \& Oxford UK.

Korstanje, M.A.

2001 The rol of wild resources in productive societies: northwestern Argentina's rock shelter cases. Abstracts of the SAA Meeting, New Orleans.

Korstanje M. A.

2003 Microfósiles y agricultura prehispánica: primeros resultados de un análisis múltiple en el Noroeste argentino. En Zucol, A.F., Osterrieth, M. y M. Brea (Eds) Fitolitos. Estado actual de sus conocimientos en América del Sur: pp - pp.

Korstanje, M.A.

2005 La organización del trabajo en torno a la producción de alimentos en sociedades agropastoriles formativas (Provincia de Catamarca, Republica Argentina). Tesis Doctoral Inédita. Instituto de Arqueología y Museo, Facultad de Ciencias Naturales e Instituto Miguel Lillo, Universidad Nacional de Tucumán.

Korstanje, M.A. y A.E. Würschmidt 
1999 Producir y recolectar en los valles altos del NOA: Los Viscos como caso de estudio. En: En los tres reinos: prácticas de recolección en el cono sur de América, Aschero C, Korstanje, A, Vuoto P (eds.). Instituto de Arqueología y Museo, Universidad Nacional de Tucumán: San Miguel de Tucumán; 151-160.

Krapovickas, P.

1955 El yacimiento de Tebenquiche (Puna de Atacama). Publicaciones del Instituto de Arqueología, III. Buenos Aires, Universidad de Buenos Aires.

Krapovickas, $\mathrm{P}$.

1958-1959 Arqueología de la Puna argentina. Anales de Arqueología y Etnología 14-15: 52113.

Kvist, L.P. y M. Moraes R.

2006 Plantas psicoactivas. En: M. Moraes R., B. Ollgaard, L.P. Kvist, F. Borchsenius y H. Balslev (eds.) Botánica Económica de los Andes Centrales. Universidad Mayor de San Andrés, La Paz. Pp. 294-312.

Lamming-Emperaire A.

1967 Guia para o estudo das indústrias líticas de América do Sul. Manuais de Arqueología 2. Centro de Ensino e Pesquisas Arqueológicas, Paraná.

Lazzari, M.

1997 La economía más allá de la subsistencia: intercambio y producción lítica en el Aconquija. Arqueología No 7: 9-50.

Lazzari, M.

1999a Nuevos datos sobre la procedencia de obsidianas en el Aconquija y áreas aledañas. Cuadernos INAPL 18:243-256. Buenos Aires.

Lazzari, M

1999b Objetos viajeros e imágenes espaciales: las relaciones de intercambio y la producción del espacio social. Anais da I Reuniao de Teoría Arqueologica na America do Sul. Revista do 
Museo de Arqueología y Etnologia. P.P.A. Funari, E.G. Neves e I. Podgorny. Universidad de San Pablo, Brasil. Suplementos 3: 371-385.

Lazzari, M.

2003 Archaeological visions: gender, landscape, and optic knowledge. Journal of Social Archaeology 3(2): 194-222.

Lazzari, M.

2005 The texture of things: objects, people and social spaces in NW Argentina (First milennium AD) En: L. Meskell (ed.) Archaeologies of Materiality Backwell, Oxford. Pp. 126161.

Lazzari, M.

2006. Traveling Things and the Production of Social Spaces: An Archaeological Study of Circulation and Value in North Western Argentina. Tesis de doctorado inédita, Departamento de Antropología, Universidad de Columbia.

Lema, V.

2009 Domesticación vegetal y grados de dependencia humano-planta en el desarrollo cultural prehispánico del Noroeste argentino. Tesis Doctoral Inédita. FCNyM. Universidad Nacional de La Plata.

Lema, V., M. Giovannetti, C. Deschamps, A. Capparelli y R. Raffino 2009 Análisis de restos faunísticos en el sitio inkaico El Shincal (Catamarca, Argentina). Comparación con información arqueobotánica y análisis cerámico. En: A. Capparelli, A. Chevalier y R. Piqué (Coords.) La alimentación en la América precolombina y colonial: una aproximación interdisciplinaria. Treballs d’Etnoarqueología 7: 97-112. Madrid.

Lennstrom, H.A. y C.A. Hastorf

1992 Testing Old Wives’ Tales in Paleoethnobotany: A Comparison of Bulk and Scatter Sampling Schemes from Pancán, Peru. Journal of Archaeological Science 19:205-229.

Leroi-Gourhan, A.

1971 L'homme et la matière. Editions Albin Michel, Paris. 
López, C.

1999 Experimentación para la recuperación de macrovestigios vegetales arqueológicos. Publicaciones de Arqueología No 50 CIFFyH. 1997-98. Córdoba.

López Campeny, S. M. L.

2000 Tecnología, iconografía y ritual funerario. Tres dimensiones de análisis de los textiles formativos del Sitio Punta de la Peña 9 (Antofagasta de la Sierra, Argentina). Estudios Atacameños 20: 29-65. San Pedro de Atacama, Chile.

López Campeny, S. M. L.

2001a Actividades domésticas y organización del espacio intrasitio. El sitio Punta de la Peña 9. Antofagasta de la Sierra (Prov. de Catamarca). Trabajo Final inédito de Carrera de Arqueología. Facultad de Ciencias Naturales e IML, Universidad Nacional de Tucumán. Tucumán

López Campeny, S. M. L.

2001b El hogar, los ancestros y el corral: reocupación y variabilidad en el uso del espacio en unidades domésticas arqueológicas (Sitio Punta de la Peña 9, Antofagasta de la Sierra, Catamarca). Actas del XIV Congreso Nacional de Arqueología Argentina, Rosario. En prensa.

Lupo, L.

1998 Estudio sobre la lluvia polínica actual y la evolución del paisaje a través de la vegetación durante el Holoceno en la cuenca del río Yavi. Borde Oriental de la Puna, Noroeste Argentino. Bamberg, República Federal de Alemania.

Llano, C.

2008 El registro arqueobotánico en el sitio Arroyo Malo 3, alto valle del Atuel, Mendoza, Argentina. Intersecciones en Antropología 9: 133-143. Facultad de Ciencias Sociales UNCPBA. Olavarría.

Mansur Franchomme, M.E.

1987 El análisis funcional de artefactos líticos. Cuadernos Serie Técnica 1. Instituto Nacional de Antropología. 
Manzanilla, L.

1986 Introducción En Manzanilla L. (ed.) Unidades Habitacionales Mesoamericanas y sus Áreas de Actividad. Arqueología, Serie Antropológica 76: 9-18. UNAM, México.

Manzanilla, L.

1990 Niveles de análisis en el estudio de unidades habitacionales. Revista Española de Antropología Americana 20: 9-18.

Marconetto, M.B.

2005 Recursos forestales y el proceso de diferenciación social en tiempos prehispánicos en el valle de Ambato, Catamarca. Tesis Doctoral Inédita FCNyM Universidad Nacional de La Plata.

Marconetto, N. Oliszewski y M.P. Babot (comps.) Paleoetnobotánica del Cono Sur: Estudios de casos y propuestas metodológicas. Museo de Antropología, Facultad de Filosofía y Humanidades, Universidad Nacional de Córdoba. Pp. 25-48.

Marinval P.

1988 Recherches experimentales sur l'acquisition des donées en Paléocarpologie. Révue d’Archéometrie 10 (1986): 57-68.

Markgraf, V.

1985 Paleoenvironmental history of the last 10000 years of northwestern Argentina. Zentrablatt fur Geologie und Paläontologie, 11/12:1739-1749.

Märkle, T. y M. Rösch

2008 Experiments on the effects of carbonization on some cultivated plant seeds Vegetation History and Archaeobotany 17(Supl. 1): S257-S263.

Martin, A.C. y W.D. Barkley

2000 Seed Identification Manual. The Blackburn Press, New Jersey.

Martínez, L. 
1999 Diversidad cerámica en la Falda del Aconquija. Tesis de Licenciatura en Antropología. FFyL. Universidad de Buenos Aires. Ms.

Martínez Ungría, O.

1989 Notas acerca de la Quinoa y el Amaranto. Cultivos indígenas en Expansión. Ediciones RAE, La Plata.

Meldem, D.

1996. Botanical Remains at Yutopian. Informe ms.

Meyer, F.C.

1980 Carbonized food plants of Pompeii, Herculaneum, and the villa at Torre Annunziata. Economic Botany 34 (4):401-347.

Miante Alzogaray, A.M y J. Cámara Hernández

1996 Restos arqueológicos de maíz (Zea mays ssp mays) de Pampa Grande, Provincia de Salta, Argentina. Relaciones de la Sociedad Argentina de Antropología XXI: 149-305.

Mikcisek, C.H.

1987 Formation processes of the archaeobotanical record. Advances in archaeological Method and Theory 10: 211-247.

Millar, N.

1989 What mean these seeds: a comparative approach to archaeological seed analysis. Historical Archaeology 23: 50-59.

Minnis, P.E.

1978 Paleoethnobotanical indicators of prehistoric environmental disturbance: a case study. En The nature and status of ethnobotany Editado por R.I. Ford, pp. 347-366 Anthropological Papers vol. 67. Museum of Anthropology, University of Michigan.

Minnis, P. E.

1981 Seeds in archaeological sites: sources and some interpretative problems. American Antiquity 46 (1):143-152. 
Minnis, P.y S. Le Blanc

1976 An efficient, inexpensive arid flotation system. American Antiquity 41(4): 491-492.

Morlans, M.C.

1995 Regiones naturales de Catamarca. Provincias geológicas y provincias fitogeográficas. Revista de Ciencia y Técnica 2:1-36. Universidad de Catamarca. San Fernando del Valle de Catamarca.

Munson, P.J., P.W. Parmalee y R.A. Yarnell

1971 Subsistence ecology of Scovill: a Terminal Middle Woodland village. American Antiquity 36 (4):410-431.

Nardo, R. y S. Chertudi

1969-1970 Instrumentos arcaicos para majar y moler en San Juan (Argentina). Revista de Etnografía 13(26): 387-418 y 14(27): 137-188. Oporto.

Nielsen, A.E.

2001 Evolución del espacio doméstico en el Norte de Lípez (Potosí, Bolivia): ca. 900-1700 d.C. Estudios Atacameños 21: 41-61. San Pedro de Atacama, Chile.

Niembro Rocas, A.

1989 Semillas de plantas leñosas. Morfología comparada. Limusa, México D. F.

Núñez, L.A. y T.D. Dillehay

1979 Movilidad giratoria, armonía social y desarrollo en los Andes meridionales: patrones de tráfico e interacción económica (ensayo). Edición numerada: 22. Universidad del Norte, Chile.

Núñez, L. y M. Grosjean

1994 Cambios Ambientales pleistoceno-holocénicos: ocupación humana y uso de recursos en la puna de Atacama (norte de Chile). Estudios Atacameños 11:11-24. San Pedro de Atacama, Chile. 
Núñez, L., M. Grosjean, B. Messerli y H. Schrelier

1997 Cambios ambientales holocénicos en la Puna de Atacama y sus implicancias paleoclimáticas. Estudios Atacameños 12:31-40. San Pedro de Atacama, Chile.

Núñez Regueiro, V.A.

1971 La cultura Alamito de la subárea Valliserrana del Noroeste Argentino. Journal de la Société des Américanistes 60:7-62. Paris.

Nuñez Regueiro, V.A.

1998. Arqueología, historia y antropología de los sitios de Alamito. Ediciones INTERDEA: Tucumán.

Nuñez Regueiro V.A. 1974. Conceptos instrumentales y marco teórico en relación al análisis del desarrollo cultural del Noroeste Argentino. Revista del Instituto de Antropología 5: 169190.

Oliszewski, N.

2003 Test experimental de flotación aplicado en sitios arqueológicos del campo del Pucará. Cuadernos, FHyCS, EdiUNJU 20: 365-371.

Oliszewski, N.

2004 Utilización de recursos vegetales en Campo del Pucará (Andalgalá, Catamarca) durante el Período Formativo (200-500 d.C.). Análisis de macrorrestos. Tesis de Doctorado en Arqueología, Facultad de Ciencias Naturales e Instituto Miguel Lillo, Universidad Nacional de Tucumán.

Oliszewski, N.

2005 Archaeobotany of archaeological sites from Northwest Argentina (1750-1450 B.P.): ceremonial use or rubbish dumps? Vegetation History and Archaeobotany 14: 465-471.

Oliszewski, N.

2008 Metodología para la identificación subespecífica de maíces arqueológicos. Un caso de aplicación en el noroeste de Argentina En: Archila S., Giovannetti M. y V. Lema (Eds.) 
Arqueobotánica y Teoría Arqueológica. Discusiones desde Suramérica. Ediciones Uniandes, Bogotá. Pp 181-202.

Oliszewski, N., J.G. Martínez y M.A. Caria

2008 Ocupaciones prehispánicas en una quebrada de altura: el caso de Cueva de los Corrales

1 (El Infiernillo, Tafí del Valle, Tucumán) Relaciones de la Sociedad Argentina de Antropología XXXIII: 209-221.

Oliszewski, N. y D.E. Olivera

2009 Variabilidad racial de macrorrestos arqueológicos de Zea mays (Poaceae) y sus relaciones con el proceso agropastoril en la Puna Meridional argentina (Antofagasta de la Sierra (Catamarca). Darwiniana 47(1): 76-91.

Olivera, D. E.

1991 Tecnología y estrategias de adaptación en el Formativo (Agro.alfarero temprano) de la Puna Meridional Argentina. Un caso de estudio: Antofagasta de la Sierra (Provincia de Catamarca) Tesis Doctoral Inédita. Facultad de Ciencias Naturales y Museo. Universidad Nacional de la Plata.

Olivera, D.E

2000 Que diez mil años no es nada... En Puna e historia. Antofagasta de la Sierra, Catamarca, editado por S. García, D. Rolandi y D. Olivera, pp. 13-52. AINA y Ediciones del Tridente, Buenos Aires.

Olivera, D.E.

2001. Sociedades Agropastoriles Tempranas: el Formativo Inferior del Noroeste Argentino. En Historia Argentina Prehispánica, Tomo I, Berberián E, Nielsen A (eds.). Editorial Brujas: Córdoba; 83-125.

Olivera, D., P. Tchilinguirian y L. Grana

2004 Paleoambiente y arqueología en la Puna meridional argentina: archivos ambientales, escalas de análisis, registro arqueológico. Relaciones de la Sociedad Argentina de Antropología XXIX:229-247. Buenos Aires. 
Ortloff, C. y A. L. Kolata

1993 Climate and collapse: Agroecological perspectives on the decline of the Tiwanaku State. Journal of Archaeological Science 20 (2): 195-221.

Parodi L.R.

1932 Notas preliminares sobre plantas sudamericanas cultivadas en la provincia de Jujuy. GAEA IV(1): 21-28.

Parodi, L.R.

1978 [1959] Enciclopedia argentina de agricultura y jardinería. Tomo 1 Vol. 1. ACME, Buenos Aires.

Parodi, L.R.

1966 La agricultura aborigen argentina. Editorial Eudeba, Buenos Aires.

Parodi, L.R. y A.I. Pastore

1939 Géneros de plantas cultivadas representados en la flora indígena de la República Argentina. Physis XVIII: 255-268.

Pearsall, D.

1988 Interpreting the meaning of macrorremain abundance: the impact of source and context. En Current Paleoethnobotany editado por C.A. Hastorf and V.S. Popper. The University of Chicago Press, Chicago and London.Pp. 53-71.

Pearsall, D.M.

2001 [1989] Paleoethnobotany: a handbook of procedures. Academic Press

Pendleton, $\mathrm{M}$.

1983 A comment concerning: “Testing Flotation Recovering Rates”. American Antiquity 48 (3): 615-616.

Pereyra Domingorena, L.

2007 Análisis petrográfico de los recipientes cerámicos del sitio Cardonal. II Congreso Argentino y I Latinoamericano de Arqueometría. Libro de resúmenes, pp, 21. 
Pérez Gollán, J. A.

2000. El Jaguar en Llamas (la Religión en el Antiguo Noroeste Argentino). En Nueva Historia Argentina. Tomo I, Los Pueblos Originarios y La Conquista. Págs. 229-257.

Pérez Gollan, J. A. e I. Gordillo

1993 Religión y alucinógenos en el antiguo Noroeste argentino. Ciencia Hoy 4(22): 50-63.

Petetin, C. A. y E. P. Molinari

1982 Reconocimiento de semillas de malezas. Colección Científica del INTA, Buenos Aires.

Planchuela, A.M.

1975 Estudio de los frutos y semillas del género Chenopodium en Argentina. Darwiniana 19: 528-565.

Pochettino, M.L.

1985 Disemínulos utilizados por los aborígenes del Noroeste de la República Argentina. Tesis Doctoral Inédita. Facultad de Ciencias Naturales y Museo. Universidad Nacional de La Plata.

Pochettino, M.L., A. Cortella y M. Ruiz

1999 Hallucinogenic Snuff from Northwestern Argentina: Microscopical identification of Anadenanthera Colubrina var. Cebil (Fabaceae) in powdered archaeological material. Economy Botany 53(2): 127-132; The New York Botanical Garden Press, New York.

Pochettino, M.L. y M.C. Scattolin

1991 Identificación y significado de frutos y semillas carbonizados de sitios arqueológicos formativos de la ladera occidental del Aconquija (Prov. de Catamarca, Argentina). Revista del Museo de La Plata (NS) Sección Antropología, IX (71): 169-181. La Plata.

Popper, V.

1988 Selecting quantitative measurements in Paleoehnobotany. En Current Paleoethnobotany editado por C.A. Hastorf and V.S. Popper. The University of Chicago Press, Chicago and London.Pp. 53-71. 
Popper, V.S. y C.A. Hastorf

1988 Introduction En Current Paleoethnobotany editado por C.A. Hastorf and V.S. Popper. The University of Chicago Press, Chicago and London. pp. 1-16.

Quesada, M. N.

2007 Paisajes agrarios del área de Antofalla. Procesos de trabajo y escalas sociales de la producción agrícola (Primer y segundo milenios d.C.). Tesis Doctoral inédita. Facultad de Ciencias Naturales y Museo, Universidad Nacional de La Plata. La Plata.

Quinteros, R.A.

1997 Hacia una tipología de artefactos de molienda. En Libro de Resúmenes XII Congreso Nacional de Arqueología Argentina, Pp. 178-179. Universidad Nacional dela Plata, La Plata.

Ragonese, A. E. y R. Martínez Crovetto

1947. Plantas Indígenas de la Argentina con frutos o semillas comestibles. Publicación Técnica del Ministerio de Agricultura de la Nación, Dirección general de Laboratorios e Investigaciones, Instituto de Botánica 9 (Nueva Serie): 157-216.

Raffino, R.

1975 Potencial ecológico y modelos económicos en el NOA. Relaciones de la sociedad Argentina de Antropología IX (NS): 21-45.

Raffino, R.A.

1977 Las aldeas del Formativo Inferior de la Quebrada del Toro (Pcia. de Salta, Argentina) Obra del Centenario del Museo de La Plata 2: 253-299. Antropología. Universidad Nacional de La Plata.

Raffino, R.A. y J. Togo

1975 El yacimiento arqueológico “Cerro El Dique” (Quebrada del Toro, Provincia del Salta). Nota preliminar. Actas y Trabajos del $1^{\circ}$ Congreso de Arqueología Argentina, Rosario. Pp. 113-124.

Rapoport, A. 
1990 Systems of activities and systems of settings. En Kent S. (Ed.) Domestic Architecture and Use of Space. Cambridge University Press, Cambridge. Pp. 9-20.

Renfrew, J.M.

1973 Palaeoethnobotany. Columbia University Press, New York.

Rice, D.

1993 Late Intermediate Period Domestic Architecture and Residential Organization at La Yaral. En: M. Aldenderfer (ed.) Domestic Architecture, Ethnicity and Complementarity in the South-Central Andes. University of Iowa Press. Pp.: 66-82.

Rodríguez, M.F.

1999a. Arqueobotánica de Quebrada Seca 3 (Puna Meridional Argentina): Especies vegetales utilizadas en la confección de artefactos durante el Arcaico. Relaciones de la Sociedad Argentina de Antropología 24:159-184.

Rodríguez, M.F.

1999b. Plant species (Families: Poaceae, Asteraceae, Fabaceae and Solanaceae) at an archaeological site of the Southern Argentine Puna. Journal of Ethnobiology 19(2):229-247.

Rodríguez, M.F.

2004. Cambios en el uso de los recursos vegetales durante el Holoceno en la Puna meridional Argentina. Chungara, Revista de Antropología Chilena, Volumen Especial: 403-413.

Rodríguez, M. F.

2006 El uso de las plantas y el espacio doméstico en la Puna meridional argentina a comienzos del Holoceno Tardío. Sitio arqueológico Punta de la Peña 4, capa 3x/y. Chungara, Revista de Antropología Chilena 38(2): 253-267.

Rodríguez, M.F. y C.A. Aschero

2007 Archaeological evidence of Zea mays L. (Poaceae) in Southern Argentinean Puna (Antofagasta de la Sierra, Catamarca) Journal of Ethnobiology 27(2): 256-271.

Roldán, M.F. 
1999 Instrumentos líticos pulidos: determinación de la diversidad funcional en el grupo tipológico “manos de conana”. En Libro de Resúmenes del XIII Congreso Nacional de Arqueología Argentina, Pp. 20-21. Cabildo Histórico de la Ciudad de Córdoba, Córdoba.

Rossen, J.

1998a. Archaobotanical Remains from the Yutopian site, Argentina (1998 Field Season) Informe 1. MS

Rossen, J.

1998b. Archaobotanical Remains from the Yutopian site, Argentina (1998 Field Season) Informe 2. MS

Rossen, J., T. D. Dillehay y D. Ugent

1996 Ancient Cultigens or modern intrusions? Evaluating plant remains in Andean case study. Journal of Anthropological Science 23: 391-407.

Ruiz Leal, A.

1972 Flora Popular Mendocina. En Deserta 3. Instituto de Investigaciones de las Zonas áridas y semiáridas de la provincia de Mendoza.

Sampietro, M.

2002 Contribución al conocimiento geoarqueológico del valle de Tafí, Tucumán, Argentina. Tesis Doctoral Inédita. Facultad de Ciencias Naturales e Instituto Miguel Lillo. Tucumán.

Sayago, J. M, M. M. Collantes y M. A. Caria

2001 Los efectos de la anomalía climática medieval sobre las culturas del Formativo y su relación con los futuros cambios climáticos en el noroeste argentino. Primera Reunión de Geología Ambiental y ordenación del Territorio. Mar del Plata, publicado en CD.

Scattolin, M.C.

1990 Dos asentamientos formativos al pie del Aconquija: el sitio Loma Alta. Gaceta Arqueológica Andina, V(17) :85-100. Lima.

Scattolin, M.C. 
1994a Posibilidades y restricciones al crecimiento en comunidades aldeanas formativas del Aconquija. Actas y Memorias del XI Congreso Nacional de Arqueología Argentina. Revista del Museo de Historia Natural de San Rafael (Mendoza). Tomo XIII (1/4), pp. 169.

Scattolin, M.C.

1994b Espacio doméstico y agrario en el Aconquija. Actas del XI Congreso Nacional de Arqueología Argentina. San Rafael. Mendoza. En prensa.

Scattolin, M.C.

1994c. Un circuito ganadero en el Aconquija. Revista de la Escuela de Antropología II:99109. Facultad de Humanidades y Artes, Universidad Nacional de Rosario.

Scattolin, M.C.

2000 Santa María durante el Primer Milenio A. D. ¿Tierra Baldía? Arstryck 95-98: 63-83. Etnografiska Museet i Göteborg. Suecia.

Scattolin, M.C.

2001 Organización residencial y arquitectura en el Aconquija durante el primer milenio A.D. Actas del XIII Congreso Nacional de Arqueología Argentina: 439-449. Córdoba.

Scattolin, M C.

2003a Los ancestros de Calchaquí: una visión de la colección Zavaleta. Cuadernos 20: 51-79. Facultad de Humanidades y Ciencias Sociales. Universidad Nacional de Jujuy.

Scattolin, M.C.

2003b Representaciones sexuadas y jerarquías sociales en el Noroeste argentino prehispánico. Acta Americana 11(1): 31-48. Suecia.

Scattolin, M. C.

2004a Recursos arquitectónicos y estilos cerámicos en los siglos IX y X d. C. en el valle de Santa María (Catamarca, Argentina). Taller “Local, regional, global. Los Valles Calchaquíes: prehistoria, protohistoria e historia” Etnologiska Studier 46:63-98. Göteborg.

Scattolin, M.C. 
2004b Categorías indígenas y ordenaciones arqueológicas en el Noroeste argentino. En: Hacia una arqueología de las arqueologías sudamericanas, A. Haber (editor), pp. 53-82. Ediciones Uniandes, Bogotá.

Scattolin, M.C.

2006a Contornos y confines del período formativo en el Noroeste argentino. El universo iconográfico pre-calchaquí en el valle de Santa María. Estudios Atacameños 32:119-139. San Pedro de Atacama, Chile.

Scattolin, M.C.

2006b Categoremas indígenas y designaciones arqueológicas en el noroeste argentino prehipánico. Chungara, Revista de antropología chilena 38(2): 185-196. Tarapacá.

Scattolin, M.C.

2006c La mujer que carga el cántaro. En: Género y etnicidad en la arqueología de Sudamérica. Williams, V. y B. Alberti (editores) Serie teórica No. 4:43-72. INCUAPA, Olavarria.

Scattolin, M.C.

2007a Un examen del espacio residencial y productivo en el Aconquija. Shincal 7:135-149. Escuela de Arqueología, Catamarca.

Scattolin, M.C.

2007b Estilos como recursos en el Noroeste argentino. En: Nielsen A.E, Rivolta M.C., Seldes V. Vásquez, M. y P.H. Mercolli (Comps.) Procesos Sociales Prehispánicos en el Sur Andino. La Vivienda, la Comunidad y el Territorio. Editorial Brujas, Córdoba. Pp- 291-322.

Scattolin, M.C.

2007c Santa María antes del año mil. Fechas y materiales para una historia cultural. En: Williams, V., B. Ventura, A. Callegari y H. Yacobaccio (eds.), Sociedades Precolombinas Surandinas: Temporalidad, Interacción y Dinámica Cultural del NOA en el Ámbito de los Andes Centro-Sur, pp. 203-219. Buenos Aires, Instituto de Arqueología, Facultad de Filosofía y Letras, Universidad de Buenos Aires. 
Scattolin, M.C. (Dir.)

2008 Antiguo Calchaquí. Arqueología aldeana de los valles del NOA. Proyecto de Investigación. CONICET PIP 11220080100256.

Scattolin, M.C. y M.E. Albeck

$1994 \mathrm{El}$ asentamiento humano en la falda occidental del Aconquija (Catamarca, Argentina).

Shincal 4: 35-65. Escuela de Arqueología, Catamarca.

Scattolin, M.C., M.F. Bugliani, A.D. Izeta, M. Lazzari, L. Pereyra Domingorena y L. Martínez

2001 Conjuntos materiales en dimensión temporal. El sitio Formativo “Bañado Viejo” (Valle de Santa María, Tucumán). Relaciones de la Sociedad Argentina de Antropología 26:167192. Buenos Aires.

Scattolin, M.C., M.F. Bugliani, L. Pereyra Domingorena, L.I. Cortés

2005 La señora de los anillos, entre otras tumbas presantamarianas de Yocavil. Intersecciones en Antropología 6: 29-41. Olavarría.

Scattolin, M.C., M.F. Bugliani, C.M. Calo, L.I. Cortés, L. Pereyra Domingorena, A.D. Izeta. 2009a Pequeños mundos: prácticas, maneras de hacer y afinidades en las aldeas del valle del Cajón, Catamarca. Relaciones de la Sociedad Argentina de Antropología 34: 249-272. Buenos Aires.

Scattolin, M.C., L.I. Cortés, M.F. Bugliani, C.M. Calo, L. Pereyra Domingorena, A.D. Izeta, M. Lazzari

2009b Built landscapes of everyday life: a house in an early agricultural village of northwestern Argentina. World Archaeology 41(3): 396-414 Routledge.

Scattolin M.C., L.I. Cortés, C.M. Calo, L. Pereyra Domigorena, J. Izaguirre 2007-2008 Una máscara metálica del valle del Cajón, Catamarca, Argentina. Revista Arqueología 14: 229-237. Universidad de Buenos Aires.

Scattolin, M.C., L.I. Cortés, M.F. Bugliani, M.C. Calo, A.D. Izeta, M. Lazzari y J. Izaguirre 
2007a Una aldea formativa en el valle del Cajón (habitar, circular, hacer): Libro de resúmenes del XVI Congreso Nacional de Arqueología Argentina. Revista Pacarina 2: 337-341. Universidad Nacional de Jujuy.

Scattolin, M.C. y J.M. Gero

1994 Rethinking Household Arrangements of the Argentinian Early Formative: Preliminary Excavations at Yutopian, Province of Catamarca. Trabajo presentado al 13th. Annual Northeast Conference on Andean Archeology and Ethnohistory. Ithaca. MS.

Scattolin, M.C. y J.M. Gero

1999 Consideraciones sobre fechados radiocarbónicos de Yutopián (Catamarca, Argentina). Actas del XII Congreso Nacional de Arqueología Argentina. Tomo III:352-357. La Plata, Universidad Nacional de La Plata.

Scattolin, M.C. y A. Korstanje

1994. Tránsito y Frontera en los Nevados del Aconquija. Arqueología 4:165-195. Facultad de Filosofía y Letras. Universidad de Buenos Aires.

Scattolin, M.C. y M. Lazzari

1998 Tramando redes: obsidianas al oeste del Aconquija. Estudios Atacameños 14:189-209. San Pedro de Atacama, Chile.

Scattolin, M.C., L. Pereyra Domingorena, L.I. Cortés, M.F. Bugliani, C.M. Calo, A.D. Izeta y M. Lazzari

2007b Cardonal: una aldea formativa entre los territorios de valles y puna. Cuadernos UNJU 32: 211-225. Facultad de Humanidades y Ciencias Sociales Universidad Nacional de Jujuy.

Schäbitz, F., L. Lupo, J. Kulenmeyer y J. Kulenmeyer

2001 Variaciones en la vegetación, el clima y la presencia humana en los últimos 15000 años en el borde oriental de la puna, provincias de Jujuy y Salta, noroeste argentino. Asociación paleontológica argentina. Publicación especial 8: 155-162

Schiffer, M.B.

1972 Archaeological Context and Systemic Context. American Antiquity 37: 156-165. 
Schiffer, M.B.

1983 Toward the identification of formation processes. American Antiquity 48(4): 675-706.

Schiffer, M.B.

1987 Formation procces of the archaeological record. Journal of Archaeological Science 8: 367-369.

Schreiter, R.

1919. Distintas clases de sepulturas antiguas observadas en los Valles Calchaquíes. Ueberreicht com Verfasser. Sonderabdruck aus Zeitschrift des Deutschen Wissenchaftlichen Vereins zur Kultur-und Landeskcnde Argentiniens. Buenos Aires.

Semenov, S.

1964 Prehistoric Technology. Barnes y Nobel, New York.

Sempé de Gómez Llánez, M.C.

1975 Algunas consideraciones sobre la Arqueología del Valle de Abaucán. Actas y Trabajos $1^{\circ}$ Congreso de Arqueología Argentina. Rosario.

Sing, S., Gepts P.M. y D.G. Debouck

1991 Races of common bean (PH. vulgaris, Fabaceae) Economic Botany 45(3): 379-396.

Somonte, C.

2007 Espacios persistentes y producción lítica en Amaicha del Valle, Tucumán. En P. Arenas,

B. Manasse y E. Noli (comps.) Paisajes y procesos sociales en Tafí del Valle, p. 47-78. Tucumán, Universidad Nacional de Tucumán.

Spalleti, L.

1984 Revisión sobre el significado sedimentológico de algunas propiedades morfométricas, con especial referencia a los conceptos de ecuanticidad y esfericidad de los clastos. Boletín Sedimentológico 2(2-3): 67-80.

Spalletti, L.A. y J.A. Salazar 
1988 Sedimentología de una unidad arqueológica de Tafí del Valle y análisis composicional de las cerámicas asociadas. En E. Berberián (dir.) Sistemas de asentamiento prehispánicos en el valle de Tafí, p. 21-51. Córdoba, Comechingonia.

Stanish, C.

1989 Household archaeology: testing models of zonal complementarity in the south central Andes. American Anthropologist 91: 7-24.

Stewart, R.B. y W. Robertson III

1971 Moisture and Seed Carbonization. Economic Botany 25 (4):381.

Storni, J.S.

1937 Vegetales que utilizaban nuestros indígenas para su alimentación. Editorial de la Universidad de Tucumán.

Strecker, M.

1987. Late Cenozoic landscape in Santa María Valley, Northwestern Argentina. Tesis Doctoral. Inédita. Cornell University. Ithaca.

Struever, S.

1968 Flotation Techniques for recovery of small-scale archaeological remains. American Antiquity 33: 353-362.

Taboada, C. y C. Angiorama

2003 Buscando los indicadores arqueológicos de la Unidad Doméstica. Cuadernos 20: 393407. Universidad Nacional de Jujuy.

Tagle, M.B. y M.T. Planella

2002 La Quinoa en la zona central de Chile. Supervivencia de una tradición prehispana. Editorial Iku, Santiago de Chile.

Tapia, M. 
1990 Cultivos andinos subexplotados y su aporte a la alimentación. Santiago de Chile: Organización de las Naciones Unidas para la Agricultura y la Alimentación, FAO.

Tarragó, M.N.

1980. El Proceso de Agriculturización en el Noroeste Argentino, Zona Valliserrana. En Actas del V Congreso Nacional de Arqueología Argentina 1: 121-218. Facultad de Filosofía, Humanidades y Arte, Universidad Nacional de San Juan: San Juan.

Tarragó, M.N.

1996 El Formativo en el Noroeste argentino y el Alto Valle Calchaquí. Revista del Museo de Historia Natural de San Rafael, Mendoza 23(1-4): 103-119.

Tarragó, M.N.

2007 Ámbitos domésticos y de producción artesanal en el Noroeste Argentino prehispánico. Intersecciones en Antropología 8: 87-100. Olavarría.

Ten Kate, H. F.

1893. Rapport sommaire sur une excursion archéologique dans les provinces de Catamarca, de Tucumán et Salta. Revista del Museo de La Plata V: 331-384.

Tilley, C.

1994 A Phenomenology of Landscape. Berg. Londres.

Thompson, R.G.

1998 Phytolit Analysis of Food Residues in Yutopian Ceramics. Report prepared for Dr. Joan Gero MS.

Thompson, L., M. Davis, Moseley-Thompson E.

1994. Glacial records of global climate: A 1500 year tropical ice core record of climate. Human Ecology Vol 22, Nro 1, 83-95. Plenum Press.

Thompson, L.G. , M. E. Davis, E. Mosley-Thompson, T. Sowers, K. Henderson, V. Zagorodnov, P. Lin, V. Mikhalenko, R. Campen, J. Bolzan, J. Cole-Dai \& B. Francou 1998 A 25.000 Year tropical climate history from Bolivian ice cores. Science 282: 1858-1864 
Toll, M.

1988 Flotation sampling: problems and some solutions, with examples from the American Southwest. En Current Paleoethnobotany, editado por C. Hastorf y E. Popper, pp. 36-52. Prehistoric Archaeology and Ecology Series.

Turner, J. C. M.

1973 Descripción geológica de la Hoja 11d, Laguna Blanca. Boletín 142. Servicio Nacional Minero Geológico. Buenos Aires.

Valero Garcés, B.L., A. Delgado-Huertas, N. Ratto, A. Navas y L. Eduards

2000 Paleohydrology of Andean saline lakes from sedimentological and isotopic record, Northwestern Argentina. Journal of Paleolimnology 24: 343-359

Valero Garcés, B., N. Ratto, A. Moreno, A. Navas y A. Delgado Huertas 2005 Los lagos del altiplano de Atacama y el noroeste argentino como sensores de cambios hidrológicos durante el holoceno. En prensa en Cuaternario de América Central y del Sur. Universidad Nacional de México.

Van der Veen, $M$.

1985 Carbonized seeds, sample size and on-site sampling. In: Palaeoenvironmental Investigations: Research desing, methods and data analysis. Fieller, Gilbertson \& Ralph (eds.) British Academic Reports. Pp.: 165-174.

Vaquer, J.M.

2007 De vuelta a la casa. Algunas consideraciones sobre el espacio doméstico desde la arqueología de la práctica. En: Nielsen A.E., M.C. Rivolta, V. Seldes, M.M. V’zquez y P.H. Mercolli (Comp.) Procesos Sociales Prehispánicos en el Sur Andino. La Vivienda, la Comunidad y el Territorio. Pp. 11-36. Editorial Brujas. Córdoba.

Villafuerte, C.

1984 Diccionario de árboles, arbustos y yuyos en el folklore argentino. Editorial Plus Ultra. Buenos Aires. 
Wagner, G.E.

1982. Testing flotation recovery rates. American Antiquity 47(1):288-292.

Wagner, G.E.

1988 Comparability among recovery techniques. En Current Paleoethnobotany: Analitical methods and cultural interpretations of archaeological plant remains. Edited by Hastorf C. and V. Popper. University Chicago Press.

Watson, P.J.

1976 In Pursuit of Prehistoric subsistence: A comparative account of some contemporary flotation techniques. Mid-Continental Journal of Archaeology 1, 77-100.

Weiser, W.

1920-28. Diarios y libretas de campo de las expediciones B. Muniz Barreto. Departamento Arqueología. Museo de La Plata. MS.

Wilk, R.R. y Ashmore W. (eds.)

1988 Household and Community in the Mesoamerican Past, Albuquerque: University of New Mexico Press.

Wilk, R.R. and Rathje W.L. (eds.) (1982) 'Archaeology of the Household: Building a Prehistory of Domestic Life', American Behavioral Scientist 25, 6: 611-725.

Williams, D.

1973. Flotation at Siraf, Antiquity 47: 288-292

Wilson, D.G. 1984. The carbonization of weed seeds and their representation in macrofossil assemblages. In Plants and Ancient Man: studies in palaeoethnobotany, Proceedings of the sixth symposium of the International Workgroup for Paleoethnobotany. Edited by W. Van Zeist and W. A. Casparie. Rotterdam: A. A. Balkema.

Wright, P.J.

2005 Flotation samples and domes paleoethnobotanical implications. Journal of Archaeological Science 32: 19-26. 
Würschmidt, A.E. y A. Korstanje

1998-1999 Maíz en la cocina: primeras evidencias de fitolitos en sitios arqueológicos del NO argentino. Cuadernos del Instituto Nacional de Antropología y Pensamiento Latinoamericano 18: 457-468. Buenos Aires.

Yacobaccio, $\mathrm{H}$.

1994 Hilos conductores y nudos gordianos: problemas y perspectivas en la arqueología de cazadores-recolectores puneños. Rumitacana 1:19-21. San Fernando del Valle de Catamarca.

Zink, A. y J. M. Sayago

1998 Climatic periodicity during the late Peistocene from a loess-paleosol sequence in Northwest Argentina. En: Internacional Congress of Soil Science. Symposium 16:1-7, Montpellier, Francia. Descritos.

Zuloaga, F. O. y O. Morrone (eds.)

1994-1999 Catálogo de las plantas vasculares de la República Argentina (3 Volúmenes) Missouri Botanical Garden. Versión on-line actualizada disponible en http://www2.darwin.edu.ar/Proyectos/FloraArgentina/FA.asp. Acceso: 10-03-10. 


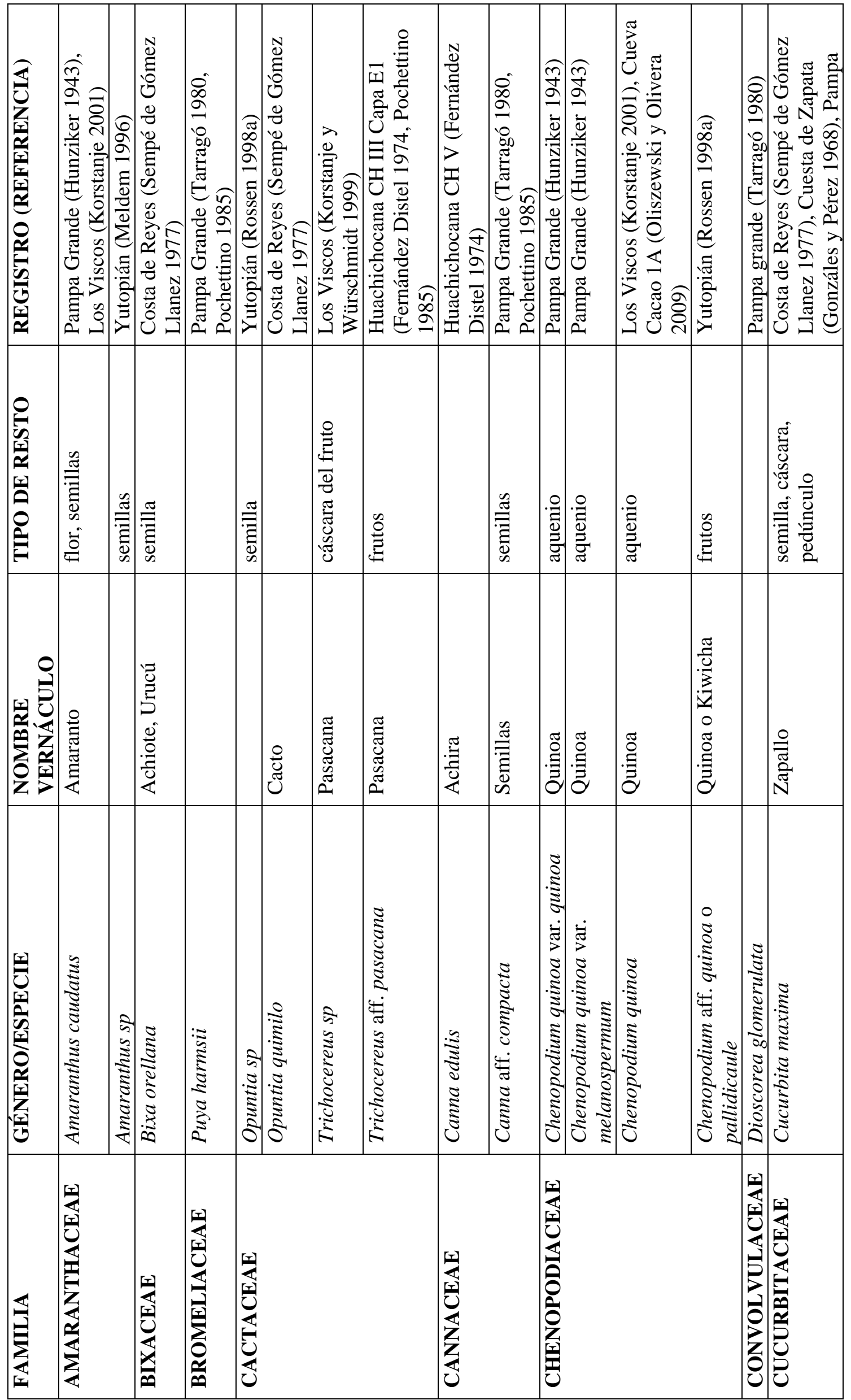


Frutos y semillas hallados en sitios arqueologicos del Noroeste argentino (primer milenio d.C.)

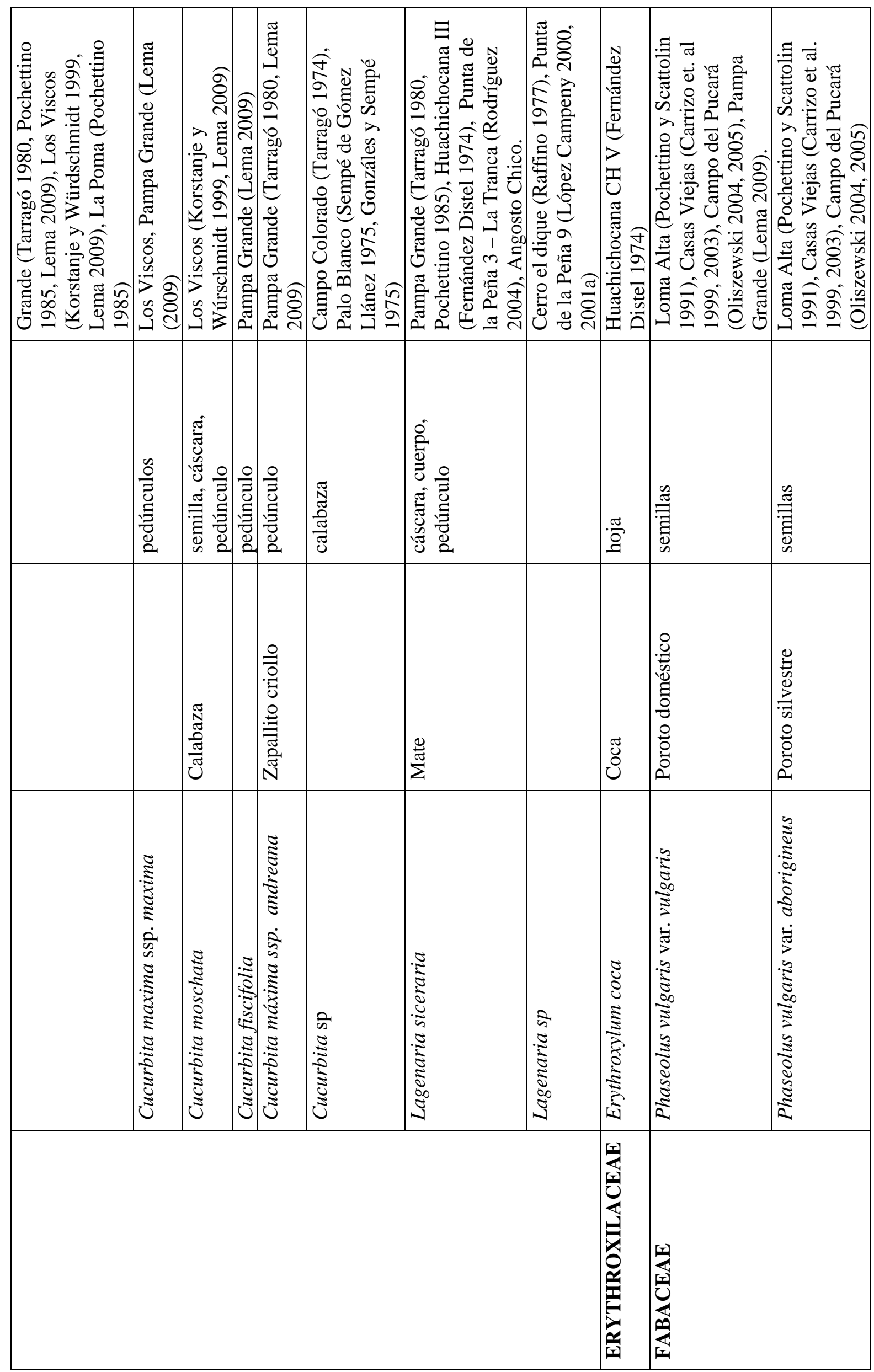




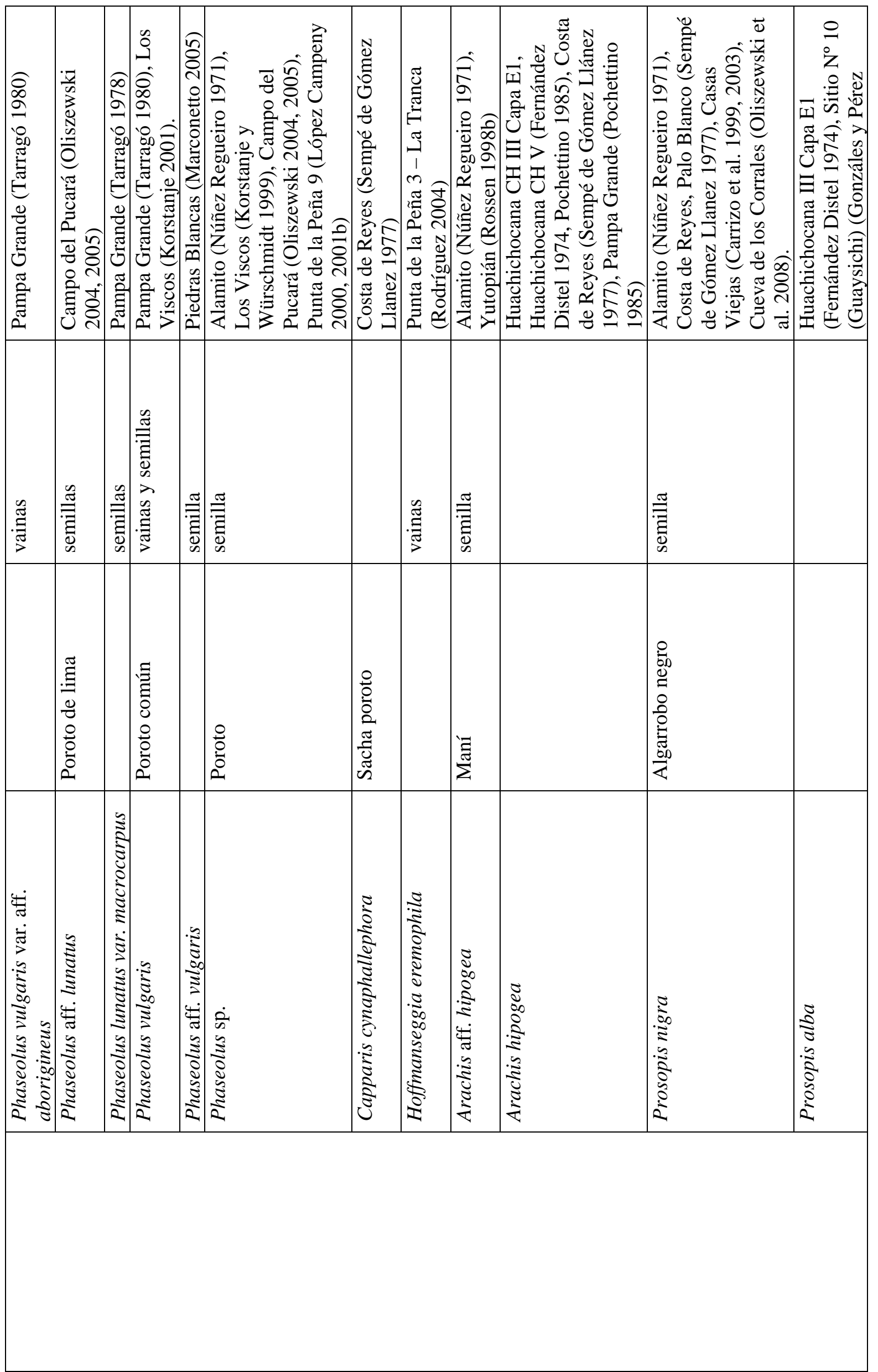


Frutos y semillas hallados en sitios arqueologicos del Noroeste argentino (primer milenio d.C.)

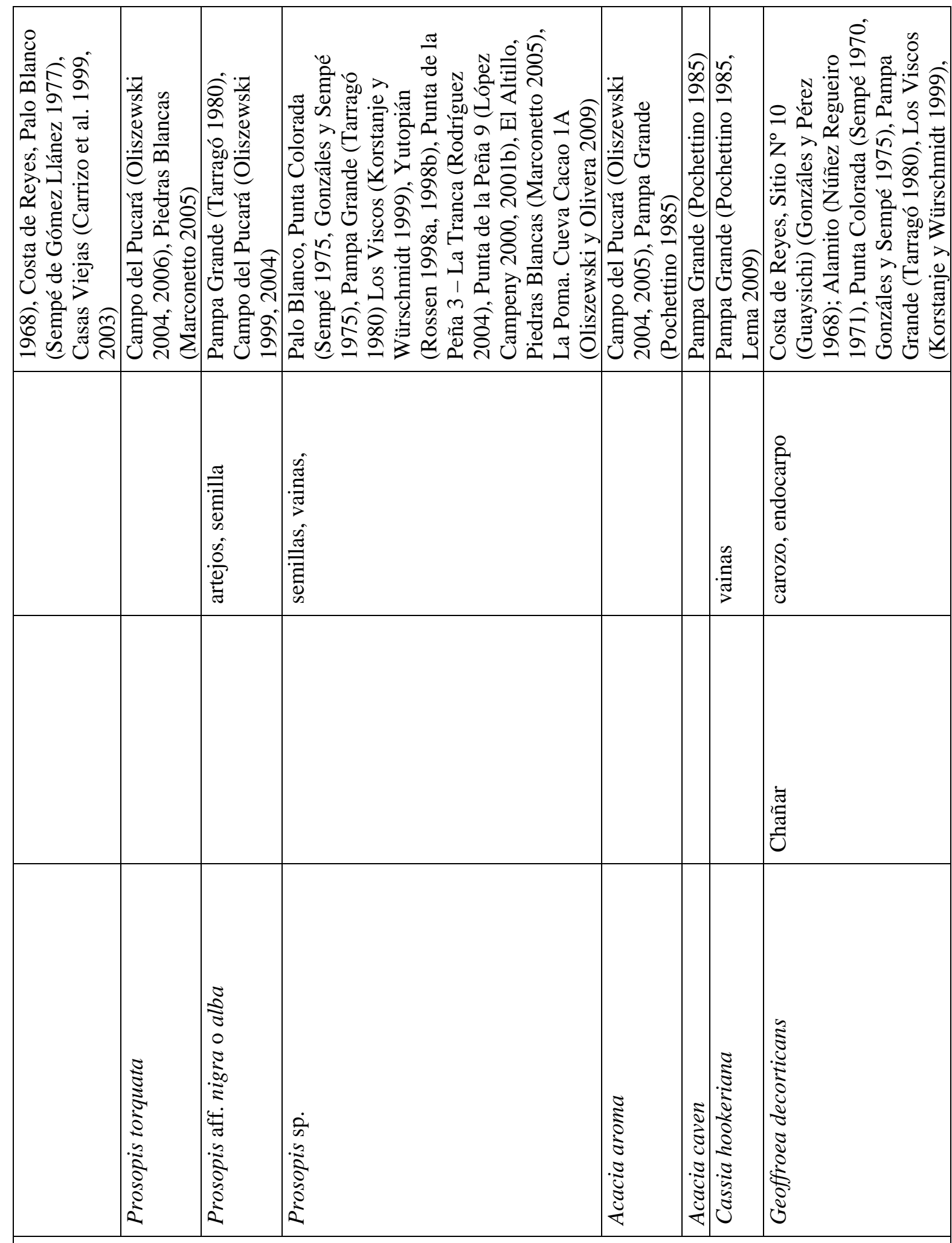


Frutos y semillas hallados en sitios arqueologicos del Noroeste argentino (primer milenio d.C.)

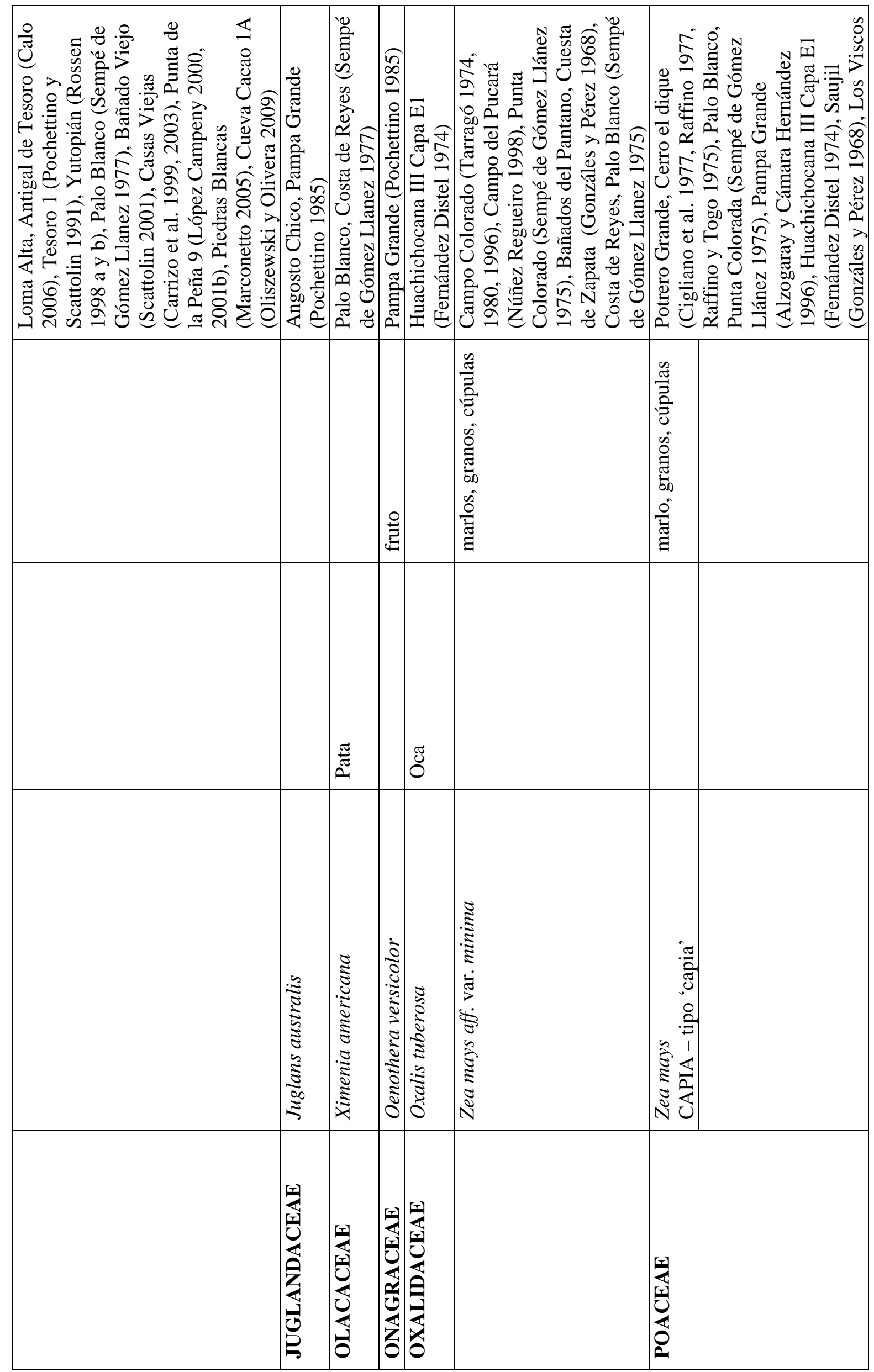


Frutos y semillas hallados en sitios arqueologicos del Noroeste argentino (primer milenio d.C.)

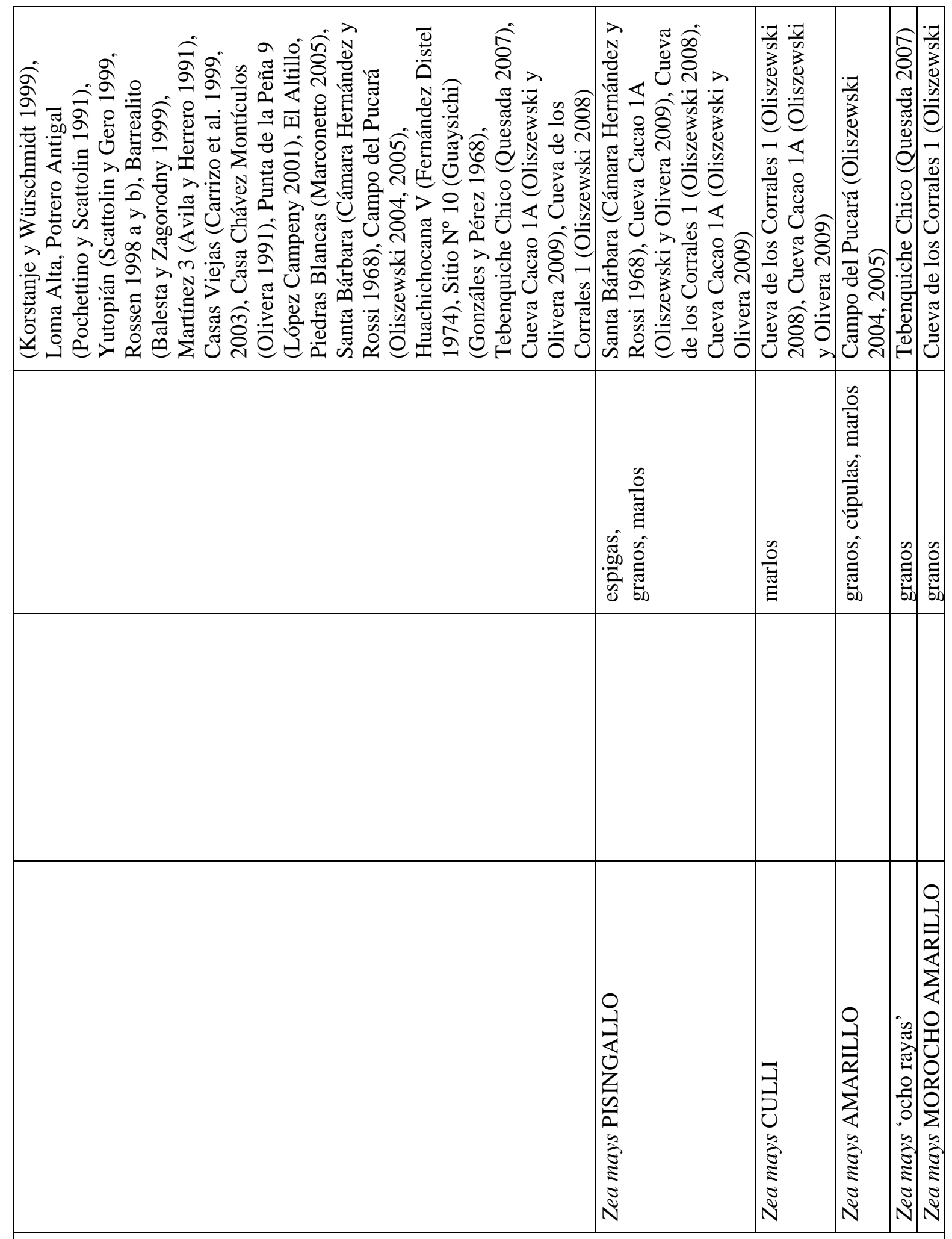


Frutos y semillas hallados en sitios arqueologicos del Noroeste argentino (primer milenio d.C.)

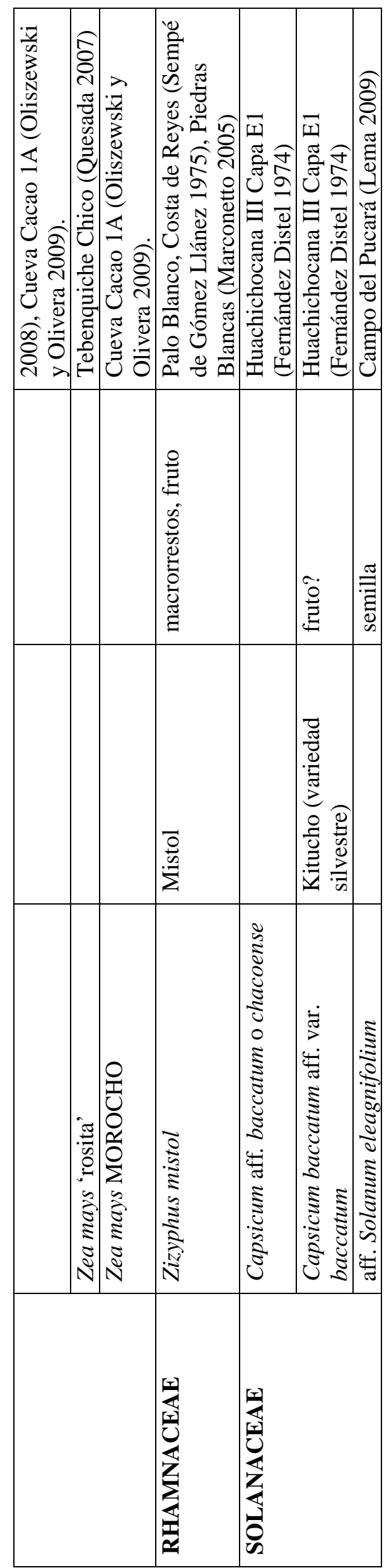


1- Código identificatorio del artefacto (variable de identificación): incluye el número de hallazgo del artefacto precedido de la sigla correspondiente a la denominación de la Estructura de procedencia (E1, E2, E3, E4, E5).

2- Unidad de excavación (variable de procedencia): comprende el número de catálogo de la unidad de excavación (CAT) seguido de la descripción de su ubicación.

3- Estado de conservación de la pieza (variable de estado): se indica si la pieza se encuentra a- entera, b- fracturada o en estado c- indeterminado (ver también Babot 1999).

4- Posición de hallazgo (variable de procedencia): se indica la posición en que fue hallado el artefacto pasivo respecto de sus caras activas de molienda (en base a Adams 1996)

a- Superficie activa hacia arriba

b- Superficie activa hacia abajo

c- Superficie activa de costado

d- Superficies activas hacia arriba y abajo

e- Múltiples superficies activas

f- No registrado

g- Indeterminado

5- Características del descarte (variable de procedencia): Se da cuenta si el artefacto fue a- Dejado en ofrenda

b- Descartada en el lugar de uso (residuo primario)

c- Descartada en un lugar diferente al de uso (residuo secundario)

d- Abandonada (residuo de facto)

e- Indeterminado

6- Portabilidad (variable morfológico-funcional): hace referencia a la posibilidad y/o conveniencia de transporte de los artefactos, determinada principalmente por su peso, volumen, forma y situación en el espacio. Aunque generalmente no es posible determinar si estas variables pudieron ser controladas mediante el accionar grupal o la implementación de medios de transporte adecuados, la portabilidad solo se indica de manera general si los artefactos son

a- Inmueble o fijo

b- Mueble o móvil

c- Indeterminado

7- Medidas de los ejes principales de la pieza (variable dimensional): Estas medidas han sido tomadas en centímetros y corresponden a las dimensiones máximas de la pieza tomadas sobre tres ejes mutuamente perpendiculares. 
a- Largo máximo: o eje longitudinal, corresponde al largo máximo de la pieza.

b- Ancho máximo: o eje transversal, corresponde al ancho máximo de la pieza.

c- Espesor máximo: o eje menor, corresponde al espesor máximo de la pieza.

8- Forma de la pieza (variable morfológico-funcional): se define por su semejanza con cuerpos geométricos. Babot (2004) toma como referencia el diagrama propuesto por Zingg (en Spalletti 1984) que le permite determinar objetivamente la forma general de una pieza a partir de una serie de razones entre sus ejes c/b y b/a (definidos en el apartado anterior), las que determinan en total cuatro formas básicas:

a- Discoidal: u oblada, con b/a mayor que 2/3 $(0,66)$ y c/b menor que 2/3.

b- Esférica: equiaxial o ecuante con b/a mayor que 2/3 y c/b mayor que 2/3.

c- Laminar: triaxial o elipsoidal con b/a menor que 2/3 y c/b menor que 2/3.

d- Cilíndrica: o prolada, con b/a menor que 2/3 y c/b mayor que 2/3.

9- Posición de la cara activa respecto del eje longitudinal de la pieza (variable morfológico-funcional):
a- Paralela
b- Perpendicular
c- Oblicua
d- Curva
e- Indeterminado

10- Forma de la cara activa (variable morfológico-funcional): se tuvo en cuenta la forma general de la curvatura de las caras activas, describiéndose el tipo de curvatura observada en sección longitudinal y transversal
a- Convexa
b- Cóncava
c- Plana
d- Indeterminado

11- Disposición de la oquedad respecto del eje longitudinal del artefacto (variable morfológico-funcional): refiere a la orientación de la oquedad con relación al eje mayor del artefacto
a- Vertical
b- Horizontal
c- Oblicua
d- Indeterminado 
12- Profundidad máxima de la oquedad (variable dimensional): esta medida se expresó en centímetros, perpendicularmente a la sección transversal de la oquedad, desde la boca hasta el fondo.

13- Presencia de rastros macroscópicos de uso y mantenimiento (variable morfológico funcional): Se describen aquí aquellos rasgos empleados por Babot (2004) y definidos sobre la base de la clasificación de Mansur-Fanchomme (1987).
a- Esquirlamientos
b- Redondeo, alisado o pulido de superficies o bordes
c- Estrías
d- Rastros de residuos orgánicos o inorgánicos
e- Indeterminado

14- Modo de acción (variable morfológico-funcional): se indica el movimiento llevado a cabo para obtener el resultado requerido. Estos pueden ser de tres tipos generales que se definen en base a las variables Posición de la cara activa, Forma de la cara activa y Rastros macroscópicos de uso y mantenimiento:

a- Movimientos de presión vertical o puntual

b- Movimientos de presión deslizante o con desplazamiento

c- Movimientos de percusión

d- Indeterminado

15- Posición durante el uso (variable morfológico-funcional):

a- Artefacto de molienda pasivo o inferior

b- Artefacto de molienda activo o superior

c- Artefacto pasivo o inferior indefinido

d- Artefacto activo o superior indefinido

e- Artefacto de molienda de posición indeterminada

f- Artefacto de posición indeterminada

g- Indeterminado 


\begin{tabular}{|c|c|c|c|c|c|c|c|c|}
\hline 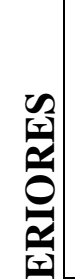 & 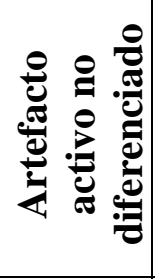 & 召 & ' & ' & 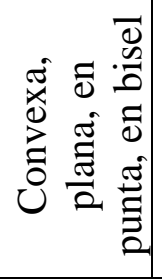 & ' & ' & ' \\
\hline $\begin{array}{l}5 \\
5 \\
0 \\
\infty \\
0 \\
2 \\
0 \\
0 \\
0 \\
\infty\end{array}$ & 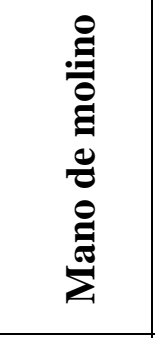 & $\begin{array}{l}\text { 客 } \\
\text { 足 }\end{array}$ & 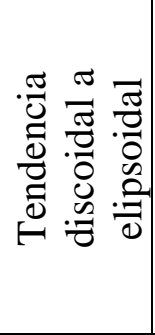 & 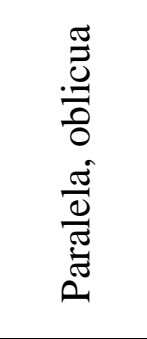 & 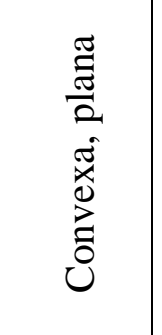 & ' & 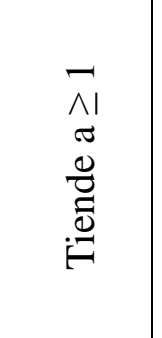 & 1 \\
\hline 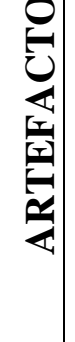 & 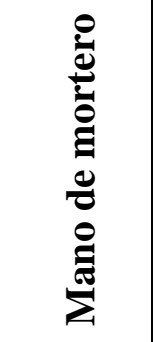 & $\begin{array}{l}\text { 召 } \\
\text { 足 }\end{array}$ & 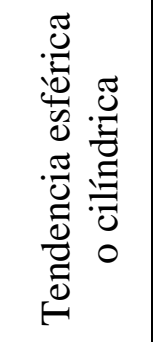 & 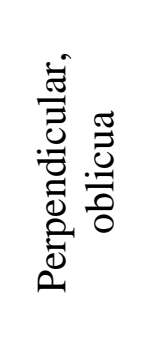 & 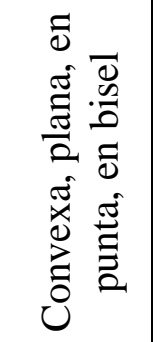 & & $\vec{v}$ & ' \\
\hline 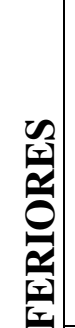 & 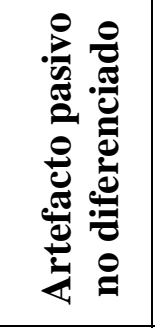 & ' & ' & ' & ' & ' & ' & 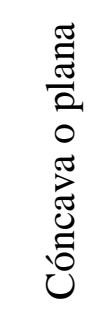 \\
\hline 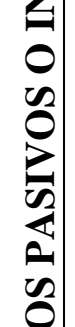 & 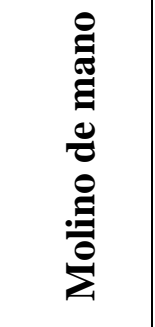 & 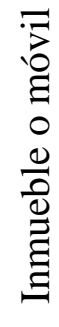 & 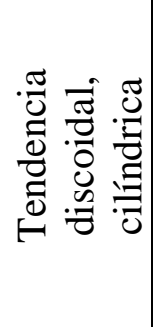 & 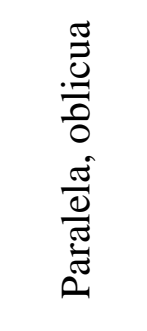 & 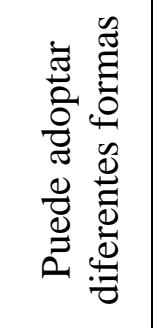 & 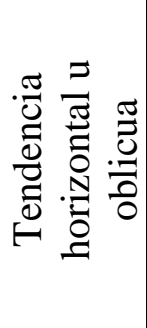 & $\vec{\wedge}$ & 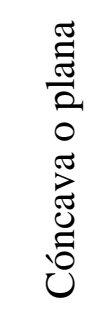 \\
\hline 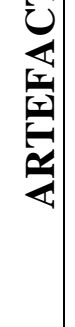 & 总 & 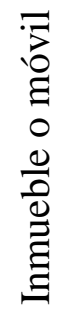 & 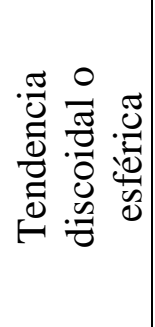 & 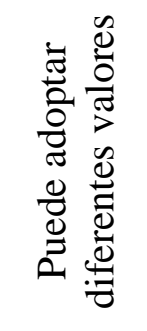 & 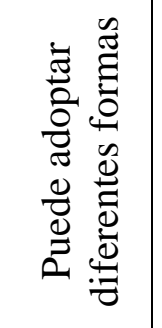 & 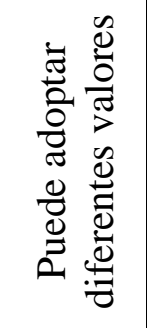 & $\vec{\wedge}$ & 芯 \\
\hline & 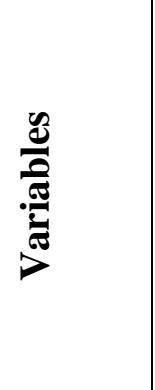 & 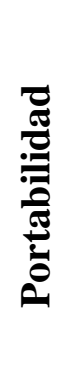 & 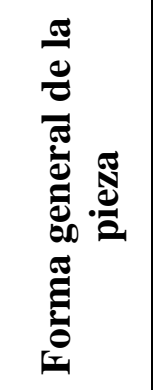 & 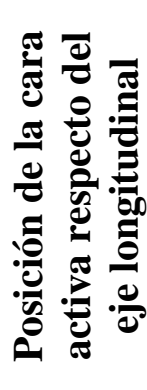 & 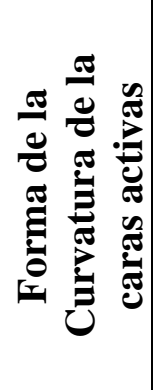 & 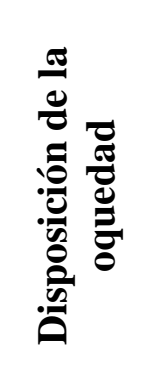 & 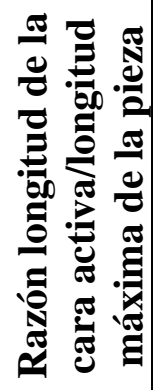 & 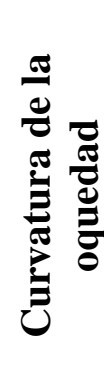 \\
\hline
\end{tabular}


Valores de referencia empleados comparativamente en la identificación de tipos de artefactos de molienda presentes en Cardonal (en base a Babot 2004)

\begin{tabular}{|c|c|c|c|c|}
\hline 1 & ' & 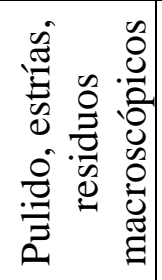 & ' & 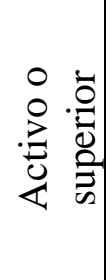 \\
\hline ' & ' & 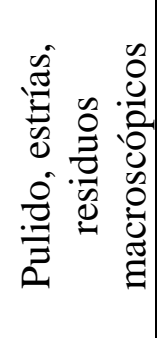 & 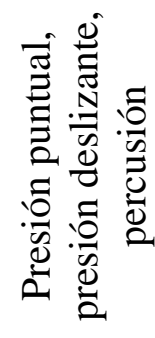 & 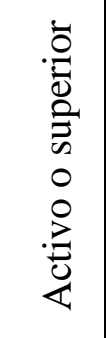 \\
\hline ' & ' & 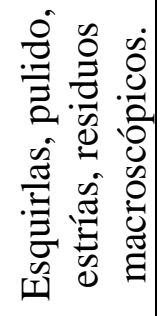 & 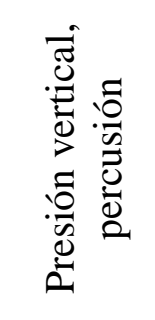 & 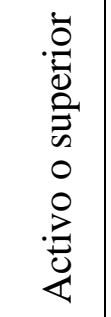 \\
\hline ' & ' & 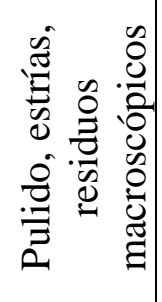 & ' & 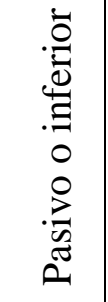 \\
\hline 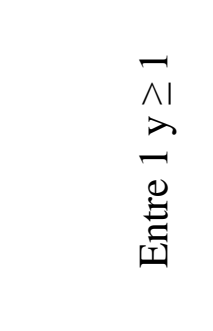 & 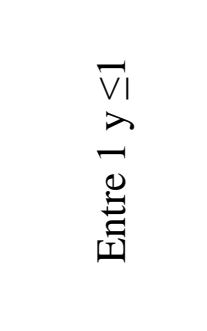 & 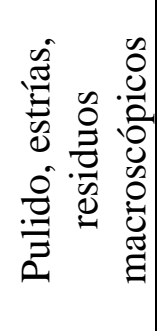 & 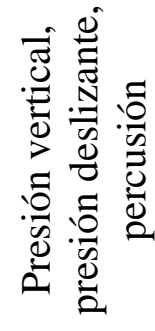 & 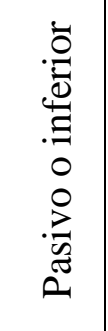 \\
\hline $\begin{array}{l}\overrightarrow{-} \\
\mathrm{VI} \\
0 \\
-1 \\
\wedge I\end{array}$ & $\begin{array}{l}\overrightarrow{V I} \\
0 \\
-1 \\
\wedge 1\end{array}$ & 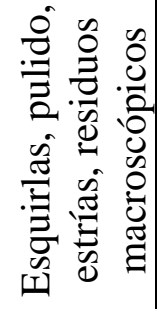 & 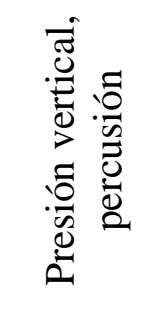 & 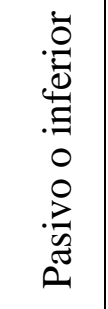 \\
\hline 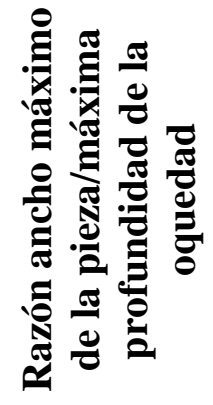 & 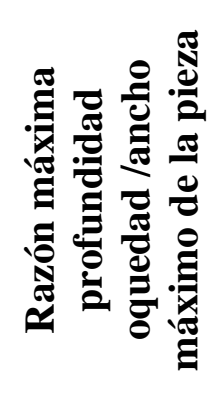 & 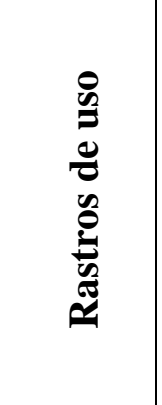 & 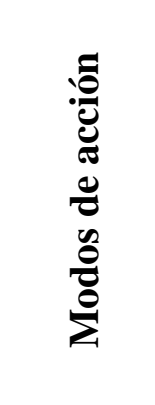 & 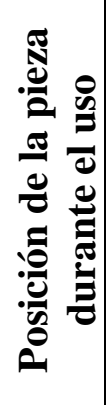 \\
\hline
\end{tabular}


Las plantas silvestres utilizadas actualmente en La Quebrada que integran

\begin{tabular}{|c|c|c|c|}
\hline $\begin{array}{l}\text { NOMBRE } \\
\text { VERNÁCULO }\end{array}$ & FAMILIA & ESPECIE & USO \\
\hline Albahaca de vaca & ASTERACEAE & aff. Tagetes & Aromática \\
\hline Algarrobo & FABACEAE & Prosopis nigra (Griseb.) Hieron. & Alimenticia, construcción \\
\hline Añagua & FABACEAE & Adesmia sp. & Combustible \\
\hline Arca, Arcayuyo & CHENOPODIACEAE & Chenopodium graveolens Willd. & Aromática \\
\hline Azafrán medicinal & ASTERACEAE & $\begin{array}{l}\text { aff. Chuquiraga longuiflora } \\
\text { (Griseb.) Hieron. }\end{array}$ & Medicinal \\
\hline Borraja & ASTERACEAE & Cajophora coronata & Medicinal \\
\hline Cardón & CACTACEAE & Trichocereus aff. Pasacana & Combustible, construcción \\
\hline Chachacoma & ASTERACEAE & Chuquiraga aff. Rotundifolia & Medicinal \\
\hline Champita & CIPERACEAE & varias ssp. & Forrajera \\
\hline $\begin{array}{l}\text { Chano, Chano, } \\
\text { Charroa }\end{array}$ & ASTERACEAE & Ophryosporus charua & Medicinal \\
\hline Cola de león & VERBENACEAE & Verbena seriphioides & Forrajera \\
\hline Colita de oveja & FABACEAE & Lupinus aureonitens & Forrajera \\
\hline Copa-tola & ASTERACEAE & Artemisia сора & Aromática \\
\hline Cortadera & POACEAE & Cortaderia sp. & Cestería \\
\hline Ducle & CACTACEAE & & Ornamental \\
\hline Jaboncillo & POACEAE & Panicum chloroleucum & Forrajera \\
\hline Jarilla & ZIGOPHYLLACEAE & Larrea divaricata & Combustible \\
\hline Maravilla, Viscol & ASTERACEAE & Flourensia riparia & Combustible, forrajera \\
\hline Matico & ASTERACEAE & Marrubium vulgare & Medicinal \\
\hline Mecho & CONVOLVULACEAE & Ipomea sp. & Tóxica \\
\hline Menta mulata & LAMIACEAE & Mentha acuatica & Aromática \\
\hline Molle, Molli & ANACARDIACEAE & Schinus fasciculata & $\begin{array}{l}\text { Alimenticia, combustible, } \\
\text { tintórea }\end{array}$ \\
\hline Monte negro & ASTERACEAE & Cyclolepis genistoides & Combustible \\
\hline Monte negro & ZIGOPHYLLACEAE & Plectrocarpa sp. & Combustible \\
\hline Muña-muña & LAMIACEAE & Satureja parviflora & $\begin{array}{l}\text { Medicinal, afrodisíaco, } \\
\text { aromática }\end{array}$ \\
\hline Muña-muña & LAMIACEAE & Satureja parvifolia & $\begin{array}{l}\text { Medicinal, afrodisíaco, } \\
\text { aromática }\end{array}$ \\
\hline Nencia & GENTIANACEAE & aff. Gentianella & Medicinal \\
\hline Paico & CHENOPODIACEAE & Chenopodium ambrosioides & Medicinal \\
\hline Palam-palam & SOLANACEAE & Nicotiana glauca & Tóxica para el ganado \\
\hline Pasacana & CACTACEAE & Trhichocereus pasacana & Comestible \\
\hline Pasto de raíz & POACEAE & Pennisetum chilense & Forrajera \\
\hline Pata colorada, Cania & ASTERACEAE & Senecio aff. Tilcariensis & Forrajera \\
\hline Pichana & ASTERACEAE & Psila spartioides & Manufactura de escobas \\
\hline Poleo & VERBENACEAE & Lippia aff. Turbinata & Cestería \\
\hline Pusquillo & CACTACEAE & aff. Trichocereus huascha & Alimenticia \\
\hline Quinchamal & ASTERACEAE & Baccharis aff. Grisenbachii & Forrajera \\
\hline Rica-rica & VERBENACEAE & Acantholippia aff. Salsoloides & Aromática \\
\hline Rupachico & ASTERACEAE & & Cosmético \\
\hline Sacha poroto & FABACEAE & Lathyrus sp. & Forrajero \\
\hline Santamaría & ASTERACEAE & Tanacetum parthenium & Medicinal \\
\hline Sombra de toro & ASTERACEAE & Baccharis aff. Grisenbachii & Combustible \\
\hline Tola blanquita & ASTERACEAE & Senecio aff. Crysolepis & $\begin{array}{l}\text { Forrajera, elaboración de } \\
\text { llicta }\end{array}$ \\
\hline Tola macho & ASTERACEAE & Parastrephia quadrangularis & Combustible \\
\hline Yerbabuena & LAMIACEAE & Mentha acuatica & Aromática \\
\hline
\end{tabular}




\begin{tabular}{llll}
\hline Yuyo colorado & POACEAE & Deyeuxia $s p$. & Forrajera \\
\hline & ASTERACEAE & Mutisia $s p$. & Ornamental \\
\hline & POACEAE & Boutelowa aff. curtipendula & Forrajera \\
\hline
\end{tabular}


Especies que integran la colección de referencia de frutos y semillas comestibles del Noroeste argentino

\begin{tabular}{|c|c|c|c|c|}
\hline $\begin{array}{l}\text { NOMBRE } \\
\text { VERNACULO }\end{array}$ & FAMILIA & ESPECIE & PROCEDENCIA & $\begin{array}{l}\text { ÓRGANO } \\
\text { COLECTADO }\end{array}$ \\
\hline Achira & CANNACEAE & Canna edulis & Buenos Aires & semillas \\
\hline $\begin{array}{l}\text { Algarrobo } \\
\text { blanco }\end{array}$ & FABACEAE & Prosopis alba & Cafayate, Salta & vainas, semillas \\
\hline Amaranto & AMARANTACEAE & Amaranthus caudatus & Buenos Aires (1) & semillas \\
\hline \multirow[t]{2}{*}{ Amaranto } & AMARANTACEAE & Amaranthus caudatus & & semillas \\
\hline & & & Perú (1) & \\
\hline Anco, Zapallo & CUCURBITACEAE & Cucurbita maxima & $\begin{array}{l}\text { Yutopián, } \\
\text { Catamarca }\end{array}$ & $\begin{array}{l}\text { semillas, pericarpio, } \\
\text { pedúnculos }\end{array}$ \\
\hline Anco, Zapallo & CUCRBITACEAE & Cucurbita maxima & $\begin{array}{l}\text { El Bañado, } \\
\text { Tucumán }\end{array}$ & pedúnculos, semillas \\
\hline Anco, zapallo & CUCURBITACEAE & Cucurbita maxima & $\begin{array}{l}\text { Yutopián, } \\
\text { Catamarca }\end{array}$ & semillas \\
\hline $\begin{array}{l}\text { Aromo, } \\
\text { Espino, } \\
\text { Churqui }\end{array}$ & FABACEAE & Acacia caven & $\begin{array}{l}\text { San Rafael, } \\
\text { Mendoza }\end{array}$ & vainas, semillas \\
\hline Cañiwa & CHENOPODIACEAE & $\begin{array}{l}\text { Chenopodium } \\
\text { pallidicaule }\end{array}$ & Perú (1) & semillas, pericarpios \\
\hline Capia & POACEAE & Zea mays & $\begin{array}{l}\text { Santa María, } \\
\text { Catamarca } \\
\text { (comercio) } \\
\end{array}$ & granos \\
\hline Capia peruano & POACEAE & Zea mays & $\begin{array}{l}\text { Yutopián, } \\
\text { Catamarca }\end{array}$ & granos, marlo \\
\hline Cayote & CUCURBITACEAE & Cucurbita fiscifolia & Salta (1) & semillas \\
\hline Cebil & FABACEAE & $\begin{array}{l}\text { Anadenanthera } \\
\text { colubrina var. cebil }\end{array}$ & Buenos Aires & semillas, vainas \\
\hline Chañar & FABACEAE & Geoffroea decorticans & $\begin{array}{l}\text { Santa María, } \\
\text { Catamarca }\end{array}$ & $\begin{array}{l}\text { frutos, endocarpos, } \\
\text { semillas }\end{array}$ \\
\hline Coca & ERITHROXILACEAE & Erithroxylum coca & Jujuy (1) & semillas \\
\hline $\begin{array}{l}\text { Kitucho, Aji } \\
\text { picante, } \\
\text { Putaparió } \\
\end{array}$ & SOLANACEAE & Capsicum baccatum & Bolivia (2) & semillas, frutos desecados \\
\hline $\begin{array}{l}\text { Lokoto, } \\
\text { Rocoto }\end{array}$ & SOLANACEAE & Capsicum pubescens & Bolivia (2) & semillas, frutos desecados \\
\hline Maiz & POACEAE & Zea mays & $\begin{array}{l}\text { El Bañado, } \\
\text { Tucumán }\end{array}$ & marlos vs. \\
\hline Maiz & POACEAE & Zea mays & $\begin{array}{l}\text { Lagunita, } \\
\text { Catamarca }\end{array}$ & marlos vs. \\
\hline Maíz pinto & POACEAE & Zea mays & Jujuy (2) & granos \\
\hline $\begin{array}{l}\text { Maíz } \\
\text { pisingallo }\end{array}$ & POACEAE & Zea mays & Buenos Aires (1) & granos \\
\hline $\begin{array}{l}\text { Maíz } \\
\text { pisingallo }\end{array}$ & POACEAE & Zea mays & Buenos Aires (1) & granos \\
\hline Maíz reventón & POACEAE & Zea mays & Bolivia (2) & granos \\
\hline Maní salteño & FABACEAE & Arachis hypogea & Salta (1) & pericarpios, semillas \\
\hline Mate & CUCURBITACEAE & Lagenaria siceraria & Buenos Aires & semillas \\
\hline Oca & OXALIDACEAE & Oxalis tuberosa & Bolivia (2) & tubérculo desecado \\
\hline Papa & SOLANACEAE & Solanum tuberosum & $\begin{array}{l}\text { Yutopián, } \\
\text { Catamarca }\end{array}$ & tubérculo desecado \\
\hline Poroto común & FABACEAE & $\begin{array}{l}\text { Phaseolus vulgaris var. } \\
\text { vulgaris }\end{array}$ & Jujuy & semillas \\
\hline $\begin{array}{l}\text { Poroto de } \\
\text { manteca }\end{array}$ & FABACEAE & Phaseolus lunatus & Buenos Aires (1) & semillas \\
\hline $\begin{array}{l}\text { Poroto } \\
\text { manchadito }\end{array}$ & FABACEAE & $\begin{array}{l}\text { Phaseolus vulgaris var. } \\
\text { vulgaris }\end{array}$ & Buenos Aires (1) & semillas \\
\hline $\begin{array}{l}\text { Poroto negro } \\
\text { (tipo feijao) }\end{array}$ & FABACEAE & $\begin{array}{l}\text { Phaseolus vulgaris var. } \\
\text { vulgaris }\end{array}$ & Buenos Aires (1) & semillas \\
\hline Quinoa & CHENOPODIACEAE & Chenopodium quinoa & Buenos Aires (1) & semillas \\
\hline Tuna & CACTACEAE & Opuntia ficus-indica & Buenos Aires & semillas \\
\hline
\end{tabular}


Especies que integran la colección de referencia de frutos y semillas comestibles del Noroeste argentino

\begin{tabular}{lllll}
\hline $\begin{array}{l}\text { Tusca, Aromo } \\
\text { negro, } \\
\text { Espinillo }\end{array}$ & FABACEAE & Acacia aroma & $\begin{array}{l}\text { Cerrillos, } \\
\text { Catamarca }\end{array}$ & vainas, semillas \\
\hline $\begin{array}{l}\text { Urucú, } \\
\text { Achiote }\end{array}$ & BIXACEAE & Bixa orellana & Buenos Aires (1) & semillas \\
\hline
\end{tabular}

(1) producto comercial. 


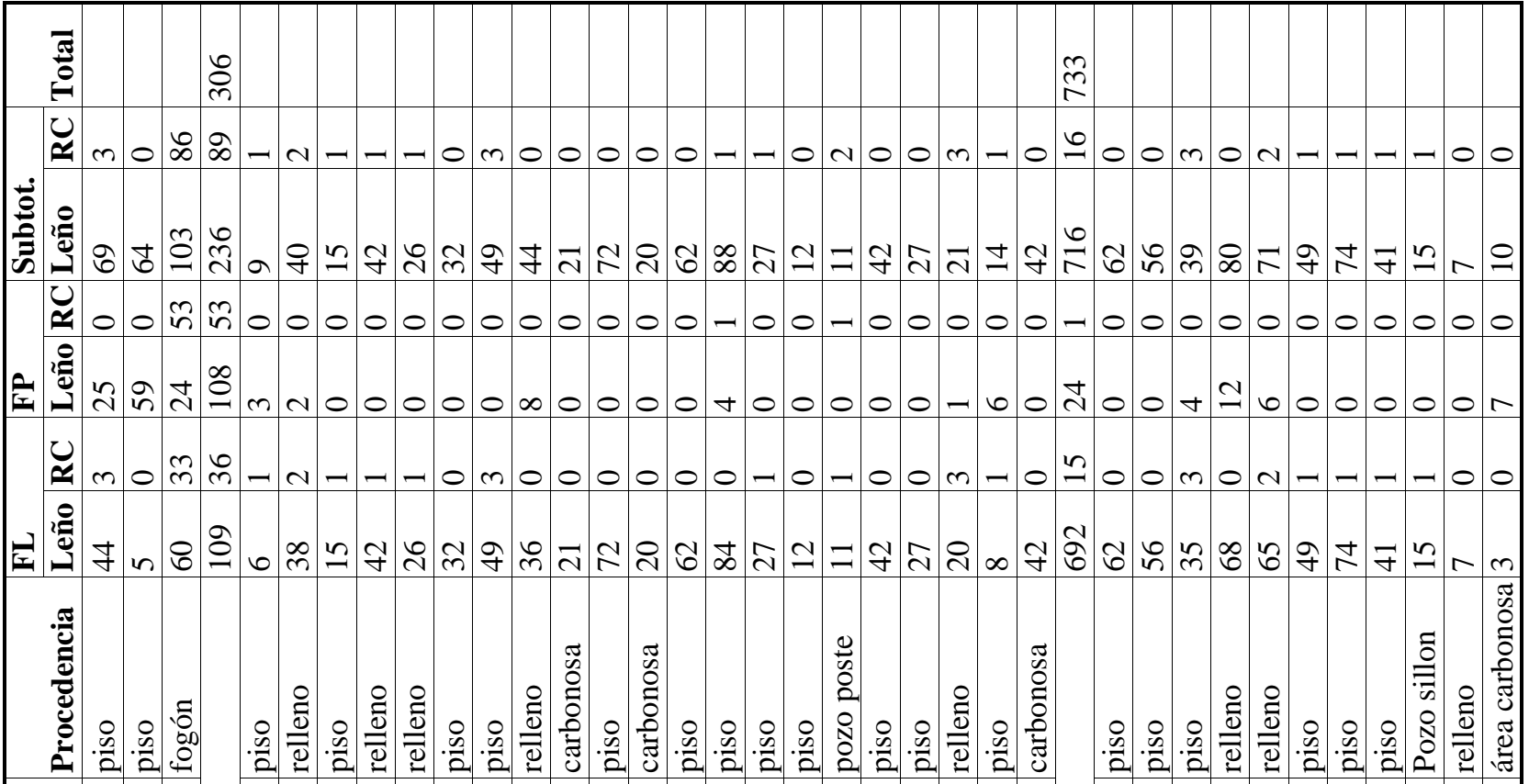

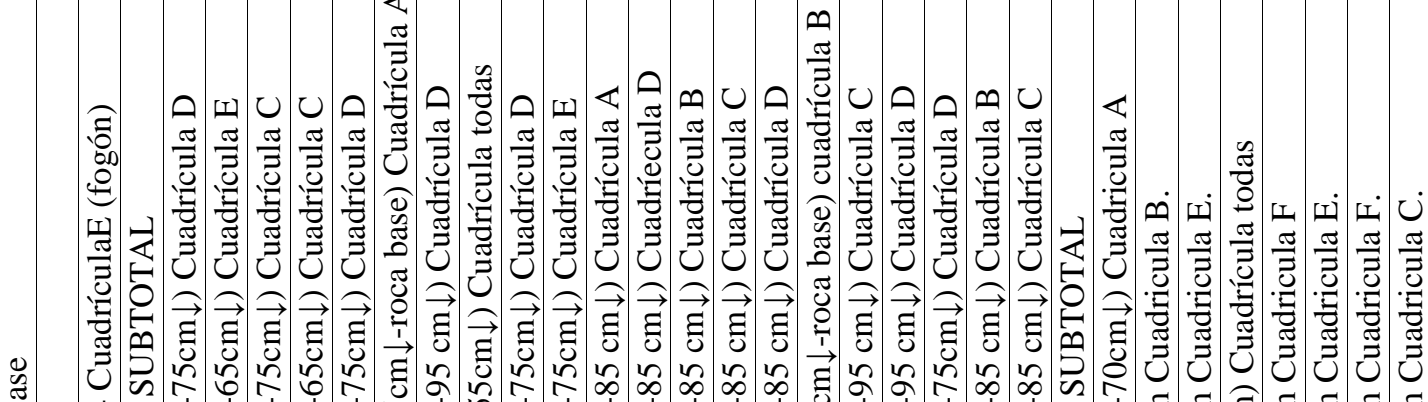

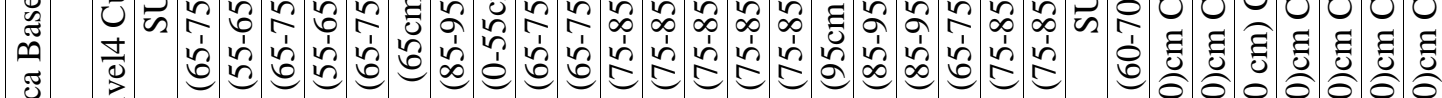

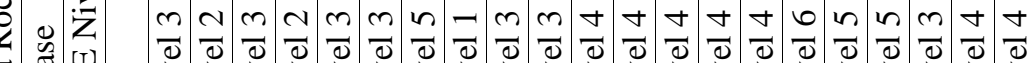

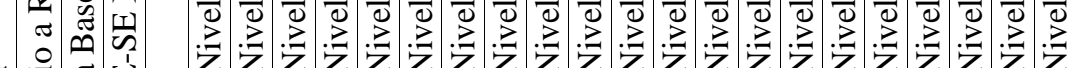

:

:

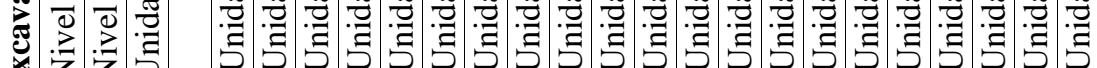

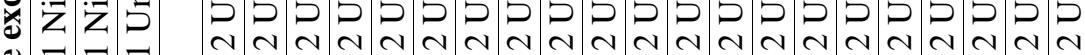

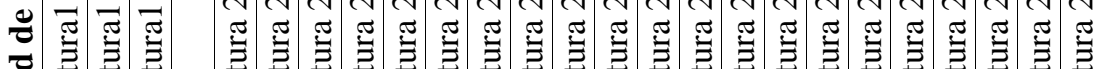

T)

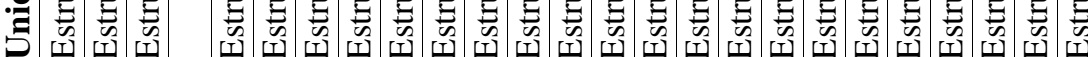

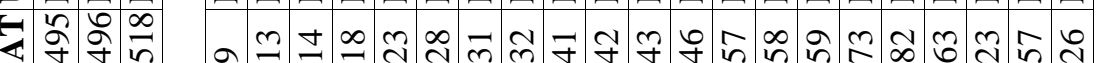

๑

จ

ง

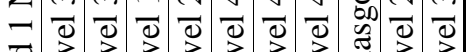

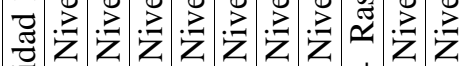

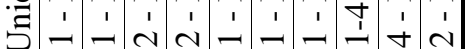
m $\supset \supset \supset \supset \supset \supset \supset$

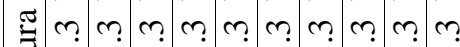

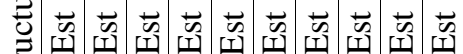

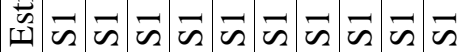

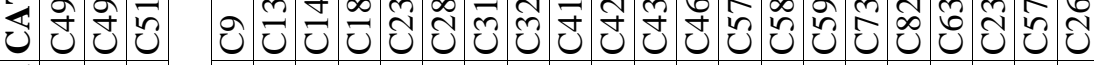
ஸ் $\dot{z}+4 m+h m+n \infty 0$ m 


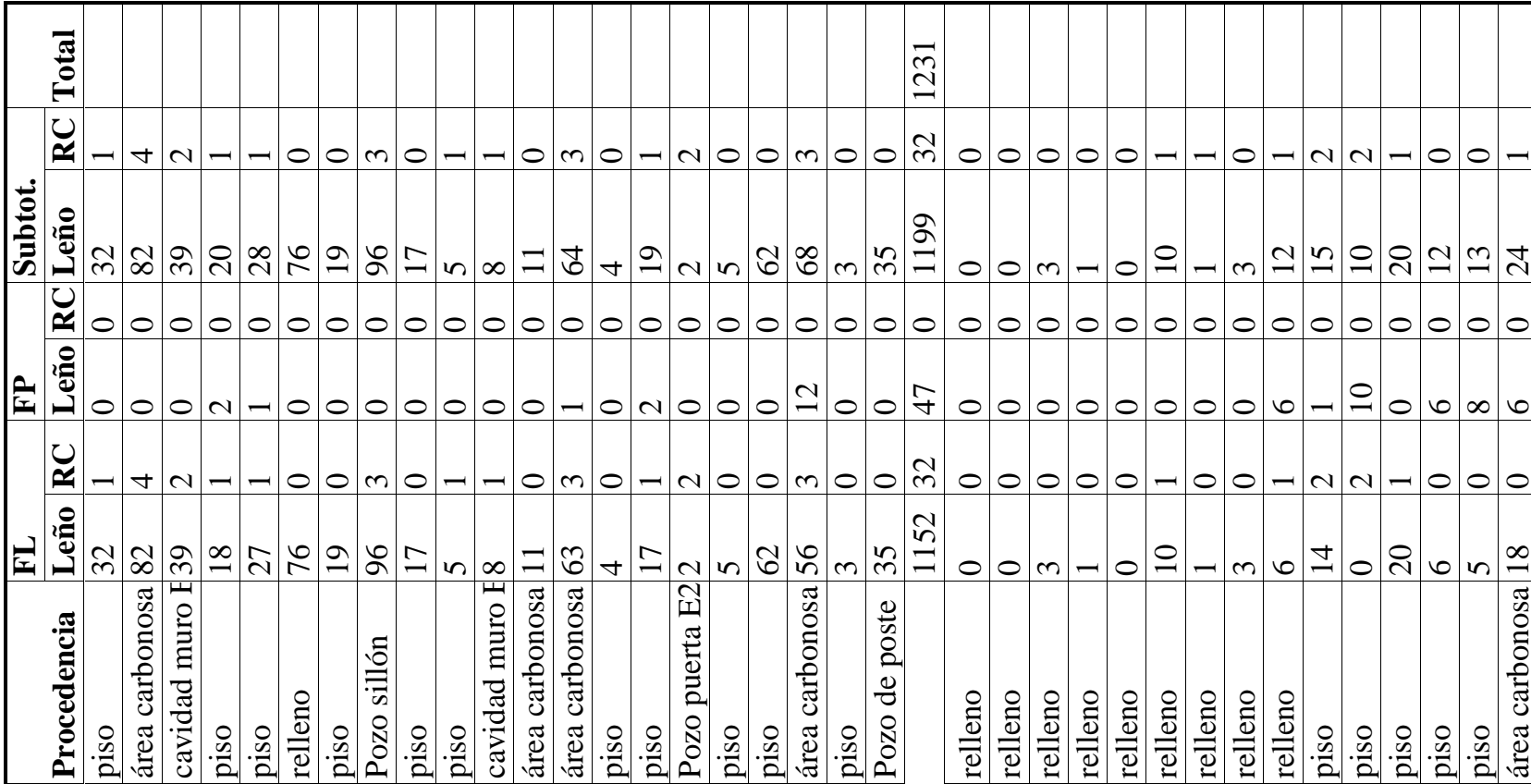

ن ن ن ن ن

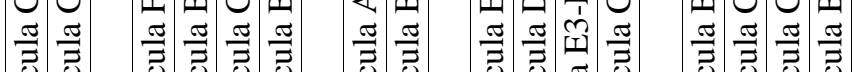

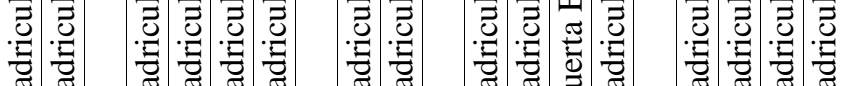

齐

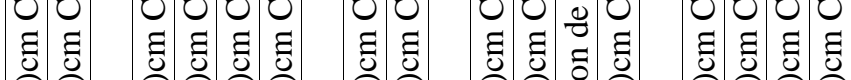

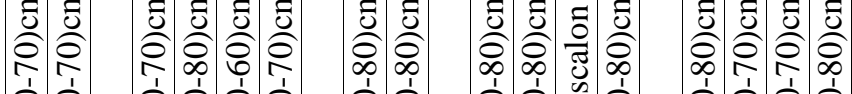

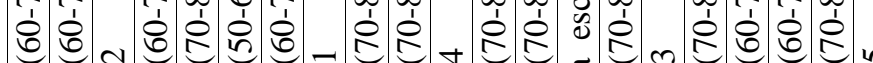

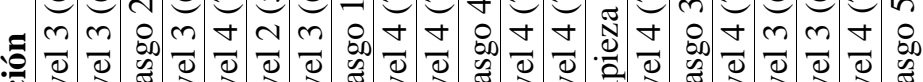

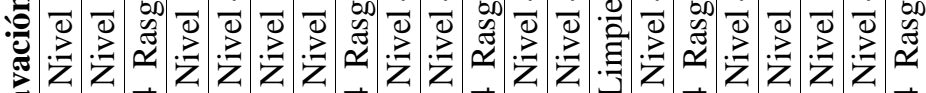

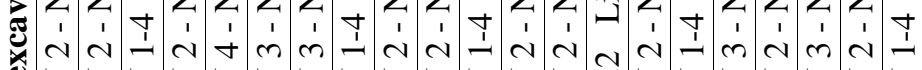

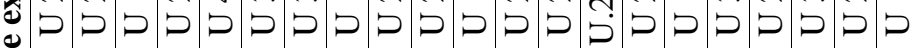
-

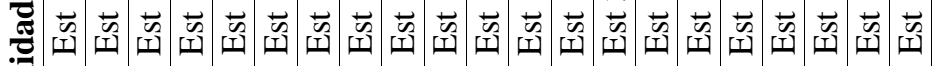

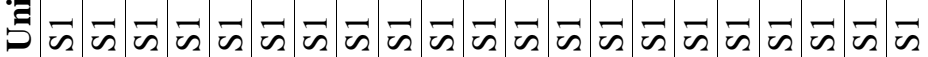
甘 ડૈتี

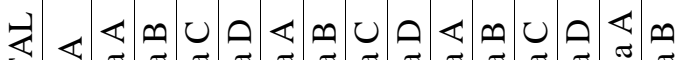

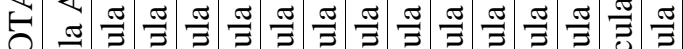

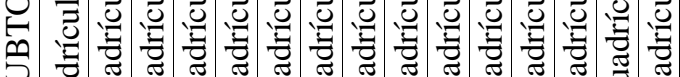
is $373 \quad 3 \quad 3 \quad 3 \quad 3 \quad 30$

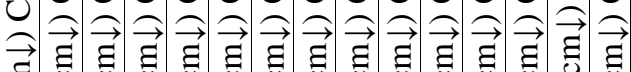

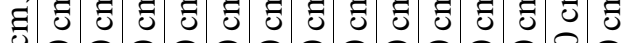

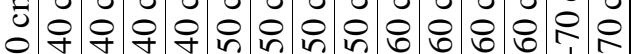
ले

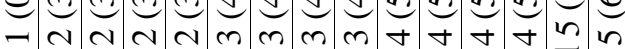

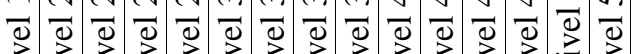

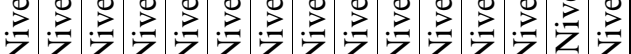

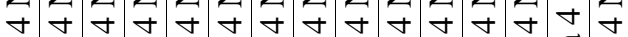

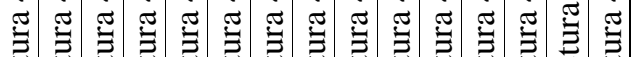

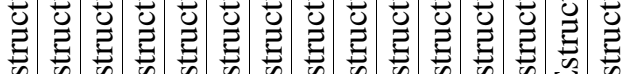

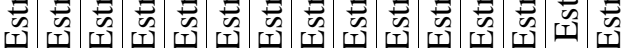
ஃ ஊ

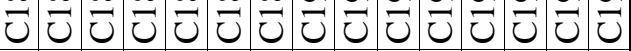

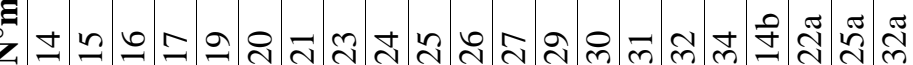



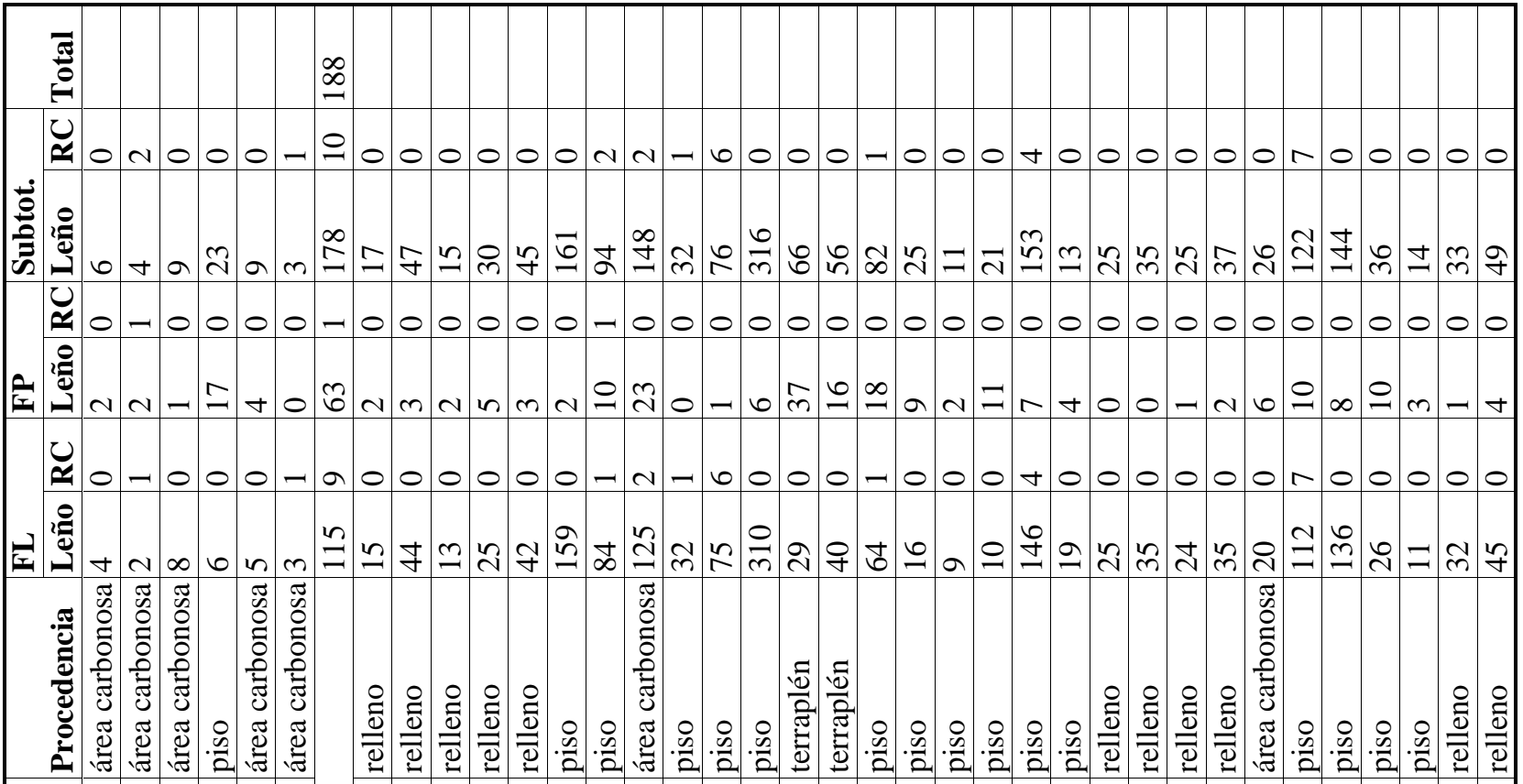

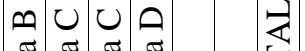

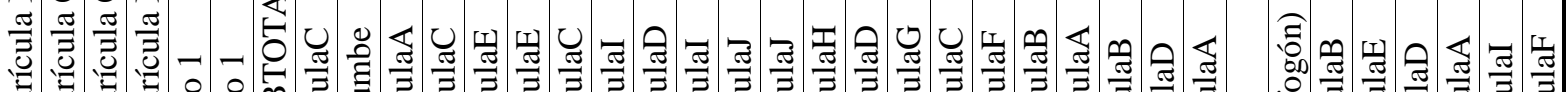

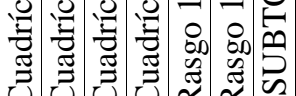
苟勇

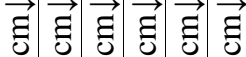

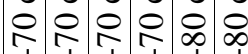
=

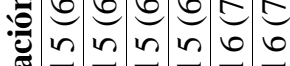

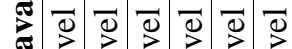

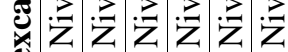

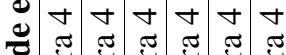

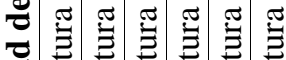
:

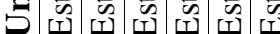

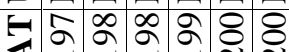

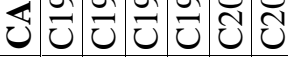
Ż

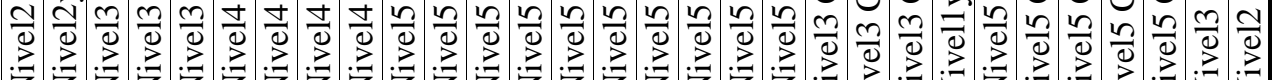

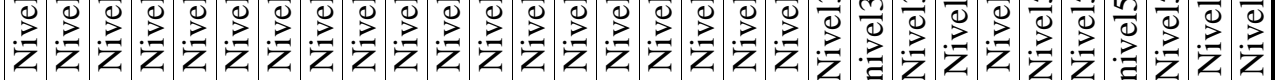

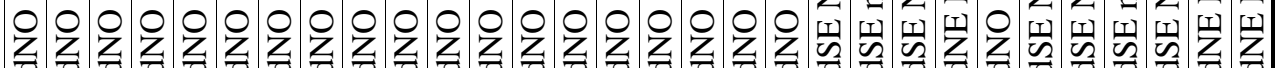

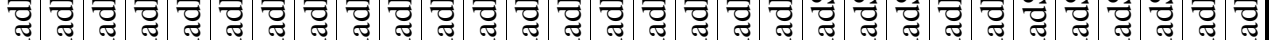

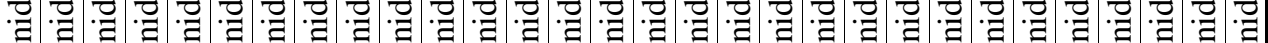

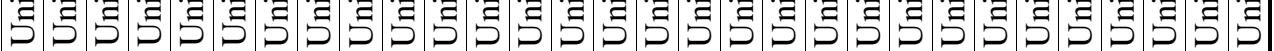

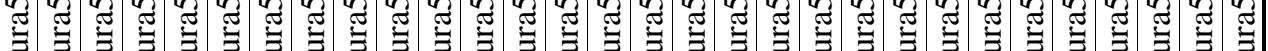

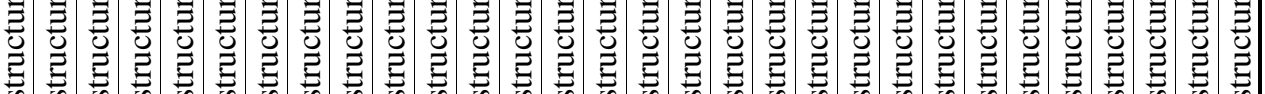

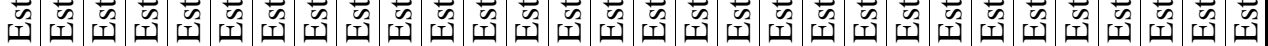

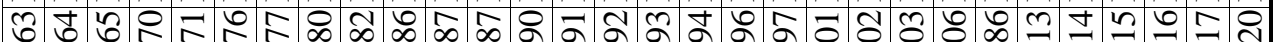
ปै ָै ปै 


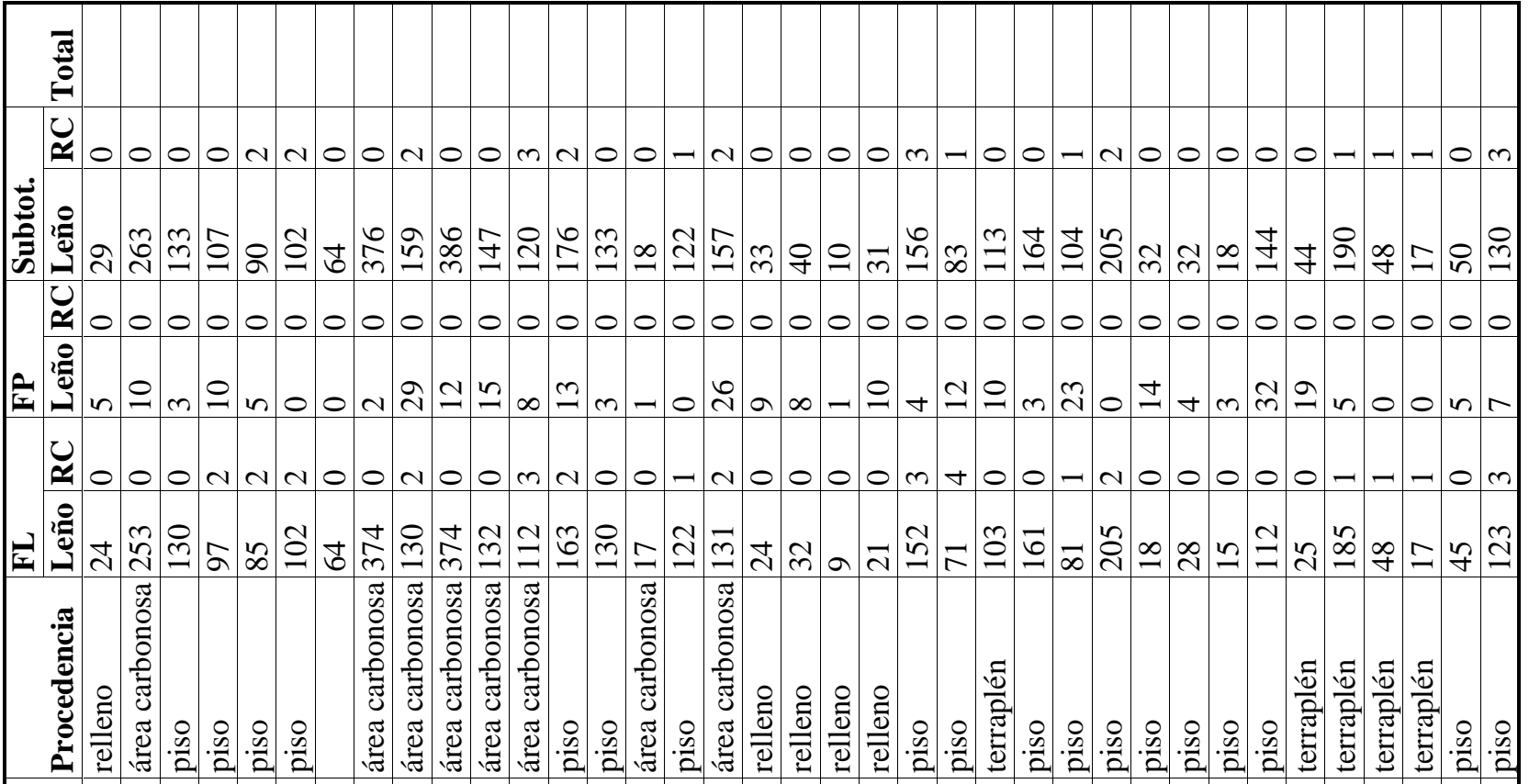

它

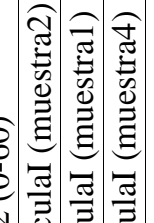

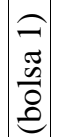

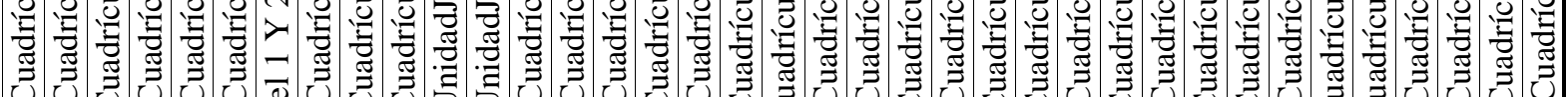

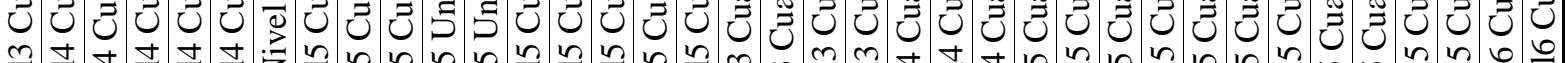

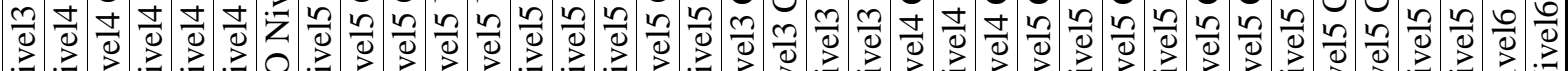

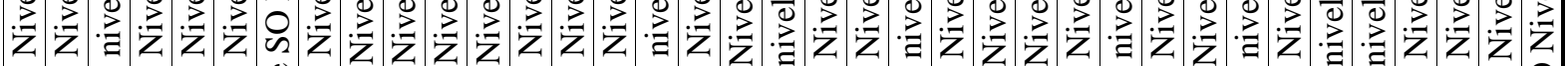

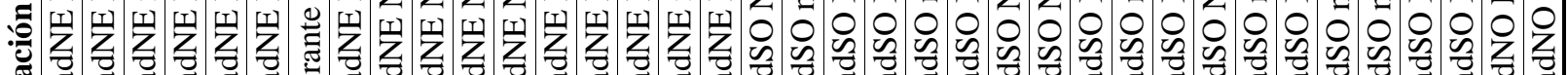

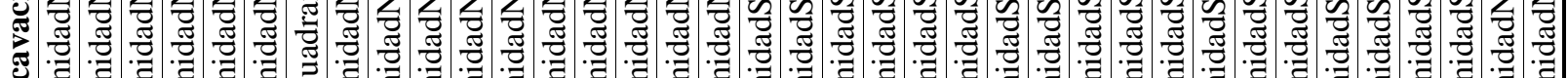
ชิ ஏ

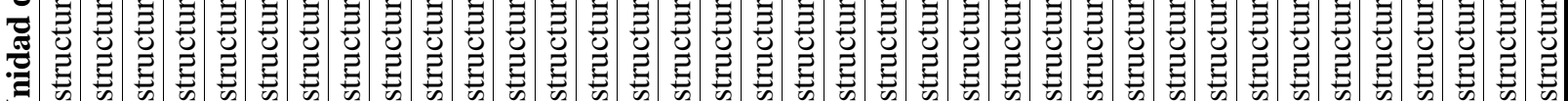

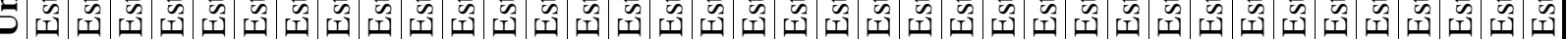
కL

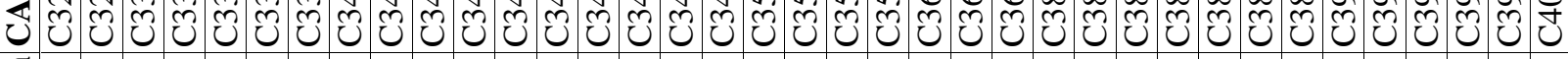

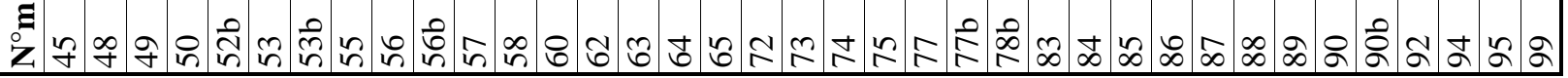


m0000nm-0h-400000n:00040000000n

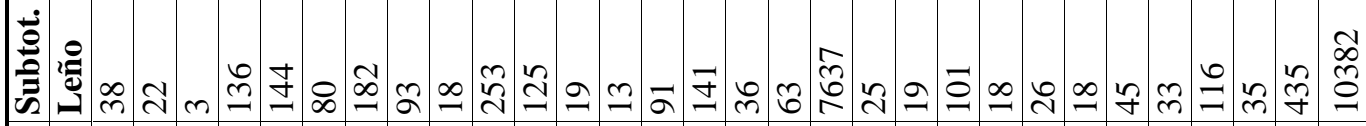
$\approx 00000000000000000-100000000000$ h 藏哭

然 U o.000nm-0h-700000n

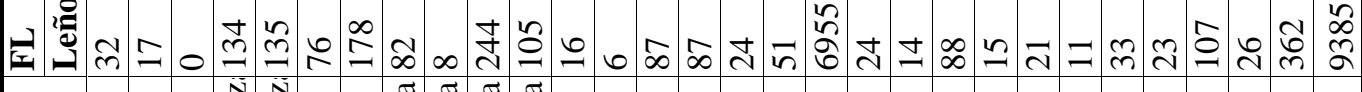

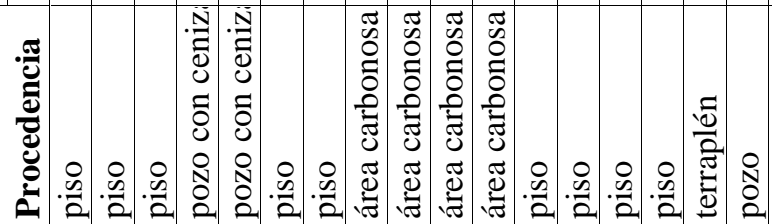

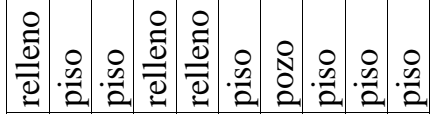

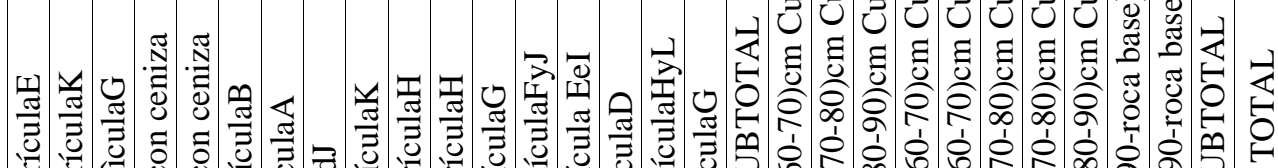

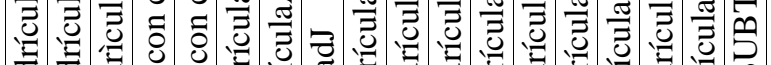

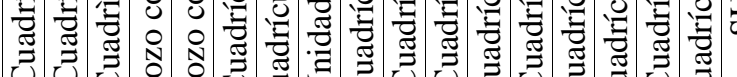
ป

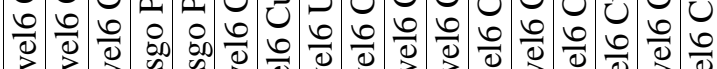

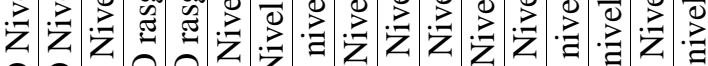
:

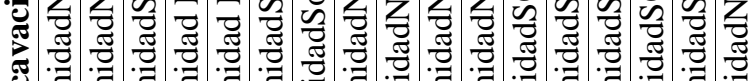

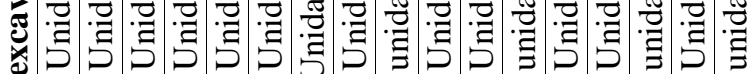

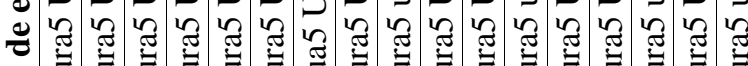

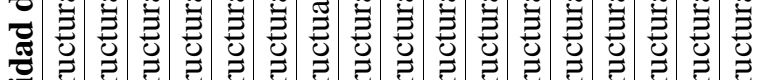

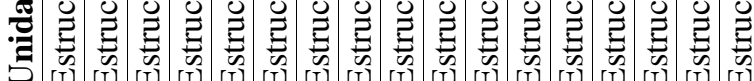

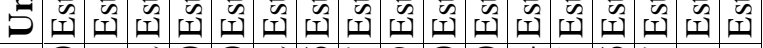

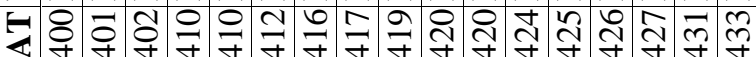

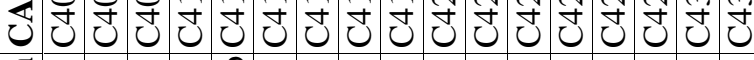

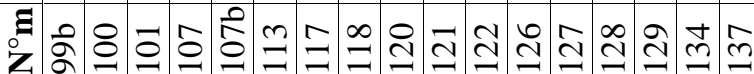

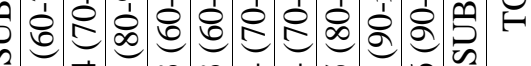

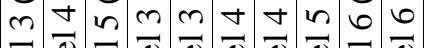

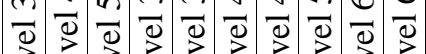

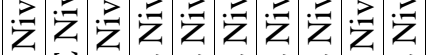
檪

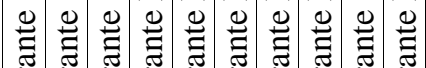
莺苞

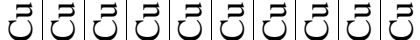
م

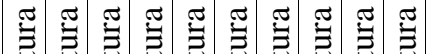
约

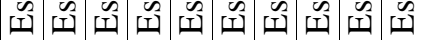

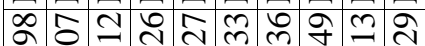

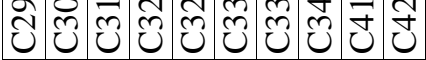

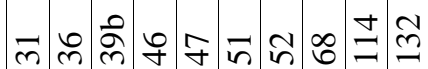




\begin{tabular}{|c|c|c|c|}
\hline CAT & Unidad de excavación & Procedencia & RestosCarpológicos \\
\hline C5 & Estructura2 Unidad1 Nivel2 $(55-65 \mathrm{~cm})$ Cuadrícula D & RELLENO & 1 \\
\hline C68 & Estructura2 Unidad4 CuadriculaA Nivel6 & PISO & 2 \\
\hline C128 & Estructura3 Unidad3 Nivel3 (60-70)cm CuadriculaC. & PISO CARBONOSO & 1 \\
\hline C197 & Estructura 4 Nivel $5(60-70 \mathrm{~cm})$ Cuadrícula B & PISO CARBONOSO & 1 \\
\hline C198 & Estructura 4 Nivel $5(60-70 \mathrm{~cm})$ Cuadrícula C & PISO CARBONOSO & 1 \\
\hline C340 & Estructura5 Unidad N.E. Cuadrícula I Nivel 5 & ÁREA FOGÓN & 11 \\
\hline C374 & Estructura5 Unidad S.O. Nivel4 (70-80)cm CuadrículaJ & PISO & 2 \\
\hline C517 & Estructura1 Sector NE/SE CuadrículaE Nivel3 (105-115cm) & PISO & 3 \\
\hline C518 & Estructura1 Sector NE/SE CuadrículaE Nivel 4 (115-125cm) & FOGÓN & 3 \\
\hline C522 & Estructura1 Sector NE/SE CuadrículaD Nivel4 (115-125cm) & PISO & 3 \\
\hline C523 & Estructura1 Sector NE/SE CuadrículaF Nivel4 (115-125cm) & PISO & 3 \\
\hline C525 & Estructura1 SectorNE/SE CuadrículaC Nivel4 (115-125cm) & PISO & 4 \\
\hline \multicolumn{3}{|c|}{ TOTALES } & 35 \\
\hline
\end{tabular}




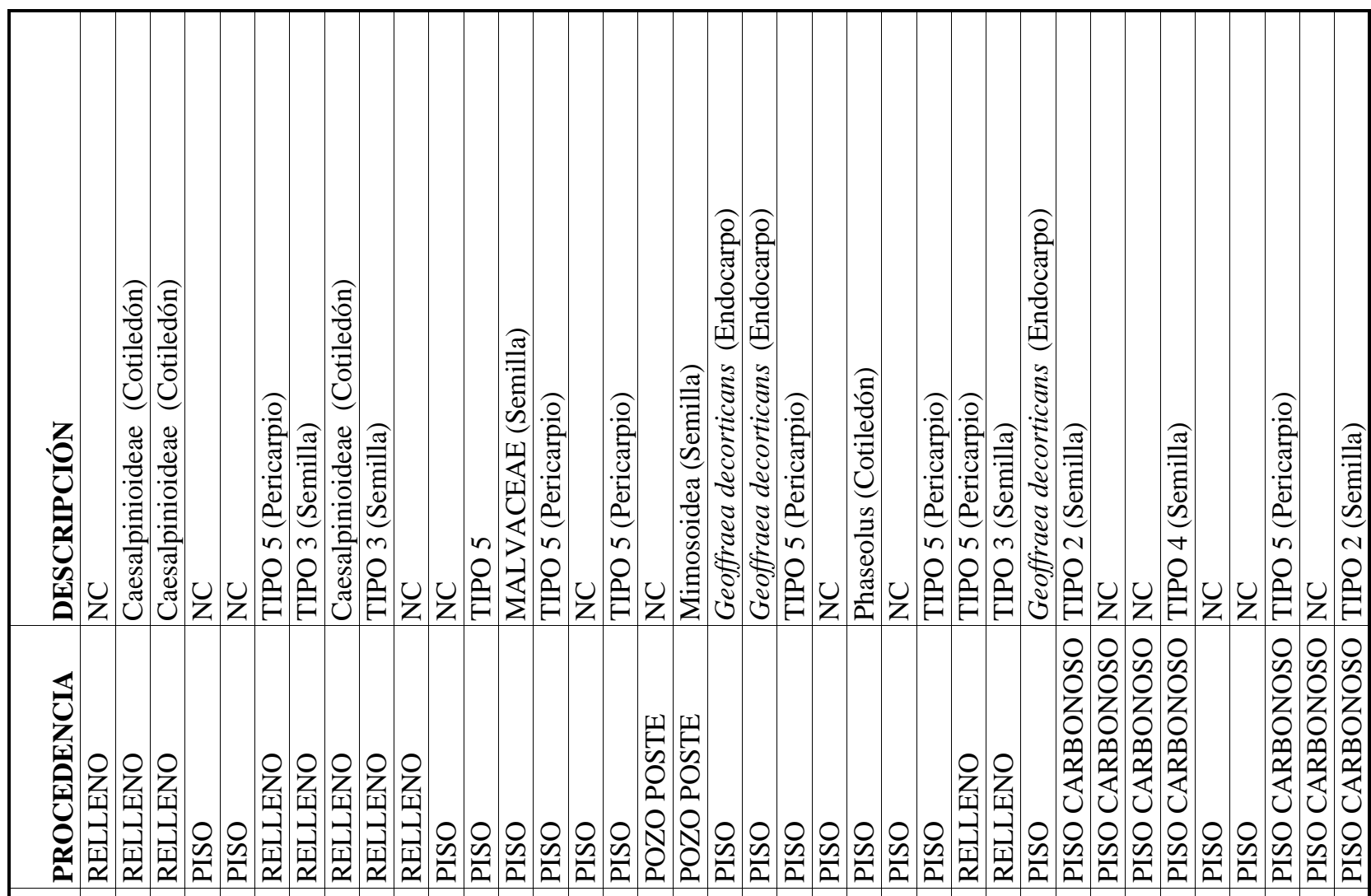

$\infty \infty$

$\cup \cup \cup$ 되

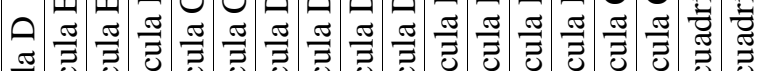

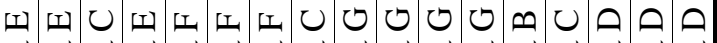

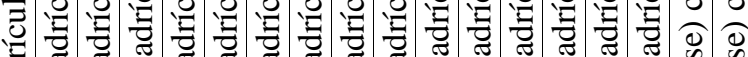
:

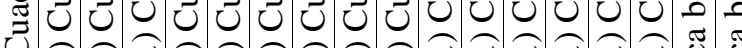

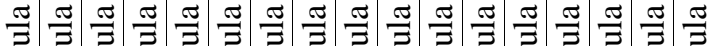

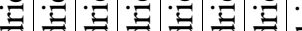

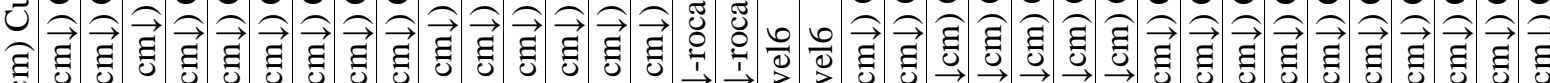
L L

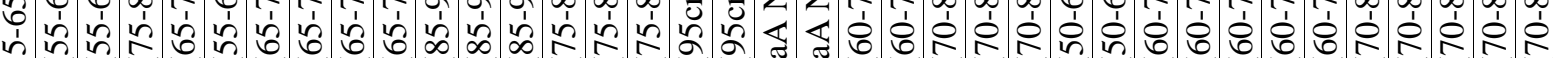

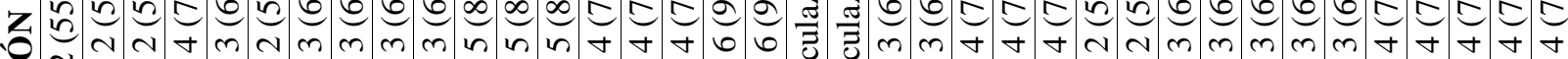

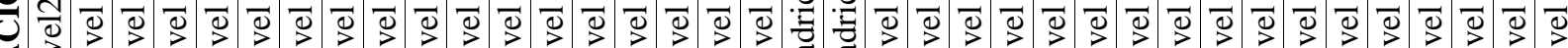

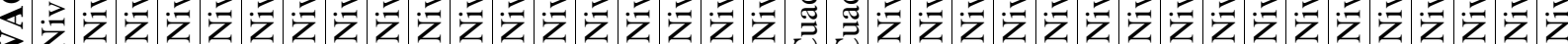

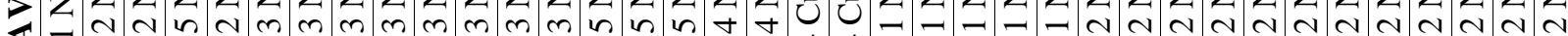

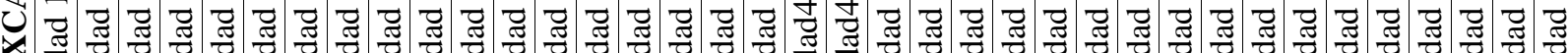

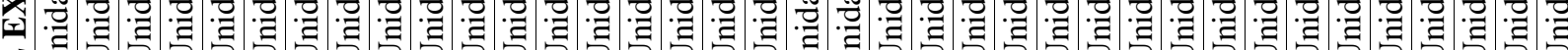

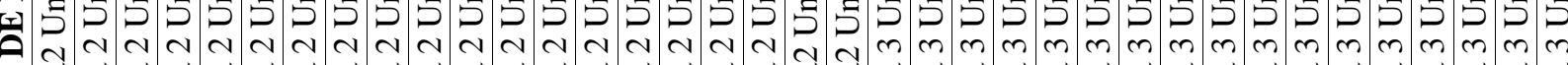

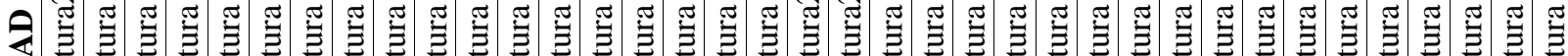
)

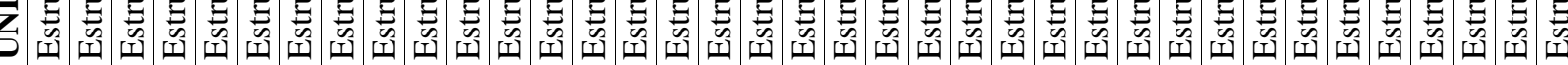
பn m પૅ 国 $\sim$ N 


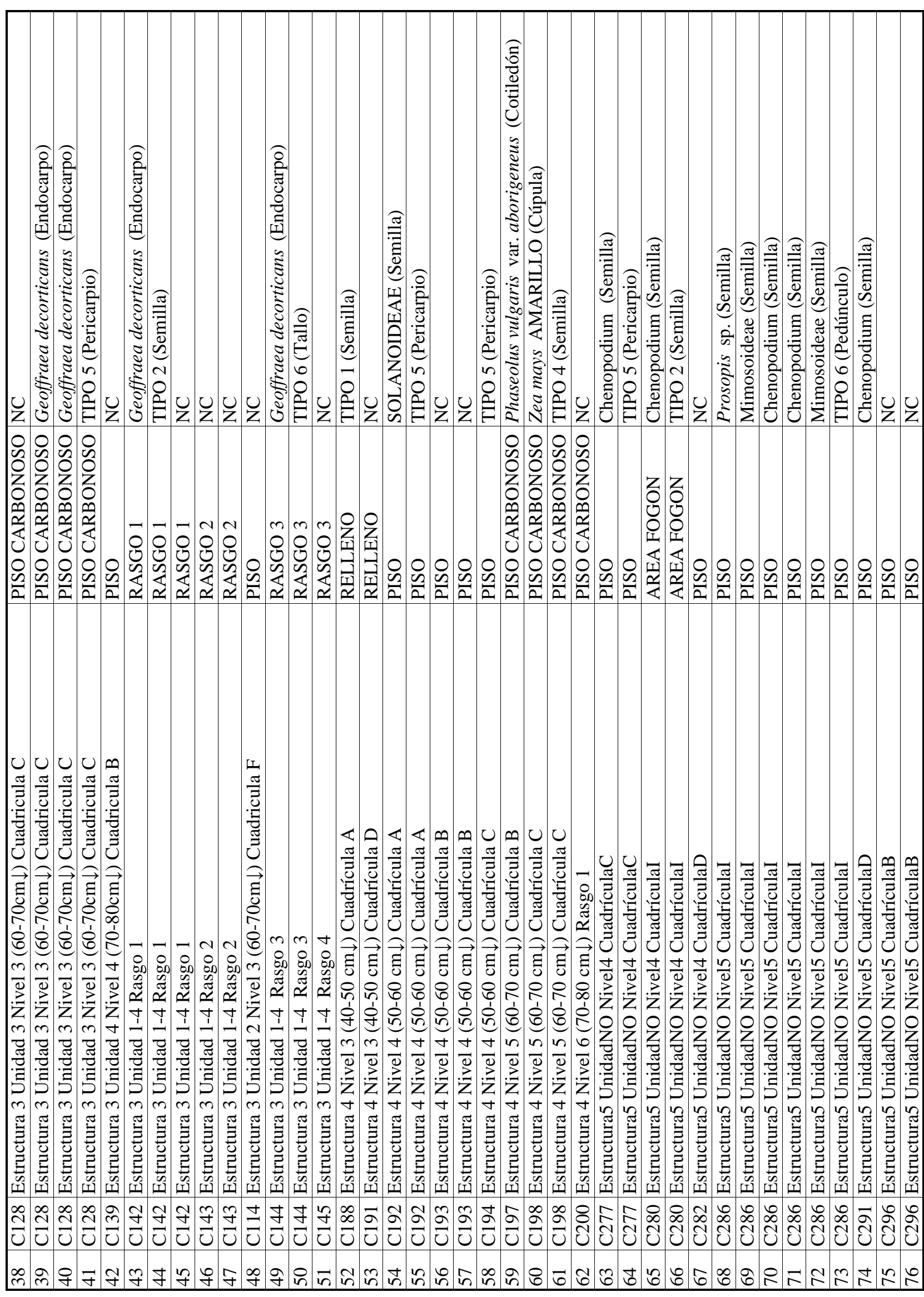

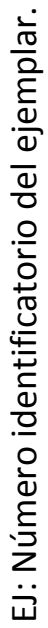




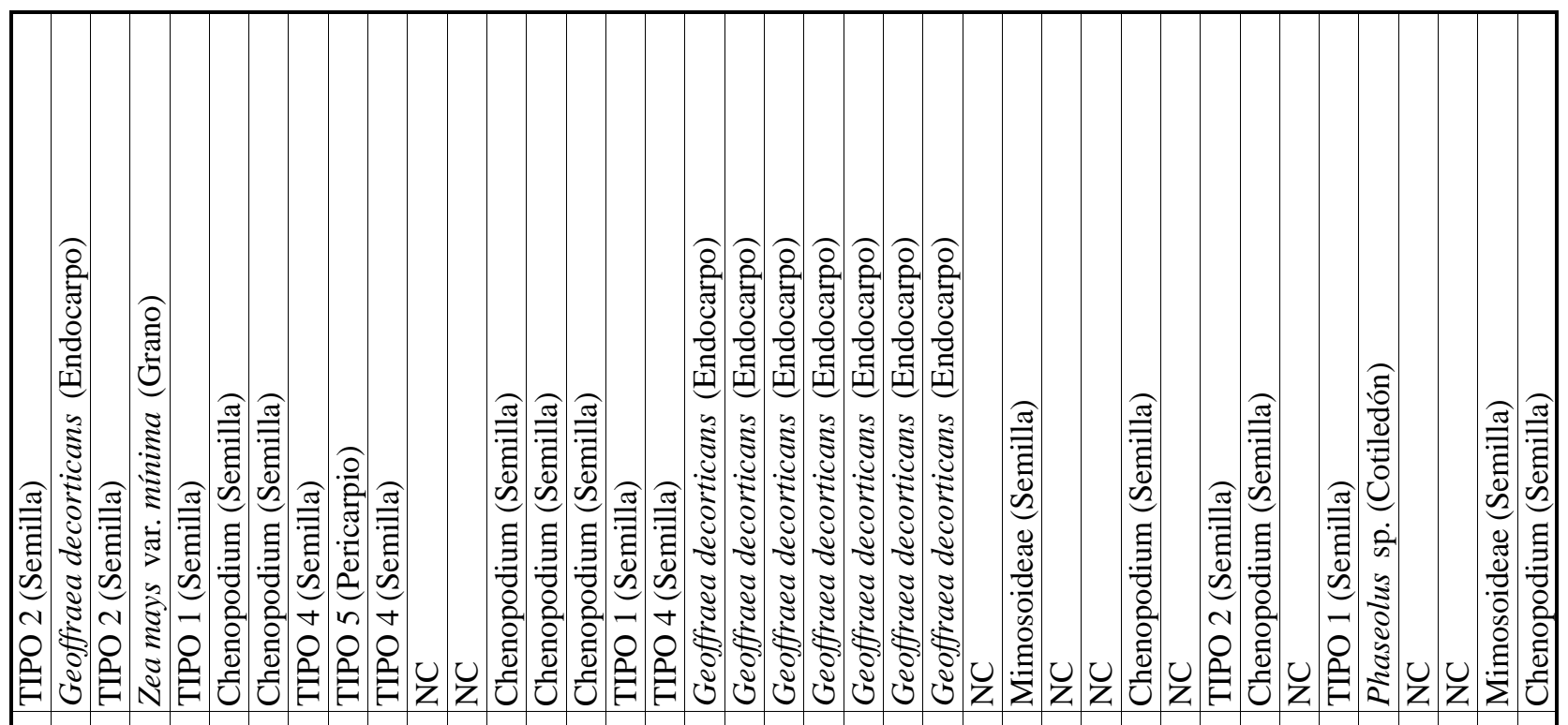

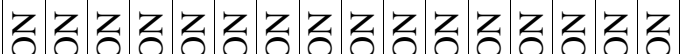

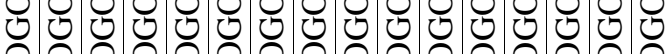

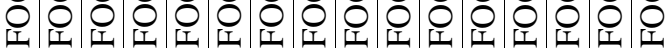

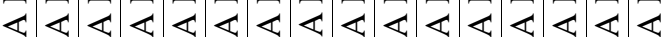

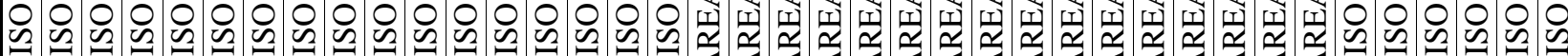

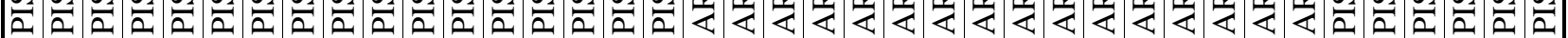

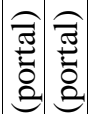

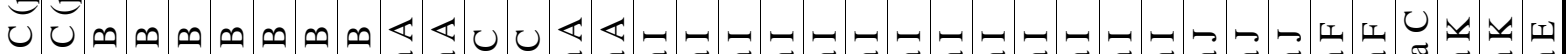

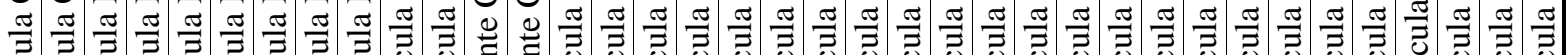

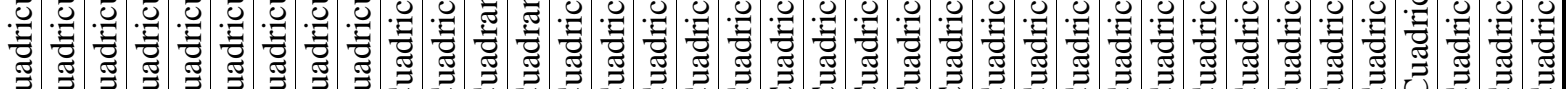

孔

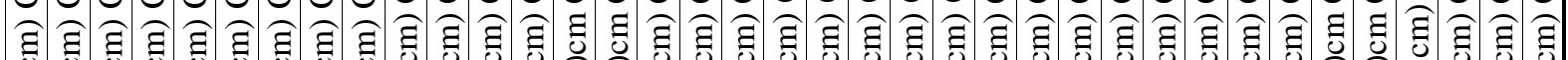

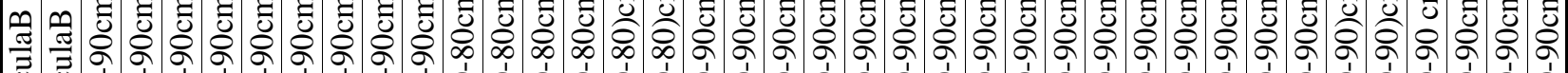
氕

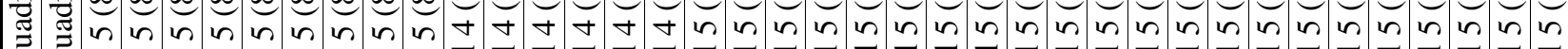

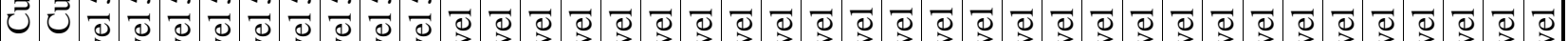

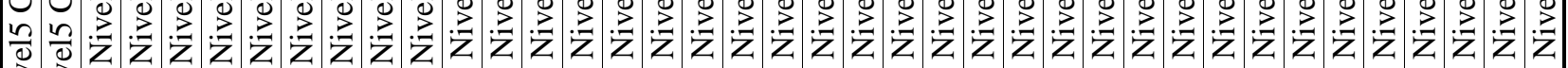

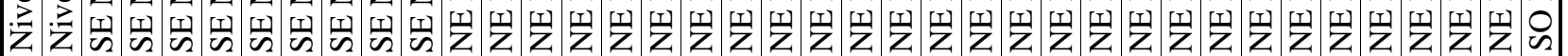

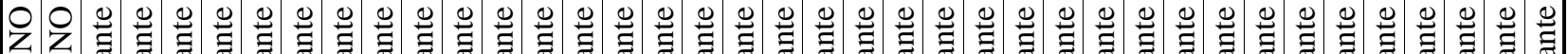

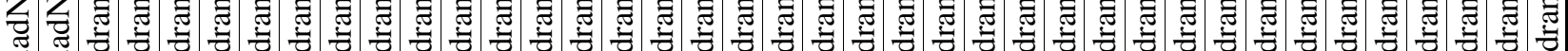

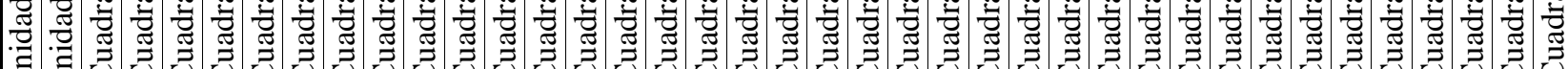

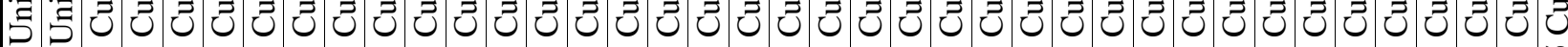
崖

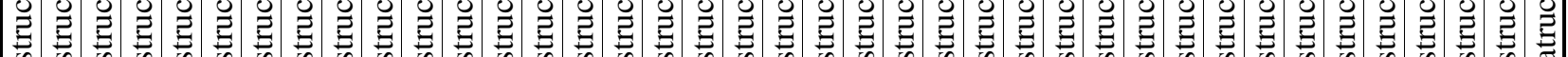

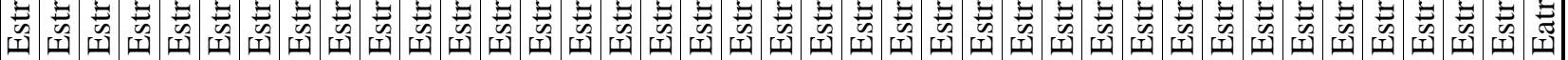

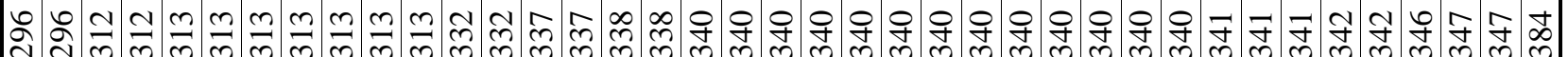

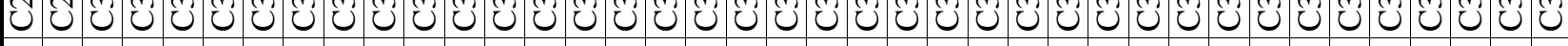

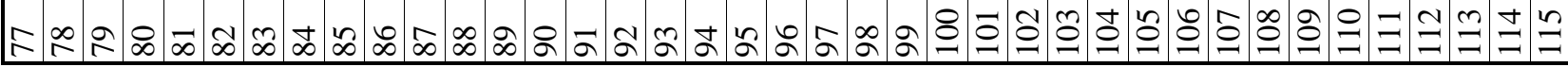



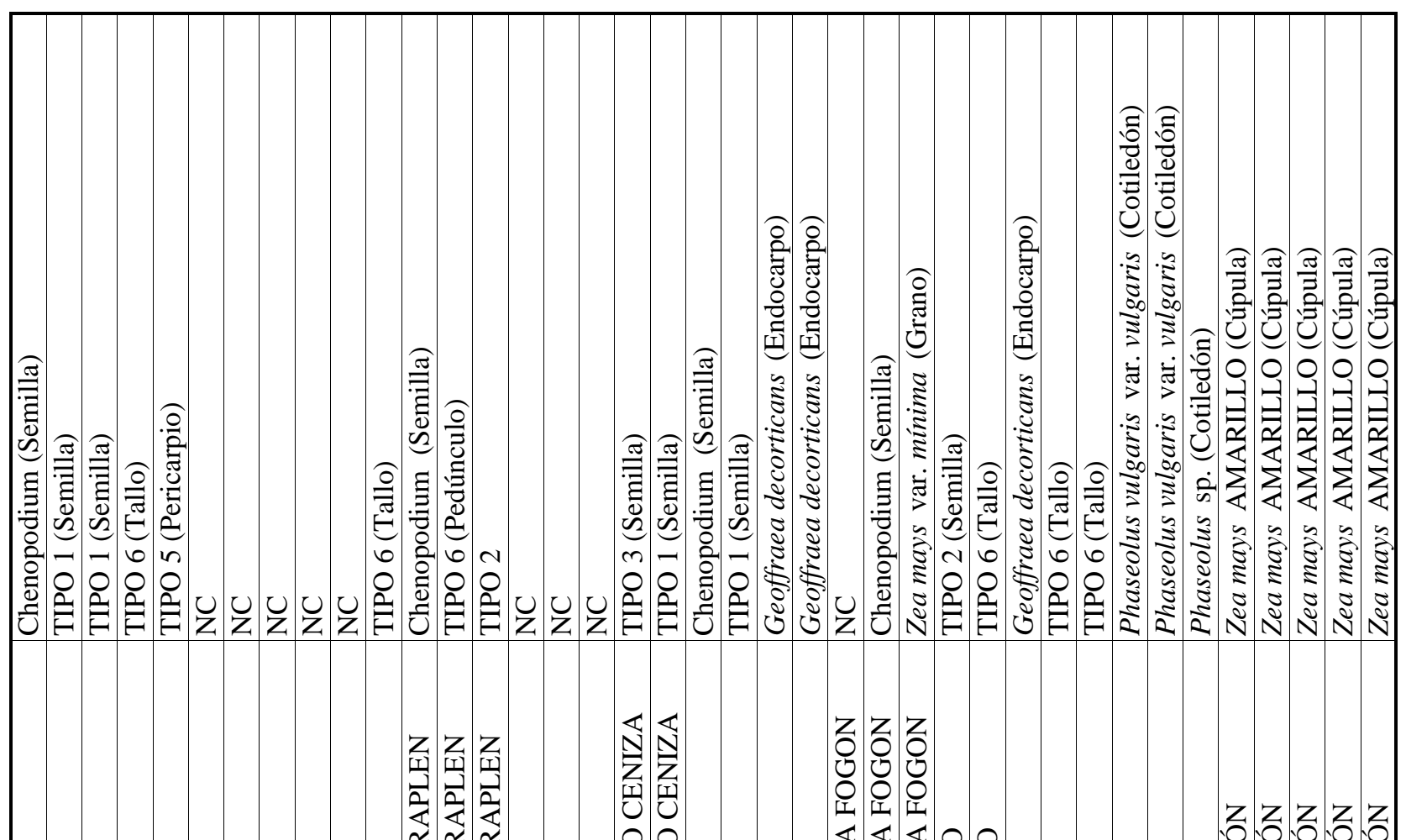

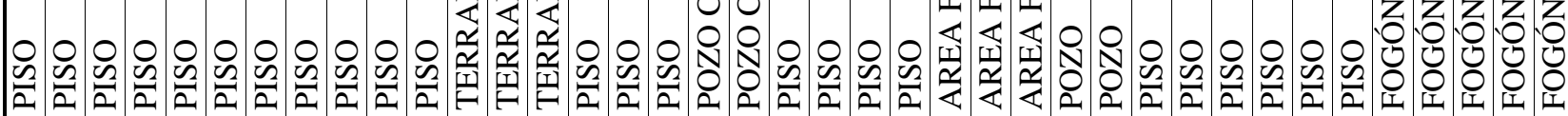

디 디 디 디 디 디 디 디 디

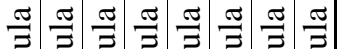

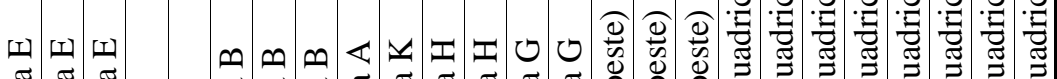

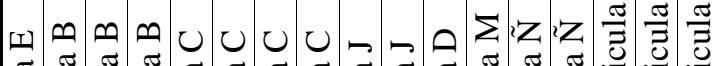

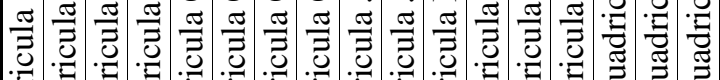

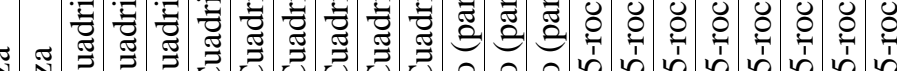
N N

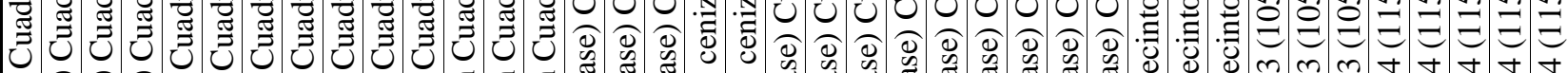

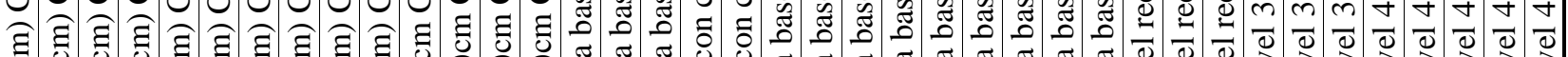

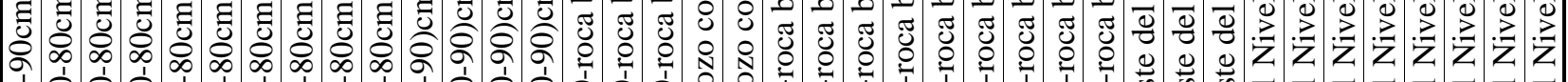

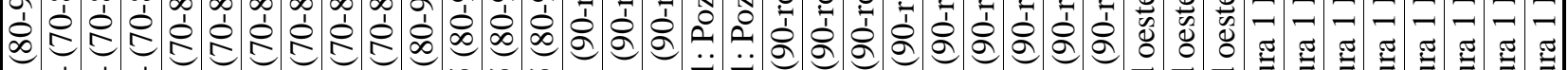

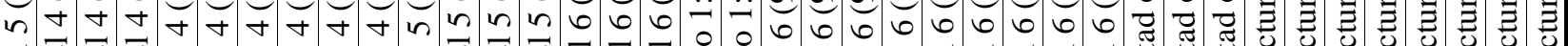

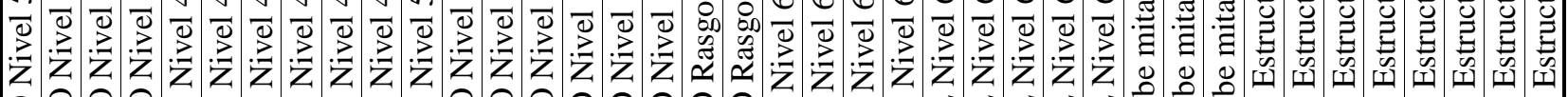

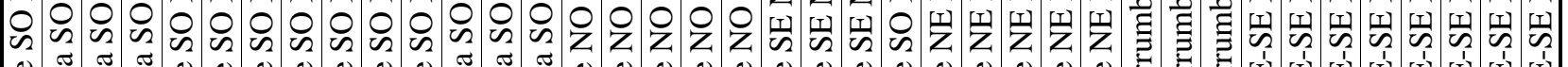

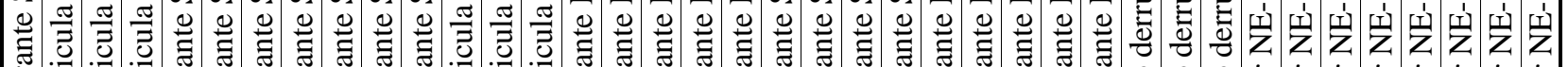

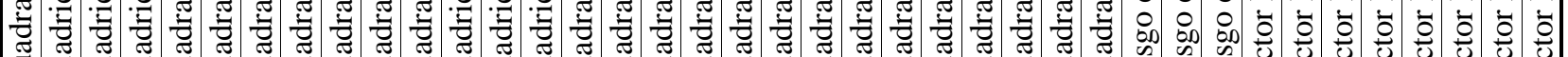

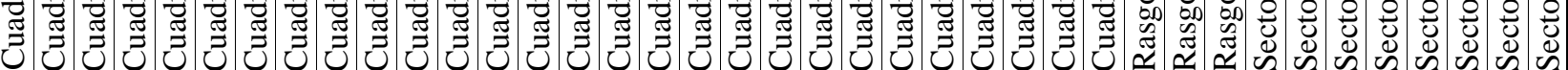

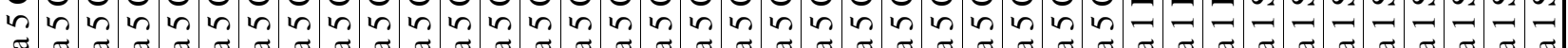

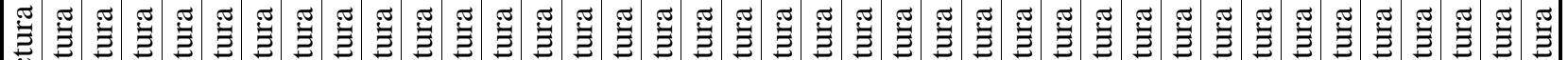

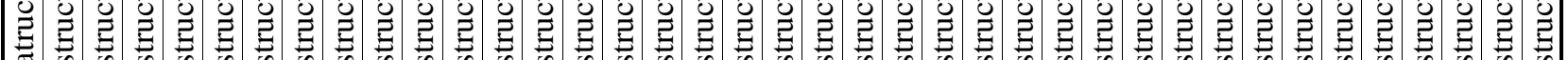

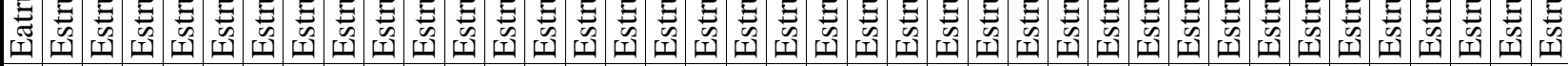

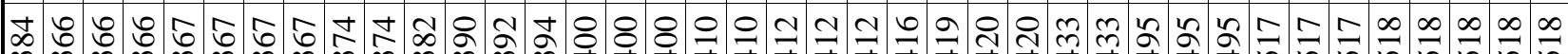

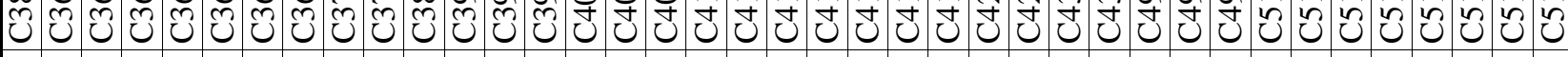

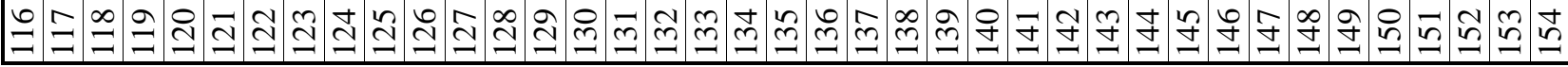




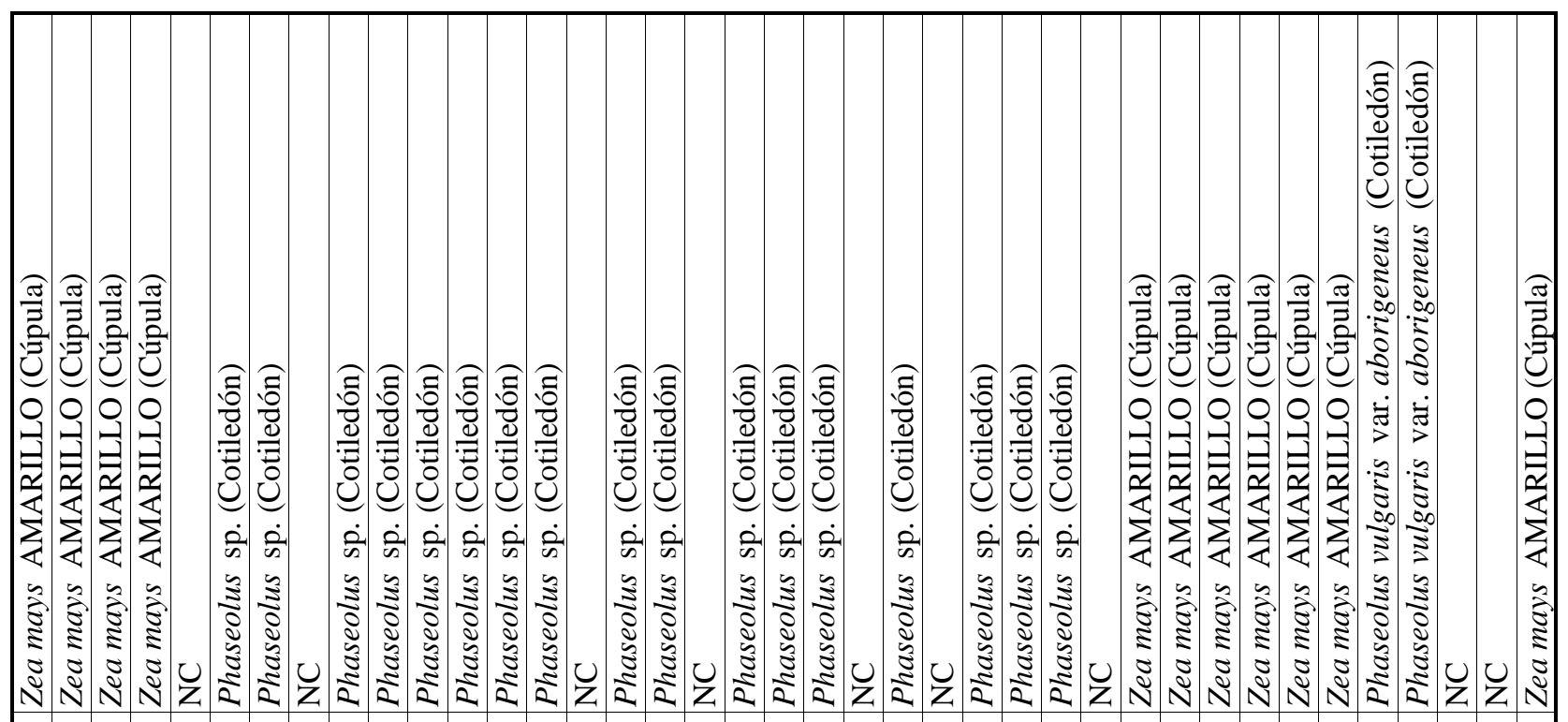

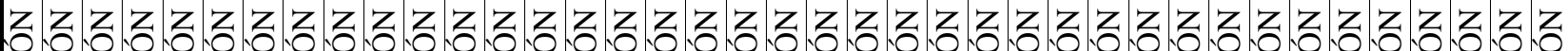

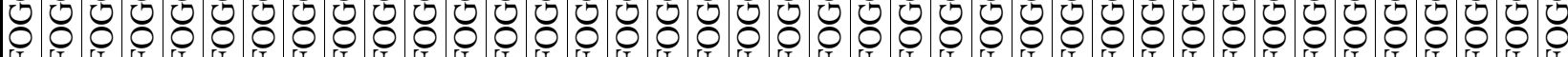

ش

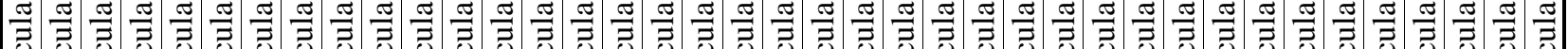

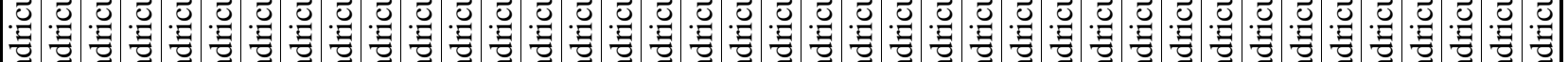

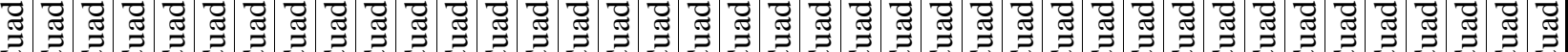
ป U ○ ०

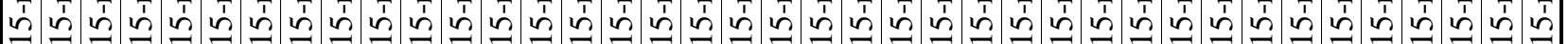

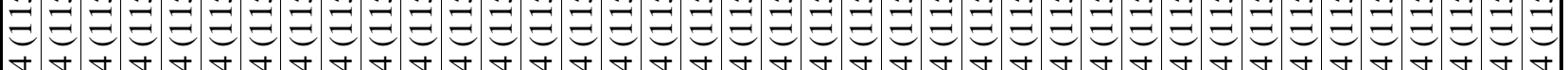

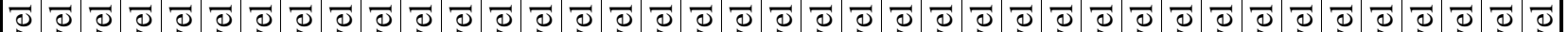

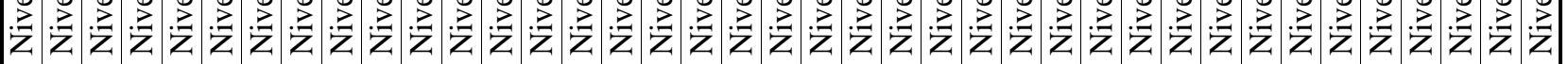

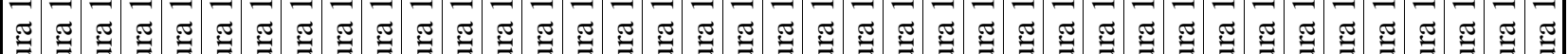

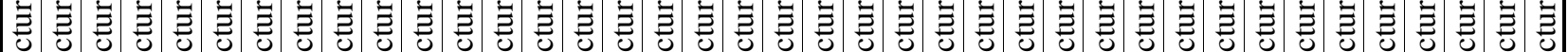

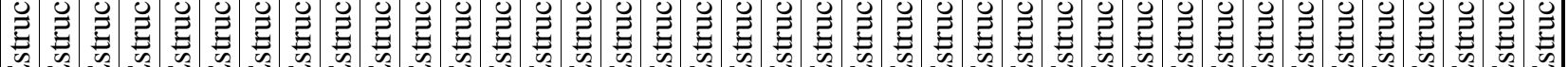

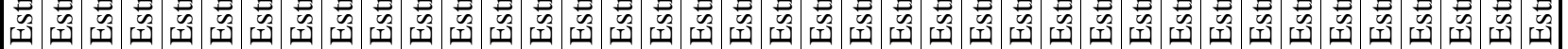

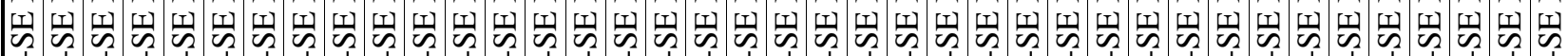

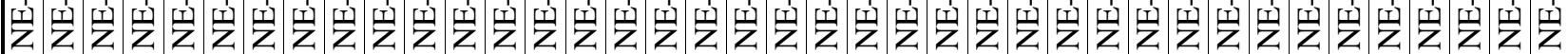
g

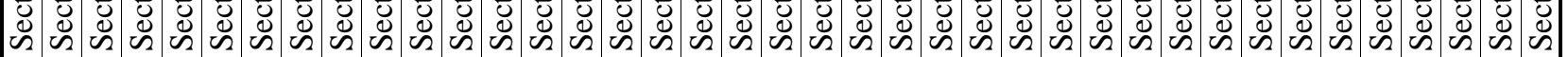

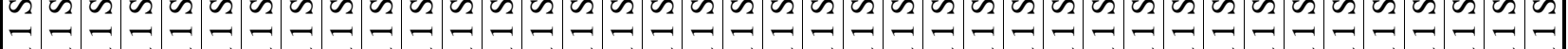

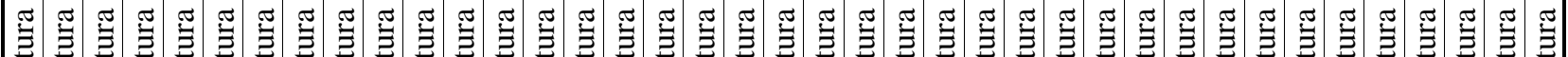

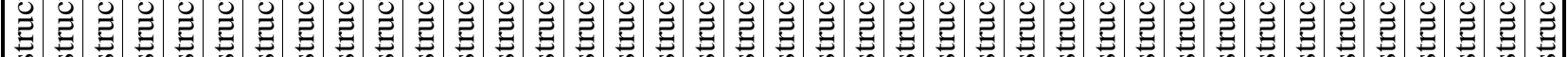

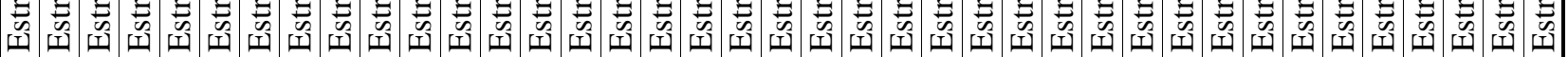

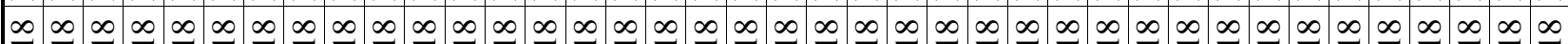

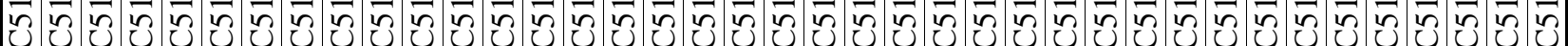

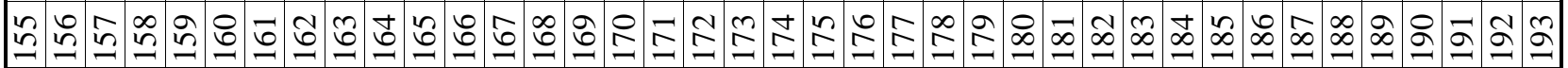




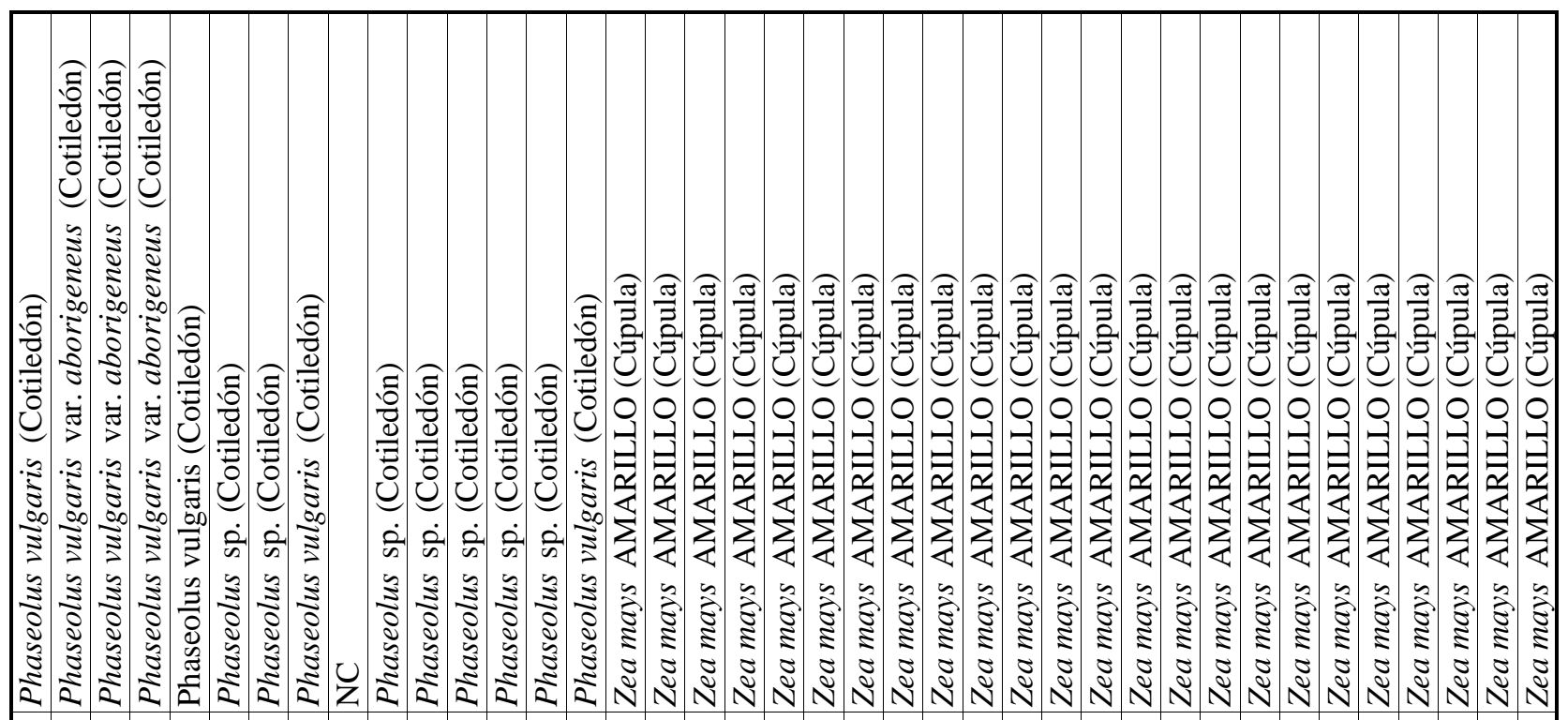

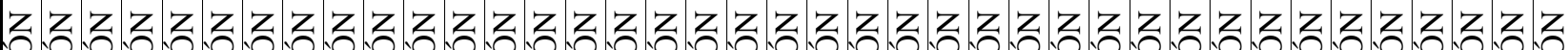

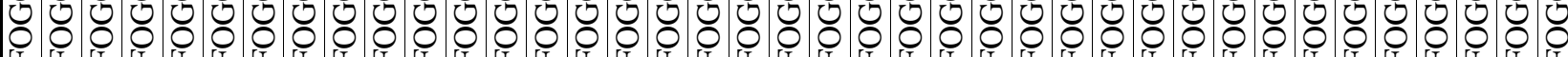

м

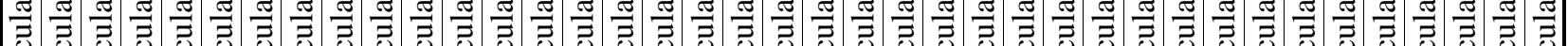

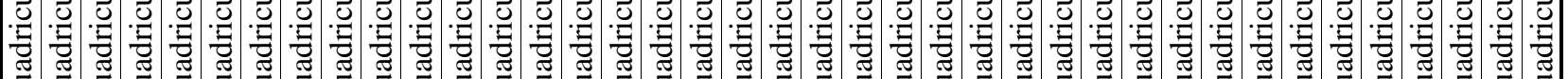

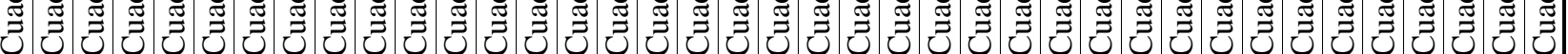

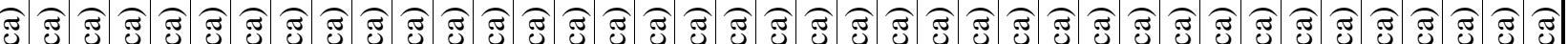
○

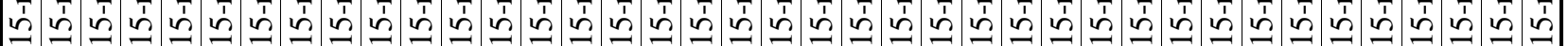

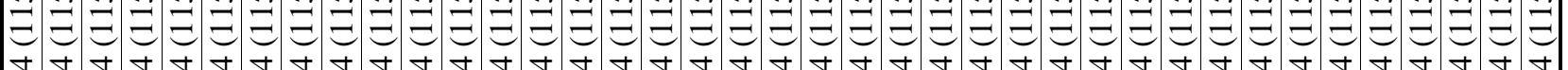

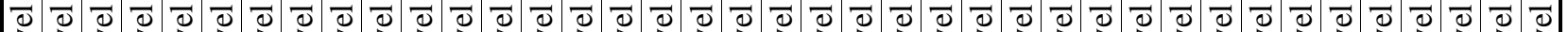

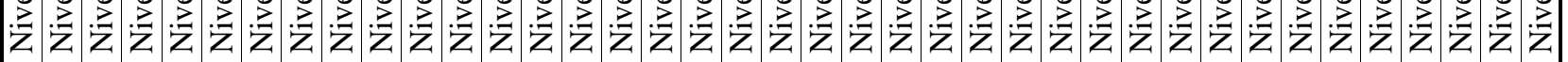

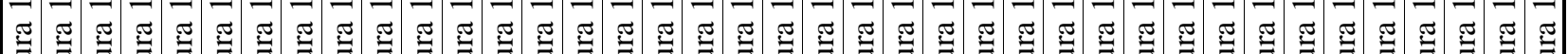

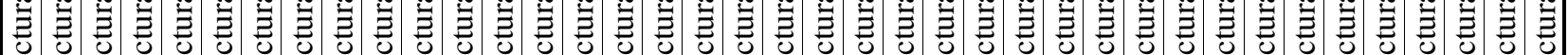

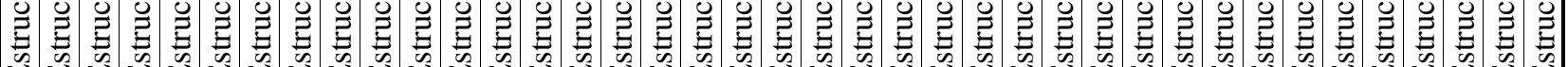

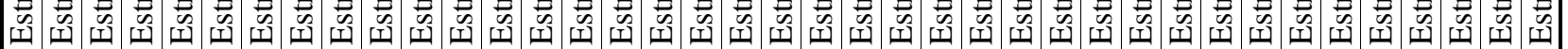

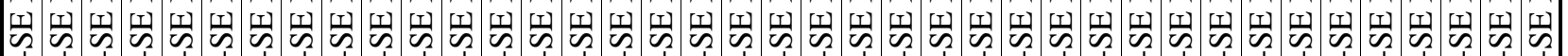

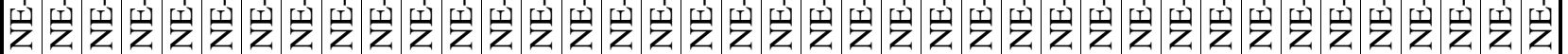
g

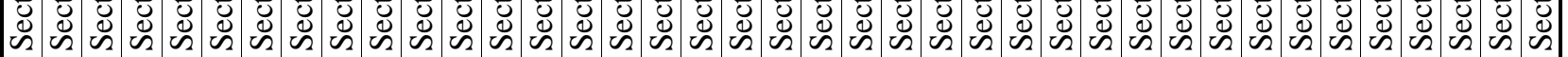

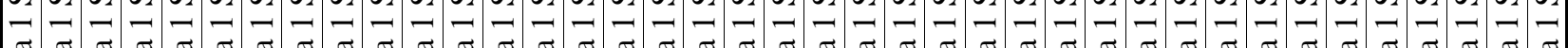

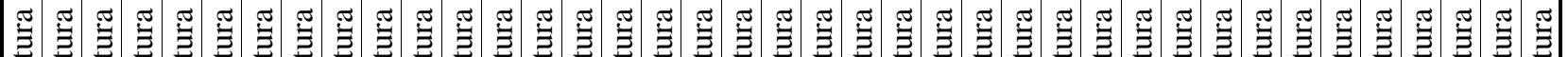

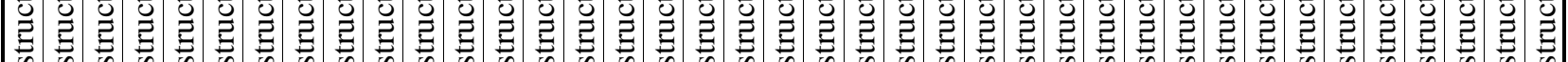

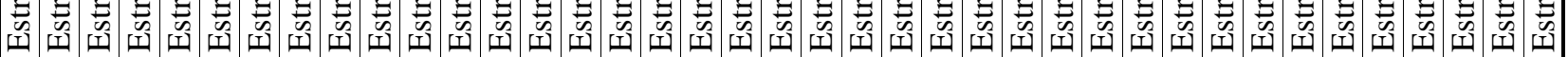

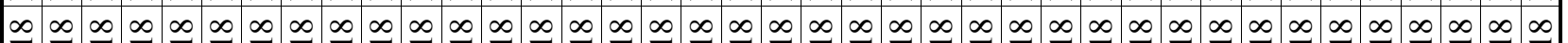

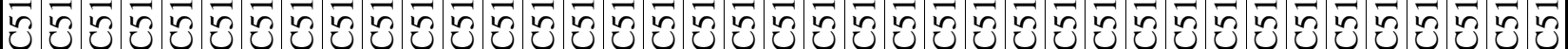

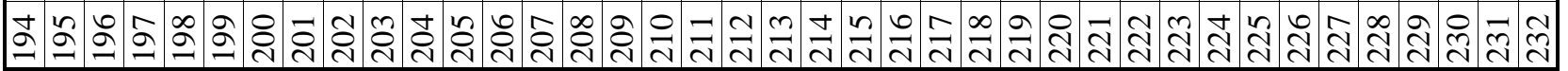




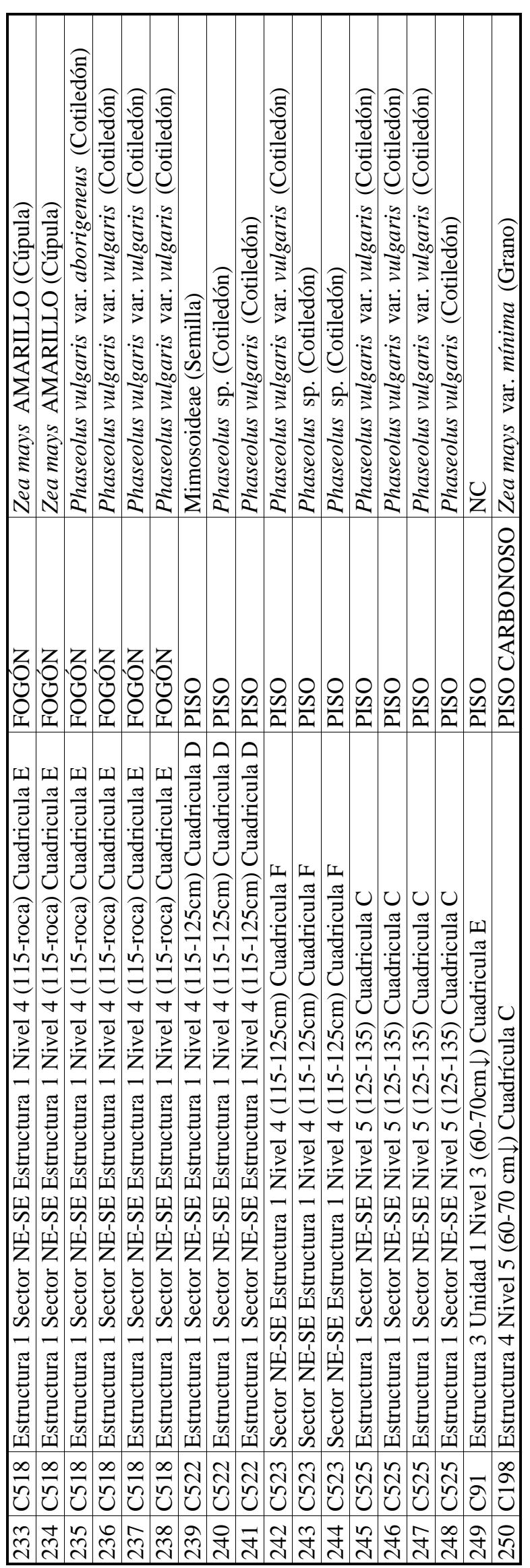

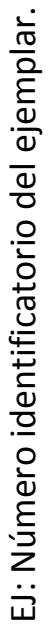




\begin{tabular}{|c|c|c|c|}
\hline $\mathbf{N}^{\circ}$ ID & CAT & ESTADO CONSERVADO & PROCEDENCIA \\
\hline E1-C98 & C510 & completo & piso \\
\hline E1-M10 & C515 & fragmento & piso \\
\hline E1-C1 & C232 & fragmento & pozo de poste \\
\hline E1-C2 & C232 & fragmento & pozo de poste \\
\hline E1-C3 & C234 & completo & relleno \\
\hline E1-C4 & C234 y C235 & completo, base perforada & piso \\
\hline E1-C5 & C234 y C235 & fragmento & relleno \\
\hline E1-C6 & C235 & fragmento & relleno \\
\hline E1-C7 & C240 & fragmento & piso \\
\hline E1-C8 & C240 & completo & piso \\
\hline E1-C9 & C240 & completo & piso \\
\hline E1-C10 & C241 & completo & relleno \\
\hline E1-C11 & C250 & completo & sobre pared Este \\
\hline E1-C12 & C515 & fragmento & piso \\
\hline E1-M11 & C240 & completo & piso \\
\hline E1-M12 & C242 & completo & relleno \\
\hline E1-M13 & C245 & completo & piso \\
\hline E1-M1002 & C495 & completo & área de derrumbe \\
\hline E1-M1000 & C495 & completo & área de derrumbe \\
\hline E1-M1001 & C510 & completo & relleno \\
\hline E1-M1003 & C510 & completo & relleno \\
\hline E1-M1004 & C511 & completo & piso \\
\hline E1-M1006 & C515 & completo & piso \\
\hline E1-M1007 & C515 & completo & piso \\
\hline E1-M1008 & C515 & completo & piso \\
\hline E1-M1009 & C515 & completo & piso \\
\hline E1-M1011 & C515 & completo & piso \\
\hline E1-M1012 & C515 & completo & piso \\
\hline E1-M1005 & C516 & completo & relleno \\
\hline E1-M1010 & C526 & completo & piso \\
\hline E2-C1 & C15 & fragmento & pared \\
\hline E2-C2 & C15 & fragmento & pared \\
\hline E2-C3 & C15 & completo, base perforada & pared, invertido \\
\hline E2-C4 & $? ?$ & completo & relleno \\
\hline E2-C5 & $\mathrm{C} 26$ & completo & piso \\
\hline E2-C9 & C47 & fragmento & relleno \\
\hline E2-C10 & $\mathrm{C} 47$ & fragmento & relleno \\
\hline E2-C11 & C16 & fragmento & relleno \\
\hline E2-C14 & C18 & fragmento & relleno \\
\hline E2-M1 & $\mathrm{C} 2$ & completo & en "repisa" en la pared \\
\hline E2-M3 & $\mathrm{C} 2$ & completo & en "repisa" en la pared \\
\hline E2-M5 & C9 & completo & relleno \\
\hline E2-M6 & C9 & completo & relleno \\
\hline E2-M7 & C9 & completo & relleno \\
\hline E2-M9 & C15 & completo & relleno \\
\hline E2-M10 & C15 & completo & relleno \\
\hline E2-M11 & C17 & completo & relleno \\
\hline E2-M12 & C17 & completo & relleno \\
\hline E2-M13 & C15 & completo & relleno \\
\hline E2-M14 & C249 & completo & relleno \\
\hline E2-M15 & C15 & completo & relleno \\
\hline E2-M16 & C15 & completo & relleno \\
\hline E2-M17 & C18 & completo & relleno \\
\hline E2-M18 & C249 & completo & relleno \\
\hline E2-M19 & C17 & fragmento & relleno \\
\hline E2-M20 & C19 & completo & relleno \\
\hline E2-M21 & C18 & fragmento & relleno \\
\hline E2-M22 & C19 & fragmento & relleno \\
\hline E2-M24 & $\mathrm{C} 26$ & completo & piso \\
\hline
\end{tabular}




\begin{tabular}{|c|c|c|c|}
\hline $\mathbf{N}^{\circ}$ ID & CAT & ESTADO CONSERVADO & PROCEDENCIA \\
\hline E2-M26 & C24 & fragmento & piso \\
\hline E2-M27 & C32 & fragmento & relleno \\
\hline E2-M29 & $\mathrm{C} 24$ & completo & piso \\
\hline E2-M30 & $\mathrm{C} 24$ & completo & piso \\
\hline E2-M31 & C31 & completo & piso \\
\hline E2-M33 & C29 & completo & piso \\
\hline E2-M34 & C30 & fragmento & piso \\
\hline E2-M35 & C32 & fragmento & derrumbe \\
\hline E2-M36 & C32 & fragmento & derrumbe \\
\hline E2-M38 & C34 & fragmento & derrumbe \\
\hline E2-M39 & C50 & fragmento & relleno \\
\hline E2-M40 & $\mathrm{C} 50$ & completo & relleno \\
\hline E2-M41 & C39 & completo & derrumbe \\
\hline E2-M42 & C41 C42 & completo & piso \\
\hline E2-M43 & C54 & completo & relleno \\
\hline E2-M44 & C54 & fragmento & relleno \\
\hline E2-M46 & C53 & fragmento & relleno \\
\hline E2-M47 & $\mathrm{C} 20$ & completo & relleno \\
\hline E2-M48 & $\mathrm{C} 20$ & completo & relleno \\
\hline E2-M49 & C15 & completo & relleno \\
\hline E2-M50 & C15 & fragmento & relleno \\
\hline E2-M51 & C56 & completo & piso \\
\hline E2-M53 & C56 & completo & piso \\
\hline E2-M54 & C57 & completo & piso \\
\hline E2-M55 & C57 & completo & piso \\
\hline E2-M56 & C54 & fragmento & relleno \\
\hline E2-M57 & C59 & completo & piso \\
\hline E2-M58 & $\mathrm{C} 46$ & completo & piso \\
\hline E2-M59 & C46 & completo & piso \\
\hline E2-M61 & C73 & completo & dentro del pozo de poste \\
\hline E2-M62 & C73 & completo & dentro del pozo de poste \\
\hline E2-M63 & C38 & completo & relleno \\
\hline E2-M64 & C38 y C42 & completo & relleno \\
\hline E2-M65 & $\mathrm{C} 44$ & completo & piso \\
\hline E3-C1 & C80 y C82 & completo & derrumbe \\
\hline E3-C2 & C84, C90, C97 & completo, partido a la mitad & piso \\
\hline E3-C3 & C99 y C106 & fragmento & derrumbe \\
\hline E3-C4 & C101 & completo & relleno \\
\hline E3-C5 & C38 & fragmento & área de derrumbe \\
\hline E3-C6 & C38-C42 & fragmento & Piso \\
\hline E3-C7 & \begin{tabular}{|l|l}
$\mathrm{C} 44$ & $\mathrm{C}$ \\
\end{tabular} & completo & área de derrumbe \\
\hline E3-C8 & \multicolumn{2}{|c|}{ C105-C107-C114-C11f completo, base perforada } & piso, invertido \\
\hline E3-C9 & \begin{tabular}{|l|l} 
C116-C121 & 1 \\
\end{tabular} & fragmento & pared \\
\hline E3-C10 & C136 & completo & piso \\
\hline E3-C11 & C116 & completo & piso, contra de la pared \\
\hline E3-C12 & C114 & completo & piso \\
\hline E3-C13 & C122 & completo & área de derrumbe \\
\hline E3-C14 & C125 & completo & piso (próx. puerta a E2) \\
\hline E3-C15 & C125 & completo & piso (próx. puerta a E2) \\
\hline E3-C16 & C125 & completo & área de derrumbe \\
\hline E3-C17 & C126 & completo & piso \\
\hline E3-C18 & C128 & fragmento & pozo \\
\hline E3-C19 & C121 & completo & piso \\
\hline E3-C20 & C99, C106, C115, C12C & completa, base perforada & puerta \\
\hline E3-M1 & \begin{tabular}{|l|l}
$\mathrm{C} 80$ & 1 \\
\end{tabular} & fragmento & relleno \\
\hline E3-M2 & C86 & fragmento & área de derrumbe \\
\hline E3-M3 & C86 & completo & área de derrumbe \\
\hline E3-M4 & C86 & completo & área de derrumbe \\
\hline E3-M5 & C91 & fragmento & relleno \\
\hline
\end{tabular}




\begin{tabular}{|c|c|c|c|}
\hline $\mathbf{N}^{\circ}$ ID & CAT & ESTADO CONSERVADO & PROCEDENCIA \\
\hline E3-M6 & C99 & fragmento & relleno \\
\hline E3-M7 & C107 & fragmento & relleno \\
\hline E3-M9 & C107 & completo & área de derrumbe \\
\hline E3-M11 & C93 & completo & área de derrumbe \\
\hline E3-M12 & C94 & completo & piso \\
\hline E3-M13 & C149 & fragmento & relleno \\
\hline E3-M14 & C94 & completo & piso \\
\hline E3-M15 & C94 & completo & piso \\
\hline E3-M16 & C94 & completo & piso \\
\hline E3-M17 & C97 & completo & piso \\
\hline E3-M18 & C103 & completo & relleno \\
\hline E3-M20 & C95 & fragmento & piso \\
\hline E3-M21 & C98 & completo & piso \\
\hline E3-M22 & C98 & completo & piso \\
\hline E3-M23 & C98 & completo & piso \\
\hline E3-M25 & C111 & completo & piso \\
\hline E3-M26 & C115 & completo & piso \\
\hline E3-M27 & C113 & completo & piso \\
\hline E3-M28 & C113 & completo & piso \\
\hline E3-M29 & C114 & fragmento & piso \\
\hline E3-M30 & C147 & completo & relleno \\
\hline E3-M31 & C147 & completo & relleno \\
\hline E3-M32 & C114 & completo & piso (próx. puerta a E1) \\
\hline E3-M33 & C116 & fragmento & piso (próx. puerta a E1) \\
\hline E3-M34 & C116 & completo & piso (próx. puerta a E1) \\
\hline E3-M35 & C115 & completo & piso \\
\hline E3-M36 & C116 & completo & piso \\
\hline E3-M37 & C131 & fragmento & relleno \\
\hline E3-M38 & C156 & fragmento & área de derrumbe \\
\hline E3-M39 & C122 & completo & área de derrumbe \\
\hline E3-M40 & C122 & completo & piso \\
\hline E3-M42 & C127 & completo & pared \\
\hline E3-M42b & C127 & completo & relleno \\
\hline E3-M43 & C128 & completo & piso \\
\hline E3-M44 & C128 & completo & piso \\
\hline E3-M45 & C128 & completo & pozo \\
\hline E3-M46 & C128 & completo & pozo \\
\hline E3-M47 & C117 & completo & piso \\
\hline E3-M48 & C142 & fragmento & pozo \\
\hline E3-M49 & C142 & completo & pozo \\
\hline E3-M52 & C142 & completo & pozo \\
\hline E3-M54 & C142 & fragmento & pozo \\
\hline E3-M55 & 121 & fragmento & pizo \\
\hline E3-M56 & 121 & completo & pizo \\
\hline E3-M57 & C121 & fragmento & pizo \\
\hline E3-M58 & 146 & fragmento & pozo \\
\hline E3-M59 & 145 & completo & pozo \\
\hline E3-M60 & C121 & completo & piso \\
\hline E3-M61 & C156 & completo & pared \\
\hline E3-M62 & C 148 & completo & pared \\
\hline E3-M63 & C147 & completo & pared \\
\hline E3-M64 & C158 & fragmento & pared (puerta) \\
\hline E3-M65 & C158 & completo & pared (puerta) \\
\hline E3-M66 & C 153 & completo & piso \\
\hline E4-C1 & C185 & fragmento & relleno \\
\hline E4-C2 & C188 & completo & relleno \\
\hline E4-C3 & C188 & fragmento & relleno \\
\hline E4-C4 & C189 & fragmento & relleno \\
\hline E4-C5 & C189 & fragmento & relleno \\
\hline
\end{tabular}




\begin{tabular}{|c|c|c|c|}
\hline $\mathbf{N}^{\circ}$ ID & CAT & ESTADO CONSERVADO & PROCEDENCIA \\
\hline E4-C6 & C189 & fragmento & relleno \\
\hline E4-M1 & C180 & fragmento & relleno \\
\hline E4-M2 & C180 & fragmento & relleno \\
\hline E4-M3 & C180 & fragmento & relleno \\
\hline E4-M4 & C188 & completo & relleno \\
\hline E4-M5 & C188 & fragmento & relleno \\
\hline E4-M6 & C185 & completo & relleno \\
\hline E4-M7 & C199 & fragmento & piso \\
\hline E4-M8 & C199 & fragmento & piso \\
\hline E4-M9 & C198 & completo & piso \\
\hline E5-C2 & C285 & fragmento & relleno \\
\hline E5-C3 & 285 & fragmento & pared \\
\hline E5-C4 & 285 & fragmento & relleno \\
\hline E5-C5 & 306 & fragmento & área de derrumbe \\
\hline E5-C6 & 306 & fragmento & área de derrumbe \\
\hline E5-C7 & 306 & fragmento & área de derrumbe \\
\hline E5-C8 & 306 & fragmento & área de derrumbe \\
\hline E5-C9 & 306 & fragmento & área de derrumbe \\
\hline E5-C10 & 306 & fragmento & área de derrumbe \\
\hline E5-C11 & 306 & completo & relleno, invertido \\
\hline E5-C12 & 339 & fragmento & relleno \\
\hline E5-C14 & 339 & fragmento & relleno \\
\hline E5-C15 & 339 & fragmento & derrumbe \\
\hline E5-C16 & 374 & completo & derrumbe \\
\hline E5-C17 & 390 & completo & terraplén, invertido \\
\hline E5-C19 & 390 & completo & piso \\
\hline E5-C20 & 411 & fragmento & piso \\
\hline E5-C22 & 433 & completo & piso \\
\hline E5-C23 & 433 & completo & piso \\
\hline E5-C24 & 433 & fragmento, base perforada & piso \\
\hline E5-M1 & C265 & fragmento & área de derrumbe \\
\hline E5-M2 & C265 & completo & área de derrumbe \\
\hline E5-M3 & 265 & fragmento & área de derrumbe \\
\hline E5-M4 & 265 & fragmento & área de derrumbe \\
\hline E5-M5 & 265 & fragmento & área de derrumbe \\
\hline E5-M6 & 265 & completo & área de derrumbe \\
\hline E5-M7 & 265 & completo & área de derrumbe \\
\hline E5-M8 & 282 & completo & pared terraplén \\
\hline E5-M9 & 282 & completo & pared terraplén \\
\hline E5-M10 & 283 & completo & pared terraplén \\
\hline E5-M11 & 283 & fragmento & pared terraplén \\
\hline E5-M13 & 283 & fragmento & dentro del terraplen \\
\hline E5-M14 & 284 & fragmento & dentro del terraplen \\
\hline E5-M17 & C285 & completo & área de derrumbe \\
\hline E5-M18 & C285 & completo & área de derrumbe \\
\hline E5-M20 & C285 & completo & área de derrumbe \\
\hline E5-M22 & C285 & fragmento & área de derrumbe \\
\hline E5-M23 & C287 & completo & área de derrumbe \\
\hline E5-M24 & C290 & fragmento & área de derrumbe \\
\hline E5-M25 & C290 & completo & área de derrumbe \\
\hline E5-M26 & C287 & fragmento & área de derrumbe \\
\hline E5-M27 & C288 & fragmento & área de derrumbe \\
\hline E5-M28 & C291 & fragmento & área de derrumbe \\
\hline E5-M29 & C291 & fragmento & área de derrumbe \\
\hline E5-M31 & C286 & fragmento & área de derrumbe \\
\hline E5-M32 & C287 & fragmento & área de derrumbe \\
\hline E5-M33 & C291 & fragmento & área de derrumbe \\
\hline E5-M35 & C286 & completa & área de derrumbe \\
\hline E5-M36 & C286 & fragmento & área de derrumbe \\
\hline
\end{tabular}




\begin{tabular}{|c|c|c|c|}
\hline $\mathbf{N}^{\circ}$ ID & CAT & ESTADO CONSERVADO & PROCEDENCIA \\
\hline E5-M37 & C293 & fragmento & área de derrumbe \\
\hline E5-M44 & C293 & completo & relleno \\
\hline E5-M46 & C306 & completo & relleno \\
\hline E5-M47 & C306 & completo & área de derrumbe \\
\hline E5-M48 & C306 & completo & área de derrumbe \\
\hline E5-M49 & 306 & completo & área de derrumbe \\
\hline E5-M50 & C306 & fragmento & área de derrumbe \\
\hline E5-M51 & C306 & completo & área de derrumbe \\
\hline E5-M52 & C306 & completo & área de derrumbe \\
\hline E5-M54 & C306 & fragmento & área de derrumbe \\
\hline E5-M55 & C306 & fragmento & área de derrumbe \\
\hline E5-M56 & C306 & completo & área de derrumbe \\
\hline E5-M57 & C306 & completo & área de derrumbe \\
\hline E5-M59 & C306 & completo & área de derrumbe \\
\hline E5-M60 & C306 & fragmento & área de derrumbe \\
\hline E5-M61 & C306 & completo & área de derrumbe \\
\hline E5-M62 & C306 & completo & área de derrumbe \\
\hline E5-M64 & C308 & fragmento & piso \\
\hline E5-M65 & C308 & completo & piso \\
\hline E5-M71 & C319 & completo & relleno \\
\hline E5-M72 & C319 & completo & relleno \\
\hline E5-M73 & C318 & completo & relleno \\
\hline E5-M75 & C318 & completo & relleno \\
\hline E5-M77 & C317 & completo & relleno \\
\hline E5-M81 & C334 & fragmento & piso \\
\hline E5-M83 & C334 & fragmento & piso \\
\hline E5-M85 & C339 & fragmento & relleno \\
\hline E5-M86 & C339 & fragmento & relleno \\
\hline E5-M88 & C339 & fragmento & relleno \\
\hline E5-M90 & C339 & completo & relleno \\
\hline E5-M91 & C339 & fragmento & relleno \\
\hline E5-M92 & C339 & completo & relleno \\
\hline E5-M93 & C339 & fragmento & relleno \\
\hline E5-M94 & C339 & fragmento & relleno \\
\hline E5-M95 & C339 & completo & relleno \\
\hline E5-M96 & C339 & completo & relleno \\
\hline E5-M97 & C339 & completo & relleno \\
\hline E5-M98 & C339 & fragmento & relleno \\
\hline E5-M99 & C339 & fragmento & relleno \\
\hline E5-M100 & C339 & fragmento & relleno \\
\hline E5-M101 & C339 & fragmento & relleno \\
\hline E5-M102 & C339 & completo & relleno \\
\hline E5-M103 & C339 & completo & relleno \\
\hline E5-M105 & C339 & completo & relleno \\
\hline E5-M108 & C341 & completo & piso \\
\hline E5-M109 & C339 & fragmento & relleno \\
\hline E5-M110 & C339 & fragmento & relleno \\
\hline E5-M111 & C339 & completo & relleno \\
\hline E5-M112 & C344 & fragmento & piso \\
\hline E5-M113 & C344 & completo & piso \\
\hline E5-M114 & C344 & completo & piso \\
\hline E5-M115 & C345 & completo & piso \\
\hline E5-M116 & C345 & completo & piso \\
\hline E5-M118 & C350 & fragmento & área de derrumbe \\
\hline E5-M119 & C350 & fragmento & área de derrumbe \\
\hline E5-M121 & C357 & fragmento & relleno \\
\hline E5-M122 & C355 & completo & relleno \\
\hline E5-M123 & C355 & completo & relleno \\
\hline E5-M124 & C363 & fragmento & relleno \\
\hline
\end{tabular}




\begin{tabular}{|c|c|c|c|}
\hline $\mathbf{N}^{\circ}$ ID & CAT & ESTADO CONSERVADO & PROCEDENCIA \\
\hline E5-M125 & C363 & completo & relleno \\
\hline E5-M126 & C368 & fragmento & piso \\
\hline E5-M127 & C373 & completo & piso \\
\hline E5-M130 & C382 & completo & piso \\
\hline E5-M131 & C382 & completo & en pared terraplén (cuña) \\
\hline E5-M132 & C382 & completo & piso \\
\hline E5-M134 & C391 & fragmento & piso \\
\hline E5-M135 & C391 & completo & piso \\
\hline E5-M136 & C399 & fragmento & piso \\
\hline E5-M137 & C399 & completo & piso \\
\hline E5-M139 & C400 & completo & piso \\
\hline E5-M140 & C399 & completo & piso \\
\hline E5-M141 & C399 & completo & piso \\
\hline E5-M142 & C406 & completo & piso \\
\hline E5-M144 & C406 & completo & piso \\
\hline E5-M145 & C414 & fragmento & piso \\
\hline E5-M146 & C414 & fragmento & piso \\
\hline E5-M147 & C415 & fragmento & piso \\
\hline E5-M148 & C415 & fragmento & piso \\
\hline E5-M150 & C418 & fragmento & piso \\
\hline E5-M151 & C418 & completo & piso \\
\hline E5-M152 & C422 & completo & piso \\
\hline E5-M159 & C422 & fragmento & en pared terraplén (cuña) \\
\hline E5-M160 & C291 & completo & en pared terraplén (cuña) \\
\hline E5-M161 & C291 & completo & piso \\
\hline E5-M162 & C291 & completo & piso \\
\hline E5p-M39 & C298 & completo & área de derrumbe \\
\hline E5p-M40 & C298 & completo & área de derrumbe \\
\hline E5p-M41 & C298 & fragmento & área de derrumbe \\
\hline E5p-M42 & C299 & completo & relleno \\
\hline E5p-M43 & C299 & fragmento & relleno \\
\hline E5p-M66 & C307 & completo & piso \\
\hline E5p-M67 & C307 & completo & piso \\
\hline E5p-M68 & C312 & completo & pared \\
\hline E5p-M69 & C312 & completo & pared \\
\hline E5p-M82 & C336 & completo & piso \\
\hline E5p-M120 & C349 & completo & piso \\
\hline E5p-M153 & C429 & completo & piso \\
\hline E5p-M154 & C429 & fragmento & piso \\
\hline E5p-M156 & C429 & fragmento & pozo \\
\hline E5p-M157 & C429 & fragmento & pozo \\
\hline E5p-M158 & C429 & fragmento & pozo \\
\hline
\end{tabular}




\begin{tabular}{|c|c|c|c|c|c|c|c|c|c|c|c|c|c|c|c|c|c|}
\hline 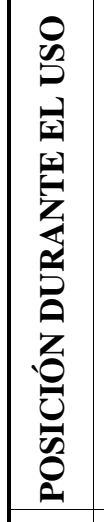 & 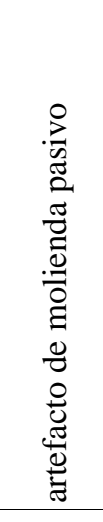 & 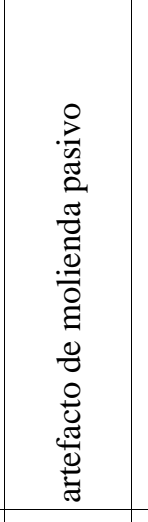 & 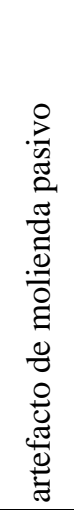 & 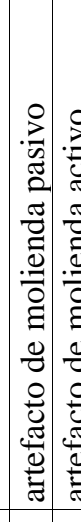 & 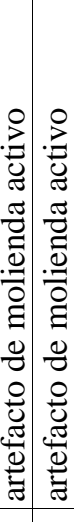 & 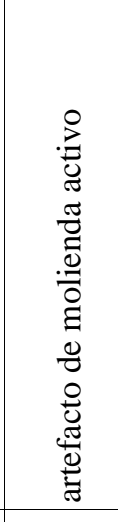 & 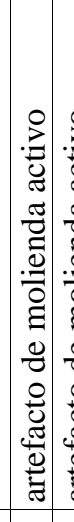 & 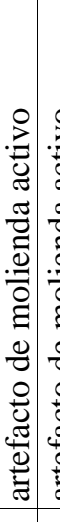 & 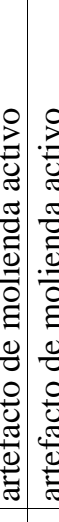 & 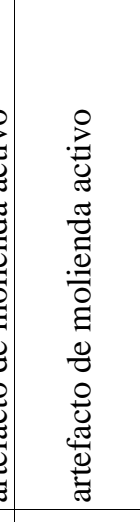 & 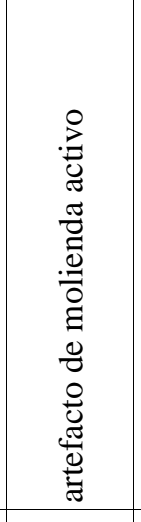 & 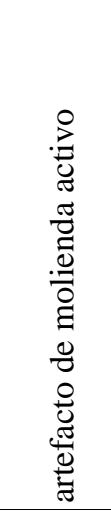 & 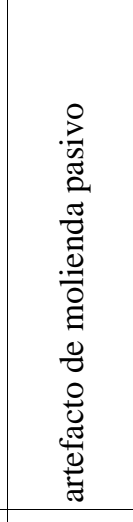 & 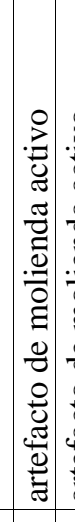 & 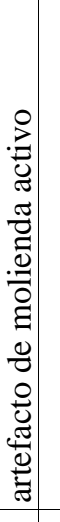 & 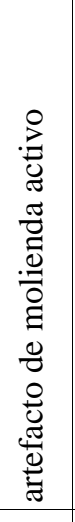 & 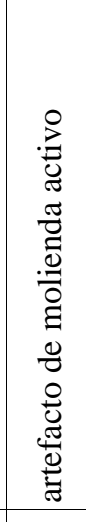 \\
\hline 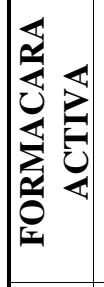 & 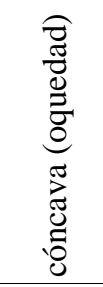 & 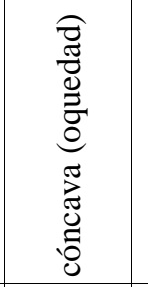 & 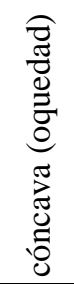 & $\frac{\pi}{\tilde{a}} \mathrm{~g}$ & 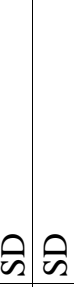 & คิ & is & की & $\vec{n}$ & के & 命 & की & 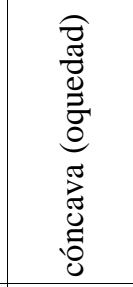 & $\frac{\pi}{2}$ & 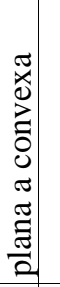 & 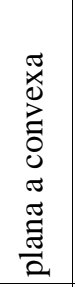 & $\begin{array}{l}\tilde{u} \\
\stackrel{u}{u} \\
\stackrel{0}{0}\end{array}$ \\
\hline$\varangle \widehat{\widehat{\mathrm{g}}}$ & 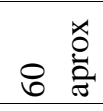 & के & $\exists$ & कीज & की & कs & की & की & $\vec{\omega}$ & के & के & के & ஜ & $\infty$ & $\Lambda$ & $\approx$ & $\exists$ \\
\hline$-\widehat{\hat{\mathrm{E}}}$ & ৪ & की & $\stackrel{\sim}{\sim}$ & की & की & के & की & & $\overrightarrow{\hat{s}} \mathrm{\theta}$ & के & के & के & $\vec{\lambda}$ & $\stackrel{\Rightarrow}{\rightarrow}$ & $\stackrel{0}{-1}$ & $\stackrel{\infty}{\sim}$ & 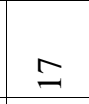 \\
\hline 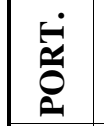 & 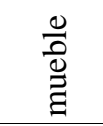 & 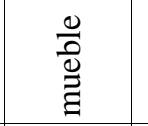 & 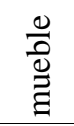 & 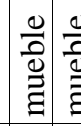 & 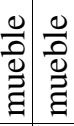 & $\begin{array}{l}\frac{\mathscr{O}}{0} \\
\overrightarrow{\underline{\Xi}}\end{array}$ & 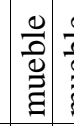 & 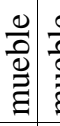 & & 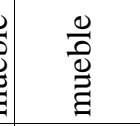 & $\begin{array}{l}\frac{0}{0} \\
\stackrel{\vec{g}}{\Xi}\end{array}$ & $\begin{array}{l}\stackrel{0}{0} \\
\vec{\Xi} \\
\vec{g}\end{array}$ & 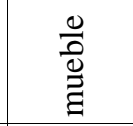 & 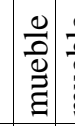 & $\begin{array}{l}\frac{a}{0} \\
\stackrel{0}{\Xi} \\
\vec{\Xi}\end{array}$ & $\begin{array}{l}\frac{0}{0} \\
\frac{a}{\Xi}\end{array}$ & $\begin{array}{l}\frac{\ddot{\theta}}{\vec{\theta}} \\
\vec{\Xi}\end{array}$ \\
\hline 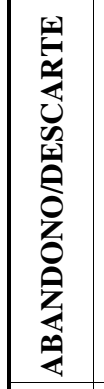 & 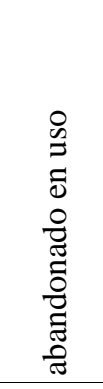 & 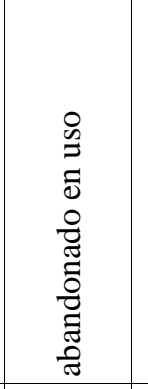 & 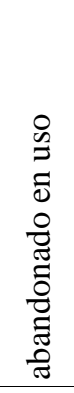 & 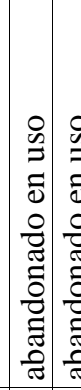 & 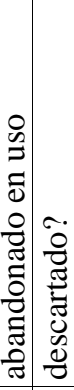 & 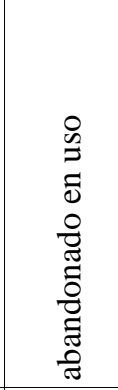 & 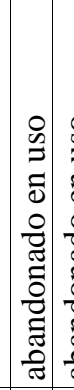 & 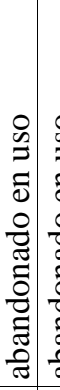 & 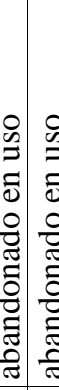 & 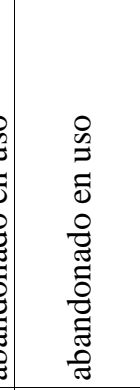 & 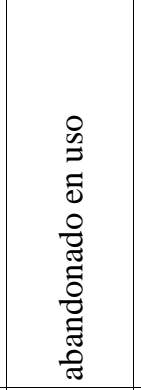 & 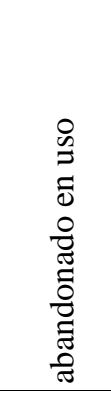 & 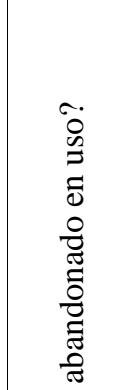 & 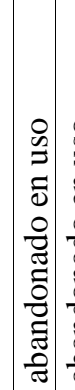 & 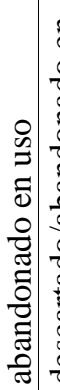 & 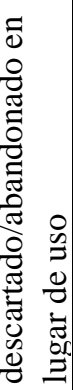 & 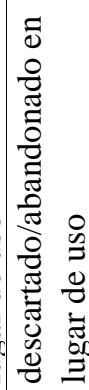 \\
\hline $\begin{array}{ll}n & \\
0 & n \\
& 0 \\
0 & 0\end{array}$ & z & 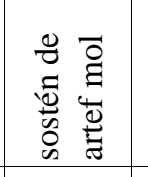 & そ) & Z & \begin{tabular}{l|l}
0 \\
$z$ & 0 \\
$z$
\end{tabular} & 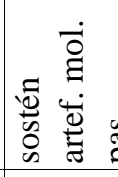 & $\dot{\theta}$ & & & 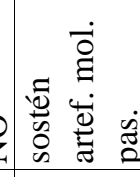 & 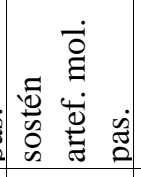 & 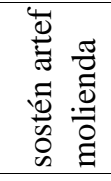 & 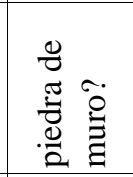 & & $\begin{array}{l}0 \\
z\end{array}$ & $\stackrel{\imath}{z}$ & $\begin{array}{l}0 \\
\mathrm{z}\end{array}$ \\
\hline 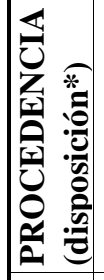 & . & . & $\stackrel{\circ}{a}$ & : & 足 & $\stackrel{\circ}{\not 2}$ & 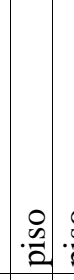 & 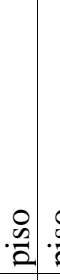 & $\begin{array}{c}0 \\
\vdots \\
0\end{array}$ & $\stackrel{0}{a}$ & $\stackrel{0}{a}$ & $\stackrel{\circ}{a}$ & 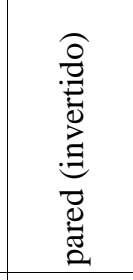 & 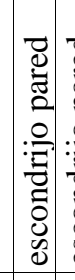 & 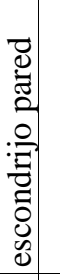 & $\stackrel{0}{a}$ & . \\
\hline 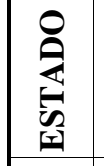 & 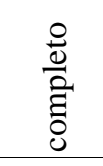 & 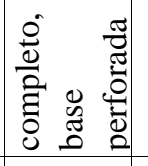 & 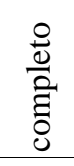 & 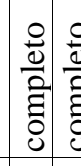 & 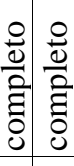 & $\frac{0}{\frac{0}{0}}$ & 원 & 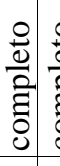 & 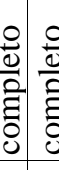 & $\frac{0}{\frac{0}{2}}$ & $\frac{0}{\frac{0}{2}}$ & 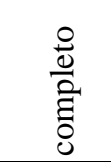 & 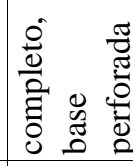 & 본 & 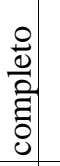 & $\frac{0}{\frac{0}{0}}$ & 递 \\
\hline 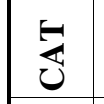 & 옥 & 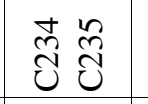 & 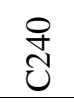 & 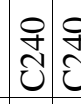 & 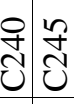 & $\overrightarrow{\vec{I}}$ & 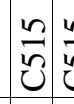 & 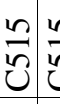 & & 늠 & 늑 & $\begin{array}{l}\text { N } \\
\text { Dु }\end{array}$ & $\stackrel{\mathscr{L}}{\cup}$ & ปิ & $\mathcal{U}$ & 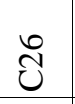 & $\stackrel{\Xi}{U}$ \\
\hline 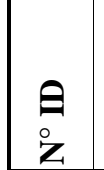 & 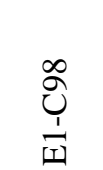 & 㐫 & 裍 & 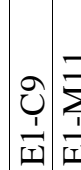 & 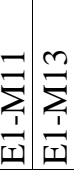 & 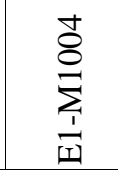 & 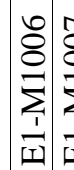 & 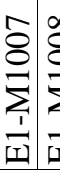 & & $\begin{array}{l}\vec{F} \\
\sum_{i} \\
\dot{1} \\
\dot{I}\end{array}$ & 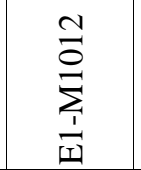 & 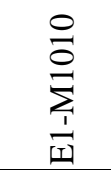 & $\begin{array}{l}\text { Uે } \\
\text { İ } \\
\text { In }\end{array}$ & 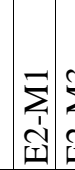 & 甚 & 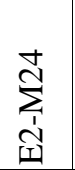 & 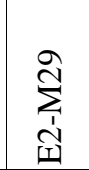 \\
\hline
\end{tabular}




\begin{tabular}{|c|c|c|c|c|c|c|c|c|c|c|c|c|c|c|c|}
\hline 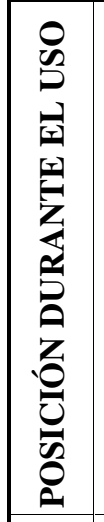 & 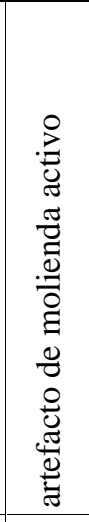 & 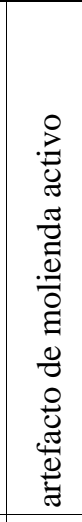 & 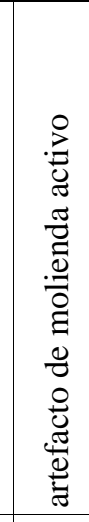 & 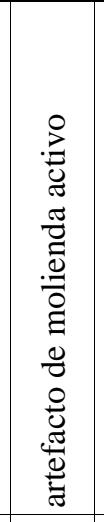 & 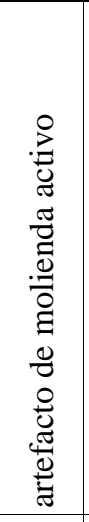 & 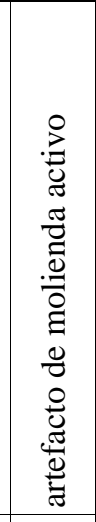 & 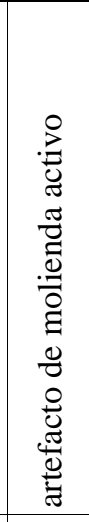 & 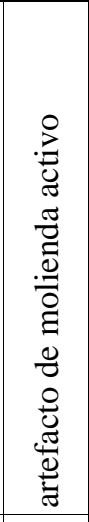 & 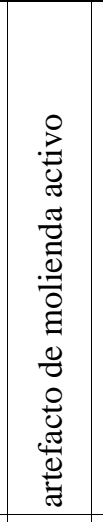 & 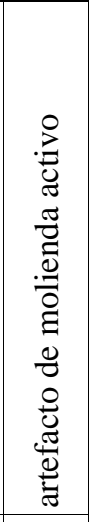 & 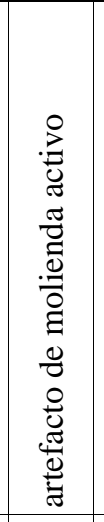 & 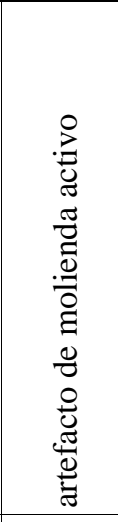 & 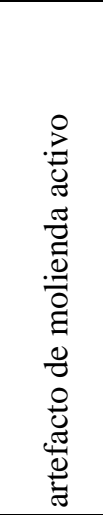 & 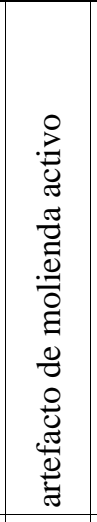 & 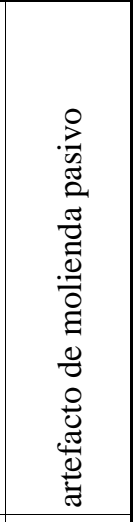 \\
\hline 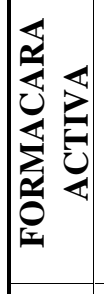 & $\begin{array}{l}\tilde{u} \\
\stackrel{\tilde{u}}{0} \\
\stackrel{0}{0}\end{array}$ & $\begin{array}{l}\tilde{x} \\
\stackrel{\tilde{x}}{0} \\
\stackrel{0}{0}\end{array}$ & $\begin{array}{l}\tilde{u} \\
\stackrel{\tilde{u}}{0} \\
\stackrel{0}{0}\end{array}$ & 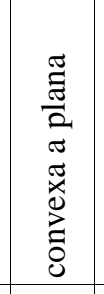 & $\begin{array}{l}\tilde{u} \\
\stackrel{\tilde{u}}{0} \\
\stackrel{0}{0}\end{array}$ & $\begin{array}{l}\tilde{x} \\
\stackrel{\tilde{x}}{0} \\
\stackrel{0}{0}\end{array}$ & $\begin{array}{l}\tilde{\tilde{u}} \\
\stackrel{\tilde{0}}{0} \\
\tilde{0}\end{array}$ & $\begin{array}{l}\tilde{x} \\
\stackrel{\tilde{x}}{0} \\
\stackrel{0}{0}\end{array}$ & $\begin{array}{l}\tilde{x} \\
\stackrel{\tilde{x}}{0} \\
\stackrel{0}{0}\end{array}$ & 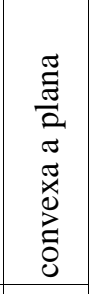 & $\begin{array}{l}\tilde{x} \\
\stackrel{\tilde{x}}{0} \\
\stackrel{0}{0}\end{array}$ & $\begin{array}{l}\tilde{\mathbb{x}} \\
\stackrel{\tilde{u}}{\tilde{0}} \\
\stackrel{0}{u}\end{array}$ & $\begin{array}{l}\tilde{\mathbb{x}} \\
\stackrel{0}{0} \\
\stackrel{0}{0}\end{array}$ & $\begin{array}{l}\tilde{x} \\
\stackrel{\tilde{x}}{0} \\
\stackrel{0}{0}\end{array}$ & 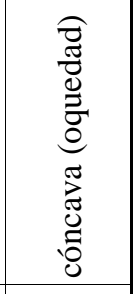 \\
\hline$\varangle \widehat{\widehat{\mathrm{E}}}$ & $\ddot{m}$ & $\stackrel{m}{\sim}$ & $\begin{array}{l}L^{\circ} \\
\infty\end{array}$ & 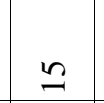 & $\stackrel{20}{\sim}$ & $\stackrel{\llcorner}{\stackrel{2}{+}}$ & $\stackrel{10}{=}$ & ㄱ. & $\stackrel{10}{=}$ & $\approx$ & $\stackrel{\infty}{\sim}$ & $\stackrel{m}{\rightarrow}$ & $\Lambda$ & 孚 & 우 \\
\hline$-\widehat{\hat{\mathrm{E}}}$ & \pm & $\stackrel{ㅁ}{\sim}$ & $\exists$ & $\stackrel{\theta}{\sigma}$ & $\stackrel{10}{\sim}$ & $a$ & $\stackrel{0}{\sim}$ & $\stackrel{v}{\nu}$ & $\underset{\sim}{\sim}$ & ( & $\stackrel{\sim}{N}$ & $\stackrel{n}{-}$ & $\infty$ & 占 & $\approx$ \\
\hline 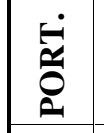 & 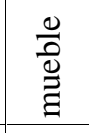 & $\begin{array}{l}\frac{0}{0} \\
\stackrel{\Xi}{\Xi} \\
\end{array}$ & $\begin{array}{l}\frac{0}{0} \\
\stackrel{\Xi}{\Xi} \\
\end{array}$ & $\begin{array}{l}\frac{\vartheta}{0} \\
\stackrel{\Xi}{\Xi} \\
\text { a }\end{array}$ & $\begin{array}{l}\frac{0}{0} \\
\stackrel{\Xi}{\Xi} \\
\end{array}$ & $\begin{array}{l}\frac{\vartheta}{0} \\
\stackrel{\Xi}{\Xi}\end{array}$ & $\begin{array}{l}\frac{0}{0} \\
\stackrel{0}{\Xi} \\
\end{array}$ & 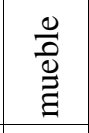 & $\begin{array}{l}\frac{0}{0} \\
\stackrel{0}{\vec{g}} \\
\end{array}$ & $\begin{array}{l}\frac{0}{0} \\
\stackrel{\Xi}{\Xi}\end{array}$ & $\begin{array}{l}\frac{0}{0} \\
\stackrel{0}{\vec{g}} \\
\end{array}$ & $\begin{array}{l}\frac{0}{0} \\
\stackrel{0}{\Xi} \\
\end{array}$ & $\begin{array}{l}\frac{0}{0} \\
\stackrel{\vec{a}}{\Xi} \\
\end{array}$ & $\begin{array}{l}\frac{a}{0} \\
\vec{\Xi} \\
\vec{E}\end{array}$ & 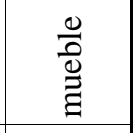 \\
\hline 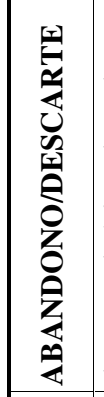 & 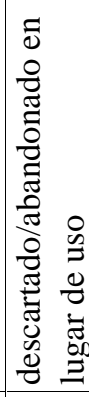 & 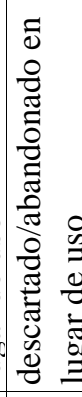 & 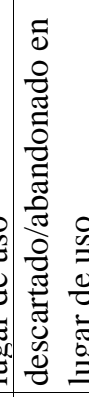 & 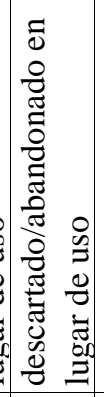 & 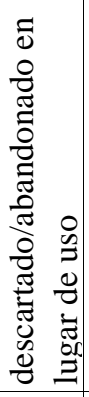 & 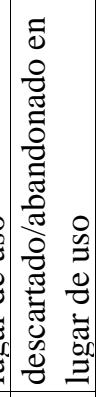 & 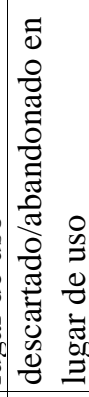 & 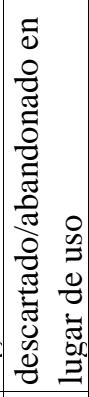 & 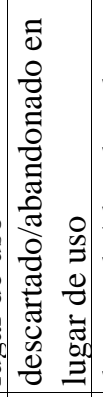 & 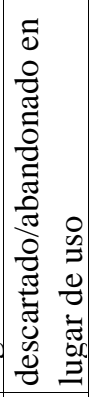 & 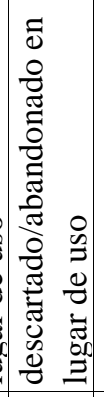 & 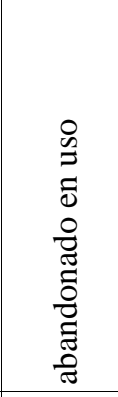 & 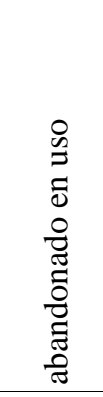 & 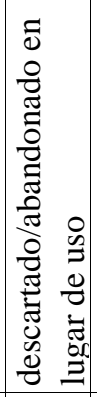 & 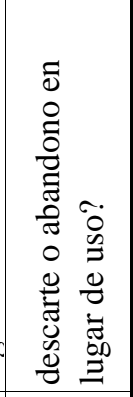 \\
\hline $\begin{array}{ll}n & \\
0 & n \\
& 0 \\
0 & 0 \\
0\end{array}$ & z & そ) & そ) & そ) & そ) & $\stackrel{\circ}{z}$ & そ) & そ) & そ) & そ) & そ) & 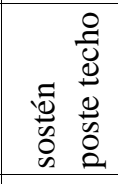 & 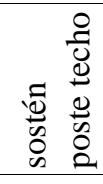 & そ) & $\stackrel{\varrho}{z}$ \\
\hline 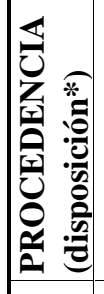 &. & $\stackrel{0}{a}$ & . &.$\frac{0}{2}$ & . & . & . & . & 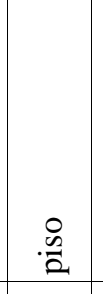 & .0 .0 &.$\frac{0}{2}$ & 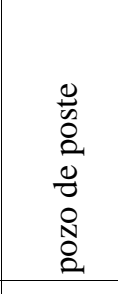 & 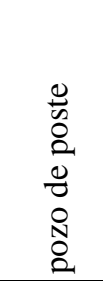 & .0 .0 & 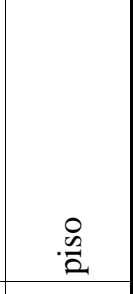 \\
\hline 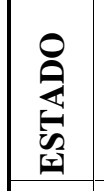 & $\frac{\stackrel{0}{\frac{0}{a}}}{\text { है }}$ & $\frac{0}{\frac{0}{a}}$ & 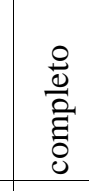 & $\begin{array}{l}\frac{0}{0} \\
\frac{\vec{\Xi}}{0} \\
0\end{array}$ & $\frac{\stackrel{0}{\frac{0}{a}}}{\bar{\Xi}}$ & $\frac{8}{\frac{0}{2}}$ & 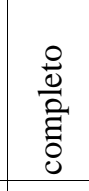 & $\frac{0}{\frac{0}{0}}$ & $\begin{array}{l}\frac{0}{0} \\
\frac{\bar{\Xi}}{0} \\
0\end{array}$ & $\frac{0}{\frac{0}{0}}$ & 苞 & 華 & $\frac{0}{\frac{0}{0}}$ & 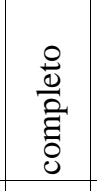 & 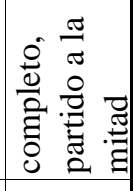 \\
\hline 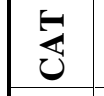 & 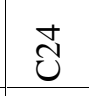 & $\overrightarrow{\tilde{v}}$ & $\stackrel{\mathcal{U}}{ }$ & ปี & 岂 & นึ & 仓ુ & טુ & นึ่ & $\stackrel{f}{0}$ & $\stackrel{0}{u}$ & $\hat{0}$ & $\hat{U}$ & $\stackrel{8}{J}$ & गิ \\
\hline $\begin{array}{l}\text { O } \\
\text { z }\end{array}$ & 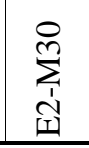 & $\underset{\substack{i \\
\sum^{n}}}{\vec{m}}$ & $\begin{array}{l}\sum_{i=1}^{m} \\
N_{\mid=1}^{m}\end{array}$ & $\underset{\substack{1 \\
\sum_{1}^{N}}}{\mathcal{N}}$ & 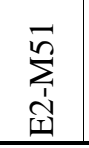 & $\begin{array}{l}\sum_{i=1}^{n} \\
N_{\mid=1}^{n} \\
\end{array}$ & 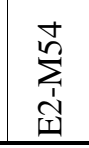 & 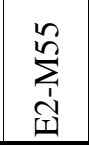 & $\begin{array}{l}\sum_{i=1}^{0} \\
\text { in } \\
.1\end{array}$ & in & 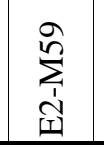 & $\begin{array}{l}\vec{b} \\
\sum_{i}^{\infty} \\
\tilde{\mid c} \\
\end{array}$ & 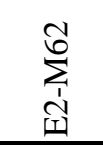 & $\begin{array}{l}\sum_{i}^{0} \\
\stackrel{1}{0} \\
\text { N1 }\end{array}$ & 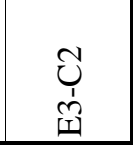 \\
\hline
\end{tabular}




\begin{tabular}{|c|c|c|c|c|c|c|c|c|c|c|c|c|c|c|c|c|}
\hline $\begin{array}{l}0 \\
0 \\
0 \\
1 \\
1 \\
1 \\
01 \\
z \\
\vdots \\
5 \\
0 \\
0 \\
\vdots \\
0 \\
0 \\
0 \\
0 \\
0\end{array}$ & 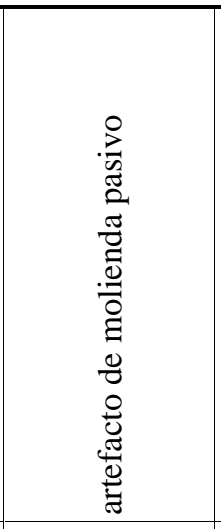 & 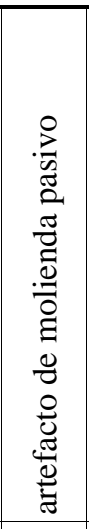 & 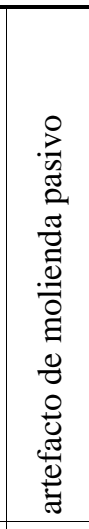 & 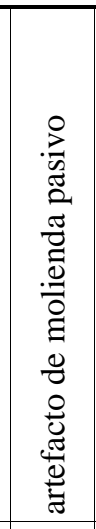 & 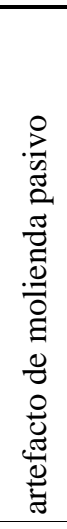 & 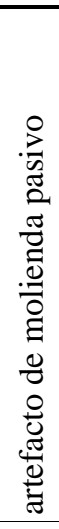 & 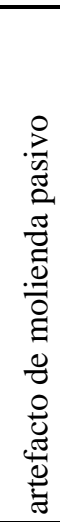 & 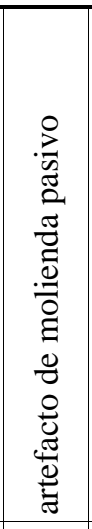 & 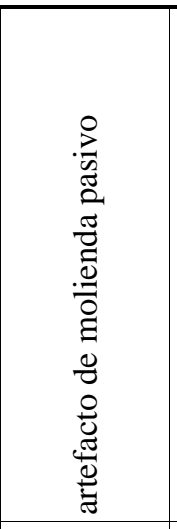 & 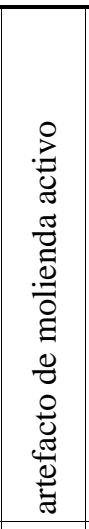 & 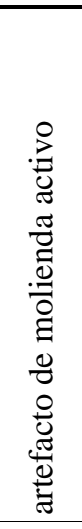 & 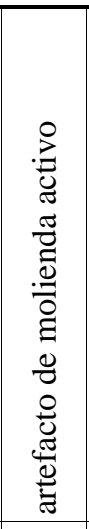 & 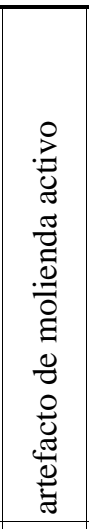 & 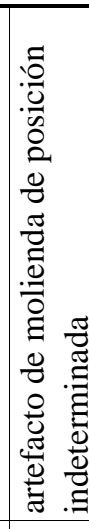 & 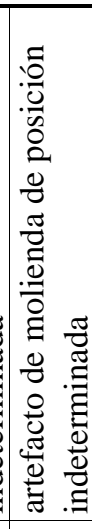 & 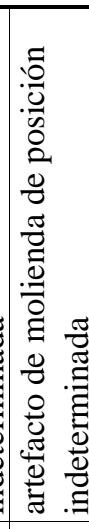 \\
\hline 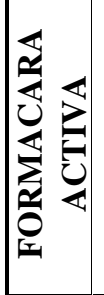 & 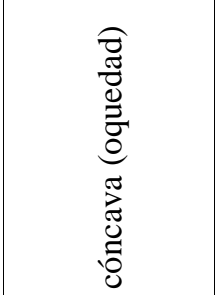 & 苞 & 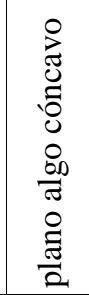 & 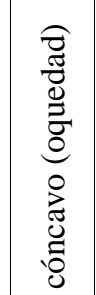 & 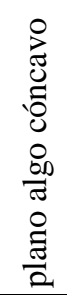 & 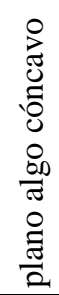 & 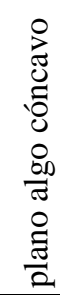 & 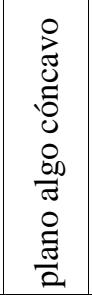 & 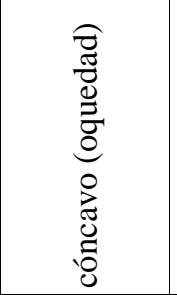 & 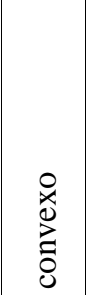 & 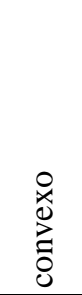 & 离 & 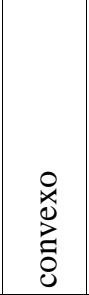 & 芯 & 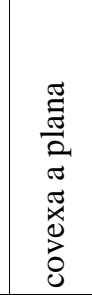 & 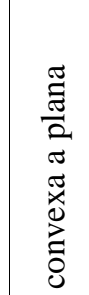 \\
\hline « & $\stackrel{\mathscr{q}}{\forall}$ & 우 & \pm & $\mathscr{\sigma}$ & ลี & $\bar{\lambda}$ & $\stackrel{\infty}{\sim}$ & $\ddot{N}$ & $\mathscr{F}$ & 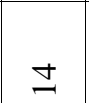 & $\approx$ & $\stackrel{\infty}{\sim}$ & $\stackrel{m}{-}$ & 孚 & 孚 & 点 \\
\hline$-\widehat{\hat{\mathrm{g}}}$ & $\infty$ & 요 & $\stackrel{\infty}{\sim}$ & $\stackrel{\sigma}{\sigma}$ & $\vec{m}$ & ঙे & $\stackrel{\sim}{\sim}$ & $\vec{m}$ & 뭉 & 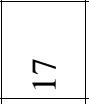 & $\stackrel{\oplus}{\sim}$ & $\vec{\sim}$ & $\underset{ت}{ \pm}$ & 号 & 号 & 号 \\
\hline 菑 & $\begin{array}{l}\frac{0}{\tilde{Q}} \\
\stackrel{\vec{g}}{\Xi}\end{array}$ & $\begin{array}{l}\frac{\mathscr{2}}{2} \\
\frac{0}{\vec{g}}\end{array}$ & 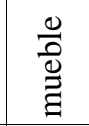 & 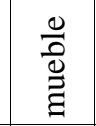 & 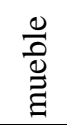 & $\begin{array}{l}\frac{0}{0} \\
\stackrel{0}{\Xi} \\
\end{array}$ & $\begin{array}{l}\frac{0}{0} \\
\stackrel{\Xi}{\Xi}\end{array}$ & 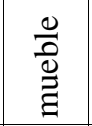 & $\begin{array}{l}\frac{0}{0} \\
\stackrel{0}{\Xi} \\
\end{array}$ & 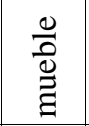 & 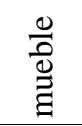 & $\begin{array}{l}\frac{0}{0} \\
\stackrel{\vec{g}}{\Xi} \\
\end{array}$ & 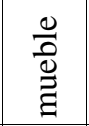 & 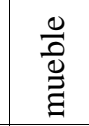 & 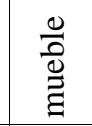 & $\begin{array}{l}\frac{0}{0} \\
\stackrel{\vec{g}}{0}\end{array}$ \\
\hline 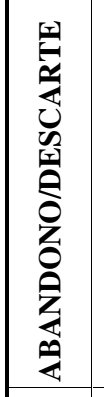 & 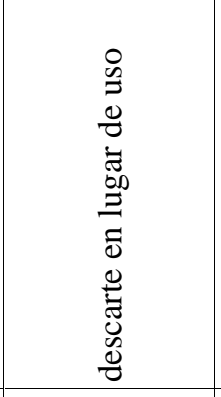 & 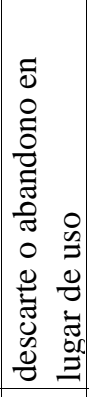 & 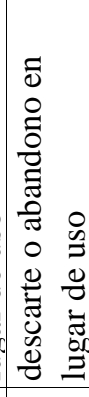 & 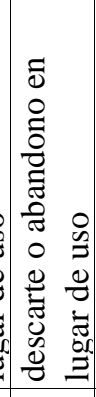 & 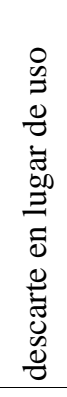 & 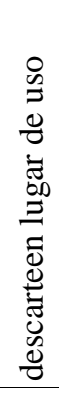 & 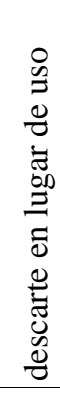 & 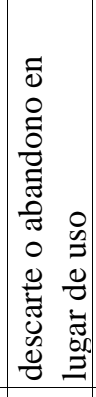 & $\begin{array}{l}0 \\
0 \\
0 \\
0 \\
0 \\
0 \\
0 \\
0 \\
\overline{0} \\
\tilde{0}\end{array}$ & 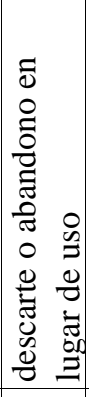 & 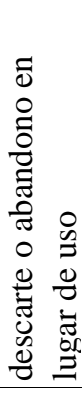 & 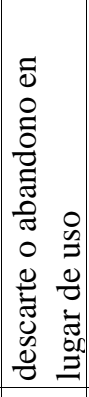 & 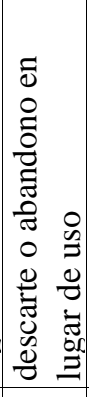 & 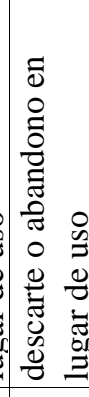 & 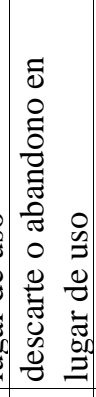 & 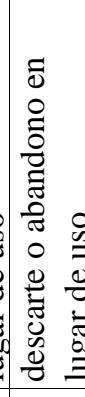 \\
\hline $\begin{array}{l}n \\
0 \\
2 \\
0 \\
0 \\
0\end{array}$ & z & そ & Z & Z & Z & ○ & Z & Z & $\stackrel{0}{Z}$ & Z & Z & Z & Z & Z & Z & Z \\
\hline 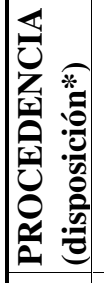 & 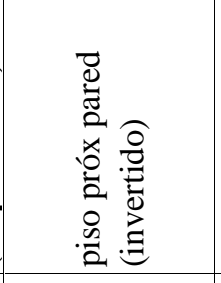 & $\stackrel{\circ}{2}$ & 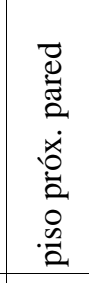 & $\stackrel{0}{a}$ & $\stackrel{0}{20}$ & $\stackrel{0}{2}$ & .0 & . & 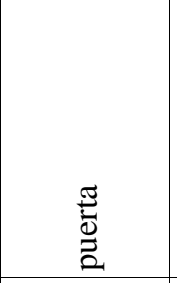 & $\stackrel{\circ}{20}$ & $\stackrel{0}{a}$ & $\stackrel{0}{a}$ & $\stackrel{\circ}{\not 2}$ & $\stackrel{0}{a}$ & $\stackrel{\circ}{20}$ & $\stackrel{\circ}{\circ}$ \\
\hline 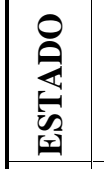 & 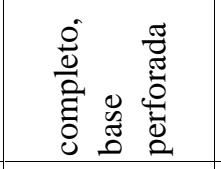 & $\frac{0}{\frac{0}{2}}$ & 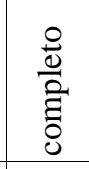 & $\frac{0}{\frac{0}{2}}$ & $\frac{0}{\frac{0}{2}}$ & $\frac{8}{\frac{0}{0}}$ & 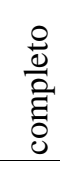 & $\frac{0}{\frac{0}{2}}$ & 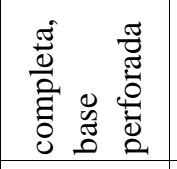 & $\frac{0}{\frac{0}{2}}$ & $\frac{O}{\frac{0}{0}}$ & $\frac{\stackrel{0}{u}}{\frac{0}{0}}$ & $\frac{0}{\frac{0}{2}}$ & $\frac{0}{\frac{0}{0}}$ & $\frac{0}{\stackrel{0}{0}}$ & 荇 \\
\hline 弍 & 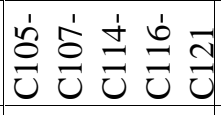 & $\begin{array}{l}0 \\
\tilde{m} \\
u\end{array}$ & $\begin{array}{l}\bullet \\
\stackrel{-}{u}\end{array}$ & $\underset{ت}{ت}$ & 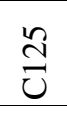 & 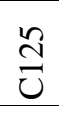 & $\stackrel{\text { I }}{U}$ & $\vec{\Xi}$ & 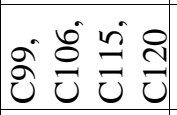 & త్ర & త్ర & త্ & త్ర & बิ & @̊ & @̊ \\
\hline $\begin{array}{l}\text { O } \\
0 \\
\mathbf{z}\end{array}$ & $\begin{array}{l}\infty \\
\vdots \\
1 \\
m \\
\end{array}$ & 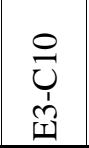 & 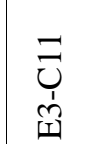 & 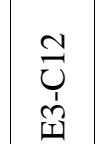 & 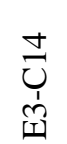 & 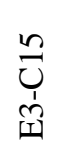 & 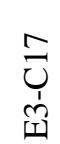 & 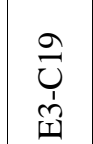 & 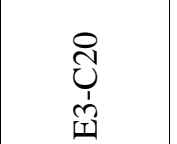 & $\underset{\substack{1 \\
N_{1}}}{\stackrel{N}{1}}$ & $\sum_{\substack{1 \\
\mid=1}}^{ \pm}$ & $\sum_{\substack{1 \\
\mid=1}}^{\infty}$ & $\begin{array}{l}0 \\
\sum_{1}^{1} \\
\infty=1 \\
=1\end{array}$ & $\sum_{\substack{1 \\
\pm=1}}^{\hat{F}}$ & $\sum_{\substack{1 \\
\tilde{I}}}^{\vec{I}}$ & $\sum_{\substack{1 \\
\infty}}^{\tilde{I}}$ \\
\hline
\end{tabular}




\begin{tabular}{|c|c|c|c|c|c|c|c|c|c|c|c|c|c|c|c|c|c|c|}
\hline 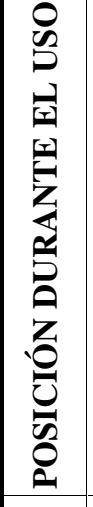 & 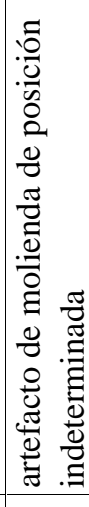 & 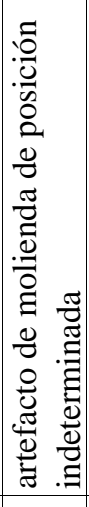 & 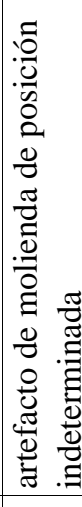 & 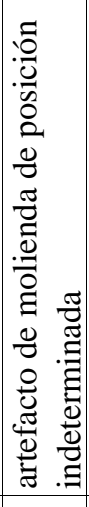 & 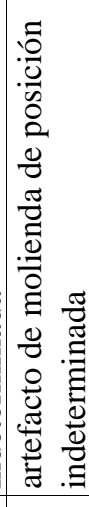 & 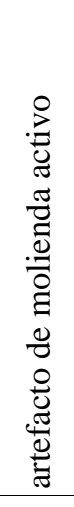 & 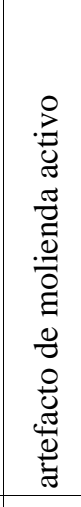 & 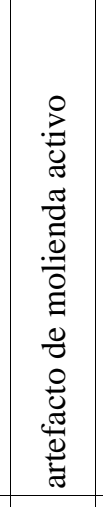 & 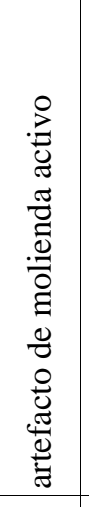 & 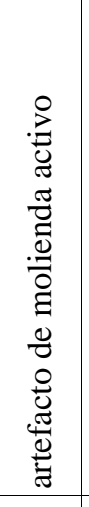 & 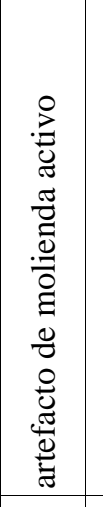 & 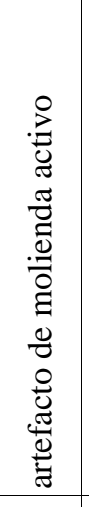 & 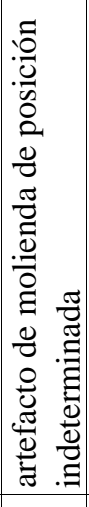 & 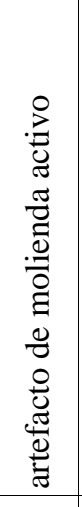 & 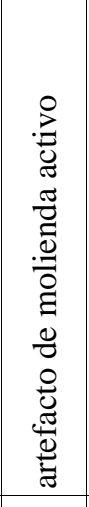 & 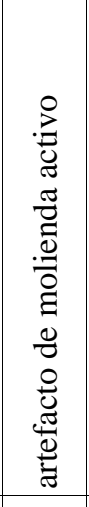 & 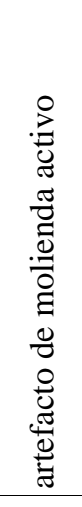 & 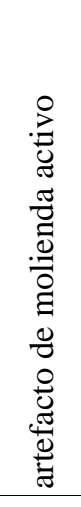 \\
\hline 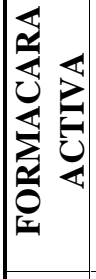 & 己े & $\begin{array}{l}\tilde{x} \\
\stackrel{\tilde{x}}{0} \\
\stackrel{0}{0}\end{array}$ & 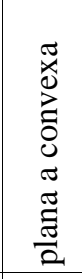 & $\begin{array}{l}\tilde{a} \\
\stackrel{\tilde{u}}{0} \\
\stackrel{0}{0}\end{array}$ & $\begin{array}{l}\frac{\pi}{\pi} \\
\frac{\pi}{2} \\
\pi \\
\pi \\
\tilde{\pi} \\
0 \\
0 \\
0 \\
0\end{array}$ & 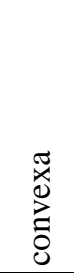 & 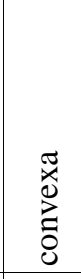 & $\begin{array}{l}\tilde{x} \\
\stackrel{\tilde{x}}{0} \\
\stackrel{0}{0}\end{array}$ & 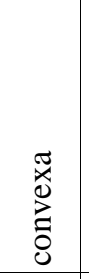 & $\begin{array}{l}\tilde{x} \\
\stackrel{\tilde{u}}{0} \\
\stackrel{0}{0}\end{array}$ & $\begin{array}{l}\tilde{\ddot{u}} \\
\stackrel{0}{0} \\
\stackrel{0}{0}\end{array}$ & 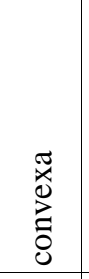 & $\begin{array}{l}\tilde{x} \\
\stackrel{\tilde{x}}{0} \\
\stackrel{0}{0}\end{array}$ & $\begin{array}{l}\tilde{x} \\
\stackrel{\tilde{x}}{0} \\
\stackrel{0}{0}\end{array}$ & $\begin{array}{l}\tilde{x} \\
\stackrel{\tilde{x}}{0} \\
\stackrel{0}{u}\end{array}$ & $\begin{array}{l}\tilde{x} \\
\stackrel{\tilde{x}}{0} \\
\stackrel{0}{0}\end{array}$ & $\begin{array}{l}\tilde{u} \\
\stackrel{\tilde{u}}{0} \\
\stackrel{0}{0}\end{array}$ & $\begin{array}{l}\tilde{x} \\
\stackrel{\tilde{x}}{0} \\
\stackrel{0}{0}\end{array}$ \\
\hline$\varangle \widehat{\underline{\mathrm{g}}}$ & 孚 & 号 & 号 & 号 & 点 & $\approx$ & $\stackrel{m}{\rightarrow}$ & $\stackrel{2}{\sim}$ & $\stackrel{\infty}{\sim}$ & $\stackrel{\infty}{\sim}$ & $\exists$ & 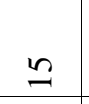 & 孚 & $\stackrel{M}{\sim}$ & $\exists$ & $\underset{工}{ \pm}$ & $\exists$ & $\exists$ \\
\hline$-\widehat{\underline{\Xi}}$ & $\frac{r}{z}$ & 号 & 号 & 号 & 占 & $\stackrel{0}{-1}$ & $\vec{\sim}$ & $\stackrel{\mathscr{N}}{ }$ & $\stackrel{\sim}{v}$ & $\stackrel{\infty}{\sim}$ & $\underset{\sim}{\sim}$ & $\stackrel{\curvearrowright}{ }$ & 孚 & $\underset{J}{ \pm}$ & $\underset{工}{ \pm}$ & $\stackrel{\sim}{N}$ & $\underset{7}{\sim}$ & $\stackrel{\infty}{\sim}$ \\
\hline 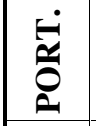 & $\begin{array}{l}\frac{0}{0} \\
\stackrel{\Xi}{\Xi}\end{array}$ & $\begin{array}{l}\frac{0}{0} \\
\stackrel{\Xi}{\Xi}\end{array}$ & $\begin{array}{l}\frac{0}{0} \\
\frac{\Xi}{\Xi}\end{array}$ & $\begin{array}{l}\frac{0}{0} \\
\stackrel{\Xi}{\vec{\Xi}}\end{array}$ & $\begin{array}{l}\frac{\vartheta}{0} \\
\stackrel{\Xi}{\vec{E}}\end{array}$ & 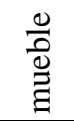 & $\begin{array}{l}\frac{\varrho}{\overrightarrow{0}} \\
\stackrel{\vec{\Xi}}{\vec{a}}\end{array}$ & $\begin{array}{l}\frac{0}{0} \\
\stackrel{\Xi}{\Xi}\end{array}$ & $\begin{array}{l}\frac{0}{0} \\
\stackrel{\Xi}{\Xi}\end{array}$ & $\begin{array}{l}\frac{0}{0} \\
\stackrel{\Xi}{\Xi}\end{array}$ & $\begin{array}{l}\frac{0}{0} \\
\frac{\Xi}{\Xi}\end{array}$ & $\begin{array}{l}\frac{0}{0} \\
\stackrel{\Xi}{\Xi}\end{array}$ & $\begin{array}{l}\frac{\ddots}{0} \\
\stackrel{\Xi}{\Xi}\end{array}$ & $\begin{array}{l}\frac{0}{0} \\
\stackrel{\Xi}{\Xi}\end{array}$ & $\begin{array}{l}\stackrel{0}{0} \\
\stackrel{\vec{\Xi}}{\vec{Z}}\end{array}$ & $\begin{array}{l}\frac{0}{0} \\
\stackrel{\Xi}{\Xi}\end{array}$ & $\begin{array}{l}\frac{\varrho}{\partial} \\
\stackrel{\Xi}{\Xi}\end{array}$ & $\begin{array}{l}\stackrel{0}{0} \\
\stackrel{\Xi}{\Xi} \\
\end{array}$ \\
\hline 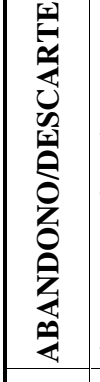 & 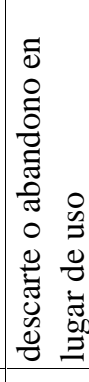 & 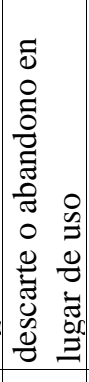 & 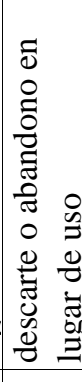 & 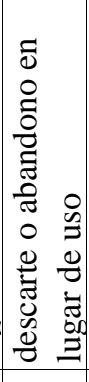 & 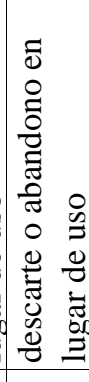 & 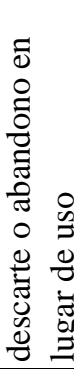 & 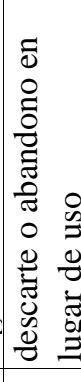 & 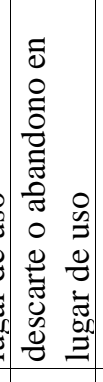 & 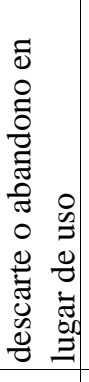 & 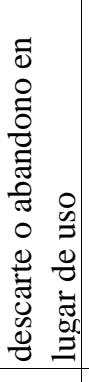 & 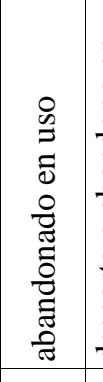 & 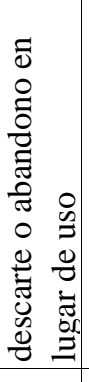 & 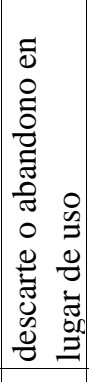 & 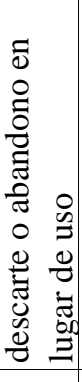 & 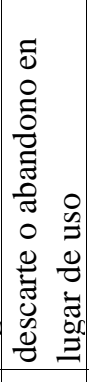 & 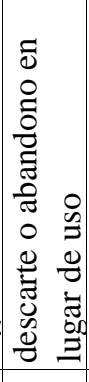 & 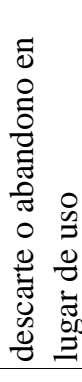 & 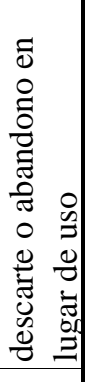 \\
\hline 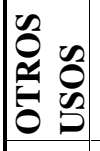 & ২ & そ & そ & z & そ & そ) & ○ & そ & そ & そ & 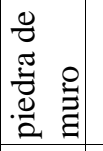 & $\stackrel{0}{z}$ & そ & そ & そ & そ & $\stackrel{\circ}{z}$ & そ) \\
\hline 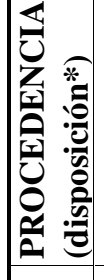 & $\frac{0}{2}$ & $\stackrel{\circ}{a}$ & $\stackrel{\circ}{2}$ & .̊. & $\stackrel{\circ}{a}$ & $\stackrel{0}{a}$ & $\stackrel{\circ}{2}$ & $\stackrel{\circ}{a}$ & $\stackrel{\circ}{2}$ & $\stackrel{\circ}{2}$ & $\begin{array}{l}\text { 岕 } \\
\text { 心 } \\
\end{array}$ & $\stackrel{0}{a ̈}$ & $\stackrel{\circ}{a}$ & $\begin{array}{l}\text { N. } \\
\stackrel{2}{2}\end{array}$ & $\begin{array}{l}\text { N. } \\
\text {. }\end{array}$ & $\stackrel{\mathscr{n}}{a}$ & $\begin{array}{l}\text { ̊̊ } \\
\text { o } \\
\text {. }\end{array}$ & $\begin{array}{l}\text { No } \\
\stackrel{2}{2}\end{array}$ \\
\hline 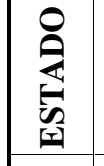 & 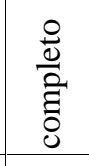 & 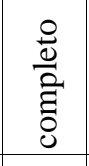 & 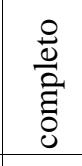 & 递 & 总 & 宽 & 总 & 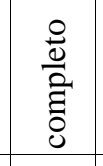 & 苛 & 沊 & 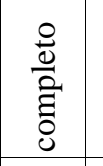 & 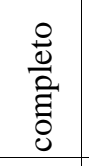 & 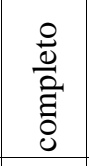 & 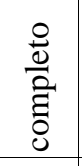 & 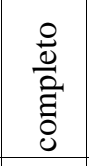 & 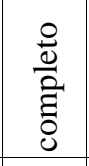 & 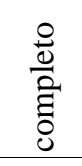 & $\begin{array}{l}\frac{0}{0} \\
\frac{0}{\bar{\Xi}} \\
\text { d }\end{array}$ \\
\hline 甚 & $\stackrel{\infty}{8}$ & $\vec{\exists}$ & $\stackrel{L}{\stackrel{1}{二}}$ & $\stackrel{m}{=}$ & $\stackrel{m}{\vec{u}}$ & $\underset{U}{\vec{U}}$ & $\stackrel{\bullet}{=}$ & $\stackrel{L}{\stackrel{1}{U}}$ & $\stackrel{\bullet}{ت}$ & $\begin{array}{l}\text { ป } \\
\text { U }\end{array}$ & $\begin{array}{c}\hat{U} \\
\text { U }\end{array}$ & $\begin{array}{l}\stackrel{\sim}{\sim} \\
\tilde{U}\end{array}$ & $\stackrel{\stackrel{\infty}{\sim}}{\tilde{U}}$ & $\begin{array}{l}\stackrel{\sim}{\sim} \\
\cup\end{array}$ & $\stackrel{\stackrel{\sim}{\sim}}{U}$ & $\hat{~}$ & $\stackrel{\mathcal{J}}{\mathcal{U}}$ & $\stackrel{\mathcal{J}}{\mathcal{U}}$ \\
\hline 目 & 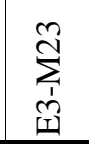 & $\underset{\substack{1\\
}}{\stackrel{L}{N}}$ & $\begin{array}{l}0 \\
\sum_{1}^{1} \\
M=1 \\
=1\end{array}$ & 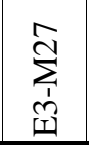 & $\sum_{\substack{1 \\
\mid=1}}^{\infty}$ & $\prod_{\substack{1 \\
N_{I=1}^{N}}}$ & $\sum_{\substack{1 \\
m=1}}^{+}$ & $\sum_{\substack{1 \\
m_{1}^{\infty}}}^{\infty}$ & $\sum_{\substack{1 \\
\infty}}^{\infty}$ & $\sum_{\substack{1 \\
1}}^{+}$ & 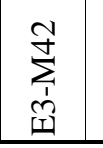 & $\sum_{\substack{1 \\
I}}^{\infty}$ & 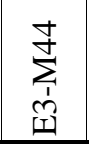 & 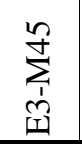 & $\sum_{\substack{1 \\
\infty \\
I=1}}^{O}$ & $\underset{\substack{1 \\
\mid=1}}{\stackrel{O}{1}}$ & $\sum_{\substack{1 \\
\mid=1}}^{P}$ & 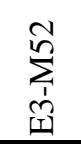 \\
\hline
\end{tabular}




\begin{tabular}{|c|c|c|c|c|c|c|c|c|c|c|c|c|c|c|c|c|c|c|c|c|c|}
\hline 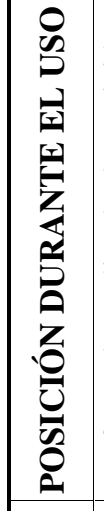 & 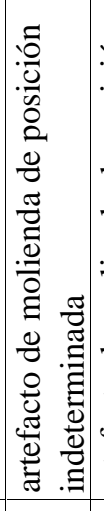 & 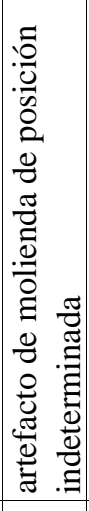 & 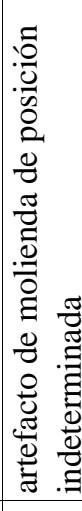 & 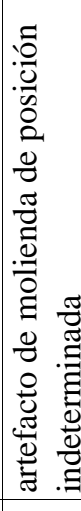 & 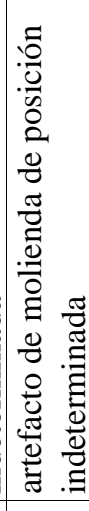 & 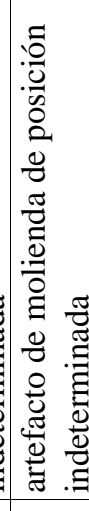 & 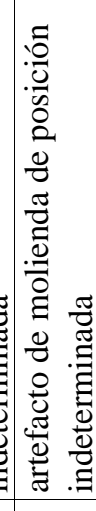 & 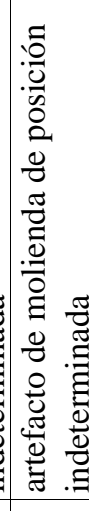 & 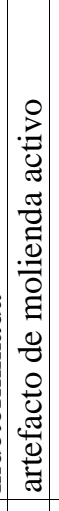 & 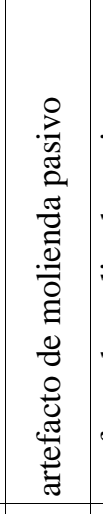 & 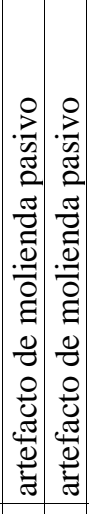 & 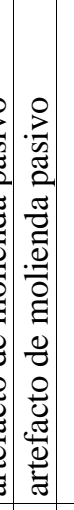 & 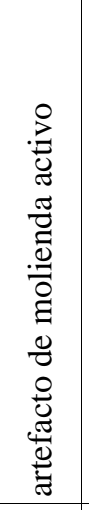 & 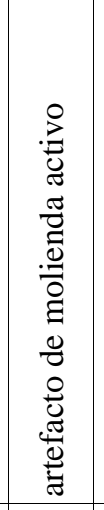 & 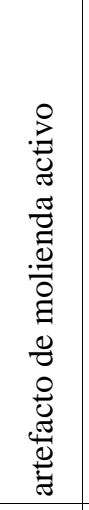 & 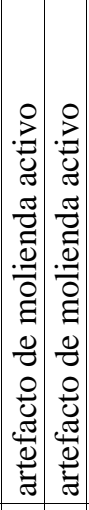 & 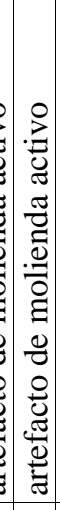 & 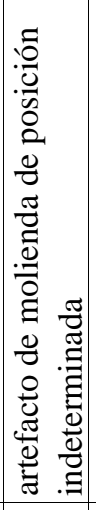 & 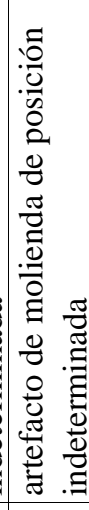 & 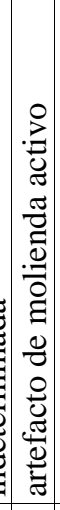 & 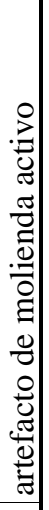 \\
\hline 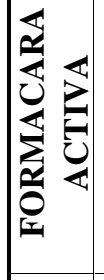 & $\begin{array}{l}\tilde{\tilde{u}} \\
\stackrel{\tilde{u}}{0} \\
\stackrel{0}{0}\end{array}$ & $\begin{array}{l}\tilde{x} \\
\stackrel{\tilde{x}}{\tilde{u}} \\
\overrightarrow{0}\end{array}$ & $\begin{array}{l}\tilde{x} \\
\stackrel{\tilde{x}}{\tilde{u}} \\
\overrightarrow{0}\end{array}$ & $\begin{array}{l}\tilde{x} \\
\stackrel{\tilde{x}}{\tilde{d}} \\
\overrightarrow{0}\end{array}$ & $\begin{array}{l}\tilde{u} \\
\stackrel{\tilde{u}}{0} \\
\stackrel{\tilde{0}}{0}\end{array}$ & $\begin{array}{l}\tilde{u} \\
\stackrel{\tilde{u}}{0} \\
\stackrel{0}{0}\end{array}$ & $\begin{array}{l}\tilde{u} \\
\stackrel{\tilde{u}}{0} \\
\stackrel{0}{0}\end{array}$ & $\begin{array}{l}\tilde{x} \\
\stackrel{\tilde{x}}{0} \\
\stackrel{0}{0}\end{array}$ & 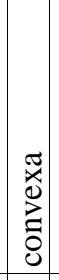 & 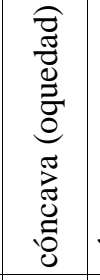 & 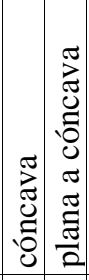 & 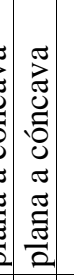 & $\begin{array}{l}\tilde{u} \\
\stackrel{\tilde{u}}{0} \\
\stackrel{\tilde{u}}{0}\end{array}$ & 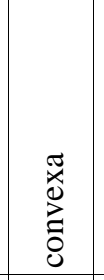 & $\begin{array}{l}\tilde{u} \\
\stackrel{\tilde{u}}{u} \\
\stackrel{\overrightarrow{0}}{0}\end{array}$ & 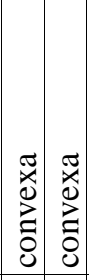 & 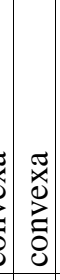 & $\begin{array}{l}\tilde{x} \\
\stackrel{\tilde{u}}{0} \\
\stackrel{0}{0}\end{array}$ & 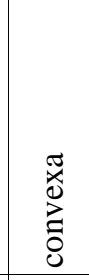 & & 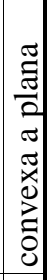 \\
\hline$\varangle \widehat{\text { 国 }}$ & 号 & 号 & 号 & 号 & 号 & 号 & 号 & 号 & o & 艺 & 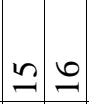 & q & $\stackrel{L}{\stackrel{L}{\sim}}$ & $\theta$ & $\Xi$ & $\stackrel{\infty}{\infty}{ }_{\infty}$ & 음 & 号 & 号 & & مू \\
\hline এ & 品 & 号 & 孚 & 号 & 号 & 号 & 孚 & 孚 & $\exists$ & 号 & 글 & $\frac{a}{z}$ & $\begin{array}{l}\stackrel{L}{0} \\
\stackrel{\sim}{\sim}\end{array}$ & $\exists$ & 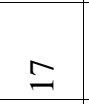 & 잉 & $\exists$ & 点 & 孚 & $\exists$ & $ㅇ$ \\
\hline 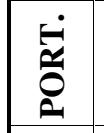 & 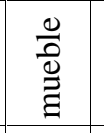 & 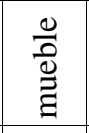 & 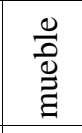 & 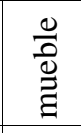 & $\begin{array}{l}\frac{0}{0} \\
\frac{\Xi}{\vec{a}}\end{array}$ & 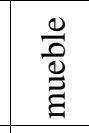 & 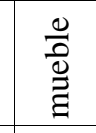 & 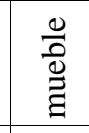 & 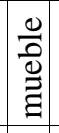 & 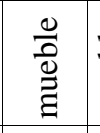 & 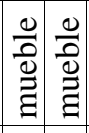 & 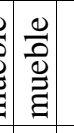 & $\begin{array}{l}\stackrel{\varrho}{\Omega} \\
\stackrel{\Xi}{\Xi}\end{array}$ & 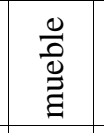 & 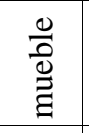 & 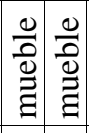 & 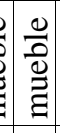 & $\begin{array}{l}\stackrel{0}{0} \\
\stackrel{\Xi}{\Xi} \\
\end{array}$ & 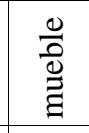 & & $\begin{array}{l}\text { : } \\
\stackrel{\Xi}{\Xi} \\
\text { : }\end{array}$ \\
\hline 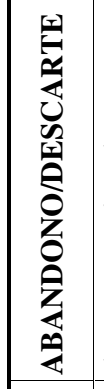 & 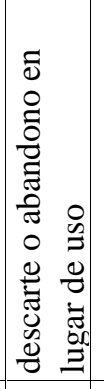 & 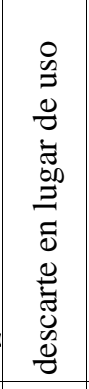 & 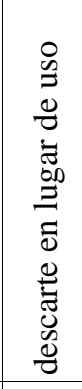 & 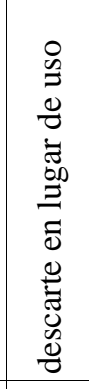 & 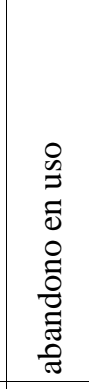 & 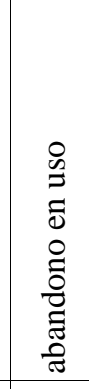 & 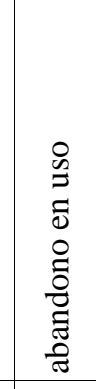 & 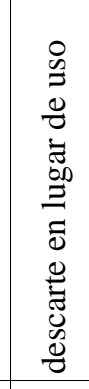 & 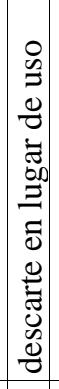 & 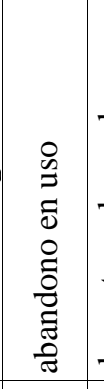 & 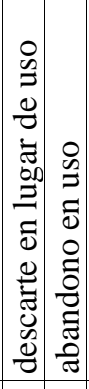 & 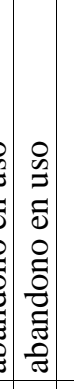 & 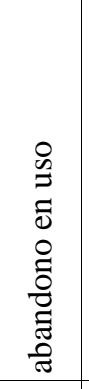 & 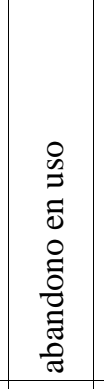 & 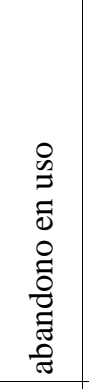 & 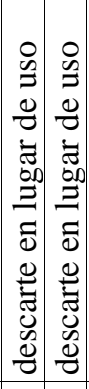 & 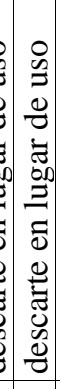 & 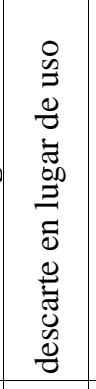 & 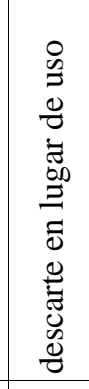 & 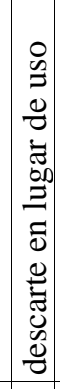 & 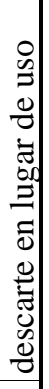 \\
\hline $\begin{array}{ll}n & \\
0 & n \\
& 0 \\
0 & 0\end{array}$ & Z & $\begin{array}{l}0 \\
z\end{array}$ & そ & $\stackrel{0}{Z}$ & 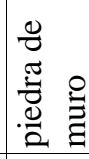 & 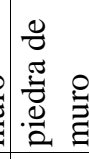 & 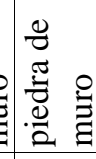 & 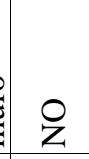 & $\begin{array}{l}0 \\
z\end{array}$ & そ & $\begin{array}{ll}0 & 0 \\
z & z\end{array}$ & $\begin{array}{l}1 \\
0 . \\
z\end{array}$ & 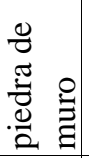 & 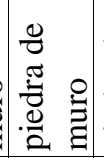 & 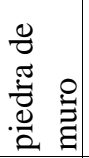 & $\begin{array}{ll}0 & 0 \\
z & z\end{array}$ & $\begin{array}{l}0 \\
z\end{array}$ & Z & z & & z \\
\hline 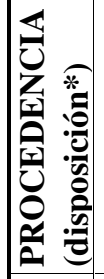 & $\frac{0}{2}$ & $\begin{array}{l}\stackrel{8}{2} \\
\stackrel{2}{2}\end{array}$ & .0 & $\stackrel{\circ}{a}$ & 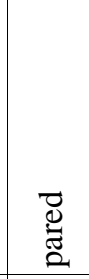 & 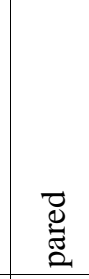 & 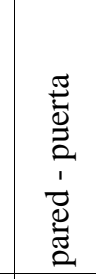 & $\stackrel{\circ}{a}$ & $\begin{array}{c} \\
0 \\
0 \\
0 \\
0.0\end{array}$ & 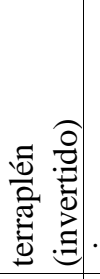 & \begin{tabular}{|c|c|} 
\\
0 \\
0 \\
0
\end{tabular} & $\frac{0}{2}$ & 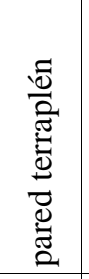 & 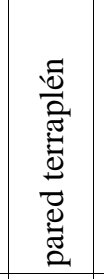 & 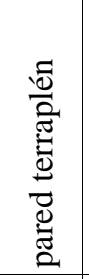 & \begin{tabular}{c|c}
0 & 0 \\
$\frac{0}{2}$ & $\frac{n}{a}$ \\
\end{tabular} & 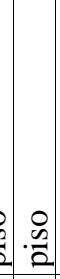 & $\stackrel{0}{2}$ & $\stackrel{0}{20}$ & & . \\
\hline 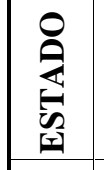 & 递 & 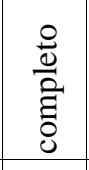 & $\frac{\stackrel{8}{\frac{0}{\pi}}}{\stackrel{\Xi}{0}}$ & 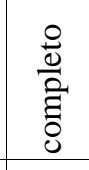 & $\frac{\stackrel{0}{0}}{\bar{\Xi}}$ & $\frac{0}{\frac{0}{\ddot{Z}}}$ & $\frac{\stackrel{0}{\frac{0}{a}}}{\frac{\bar{\sigma}}{0}}$ & 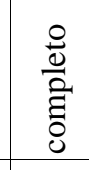 & 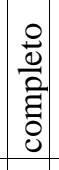 & 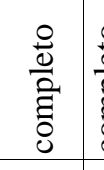 & 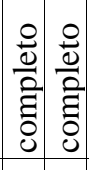 & : & $\begin{array}{l}\frac{O}{0} \\
\overline{\tilde{I}} \\
\text { U. }\end{array}$ & 菤 & $\begin{array}{l}\stackrel{0}{0} \\
\overline{\tilde{\Xi}} \\
0\end{array}$ & 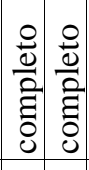 & $\frac{2}{\frac{8}{0}}$ & 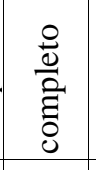 & $\frac{\stackrel{0}{\frac{\pi}{a}}}{\frac{\bar{\Xi}}{0}}$ & 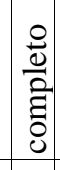 & 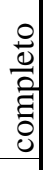 \\
\hline 兒 & $\underset{\nearrow}{\neg}$ & $\stackrel{\stackrel{\text { P }}{7}}{ }$ & $\vec{ت}$ & $\begin{array}{l}\text { Lొ } \\
\text { பี }\end{array}$ & Ů & 守 & 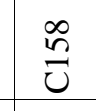 & $\underset{\sim}{\stackrel{n}{\sim}}$ & $\begin{array}{l}\infty \\
\stackrel{\infty}{\sigma} \\
\tilde{U}\end{array}$ & ஓ्ల & 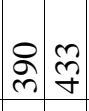 & $\tilde{\tilde{\vartheta}}$ & ๙ & $\stackrel{\sim}{\sim}$ & $\begin{array}{c}m \\
\stackrel{N}{N} \\
\end{array}$ & 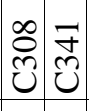 & 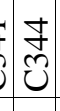 & Ð & 足 & & $\begin{array}{l}\widehat{N} \\
\hat{0} \\
0\end{array}$ \\
\hline $\begin{array}{l}\text { O } \\
\text { 足 }\end{array}$ & 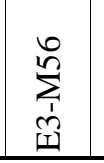 & $\sum_{\substack{1 \\
1}}^{\infty}$ & $\sum_{\substack{1 \\
\mid=1 \\
.1}}^{\infty}$ & $\sum_{\substack{1 \\
\mid=1}}^{\overrightarrow{0}}$ & $\sum_{\substack{1 \\
\infty \\
\mid=1}}^{\infty}$ & $\sum_{\substack{1 \\
=1}}^{\infty}$ & $\begin{array}{l}\sum_{1}^{L} \\
\prod_{I I}^{0} \\
\end{array}$ & $\begin{array}{l}\infty \\
\sum_{1}^{\infty} \\
\infty \\
=1 \\
\end{array}$ & 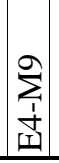 & 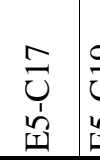 & 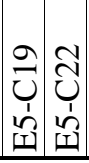 & 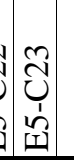 & $\sum_{\substack{1 \\
\text { 足 }\\
}}^{\infty}$ & 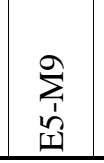 & $\sum_{\substack{1 \\
1 \\
\text { 足 }}}^{0}$ & 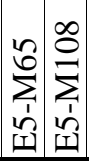 & 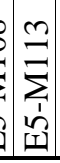 & 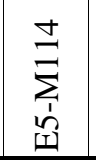 & 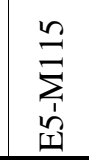 & 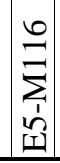 & 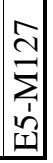 \\
\hline
\end{tabular}




\begin{tabular}{|c|c|c|c|c|c|c|c|c|c|c|c|c|c|c|c|c|c|c|c|c|c|}
\hline 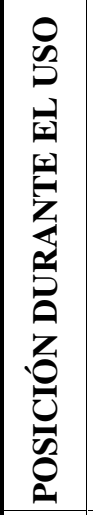 & 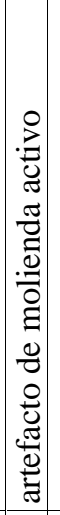 & 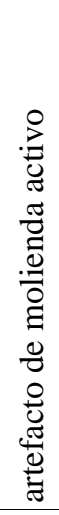 & 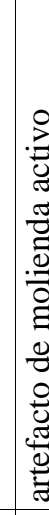 & 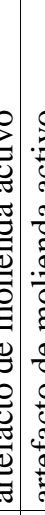 & & & & 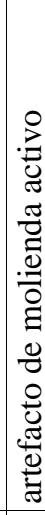 & 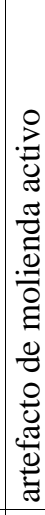 & 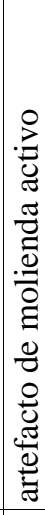 & & 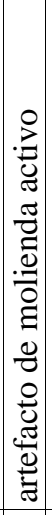 & 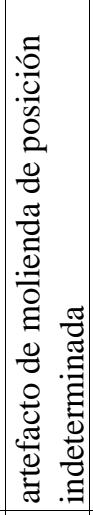 & 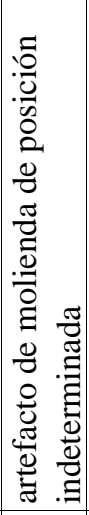 & 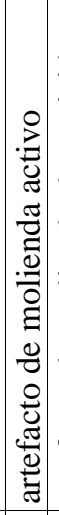 & 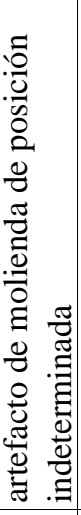 & 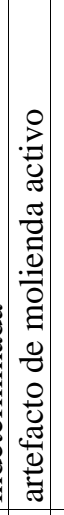 & 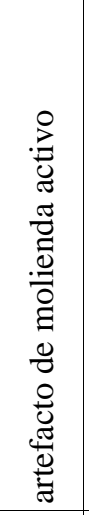 & 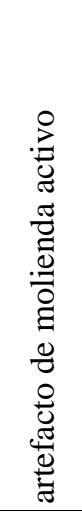 & 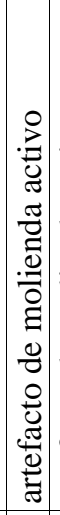 & 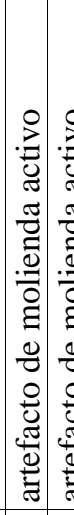 \\
\hline 帘 & 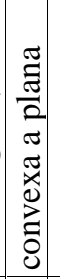 & $\begin{array}{l}\tilde{x} \\
\stackrel{0}{0} \\
\stackrel{0}{0}\end{array}$ & $\begin{array}{l}\tilde{a} \\
\stackrel{0}{0} \\
\tilde{u}\end{array}$ & 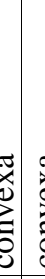 & $8 \pi$ & & & & & $\begin{array}{l}\tilde{x} \\
\ddot{u} \\
\grave{z} \\
\tilde{u}\end{array}$ & & & 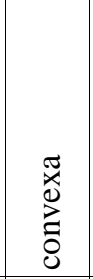 & $\begin{array}{l}\tilde{u} \\
\stackrel{\tilde{u}}{u} \\
\stackrel{0}{0}\end{array}$ & 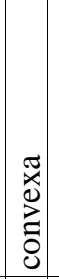 & 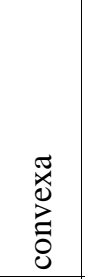 & 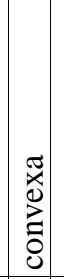 & $\begin{array}{l}\tilde{x} \\
\stackrel{\tilde{x}}{0} \\
\stackrel{0}{0}\end{array}$ & $\begin{array}{l}\tilde{u} \\
\stackrel{u}{u} \\
\stackrel{\partial}{0}\end{array}$ & 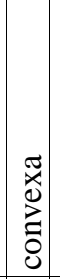 & $\mid \begin{array}{l}\tilde{u} \\
\stackrel{u}{u} \\
\stackrel{\Xi}{u}\end{array}$ \\
\hline$\varangle \widehat{\hat{\mathrm{g}}}$ & & $\stackrel{10}{\exists}$ & \pm & & & & & $\infty$ & $\exists$ & $\exists$ & & $\begin{array}{c}\qquad 0 \\
\infty^{\circ}\end{array}$ & 号 & 号 & $\infty$ & 孚 & $\stackrel{10}{\Omega}$ & $\exists$ & $=$ & $\underset{\sim}{\infty}$ & {$\left[\begin{array}{l}10 \\
\infty \\
\infty\end{array} \mid\right.$} \\
\hline$-\widehat{\hat{\mathrm{B}}}$ & & $\begin{array}{l}\stackrel{L}{\rho} \\
\tilde{\vartheta}^{-1}\end{array}$ & $\underset{7}{7}$ & & & & & $\stackrel{m}{\sim}$ & $\exists$ & $\begin{array}{l}10 \\
0 \\
0\end{array}$ & & $\begin{array}{c}L 2 \\
\sigma^{2}\end{array}$ & 孚 & 孚 & $\stackrel{\sim}{\sim}$ & 号 & $\sigma$ & $\exists$ & 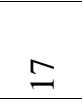 & $\approx$ & \\
\hline 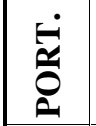 & 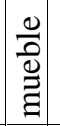 & 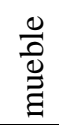 & $\frac{0}{\frac{0}{0}}$ & 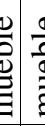 & $\frac{a}{2}$ & & & $\frac{9}{\frac{8}{8}}$ & & 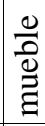 & & 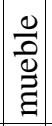 & $\begin{array}{l}\frac{\mathscr{\theta}}{0} \\
\stackrel{\Xi}{\Xi}\end{array}$ & $\begin{array}{l}\frac{\mathscr{D}}{0} \\
\stackrel{\Xi}{\Xi}\end{array}$ & $\begin{array}{l}\frac{a}{2} \\
\stackrel{\vec{g}}{\vec{z}}\end{array}$ & $\begin{array}{l}\frac{\mathscr{a}}{\widetilde{\Xi}} \\
\stackrel{\Xi}{\Xi}\end{array}$ & 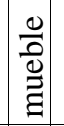 & 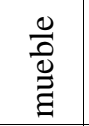 & 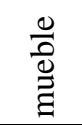 & 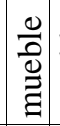 & 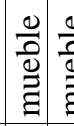 \\
\hline 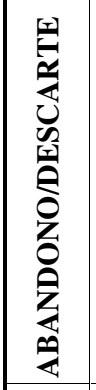 & 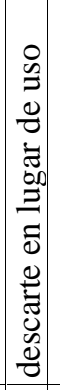 & $\begin{array}{l}0 \\
0 \\
\Xi \\
0 \\
0 \\
0 \\
0 \\
0 \\
\tilde{0} \\
\tilde{0}\end{array}$ & 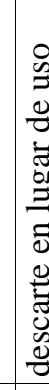 & 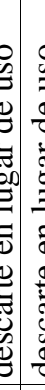 & 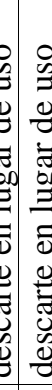 & 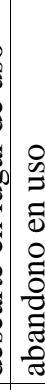 & 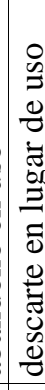 & 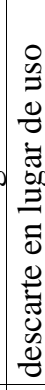 & 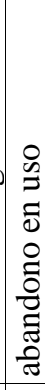 & 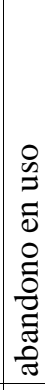 & & 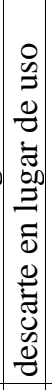 & 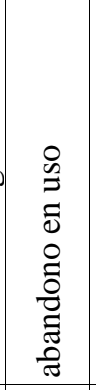 & 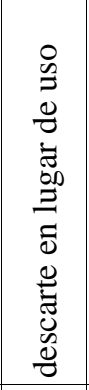 & 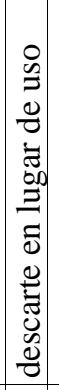 & 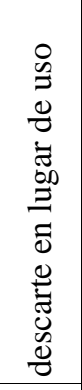 & 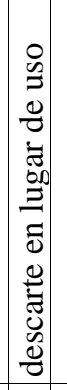 & 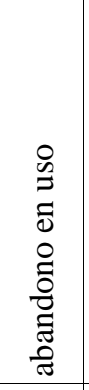 & 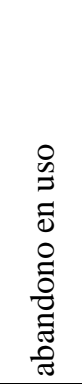 & 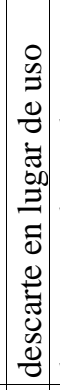 & 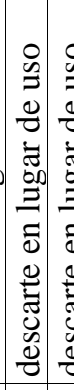 \\
\hline $\begin{array}{l}n \\
0 \\
0 \\
0 \\
0 \\
0 \\
0\end{array}$ & z & 。 & & & & & & & & & & $\begin{array}{l} \\
0 \\
0 \\
Z\end{array}$ & 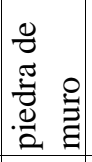 & Z & $\begin{array}{l}0 \\
z\end{array}$ & $\stackrel{\circ}{z}$ & $\begin{array}{l}. \\
0 . \\
0 . \\
2 .\end{array}$ & 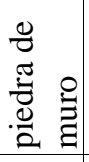 & 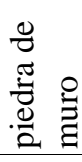 & ○े & $\begin{array}{l}0 \\
\mathbf{z}\end{array}$ \\
\hline 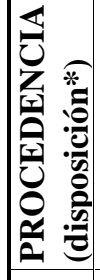 &. & 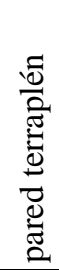 & . & 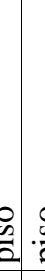 & & & & & & & & $\begin{array}{l}0 \\
20 \\
2\end{array}$ & 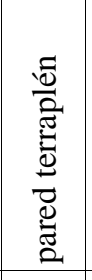 &.$\stackrel{0}{2}$ & .气̊ & $\stackrel{0}{2}$ &.$\stackrel{\circ}{2}$ & 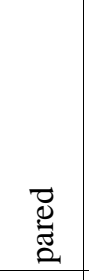 & 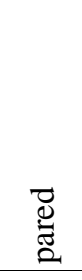 & & $\frac{0}{a}$ \\
\hline 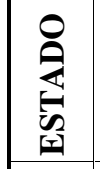 & 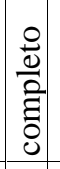 & 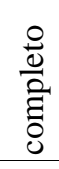 & 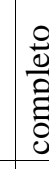 & 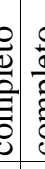 & & & & ठิ & & & & & 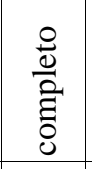 & 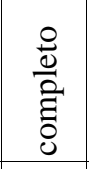 & $\begin{array}{l}\frac{0}{0} \\
\frac{0}{0} \\
\frac{0}{0}\end{array}$ & 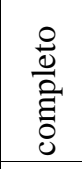 & 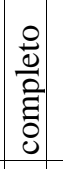 & 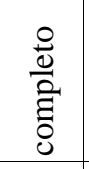 & 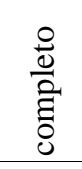 & 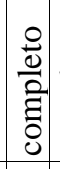 & 递 \\
\hline 朵 & $\begin{array}{c}\approx \\
\infty \\
\tilde{v}\end{array}$ & $\begin{array}{l}\infty \\
\tilde{U} \\
\tilde{U}\end{array}$ & $\tilde{U}$ & 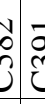 & & & & 0 & 0 & & & & $\overline{\mathcal{U}}$ & సે & స్తి & 今ે & $\begin{array}{l}\hat{D} \\
\hat{ల}\end{array}$ & $\stackrel{\widetilde{\vartheta}}{3}$ & $\stackrel{\widetilde{O}}{\tilde{U}}$ & $\begin{array}{l}0 \\
\tilde{D} \\
0\end{array}$ & ) \\
\hline $\begin{array}{l}\text { 至 } \\
\text { z }\end{array}$ & 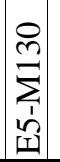 & 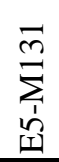 & $\sum_{1}^{m}$ & $\frac{5}{5}$ & $\hat{n}$ & $\sum_{i}^{m}$ & 17 & $\sum_{1}^{F}$ & $\underset{\sum}{\mathcal{F}}$ & 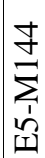 & & 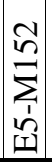 & $\sum_{\substack{1 \\
\mid}}^{0}$ & 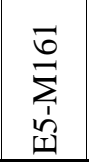 & 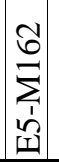 & $\sum_{1}^{\infty}$ & $\mid \begin{array}{l}\hat{0} \\
\sum_{1}^{0} \\
\Lambda_{1}\end{array}$ & $\sum_{i}^{\infty}$ & $\sum_{i}^{\infty}$ & $\sum_{\substack{1 \\
\infty \\
\infty}}^{\infty}$ & $\mid \begin{array}{l}\vec{i} \\
\vdots \\
\Lambda_{1}\end{array}$ \\
\hline
\end{tabular}




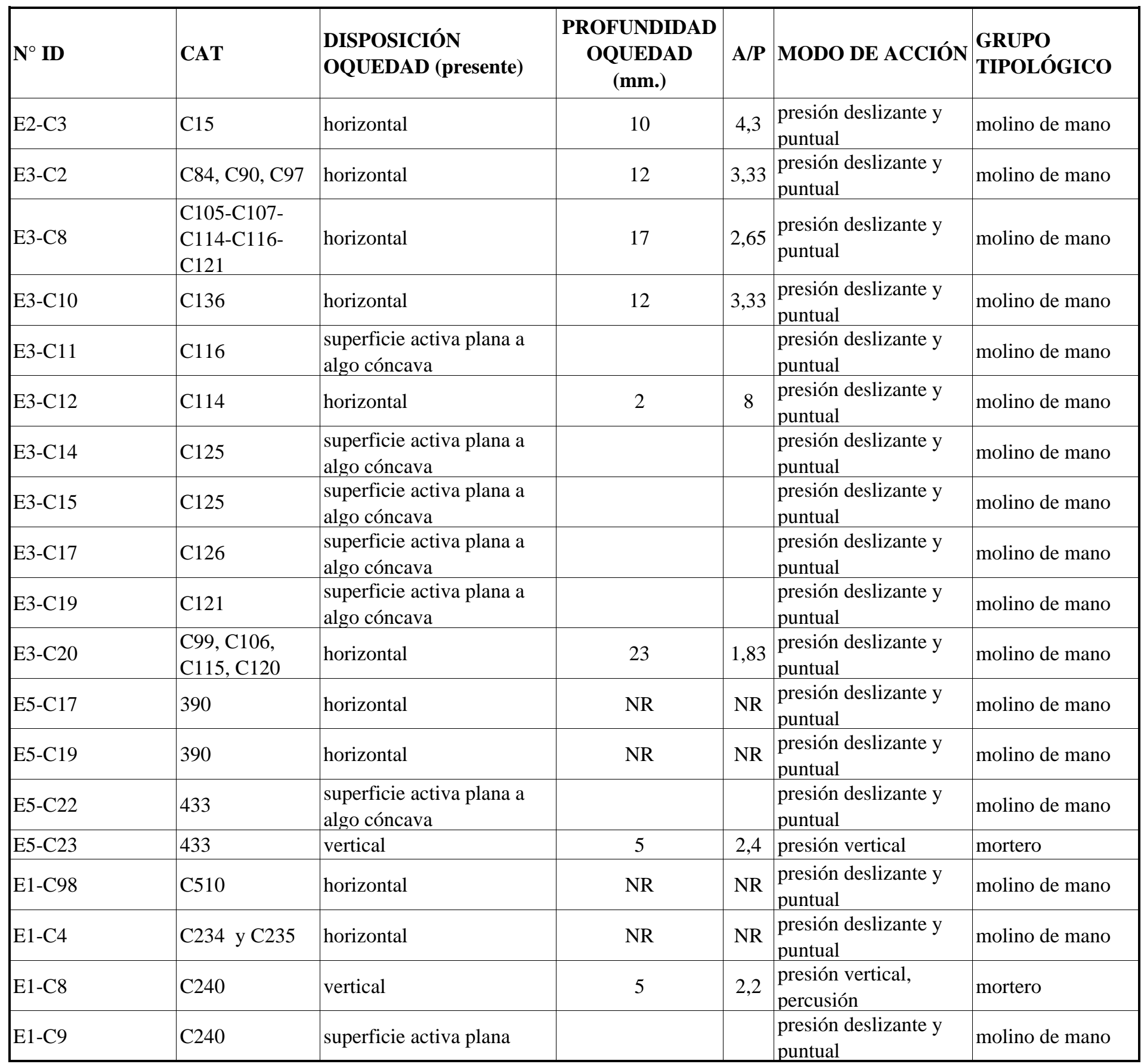




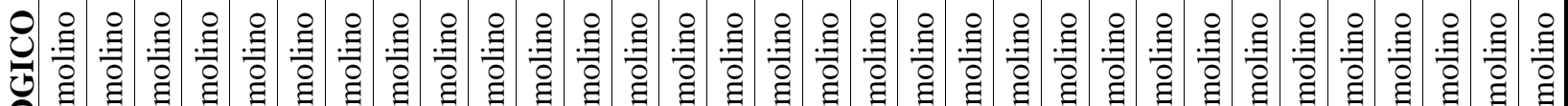

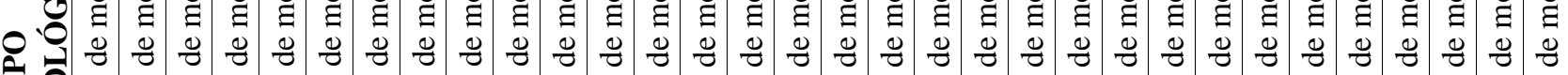

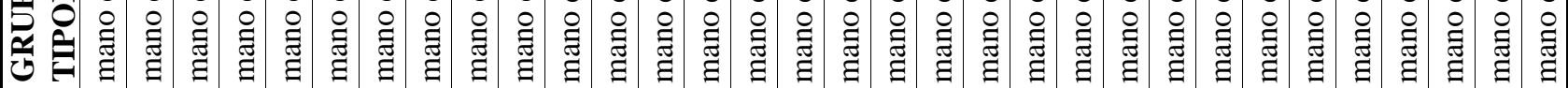

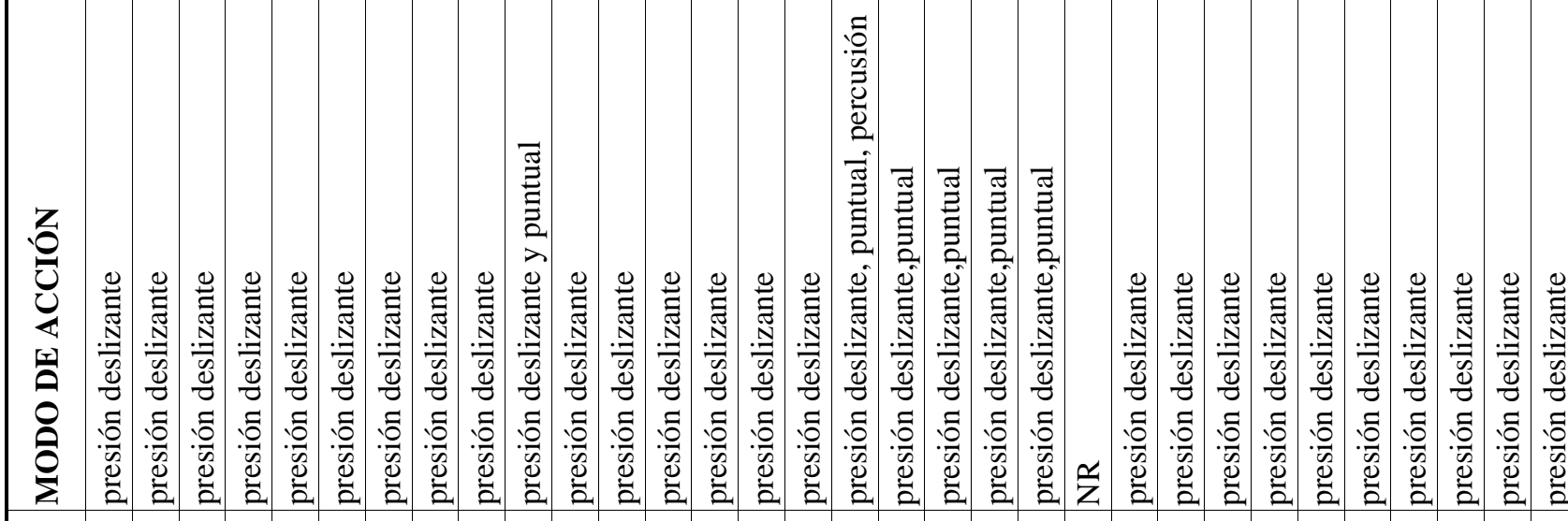

\section{离}

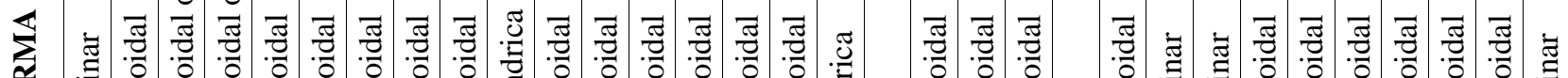

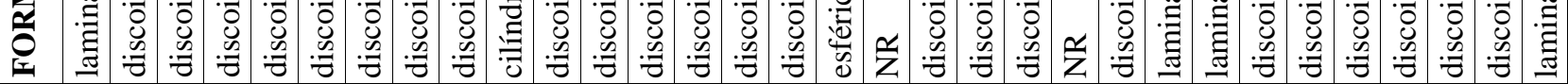

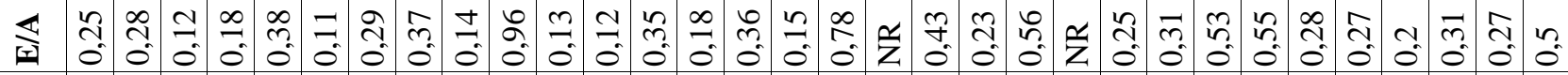

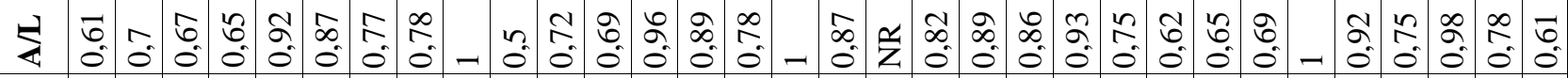
范

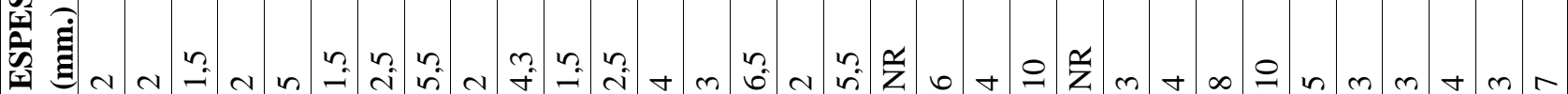
䑻

ㄴ.

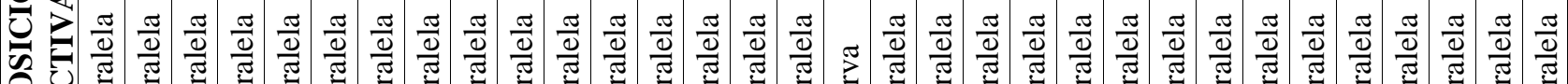

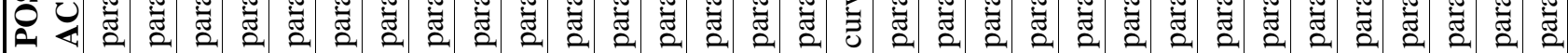

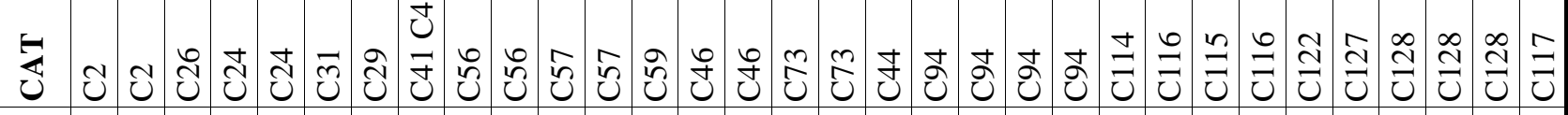

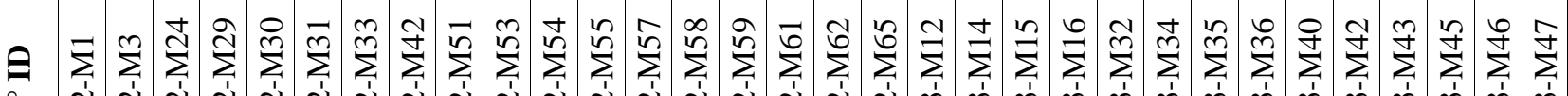

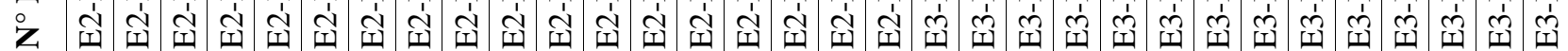




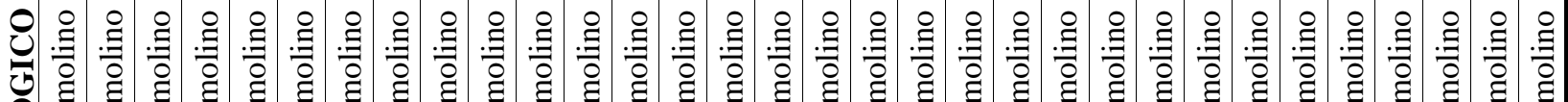

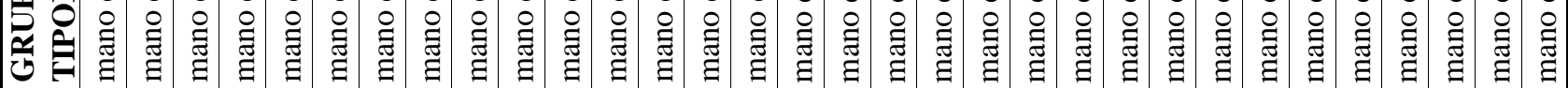

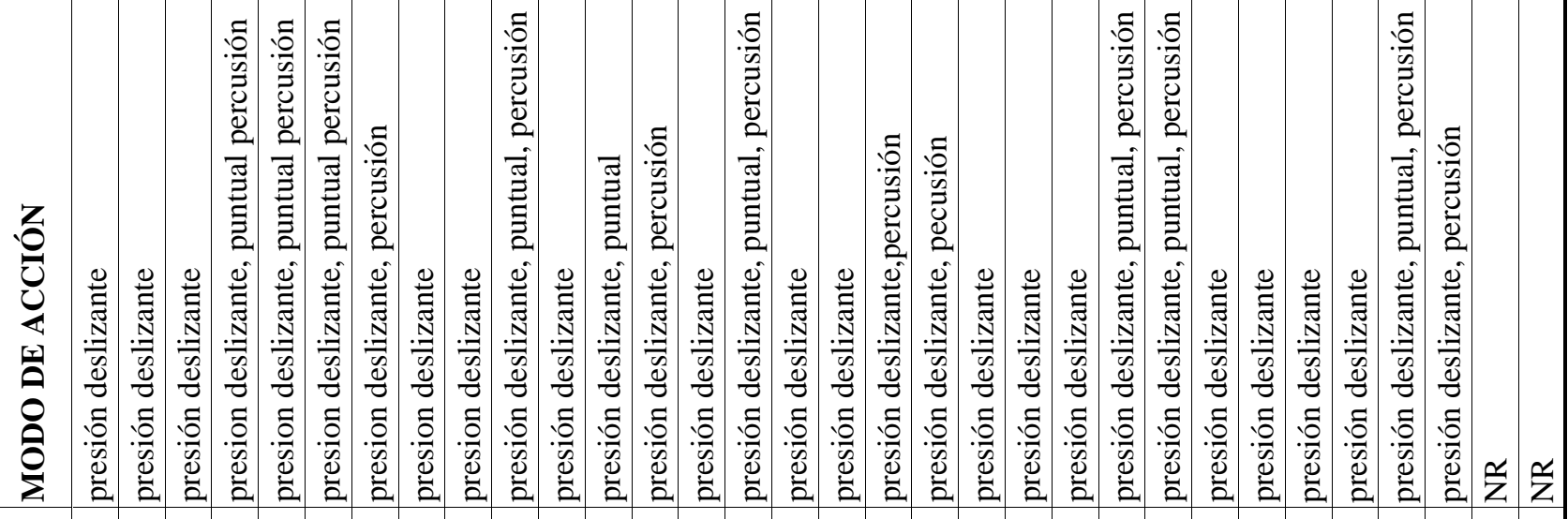

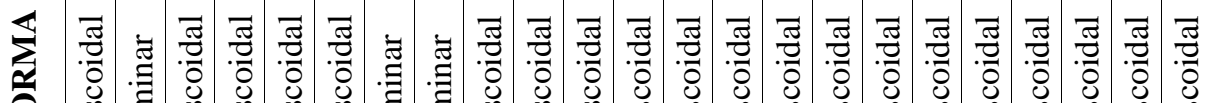

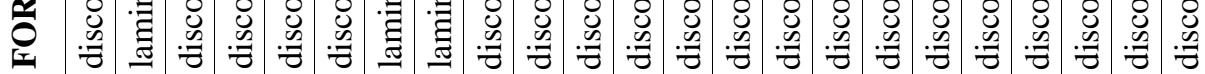

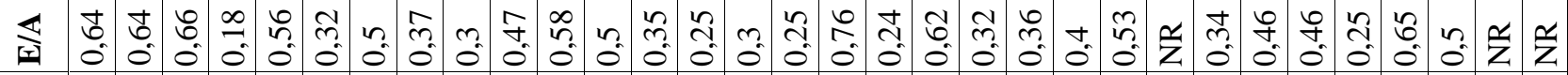

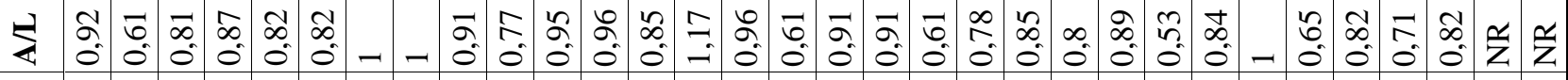

苍

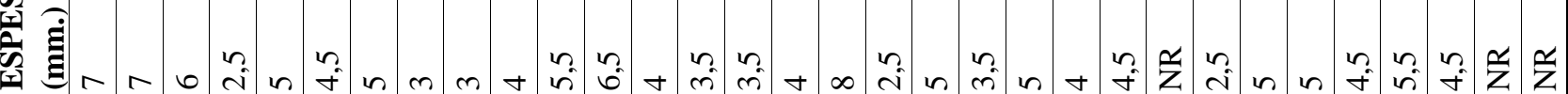

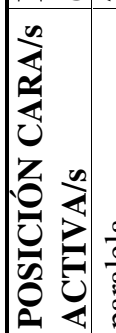

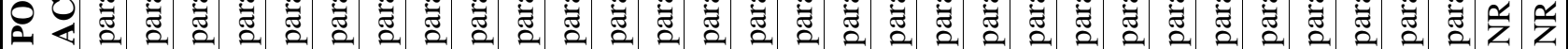

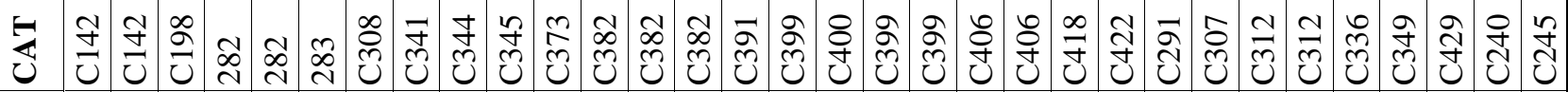

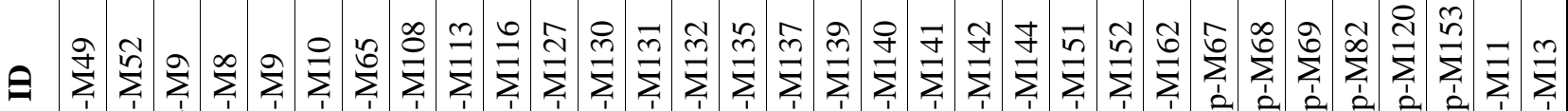

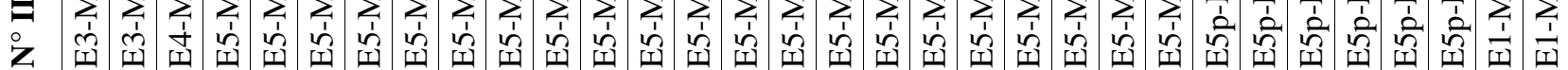




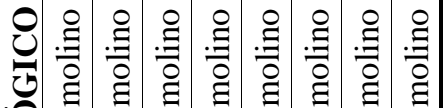

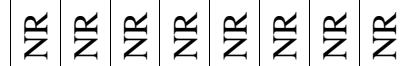

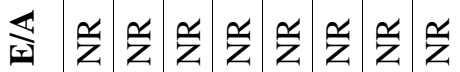

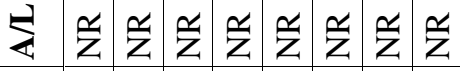

웅

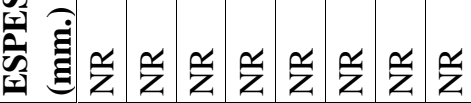

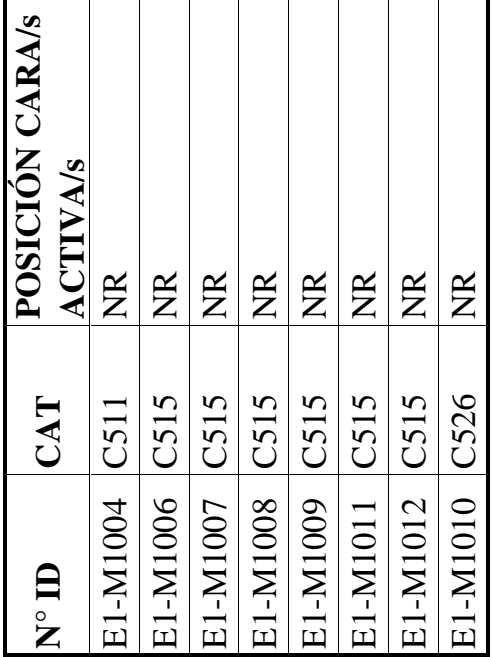




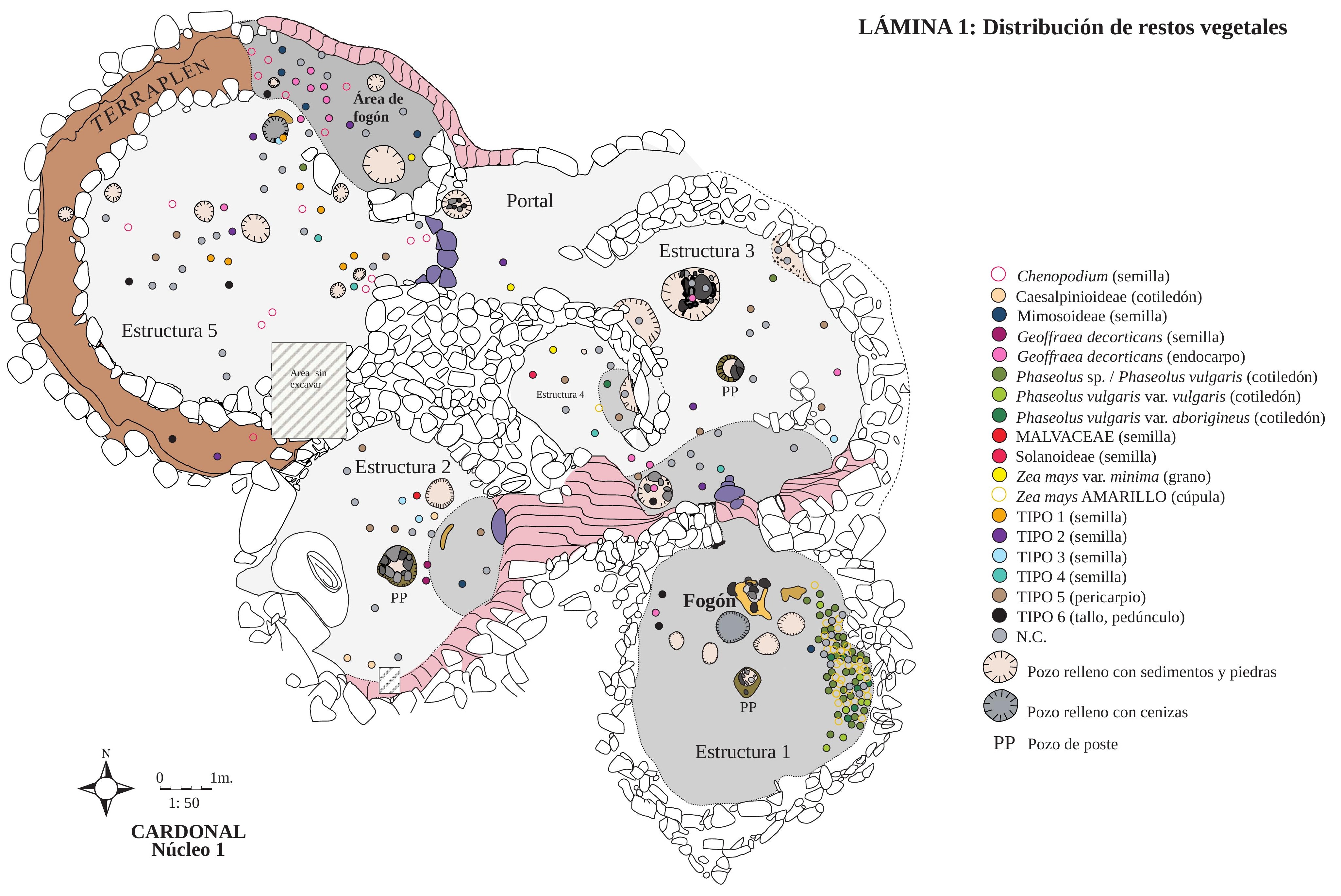




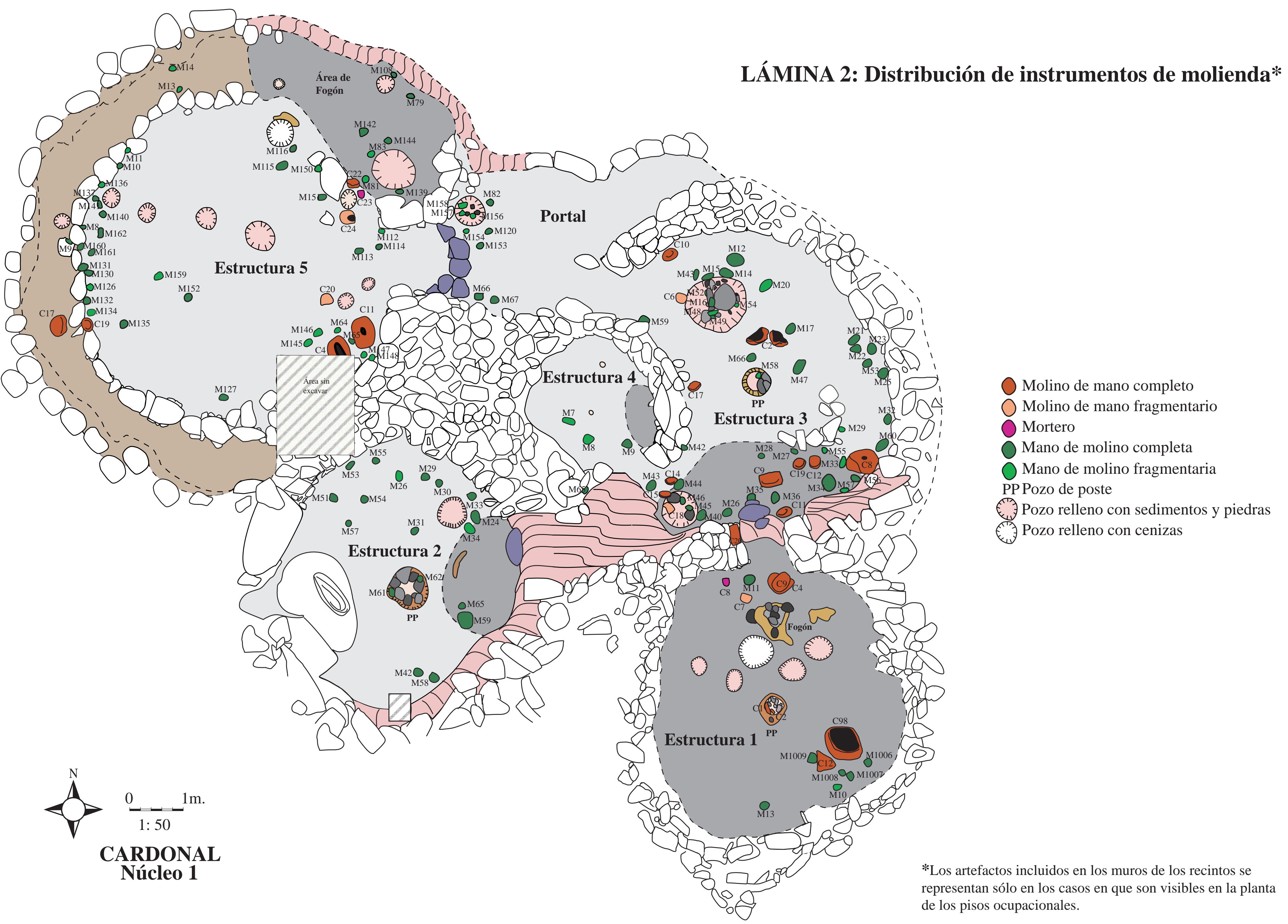

